\title{
Ein bronzezeitlicher Familienclan als genetisches Archiv \\ Morphologisch-paläogenetische Bearbeitung des Skelettkollektivs aus der Lichtensteinhöhle
}

\author{
Dissertation \\ zur Erlangung des mathematisch-naturwissenschaftlichen Doktorgrades \\ "Doctor rerum naturalium" \\ der Georg-August-Universität Göttingen \\ im Promotionsprogramm Grundprogramm Biologie \\ der Georg-August University School of Science (GAUSS) \\ vorgelegt von \\ Verena Seidenberg \\ aus Hamburg
}


Betreuungsausschuss:

Prof. Dr. Bernd Herrmann

Prof. Dr. Michael Klintschar

Dr. Susanne Hummel

Mitglieder der Prüfungskommission:

Referent: Prof. Dr. Bernd Herrmann

Korreferent: Prof. Dr. Michael Klintschar

Weitere Mitglieder der Prüfungskommission:

Prof. Dr. Julia Ostner

Prof. Dr. Thomas Friedl

PD Dr. Thomas Hörnschemeyer

Dr. Susanne Hummel

Tag der mündlichen Prüfung: 29.09.2016 
Diese Arbeit wurde angefertigt in der Abteilung Historische Anthropologie und Humanökologie des Johann-Friedrich-Blumenbach Institutes für Zoologie und Anthropologie der Georg-AugustUniversität Göttingen im Rahmen des Projektes: „Leben in der Bronzezeit - Anthropologischpaläogenetische Untersuchungen an den Skelettresten des Familienclans und assoziierter Bestattungen aus der Lichtensteinhöhle“. Das Projekt wurde gefördert vom Ministerium für Wissenschaft und Kultur (MWK) des Landes Niedersachsen, Förderkennzeichen: 11.2-7620210-4/09. Projektleiterin: Dr. Susanne Hummel. 


\section{Inhaltsverzeichnis}

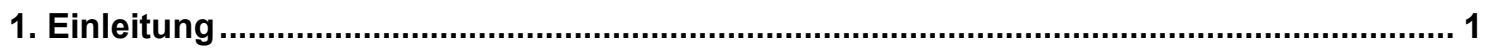

1.1 Fundgeschichte der Lichtensteinhöhle .............................................................. 1

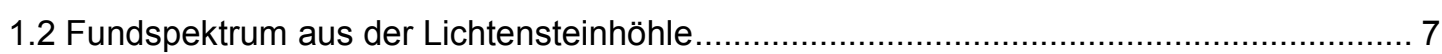

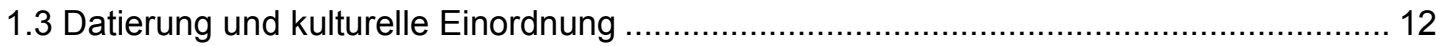

1.4 Anthropologische Bearbeitungsgeschichte der Lichtensteinhöhle ................................ 13

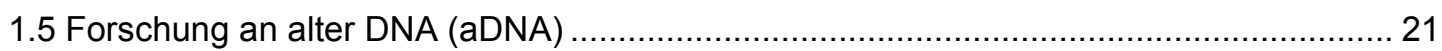

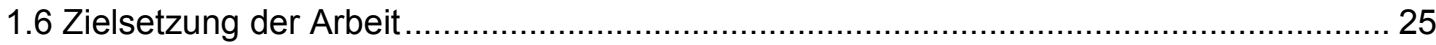

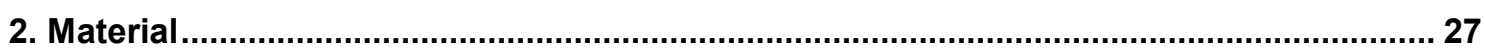

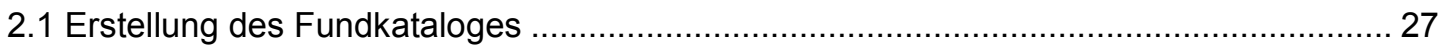

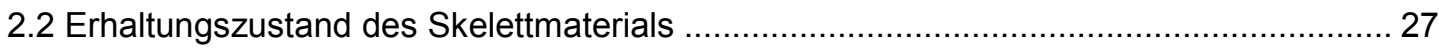

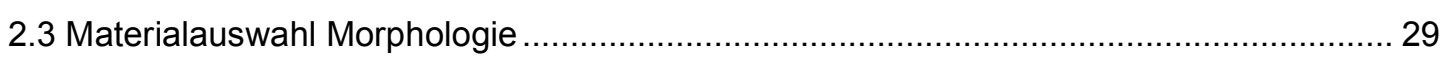

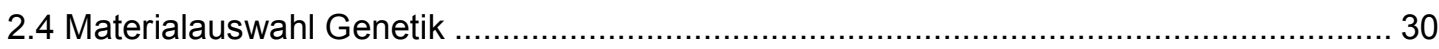

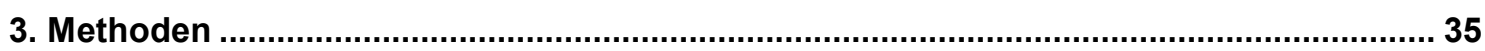

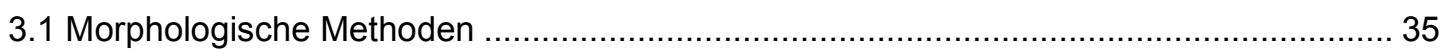

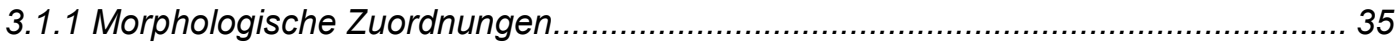

3.1.2 Dokumentation pathologischer Befunde und anderer morphologischer

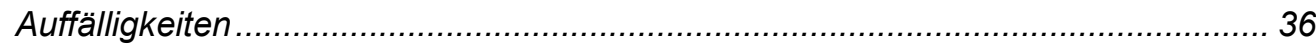

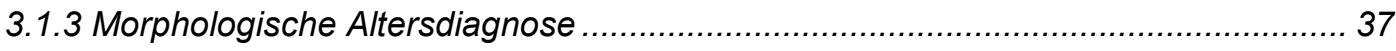

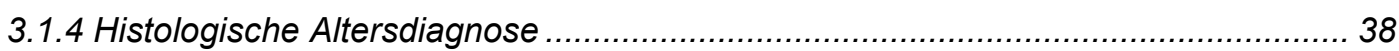

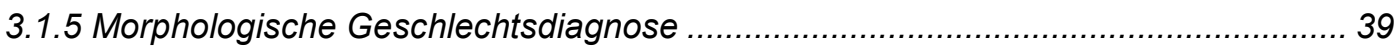

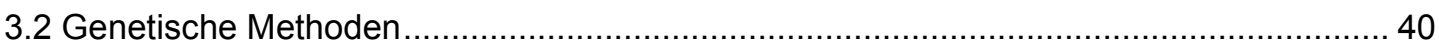

3.2.1 Arbeiten mit ancient DNA - Kontaminationsprävention und

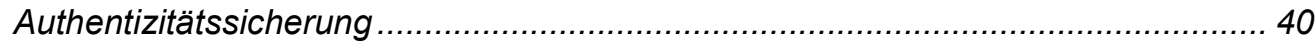

3.2.2 Molekulargenetische Verwandtschaftsanalyse/Markerauswahl.............................. 42

3.2.3 Entwicklung molekulargenetischer Analysesysteme ......................................... 46

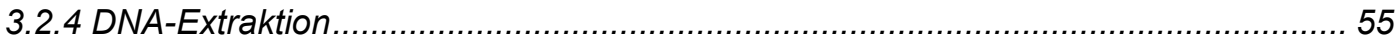

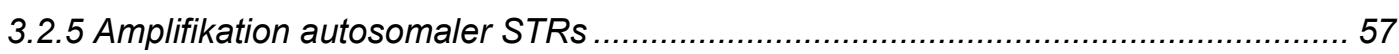

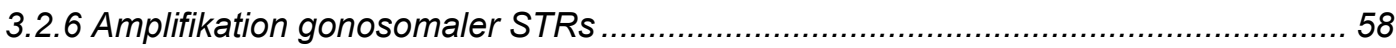

3.2.7 Amplifikation und Sequenzierung der mitochondrialen HVR I und II ...................... 60

3.2.8 Amplifikation und SBE-Analyse der AB0-Blutgruppen-SNPs ............................... 61

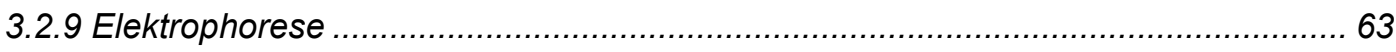

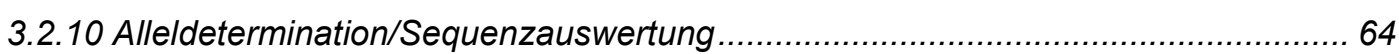

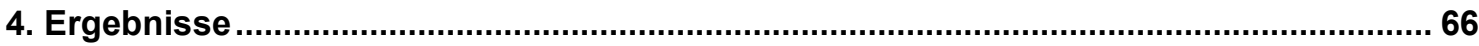

4.1 Zuordnung von Skelettelementen zu Individuen/Individuenzahl .................................66

4.2 Pathologische Befunde und andere Auffälligkeiten .................................................... 78

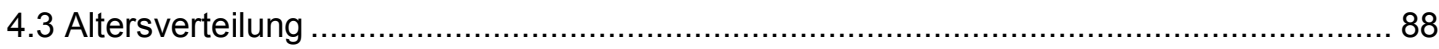

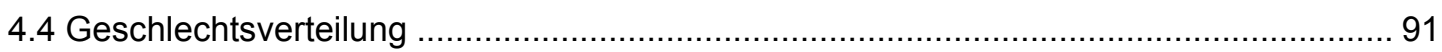

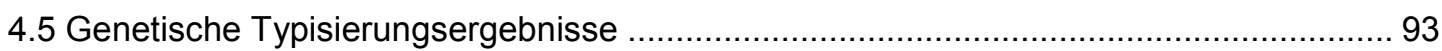

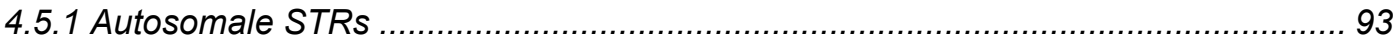

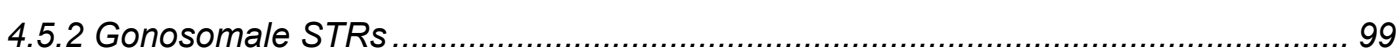

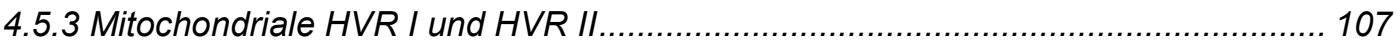


5. Ableitungen aus den Datensätzen ..................................................................... 114

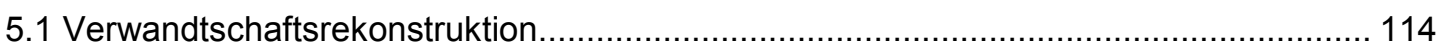

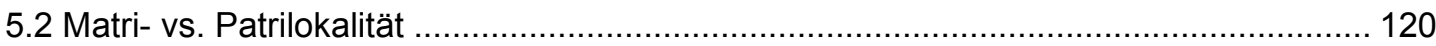

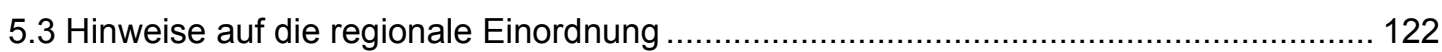

6. Ergebnisse vorheriger und begleitender Forschungsarbeiten zur Lichtensteinhöhle 126

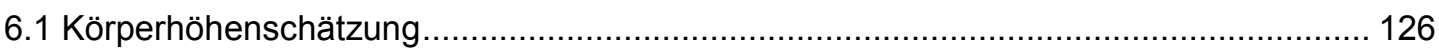

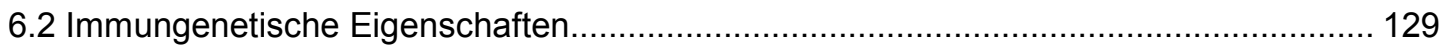

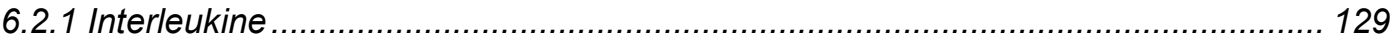

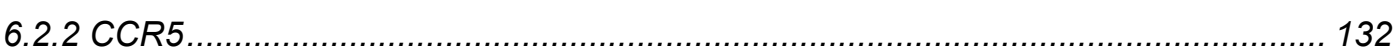



6.2.4 ABO

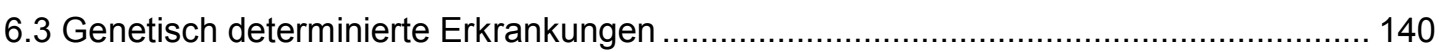

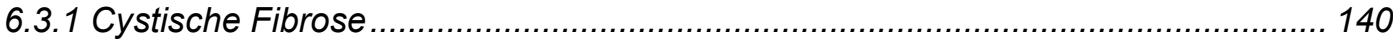

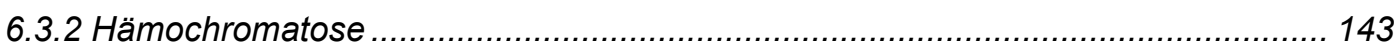

6.4 Laktosetoleranz und Subsistenzstrategien ........................................................... 146

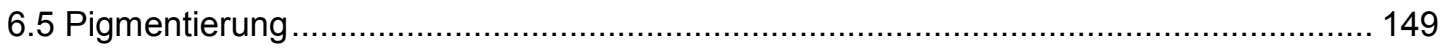

6.6 Dopamin Rezeptor D4 VNTR und Risikoverhalten..................................................... 154

6.7 Auswertung von Streumustern, Färbung und Textur der Knochen sowie des

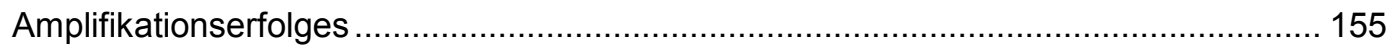

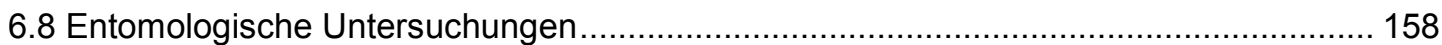

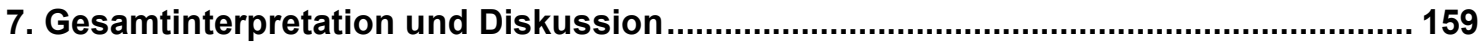

7.1 Demografische Struktur der Population aus der Lichtensteinhöhle ............................. 159

7.2 Nutzungsdauer und Nutzungsart der Lichtensteinhöhle ......................................... 165

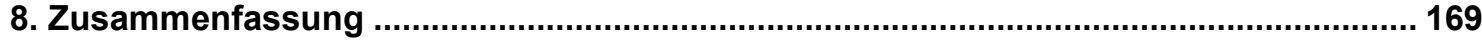

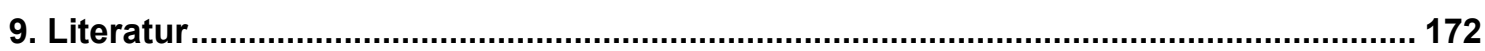

10. Anhang A

10.1 Datenblätter zu den Individuen aus der Lichtensteinhöhle...................................... 191

10.2 Liste der Examensarbeiten zur Lichtensteinhöhle .................................................... 252

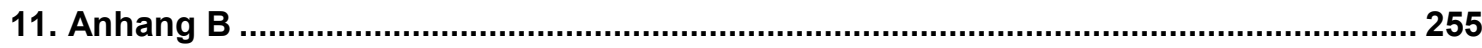

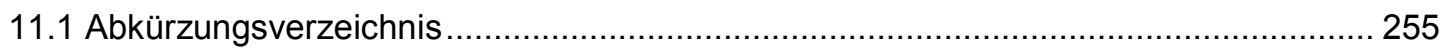

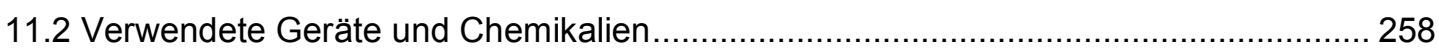

11.3 Verwendete Software, Internetseiten und Dateien auf der beigefügten CD ............... 261

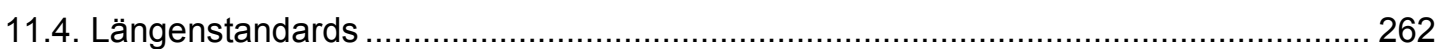




\section{Einleitung}

\subsection{Fundgeschichte der Lichtensteinhöhle}

Bei der Lichtensteinhöhle handelt es sich um eine Klufthöhle im Nordwesthang des Lichtensteins, einem Berg der Harzausläufer am Rande des Sösetals. Auf diesem Berg befinden sich die Reste der gleichnamigen, mittelalterlichen Burg „Lichtenstein“. Auf der Suche nach einem von dieser Burg ins Tal herabführenden Fluchttunnel wurde im Jahre 1972 zunächst ein enger Felsspalt entdeckt, welcher sich zu einer - zuerst lediglich geologisch interessanten - Klufthöhle erweiterte, die nach ca. $48 \mathrm{~m}$ mit einer unpassierbaren Engstelle endete (Kempe und Vladi 1988).

Der $261 \mathrm{~m}$ hohe Lichtenstein (siehe Abb. 1) ist Teil des Gipskarstgebietes des südwestlichen Harzrandes. Die nur wenige Meter unter der Oberfläche verlaufende Lichtensteinhöhle entstand aus Kluftstrukturen im Gipsgestein aus sogenannten Anastosomen, fünf bis zehn Zentimeter weiten Röhren, welche sich unter dem damaligen Grundwasserspiegel unter dem Druck aufsteigender Tiefenwässer bildeten. Nachdem

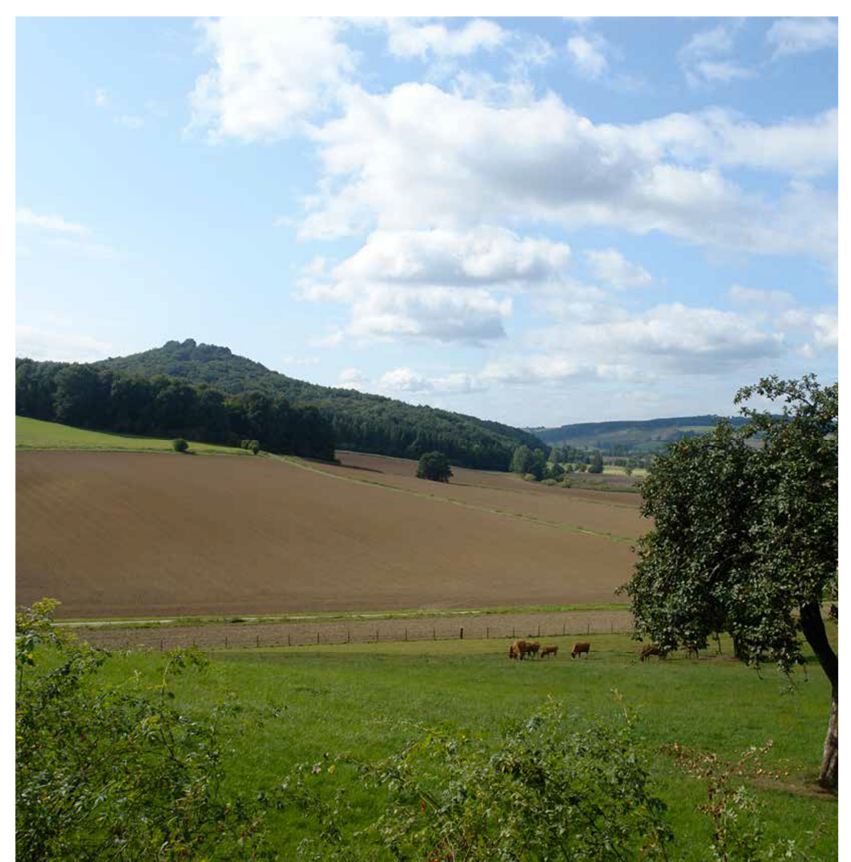

Abb. 1: Blick auf den Lichtenstein. Dort, wo auf der Bergkuppe die höheren Baumwipfel zu erkennen sind, befinden sich die Überreste der prähistorischen Burg Lichtenstein (aus Flindt und Hummel 2014).

sich der Grundwasserspiegel in der Region gesenkt hatte, führte versickerndes Regenwasser zur Entstehung eines unterirdischen Bachs, welcher sich mit starker Strömung und hoher Lösungskraft mehrere Meter tief in den Gips einschnitt. Mit weiter fallendem Grundwasserspiegel blieben die ausgewaschenen Hohlräume vor spätestens 50.000 Jahren - nun trockengefallen - als sogenannte Cañonhöhle zurück. Diese recht seltene Entstehungsgeschichte ist heute an den charakteristischen, kluftartigen, schmalen Räumen mit dachförmigem Querschnitt sowie an den teilweise an den Wänden erhalten gebliebenen Fließfacetten zu erkennen. Eine geologische Besonderheit ist die Lichtensteinhöhle zum einen aufgrund ihrer ungewöhnlich großen Gesamtlänge von - nach Entdeckung aller Höhlenteile ermittelten - rund 135 m und vor allem, weil 
sie bis heute erhalten geblieben ist. Aufgrund der hohen Löslichkeit des Gipses entstehen Höhlen in Gipsgestein meist innerhalb weniger Jahrtausende und verschwinden in ähnlichen Zeiträumen auch wieder (Kempe und Vladi 1988, Flindt 1998, Flindt und Hummel 2014).

Im Februar 1980 konnte die Engstelle am Ende der 1972 entdeckten Klufthöhle künstlich erweitert und somit überwunden werden. Damit wurde der Durchbruch in eine weitere, ca. $8 \mathrm{~m}$ lange, enge Spalte geschaffen, an deren scheinbaren Ende einige menschliche Röhrenknochen sowie ein menschlicher Unterkiefer gefunden wurden. Zwischen den Knochen befand sich ein schlichter Ring aus Bronzedraht, welcher einen ersten Hinweis darauf lieferte, dass die Knochen aus prähistorischer Zeit stammten. Bei genaueren Untersuchungen des Endes der Spalte, in der die Knochen lagen, stellte sich heraus, dass eine weitere Engstelle vorhanden war, welche in noch tiefer im Berg liegende Bereiche weiterführte und zunächst nicht aufgefallen war, da sie durch Gipssinter (= auskristallisierter Gips) und weitere Knochen nahezu vollständig verfüllt war. Nach Freilegen des Durchstieges konnte in eine kleine Höhlenkammer vorgedrungen werden. Dieser Raum wurde später als Grabkammer benannt. Der Durchbruch in diese Höhlenkammer stellte die Entdeckung des archäologisch und auch anthropologisch interessanten Teils der Höhle dar (Flindt 1996, Flindt und Hummel 2014).

In der Grabkammer wurden zahlreiche Knochen von mehreren Personen und Bronzegegenstände gefunden. Die Menschenknochen lagen größtenteils komplett disloziert in der Höhle verstreut und waren mit einer Gipssinterschicht überzogen, welche zeigte, dass die Funde über Jahrtausende völlig unberührt überdauert hatten (Flindt 1996).

Es stellte sich bald heraus, dass auch über die Grabkammer hinaus eine Fortsetzung der Höhle existierte. Es folgten vier weitere Höhlenkammern, welche - nach den Mitgliedern des Teams der Erstbefahrer - als Horstspalte, Fiddikluft, Reinhardsgrotte und Berndsaal benannt wurden. Die einzelnen Höhlenabschnitte waren durch zum Teil extreme Engstellen miteinander verbunden (z.B. Uwes Schluf oder Damoklesschluf) (Flindt 1996). Eine Übersicht über die Anordnung aller Höhlenabschnitte zueinander findet sich in Abb. 2. 


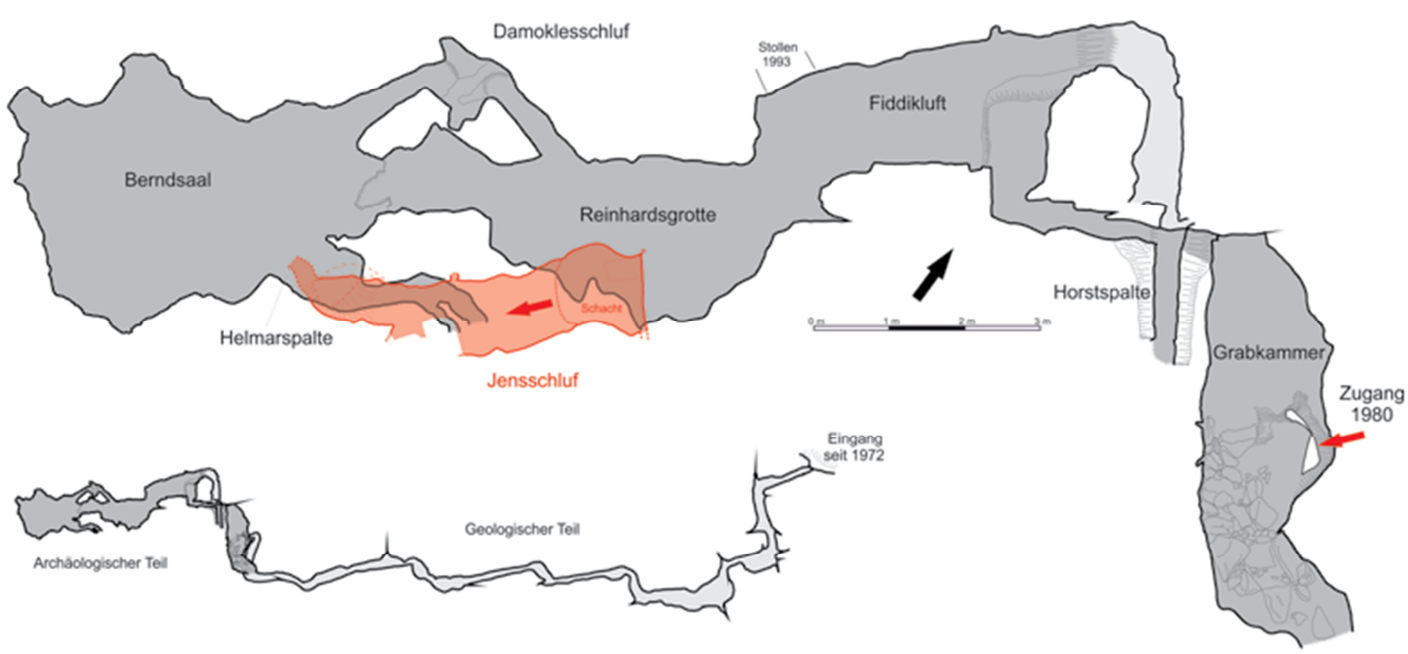

Abb. 2: Übersicht über den gesamten Höhlengrundriss (unten) und - vergrößert - über die Anordnung der einzelnen Höhlenkammern zueinander im fundführenden, archäologischen Teil (oben) (aus Flindt und Hummel 2014).

Die Räume weisen insgesamt eine Fläche von lediglich ca. $30 \mathrm{~m}^{2}$ auf und sind teilweise so niedrig, dass eine Fortbewegung weitestgehend nur auf Knien oder auf dem Bauch möglich war. Nur der Berndsaal, die größte der Höhlenkammern, war etwas höher, so dass hier teilweise annähernd Stehhöhe erreicht wurde. In allen fünf Räumen fand sich, unter einem Überzug aus unberührtem Gipssinter, nahezu flächendeckend ein Durcheinander von Menschen- und Tierknochen durchsetzt mit Bronzefunden (siehe Abb. 3) (Flindt und Hummel 2014).

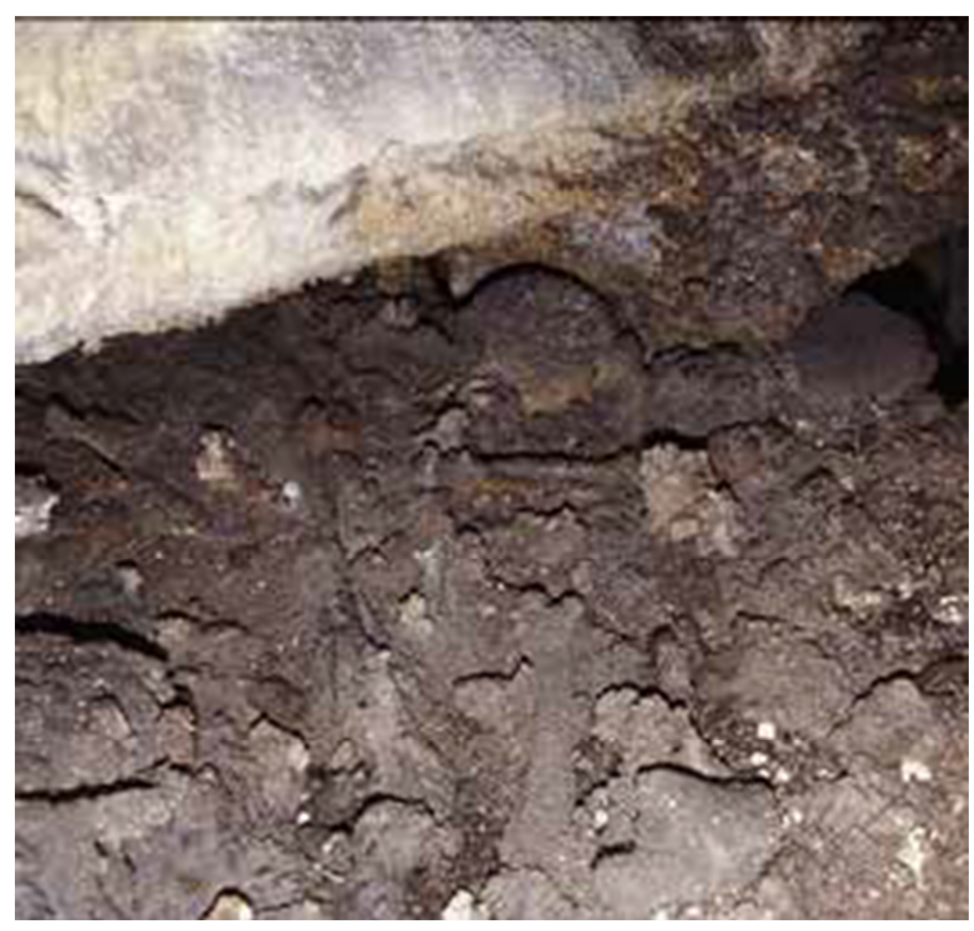

Abb. 3: Mit Gipssinter überzogene Menschenknochen in der Fiddikluft (aus Flindt und Hummel 2014). 
Direkt nach der Entdeckung des archäologischen Teils der Höhle wurde bereits mit einer fotografischen, beschreibenden und zeichnerischen Dokumentation begonnen. Es konnte jedoch vorerst keine genauere wissenschaftliche Untersuchung der bronzezeitlichen Hinterlassenschaften vorgenommen werden, da das Geld für eine reguläre Forschungsgrabung fehlte. So wurde zunächst nur der Zugang mit einer massiven Eisentür verschlossen um die Befunde zu schützen, bis eine solche Grabung möglich wäre (Flindt 1996, Flindt und Hummel 2014).

Im Jahr 1992 wurde jedoch ein Handlungsdruck erzeugt, da die Stahltür am Höhleneingang von Raubgräbern aufgebrochen wurde, welche bis in den fundführenden Teil der Höhle vordringen konnten. Hierbei verursachten die Raubgräber oberflächlich massive Verwüstungen und entwendeten vermutlich eine unbekannte Zahl von Knochen und Bronzeartefakten. Bei der Befahrung der Höhle nachdem der Raubgräber-Einbruch entdeckt wurde, wurde zunächst von weitreichenden Zerstörungen der unwiederbringlichen, bronzezeitlichen Befunde ausgegangen. Später stellte sich jedoch zum Glück heraus, dass das Bild der Verwüstung auf den ersten Blick schlimmer gewirkt hatte, als es tatsächlich war. Die harte Gipssinterschicht, welche die Knochen über Jahrtausende geschützt hatte, hatte sich auch gegen die Raubgräber als guter Schutzschild erwiesen. Somit blieben die Zerstörungen deutlich oberflächlicher und kleinräumiger als befürchtet. Nach einem Aufruf in der Presse, in dem die große wissenschaftliche Bedeutung des Fundmaterials herausgestrichen wurde, wurden tatsächlich einige entwendete Knochen und Artefakte anonym zurückgegeben. Hierbei handelte es sich um drei menschliche Schädel und ca. 20 Kleinfunde, meist aus Bronze (Flindt 1996, Flindt und Hummel 2014).

Um zu verhindern, dass die wertvollen Funde durch ähnliche Vorfälle möglicherweise weiter zerstört würden, wurde im Jahr 1993 mit der wissenschaftlichen Befundung und Bergung der Funde aus der Lichtensteinhöhle begonnen. Die Ausgrabung und Dokumentation musste durch die natürlichen Gegebenheiten in der Höhle unter extremen Bedingungen stattfinden. In der Höhle ist es nicht nur extrem eng, sondern auch kalt und nass. Im Inneren der Höhle herrschen über das ganze Jahr hinweg Temperaturen von max. $8^{\circ} \mathrm{C}$. Grabungskampagnen waren nur in den wärmeren Monaten des Jahres möglich (Flindt 1998). Die Bergung aller Funde dauerte über viele Grabungskampagnen hinweg bis 2013 an.

Vor Beginn der Grabungen musste zunächst ein künstlicher Eingang direkt in den fundführenden Teil der Höhle geschaffen werden, da die ständige Benutzung des 
Kriechganges ein Bergungsvorhaben nahezu unmöglich gemacht hätte. Da die Höhle relativ dicht hinter dem Steilhang des Lichtensteins verläuft, konnte ein künstlicher Zugangsstollen mit einem Querschnitt etwa $70 \times 90 \mathrm{~cm}$ und einer Länge von ca. $3 \mathrm{~m}$ geschaffen werden, der in die Fiddikluft - den statisch stabilsten Raum - mündet (Flindt 1996, Flindt und Hummel 2014). Bei der Ausgrabung wurde nach dem Prinzip der natürlichen Schichten vorgegangen, wobei die Sedimentschichten mitsamt den eingelagerten Funden in umgekehrter Reihenfolge $\mathrm{zu}$ ihrer Entstehung sorgfältig nacheinander bis auf den gewachsenen Boden abgetragen werden. Der Vorteil hierbei ist, dass bei diesem Vorgehen Hinweise auf zeitliche Abfolgen gut dokumentiert werden können. Aufgrund der Enge in der Höhle konnten die Schichten nicht in einem größeren Planum abgetragen werden. Daher erfolgte die Bergung unter Einteilung der einzelnen Höhlenräume in Quadranten von jeweils $50 \times 50 \mathrm{~cm}$ Kantenlänge, die nacheinander schichtweise abgetragen wurden. Alle freigelegten Schichtoberflächen wurden jeweils fotografisch und zeichnerisch dokumentiert (Flindt und Hummel 2014). So wie der 1972 entdeckte Kriechgang kein praktikabler Zugang für die Bergungsaktivitäten war, war davon auszugehen, dass auch die prähistorische menschliche Population, welche die Höhle nutzte, nicht auf diesem Wege die Höhle regulär betreten haben dürften. Der historische Eingang war jedoch lange nicht bekannt. Eine Vermutung war, dass die Höhle über die Helmarspalte, einen nahezu senkrechten Schacht, welcher vom Berndsaal in die Höhe führt, betreten wurde. Dieser Schacht führt jedoch nicht bis an die Erdoberfläche, sondern endet nach ca. $7 \mathrm{~m}$ an großen Blocksteinen. Längere Zeit wurde vermutet, dass es sich hier um den intentional durch die prähistorische Population oder durch einen natürlichen Versturz verschlossenen prähistorischen Zugang handelte (Flindt 1998). Erst 2008 wurde entdeckt, dass nach ca. $5 \mathrm{~m}$ ein zunächst durchgehend komplett mit Erdsediment verfüllter Horizontalgang von der Helmarspalte abzweigt (Flindt et al. 2012). Bis 2013 wurde dieser als Jensschluf benannte, rund $4 \mathrm{~m}$ lange Horizontalgang, welcher teilweise sehr eng ist, komplett ausgegraben. Am Ende des Jensschlufs führt ein ca. $5 \mathrm{~m}$ hoher Schacht an die Erdoberfläche (Flindt et al. 2013). In prähistorischen Zeiten dürfte dieser Eingangsschacht allerding noch etwas länger gewesen sein, da die damalige Erdoberfläche wohl über die Jahrtausende hinweg durch Erosion etwas abgetragen wurde. Aufgrund dieser natürlichen Erosion konnten in der Umgebung um den historischen Zugangsschacht auch keinerlei Spuren der Aktivitäten der prähistorischen 
Population oder hinterlassene Artefakte mehr gefunden werden (Flindt und Hummel 2014).

Bei der Ausgrabung in den verschiedenen Höhlenkammern wurde deutlich, dass die Höhle durch die prähistorische Population gezielt für die Nutzung hergerichtet wurde. Im gesamten archäologischen Teil der Höhle war der zerklüftete Boden planiert worden. Das hierfür genutzte, teilweise in die Höhle eingebrachte, Sediment enthielt zahlreiche intakte und fragmentierte Tierknochen. An einigen Engstellen wurden künstliche Erweiterungen vorgenommen. Spuren dieser Arbeiten sind unter anderem in der Helmarspalte, im Berndsaal und auch im Durchgang von der Reinhardsgrotte in die Fiddikluft zu sehen. Ein aufgefundener, abgeplatzter Gesteinssplitter weist darauf hin, dass hierfür Flussgeröll verwendet wurde (Flindt und Hummel 2014).

So wie die Planierschicht in der gesamten Höhle die Basis bildete, fand sich überall zuoberst eine bis zu $30 \mathrm{~cm}$ starke Schicht aus vorwiegend Menschenknochen. Darunter war durchgängig eine dünne Schicht aus dunklem humushaltigem Sediment. Dieses könnte eventuell von Polstermaterial, wie z.B. Moos oder Heu, herrühren, welches im Laufe der Zeit verrottet war. Die Knochenlage war durchsetzt mit Bronzefunden. So wie die Knochen weitestgehend disloziert vorlagen, traf dies auch auf die Bronzefunde zu. Nur in Einzelfällen waren einzelne Schmuckgegenstände mit bestimmten Knochen/Individuen assoziiert. Neben Objekten aus Bronze wurde auch ein breites Spektrum von Schmuckobjekten aus anderen Materialien geborgen. Auffällig ist allerdings, dass in der Knochenschicht keine Keramiken gefunden wurden, wie man sie als Grabbeigaben erwarten würde (Flindt 1996, Flindt et al. 2013, Flindt und Hummel 2014).

In den hinteren Höhlenabschnitten stellt die Schicht mit den Menschenknochen die einzige Fundschicht dar. Im Berndsaal jedoch findet sich unter der Knochenschicht eine bis zu $40 \mathrm{~cm}$ starke, abwechseln grau und schwarz gefärbte Schicht mit Spuren von diversen Feuerstellen. In den Rissen und Spalten der Decke des Berndsaals sind hierzu passend teilweise noch Rußspuren zu sehen. Die Feuerstellen befanden sich i.d.R. direkt auf dem Höhlenboden, nur in einem Fall in der untersten - und damit ältesten - Schicht in diesem Brandhorizont, wurde eine Feuerstelle mit kleinen Steinen hergerichtet. In den Brandschichten des Berndsaals wurden, neben reichlich Holzkohle und angekohlten Resten von Feuerholz, auch Reste von rituellen Mahlzeiten gefunden. Dabei handelte es sich um Tierknochen, verkohlte Pflanzenreste und in dieser Fundschicht mit größeren 
Mengen von Tonscherben auch Überreste von Keramiken (Flindt 1996, Flindt et al. 2013, Flindt und Hummel 2014).

Diese Schichtung im Berndsaal mit dem unterschiedlichen Fundinventar stellt einen Hinweis darauf dar, dass es in diesem Höhlenabschnitt einen Nutzungswechsel von einer Nutzungsphase, die vorwiegend durch Kulthandlungen geprägt war, hin zu einer Phase der Knochenablage, gegeben hat. Der Berndsaal ist mit rund $9 \mathrm{~m}^{2}$ und zumindest teilweise Stehhöhe der geräumigste Höhlenabschnitt und damit als einziger der Höhlenräume für jegliche Art von Kulthandlungen geeignet. Hinweise auf Kulthandlungen im Berndsaal liefern auch aufgefundene Gegenstände, denen nicht ohne weiteres ein praktischer Nutzen zugeordnet werden kann, wie z.B. Fossilien oder Biberzähne (Flindt und Hummel 2014).

Neben dem Berndsaal ist der Jensschluf der einzige Höhlenabschnitt mit einer komplexeren Schichtung aus mehreren unterschiedlich gefärbten und zusammengesetzten Fundhorizonten. Hier findet sich auf dem Planierhorizont zunächst eine Schicht mit vielen intakten oder fragmentierten Tierknochen, in der im Eingangsschachtbereich auch menschliche Überreste gefunden wurden. Darüber folgt ein Horizont aus dunkel gefärbten Schichten mit Brandresten, verkohlten Pflanzenresten, Überresten von Gefäßkeramiken und Bronzen. Zuoberst findet sich im Jensschluf eine Schicht mit kaum noch besonderen Einlagerungen (Flindt et al 2013, Flindt und Hummel 2014).

\subsection{Fundspektrum aus der Lichtensteinhöhle}

Bei den Ausgrabungen in der gesamten Höhle wurden insgesamt 4.342 menschliche Knochen geborgen, welche weitestgehend disloziert in den Höhlenkammern verstreut lagen (siehe Abb. 4). Befunde wie z.B. die Knochen des Arms eines Kindes, welche in annähernd anatomisch korrekter Anordnung im Berndsaal aufgefunden wurden, stellen hierzu eine Ausnahme dar (siehe Abb. 5). Teilweise schienen die Knochen jedoch gezielt an den Höhlenwänden arrangiert worden $\mathrm{zu}$ sein, wie einige Bündel aus Langknochen (siehe Abb. 6) oder an den Wänden aufgereihte Schädel belegen (Flindt und Hummel 2014). 


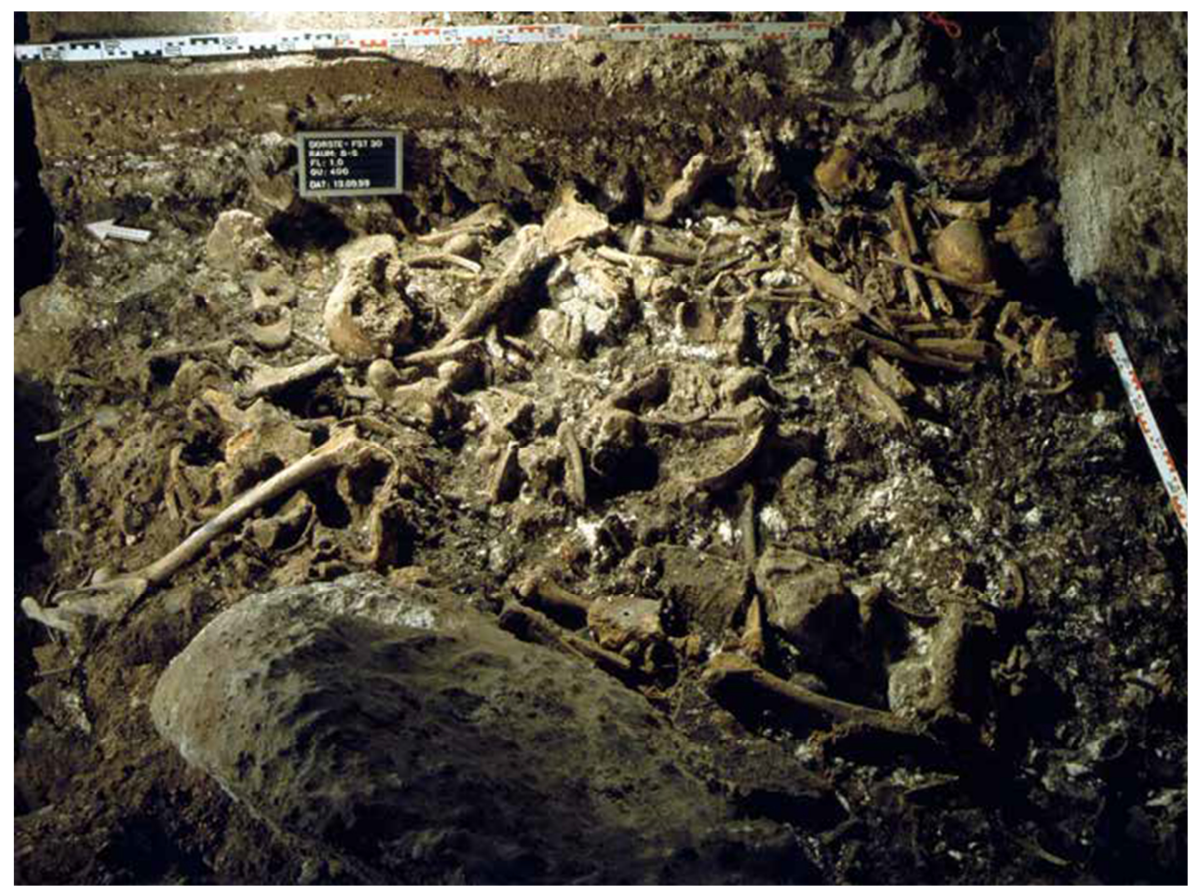

Abb. 4: Blick auf die freigelegten, disloziert vorliegenden, menschlichen Knochen im Berndsaal (aus Flindt und Hummel 2014).

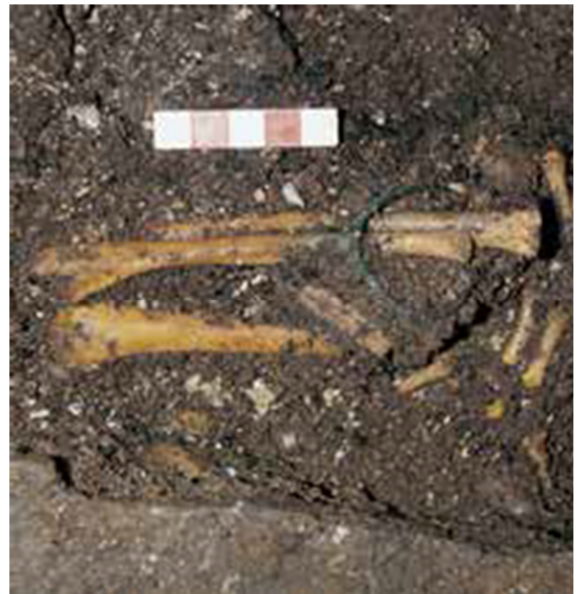

Abb. 5: Armknochen eines Kindes in annähernd anatomisch korrekter Lage in der Reinhardsgrotte (aus Flindt und Hummel 2014).

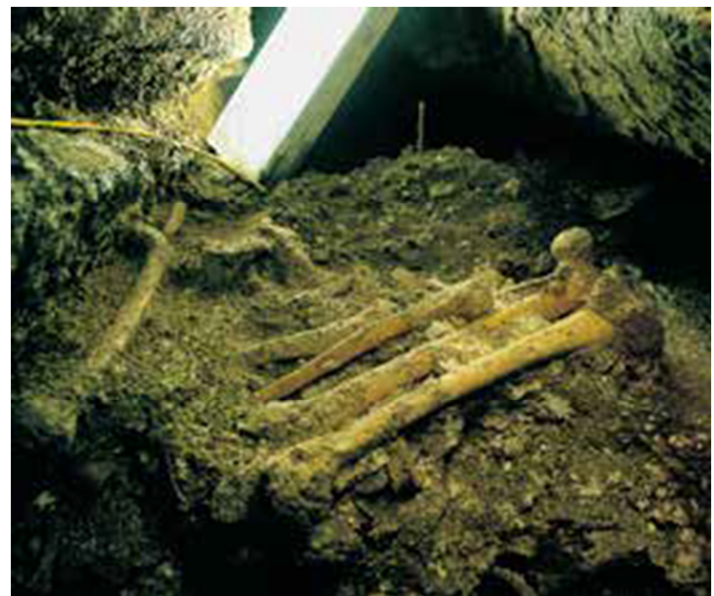

Abb. 6: Anscheinend gezielt abgelegtes „Knochenbündel“ aus mehreren Langknochen im Berndsaal (aus Flindt und Hummel 2014).

Neben den Knochen menschlicher Herkunft wurden zudem an die 10.000 Tierknochen von Wild- und Haustieren geborgen. Hierbei handelt es sich um Knochen von Reh, Hirsch, Wildschwein, Rind, Pferd, Hausschwein und Hund (Schoon 2010). Die Tierknochen stellen wohl weitestgehend Speiseabfälle dar, da die Überreste zum Teil angebrannt und mit Schnittspuren versehen sind. Als Werkzeuge zum Zerlegen wurden vermutlich auch die aufgefundenen Hacken aus Hirschgeweih verwendet (Schoon 2010, Flindt und Hummel 2014). 
Aufgefunden wurde auch ein breites Spektrum von - zumeist verkohlten Pflanzenresten in den Brandschichten im Berndsaal. Insgesamt lassen sich die pflanzlichen Überreste 120 verschiedenen Arten zuordnen. Vertreten sind neben Wildfrüchten, verschiedenen Duft- Würz- und Blühpflanzen auch Feldfrüchte wie Ackerbohne, Erbsen, Lein und die Getreidearten Gerste, Emmer, Dinkel, Saat- und Zwergweizen (Flindt und Hummel 2014).

Die rund 2.300 Tonscherben, welche vor allem in den Brandschichten im Berndsaal gefunden wurden, stammen von etwa 50 verschiedenen Gefäßen (siehe Abb. 7). Hierbei handelt es sich größtenteils um wohl vor Ort hergestellte Haushaltskeramik, aber auch einige Gefäße mit vergleichsweise hoher Fertigungsqualität konnten identifiziert werden. Letztere wurden wohl aus benachbarten Regionen importiert (Flindt und Hummel 2014).
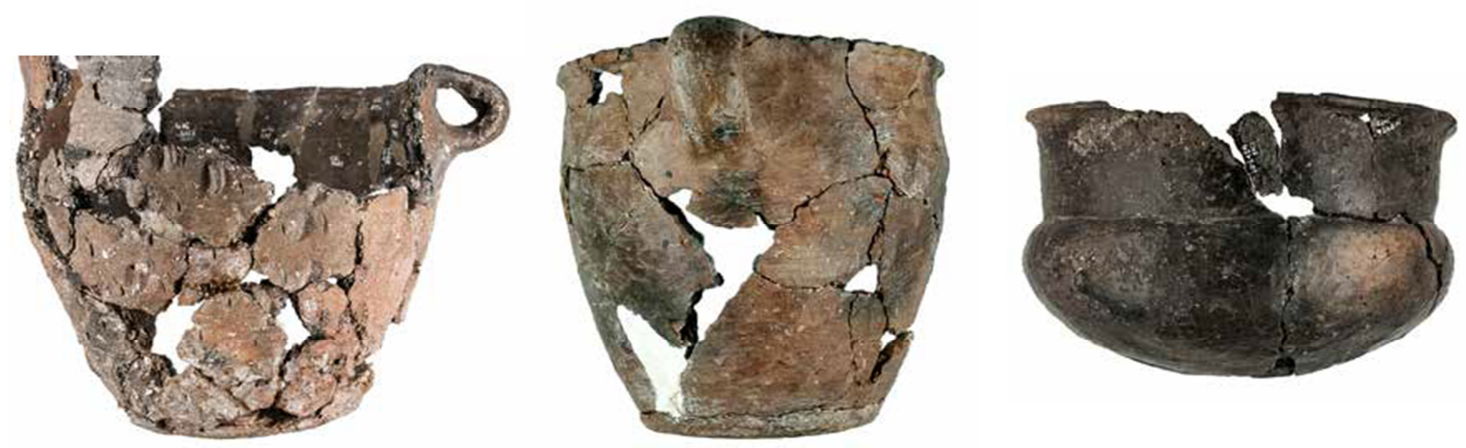

Abb. 7: Aus den in der Lichtensteinhöhle gefundenen Tonscherben rekonstruierte Keramiken (aus Flindt und Hummel 2014).

Insgesamt wurden 215 Bronzefunde geborgen, welche größtenteils aus der Menschenknochenschicht stammen. Bei den Bronzefunden (siehe Abb. 8) ist lediglich ein relativ begrenztes Formenspektrum vertreten. Mit wenigen Ausnahmen ist der Bronzeschmuck recht kleinteilig und einfach. Hierbei handelt es sich weitestgehend wohl um die normale Alltags-, Schmuck- und Trachtausstattung der bestatteten Individuen und nicht um eine spezielle Extraausstattung für das Jenseits. Im hinteren Höhlenteil - in Horstspalte und Grabkammer - wurde, im Vergleich zu den anderen Höhlenabschnitten, mehr und teilweise auch etwas aufwändiger gearbeiteter Bronzeschmuck gefunden (Flindt und Hummel 2014). 


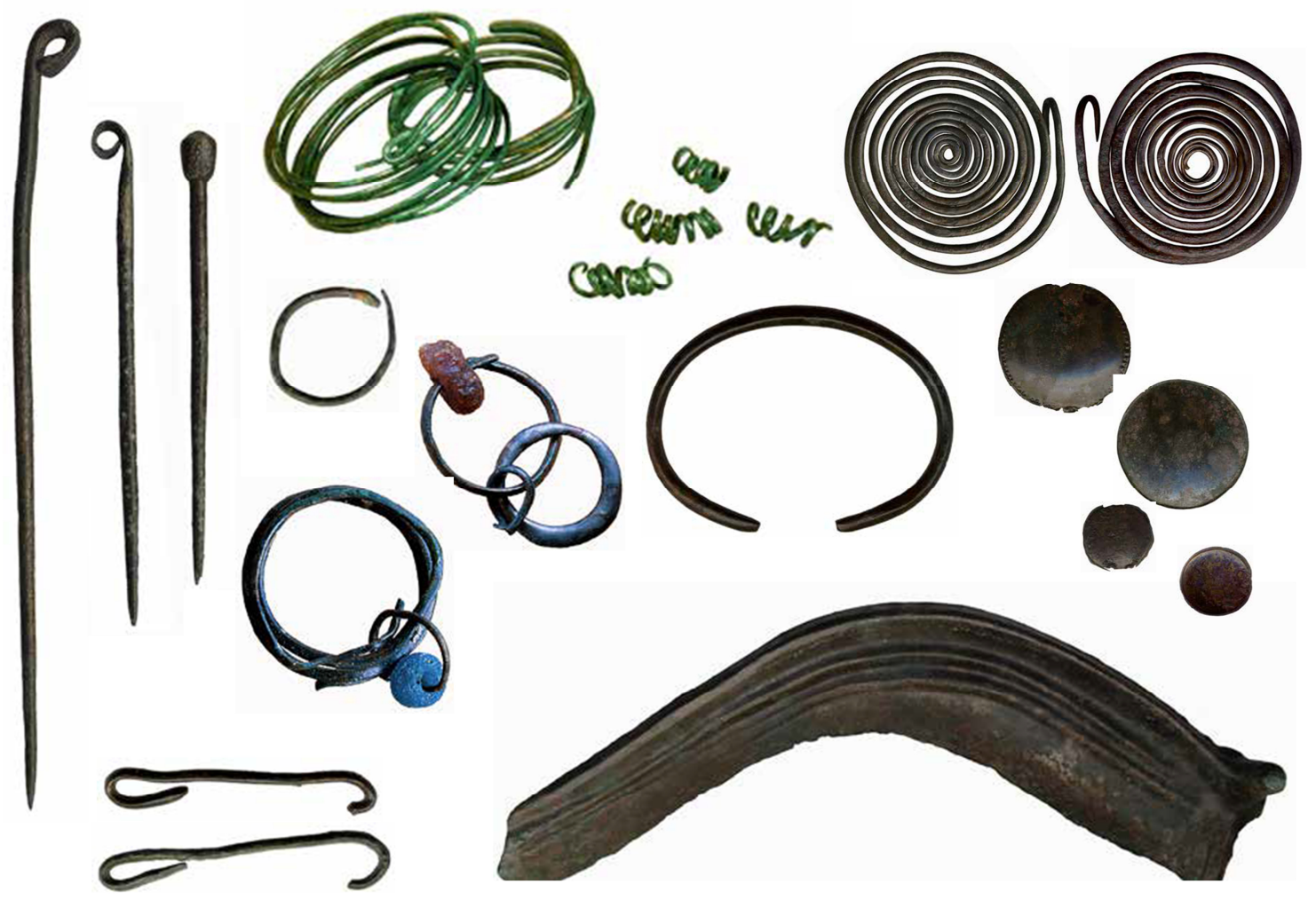

Abb. 8: Ausschnitt aus dem Bronzefundinventar aus der Lichtensteinhöhle (aus Flindt und Hummel 2014).

$\mathrm{Zu}$ den aufgefundenen Schmuckgegenständen aus anderen Materialien (siehe Abb. 9) zählen z.B. durchbohrte Kieselsteine, durchbohrte Hundezähne, durchbohrte Knochenscheiben, Hechtwirbel mit erweitertem Rückenmarkskanal - was darauf hinweist, dass es sich hier um Schmuck und nicht einfach um Nahrungsüberreste handelt - und Perlen aus Glas und Bernstein. Die Perlen aus Glas und Bernstein dürften Luxusgüter gewesen sein, welche recht selten waren und über größere Entfernungen gehandelt wurden (Flindt und Hummel 2014). 



Abb. 9: Ausschnitt aus dem Spektrum an Schmuckgegenständen aus verschiedenen Materialien aus der Lichtensteinhöhle (aus Flindt und Hummel 2014).

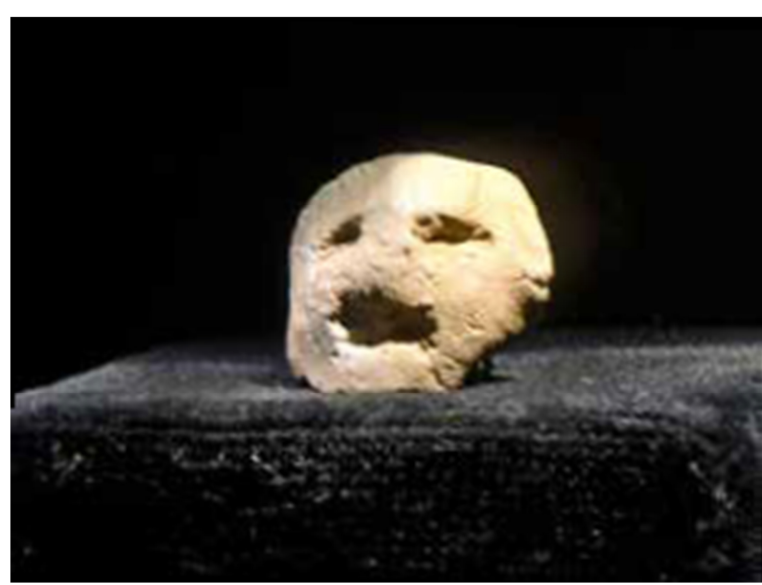

Abb. 10: Plastik aus gebranntem Ton, welche vermutlich ein menschliches Gesicht darstellen soll (aus Flindt und Hummel 2014).
Um einen sehr interessanten und ungewöhnlichen Fund handelt es sich bei einer kleinen Plastik aus gebranntem Ton, welche ein wohl menschliches Gesicht darstellen soll, welche ebenfalls in der Knochenschicht gefunden wurde (siehe Abb. 10). Dieser Fund kann jedoch vorerst nicht weiter interpretiert werden, da keine Vergleichsstücke bekannt sind (Flindt und Hummel 2014). 


\subsection{Datierung und kulturelle Einordnung}

Bereits bei der Erstbefahrung in den 1980er Jahren konnte aufgrund der vorgefundenen Bronzeartefakte eine erste Datierung erfolgen. Basierend auf zunächst nur wenigen Bronzefunden war diese Datierung vor Beginn der Ausgrabungen zwangsläufig lediglich relativ grob und ordnete die Funde ungefähr in die Urnenfelder-Bronzezeit (1.200-800 v. Chr.) ein. Für diese Epoche stellen die Funde aus der Lichtensteinhöhle eine Besonderheit dar, da die Menschenknochen damit aus einer Zeit stammen, in der in Südniedersachsen allgemein die Leichenverbrennung mit Bestattung des Leichenbrandes auf Urnenfeldern vorherrschte (Flindt 1998).

Die Urnenfelderkultur wird unterteilt in die Hauptstufen Hallstatt A ( $\mathrm{Ha}$ A) und Hallstatt B (Ha B) mit den Teilstufen $A_{1}$ und $A_{2}$ bzw. $B_{1}$ und $B_{2 / 3}$. Nach Abschluss der Bergungsarbeiten erlaubte die Gesamtheit der Grabungsfunde eine genauere Einordnung.

Die Gesamtheit der Bronzefunde in der Menschenknochenschicht fügt sich recht gut in das Spektrum der jüngeren Urnenfelderzeit, der Stufe Ha B (10.-8. Jh. v. Chr.) ein, wobei ein Schwerpunkt auf dem jüngeren Abschnitt Ha $\mathrm{B}_{2 / 3}$ (9.-8. Jh. v. Chr.) zu liegen scheint. Im hinteren Teil der Höhle war die Menschenknochenschicht die einzige Schicht, daher war aus den Befunden für diese Höhlenabschnitte keine genauere Eingrenzung möglich (Flindt und Hummel 2014).

Besonders aufschlussreich, was Hinweise auf den Nutzungszeitraum angeht, ist die differenzierte Betrachtung des Brandschichtenhorizontes und der Menschenknochenschicht im Berndsaal. Hier sind die Bronzefunde aus der Menschenknochenschicht wohl ausschließlich der Stufe $\mathrm{Ha} \mathrm{B}_{2 / 3}$ zuzuordnen. Im Brandschichtenhorizont im Berndsaal wurden kaum aussagekräftige Bronzefunde vorgefunden, jedoch wurde direkt von der Planierschicht eine Bronzenadel mit hakenförmig umgebogenem Kopf geborgen, deren Fertigungsart wohl nur bis in die Stufe Ha $\mathrm{B}_{1}$ nachgewiesen wurde. Da diese Hakenkopfnadel aufgrund ihrer Lage ganz zu Beginn der Höhlennutzung eingebracht worden sein muss, ist der Nutzungsbeginn der Höhle mithilfe dieses Fundes spätestens in das 10. Jh. v. Chr. zu datieren (Flindt und Hummel 2014).

Die aus den 2.300 Tonscherben teilweise wieder zusammensetzbaren Keramiken geben zum einen Hinweise auf verschiedene kulturelle Einflüsse, sowohl aus dem südöstlichen bzw. südlichen Harzvorland (Bronzekreis Mittelsaale, Unstrutgruppe), als auch aus nördlichen und nordwestlichen angrenzenden Regionen. Zum anderen geben die 
verschiedenen Keramiken Datierungshinweise in die Stufen $\mathrm{Ha} \mathrm{A}_{2}-\mathrm{Ha} \mathrm{B}_{1}$, Ha $\mathrm{B}_{1}-\mathrm{Ha}$ $\mathrm{B}_{2 / 3}$, oder Ha $\mathrm{B}_{1}$ (Flindt und Hummel 2014).

Im Jensschluf stützt eine bronzene Knopfsichel, die mit der Planierschicht assoziiert ist, die Hinweise über die Hakenkopfnadel aus dem Berndsaal, dass der Nutzungsbeginn spätestens im 10. Jh. v. Chr. lag, da diese Art Sicheln nur bis in die Stufe Ha $B_{1}$ nachgewiesen sind. In der oberhalb der Sichel liegenden dunklen Schicht im Jensschluf fanden sich zwei Hakenspiralen, welche in das 9. Jh. v. Chr. ( $\left.\mathrm{Ha}_{2 / 3}\right)$ einzuordnen sind. Hinweise auf das Ende der Nutzung der Höhle werden über Keramikscherben von der Oberfläche des dunklen Schichtenpaketes im Jensschluf erlangt. Diese Keramikscherben stammen von einer Schale, welche in die Stufe $\mathrm{Ha} \mathrm{B}_{2 / 3}$ einzuordnen ist. Somit ergibt sich in der Gesamtschau eine Nutzung vom 10. Jh. v. Chr. bis ins 9. Jh. v. Chr. hinein (Flindt und Hummel 2014).

\subsection{Anthropologische Bearbeitungsgeschichte der Lichtensteinhöhle}

Die Funde und Befunde aus der Lichtensteinhöhle warfen viele Fragen auf. Natürlich stellte sich die Frage danach, wie die Menschen zu Tode gekommen waren; und damit verknüpft die Frage danach, wie die Überreste in die Höhle gekommen waren. Die Höhle scheint $\mathrm{zu}$ eng, um Leichen hinein $\mathrm{zu}$ verbringen. Eine naheliegende Erklärungsmöglichkeit wäre, dass die Menschen noch lebendig selbständig die Höhle betreten hatten und erst dort ums Leben gekommen waren. Somit wurde in ersten Interpretationsversuchen zunächst angenommen, dass es sich um eine Menschenopferstätte handelte (Flindt 1996). Ein Unglück, wie z.B. das Verschüttetoder Eingeschlossenwerden der Menschen, von denen die Überreste stammen, konnte ausgeschlossen werden, da unter Annahme eines solchen Szenarios nicht erklärbar wäre, warum die Knochen weitestgehend disloziert bzw. arrangiert aufgefunden wurden.

Hinweise in Richtung einer Beantwortung dieser Fragen konnten aus der anthropologischen Bearbeitung der menschlichen Überreste erhofft werden. Dank der konstant niedrigen Temperaturen von $4-8{ }^{\circ} \mathrm{C}$ in der Höhle und der schützenden und konservierenden Gipssinterschicht war der Erhaltungszustand der Knochen und - wie sich bei den nachfolgenden Analysen zeigte - auch der der enthaltenen DNA sehr gut (Schultes 1997). Um die Knochen und die DNA auch nach der Ausgrabung aus der Höhle weiterhin bestmöglich zu erhalten, wurden sie direkt nach der Bergung in eine extra gebaute Kühlkammer in der Abteilung Historische Anthropologie und 
Humanökologie der Universität Göttingen überführt und werden dort seitdem bei $-20^{\circ} \mathrm{C}$ gelagert. Anthropologisch bearbeitet werden die Funde aus der Lichtensteinhöhle kontinuierlich seit Beginn der Grabungskampagnen unter anderem in mehreren durch das Niedersächsische Ministerium für Wissenschaft und Kultur (MWK) geförderten Projekten.

Nach den jeweiligen Grabungskampagnen wurden kontinuierlich sämtliche neu geborgenen Skelettelemente morphologisch befundet. Hierbei erfolgte zunächst eine Identifikation des Skelettelementes und eine Deskription mit besonderem Augenmerk auf möglicherweise vorhandenen pathologischen Veränderungen oder Dekompositionsphänomenen. Beim Vorliegen geeigneter Skelettelemente wurden Hinweise auf Alter, Geschlecht sowie die Werte für verschiedene Messstrecken zur Körperhöhenschätzung aufgenommen. In einigen Fällen wurde auch eine histologische Altersschätzung vorgenommen.

Nach den ersten morphologischen Befunden schien zwar die Altersklasse Infans I unterrepräsentiert, jedoch waren grundsätzlich alle Altersklassen vertreten. Dies weckte erste Zweifel an der Theorie der Nutzung der Höhle als Opferstätte. Verstärkt wurden diese Zweifel dadurch, dass an den Knochen keinerlei Spuren von Gewalteinwirkung feststellbar waren. Zusammen mit dem ermittelten ausgewogenen Geschlechterverhältnis deutet aus anthropologischer Sicht alles eher auf eine Nutzung der Höhle als Bestattungsplatz und nicht als Opferstätte hin (Schultes 2000).

Erste Tests zeigten schnell, dass DNA Analysen aus den 3.000 Jahre alten Bronzezeitlichen Knochen möglich sind (Schultes 1997, Burger et al. 1999, Haack 1999). In einem ersten MWK-geförderten Projekt konnten über molekulargenetische Analysen an einigen Femora aus der Lichtensteinhöhle Verwandtschaftsbeziehungen zwischen einigen Bestatteten festgestellt werden (Schultes 1997). Diese ersten molekulargenetischen Verwandtschaftsnachweise sprachen ebenfalls bereits deutlich gegen die ursprüngliche Theorie, dass es sich bei der Lichtensteinhöhle um eine Opferstätte handelte, sondern machten eine Nutzung als Bestattungsort wahrscheinlicher.

Nach den ersten Nachweisen von Verwandtschaftsbeziehungen zwischen einigen Individuen aus der Lichtensteinhöhle wurden in einem zweiten MWK-geförderten Projekt umfassendere Verwandtschaftsanalysen vorgenommen. Hierbei wurden vorwiegend craniale Elemente (Zähne und Felsenbein) als Untersuchungsmaterial verwendet (Schilz 2006). Mittels genetic fingerprinting sowie der Untersuchung 
mitochondrialer und Y-chromosomaler Haplotypen konnten in diesem Bearbeitungsabschnitt 40 Individuen identifiziert und ein Stammbaum rekonstruiert werden (siehe Abb. 11). Der von Schilz (2006) ermittelte Stammbaum zeigt für 28 der 40 damals bekannten Individuen Verwandtschaftsbeziehungen auf. Damit war eine Nutzung der Lichtensteinhöhle als Opferstätte nahezu sicher auszuschließen zumindest für den größten Teil der Nutzungsdauer (Schilz 2006). Ein Nutzungswechsel von einer Opferstätte zu einem Bestattungsplatz ist zwar potentiell möglich, scheint aber sehr unwahrscheinlich, da an den Knochen ja jegliche Spuren von Gewalteinwirkung fehlen.

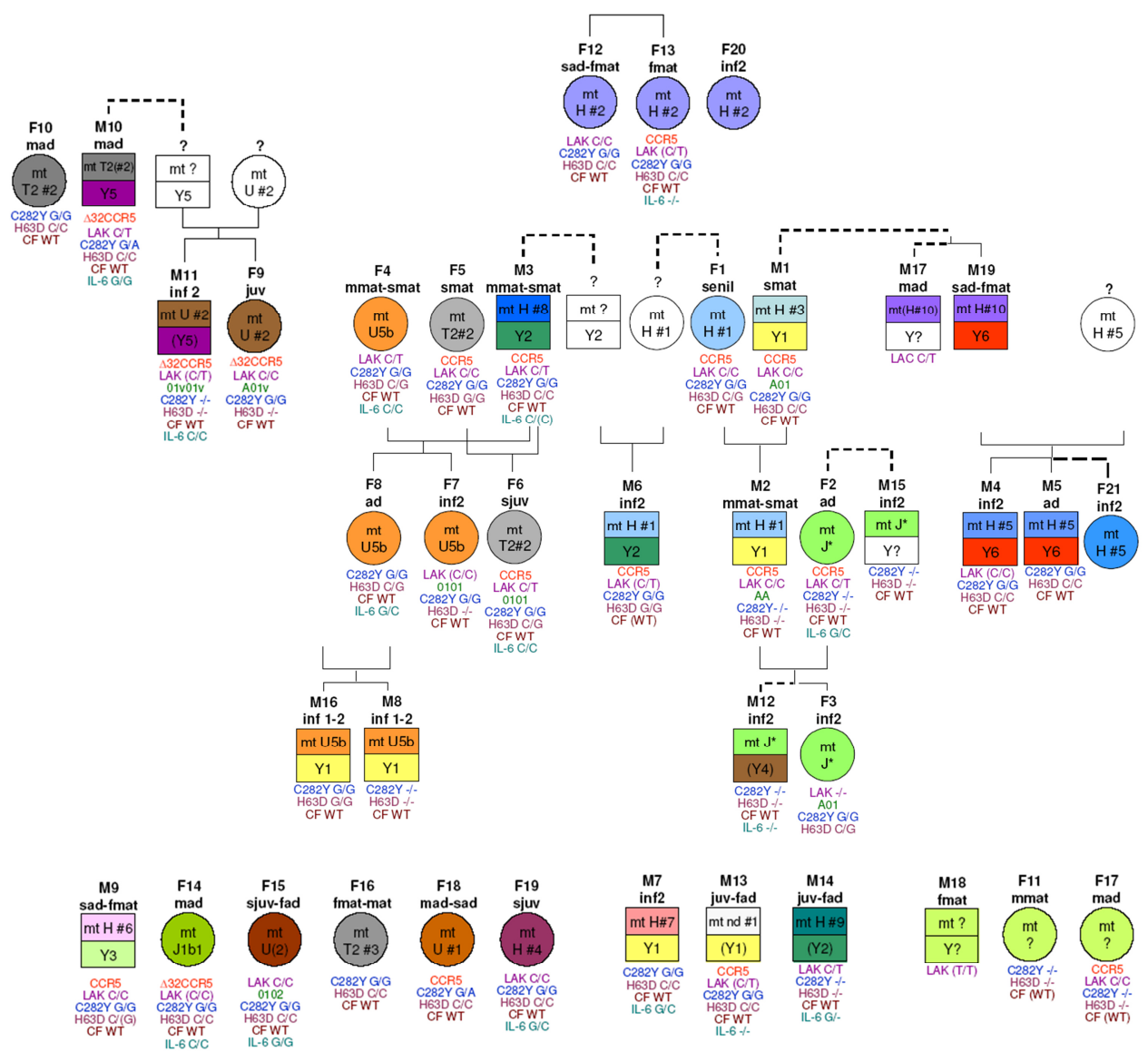

Abb. 11: Stammbaum für die Individuen aus der Lichtensteinhöhle (aus Schilz 2006). Männliche Individuen sind durch ein zweigeteiltes Quadrat symbolisiert. Im oberen Abschnitt ist der mitochondriale Haplotyp des jeweiligen Individuums angegeben, im unteren Abschnitt der Y-chromosomale Haplotyp. Weibliche Individuen sind durch einen Kreis symbolisiert, in dem der mitochondriale Haplotyp vermerkt ist. Gleiche Farben stehen für gleiche Haplotypen. 
Parallel zu den Untersuchungen an den cranialen Elementen, mit dem Ziel der Verwandtschaftsrekonstruktion, wurden Reihenuntersuchungen der genetischen Fingerabdrücke an Humeri (Mußlick 2005), Radii (Gaertner 2005), Tibiae (Croll 2005) und Calcanei (Klingner 2005) vorgenommen. Diese ersten Versuche, mehrere der disloziert vorliegenden Knochen einander zuzuordnen, sollten vor allem dazu dienen, über die Streumuster der Knochen eines jeweiligen Individuums Hinweise auf Bewegungsmuster der bronzezeitlichen Population innerhalb der Höhle und - davon abgeleitet - auf den damals noch nicht bekannten historischen Eingang zu erlangen.

Weitere Reihenuntersuchungen genetischer Fingerabdrücke wurden an verschiedenen Skelettelementen vorgenommen, welche als von Individuen der Altersklassen Infans I oder Infans II stammend eingeordnet werden konnten. Ziel dieser Arbeit war es, zu einem möglicherweise trepanierten Schädel (Fundnummer DO 3757) über den genetischen Fingerabdruck weitere Knochen zuzuordnen. Dies sollte Material für umfangreichere Untersuchungen nach einem - möglicherweise durch einen genetischen Defekt und damit verbundene physische oder psychische Auffälligkeiten bedingten Grund für die Behandlung mit einer Trepanation aufzeigen (Stauch 2005).

Aufgrund der Tatsache, dass nicht kremierte menschliche Knochen einer größeren Anzahl von Individuen überliefert waren und aufgrund des außergewöhnlich guten DNA Erhalts bot sich mit den Knochenfunden aus der Lichtensteinhöhle die Möglichkeit, tieferen Einblick in einen bronzezeitlichen Genpool zu erlangen. Diese wurde im Rahmen mehrerer molekulargenetischer Arbeiten zu verschiedenen Fragestellungen zu diversen Themenkomplexen genutzt.

Eine ganze Reihe von Arbeiten beschäftigte sich mit der Untersuchung der immungenetischen Ausstattung der Menschen, welche in der Lichtensteinhöhle bestattet waren. Es konnte ein PCR/RFLP- (polymerase chain reaction/restriction fragment length polymorphism) basiertes Analysesystem zur Untersuchung der AB0 Blutgruppeneigenschaften an degradierter DNA etabliert und auf einige Individuen aus der Lichtensteinhöhle angewandt werden (Hummel 2002, Schmidt 2004). Des Weiteren wurden in zwei Examensarbeiten single nucleotide polymorphisms (SNPs) der immungenetisch relevanten Gene IL6 (Interleukin 6) und IL10 (Interleukin 10) auf ihre Allelausprägung in den Individuen aus der Lichtensteinhöhle untersucht (Puder 2005, Suray 2007). Mit den immungenetisch relevanten Interleukinen und weiteren SNPs in den, ebenfalls in die Immunantwort des menschlichen Organismus involvierten, Tolllike Rezeptoren (TLRs) beschäftigte sich eine Dissertation zum Thema 
immungenetische Marker im Wandel der Zeit (Pepperl 2008). Als prähistorische Kontrollgruppe wurden in dieser Arbeit die Individuen aus der Lichtensteinhöhle herangezogen und auf alle untersuchten Marker hin analysiert. Eine Sonderstellung unter den immungenetischen Markern nimmt eine Variante im CCR5- (Cystein-Cystein linked Chemokin-Rezeptor 5) Gen ein, welche bei homozygotem Vorliegen eine Resistenz gegen das HI-Virus mit sich bringt (Dean et al. 1996). Diese für die Aidsforschung relevante Mutation wurde für die Individuen aus der Lichtensteinhöhle im Rahmen einer Examensarbeit analysiert (Bertermann 2004, Hummel et al. 2005).

Motivation für einige Arbeiten zu genetischen Varianten, welche über das individuelle Leben und Sterben eines Menschen entscheiden können, war die relativ große Anzahl vor allem männlicher - Individuen, welche in der Altersklasse Infans II verstorben waren. Da an den Knochen keine Spuren von Gewalteinwirkungen, wie z.B. durch Unfälle, zu sehen waren, welche todesursächlich hätten sein können, wurden die Individuen aus der Lichtensteinhöhle auf einige genetisch bedingte Krankheiten untersucht, die ein frühes Ableben erklären könnten. So verursacht z.B. die deltaF508Mutation im CFTR-Gen (Cystische-Fibrose-Transmembran-Regulator) die Krankheit Cystische Fibrose (auch Mukoviszidose genannt), welche i.d.R. zu einem relativ frühen Tod führt und wurde an den Knochen der Individuen aus der Lichtensteinhöhle untersucht (Scholten 2006). Die erbliche Eisenspeicherkrankheit (Hämochromatose), verursacht durch Mutationen im HFE-Gen (High Iron Fe), führt unbehandelt bei männlichen Individuen ebenfalls zu einer geminderten Lebenserwartung, weshalb die Individuen aus der Lichtensteinhöhle auf entsprechende Mutationen untersucht wurden (Krause 2006).

Ein Themenkomplex, welcher in der historischen Anthropologie von großem Interesse ist, beschäftigt sich mit der Erforschung von Subsistenzstrategien (prä-) historischer Populationen. In diesen Themenkomplex fallen die Untersuchungen des Laktosetoleranzmarkers C/T 13910, welcher die Expression des Laktasegens und damit die Fähigkeit, Milchzucker zu verdauen, beeinflusst (Fulge 2005).

Vor allem in der forensischen Genetik ist seit einigen Jahren die Forschung zur Rekonstruktion der Pigmentierung von Augen, Haaren und Haut mittels molekulargenetischer Methoden aus Spurenmaterial in den Focus gerückt. Diese Forschung ist auch für die historische Anthropologie von Interesse, wenn es darum geht, uns ein genaueres Bild vom äußeren Erscheinungsbild (prä-) historischer Individuen $\mathrm{zu}$ machen. Insbesondere für die Anfertigung von plastischen 
Rekonstruktionen zur Ausstellung in Museen wären wissenschaftlich fundierte Hinweise auf die realitätsgetreue Pigmentierung von Vorteil. Da die entsprechende Grundlagenforschung inzwischen belastbar genug ist, wurden für die Rekonstruktion von Pigmentierungsmerkmalen verschiedene Analysezugänge entwickelt (Schmidt 2004, Söchtig 2009).

Zwei weitere Examensarbeiten beschäftigten sich mit der Frage, ob sich im Erbgut der rezenten Bevölkerung in der Region um die Lichtensteinhöhle populationsgenetisch gesehen noch Spuren der genetischen Ausstattung der prähistorischen Population finden lassen. Anlass hierfür war die Tatsache, dass einige der für die prähistorischen Individuen ermittelten Y-chromosomalen Haplotypen gar keine oder nur sehr wenige Treffer bei der Abfrage in einer Datenbank mit weltweiten Frequenzdaten Ychromosomaler Haplotypen ergaben (Schilz 2006). Zusammen mit der Tatsache, dass Siedlungsspuren in der Region um die Lichtensteinhöhle auf eine kontinuierliche Besiedlung seit der Bronzezeit hinweisen, regte dies dazu an, populationsgenetische Daten rezenter Individuen in der Region zu erheben und über einen Vergleich mit den Datensätzen der bronzezeitlichen Individuen nach populationsgenetischen Hinweisen zu suchen, welche möglicherweise eine 3.000 Jahre lange Siedlungskontinuität stützen (Riesen 2007, Otto 2007). Es konnten tatsächlich zwei Personen identifiziert werden, die zu dem weltweit einzigartigen Y-Haplotypen Y1 die nach 3.000 Jahren statistisch zu erwartenden ca. 2 Abweichungen in ihrem Y-chromosomalen Muster aufweisen (Riesen 2007). Bei diesen beiden Personen handelt es sich mit einiger Wahrscheinlichkeit um Nachfahren der Menschen aus der Lichtensteinhöhle in direkter männlicher Linie. Zudem gab es eine Reihe von Personen, deren Y-chromosomale Haplotypen eine ähnliche Nähe zu dem Y-chromosomalen Haplotypen Y3 eines Individuums aus der Höhle aufwiesen. Da dieses Y-chromosomale Muster jedoch keine derartige weltweite Einzigartigkeit aufweist wie der Y-chromosomale Haplotyp Y1, kann hier lediglich abgeleitet werden, dass sich statistisch gesehen unter diesen Personen einige direkte Nachfahren der Menschen aus der Lichtensteinhöhle befinden, es kann jedoch nicht genau gesagt werden, welche Personen dies sind.

Die Ergebnisse der oben aufgeführten, anthropologischen Forschungsarbeiten wurden für eine museale Präsentation aufbereitet und sind - gemeinsam mit den Forschungsergebnissen der Archäologie, Archäozoologie und Archäobotanik - seit Juni 2008 in einer Dauerausstellung im Höhlen Erlebnis Zentrum Iberger Tropfsteinhöhle zu sehen (http://www.hoehlen-erlebnis-zentrum.de/). Von besonders großem Interesse für 
die Öffentlichkeit sind hierbei der Nachbau eines Teils der Höhle, die plastischen Rekonstruktionen dreier Individuen aus der Lichtensteinhöhle als Büsten, basierend auf den aufgefundenen Schädeln, und die Identifikation der wahrscheinlichen Nachfahren der Individuen aus der Lichtensteinhöhle.

In den Arbeiten, in welchen Reihenuntersuchungen genetischer Fingerabdrücke an Humeri, Radii, Tibiae und Calcanei (Mußlick 2005, Gaertner 2005, Croll 2005, Klingner 2005) vorgenommen wurden, konnten nicht nur einige der disloziert vorliegenden Knochen den bislang untersuchten cranialen Elementen oder Femora zugeordnet werden, es wurden auch bislang noch nicht bekannte STR- (short tandem repeat) Profile festgestellt. Damit ergaben sich also erste Hinweise darauf, dass mehr Individuen in der Höhle sein könnten, als allein durch die molekulargenetische Untersuchung cranialer Elemente und Femora zu erfassen waren. Infolge dessen wurden Arbeiten vorgenommen, welche zum Ziel hatten, die aufgefundenen Langknochen sowie die Knochen des Schulter- und Beckengürtels, zunächst mittels morphologischer Methoden, zu Individuen zu sortieren (Schiel 2008, Jungk 2008, Hollerbuhl 2009, Schubert 2009).

Die Arbeiten von Schiel (2008), Jungk (2008), Hollerbuhl (2009) und Schubert (2009) bestätigten eindeutig, dass die disloziert aufgefundenen Knochen in der Lichtensteinhöhle tatsächlich von deutlich mehr Individuen stammten, als bisher angenommen. Über die morphologischen Zuordnungen konnten 59 Individuen identifiziert werden. Ein Teil dieser Individuen war bereits zumindest mit ihrem genetischen Fingerabdruck auch molekulargenetisch erfasst, zum Ende der morphologischen Arbeiten lagen jedoch auch 6 Individuen vor, bei denen noch für keinen der einander zugeordneten Knochen genetische Daten erhoben worden waren.

Neben der Identifikation von deutlich mehr Individuen lieferten die Arbeiten zur morphologischen Zuordnung noch einen weiteren sehr interessanten Hinweis. Bei den morphologischen Zuordnungen wurden alle vollständigen Knochen einbezogen sowie auch fragmentierte Knochen, solange sie noch ausreichend beurteilbare und vergleichbare Merkmale aufwiesen. Für einige der hieraus resultierenden Individuen konnten mit großer Plausibilität alle Langknochen der oberen und unteren Extremitäten sowie alle Knochen des Schulter- und Beckengürtels zueinander geordnet werden. Bei einigen Individuen fanden sich jedoch für manche Skelettelementtypen keine Knochen, welche die passenden Alters-, Längen- und Robustizitätsmerkmale aufwiesen. Tatsächlich konnte keines der Individuen als „,vollständig“ vermerkt werden. Es war 
viel mehr die Regel, dass einzelne bis viele Knochen eines Individuums fehlten, d.h., nicht in der Höhle aufgefunden worden waren. So fehlten z.B. beim Individuum 11 die linke Clavicula und das Os sacrum (siehe Abb. 12); beim Individuum 12 die linke Clavicula, die rechte Scapula und die rechte Ulna (siehe Abb. 12). Das Individuum 1 war bis auf zwei kleine Teile des Beckens tatsächlich nur durch die obere Körperhälfte repräsentiert (siehe Abb. 12).

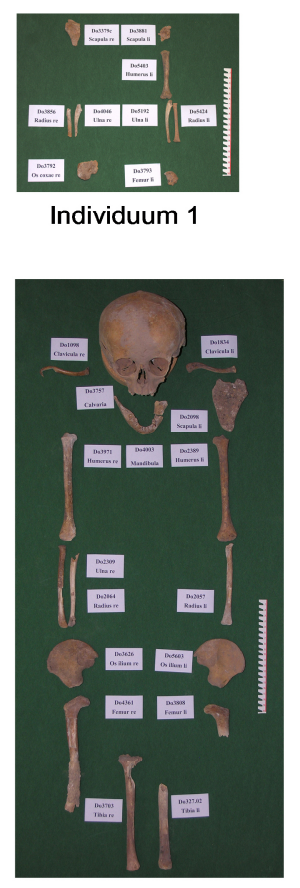

Individuum 4 $=$ M8 im Stammbaum

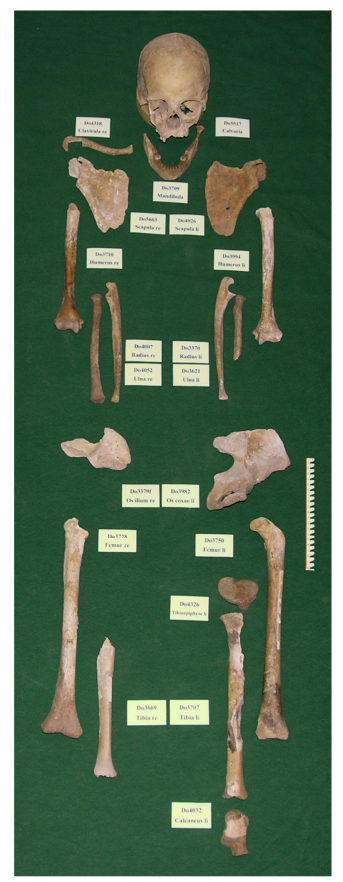

Individuum 11 = F6 im Stammbaum

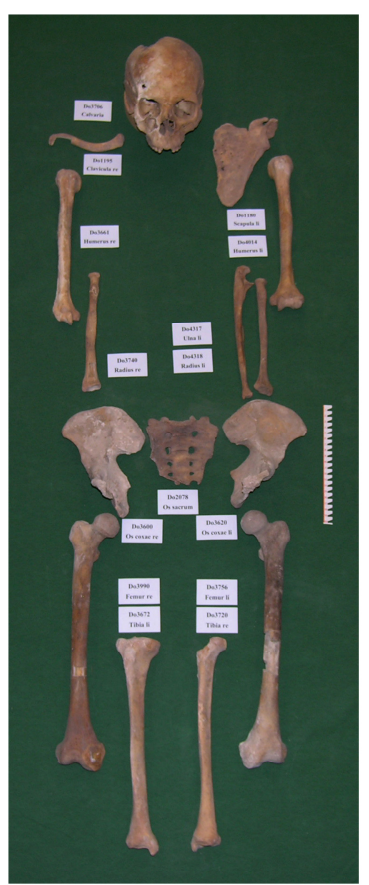

Individuum 12 = F5 im Stammbaum

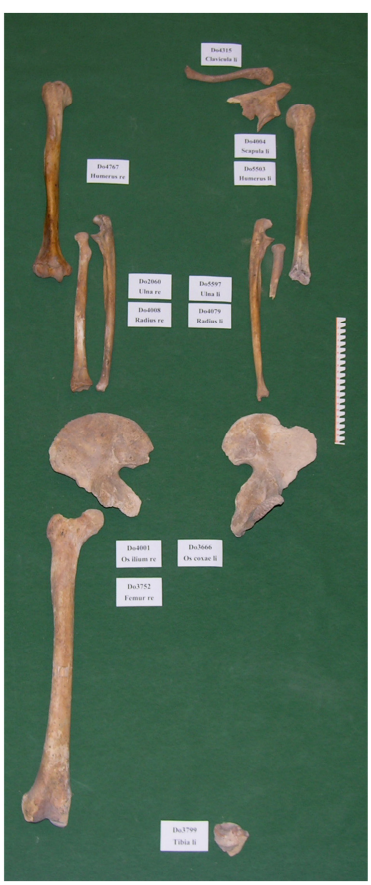

Individuum 15

Abb. 12: Morphologisch zu Individuen geordnete Knochen (Stand Hollerbuhl 2009, Schubert 2009).

Das Fehlen von Knochen warf natürlich die Frage nach dem „warum“ auf. Es kommen verschiedene Erklärungen in Frage. Zum einen könnten die Knochen natürlich durch Degradierung vergangen sein. Dies scheint allerdings relativ unwahrscheinlich, da es sich bei den fehlenden Knochen in vielen Fällen um große Langknochen handelt. Degradierung bis zur kompletten Auflösung wäre für kleinere, spongiöse Knochen durchaus zu erwarten, aber dass so viele größere Knochen davon betroffen sein sollten, scheint angesichts des allgemeinen Erhaltungszustandes und der guten Konservierungsbedingungen in der Höhle nicht plausibel. Es kann zwar grundsätzlich vorkommen, dass in verschiedenen Substraten auch sehr kleinräumig große Unterschiede in den chemisch-physikalischen Bedingungen - z.B. den pH-Wert betreffend - gegeben sind, was dazu führen kann, dass verschiedene Körperregionen 
eines liegend bestatteten Skelettes erhalten und andere komplett vergangen sind (Grupe 2007, Assis et al. 2015). Allerdings gibt es aus der Erhaltung der ja quasi flächendeckend aufgefundenen Knochenlage in der Lichtensteinhöhle keine Hinweise darauf, dass es Stellen in der Höhle gab, die ein entsprechend extrem abweichendes, ungünstiges Liegemilieu aufwiesen. Eine zweite Möglichkeit wäre, dass die Menschen, welche die Bestattungen vorgenommen und die Kulthandlungen im Berndsaal abgehalten hatten, Knochen wieder mit aus der Höhle hinaus genommen haben. Als eine dritte Möglichkeit käme in Frage, dass nicht alle Knochen in die Höhle eingebracht wurden, d.h. dass es sich bei der Lichtensteinhöhle nicht um einen Primär- sondern um einen Sekundärbestattungsplatz handelt.

\subsection{Forschung an alter DNA (aDNA)}

Die Forschung an alter DNA (aDNA) ist - verglichen mit anderen Disziplinen - immer noch ein relativ junges Forschungsgebiet. Zu Beginn, in den 1980er Jahren, stand zunächst die Sondierung der Möglichkeiten im Vordergrund, d.h. der basale Nachweis der Überdauerungsfähigkeit von Nukleinsäuren in verschiedenen Geweben menschlicher und tierischer Herkunft (Doran et al. 1986, Hagelberg et al. 1989, Hummel und Herrmann 1991). Inzwischen - nach drei Jahrzehnten - ist die aDNAForschung eine fest etablierte Disziplin, welche, über die Bereitstellung biologischer Daten, zur Lösung komplexer Problematiken auf der Grenze zwischen Geistes- und Naturwissenschaften beiträgt. Neben den verschiedensten inhaltlichen Fragestellungen ist die Forschung an alter DNA von Anfang an und bis heute begleitet von den Themen Authentizitätssicherung und Methodenweiterentwicklung.

Die Authentizitätssicherung spielt eine wichtige Rolle, da in altem Probenmaterial oft nur geringste Mengen an DNA überdauert haben, so dass bereits die Kontamination mit kleinsten Mengen moderner DNA zur Überdeckung der authentischen Signale und somit zu falschen Ergebnissen führen kann. Aufgrund dieser Problematik wurden in den letzten Jahrzehnten verschiedene Konzepte zur Authentizitätssicherung verfolgt. Ein Konzept fordert die Einbindung zweier unterschiedlicher Laborstandorte, in denen die Untersuchungen unabhängig repliziert werden sollen (Cooper und Poinar 2000, Hofreiter et al. 2001). Dieses Vorgehen ist insbesondere bei Analysen vergleichsweise konservativer DNA-Sequenzen sinnvoll, wie sie z.B. bei Fragen zur Migration, zur Phylogenie oder zur Evolution von Organismen untersucht werden. Beinhalten die Analysen hingegen die Untersuchung hochpolymorpher chromosomaler Sequenzen, die 
in jeder Generation der Neukombination unterliegen - wie z.B. die autosomalen STRs, welche den Genetischen Fingerabdruck bilden - so kann, über den replizierbaren Nachweis eines individuellen Musters und den Abgleich mit den genetischen Mustern der Bearbeiter, eine Kontamination i.d.R. ausgeschlossen bzw. zumindest aufgedeckt werden (Alonso et al. 2001, Capelli et al. 2003, Hummel 2003, Bouakaze et al. 2009).

Aufgrund der oft so geringen Targetkopienanzahl in alten Probenmaterialien bedeutet die Arbeit mit alter DNA häufig Arbeiten an der Grenze des Machbaren. Es ist notwendig, technische Entwicklungen im Bereich der molekularen Genetik zu verfolgen und Neuerungen, welche eine größere Sensitivität und/oder Zuverlässigkeit liefern, möglichst gut $\mathrm{zu}$ adaptieren. Eine der aktuellsten und absehbar einflussreichsten Entwicklungen in der aDNA-Forschung stellt z.B. der Einsatz von next generation sequencing (NGS) zur Darstellung gesamter genetischer Inventare dar (z.B. Kircher 2012). So konnten beispielsweise neue Erkenntnisse zur menschlichen Bevölkerungsgeschichte durch die Sequenzierungen größerer Teile eines Neandertaler-Genoms gewonnen werden (Green et al. 2010, Stoneking und Krause 2011). Aber auch basale Techniken, wie z.B. Extraktionsverfahren oder PCR Systeme, werden immer weiter entwickelt und optimiert (z.B. Amory et al. 2011, Campos et al. 2012, Seidenberg et al. 2012) und tragen damit zur Maximierung von Erkenntnismöglichkeiten bei.

Mit dem aktuellen Methodenrepertoire wird in verschiedenen Fragestellungsbezügen degradierte DNA menschlicher, tierischer, aber auch mikrobieller Herkunft analysiert. So können durch den molekulargenetischen Nachweis von humanpathogenen Mikroorganismen in menschlichem Skelettmaterial Krankheitsbelastungen historischer Bevölkerungen ermittelt (Matheson et al. 2009, Tsangaras und Greenwood 2012) oder historische Szenarien geprüft werden (Grumbkow et al. 2011). Im Forschungsschwerpunkt der conservation genetics und Umweltgeschichte werden aDNAMethoden zur Analyse prähistorischer Säugetierpopulationen eingesetzt, z.B. im Zusammenhang mit der Erforschung von Domestikationsprozessen (Edwards et al. 2007, Larson et al. 2007, Svensson und Götherström 2008, Cieslak et al. 2010, Gravlund et al. 2012, Ishida et al. 2012). Neben diesen überwiegend naturwissenschaftlich ausgerichteten Forschungsgebieten profitieren jedoch insbesondere die in den Geistes- und Kulturwissenschaften angesiedelten Forschungsvorhaben der Anthropologie und Archäologie von der mittlerweile fest etablierten Methodik. 
Ein Schwerpunkt liegt in der Analytik populationsgenetischer Daten, die zur Klärung prinzipiell verwandter Fragestellungen, wenn auch in grundlegend verschiedenen zeitlichen Dimensionen, eingesetzt werden. In diesen Zusammenhängen sind insbesondere mitochondriale Haplotypen von Interesse, mit deren Hilfe die Evolution des modernen Menschen beleuchtet wurde (z.B. Lalueza-Fox und Gilbert 2011). Ergänzt um Y-chromosomale Haplotypen werden die mitochondrialen Haplotypen auch zur Erforschung der wesentlich jüngeren Besiedelungs- und Kulturgeschichte auf verschiedenen Kontinenten eingesetzt (Underhill und Kivisild 2007). So wurden z.B. von Fehren-Schmitz et al. (2011) südamerikanische Migrationsmuster beschrieben. Die Neolithische Revolution und ihre populationsgenetischen Auswirkungen sind Forschungsgegenstand der Arbeiten von Haak et al. (2005), Lacan et al. (2011) und Sampietro et al. (2007).

Ein weiterer Schwerpunkt in der Beschreibung menschlicher Kulturgeschichte liegt in der Rekonstruktion von Heiratsmustern und, damit verknüpft, von Familienstrukturen innerhalb menschlicher Populationen. Molekulargenetische Verwandtschaftsrekonstruktionen können zur Aufdeckung sozialer Strukturen in (prä-) historischen Gesellschaften beitragen (Di Bernado et al. 2009, Gamba et al. 2011, Haak et al. 2008). In diesen Themenkomplex fällt z.B. der Nachweis patrilokaler Residenz im alemannischen Weingarten (Gerstenberger et al. 2002). Auch Teile der bereits vorgenommenen Forschung an den Funden aus der Lichtensteinhöhle (Schilz 2006) und der vorliegenden Forschungsarbeit sind in diesen Themenkomplex einzuordnen. Dass die Rekonstruktion von Verwandtschaftsbeziehungen eine der grundlegendsten Fragestellungen in der aDNA-Forschung ist, belegt auch die Tatsache, dass bereits eine der ersten Arbeiten zur Analyse von Makromolekülen aus prähistorischen Überresten genau diese verfolgte (Hansen und Gürtler 1983). Diese zunächst noch mittels HLATypisierungen angegangenen Versuche zur Verwandtschaftsrekonstruktion an Mumien der Inuit wurden später von Gilbert et al. (2007) mit modernen PCR-gestützten genetischen Analysen weiterverfolgt.

Etwas indirekter geeignet, weitere Aspekte von Kultur- und Siedlungsgeschichte näher $\mathrm{zu}$ beleuchten, sind auch die Analysen von genetischen Varianten, welche einen Selektionsvorteil im Kontext bestimmter kultureller oder umwelthistorischer Wandlungen mit sich brachten. So tragen beispielsweise die Nachweise von neolithischer Milchzuckerunverträglichkeit (Burger et al. 2007) und einer Variante des CCR5-Genes in bronzezeitlichen Skeletten (Hummel et al. 2005) zu diesem 
Fragenkomplex bei. Ebenso sind auch Untersuchungen zu zeitlichen und räumlichen Verteilungsmustern verschiedener genetischer Varianten, die entweder krankheitsauslösenden oder den Immunstatus betreffenden Charakter haben grundsätzlich geeignet, zu bevölkerungsgeschichtlichen Fragestellungen beizutragen. Beispiele hierfür sind Nachweise von Sichelzellanämie (Faerman et al. 2000), Mukoviszidose (Bramanti et al. 2000) oder Interleukinvarianten (Larcombe et al. 2005) aus archäologischem Skelettmaterial.

Weitere Zweige der aDNA-Forschung beschäftigen sich weniger mit populations- bzw. kulturgeschichtlichen Aspekten, sondern mit enger an einzelne Individuen geknüpften Fragestellungen. Eine dieser Fragestellungen betrifft z.B. die Identifizierung der Überreste historischer Persönlichkeiten über den Verwandtschaftsnachweis (z.B. Malmström et al. 2012). Von großem öffentlichen Interesse begleitet wurde die Kontroverse um die Identifizierung der sterblichen Überreste des Zaren Nikolaus II und seiner Familie, die in jüngerer Zeit nach jahrelangem Zweifel abschließend geklärt werden konnte (Rogaev et al. 2009). Ebenfalls von großem öffentlichen Interesse begleitet wurden die Untersuchungen an 2.500 Jahre alten Überresten eines eisenzeitlichen Mädchens aus dem niedersächsischen Uchter Moor, einem der ältesten Moorleichenfunde Deutschlands (Püschel et al. 2005).

Durch die, vor allem auch im Interesse der Rechtsmedizin vorangetriebene, Grundlagenforschung der letzten Jahre bezüglich der Rekonstruktion der Pigmentierung von Augen-, Haar- und Hautfarbe wurden auch für die aDNA-Forschung neue Werkzeuge zur Verfügung gestellt, um das äußere Erscheinungsbild unserer (prä-) historischen Vorfahren zu rekonstruieren (Bouakaze et al. 2009). Damit wird es möglich, ein wissenschaftlich fundiertes, greifbares Bild unserer Vorfahren lebendig werden $\mathrm{zu}$ lassen, was insbesondere für die Vermittlung auch abstrakterer Forschungsinhalte an ein breites Publikum - zum Beispiel in Museen - von herausragender Bedeutung ist. 


\subsection{Zielsetzung der Arbeit}

Ziel der aktuellen Forschungsarbeit ist die Erweiterung der bereits durchgeführten anthropologisch-paläogenetischen Untersuchungen (siehe Kapitel 1.4) auf die mittlerweile vollständig geborgenen Bestatteten. $\mathrm{Zu}$ Beginn des Projektes soll die tatsächliche Individuenzahl mittels morphologischer Methoden bestimmt sowie über molekulargenetische Analysen des genetischen Fingerabdruckes abgesichert werden. Im Rahmen dieses Arbeitsabschnittes soll eine morphologische Untersuchung aller Skelettelemente erfolgen und die Zuordnung der dislozierten Skelettelemente zu den einzelnen Individuen mit Hilfe der morphologischen und genetischen Methoden weitest möglich durchgeführt werden. In begleitenden Arbeiten soll auf Muster in der Verteilung der Knochen bezüglich verschiedener Aspekte geprüft werden, woraus Hinweise auf Nutzungsart, Nutzungsdauer und mögliche Nutzungswechsel der Höhle gewonnen werden sollen.

Die rekonstruierten Individuen sollen morphologisch und histologisch untersucht werden um Daten zu Alter, Geschlecht, Körperhöhe und ggf. vorhandener Besonderheiten - wie z.B. Spuren von Erkrankungen oder Verletzungen - zu gewinnen. Diese Daten ermöglichen zum einen eine Rekonstruktion der demografischen Struktur der Population und können zum anderen Aufschluss über individuelle und kollektive Biographien geben.

Neben den morphologischen und histologischen Untersuchungen sollen umfassende molekulargenetische Analysen durchgeführt werden. Ein Schwerpunkt hierbei liegt in der Fortsetzung der Verwandtschaftsrekonstruktion unter Einbeziehung aller inzwischen identifizierten Individuen. Für den Teil der Individuen, für den dies bis dahin noch nicht erfolgt ist, sollen die genetischen Fingerabdrücke sowie die mitochondrialen und Ychromosomalen Haplotypen ermittelt werden und mittels dieser Daten die genealogische Struktur der Bestatteten weiter aufgeklärt und Lücken im vorhandenen Stammbaum geschlossen werden. Die Y-chromosomalen Haplotypen sollen zudem populationsgenetisch ausgewertet werden um eventuell Hinweise auf eine geografische Herkunft der bestatteten Population zu erlangen.

In begleitenden Arbeiten sollen ferner für eine Reihe verschiedenster genetischer Marker die bereits vorhandenen Daten um die von neu identifizierten Individuen ergänzt bzw. Daten für alle Individuen erhoben werden. Dies geschieht mit der Absicht, Fragen zur Krankheitsbelastung, Subsistenzstrategie, immungenetischen Ausstattung und zum Phänotyp der Individuen zu beantworten. Hierzu gehören die 
immungenetischen Marker CCR5, AB0 und Rhesusfaktor, Marker der Laktosetoleranz sowie Marker, die Aufschluss über Augen- und Haarfarbe der Individuen geben. Zusätzlich zu den individualbiografischen Informationen, die z.T. aus diesen Analysen abgeleitet werden können, können diese Daten auch in einem übergeordneten evolutionsbiologischen und bevölkerungsgeschichtlichen Kontext relevant sein. Mit der Gesamtheit der genetischen Arbeiten soll die Grundlage für die Erschließung eines bronzezeitlichen genetischen Archivs geleistet werden. Zum Abschluss der Arbeiten soll eine Gesamtschau und Gesamtinterpretation unter Einbeziehung von Ergebnissen der archäologischen Forschung erfolgen. 


\section{Material}

\subsection{Erstellung des Fundkataloges}

Mit Beginn der Bergung der menschlichen Skelettelemente und der anthropologischen Bearbeitung wurde mit der Erstellung eines umfassenden Fundkataloges begonnen. Während der Grabung wurde nicht jedes Skelettelement einzeln mit einer separaten Fundnummer erfasst. Die Mehrheit der Knochen war in Sammeltüten geborgen worden. Anfänglich erfolgten eine Bestandsaufnahme und eine Bestimmung des jeweiligen Skelettelements. Zu Beginn dieser Arbeit wurden die Sammelfunde aufgeteilt und jedes Skelettelement mit einer eindeutigen Unterfundnummer versehen. Dabei wurden die morphologischen Bestimmungen überprüft und ggf. korrigiert. Es wurde eine Access Datenbank erstellt, in der 4.342 Datensätze - bestehend aus Fundnummer, Skelettelement, Erhaltungszustand, wenn möglich Geschlechtsbestimmung und Altersbestimmung - erfasst sind (siehe beigefügte CD: Lichtensteinhöhle Fundkatalog Menschenknochen.accdb). Einige wenige Fundnummern umfassen weiterhin mehrere Knochenfragmente. Funde, bei denen nicht genau festgestellt werden konnte, von wie vielen Knochen die Fragmente stammten, wurden nicht separiert. Dies traf z.B. häufiger bei fragmentierten Rippen oder auch bei kleinsten, nicht weiter zu identifizierenden Knochenfragmenten bzw. Knochensplittern zu.

\subsection{Erhaltungszustand des Skelettmaterials}

Das Skelettmaterial aus der Lichtensteinhöhle war bis zur Bergung von einer Gipssinterschicht überzogen. Diese zeigte durch ihre Intaktheit und Dicke, dass die Fundsituation seit prähistorischer Zeit nicht gestört worden war und dass das Material über mehrere tausend Jahre permanent einem basischen Milieu und den niedrigen Temperaturen (ca. 4-8 ${ }^{\circ} \mathrm{C}$ ) in der Höhle ausgesetzt war. Diese Bedingungen sind optimal für den Erhalt der Knochenstruktur und - wie sich bei den ersten molekulargenetischen Analysen bestätigte - auch der eingeschlossenen DNA. Ein großer Teil der Knochen befand sich in einem hervorragenden Erhaltungszustand. Allerdings variierte der Erhaltungszustand über die Höhlenabschnitte hinweg in Abhängigkeit von z.B. Kontakt zu Sediment in einigen Abschnitten. Während im Berndsaal die Knochen mehrheitlich intakt waren, fand sich in der Reinhardsgrotte und der Fiddikluft neben intakten Elementen auch ein großer Anteil an zerbrochenen und/oder stark degradierten Knochen. Die Abbildungen 13-18 geben einen Eindruck der Bandbreite des Erhaltungszustandes des Skelettmaterials wieder. Neben 
unterschiedlichem Degradierungszustand weisen einige Elemente des Knochenmaterials Auffälligkeiten, wie z.B. Verfärbungen durch Vivianit oder Kupfer, Brushitausblühungen, Spuren oder Verfärbungen durch Mikroorganismenbefall, oder Spuren von Feuer bzw. Hitzeeinwirkung, auf.

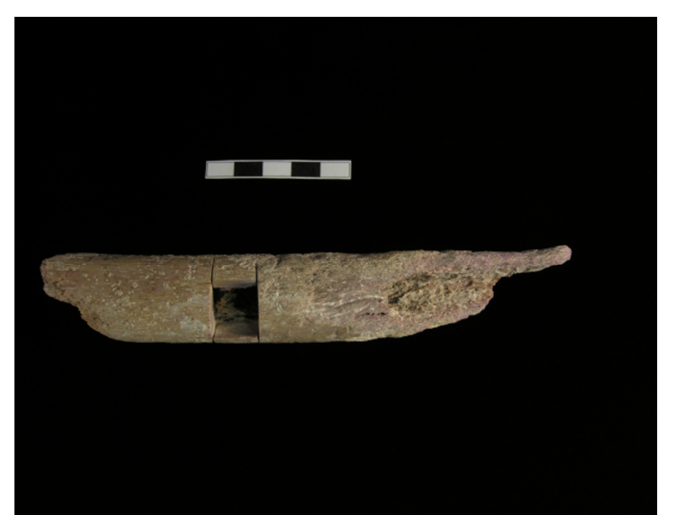

Abb. 13: Fragment eines Femurs (DO 87.11) mit Verfärbungen durch Vivianit.

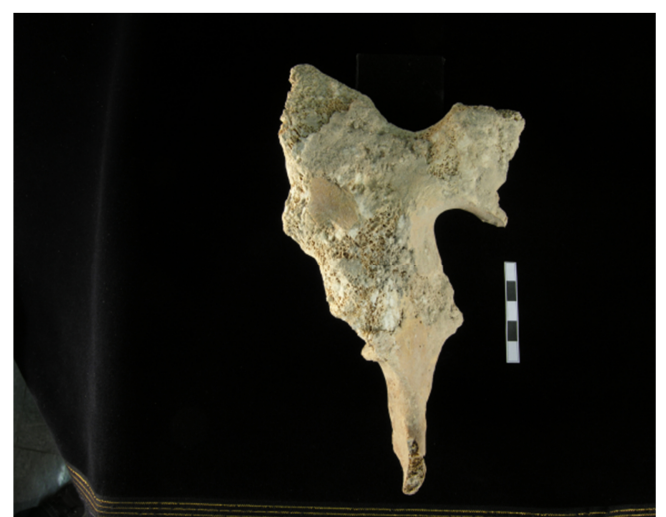

Abb. 15: Beckenfragment DO 481 mit Brushitausblühungen.

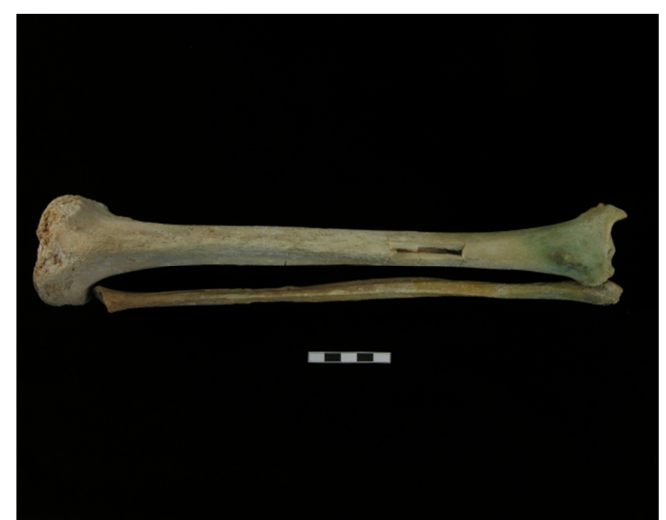

Abb. 14: Sehr gut erhaltene Tibia DO E 06 und dazugehörige Fibula DO 1775.02 mit Kupferverfärbungen im Knöchelbereich.

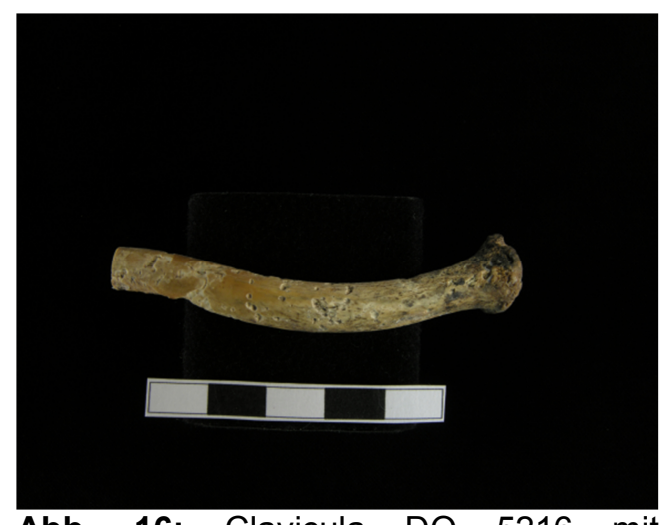

Abb. 16: Clavicula DO 5216 mit schwärzlichen Verfärbungen durch Mikroorganismenbefall. 


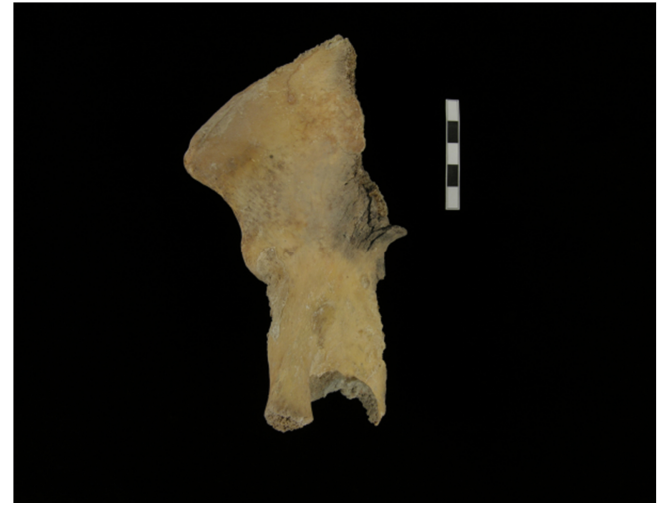

Abb. 17: Beckenfragment DO 383 mit schwärzlichen Verfärbungen durch Hitzeeinwirkung.

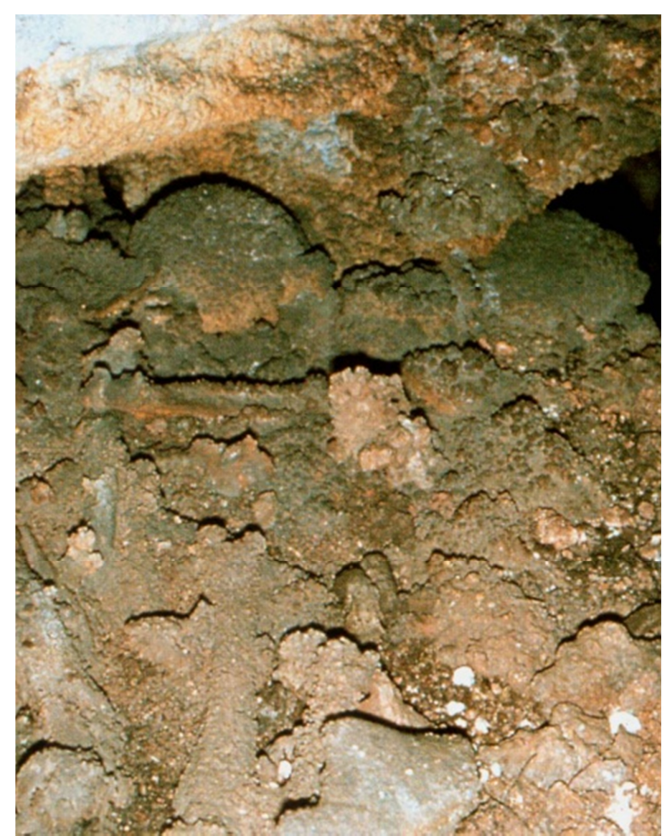

Abb. 18: Ausschnitt der Fundsituation in der Fiddikluft. $\mathrm{Zu}$ sehen ist im oberen Bereich ein Stück Felswand und darunter die mit Gipssinter überzogene Knochenlage (aus Flindt und Hummel 2014).

\subsection{Materialauswahl Morphologie}

Für die morphologischen Zuordnungen wurden alle Langknochen der oberen und unteren Extremität sowie die Elemente des Schulter- und Beckengürtels herangezogen. Hierbei wurden neben intakten Knochen auch Knochenfragmente einbezogen, solange ausreichend Charakteristika für einen Vergleich vorhanden waren. Ausgenommen wurden sehr kleine Fragmente, z.B. wenn bei einem Langknochen nicht einmal der Knochendurchmesser festgestellt werden konnte. Unter der Annahme, dass es wahrscheinlicher ist, Knochen eines Individuums in räumlicher Nähe aufzufinden, als über eine längere Strecke verstreut, wurden die Vergleiche für die Zuordnungen zunächst innerhalb der einzelnen Höhlenabschnitte vorgenommen (Schiel 2008, Jungk 2008, Hollerbuhl 2009, Schubert 2009). Im Anschluss wurde für noch nicht bereits zugeordnete Skelettelemente der Vergleich auf die anderen Höhlenabschnitte ausgeweitet. Zu Beginn dieser Arbeit wurden - aufbauend auf die vorhergegangenen Arbeiten - die morphologischen Zuordnungen über alle Höhlenabschnitte hinweg abgeschlossen. Hierbei wurden vor allem die bisher nicht eindeutigen Fälle untersucht. Im Zweifelsfall wurde eine Zuordnung nach nicht vorhandenen Gegenhinweisen aufgrund von Plausibilität vorgenommen; basierend auf dem Parsimonieprinzip, dass es wahrscheinlicher ist, dass ein Knochen $\mathrm{zu}$ einem bereits existierenden 
Knochenensemble gehört, als dass er ein weiteres, separates, nur durch diesen einen Knochen vertretenes Individuum darstellt.

\subsection{Materialauswahl Genetik}

Genetische Analysen waren ursprünglich vorwiegend an linken Femora und cranialen Elementen vorgenommen worden (Schultes 2000, Schilz 2006). Durch Reihentypisierungen in mehreren Examensarbeiten mit verschiedenen Fragestellungen wurden auch Daten des genetischen Fingerabdruckes für Humeri, Radii, Tibiae und Calcanei und einzelne weitere Skelettelemente generiert (Croll 2005, Gaertner 2005, Klingner 2005, Mußlick 2005). Diese Arbeiten wurden vor den morphologischen Zuordnungen der einzelnen Elemente zu Individuen durchgeführt. Eine weitere Examensarbeit - durchgeführt im Anschluss an die morphologischen Zuordnungen untersuchte gezielt bestimmte Knochen, die die Anknüpfpunkte für die Zuordnungen von oberer zu unterer Körperhälfte bilden, um diese morphologischen oben-untenZuordnungen molekulargenetisch zu überprüfen (Becker 2011).

In dieser Arbeit wurden alle bereits vorhandenen molekulargenetischen Ergebnisse berücksichtigt. Teilweise noch unsichere oder zwischen den verschiedenen Arbeiten nicht konsistente Daten wurden erweitert oder geprüft. Durch Umordnungen von zunächst morphologisch zugeordneten Elementen, bei denen die ersten molekulargenetischen Überprüfungen ergaben, dass diese Zuordnungen nicht richtig waren, wurden in einigen Fällen weitere Zuordnungsprüfungen bzw. Ergänzungen von Daten notwendig. Insbesondere war dies der Fall, wenn sich durch weitere Zuordnungen bzw. Umordnungen neu entstandene Individuen ergaben. In solchen Fällen mussten nicht nur die genetischen Fingerabdrücke generiert, sondern auch die für die Verwandtschaftsanalyse benötigten mitochondrialen und Y-chromosomalen Haplotypen ermittelt werden. Die beiden letzteren Datenqualitäten mussten für eine ganze Reihe von neu entstandenen, bisher nur durch einen individuellen genetischen Fingerabdruck identifizierten, Individuen analysiert werden.

Durch die ausführlichen vorhergegangenen Bearbeitungsphasen konnte in dieser Arbeit für einige Knochen auf bestehende DNA-Extrakte zurückgegriffen werden, in anderen Fällen stand Knochenpulver zur Verfügung, eine Reihe von Knochen musste jedoch erstmalig oder neu beprobt werden. Insgesamt wurde in dieser Arbeit von fast allen Individuen mindestens ein Skelettelement untersucht, in einigen Fällen auch bis zu vier 
verschiedene. Tabelle 1 gibt eine Übersicht, welche Skelettelemente von den jeweiligen Individuen untersucht und welche Markerqualitäten jeweils analysiert wurden.

Die Namen der Individuen setzen sich zusammen aus der Abkürzung „DO“ für Dorste (nächst gelegene Ortschaft zur Lichtensteinhöhle), der/den Abkürzung/en für die Höhlenabschnitte, aus denen die zueinander geordneten Skelettelemente stammen sowie der Fundnummer eines gut erhaltenen, repräsentativen Knochens des jeweiligen Individuums.

Tabelle 1: Übersicht über die Skelettelemente, die molekulargenetisch bearbeitet wurden, ihre Individuenzugehörigkeit und die Art der untersuchten genetischen Marker.

\begin{tabular}{|c|c|c|c|c|c|c|c|}
\hline Individuum [DO \#] & $\begin{array}{l}\text { Knochen } \\
\text { Fund Nr. }\end{array}$ & Element & STRs & Y STRs & HVR I & HVR II & $\begin{array}{c}\text { Sex } \\
\text { Multiplex }\end{array}$ \\
\hline \multirow[t]{4}{*}{ FK/HS/RG 35 (M4) } & DO 58.16 & Hu re & + & & & & \\
\hline & DO 107 & Ti re & + & & & & \\
\hline & DO 900.03 & Calv & + & & & & \\
\hline & DO 934.01 & Hu li & + & & & & \\
\hline \multirow[t]{3}{*}{ FK/RG/BS 38 (F1) } & DO 39 & Ti re & + & & & & \\
\hline & DO 40 & Hu li & + & & & & \\
\hline & DO 72.01 & UI li & + & & & & \\
\hline \multirow[t]{3}{*}{ RG/FK 57.02 (M17/M19) } & DO 57.02 & Fe li & + & & & & \\
\hline & DO 58.13 & Hu li & + & & & & \\
\hline & DO OF 2 & Hu re & + & & & & \\
\hline \multirow[t]{2}{*}{ RG/FK 58.01} & DO 58.01 & Fe li & + & & + & & \\
\hline & DO 65.03 & Ti li & + & & + & + & \\
\hline \multirow[t]{3}{*}{ RG/FK 58.03 (M13) } & DO 58.03 & Fe li & + & + & + & + & \\
\hline & DO 65.01 & Fe re & + & + & + & + & \\
\hline & DO 533.02 & Ti re & & + & & & \\
\hline \multirow[t]{3}{*}{ RG/FK/KS 58.08 (M7) } & DO 58.08 & Fe re & + & & + & & \\
\hline & DO 220 & Ti li & + & & & & \\
\hline & DO 926.03 & Hu re & + & & & & \\
\hline RG/HS/BS 65.05 & DO 65.05 & Hu re & + & & + & + & \\
\hline \multirow[t]{2}{*}{ RG 66.02} & DO 58.06 & Fe re & + & & & & \\
\hline & DO 66.02 & Fe li & + & + & + & + & \\
\hline \multirow[t]{3}{*}{ RG/FK 67.03 (F10/F17) } & DO 67.03 & Fe re & + & & & & \\
\hline & DO 300.01 & Fe li & + & & & & \\
\hline & DO 411.01 & Hu re & + & & & & \\
\hline BS 133.01 & DO 133.01 & Hu li & + & + & + & + & \\
\hline \multirow[t]{5}{*}{ RG/GK/BS 183.01 (M11) } & DO 183.01 & Fe li & + & + & & & \\
\hline & DO 204.02 & Fe re & + & + & & & \\
\hline & DO 305.01 & Hu li & + & & & & \\
\hline & DO 398.02 & Z 36 & + & & & & \\
\hline & DO 1004.01 & Hu re & + & & & & \\
\hline
\end{tabular}


Fortsetzung Tabelle 1: Übersicht über die Skelettelemente, die molekulargenetisch bearbeitet wurden, ihre Individuenzugehörigkeit und die Art der untersuchten genetischen Marker.

\begin{tabular}{|c|c|c|c|c|c|c|c|}
\hline Individuum [DO \#] & $\begin{array}{l}\text { Knochen } \\
\text { Fund Nr. }\end{array}$ & Element & STRs & Y STRs & HVR I & HVR II & $\begin{array}{c}\text { Sex } \\
\text { Multiplex }\end{array}$ \\
\hline RG/BS 187 & DO 187 & Hu re & + & & + & + & \\
\hline RG/FK/BS 516 & DO 516 & Hu li & + & & + & + & \\
\hline \multirow[t]{3}{*}{ FK/RG/HS/BS 901.01 (M18/F16) } & DO 901.01 & Fe re & + & & + & & \\
\hline & DO 914.01 & Hu re & + & & & & + \\
\hline & DO R 2 & Calv & + & & & & + \\
\hline \multirow[t]{3}{*}{ FK/RG/HS 902.01 (M10) } & DO 480.01 & Mand & + & & & & \\
\hline & DO 902.01 & Fe li & & & + & & \\
\hline & DO OF 1 & Hu li & + & & & & \\
\hline \multirow[t]{3}{*}{ FK/HS/RG/BS 903.01} & DO 900.01 & Fe re & + & & & & \\
\hline & DO 901.03 & Ti re & + & & + & + & \\
\hline & DO 903.01 & Fe li & + & & & & \\
\hline FK/RG/HS/BS 903.02 & DO 58.04 & Fe re & + & + & + & + & \\
\hline FK/RG/JS 904.04 & DO 904.04 & Fe re & + & & + & + & \\
\hline \multirow[t]{2}{*}{ FK/RG 905.01 (M14) } & DO 901.02 & Hu li & + & & + & & \\
\hline & DO 905.01 & Fe li & + & + & & & \\
\hline \multirow[t]{2}{*}{ FK/RG/BS 907.01} & DO 907.01 & Fe li & + & + & + & + & \\
\hline & DO 1494 & Hu li & + & & & & \\
\hline RG/FK 1076 (M1) & DO 201 & Ti re & + & & & & \\
\hline \multirow[t]{4}{*}{ RG/FK/BS 1078 (F13) } & DO 204.01 & Hu re & + & & & & + \\
\hline & DO 385 & Fe re & + & & + & & \\
\hline & DO 1044 & Fe li & & & & & + \\
\hline & DO 1078 & Mand & + & & & & + \\
\hline \multirow[t]{2}{*}{ BS 1102 (M2) } & DO 1102 & Fe li & + & & & & \\
\hline & DO 3670 & Hu li & + & & & & \\
\hline BS/RG 1103 (F14) & DO 1103 & Fe li & + & & & & \\
\hline \multirow[t]{2}{*}{ BS/RG 1176 (F18) } & DO 199 & Fe li & + & & & & \\
\hline & DO 6458 & Hu li & + & & & & \\
\hline BS/RG/FK 1247 (F7) & DO 6495 & Hu re & + & & & & \\
\hline \multirow[t]{2}{*}{ HS/GK 1461} & DO 1461 & Ra li & + & + & + & + & + \\
\hline & DO 3157 & Ti li & + & & & & \\
\hline HS/BS 1467.01 & DO 1467.01 & $\mathrm{Hu} \mathrm{li}$ & + & + & + & + & \\
\hline \multirow[t]{2}{*}{ HS/GK/BS 1471} & DO 1471 & Fe li & + & + & + & + & \\
\hline & DO 2915 & Hu re & + & & & & \\
\hline RG/BS/DS 1482 (M3) & DO 1911 & Fe li & + & & & & \\
\hline \multirow[t]{2}{*}{ RG/BS 1500 (F2) } & DO 1827.01 & Fe re & + & & & & \\
\hline & DO 2125 & UI li & + & & & & \\
\hline \multirow[t]{3}{*}{ HS/GK 1547.01} & DO 1547.01 & Ti li & + & & + & + & \\
\hline & DO 1744.35 & Ti re & + & & + & + & \\
\hline & DO 1775.03 & Hu li & + & & & & \\
\hline
\end{tabular}


Fortsetzung Tabelle 1: Übersicht über die Skelettelemente, die molekulargenetisch bearbeitet wurden, ihre Individuenzugehörigkeit und die Art der untersuchten genetischen Marker.

\begin{tabular}{|c|c|c|c|c|c|c|c|}
\hline Individuum [DO \#] & $\begin{array}{l}\text { Knochen } \\
\text { Fund Nr. }\end{array}$ & Element & STRs & Y STRs & HVR I & HVR II & $\begin{array}{c}\text { Sex } \\
\text { Multiplex }\end{array}$ \\
\hline \multirow[t]{2}{*}{ HS/GK 1547.03} & DO 1547.03 & Hu re & + & & + & + & \\
\hline & DO 3299 & Ti re & + & & & & \\
\hline \multirow[t]{2}{*}{ HS/GK 1548.01} & DO 1462 & Hu li & + & & & & \\
\hline & DO 1548.01 & Ti re & + & + & + & + & \\
\hline \multirow[t]{3}{*}{ HS/GK 1585.03 (F19) } & DO 1585.03 & Hu re & + & & & & \\
\hline & DO 1585.07 & Fe li & + & & & & \\
\hline & DO E 06 & Ti re & + & & & & \\
\hline \multirow[t]{2}{*}{ BS/FK/GK/HS 1745.02} & DO 1745.02 & Cox li & + & & + & + & \\
\hline & DO 3622 & Fe li & + & & & & + \\
\hline RG/BS 1905 (M9) & DO 1917 & Hu re & + & & & & \\
\hline \multirow[t]{3}{*}{ BS/FK 2030.01 (M6) } & DO 2030.01 & Fe li & + & + & & & \\
\hline & DO 2102 & Cox re & + & & & & \\
\hline & DO 3630 & Hu li & + & + & + & & \\
\hline BS 2263 (M15) & DO 2263 & Mand & + & & & & \\
\hline GK/HS/RG 2588 (F15) & DO 2588 & Ti re & + & & + & & \\
\hline \multirow[t]{3}{*}{ BS 3628 (F3) } & DO 1746.05 & Pp li & + & & & & \\
\hline & DO 1746.06 & Pp re & + & & & & \\
\hline & DO 2255.03 & Hu re & + & & + & & \\
\hline \multirow[t]{2}{*}{ BS 3695 (F4) } & DO 3727 & Fe li & + & & + & & \\
\hline & DO 4013 & Hu re & + & & + & & \\
\hline \multirow[t]{2}{*}{ BS 3706 (F5/F11) } & DO 3713 & Mand & + & & & & \\
\hline & DO 3756 & Fe li & + & & & & \\
\hline \multirow[t]{2}{*}{ BS/FK 3714} & DO 3714 & Hu li & + & + & + & + & + \\
\hline & DO 4077 & Fe re & & + & & & \\
\hline \multirow[t]{2}{*}{ BS/FK 3742 (F9) } & DO 3742 & Fe li & + & & & & + \\
\hline & DO 3746 & Mand & & & & & + \\
\hline \multirow[t]{2}{*}{ BS/RG 3748 (F8) } & DO 3664 & Hu li & + & & + & & \\
\hline & DO 5521 & Hu re & + & & & & \\
\hline \multirow[t]{3}{*}{ BS 3757 (M8) } & DO 3757 & Calv & + & & + & & \\
\hline & DO 3971 & Hu re & + & & & & \\
\hline & DO 4361.01 & Fe re & & + & & & \\
\hline \multirow[t]{4}{*}{ BS/RG/FK/HS 3886 (M16) } & DO 3886 & Calv & + & & & & \\
\hline & DO 1150.01 & Fe li & & & + & & \\
\hline & DO 3793 & Fe li & + & & & & \\
\hline & DO 5403 & Hu li & + & + & + & + & \\
\hline BS/FK 4008 (M5) & DO 2096 & Ti re & + & + & & & \\
\hline \multirow[t]{2}{*}{ BS/GK 4310.01} & DO 3812 & Hu li & + & + & & & \\
\hline & DO 4310.01 & Ra re & + & & + & + & \\
\hline BS 5517 (F6) & DO 3994 & Hu li & + & & & & \\
\hline
\end{tabular}


Fortsetzung Tabelle 1: Übersicht über die Skelettelemente, die molekulargenetisch bearbeitet wurden, ihre Individuenzugehörigkeit und die Art der untersuchten genetischen Marker.

\begin{tabular}{|c|c|c|c|c|c|c|c|}
\hline Individuum [DO \#] & $\begin{array}{l}\text { Knochen } \\
\text { Fund Nr. }\end{array}$ & Element & STRs & Y STRs & HVR I & HVR II & $\begin{array}{c}\text { Sex } \\
\text { Multiplex }\end{array}$ \\
\hline \multirow[t]{2}{*}{ JS 7043.01} & DO 6962 & Fe li & + & + & & & \\
\hline & DO 7043.01 & Pp re & + & + & + & + & \\
\hline \multirow[t]{4}{*}{ JS 7075.01} & DO 7058 & Ti li & + & & & & \\
\hline & DO 7060 & Z 43 & + & & + & + & \\
\hline & DO 7075.01 & Z 14 & + & & & & \\
\hline & DO 7230 & Hu re & + & & & & \\
\hline \multirow[t]{3}{*}{ FK/KS E 11} & DO 913.01 & Ti re & + & + & + & & \\
\hline & DO E 11 & Hu re & + & + & + & + & \\
\hline & DO E 12 & Hu li & + & & & & \\
\hline E 33 (M12) & DO E 33 & Mand & + & + & & & \\
\hline E 37 (F21) & DO E 37 & Calv & + & + & & & \\
\hline \multirow[t]{3}{*}{ HS/GK N 957.01} & DO 1774.02 & Hu re & + & & & & \\
\hline & DO N 957.01 & $\mathrm{Cl}$ re & + & & + & + & \\
\hline & DO N 968.05 & Hu li & + & & & & \\
\hline \multirow[t]{2}{*}{ BS/FK/RG/HS/GK/KS N 962.01} & DO 4047 & Ti re & + & & & & \\
\hline & DO N 962.01 & Ra li & + & & + & + & \\
\hline \multirow[t]{2}{*}{ R 1 (F12) } & DO 67.02 & Fe re & + & & + & + & + \\
\hline & DO R 1 & Calv & + & & & & \\
\hline
\end{tabular}




\section{Methoden}

\subsection{Morphologische Methoden}

\subsubsection{Morphologische Zuordnungen}

Bei der morphologischen Zuordnung wurden lediglich die Langknochen der Extremitäten sowie die Elemente des Schulter- und Beckengürtels berücksichtigt. Knochen wie z.B. Wirbel oder Rippen, weisen i.d.R. keine ausreichenden Charakteristika auf, um Zuordnungen $\mathrm{zu}$ bestimmten Individuen $\mathrm{zu}$ ermöglichen. Craniale Elemente wurden über genetische Analysen an Zähnen oder Partes petrosae angeknüpft.

Die morphologischen Zuordnungen erfolgten - unter Berücksichtigung von Merkmalen, die Hinweise auf Alters- bzw. Geschlechtszugehörigkeit aufzeigen - vor allem auf Basis von Längen- und Robustizitätsmerkmalen. Zunächst fand eine grobe Sortierung in die morphologisch relativ gut zu umgrenzenden Altersklassen Infans I, Infans II und Erwachsen statt.

Innerhalb der Altersklassen wurde für jeden Knochen zunächst innerhalb des jeweiligen Knochentyps nach einem passenden Gegenstück der anderen Körperseite gesucht. Bei dieser paarweisen Zuordnung wurden kleinere Längen- bzw. Robustizitätsunterschiede toleriert, da, aufgrund von genetischer Veranlagung, Ontogenese und unterschiedlicher Belastung, zurückzuführen auf z.B. Händigkeit, zu erwarten ist, dass kein Körper hundertprozentig symmetrisch gebaut ist (Martin und Saller 1957).

Anschließend an den paarweisen Vergleich wurden Knochen innerhalb einer Extremität einander zugeordnet. Hierbei wurde neben den bereits aufgeführten Merkmalen vor allem auf die funktionale Passfähigkeit der Gelenke geachtet.

Im dritten Schritt wurden die Extremitäten mit Knochen des Schulter- bzw. Beckengürtels abgeglichen. Auch hier wurde wieder aufgrund der Kriterien Länge, Robustizität und Passgenauigkeit der Gelenke vorgegangen. Bei der Zuordnung der Ossa coxae wurde berücksichtigt, ob es an den potentiell dazu gehörigen Knochen Hinweise auf die Geschlechtszugehörigkeit des jeweiligen Individuums gab. Solche Hinweise konnten z.B. der Collo-Diaphysen-Winkel am Femur oder eine auffällige, durchgehend sehr geringe Robustizität sein. Ebenfalls berücksichtigt wurden natürlich bereits bekannte Daten zur Geschlechtszugehörigkeit aus genetischen Analysen. Abschließend wurden die so zusammengefügten oberen bzw. unteren Körperhälften einander zugeordnet. Diese Zuordnungen sind i.d. R. von allen vorgenommenen mit der größten Unsicherheit behaftet, da hier kein Symmetrievergleich oder das Testen auf 
Funktionsfähigkeit der Gelenke vorgenommen werden konnte. Das Hauptkriterium war bei diesen oben-unten-Zuordnungen vielmehr grundsätzliche Robustizität und die Stimmigkeit der Proportionen (Brothwell 1972).

\subsubsection{Dokumentation pathologischer Befunde und anderer morphologischer Auffälligkeiten}

Generell besitzt alles, was eine Abweichung von der normalen morphologischen Ausprägung darstellt, Aussagekraft in verschiedenen Zusammenhängen. Einerseits werden Aussagen bezüglich individueller Biographien möglich, zudem können bei umfassender Betrachtung Rückschlüsse auf generelle Lebensumstände ganzer Populationen gezogen werden. Im Einzelfall können Anzeichen für degenerative Erkrankungen zwar schwierig von regelhaften Alterungsprozessen abzugrenzen sein, in starker Ausprägung über viele Individuen hinweg können sie jedoch Hinweis auf eine starke körperliche Arbeitsbelastung in einer menschlichen Gesellschaft sein. Andere pathologische Veränderungen, wie z.B. Veränderungen der Oberflächenstruktur des Knochens aufgrund entzündlicher Prozesse, können Auskunft über die Krankheitsbelastung einer Population und hygienische Bedingungen geben. Aus Veränderungen der Zähne und des Zahnhalteapparates können Hinweise auf Subsistenzstrategien gezogen werden. Am Skelett erkennbare, alimentäre Erkrankungen können hinweisgebend für eine allgemeine Fehl- oder Mangelernährung der Bevölkerung sein. Ein gehäuftes Auftreten von Frakturen und anderen Traumata kann als Hinweis auf eine Beteiligung an kriegerischen Handlungen gewertet werden (Herrmann et al. 1990).

In der Regel wird im Rahmen der Befundung einer Skelettserie eine umfassende, systematische Erhebung aller dieser pathologischen Veränderungen vorgenommen. Im Falle der Skelettserie aus der Lichtensteinhöhle wurde dies durch zwei Umstände erschwert bzw. teilweise nur eingeschränkt möglich gemacht. Zum einen konnten aufgrund der dislozierten Auffindesituation kein Skelett mit allen Knochen in anatomisch korrekter Lage betrachtet werden. Wurden z.B. mehrere Wirbel mit Randleisten aufgefunden, konnte weder bestimmt werden, von welchem Individuum diese stammten, noch ob sie nicht sogar von mehreren verschiedenen Individuen stammten. Zum anderen waren nahezu alle Knochen ursprünglich mit einer dicken Gipssinterschicht überzogen, welche zum Schutz der Knochen in vielen Fällen in situ auf dem Knochen belassen wurde. Einige Knochen hatten sich über die Jahrtausende 
mit ihrer Oberfläche so fest mit der Gesteinsschicht verbunden, dass beim Entfernen derselben der Knochen massiv beschädigt worden wäre. Aufgrund dieser erschwerenden Umstände war es nicht möglich, die pathologischen Veränderungen in Gänze systematisch zu erfassen. Auffälligkeiten wurden lediglich dokumentiert und nur als Indizien bei den Interpretationen mit herangezogen.

\subsubsection{Morphologische Altersdiagnose}

Eine morphologische Altersdiagnose kann immer nur das biologische und nicht das chronologische Sterbealter widerspiegeln. Im Alterungsprozess ist der menschliche Körper regelhaften Veränderungen unterworfen, die auch Veränderungen des Skeletts und der Knochenbinnenstruktur umfassen. Neben Abnutzungserscheinungen an den Gelenken zeigt sich dies auch in bestimmten Veränderungsstadien der Facies symphysialis an den Ossa coxae, dem Obliterationsgrad der Schädelnähte und einer Auflockerung der Anordnung der Spongiosabälkchen im Hals- und Epiphysenbereich der Langknochen. In der sogenannten „Komplexen Methode“ (Acsádi und Nemeskéri 1970) werden die vier Merkmale Relief der Facies symphysialis, Spongiosastruktur in proximaler Humerus- und Femurepiphyse und Obliterationsgrad der Schädelnähte kombiniert zur Altersdiagnose erwachsener Individuen herangezogen. Hierbei erfolgt eine Einteilung in die Altersklassen Adultas (20-40 Jahre), Maturitas (40-60 Jahre) oder Senilis (ab 60 Jahre aufwärts). Innerhalb dieser drei Altersklassen ist mit der komplexen Methode i.d.R. noch eine etwas feinere Auflösung möglich, indem eine Unterteilung in z.B. früh-, mittel- oder spätadult vorgenommen wird, wobei diese Subklassen jeweils ca. 7 Jahre umfassen. Die vier zugrundeliegenden Merkmale können jedoch auch einzeln betrachtet Hinweise auf das Sterbealter erwachsener Individuen geben.

Bei subadulten Individuen gestaltet sich die morphologische Altersdiagnose zumeist etwas einfacher. Im Infans I (0-6 Jahre) und Infans II (7-12 Jahre) kann das Sterbealter anhand des Gebissstatus, d.h. der Anlage, des Durchbruchs und der Okklusion der Milch- bzw. Dauerzähne, mit ziemlich hoher Sicherheit bestimmt werden. Zudem folgt die Verknöcherung der Wachstumsfugen, sowohl an Wirbeln oder Beckenteilen, als auch an Langknochenepiphysen, einem relativ konstanten Muster. Hierüber kann auch im Jugendalter (Altersklasse Juvenis, 13-18 Jahre) und bis ins frühe Erwachsenenalter eine relativ genaue Altersdiagnose vorgenommen werden (Herrmann et al. 1990). 
Die morphologische Altersdiagnose gestaltete sich für das Skelettkollektiv aus der Lichtensteinhöhle recht schwierig, da es sich ja um zunächst disloziert vorliegende Knochen handelte. Wenn an einzelnen Knochen - wie z.B. über die Symphyse am Os coxae - konkrete Hinweise auf das Sterbealter vorhanden waren, wurden diese mit als Zuordnungskriterium herangezogen. Hierüber konnten einige Individuen bereits aufgrund einzelner oder mehrerer Merkmale altersdiagnostiziert werden. Insbesondere bei subadulten Individuen war dies recht erfolgreich möglich.

\subsubsection{Histologische Altersdiagnose}

Durch den Alterungsprozess bedingte Veränderungen des Knochens beschränken sich nicht nur auf makroskopisch sichtbare Anzeichen, wie die Auflockerung der Spongiosa. Auch innerhalb der Knochenkompakta - also in der Knochenmikrostruktur - kommt es zu regelhaften Veränderungen, die mit bestimmten Altersklassen assoziiert sind. Als sehr stoffwechselaktives Gewebe ist der menschliche Knochen zeitlebens einem ständigen Umbau unterworfen. Zu Beginn des Lebens besteht der kompakte Knochen vorwiegend aus lamellären Strukturen. Zudem gibt es einige Resorptionslakunen, da in den Wachstumsphasen der Knochenumbau - und damit auch der zeitweilige Abbau - in besonders hohem Maße stattfindet. Mit zunehmendem Lebensalter werden, zunächst ungleichmäßige, dann immer kleinere und regelmäßigere Osteone gebildet, die den lamellären Knochen schließlich vollständig ersetzen. Eine maximal dichte und gleichmäßige Osteonenstruktur weist ein Knochen i.d.R. in der Altersklasse Maturitas auf. Erst im fortgeschrittenen Lebensalter kommt es langsam zu einem Überwiegen des Knochenabbaus gegenüber dem Knochenaufbau und es kommt zu bleibenden Resorptionslakunen und einer wieder ungleichmäßigeren und aufgelockerten Mikrostruktur (Herrmann et al. 1990, Uytterschaut 1993).

Die mikromorphologische Sterbealterbestimmung bietet zudem einen Zugang, nicht nur das biologische, sondern das chronologische Individualalter zu bestimmen. Und zwar unterliegt der menschliche Zahnzement einem jährlichen Zuwachs, der sich in Form von Zuwachsringen darstellt. Über das Auszählen der Zuwachsringe unter Berücksichtigung des Zahndurchbruchalters, kann das chronologische Alter ermittelt werden (Großkopf 1990, Großkopf 2004).

Da für eine größere Anzahl erwachsener Individuen aus der Lichtensteinhöhle keine morphologische Altersdiagnose durchgeführt werden konnte, waren in vorangegangenen Arbeiten bereits Sterbealterbestimmungen über die 
Zahnzuwachsringe bzw. die Beurteilung mikromorphologischer Strukturen vorgenommen worden (Schilz 2006). Letzteres wurde in der vorliegenden Arbeit für weitere, neu hinzu gekommene Individuen durchgeführt.

Hierfür wurden mit einer Dentalbohrmaschine (Dremel ${ }^{\circledR M u l t i{ }^{\mathrm{TM}}}$ ) mit Diamantsägeblatt (Horico) Knochenfragmente mittig aus der anterioren Diaphyse der Langknochen herausgesägt. Bevorzugt werden hierfür Femora verwendet, wenn diese nicht vorhanden sind, kann auf Humeri oder Tibiae ausgewichen werden. Die Knochenfragmente wurden in eine Mischung aus dem Epoxidharz Biodur ${ }^{\circledR}$ E12 und dem Härter Biodur ${ }^{\circledR}$ E1 im Verhältnis $100 \mathrm{zu} 28$ Gewichtsteile eingebettet und zu Blöcken ausgehärtet. Die Oberflächen der Blöcke wurden zunächst plan getrimmt und dann mit einem Sägeschnittmikrotom (Leitz SP 1600) Dünnschnitte von 80-100 $\mu \mathrm{m}$ Dicke hergestellt. Die Dünnschnitte wurden getrocknet und dann mit dem Einschlussharz Eukitt ${ }^{\circledR}$ unter Deckgläsern auf Objektträgern fixiert. Nach dem Trocknen wurden die Knochenmikrostrukturen im Durchlichtmikroskop analysiert. Hierbei wurden die Strukturen mit Schnitten von altersbekannten Referenzserien abgeglichen.

\subsubsection{Morphologische Geschlechtsdiagnose}

Aufgrund der Anpassung des weiblichen Beckens an den Geburtsvorgang kann in vielen Fällen eine recht sichere Geschlechtsdiagnose über die morphologische Beurteilung des Beckens vorgenommen werden. Idealerweise wird das gesamte Becken bestehend aus den beiden Ossa coxae und dem Os sacrum beurteilt. Dies ermöglicht die Examination der Form des Beckeneingangs, der generellen Proportionen und des Angulus subpubicus. Das weibliche Becken weist einen großen, eher querovalen Beckeneingang auf, das männliche einen engeren, eher herzförmigen. Das männliche Becken ist im Gesamtaspekt schmaler und höher als das weibliche Becken. Durch diese allgemeinen Proportionen ist der Winkel, den die beiden Schambeinäste miteinander bilden, bei Frauen eher stumpf und bei Männern eher spitz. Aber auch am einzeln vorliegenden Os coxae finden sich Merkmale, die starken diagnostischen Wert haben, wie die Form und Weite der Incisura ischiadica major und die Ausprägung des Arc composé. Erstere ist beim weiblichen Becken weit und V-förmig, beim männlichen Becken eng und U-förmig. Der Arc composé ist nur bei männlichen Individuen als ein einfacher Bogen ausgeprägt, bei weiblichen Individuen hingegen als doppelter Bogen (Herrmann et al. 1990). 
Zumindest in europäischen Populationen ist zudem in einer Reihe von Merkmalen am Cranium ein deutlicher Geschlechtsdimorphismus festzustellen. Da es sich bei den cranialen Merkmalen vorwiegend um Robustizitätsmerkmale handelt, auf denen kein direkter Funktionsdruck lastet, ist in manchen Populationen - z.B. afrikanischen Ursprungs - der Dimorphismus zwischen den Geschlechtern nicht so stark ausgeprägt. Merkmale, die für eine Geschlechtsdiagnose am Cranium herangezogen werden sind u.a. die Form der Orbitae (weiblich eher rund, männlich eher rechteckig), der Arcus superciliaris (bei Männern stark ausgeprägt), der Processus mastoideus (weiblich kurz und relativ zierlich, männlich groß und breitbasig), Form und Winkel der Gonionregion (männlich ausgezogen und eher rechtwinklig, weiblich glatt und weitwinklig) oder die Ausprägung des Mentums (bei Männern stark ausgeprägt). Eine gute diagnostische Anleitung für die Geschlechtsdiagnose mittels der Merkmale an Becken und Schädel findet sich bei Herrmann et al. (1990).

Analog zur morphologischen Altersschätzung war auch die morphologische Geschlechtsdiagnose durch die dislozierte Auffindesituation der Individuen aus der Lichtensteinhöhle erschwert. Bei einzeln vorliegenden Femora kann zwar ein Hinweis auf das Geschlecht über den Collo-Diaphysen-Winkel bzw. den Condylo-DiaphysenWinkel gewonnen werden, eine sichere Geschlechtsdiagnose ist jedoch in den seltensten Fällen möglich. Bei allen morphologischen Zuordnungen wurden sämtliche zu beurteilenden, auf das Geschlecht Hinweis gebenden, Merkmale berücksichtigt. Dadurch konnte in einigen Fällen bereits auf morphologischer Ebene eine Geschlechtsdiagnose vermerkt werden.

\subsection{Genetische Methoden}

\subsubsection{Arbeiten mit ancient DNA - Kontaminationsprävention und Authentizitätssicherung}

Arbeiten mit ancientDNA heißt, in der Mehrheit der Fälle, arbeiten mit mehr oder weniger stark degradierter DNA in häufig sehr geringer Targetanzahl im DNA-Extrakt. Dies erfordert, unabhängig von der konkreten Fragestellung, die Vervielfältigung der Zielsequenzen über den Einsatz von PCR Verfahren, um über die Nachweisgrenze zu gelangen. Selbst bei den modernsten Analyseverfahren des next generation sequencing (NGS) sind für die Analyse alter DNA nur solche Protokolle geeignet, die einen Vervielfältigungsschritt enthalten (z.B. Templeton et al. 2013, Hofreiter et al. 2014, Allentoft et al. 2015, Haak et al. 2015). 
Bei der Amplifikation von aDNA können selbst geringste Mengen an Fremd-DNA die Signale der eigentlichen Proben-DNA teilweise oder gänzlich überdecken. Daher sind das strikte Einhalten von Bearbeitungsstandards und Strategien zur Authentizitätssicherung unabdingbar.

Mögliche Kontaminationen können bereits auf der Probe vorhanden sein; z.B. bei der Bergung durch das Grabungspersonal oder eine vorhergehende, archäologische Bearbeitung. Daher muss als erster Bearbeitungsschritt in der aDNA-Analytik immer eine Oberflächenreinigung erfolgen. Dies kann z.B. ein Abtragen der äußersten Knochenschichten oder eine Inkubation in Bleiche sein, welche die potentiell anhaftende DNA zerstört. Um die Proben vor Kontaminationen durch den Bearbeiter zu schützen, sollte nur mit entsprechender Schutzkleidung (Kittel, Haarhaube, Mundschutz und Einmalhandschuhe) gearbeitet werden. Sämtliche Analyseschritte müssen sehr sauber und sorgfältig durchgeführt werden, um Kreuzkontaminationen zwischen den Proben zu vermeiden. Besonders katastrophal wäre es, wenn ein aDNA-Extrakt oder ein noch nicht amplifizierter Reaktionsansatz mit bereits amplifizertem PCR Produkt kontaminiert würde. Deswegen werden die Laborbereiche strikt in einen Prä-PCR- und einen Post-PCR-Bereich getrennt und diese nur in der Richtung von Prä- nach PostPCR betreten, bis ein Wechsel der Kleidung und ein Duschvorgang stattgefunden haben.

Da selbst bei größter Vorsicht eine Kontamination nie vollständig ausgeschlossen werden sollte, sind zudem Strategien erforderlich, um erzielte Ergebnisse zu authentifizieren. Grundsätzlich werden zu diesem Zwecke in der Forschung an aDNA zwei verschiedene Konzepte verfolgt. Zum einen wird die Replikation der Untersuchungen und die Bestätigung der Ergebnisse durch ein zweites unabhängiges Labor gefordert (Cooper und Poinar 2000, Hofreiter et al. 2001). Dieses Vorgehen ist insbesondere sinnvoll, wenn ausschließlich vergleichsweise konservative DNASequenzen (wie z.B. mitochondriale DNA) untersucht werden, wie dies z.B. für Untersuchungen zur Migration, zur Phylogenie und zur Evolution von Organismen der Fall ist. In der zweiten Strategie wird die Individualität des genetischen Fingerabdruckes zur Authentifizierung genutzt. Werden die hochpolymorphen, in jeder Meiose rekombinierten STR-Marker analysiert - oder die Analyse von z.B. biallelischen SNPs mit der Analyse von STRs gekoppelt - so kann hierüber eine Individualisierung und damit Authentifizierung der Ergebnisse erfolgen. Mögliche 
Kontaminationsereignisse können sofort identifiziert werden (Alonso et al. 2001, Capelli et al. 2003, Hummel 2003, Bouakaze et al. 2009).

\subsubsection{Molekulargenetische Verwandtschaftsanalyse/Markerauswahl}

Für den molekulargenetischen Nachweis biologischer Verwandtschaft stehen mehrere Marker-Komplexe zur Verfügung, die jeweils unterschiedliche Qualitäten von Verwandtschaft aufzeigen können. Hierbei handelt es sich einerseits um die autosomalen STRs, welche den individuellen, genetischen Fingerabdruck bilden und die Feststellung direkter Verwandtschaft im Sinne einer Eltern-Kind-Beziehung zulassen, andererseits um die Y-chromosomalen STRs auf dem nicht rekombinierenden Bereich des Y-chromosoms, welche den Y-Haplotypen bilden und ausschließlich in männlicher Familienlinie vererbt werden, und weiterhin um die Sequenzpolymorphismen der mitochondrialen DNA (mtDNA), welche den mt-Haplotypen bilden und in mütterlicher Linie vererbt werden.

\section{Autosomale STRs/Genetischer Fingerabdruck}

Ein Großteil des menschlichen Genoms besteht aus nicht codierenden Sequenzen, welche wiederum zu einem großen Teil aus repetitiven Sequenzen bestehen. Unter diesen repetitiven Sequenzen gibt es die Klasse der short tandem repeats (STRs), welche durch die mehr- bis vielfache Abfolge eines sehr kurzen Wiederholungselementes charakterisiert sind. Während der Meiose kann es mit einer sehr geringen Frequenz zu Mutationen kommen, welche durch das Verrutschen der DNA-Polymerase entstehen. Hierdurch kann ein Allel entstehen, welches eine repeat unit länger oder kürzer ist. Durch Akkumulation von solchen Mutationen über viele Generationen hinweg entsteht eine Variabilität von mehreren bis vielen verschiedenen Allelen. Durch die crossing over Vorgänge während der Bildung der Keimzellen erhält jeder Mensch eine individuelle Kombination von Allelen für die verschiedenen STRLoci. Dieses Muster ist - sofern eine ausreichende Anzahl von STR-Loci analysiert wird - so individuell, dass hierüber eine eindeutige Identifizierung einer Person erreicht werden kann und wird deshalb auch als genetischer Fingerabdruck bezeichnet. Der genetische Fingerabdruck wird vor allem in der Forensik herangezogen, sowohl wenn es um die Zuordnung einer Tatortspur zu einem Verdächtigen geht als auch wenn es beim Auffinden skelettierter Überreste oder von Leichenteilen um die Identifizierung einer vermissten Person geht. Ein weiteres Anwendungsgebiet, in dem der genetische 
Fingerabdruck verwendet wird, ist die Vaterschaftsdiagnostik. Da jeder Mensch jeweils ein Allel von der Mutter und dem Vater erhält, kann durch einen Vergleich der genetischen Fingerabdrücke von Mutter, Kind und Putativvater eine Vaterschaft entweder ausgeschlossen oder mit an Sicherheit grenzender Wahrscheinlichkeit festgestellt werden.

Die Auswahl der STR-Marker, aus denen sich der genetische Fingerabdruck zusammensetzt, folgt nicht dem Zufallsprinzip. Um für Identifizierungszwecke geeignet zu sein, muss ein STR-Locus bestimmte Anforderungen erfüllen. Der STR-Locus darf keinem Selektionsdruck unterworfen sein, damit eine unabhängige Weitergabe der verschiedenen Allele sichergestellt ist. Im Idealfall folgt die Verteilung der Allelhäufigkeiten einer Gauss'schen Glockenkurve. Die Mutationsrate darf weder zu gering noch zu hoch sein, damit einerseits eine möglichst große Anzahl verschiedener Allele gegeben ist, aber andererseits Unterschiede zu den Allelen der Eltern nicht zu häufig auftreten. Zudem sollten die Loci untereinander nicht gekoppelt sein, damit die individuelle Neukombination maximal ist. Am sichersten wird dies erreicht, wenn STRLoci von verschiedenen Chromosomen untersucht werden. In den verschiedenen forensischen Standardsets finden sich somit nur äußerst selten mehrere STRs von einem Chromosom, wenn dies doch mal der Fall ist, liegen die jeweiligen STRs in verschiedenen linkage Blöcken (Butler 2005).

Weltweit sind in den jeweiligen Rechtssystemen unterschiedliche Standardsets festgelegt, welche in der forensischen Fallarbeit analysiert werden. Die generierten Datensätze werden in Datenbanken hinterlegt, um eine effiziente Suche nach Täterprofilen oder zusammenhängenden Spuren zu ermöglichen. Einige STR-Marker sind quasi in allen Ländern in diesen Standardsets enthalten, es gibt jedoch auch Unterschiede. So umfassen z.B. sowohl das US-amerikanische CODIS (Combined DNA Index System) als auch die deutsche DAD (DNA Analyse Datei) die Loci D3S1358, D8S1179, D18S51, D21S11, FIBRA/FGA, TH01 und VWA, aber CODIS zusätzlich noch D5S818, D7S820, D13S317, D16S539, CSF1PO, TPOX und die deutsche DAD noch D1S1656, D2S441, D10S1248, D12S391, D22S1045 und ACTBP2/SE33. Unterschiedliche Markersets erschweren natürlich die internationale Verbrechensbekämpfung (Butler 2015). Um mehr internationale Vergleichbarkeit zu schaffen, wurde im Jahr 2001 bereits ein Europäisches Standard Set (ESS) festgelegt, welches die Loci D3S1358, D8S1179, D18S51, D21S11, FGA, TH01, VWA umfasst (Amtsblatt der Europäischen Gemeinschaften 2001/C 187/01). Im Jahr 2009 wurde das ESS um die 
sogenannten new european standard marker D1S1656, D2S441, D10S1248, D12S391 und D22S1045 erweitert (Amtsblatt der Europäischen Union 2009/C 296/01). Bei der Auswahl der neuen ESS-Marker wurden vor allem sogenannte miniSTRs ins Auge gefasst, um neben einer internationalen Vergleichbarkeit in mehr Systemen und einer höheren discrimination power vor allem auch bessere Voraussetzungen für die erfolgreiche Amplifikation stark degradierter DNA zu schaffen (Gill et al. 2006, Schneider 2009).

Ab Januar 2017 wird das FBI ebenfalls weitere 7 Loci zusätzlich zu den bisherigen 13 CODIS-Loci für das Einstellen eines Datensatzes in das US-amerikanische National DNA Index System (NDIS) fordern. Diese zusätzlichen STR Loci beinhalten die fünf new european standard marker und die Marker D2S1338 und D19S433 (Hares 2015). Damit wird eine noch umfassendere internationale Vergleichbarkeit erreicht werden. In der vorliegenden Arbeit wurden mit zwei verschiedenen miniSTR Multiplex PCRs insgesamt 14 STR-Systeme amplifiziert. Die eine PCR wurde aus zwei bereits in der Arbeitsgruppe bestehenden Multiplex PCRs zusammengestellt und mit einem neuen lower Primer für die Amplifikation eines Abschnittes des Amelogenin Gens versehen sowie durch kleine Veränderungen optimiert (Seidenberg et al. 2012). Die andere PCR wurde neu designed. Hierbei wurde bei der Markerauswahl Rücksicht auf die bereits bestehenden Datensätze von den Knochen aus der Lichtensteinhöhle genommen, um für komplett neu ermittelte Datensätze möglichst große Vergleichbarkeit zu bisherigen Ergebnissen zu garantieren.

\section{Y-chromosomale STRs/Y-Haplotyp}

Während der Meiose kann es für einige Abschnitte des Y-Chromosoms zum crossing over mit dem X-Chromosom kommen. Den weitaus größten Bereich des YChromosoms stellt jedoch mit ca. $95 \%$ die sogenannte NRY dar (non-recombining region of the $Y$ chromosome $=$ nicht rekombinierende Region des Y-Chromosoms; Tilford et al. 2001), welche in unveränderter Form vom Vater an den Sohn vererbt wird. Wie auch auf allen anderen Chromosomen gibt es auf dem Y-Chromosom viele nicht codierende Bereiche, welche $\mathrm{zu}$ einem beachtlichen Teil aus repetitiven Sequenzen bestehen. Somit gibt es auf dem Y-Chromosom ebenfalls verschiedene STR-Loci. Bei der Meiose kann es mit einer geringen Frequenz zu Mutationen und damit zur Zu- oder Abnahme der repeat-Anzahl kommen. Hieraus resultiert eine Bandbreite von verschiedenen Y-STR-Allelen, welche sich in ihrer Länge unterscheiden. Eine Auswahl 
von geeigneten STRs auf dem nicht kombinierenden Bereich mit ausreichender Variabilität, aber nicht $\mathrm{zu}$ hoher Mutationsrate, wird für die Generierung des sogenannten Y-Haplotypen analysiert.

Aufgrund der unveränderten Weitergabe vom Vater an seine Söhne ist dieser YHaplotyp somit geeignet für die Aufdeckung von Verwandtschaft in väterlicher Familienlinie. In der Forensik wird i.d.R. eine Auswahl von 9-23 STR-Systemen analysiert, welche den minimal bzw. extended haplotype bilden (Purps et al. 2014). Für die Feststellung der väterlichen Familienlinien wurde in der vorliegenden Arbeit ein Set von 12 Markern untersucht.

\section{Mitochondriale Sequenz/mt-Haplotyp}

Bei der mtDNA eines Menschen handelt es sich um ein ringförmiges DNA-Molekül, welches i.d.R. 16.569 bp aufweist und in mehr- bis vielfacher Kopienzahl in den Mitochondrien der Zellen vorliegt. Die genaue Anzahl an Kopien ist variabel und hängt u.a. von der Stoffwechselaktivität des jeweiligen Gewebes ab. Spermien und Eizellen besitzen zwar beide eigene Mitochondrien - und somit auch die jeweilige mitochondriale DNA - jedoch gelangt die mtDNA des Spermiums bei der Befruchtung normalerweise nicht mit in die entstehende Zygote. Somit besitzt der entstehende Embryo, unabhängig von seinem Geschlecht, ausschließlich die mtDNA der Mutter. Im Gegensatz zur nuclearen DNA des Menschen sind ungefähr $93 \%$ der mtDNA codierend (Tariverdian und Buselmaier 2004). Relativ dicht beieinander liegend finden sich zahlreiche Gene, welche u.a. für die verschiedenen Untereinheiten der Atmungskette codieren. Lediglich um den origin of replication gibt es einen längeren Abschnitt, welcher nicht codierend ist, den sogenannten D-Loop. Während die codierenden Bereiche aufgrund des Funktionsdruckes zwangsläufig hoch konserviert sind, kann es im D-Loop zu nicht letalen Mutationsereignissen kommen, welche eine Variabilität dieses Abschnittes bewirken. Innerhalb des D-Loop werden drei hypervariable Regionen unterschieden (HVR I, HVR II und HVR III). Zur einfachen Beschreibung der Variabilität werden die Abweichungen der jeweiligen mitochondrialen Sequenzen zu einer definierten Referenzsequenz (rCRS = revised Cambridge Reference Sequence) angegeben. Über die Gesamtheit der Abweichungen wird der jeweilige mt-Haplotyp definiert.

Aufgrund der sukzessiven Akkumulation von Mutationen und deren Weitergabe in mütterlicher Familienlinie stellen die HVRs ein geeignetes Instrument für 
populationsgenetische Zwecke dar. Charakteristische Mutationen, die vielen verschiedenen Haplotypen gemeinsam sind, sind höchst wahrscheinlich populationsgenetisch älter und definieren Cluster von Haplotypen, welche als Haplogruppen bezeichnet werden. Die Betrachtung der weltweiten Verteilung der verschiedenen Haploguppen unterstützt die sogenannte out of africa Hypothese, nach der der Ursprung des anatomisch modernen Menschen in Afrika zu finden ist und von dort aus in verschiedenen Besiedelungswellen über den Nahen Osten die Besiedelung Europas und Asiens - und von letzterem aus schließlich auch die initiale Besiedelung Amerikas - stattgefunden hat. In der europäischen Bevölkerung sind Haplotypen der Haplogruppen H, U, J, X, K, T und V vorherrschend, wobei der größte Teil der Haplogruppe H zuzuordnen ist.

In dieser Arbeit wurden große Teile der HVR I und HVR II sequenziert, welche die Einordnung in die oben genannten, europäischen mt-Haplogruppen erlauben. Da der Erhaltungszustand der DNA aus den historischen Knochen die Amplifikation in einem Target-Fragment nicht zuließ, wurden beide Abschnitte in jeweils zwei überlappenden Fragmenten amplifiziert.

\subsubsection{Entwicklung molekulargenetischer Analysesysteme}

Für das Forschungsprojekt wurden zwei Multiplex PCR Systeme zur Amplifikation autosomaler und Y-chromosomaler STRs und ein Singleplex Amplifikationssystem für einen Abschnitt der mitochondrialen HVR II komplett neu designed. Ein weiteres Multiplex PCR System zur Amplifikation autosomaler STRs wurde aus bereits bestehenden PCR Systemen neu kombiniert und optimiert. Des Weiteren wurde ein Analysesystem zur Bestimmung der AB0-Blutgruppen mittels PCR und nachfolgender single base extension (SBE) entwickelt.

Die Multiplex Systeme zur Amplifikation autosomaler und gonosomaler STRs wurden als sogenannte miniSTR PCRs designed. Generell wird dieser Begriff für PCR Systeme verwendet, in welchen die STR-Loci mit Fragmentlängen von nicht mehr als $250 \mathrm{bp}$ amplifiziert werden, wie es z.B. beim AmpFlSTR ${ }^{\circledR}$ MiniFiler ${ }^{\mathrm{TM}}$ PCR Amplification Kit (Applied Biosystems) der Fall ist (Mulero et al. 2008). Um dies zu erreichen, müssen sowohl der upper Primer als auch der lower Primer so nah wie möglich an der repeat Struktur platziert werden (Butler et al. 2003, Coble and Butler 2005, Grubwieser et al. 2006, Asamura et al. 2007, Hill et al. 2008, Mulero et al. 2008). Der Vorteil von miniSTRs ist eine wesentlich größere Wahrscheinlichkeit, Proben erfolgreich zu 
untersuchen, welche ein hohes Maß an DNA Degradierung aufweisen (Marjanovic et al. 2009, Hughes-Stamm et al. 2011, Senge et al. 2011).

Allerdings ist die Reduktion der Amplikonlängen nicht für alle STR-Loci möglich. So ist es relativ leicht umsetzbar für Loci mit nur wenigen repeat Einheiten wie z.B. TH01, aber ist unmöglich für Loci mit sehr vielen repeat Einheiten wie z.B. das hoch diskriminierende SE33 (ACTBP2). Zudem stellen nicht alle repeat-nahen flanking regions gute Bindungsstellen für die Platzierung von Primern dar. Beim Design von umfangreicheren miniSTR Multiplex PCRs kommt als limitierender Faktor der eingeschränkte Detektionsbereich hinzu. Das Ausnutzen der 5-Farb-Technologie bei der Fragmentlängenanalyse relativiert diese Einschränkung zwar etwas, aber nichtsdestotrotz sind kommerzielle, reine miniSTR PCRs bisher mit nur maximal acht Loci verfügbar (Mulero et al. 2008). Eine Möglichkeit, dies zu umgehen, wäre die Nutzung von sogenannten spacern - also das Hinzufügen von nicht bindenden Oligonukleotiden an die Primer - um STR-Loci gleicher Länge elektrophoretisch zu diskriminieren, allerdings birgt diese Strategie ein hohes Risiko von Artefaktbildung.

Das Primerdesign wurde unter Verwendung der PrimerSelect Software (DNASTAR Lasergene 10) durchgeführt. Dabei wurden die generellen Empfehlungen zum Primerdesign befolgt, wie z.B. dass die Primer eine ähnliche Schmelztemperatur aufweisen und Primer Dimere oder Hairpins vermieden werden sollten (Dieffenbach et al. 1993, Hummel 2003). Besonderes Augenmerk wurde auf das Energieprofil der Primer gerichtet, welches so gestaltet wurde, dass das 3'-Ende jedes Primers eine niedrige Bindungsenergie hat, um unspezifische Elongationen $\mathrm{zu}$ verhindern (Hummel 2003). Um das Entstehen von split peaks aufgrund einer unvollständigen Endadenylierung zu vermeiden, wurden darauf geachtet, dass alle nicht farbmarkierten Primer am 5'-Ende ein A oder G aufwiesen (Butler 2005). Für alle Primer wurde die Spezifität für das jeweilige human target mittels einer Primer BLAST Suche (basic local alignment search tool; http://www.ncbi.nlm.nih.gov/tools/primerblast/index.cgi?LINK_LOC=BlastHome) überprüft.

Alle neu entwickelten Analysesysteme wurden vor der routinemäßigen Anwendung einer praktischen Entwicklungsphase unterzogen, in der die Mengenverhältnisse der Primer zueinander abgestimmt und die cycling Parameter so eingestellt wurden, dass eine möglichst große Sensitivität bei absoluter Spezifität erreicht wurde. 


\section{Weiterentwicklung der Heptaplex PCR zur Amplifikation autosomaler STRs}

Bei dem ersten Multiplex PCR System zur Amplifikation autosomaler STRs handelt es sich um eine Heptaplex PCR, welche die Marker D5S818, D13S317, D18S51, D21S11, FGA und TH01 mit Fragmentlängen unter 200 bp umfasst. Für die molekulare Geschlechtsbestimmung wurde ein kurzes Fragment des Amelogenin Gens integriert. Dieses Gen befindet sich auf dem X- und Y-Chromosom und weist auf dem XChromosom im Intron 1 eine 6 bp Deletion auf. Die Primer für die Loci D5S818, D13S317 wurden unverändert aus einer Oktaplex PCR übernommen (Schilz 2006), die Primer für die Loci D18S51, D21S11, FGA und TH01 wurden mit zwei kleinen Veränderungen aus einer Pentaplex PCR übernommen (Pfister 2008). An das 5'-Ende des lower Primers für TH01 wurde ein nicht bindendes A hinzugefügt und an das 5'Ende des lower Primers für FGA ein nicht bindendes AT. Dies diente einerseits dazu, der Bildung von split peaks entgegen zu wirken. Zudem wurde so erreicht, dass keine gängigen Allele verschiedener Systeme mit unterschiedlichen Fluoreszenzmarkierungen exakt dieselbe Fragmentlänge aufwiesen. Damit wurden Akkumulationen von Fluoreszenzsignalen vermieden, welche sich in der Kapillarelektrophorese als bekannte Artefakte niederschlagen würden. Für die Amplifikation des Abschnittes des Amelogenin Gens wurde ein upper Primer verwendet, welcher von Sullivan et al. (1993) beschrieben wurde. Um das Amplifikat noch kürzer zu halten als es bei Sullivan et al. der Fall ist, wurde ein neuer lower Primer designed. Hierbei musste ein mismatch von einer Base relativ weit 5' des Primers zu einem der Geschlechtschromosomen in Kauf genommen werden. Dieser mismatch wurde so gewählt, dass er zur Xchromosomalen Sequenz realisiert ist, um eher eine leicht präferentielle Amplifikation Y-chromosomaler Allele zu erzielen. Jeder upper Primer wurde mit einem der Fluoreszenzmoleküle 6FAM, HEX oder NED versehen. Die Primersequenzen, die Fluoreszenzmarkierungen und die exakten Produktlängen für die jeweiligen Loci sind in Tabelle 2 aufgeführt. Ein Überblick über die Fragmentlängen und die Anordnung in den verschiedenen Farbpanels ist in Abb. 19 dargestellt. 
Tabelle 2: Übersicht über die in der Heptaplex PCR für autosomale STRs verwendeten Primerpaare, die verwendeten Fluoreszenzfarbstoffe und die Fragmentlängen der Allelranges.

\begin{tabular}{|c|c|c|c|c|c|c|}
\hline Marker & Primer & $\begin{array}{l}\text { Fluores- } \\
\text { zenzmar- } \\
\text { kierung }\end{array}$ & Primersequenz $\left(5^{`} \rightarrow 3^{`}\right)$ & Allele & $\begin{array}{l}\text { Fragment- } \\
\text { längen- } \\
\text { range [bp] }\end{array}$ & {$[\mu \mathrm{M}]$} \\
\hline \multirow{2}{*}{$\begin{array}{l}\text { Amelo- } \\
\text { genin }\end{array}$} & up & \multirow[t]{2}{*}{ 6FAM } & CCTGGGCTCTGTAAAGAATAGTG & $\mathrm{X}$ & 86 & 0,2 \\
\hline & low_VSE & & AGCTGATGGTAGGAACTGTAAAAT & Y & 92 & 0,2 \\
\hline \multirow[t]{2}{*}{ D13S317 } & up & \multirow[t]{2}{*}{ 6FAM } & CTAACGCCTATCTGTATTTACAAATA & \multirow{2}{*}{ 8-15 } & \multirow{2}{*}{$103-131$} & 0,16 \\
\hline & low & & AGCCCAAAAAGACAGACAGA & & & 0,16 \\
\hline \multirow[t]{2}{*}{ D21S11 } & up Pf & \multirow[t]{2}{*}{ 6FAM } & CAATTCCCCAAGTGAATTGC & \multirow{2}{*}{$27-33.2$} & \multirow{2}{*}{$170-196$} & 0,24 \\
\hline & low Pf & & GGAGGTAGATAGACTGGATAGATAGAC & & & 0,24 \\
\hline \multirow[t]{2}{*}{ D18S51 } & up Pf & \multirow[t]{2}{*}{ HEX } & CACTGCACTTCACTCTGAGTGAC & \multirow{2}{*}{$10-21$} & \multirow{2}{*}{$152-196$} & 0,28 \\
\hline & low Pf & & GTGTGTGGAGATGTCTTACAATAACA & & & 0,28 \\
\hline \multirow[t]{2}{*}{ TH01 } & up Pf & \multirow[t]{2}{*}{ NED } & GCCTGTTCCTCCCTTATTTC & \multirow{2}{*}{$6-10$} & \multirow{2}{*}{$87-103$} & 0,24 \\
\hline & low2 & & ATTCCGAGTGCAGGTCACAG & & & 0,24 \\
\hline \multirow[t]{2}{*}{ D5S818 } & up & \multirow[t]{2}{*}{ NED } & GGTATCCTTATGTAATATTTTGAAGAT & \multirow{2}{*}{$7-16$} & \multirow{2}{*}{$109-145$} & 0,15 \\
\hline & low & & ATCATAGCCACAGTTTACAACATT & & & 0,15 \\
\hline \multirow[t]{2}{*}{ FGA } & up Pf & \multirow[t]{2}{*}{ NED } & AATAAAATTAGGCATATTTACAAGCTAG & \multirow{2}{*}{$18-26$} & \multirow{2}{*}{$149-179$} & 0,32 \\
\hline & low_VSE & & ATTGCTGAGTGATTTGTCTGTAATTG & & & 0,32 \\
\hline
\end{tabular}
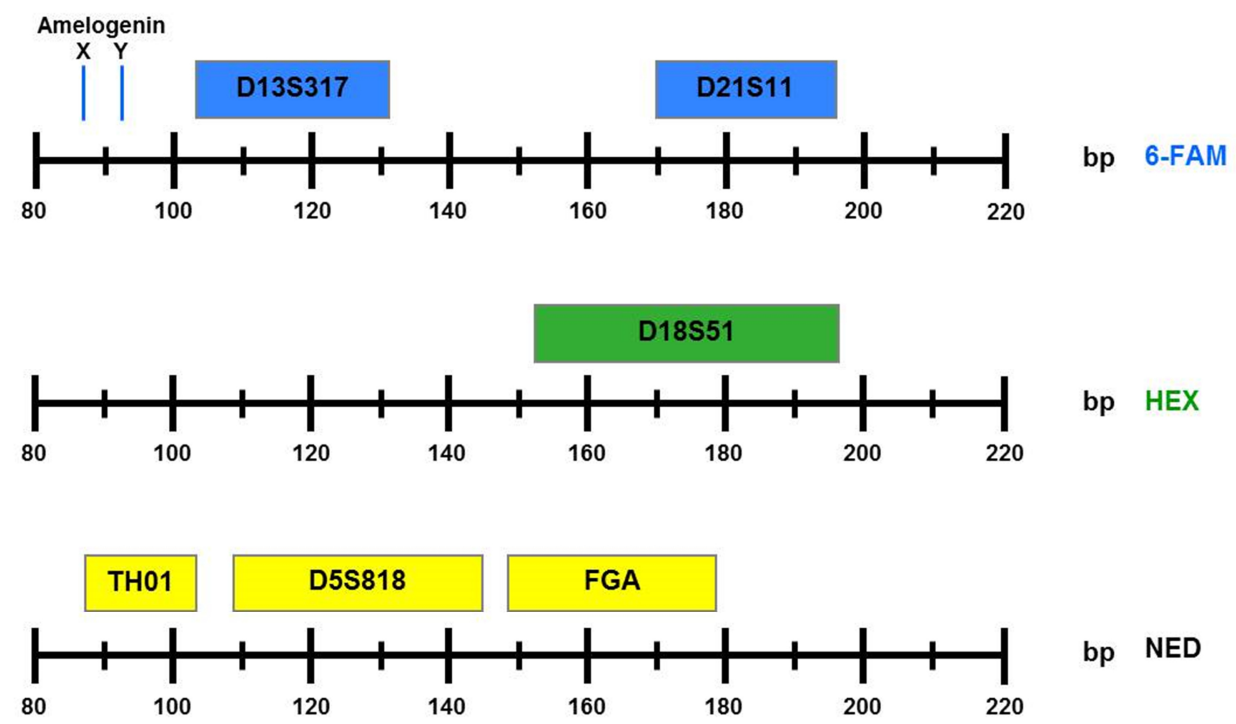

Abb. 19: Übersicht über die in der Heptaplex PCR enthaltenen autosomalen STR-Systeme, ihr jeweiliger Fragmentlängenrange und ihre Anordnung in den verschiedenen Farbpanels. 


\section{Neu design der Dekaplex PCR zur Amplifikation autosomaler STRs}

Bei dem zweiten Multiplex PCR System zur Amplifikation autosomaler STRs handelt es sich um eine Dekaplex PCR, welche die Marker D2S1338, D3S1358, D7S820, D8S1179, D9S1120, D16S539, D19S433, D21S11 und VWA sowie ebenfalls einen Abschnitt des Amelogenin Gens mit Fragmentlängen unter 240 bp umfasst. Alle Primer für die neun autosomalen STRs wurden neu designed. Lediglich für die Amplifikation des Abschnittes des Amelogenin Gens wurden dieselben Primer verwendet, welche auch in der Heptaplex PCR verwendet werden. Bei dieser PCR wurde auf die 5-FarbDetektionstechnologie zurückgegriffen, um mehr STR-Loci mit möglichst geringen Fragmentlängen analysieren zu können. Jeder upper Primer wurde mit einem der Fluoreszenzmoleküle 6FAM, HEX, NED oder ROX versehen. Die Primersequenzen, die Fluoreszenzmarkierungen und die exakten Produktlängen für die jeweiligen Loci sind in Tabelle 3 aufgeführt. Ein Überblick über die Fragmentlängen und die Anordnung in den verschiedenen Farbpanels ist in Abb. 20 dargestellt.

Tabelle 3: Übersicht über die in der Dekaplex PCR für autosomale STRs verwendeten Primerpaare, die verwendeten Fluoreszenzfarbstoffe und die Fragmentlängen des Allelranges.

\begin{tabular}{|c|c|c|c|c|c|c|}
\hline Marker & Primer & $\begin{array}{l}\text { Fluores- } \\
\text { zenzmar- } \\
\text { kierung }\end{array}$ & Primersequenz $\left(5^{`} \rightarrow 3^{`}\right)$ & Allele & $\begin{array}{l}\text { Fragment- } \\
\text { längen- } \\
\text { range [bp] }\end{array}$ & {$[\mu \mathrm{M}]$} \\
\hline \multirow{2}{*}{$\begin{array}{l}\text { Amelo- } \\
\text { genin }\end{array}$} & up & \multirow[t]{2}{*}{ 6FAM } & СCTGGGCTCTGTAAAGAATAGTG & $x$ & 86 & 0,06 \\
\hline & low_vse & & AGCTGATGGTAGGAACTGTAAAAT & Y & 92 & 0,06 \\
\hline \multirow[t]{2}{*}{ D9S1120 } & up & \multirow[t]{2}{*}{ 6FAM } & TGTGTGGGTATATATTATATGTAGTGTATAGA & \multirow{2}{*}{$9-19$} & \multirow{2}{*}{$102-142$} & 0,2 \\
\hline & low & & ATTCTTACTATAGAACATAGGACTCACATATT & & & 0,2 \\
\hline \multirow[t]{2}{*}{ VWA } & up & \multirow[t]{2}{*}{ 6FAM } & TGATAAATAGATACATAGGTTAGATAGAGATAG & \multirow{2}{*}{$10-24$} & \multirow{2}{*}{ 145-201 } & 0,2 \\
\hline & low & & ACTAGTGGATGATAAGAATAATCAGTATGT & & & 0,2 \\
\hline \multirow[t]{2}{*}{ D16S539 } & up & \multirow[t]{2}{*}{ HEX } & СТСTTCCCTAGATCAATACAGACAG & \multirow{2}{*}{$4-16$} & \multirow{2}{*}{$77-125$} & 0,16 \\
\hline & low & & АСАTCTCTGTTTTGTCTTTCAATGA & & & 0,16 \\
\hline \multirow[t]{2}{*}{ D7S820 } & up & \multirow[t]{2}{*}{ HEX } & ACCAAATATTGGTAATTAAATGTTTACTA & \multirow{2}{*}{$5-16$} & \multirow{2}{*}{$130-174$} & 0,3 \\
\hline & low & & GGGTATGATAGAACACTTGTCATAGTT & & & 0,3 \\
\hline \multirow[t]{2}{*}{ D21S11 } & up & \multirow[t]{2}{*}{ HEX } & CCAAGTGAATTGCCTTCTATCTA & \multirow{2}{*}{$24-38$} & \multirow{2}{*}{$178-234$} & 0,2 \\
\hline & low2 & & GTTGTATTAGTCAATGTTCTCCAGAG & & & 0,2 \\
\hline \multirow[t]{2}{*}{ D3S1358 } & up & \multirow[t]{2}{*}{ NED } & TCTCTTATACTCATGAAATCAACAGAG & \multirow{2}{*}{$9-20$} & \multirow{2}{*}{$92-136$} & 0,16 \\
\hline & low & & GAGCAAGACCCTGTCTCATAGA & & & 0,16 \\
\hline \multirow[t]{2}{*}{ D2S1338 } & up & \multirow[t]{2}{*}{ NED } & GCCCATAATCATGAGTTATTCAGT & \multirow{2}{*}{$10-28$} & \multirow{2}{*}{ 139-211 } & 0,2 \\
\hline & low2 & & ACATAATCCAGCTGTGGGAGG & & & 0,2 \\
\hline \multirow[t]{2}{*}{ D19S433 } & up & \multirow[t]{2}{*}{ ROX } & ATAАAААТСТTСТСТСТTТСТTССТСТ & \multirow{2}{*}{$\begin{array}{l}5.2- \\
18.2\end{array}$} & \multirow{2}{*}{$75-127$} & 0,3 \\
\hline & low3 & & AGAATAAGATTCTGTTGAAGGAAA & & & 0,3 \\
\hline \multirow[t]{2}{*}{ D8S1179 } & up & ROX & ACGGCCTGGCAACTTATATG & 710 & $137 \quad 18$ & 0,2 \\
\hline & low & & ATTGCGTGAATATGCCTTAATTTA & $1-15$ & & 0,2 \\
\hline
\end{tabular}



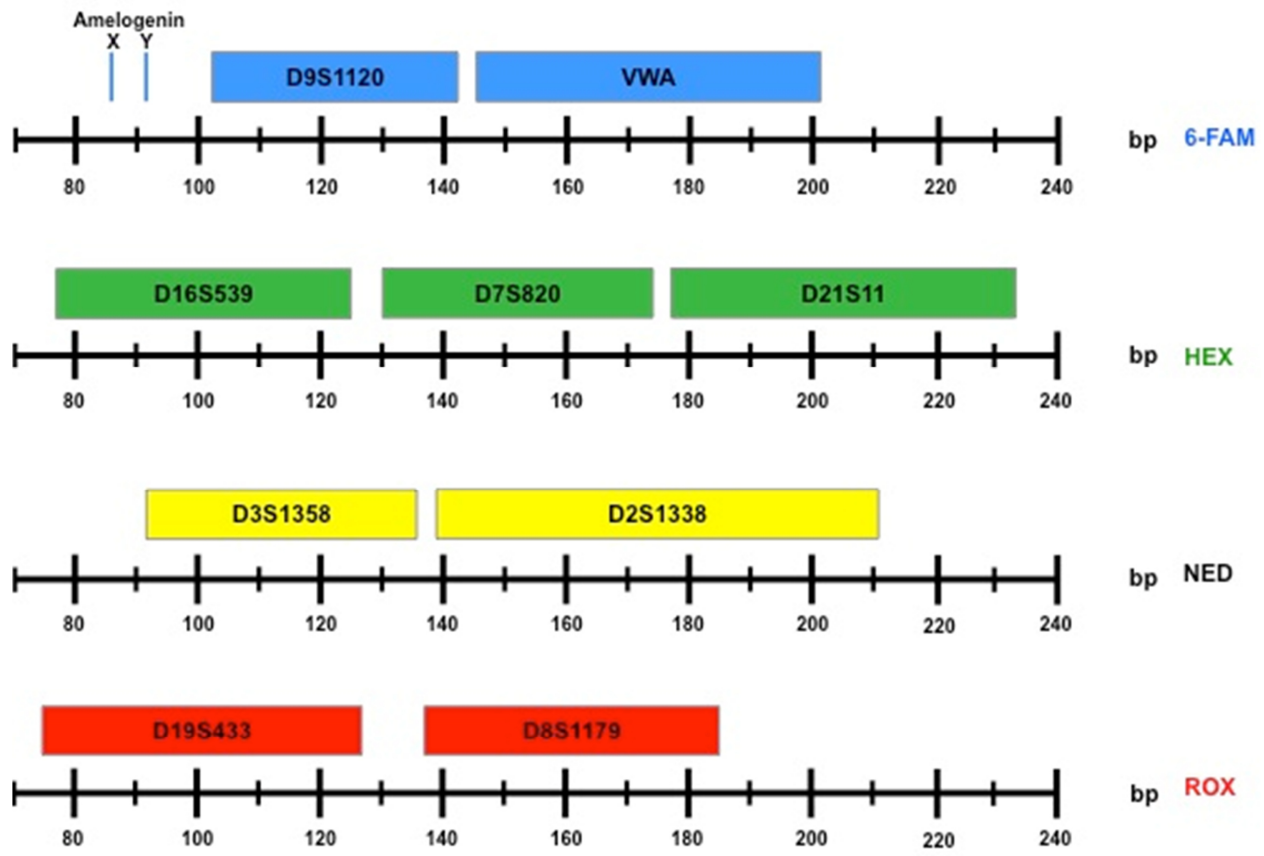

Abb. 20: Übersicht über die in der Dekaplex PCR enthaltenen autosomalen STR-Systeme, ihr jeweiliger Fragmentlängenrange und ihre Anordnung in den verschiedenen Farbpanels.

\section{Neu design der Y-Dekaplex PCR zur Amplifikation Y-chromosomaler STRs}

Für die Amplifikation Y-chromosomaler STRs wurde eine Y-Dekaplex PCR designed, welche die Systeme DYS19, DYS385, DYS389 I/II, DYS390, DYS391, DYS392, DYS393, DYS437, DYS438 und DYS439 umfasst. Alle Primer - bis auf die für das System DYS393 - wurden in Zusammenarbeit mit Philipp von Grumbkow neu designed (siehe auch Grumbkow von 2013). Die Primer für das System DYS393 wurden aus der Arbeit von Müller (2002) übernommen. Auch bei dieser PCR wurde auf die 5-Farb-Detektionstechnologie zurückgegriffen, um mehr Y-STR-Loci mit möglichst geringen Fragmentlängen analysieren zu können. Jeder upper Primer wurde mit einem der Fluoreszenzmoleküle 6FAM, HEX, NED oder ROX versehen. Die Primersequenzen, die Fluoreszenzmarkierungen und die exakten Produktlängen für die jeweiligen Loci sind in Tabelle 4 aufgeführt. Ein Überblick über die Fragmentlängen und die Anordnung in den verschiedenen Farbpanels ist in Abb. 21 dargestellt. 
Tabelle 4: Übersicht über die in der Y-Dekaplex PCR für Y-chromosomale STRs verwendeten Primerpaare, die verwendeten Fluoreszenzfarbstoffe und die Fragmentlängen des Allelranges.

\begin{tabular}{|c|c|c|c|c|c|c|}
\hline Marker & Primer & $\begin{array}{l}\text { Fluores- } \\
\text { zenzmar- } \\
\text { kierung }\end{array}$ & Primersequenz $\left(5^{`} \rightarrow 3^{`}\right)$ & Allele & $\begin{array}{l}\text { Fragment- } \\
\text { längen- } \\
\text { range [bp] }\end{array}$ & {$[\mu \mathrm{M}]$} \\
\hline \multirow[t]{2}{*}{ DYS389 } & up & \multirow[t]{2}{*}{ 6FAM } & АTССААСТСТСАТСТGTАTTATСTATGT & $9-17$ & I: 103-135 & 0,4 \\
\hline & low & & GACTGCTAGATAAATAGATAGATTGATAGAG & $24-34$ & II: 199-239 & 0,4 \\
\hline \multirow[t]{2}{*}{ DYS19 } & up & \multirow[t]{2}{*}{ 6FAM } & CTGAGTTTCTGTTATAGTGTTTTTTAATATAT & \multirow{2}{*}{$10-19$} & \multirow{2}{*}{$154-190$} & 0,15 \\
\hline & low & & ATGGGTTAAGGAGAGTGTCACTATAT & & & 0,15 \\
\hline \multirow[t]{2}{*}{ DYS438 } & up & \multirow[t]{2}{*}{ HEX } & GAATAGTTGAACGGTAAACAGTATATTT & \multirow{2}{*}{$6-14$} & \multirow{2}{*}{$77-117$} & 0,2 \\
\hline & low & & GAGTGAAACTCCATTTCAAATAGAA & & & 0,2 \\
\hline \multirow[t]{2}{*}{ DYS385 } & up & \multirow[t]{2}{*}{ HEX } & AGAGAAAGAGGAAAGAGAAAGAAAG & \multirow{2}{*}{$7-28$} & \multirow{2}{*}{ 120-204 } & 0,4 \\
\hline & low2 & & AAAAATAATCTATCTATTCCAАTTACATAGTC & & & 0,4 \\
\hline \multirow[t]{2}{*}{ DYS439 } & up & \multirow[t]{2}{*}{ NED } & GGAGACAGATAGATGATAAATAGAAGAT & \multirow{2}{*}{$9-14$} & \multirow{2}{*}{ 87-107 } & 0,1 \\
\hline & low & & АССАТСАТСТСТТТАСТТАТАСТTТСТАТС & & & 0,1 \\
\hline \multirow[t]{2}{*}{ DYS393* } & up & \multirow[t]{2}{*}{ NED } & GTGGTCTTCTACTTGTGTCAATAC & \multirow{2}{*}{$9-17$} & \multirow{2}{*}{$109-141$} & 0,15 \\
\hline & low & & AAAACTCAAGTCCAAAAAATGAGG & & & 0,15 \\
\hline \multirow[t]{2}{*}{ DYS390 } & up & \multirow[t]{2}{*}{ NED } & CATTTTGGTACCCCATAATATATTC & \multirow{2}{*}{$17-28$} & \multirow{2}{*}{$144-184$} & 0,2 \\
\hline & low2 & & AGCAATGTGTATACTCAGAAACAAG & & & 0,2 \\
\hline \multirow[t]{2}{*}{ DYS392 } & up & \multirow[t]{2}{*}{ ROX } & СТАССААТСССАТTССTTAGTAAA & \multirow{2}{*}{$6-17$} & \multirow{2}{*}{$81-111$} & 0,2 \\
\hline & low & & AAGGAAAACAAATTTTTTTTCTTGTA & & & 0,2 \\
\hline \multirow[t]{2}{*}{ DYS391 } & up & \multirow[t]{2}{*}{ ROX } & СTCTTGTGTATCTATTCATTCAATCATA & \multirow{2}{*}{$6-14$} & \multirow{2}{*}{$113-145$} & 0,2 \\
\hline & low & & AAATTGCCATAGAGGGATAGGTAG & & & 0,2 \\
\hline \multirow[t]{2}{*}{ DYS437 } & up & ROX & AGTGATCCTCCTACСTCAGTCTC & $13-17$ & $177-10$ & 0,25 \\
\hline & low & & ACCACAGATAAATATCATTCATAGATAA & $10-11$ & $111-190$ & 0,25 \\
\hline
\end{tabular}

${ }^{*}$ Primer unverändert aus Y-Nonaplex übernommen (Müller 2002)
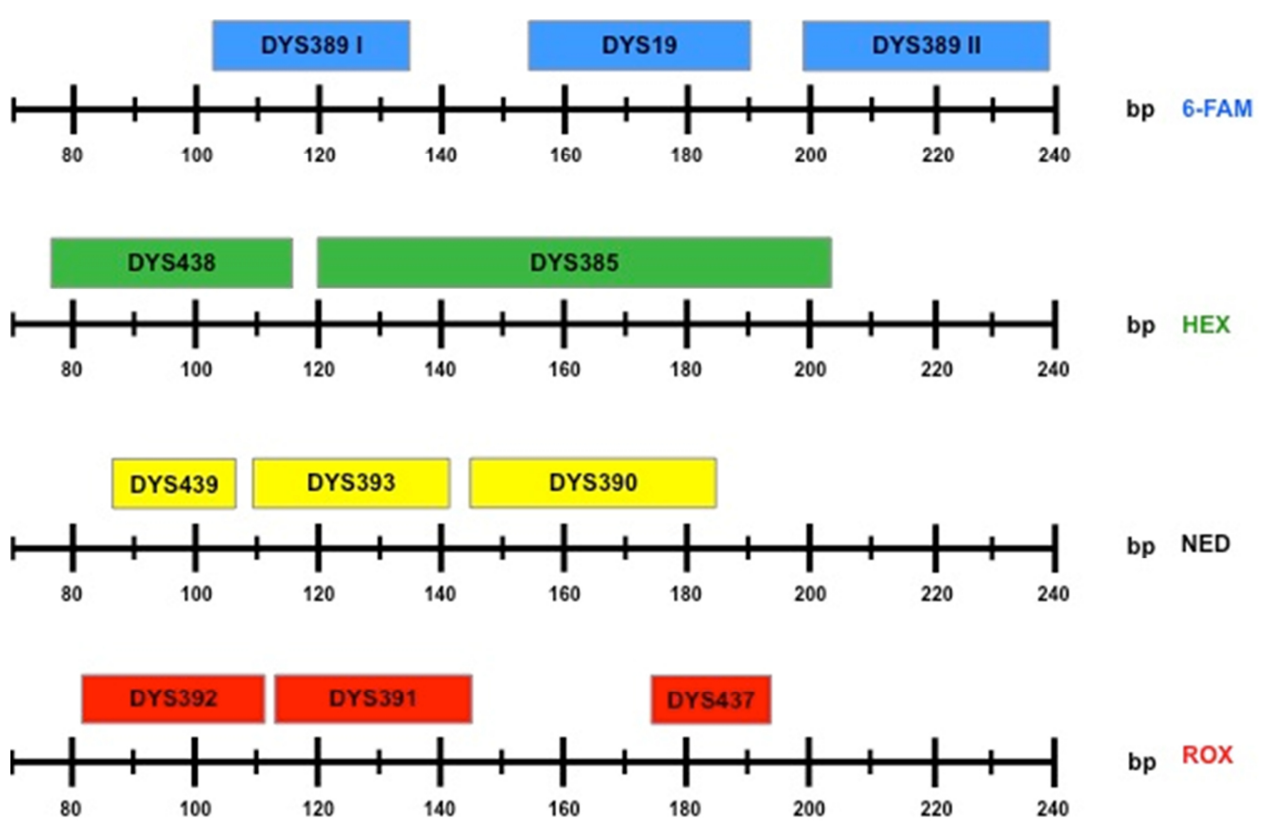

Abb. 21: Übersicht über die in der Y-Dekaplex PCR enthaltenen Y-chromosomalen STRSysteme, ihr jeweiliger Fragmentlängenrange und ihre Anordnung in den verschiedenen Farbpanels. 


\section{Design neuer Primer zur Amplifikation der mitochondrialen HVR II}

Für die Analyse der mitochondrialen HVR II wurden zwei Primerpaare entwickelt, welche diese Region in zwei überlappenden Fragmenten von 229 bp bzw. 254 bp amplifizieren. Hierbei wurde darauf geachtet, dass die Primer an Stellen platziert wurden, in denen keine bekannten Polymorphismen liegen. Dies ist wichtig, damit alle mitochondrialen Haplotypen gleichermaßen gut amplifiziert werden und es nicht bei Individuen mit bestimmten Haplotypen zu mismatches zu den Primersequenzen und damit zu einer verminderten Reaktionseffizienz oder sogar zum vollständigen Ausbleiben einer Amplifikation kommt. Die Primer wurden so designt, dass prinzipiell auch der forward primer des ersten Fragmentes und der reverse Primer des zweiten Fragmentes gemeinsam zur Generierung eines langen Amplifikates von 379 bp verwendet werden können. Die Sequenzen der vier neu designten Primer sind in Tabelle 5 aufgeführt.

Tabelle 5: Sequenzen der für die Amplifikation der HVR II verwendeten Primer.

\begin{tabular}{llll}
\hline Primer & Primersequenz $\left(5^{\star} \rightarrow 3^{`}\right)$ & Fragmentlänge & {$[\mu \mathrm{M}]$} \\
mt_H_034 & GGGAGCTCTCCATGCATTTG & $229 \mathrm{bp}$ & 0,2 \\
mt_L_262 & GGCTGTGCAGACATTCAATTGT & & 0,2 \\
mt_H_159 & TATCGCACCTACGTTCAATATTACAG & & 0,2 \\
mt_L_412 & CGCCAAAAGATAAAATTTGAAATC & & 0,2 \\
\hline
\end{tabular}

\section{Entwicklung des PCR/SBE-Systems zur ABO Blutgruppenbestimmung}

Für die Bestimmung der AB0-Blutgruppen wurde ein PCR-basiertes Analysesystem mit nachfolgender single base extension (SBE) entwickelt. Es wurden zwei Primerpaare für die Amplifikation eines 126 bp Fragmentes des Exons 6 und ein 135 bp Fragment des Exons 7 des AB0 Gens in einer Multiplex PCR designed. Mit den beiden Fragmenten werden insgesamt vier SNPs amplifiziert, mithilfe deren Allelausprägung es möglich ist, die fünf Allele A, B, 01, 01v und $02 \mathrm{zu}$ diskriminieren. Die SNPs befinden sich an Position 161 und 297 in Exon 6 und an Position 796 und 802 in Exon 7.

Das Analysesystem wurde so designed, dass die beiden AB0 Targetfragmente mit den vier SNPs gemeinsam mit drei hochdiskriminierenden STRs (D18S51, D21S11, FGA; Primersequenzen siehe Heptaplex PCR) in einer Multiplex PCR amplifiziert werden (siehe auch Georges et al. 2012). Die simultane Amplifikation von SNPs mit STRs dient der Authentizitätssicherung. SNPs sind als i.d.R. biallelische Marker nicht 
individualisierend, dies wird jedoch über die STR-Allelausprägungen und den Abgleich mit den bekannten Genotypen für den genetischen Fingerabdruck erreicht.

Die Allelausprägungen der vier SNPs wurden anschließend mittels einer Multiplex SBE Reaktion bestimmt. Beim Design der Primer für die SBE sind die Möglichkeiten der Lokalisation der Primer stark eingeschränkt, da der Primer direkt neben dem SNP liegen muss. D.h. es gibt für jeden SNP genau zwei Möglichkeiten der Primerlokalisation einmal komplementär zum upper strand und einmal komplementär zum lower strand. Wichtigstes Kriterium für die Platzierung ist bei diesen Primern, dass sie so gewählt werden, dass keine verlängerbaren Dimere möglich sind. Diese würden zur Detektion von falsch-positiven Ergebnissen bzw. von abweichenden Allelen führen. Um eine effiziente Separierung der einzelnen SBE Produkte in der Kapillarelektrophorese zu erlangen, wurden einige der SBE Primer am 5'-Ende mit unterschiedlich langen, nicht bindenden Poly-T-Schwänzen versehen.

Die Sequenzen der Primer für die PCR sind in Tabelle 6 aufgeführt, die Primer für die SBE in Tabelle 7.

Tabelle 6: Sequenzen der für die Amplifikation jeweils eines Abschnittes des Exon 6 und Exon 7 des AB0 Locus verwendeten Primer.

\begin{tabular}{llll}
\hline Primer & Primersequenz $\left(5^{`} \rightarrow 3^{`}\right)$ & Fragmentlänge & {$[\mu \mathrm{M}]$} \\
AB0 Exon 6 up & CACGCCTCTCTCCATGTGCAGTAG & 126 bp & 0,24 \\
AB0 Exon 6 low & GTGGTGTTCTGGAGCCTGAACTG & & 0,24 \\
AB0 Exon 7 up & CCCCAGTCCCAGGCCTACATC & 135 bp & 0,24 \\
AB0 Exon 7 low & GTTGGCCTGGTCGACCATCAT & & 0,24 \\
\hline
\end{tabular}

Tabelle 7: Sequenzen der für die SBE zur Bestimmung der ABO-Blutgruppen verwendeten Primer.

\begin{tabular}{lll}
\hline Primer & Primersequenz $\left(5^{`} \rightarrow 3^{`}\right)$ & {$[\mu \mathrm{M}]$} \\
\hline AB0 SBE_261 $\mathrm{f}$ & $(\mathrm{T})_{15}$ AGTAGGAAGGATGTCCTCGTGGT & 0,24 \\
AB0 SBE_297 $\mathrm{f}$ & $(\mathrm{T})_{14}$ CCATTGTCTGGGAGGGCAC & 0,16 \\
AB0 SBE_796 $\mathrm{f}$ & $(\mathrm{T})_{3}$ AGGACGAGGGCGATTTCTACTAC & 0,24 \\
\hline AB0 SBE_802 r & CGACCCCCCGAAGAACC & 0,28 \\
\hline
\end{tabular}




\subsubsection{DNA-Extraktion}

\section{Probenentnahme und -vorbereitung}

Für die molekulargenetischen Analysen wurden mit einer Dentalbohrmaschine (Dremel ${ }^{\circledR M u l t i{ }^{T M}}$ ) mit Diamantsägeblatt (Horico) kleine Knochenfragmente aus dem jeweiligen Knochen herausgesägt. Um eventuell an der Probenoberfläche anhaftende Kontaminationen zu entfernen, wurden entweder die Außenflächen mit der Beschichtung des Sägeblattes abgetragen oder es erfolgte eine Dekontamination mittels Bleiche. Für die Bleichedekontamination wurden die Proben für 15 min in $6 \%$ ige Bleiche eingelegt, dann für 15 min in Wasser gespült und schließlich über Nacht im Heizofen bei $37^{\circ} \mathrm{C}$ getrocknet.

Die Knochenfragmente wurden in einem Stahlmörser grob zerkleinert und in einer Kugelschwingmühle (Retsch) für 1-3 min bei 24 Schwingungen/s $\mathrm{zu}$ feinem Knochenpulver zermahlen. Für die DNA-Extraktionen wurden jeweils 0,25 g Knochenmehl abgewogen und der Rest des Pulvers bei $-20^{\circ} \mathrm{C}$ gelagert.

\section{DNA-Extraktion}

Die DNA-Extraktion stellt einen entscheidenden Schritt in der Analyse von aDNA dar. Die Quantität der DNA-Ausbeute und die Qualität der DNA-Aufreinigung entscheidet darüber, ob einerseits Targetsequenzen für die nachfolgenden PCR Analysen im Extrakt in ausreichender Konzentration vorhanden sind, andererseits aber auch darüber, ob die Extrakte effizient genug von inhibierenden Substanzen - wie z.B. Huminsäuren aus dem Sediment - befreit wurden, um eine effiziente Polymeraseaktivität zu gewährleisten. Deshalb wurden während der genetischen Analysen für die vorliegende Arbeit mehrere Testreihen mit Variationen verschiedener Extraktionsprotokolle vorgenommen. Es wurden verschiedene Protokolle einer automatisierten Aufreinigung unter Verwendung des BioRobot EZ1 (Qiagen) und verschiedene manuelle Protokolle mit einer Aufreinigung mittels des minElute PCR Purification Kits (Qiagen) getestet. Es zeigte sich, dass die mit dem BioRobot EZ1 hergestellten Extrakte sich durch eine bemerkenswerte Reinheit auszeichneten. Allerdings muss man bei diesem Extraktionsverfahren eine, im Vergleich zu anderen Protokollen, relativ geringe DNAAusbeute in Kauf nehmen. Die Aufreinigung mit den minElute-Säulchen entfernte zwar etwas weniger effizient potentiell inhibierende Substanzen (die Extrakte wiesen z.B. manchmal eine leichte bräunliche Färbung auf), die Extrakte wiesen jedoch eine ausgezeichnete DNA-Quantität auf. Für die Tests waren jeweils einige Proben aus der 
Lichtensteinhöhle verwendet worden. Es zeigte sich, dass sich die Aufreinigung mit den minElute-Säulchen sehr gut für das Material dieser Skelettserie eignet. Deshalb wurde die Mehrheit der Extraktionen nach diesem Protokoll hergestellt.

\section{Extraktionsprotokoll: Amicon-Aufkonzentration/minElute-Aufreinigung}

Die abgewogenen 0,25 g Knochenpulver wurden mit $3.900 \mu$ LDTA (0,5 M pH 8,0; Invitrogen) und $100 \mu$ l Proteinase $\mathrm{K}$ (Merck) für $18 \mathrm{~h}$ bei $37^{\circ} \mathrm{C}$ im Rotator inkubiert. Nach Zugabe von weiteren $50 \mu 1$ Proteinase K folgte eine weitere Inkubation für $2 \mathrm{~h}$ bei $56{ }^{\circ} \mathrm{C}$, gefolgt von einem dritten Inkubationsschritt unter Zugabe von $50 \mu$ SDS $\left(20 \mathrm{mg} / \mathrm{ml}\right.$; Sigma Life Science) für $5 \mathrm{~min}$ bei $65^{\circ} \mathrm{C}$. Dieses Verfahren bewirkt eine nahezu komplette Dekalzifizierung und Lyse des Knochenpulvers. Verbliebene Feststoffe wurden durch eine Zentrifugation für 3 min bei $3.300 \mathrm{rcf}$ sedimentiert. Der Überstand wurde in Amicon Ultra filter devices (30 K, Millipore) auf ca. $200 \mu \mathrm{l}$ aufkonzentriert. Das Konzentrat wurde mit $1.000 \mu$ PB-Puffer (Qiagen) vermischt und in zwei Schritten jeweils für $1 \mathrm{~min}$ bei $15.700 \mathrm{rcf}$ durch die Säulchen zentrifugiert. Anschließend wurden $700 \mu$ PE-Puffer (Qiagen) in die Säulchen pipettiert, $5 \mathrm{~min}$ gewartet und der Puffer ebenfalls für 1 min bei 15.700 rcf abzentrifugiert. Dieser Waschschritt wurde noch zweimal wiederholt. Die Säulchen wurden dann für ca. 20 min offen stehen gelassen um verbliebenen ethanolhaltigen Puffer abzudampfen. Die Elution erfolgte mit $60 \mu 137^{\circ} \mathrm{C}$ warmem Reinstwasser. Die Extrakte wurden bei $-20^{\circ} \mathrm{C}$ gelagert.

\section{Extraktionsprotokoll: minElute-Aufreinigung/QiaVac}

Im Verlauf der Arbeiten wurde eine Variante der minElute-Aufreinigung entwickelt, bei der ein Teil der Arbeitsschritte nicht mehr mittels Zentrifugation durchgeführt wurde, sondern über Durchsaugen der Flüssigkeiten mit dem QiaVac-Vakuumsystem (Qiagen). Die Probenlyse erfolgte genau wie im obenstehenden Absatz geschildert. Nach dem ersten Zentrifugationsschritt wurde jedoch das gesamte Volumen von $4 \mathrm{ml}$ mit $16 \mathrm{ml}$ PB-Puffer und $100 \mu$ l Sodium Acetat (3 M pH 5,2; Sigma Life Science) versetzt, nochmals für $3 \mathrm{~min}$ bei 3.300 rcf zentrifugiert und dann über Trichteraufsätze für große Volumina direkt auf die minElute-Säulchen aufgebracht und per Vakuum hindurchgesaugt. Anschließend wurden ebenfalls drei Reinigungsschritte mit dem PEPuffer durchgeführt, wobei dieser ebenfalls mit dem Vakuum durch die Membran gesaugt wurde. Es folgte eine kurze Zentrifugation für 1 min bei $15.700 \mathrm{rcf}$, um 
Pufferreste zu entfernen und der 20minütige Abdampfschritt. Die Elution wurde genauso wie oben beschrieben durchgeführt.

Für einige Extraktionen wurde eine Variation dieses Extraktionsprotokolls verwendet, bei der nach den Lyseschritten vor der Aufreinigung mittels minElute Säulchen eine zusätzliche Aufreinigung mit Phenol-Chloroform durchgeführt wird. Hierfür wurden die Überstände der Lysate mit jeweils $3 \mathrm{ml}$ Roti®-Phenol versetzt, $6 \mathrm{~min}$ bei Raumtemperatur invertiert und anschließend zur Phasentrennung $10 \mathrm{~min}$ bei $56^{\circ} \mathrm{C}$ inkubiert. Die organische Phase wurde verworfen, die wässrige Phase mit 4,5 ml Chloroform (ROTISOLV®HPLC) versetzt, wie im vorhergehenden Schritt invertiert und separiert (siehe auch Frischalowski et al. 2015).

\subsubsection{Amplifikation autosomaler STRs}

Die Darstellung autosomaler STRs zur Generierung genetischer Fingerabdrücke erfolgte durch Amplifikation in zwei verschiedenen Multiplex PCRs (siehe auch Kapitel 3.2.3). Hierbei handelt es sich einmal um eine Heptaplex PCR (Seidenberg et al. 2012), welche sechs autosomale STRs und den Geschlechtsmarker Amelogenin amplifiziert, und um eine Dekaplex PCR, welche neun autosomale STRs und ebenfalls den Geschlechtsmarker Amelogenin umfasst. Die beiden Multilex PCRs überschneiden sich im System D21S11, welches zwar in beiden PCRs enthalten ist, aber jeweils mit unterschiedlichen Primern amplifiziert wird. Insgesamt wurden also 14 verschiedene STR-Systeme für die genetischen Fingerabdrücke analysiert.

\section{Reaktionsparameter Heptaplex PCR}

Die Heptaplex PCR Reaktionen wurden in einem Volumen von $25 \mu 1$ unter Verwendung von 12,5 $\mu$ l QIAGEN Multiplex PCR Mastermix plus durchgeführt. Zu dem Mastermix wurden 2,85 $\mu$ 1 Primerset (siehe Tabelle 2, Seite 49) und bis zu 9,65 $\mu 1$ DNA-Extrakt hinzugegeben. Bei geringerem DNA-Extrakt Einsatz wurde eine von diesem abhängige Menge Wasser hinzugefügt, um auf das angestrebte Endvolumen zu kommen. Die PCR Reaktionen wurden im Eppendorf Mastercycler zunächst für 5 min auf $95{ }^{\circ} \mathrm{C}$ erhitzt, um die doppelsträngige DNA zu denaturieren und die inhibierte DNA-Polymerase im Reaktionsmix zu aktivieren. Das cycling erfolgte im two stepVerfahren über 40 Zyklen mit 1 min denaturation bei $94{ }^{\circ} \mathrm{C}$ und $2,5 \mathrm{~min}$ annealing/elongation bei $59^{\circ} \mathrm{C}$. Anschließend wurde ein delay Schritt für $45 \mathrm{~min}$ bei $60{ }^{\circ} \mathrm{C}$ durchlaufen und dann die Proben auf $10{ }^{\circ} \mathrm{C}$ heruntergekühlt. 


\section{Reaktionsparameter Dekaplex PCR}

Die Dekaplex PCR Reaktionen wurden ebenfalls in einem Volumen von $25 \mu 1$ unter Verwendung von 12,5 $\mu$ l QIAGEN Multiplex PCR Mastermix plus durchgeführt. Zu dem Mastermix wurden 1,98 $\mu 1$ Primerset (siehe Tabelle 3, Seite 50), 0,07 $\mu 1$ Ammoniumsulfat $(3 \mathrm{M})$ und bis $\mathrm{zu}$ 10,45 $\mu$ l DNA-Extrakt hinzugegeben. Bei geringerem DNA-Extrakt Einsatz wurde eine von diesem abhängige Menge Wasser hinzugefügt, um auf das angestrebte Endvolumen zu kommen. Die PCR Reaktionen wurden im Eppendorf Mastercycler ebenfalls zunächst für 5 min auf $95{ }^{\circ} \mathrm{C}$ erhitzt. Das cycling erfolgte im three step-Verfahren über 40 Zyklen mit 1 min denaturation bei $94{ }^{\circ} \mathrm{C}, 1,5$ min annealing bei $56^{\circ} \mathrm{C}$ und 1 min elongation bei $72{ }^{\circ} \mathrm{C}$. Anschließend wurde ein delay Schritt für 45 min bei $60^{\circ} \mathrm{C}$ durchlaufen und dann die Proben auf $10{ }^{\circ} \mathrm{C}$ heruntergekühlt.

\subsubsection{Amplifikation gonosomaler STRs}

Die Darstellung Y-chromosomaler STR-Systeme zur Ermittlung der Y-chromosomalen Haplotypen erfolgte durch Amplifikation in einer Dekaplex PCR (siehe Kapitel 3.2.3). Zudem wurden Amplifikationen mit einem kommerziellen Kit, dem Powerplex Y Kit (Promega), vorgenommen. Beide PCRs umfassen dieselben STR-Loci, jedoch ist die selbst designte Y-Dekaplex PCR mit durchgängig kürzeren Produktlängen speziell für die Amplifikation degradierter DNA angepasst.

Für einige Proben mit vergleichsweise schlechtem DNA Erhalt wurden zudem Amplifikationen mit einem sogenannten SexMultiplex PCR System (Schmidt 2004) durchgeführt, welches sowohl Y-chromosomale STRs (DYS391 und DYS392) als auch X-chromosomale STRs (DXS9898 und DXS6789) und den geschlechtsdiskriminierenden Marker Amelogenin umfasst. Dies bietet den Vorteil, dass für weibliche Individuen das Geschlecht nicht nur über das Ausbleiben der Ychromosomalen Signale angezeigt wird - welches auch lediglich durch konsequentes allelic dropout aufgrund zu starker DNA Degradierung zustande kommen könnte sondern durch heterozygote Signale für die X-chromosomalen STRs.

\section{Reaktionsparameter Y-Dekaplex PCR}

Die Y-Dekaplex PCR Reaktionen wurden in $25 \mu$ Ansätzen bestehend aus 12,5 $\mu 1$ QIAGEN Multiplex PCR Mastermix plus, 2,25 $\mu 1$ Primerset (siehe Tabelle 4, Seite 52), $0,25 \mu 1$ Ammoniumsulfat $(3 \mathrm{M})$ und bis zu $10 \mu$ DNA-Extrakt durchgeführt. Bei 
geringerem DNA-Extrakt Einsatz wurde eine von diesem abhängige Menge Wasser hinzugefügt, um auf das angestrebte Endvolumen zu kommen. Die PCR Reaktionen wurden im Eppendorf Mastercycler zunächst für $5 \mathrm{~min}$ auf $95^{\circ} \mathrm{C}$ erhitzt, um die doppelsträngige DNA zu denaturieren und die inhibierte DNA-Polymerase im Reaktionsmix zu aktivieren. Das cycling erfolgte zunächst über 10 Zyklen mit 1 min denaturation bei $94{ }^{\circ} \mathrm{C}, 1,5 \mathrm{~min}$ annealing bei $62{ }^{\circ} \mathrm{C}$ und 1 min elongation bei $70{ }^{\circ} \mathrm{C}$. Anschließend wurden 30 Zyklen mit 1 min denaturation bei $90{ }^{\circ} \mathrm{C}, 1,5$ min annealing bei $59^{\circ} \mathrm{C}$ und 1 min elongation bei $70^{\circ} \mathrm{C}$ durchlaufen. Abschließend folgte ein delay Schritt für 45 min bei $60{ }^{\circ} \mathrm{C}$ und das Herunterkühlen der Proben auf $10{ }^{\circ} \mathrm{C}$.

\section{Reaktionsparameter Powerplex Y Kit}

Die Amplifikationen mit dem Powerplex $\mathrm{Y}$ Kit (Promega) wurden in einem Reaktionsvolumen von 12,5 $\mu 1$ durchgeführt. Der Reaktionsansatz bestand aus 1,25 $\mu 1$ Goldstar 10×Puffer, 1,25 $\mu 1$ 10×PrimerPairMix, 0,3 $\mu$ 1 AmpliTaq Gold und bis zu 9,7 $\mu 1$ DNA-Extrakt. Bei geringerem DNA-Extrakt Einsatz wurde eine von diesem abhängige Menge Wasser hinzugefügt, um auf das angestrebte Endvolumen zu kommen. Die PCR Reaktionen wurden im Eppendorf Mastercycler zunächst für $11 \mathrm{~min}$ auf $94{ }^{\circ} \mathrm{C}$ und für 1 min auf $96{ }^{\circ} \mathrm{C}$ erhitzt, um die doppelsträngige DNA zu denaturieren und die inhibierte DNA-Polymerase im Reaktionsmix zu aktivieren. Das cycling erfolgte zunächst über 10 Zyklen mit 1 min denaturation bei $94{ }^{\circ} \mathrm{C}, 1 \mathrm{~min}$ annealing bei $60{ }^{\circ} \mathrm{C}$ und $1,5 \mathrm{~min}$ elongation bei $70^{\circ} \mathrm{C}$. Anschließend wurden 30 Zyklen mit 1 min denaturation bei $90{ }^{\circ} \mathrm{C}, 1$ min annealing bei $58^{\circ} \mathrm{C}$ und 1,5 min elongation bei $70^{\circ} \mathrm{C}$ durchlaufen. Abschließend folgte ein delay Schritt für 30 min bei $60{ }^{\circ} \mathrm{C}$ und das Herunterkühlen der Proben auf $10^{\circ} \mathrm{C}$.

\section{Reaktionsparameter SexMultiplex}

Die SexMultiplex PCR Reaktionen wurden in $25 \mu$ Ansätzen bestehend aus 12,5 $\mu 1$ QIAGEN Multiplex PCR Mastermix plus, 2,55 $\mu$ 1 Primerset (siehe Tabelle 8) und bis zu 9,95 $\mu 1$ DNA-Extrakt durchgeführt. Bei geringerem DNA-Extrakt Einsatz wurde eine von diesem abhängige Menge Wasser hinzugefügt, um auf das angestrebte Endvolumen zu kommen. Die PCR Reaktionen wurden im Eppendorf Mastercycler zunächst für 5 min auf $95^{\circ} \mathrm{C}$ erhitzt, um die doppelsträngige DNA zu denaturieren und die inhibierte DNA-Polymerase im Reaktionsmix zu aktivieren. Das cycling erfolgte über 40 Zyklen mit $40 \mathrm{~s}$ denaturation bei $94^{\circ} \mathrm{C}, 40 \mathrm{~s}$ annealing bei $50^{\circ} \mathrm{C}$ und $40 \mathrm{~s}$ elongation bei 
$72{ }^{\circ} \mathrm{C}$. Abschließend folgte ein delay Schritt für $45 \mathrm{~min}$ bei $60{ }^{\circ} \mathrm{C}$ und das Herunterkühlen der Proben auf $10^{\circ} \mathrm{C}$.

Tabelle 8: Übersicht über die in der SexMultiplex PCR verwendeten Primerpaare, die verwendeten Fluoreszenzfarbstoffe und die Fragmentlängen des Allelranges (Schmidt 2004).

\begin{tabular}{|c|c|c|c|c|c|c|}
\hline Marker & Primer & $\begin{array}{l}\text { Fluores- } \\
\text { zenzmar- } \\
\text { kierung }\end{array}$ & Primersequenz $\left(5^{‘} \rightarrow 3^{`}\right)$ & Allele & $\begin{array}{l}\text { Fragment- } \\
\text { längen- } \\
\text { range [bp] }\end{array}$ & {$[\mu \mathrm{M}]$} \\
\hline \multirow{2}{*}{$\begin{array}{l}\text { Amelo- } \\
\text { genin }\end{array}$} & up & \multirow[t]{2}{*}{ 6FAM } & CCTGGGCTCTGTAAAGAATAGTG & $\mathrm{X}$ & 86 & 0,2 \\
\hline & low_VSE & & AGCTGATGGTAGGAACTGTAAAAT & Y & 92 & 0,2 \\
\hline \multirow[t]{2}{*}{ DXS9898 } & up & \multirow[t]{2}{*}{ HEX } & CACACCTACAAAAGCTGAGATATA & \multirow{2}{*}{$8.3-15$} & \multirow{2}{*}{$130-155$} & 0,2 \\
\hline & low & & CATCCAGATAGACAGATCAATAGATT & & & 0,2 \\
\hline \multirow[t]{2}{*}{ DXS6789 } & up & \multirow[t]{2}{*}{ NED } & GTTGGTACTTAATAAACCCTCTTTT & \multirow{2}{*}{$14-25$} & \multirow{2}{*}{$120-164$} & 0,4 \\
\hline & low & & GGATCCCTAGAGGGACAGAA & & & 0,4 \\
\hline \multirow[t]{2}{*}{ DYS391 } & up & \multirow[t]{2}{*}{ 6FAM } & TTGTGTATCTATTCATTCAATCATA & \multirow{2}{*}{$7-14$} & \multirow{2}{*}{$138-166$} & 0,35 \\
\hline & low2 & & GGAATAAAATCTCCCTGGT & & & 0,35 \\
\hline \multirow[t]{2}{*}{ DYS392 } & up & \multirow[t]{2}{*}{ 6FAM } & CAAGAAGGAAAACAAATTTTTT & \multirow{2}{*}{$6-16$} & \multirow{2}{*}{$91-121$} & 0,1 \\
\hline & low & & GGATCATTAAACCTACCAATC & & & 0,1 \\
\hline
\end{tabular}

\subsubsection{Amplifikation und Sequenzierung der mitochondrialen HVR I und II}

Die mitochondriale HVR I und HVR II wurden jeweils in zwei überlappenden Fragmenten amplifiziert, welche anschließend mit der Kettenabbruchmethode nach Sanger sequenziert wurden. Für die Amplifikation der HVR I wurden die Primerpaare mt_H_15995 und mt_L_16256, bzw. mt_H_16194 und mt_L_16429 von FehrenSchmitz (2008) verwendet. Die HVR II wurde mit neu designten Primern (siehe Kapitel 3.2.3) amplifiziert.

\section{Amplifikationsparameter HVR I und HVR II}

Die Singleplex Reaktionen wurden in $25 \mu 1$ Ansätzen, bestehend aus 12,5 $\mu 1$ AmpliTaq $360^{\circ}$ Mastermix (Applied Biosystems), jeweils 0,5 $\mu 1$ einer $10 \mu \mathrm{M}$ Arbeitskonzentration upper und lower Primer und i.d.R. 1-3 $\mu$ l DNA-Extrakt, durchgeführt. Um auf das angestrebte Reaktionsendvolumen $\mathrm{zu}$ kommen, wurde eine entsprechende Menge Wasser hinzugefügt. Die PCR Reaktionen wurden im Eppendorf Mastercycler zunächst für 10 min auf $95^{\circ} \mathrm{C}$ erhitzt, um die doppelsträngige DNA zu denaturieren und die inhibierte DNA-Polymerase im Reaktionsmix zu aktivieren. Das cycling erfolgte über 40 Zyklen mit 1 min denaturation bei $95^{\circ} \mathrm{C}, 1$ min annealing bei $55^{\circ} \mathrm{C}$ (HVR I) bzw. $57^{\circ} \mathrm{C}$ (HVR II) und 1,5 min elongation bei $72{ }^{\circ} \mathrm{C}$. Abschließend wurden die Reaktionen auf $10^{\circ} \mathrm{C}$ heruntergekühlt. 


\section{Sequenzierung der Amplifikate der HVR I und HVR II}

Für die Sequenzierung wurden die PCR Produkte zunächst einem Aufreinigungsschritt unterzogen, um die im Folgenden störenden Reaktionskomponenten, wie nicht inkorporierte Primer oder dNTPs, unschädlich zu machen. Hierfür wurde eine enzymatische Aufreinigung verwendet. Vom PCR Produkt wurden 7,5 $\mu 1$ mit 2,5 $\mu 1$ rAPid Alkaline Phosphatase ( $1 \mathrm{U} / \mu \mathrm{l}$; Roche) sowie $1 \mu$ l ExoI Exonuklease $(1 \mathrm{U} / \mu \mathrm{l}$; New England Biolabs) versetzt und für $1 \mathrm{~h}$ bei $37^{\circ} \mathrm{C}$ inkubiert. Anschließend wurden die beiden Enzyme mittels einer Inkubation für 15 min bei $75^{\circ} \mathrm{C}$ inaktiviert.

Die Sequenzierung wurde unter Verwendung des BigDyeTerminator (BDT) Cycle Sequencing Kits (Applied Biosystems) durchgeführt. Die Reaktionen wurden in $20 \mu 1$ Ansätzen, bestehend aus $4 \mu \mathrm{l}$ Seq Buffer (5×), $2 \mu 1$ BDT, 0,3 $\mu 1$ einer $10 \mu \mathrm{M}$ Arbeitskonzentration des jeweiligen forward oder reverse Primers und bis zu $10 \mu \mathrm{l}$ PCR Produkt, durchgeführt. Um auf das angestrebte Reaktionsendvolumen $\mathrm{zu}$ kommen, wurde eine entsprechende Menge Wasser hinzugefügt. Die Sequenzierreaktionen wurden im Eppendorf Mastercycler zunächst für 10 min auf $96{ }^{\circ} \mathrm{C}$ erhitzt, um die doppelsträngige DNA zu denaturieren. Das cycling erfolgte über 25 Zyklen mit $10 \mathrm{~s}$ denaturation bei $96{ }^{\circ} \mathrm{C}, 5 \mathrm{~s}$ annealing bei $50{ }^{\circ} \mathrm{C}$ und 4 min elongation bei $60{ }^{\circ} \mathrm{C}$. Abschließend wurden die Proben auf $10^{\circ} \mathrm{C}$ heruntergekühlt.

Bevor die Sequenzierprodukte einer Kapillarelektrophorese zum Auslesen der genauen Basenabfolge unterzogen werden konnten, musste ein zweiter Aufreinigungsschritt erfolgen. Hierfür wurden die NucleoSeq Säulchen (Macherey \& Nagel) nach Herstellerprotokoll verwendet. Mittels Filtration durch die Gelmatrix der Säulchen werden vor allem nicht inkorporierte ddNTPs entfernt, welche sonst als Fluoreszenzartefakte in den Elektropherogrammen dargestellt würden.

\subsubsection{Amplifikation und SBE-Analyse der AB0-Blutgruppen-SNPs Amplifikationsparameter Basis-PCR}

Die Multiplex Reaktionen wurden in $25 \mu$ Ansätzen, bestehend aus 12,5 $\mu$ l QIAGEN Multiplex PCR Mastermix plus, 2,4 $\mu$ l Primerset (siehe Tabelle 6, Seite 54) und 510,1 $\mu$ l DNA-Extrakt, durchgeführt. Um auf das angestrebte Reaktionsendvolumen zu kommen, wurde eine entsprechende Menge Wasser hinzugefügt. Die PCR Reaktionen wurden im Eppendorf Mastercycler zunächst für $5 \mathrm{~min}$ auf $95^{\circ} \mathrm{C}$ erhitzt, um die doppelsträngige DNA zu denaturieren und die inhibierte DNA-Polymerase im Reaktionsmix zu aktivieren. Das cycling erfolgte über 40 Zyklen mit 1 min 
denaturation bei $94{ }^{\circ} \mathrm{C}, 1 \mathrm{~min}$ annealing bei $62{ }^{\circ} \mathrm{C}$ und 1 min elongation bei $72{ }^{\circ} \mathrm{C}$. Nach einem delay für 30 min bei $60{ }^{\circ} \mathrm{C}$ wurden die Reaktionen abschließend auf $10{ }^{\circ} \mathrm{C}$ heruntergekühlt.

Die PCR Produkte wurden im Folgenden gesplittet. Ein Teil wurde einem weiteren cycling für 5 Zyklen mit nun fluoreszenzmarkierten STR-Primern unterzogen. Ein anderer Teil wurde aufgereinigt und in die SBE zur Bestimmung der Allelausprägungen der AB0 Blutgruppen SNPs eingesetzt.

\section{SBE-Analyse der Amplifikate}

Für die SBE wurde jeweils ein Teil des PCR Produktes zunächst einem Aufreinigungsschritt unterzogen, um die im Folgenden störenden Reaktionskomponenten, wie nicht inkorporierte Primer oder dNTPs, unschädlich zu machen. Hierfür wurde eine enzymatische Aufreinigung verwendet. Vom PCR Produkt wurden 7,5 $\mu \mathrm{l}$ mit 2,5 $\mu \mathrm{l}$ rAPid Alkaline Phosphatase ( $1 \mathrm{U} / \mu \mathrm{l}$; Roche) sowie $1 \mu \mathrm{l}$ ExoI

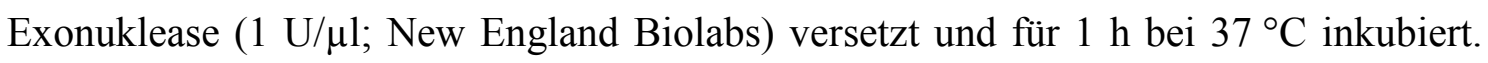
Anschließend wurden die beiden Enzyme mittels einer Inkubation für 15 min bei $75^{\circ} \mathrm{C}$ inaktiviert.

Die SBE wurde unter Verwendung des SNaPshot Ready Reaction Mix (Applied Biosystems) durchgeführt. Die Reaktionen wurden in $5 \mu$ Ansätzen bestehend aus 2,5 $\mu 1$ SNaPshot Ready Reaction Mix, 0,3 $\mu 1$ Primermix (siehe Tabelle 7, Seite 54), $20 \mu \mathrm{M}\left(\mathrm{NH}_{4}\right)_{2} \mathrm{SO}_{4}$ (Merck) und 0,7 $\mu \mathrm{l}$ PCR Produkt, durchgeführt. Um auf das angestrebte Reaktionsendvolumen $\mathrm{zu}$ kommen, wurde eine entsprechende Menge Wasser hinzugefügt. Das cycling erfolgte im Eppendorf Mastercycler über 25 Zyklen mit $10 \mathrm{~s}$ denaturation bei $96^{\circ} \mathrm{C}, 5 \mathrm{~s}$ annealing bei $50{ }^{\circ} \mathrm{C}$ und $30 \mathrm{~s}$ elongation bei $60{ }^{\circ} \mathrm{C}$. Abschließend wurden die Proben auf $4{ }^{\circ} \mathrm{C}$ heruntergekühlt.

Die SBE Produkte wurden einer zweiten Aufreinigung unterzogen. Hierfür wurden jeweils 2,5 $\mu$ l rAPid Alkaline Phosphatase (1 U/ $\mu$; Roche) zu den Reaktionen gegeben und für $1 \mathrm{~h}$ bei $37^{\circ} \mathrm{C}$ inkubiert. Anschließend wurden die beiden Enzyme mittels einer Inkubation für $15 \mathrm{~min}$ bei $75^{\circ} \mathrm{C}$ inaktiviert.

\section{Farbmarkieren der STR-Amplifikate}

Für die Detektion der STR-Allele in der Kapillarelektrophorese war es notwendig, die PCR Produkte mit Fluoreszenzfarbstoffen zu versehen. Dies wurde durch die Zugabe von farbmarkierten Primern zu einem kleinen Teil des Basis-PCR Produktes mit 
nochmaligem cyclen für 5 Zyklen vorgenommen. $\mathrm{Zu}$ dem nach Agarosegelelektrophorese (s.u.) und Abnahme des Aliquots für die SBE verbleibenden PCR Produkt wurden 1,5 U AmpliTaq Gold (Applied Biosystems), 0,6 $\mu \mathrm{M}$ 6-FAMmarkierter D21S11 upper Primer, 0,7 $\mu \mathrm{M}$ HEX-markierter D18S51 upper Primer und 0,8 $\mu \mathrm{M}$ NED-markierter FGA upper Primer hinzugefügt. Die Reaktionen wurden im Eppendorf Mastercycler zunächst für $11 \mathrm{~min}$ auf $94{ }^{\circ} \mathrm{C}$ erhitzt. Das cycling erfolgte über 3 Zyklen mit 1 min denaturation bei $94^{\circ} \mathrm{C}, 2,5$ min annealing/elongation bei $59^{\circ} \mathrm{C}$ und einer final elongation für $45 \mathrm{~min}$ bei $60^{\circ} \mathrm{C}$.

\subsubsection{Elektrophorese}

Zur Einschätzung des Amplifikationserfolges wurden die PCR Produkte zunächst in 2,5\%igen Agarosegelen (Roth) aufgetrennt. Anschließend erfolgte eine Kapillarelektrophorese in einem 310 Genetic Analyzer oder 3500 Genetic Analyzer (beides Applied Biosystems) zur genauen Fragmentlängenanalyse. Im 310 Genetic Analyzer erfolgte die Elektrophorese in einer $36 \mathrm{~cm}$ Kapillare unter Verwendung von POP 4 (performance optimized polymer) zur STR Fragmentlängenanalyse bzw. POP 6 zur Sequenzanalyse der mitochondrialen HVRs. Die Datenaufnahme erfolgt mit der ABI PRISM ${ }^{\circledR} 310$ Data Collection Software v3.1.0 bzw. ABI PRISM ${ }^{\circledR} 310$ Collection Software v2.0.2 (beides Applied Biosystems). Im Genetic Analyzer 3500 wurde ein $50 \mathrm{~cm}$ 8-Kapillar-Array und das sowohl für Fragmentlängenanalysen als auch Sequenzanalysen geeignete POP 7 verwendet. Die Datenaufnahme erfolgte mit der 3500 Series Data Collection Software v2.0 (Life Technologies).

Für die Fragmentlängenanalyse der Multiplex PCR Produkte der autosomalen oder gonosomalen STRs wurden - nach Einschätzung der Produktmenge basierend auf der Bandenintensität im Agarosegel - bis zu $2 \mu \mathrm{l}$ PCR Produkt mit $12 \mu \mathrm{l} \mathrm{HiDi-Formamid}$ (Life Technologies) und 0,25 $\mu$ lane internal length standard versetzt. Dieser Längenstandard variierte in Abhängigkeit von dem jeweiligen PCR Kit. Für die Heptaplex PCR, das Powerplex Y Kit und die SexMultiplex PCR wurde GS 500 ROX (Applied Biosystems) verwendet, für die autosomale Dekaplex PCR und die YDekaplex PCR auf dem 310 Genetic Analyzer GS 600 LIZ (Applied Biosystems) und auf dem 3500 Genetic Analyzer CC5 ILS 500 (Promega). In jedem Analysegang wurde die Allelleiter für die jeweils gerade analysierte PCR in einem Extracup im 310 Genetic Analyzer bzw. in einer Extraposition der Platte im 3500 Genetic Analyzer mitgeführt. 
Für die Allelbestimmung der AB0-Blutgruppen-SNPs wurde jeweils $1 \mu 1$ des aufgereinigten SBE Produktes mit $12 \mu$ HiDi Formamid (Applied Biosystems) und 0,25 $\mu \mathrm{l}$ des lane internal length standards GS 120 LIZ (Applied Biosystems) vermischt.

\subsubsection{Alleldetermination/Sequenzauswertung}

\section{Alleldetermination autosomaler und gonosomaler STRS}

Die Alleldetermination erfolgte für Daten vom 310 Genetic Analyzer mit der ABI PRISM ${ }^{\circledR} 310$ GeneScan Analysis Software v2.1 bzw. v3.1.2 (Applied Biosystems). Die Elektropherogramme der Proben wurden nacheinander mit dem der mitgeführten Allelleiter in Deckung gebracht und es erfolgte ein manuelles Auszählen der jeweiligen Allelausprägungen. Für die Daten vom 3500 Genetic Analyzer erfolgte die Alleldetermination automatisiert mittels der in der GeneMapper ${ }^{\circledR}$ Software v5.0 (Life Technologies) hinterlegten BinFiles. Es erfolgte jedoch zu Beginn jeder Auswertung immer eine Kontrolle der Deckung der im aktuellen Lauf mitgeführten Allelleiter mit den Positionen der Bins und ggf. eine Nachkorrektur. Nach der automatisierten Alleldetermination durch die Software wurden alle Proben auf die richtige Alleldetermination hin kontrolliert und auch hier ggf. manuelle Nachkorrekturen durchgeführt.

Die Einzeltypisierungsergebnisse aus mehreren Analysen wurden für jedes Individuum in Tabellen gesammelt und mit bereits bestehenden Daten abgeglichen. Aus allen Einzeltypisierungsergebnissen wurde schließlich ein Konsensusfingerprint bzw. ein Konsensus Y-Haplotyp gebildet. Hierbei wurden nur solche Allele als sicher gewertet, welche in mehreren Analysen repliziert generiert wurden. Nicht replizierte Allele wurden im Konsensus mit Klammern als unsichere Allele gekennzeichnet.

\section{Sequenzauswertung der mitochondrialen HVR I und HVR II}

Die Sequenzauswertung erfolgte für Daten vom 310 Genetic Analyzer zunächst mit der ABI PRISM ${ }^{\circledR}$ 310 Sequencing Analysis Software v5.1.1 (Applied Biosystems) und für die Daten vom 3500 Genetic Analyzer mit der Sequencing Analysis Software v6.0 (Life Technologies). Die Elektropherogramme der Proben wurden nacheinander auf die richtigen Zuordnungen der Basen durch die Software hin kontrolliert und ggf. manuell korrigiert. Die weitere Auswertung erfolgte für alle Daten mit dem DNASTAR Lasergene ${ }^{\circledR} 10$ Core Suite Softwarepaket v10.0.1 (DNASTAR, Inc.). Zunächst erfolgte eine weitere Kontrolle der richtigen Basenzuordnung mit der SeqMan Software. 
Anschließend wurden die Sequenzen im FASTA Format in die MegAlign Software geladen und mit der revised cambridge reference sequence (rCRS) aligniert. Die Abweichungen zur rCRS wurden für jede erfolgte Sequenzierung für jede Probe als Einzeltypisierungsergebnis tabellarisch festgehalten. Beim Übereinstimmen der Einzeltypisierungsergebnisse einer Probe wurde der Konsensus mt-Haplotyp aufgenommen. 


\section{Ergebnisse}

\subsection{Zuordnung von Skelettelementen zu Individuen/Individuenzahl}

Die Feststellung der Anzahl von Individuen ist eine Grundvoraussetzung für die Beantwortung vieler Fragestellungen und somit i.d.R. einer der ersten Schritte bei der Bearbeitung eines Skelettkollektivs. Bei disloziertem Vorliegen der Knochen gibt das am häufigsten vorkommende Skelettelement einen Hinweis auf die Mindestindividuenzahl. Für die Funde aus der Lichtensteinhöhle war die rechte Tibia das in größter Anzahl geborgene Element, worüber sich eine Mindestindividuenzahl von 51 ergibt (siehe Tabelle 9).

Tabelle 9: Übersicht über die jeweils aufgefundene Anzahl der verschiedenen Skelettelemente.

\begin{tabular}{|c|c|c|c|c|c|c|c|c|c|}
\hline Skelettelement ${ }^{a}$ & $\begin{array}{l}\text { Gesamt- } \\
\text { anzahl }\end{array}$ & $\begin{array}{l}\text { intakt } \\
\text { li. }\end{array}$ & $\begin{array}{l}\text { intakt } \\
\text { re. }\end{array}$ & $\begin{array}{c}\text { intakt } \\
\text { unpaarig }\end{array}$ & $\begin{array}{l}\text { fragmen- } \\
\text { tiert li. }\end{array}$ & $\begin{array}{l}\text { fragmen- } \\
\text { tiert re. }\end{array}$ & $\begin{array}{l}\text { fragmen- } \\
\text { tiert nd }\end{array}$ & $\begin{array}{l}\text { fragmentiert } \\
\text { unpaarig }\end{array}$ & $\% \max ^{b}$ \\
\hline Mandibula & 44 & & & 14 & & & & 30 & 73,3 \\
\hline Humerus & 91 & 20 & 19 & & 24 & 23 & 5 & & 75,8 \\
\hline Radius & 82 & 19 & 23 & & 18 & 17 & 5 & & 68,3 \\
\hline Ossa manus & 894 & & & & & & & & 27,6 \\
\hline Scapula & 76 & 11 & 14 & & 22 & 18 & 11 & & 63,3 \\
\hline Clavicula & 62 & 23 & 20 & & 4 & 12 & 3 & & 51,7 \\
\hline Tibia & 105 & 23 & 24 & & 21 & 27 & 10 & & 87,5 \\
\hline Fibula & 66 & 16 & 15 & & 9 & 8 & 18 & & 55,0 \\
\hline Ossa pedis & 689 & & & & & & & & 22,1 \\
\hline Talus & 63 & 22 & 23 & & 10 & 7 & 1 & & 52,5 \\
\hline Calcaneus & 67 & 28 & 29 & & 5 & 3 & 2 & & 55,8 \\
\hline
\end{tabular}

Die Vervollständigung der morphologischen Zuordnungen zu Individuen aufgrund von Alters-, Geschlechts- und Robustizitätsmerkmalen unter Einbeziehung molekulargenetischer Absicherungen über den genetischen Fingerabdruck und unter Berücksichtigung molekularer Geschlechtsdiagnosen (Typisierungsergebnisse siehe Tabelle 15, Kapitel 4.5.1 Autosomale STRs) ergab eine Individuenzahl von 60.

Aus Tabelle 10 ist ersichtlich, dass für keines der Skelettelemente die Knochen aller 60 Individuen aufgefunden wurden. Während von den größeren Langknochen ca. 70-90 \% 
der für 60 Individuen zu erwartenden Knochen geborgen werden konnten, sind von den etwas kleineren Knochen - wie z.B. Schulterblatt oder Clavicula - nur 63 \% bzw. 52 \% vorhanden. In noch geringerem Maße vertreten sind die sehr kleinen Knochen der Hände und Füße mit 28 \% bzw. $22 \%$.

Entsprechend dieser Sachlage konnten auch nach Abschluss der Zuordnungen lediglich zwei der Individuen alle berücksichtigten Skelettelemente zugeordnet werden (DO RG/BS/DS 1482 (M3) und DO BS 3628 (F3)). Bei einigen der übrigen Individuen fehlen nur einzelne Skelettelemente, bei anderen hingegen eine ganze Reihe von Knochen. Vier der Individuen sind lediglich durch ein craniales Element repräsentiert, dem über den genetischen Fingerabdruck keine Knochen des postcranialen Skeletts zugeordnet werden konnten. Tabelle 10 zeigt einen Überblick über die Vollständigkeit der Individuen, wobei das Os sacrum nicht berücksichtigt wurde, da es bei subadulten Individuen noch in einzelnen Sakralwirbeln vorliegt, die - wie die anderen Wirbel auch - keinem bestimmten Individuum zugeordnet werden können.

Tabelle 10: Überblick über die Vollständigkeit der Individuen aus der Lichtensteinhöhle.

\begin{tabular}{|c|c|c|c|c|}
\hline $\begin{array}{l}\text { Voll- } \\
\text { ständiqkeit }\end{array}$ & $\begin{array}{c}\text { Anzahl } \\
\text { Individuen }\end{array}$ & & Individuen [DO \#] & \\
\hline \multirow{2}{*}{$0-9 \%$} & \multirow{2}{*}{4} & BS 2263 (M15) & \multirow[t]{2}{*}{ KS 3190.11 (F20) } & \multirow[t]{2}{*}{ E 33 (M12) } \\
\hline & & E 37 (F21) & & \\
\hline $10-19 \%$ & - & & & \\
\hline $20-29 \%$ & 2 & HS/BS 1467.01 & FK/RG/HS/BS 903.02 & \\
\hline \multirow{2}{*}{$30-39 \%$} & \multirow{2}{*}{6} & RG 66.02 & RG/FK/BS 516 & FK/RG/BS 907.01 \\
\hline & & HS/GK 1461 & HS/GK 1547.03 & RG/FK R 1 (F12) \\
\hline \multirow{2}{*}{$40-49 \%$} & \multirow{2}{*}{5} & RG/FK 58.03 (M13) & RG/HS/BS 65.05 & \multirow[t]{2}{*}{ HS/GK/BS 1471} \\
\hline & & HS/GK 1547.01 & JS 7075.01 & \\
\hline \multirow{2}{*}{$50-59 \%$} & \multirow{2}{*}{5} & FK/HS/RG/BS 903.01 & FK/RG/JS 904.04 & \multirow[t]{2}{*}{ FK/RG 905.01 (M14) } \\
\hline & & BS/FK/GK/HS 1745.02 & BS/FK/RG/HS/GK/KS N 962.01 & \\
\hline \multirow{4}{*}{$60-69 \%$} & \multirow{4}{*}{11} & FK/HS/RG 35 (M4) & BS 133.01 & RG/GK/BS 183.01 (M11) \\
\hline & & RG/BS 187 & HS/GK 1548.01 & GK/HS/RG 2588 (F15) \\
\hline & & BS/FK 3714 & BS/FK 3742 (F9) & \multirow[t]{2}{*}{ BS/RG/FK/HS 3886 (M16) } \\
\hline & & BS/GK 4310.01 & HS/GK N 957.01 & \\
\hline \multirow{2}{*}{$70-79 \%$} & \multirow{2}{*}{5} & FK/RG/BS 38 (F1) & FK/RG/HS 902.01 (M10) & \multirow[t]{2}{*}{ RG/BS 1500 (F2) } \\
\hline & & RG/BS 1905 (M9) & FK/KS E 11 & \\
\hline \multirow{6}{*}{$80-89 \%$} & \multirow{6}{*}{16} & RG/FK 57.02 (M17/M19) & RG/FK 58.01 & RG/FK/KS 58.08 (M7) \\
\hline & & FK/RG/HS/BS 901.01 (M18/F16) & RG/FK 1076 (M1) & RG/FK/BS 1078 (F13) \\
\hline & & BS 1102 (M2) & BS/RG 1103 (F14) & BS/RG 1176 (F18) \\
\hline & & BS/RG/FK 1247 (F7) & HS/GK 1585.03 (F19) & BS 3695 (F4) \\
\hline & & BS 3706 (F5/F11) & BS/RG 3748 (F8) & BS 3757 (M8) \\
\hline & & BS/FK 4008 (M5) & & \\
\hline \multirow{2}{*}{$90-99 \%$} & \multirow{2}{*}{4} & RG/FK 67.03 (F10/F17) & BS/FK 2030.01 (M6) & \multirow[t]{2}{*}{ BS 5517 (F6) } \\
\hline & & JS 7043.01 & & \\
\hline $100 \%$ & 2 & RG/BS/DS 1482 (M3) & BS 3628 (F3) & \\
\hline
\end{tabular}


Auf den folgenden Seiten findet sich in Tabelle 11 eine Übersicht der jeweils zu einem Individuum zusammen geordneten Skelettelemente. Im Anhang A (Kapitel 10.1) findet sich ein Datenblatt zu jedem Individuum welches alle morphologisch und genetisch ermittelten Daten für das jeweilige Individuum sowie eine fotografische Übersichtsaufnahme enthält. 
Tabelle 11: Übersicht über die Zuordnungen der Knochen aus der Lichtensteinhöhle zu Individuen.

\begin{tabular}{|c|c|c|c|c|c|c|c|c|c|c|c|c|c|c|}
\hline \multirow{2}{*}{$\begin{array}{l}\text { Individuum } \\
\text { DO \# }\end{array}$} & \multirow{2}{*}{ Alter } & \multirow{2}{*}{$\mathbf{s}$} & \multicolumn{12}{|c|}{ Skelettelement DO \# } \\
\hline & & & Humerus & Ulna & Radius & Scapula & Clavicula & Femur & Tibia & Os coxae & $\begin{array}{c}\text { Os } \\
\text { sacrum }\end{array}$ & $\begin{array}{l}\text { Mandi- } \\
\text { bula }\end{array}$ & Calvarium & $\begin{array}{l}\text { Calca- } \\
\text { neus }\end{array}$ \\
\hline \multirow{3}{*}{$\begin{array}{l}\text { FK/HS/RG } 35 \\
\text { (M4) }\end{array}$} & \multirow{3}{*}{$\begin{array}{l}\text { inf II- } \\
\text { fjuv }\end{array}$} & re & 58.16 & & 66.04 & E 15 & & & 107 & 928.04 & & \multirow{3}{*}{4.01} & \multirow{3}{*}{900.03} & \\
\hline & & $\mathrm{li}$ & 934.01 & & & & & 35 & 32 & 113 & & & & \\
\hline & & & & & & & & & & 1850.01 & & & & \\
\hline \multirow{3}{*}{$\begin{array}{l}\mathrm{FK} / \mathrm{RG} / \mathrm{BS} 38 \\
\text { (F1) }\end{array}$} & \multirow{3}{*}{$\begin{array}{l}\text { smat- } \\
\text { sen }\end{array}$} & re & 97 & & & & 4359.01 & 105 & 39 & 57.03 & & \multirow{3}{*}{38} & \multirow{3}{*}{152} & \\
\hline & & li & 40 & 72.01 & & 512.01 & 308.03 & 26 & 27 & 87.14 & & & & \\
\hline & & & & & & 4006.01 & & & & & & & & \\
\hline \multirow{4}{*}{$\begin{array}{l}\text { RG/FK 57.02 } \\
\text { (M17/M19) }\end{array}$} & \multirow{4}{*}{ mad } & & & 66.03 & & & & & & 481 & & & & \\
\hline & & re & OF 2 & 58.17 & 1827.02 & 1580 & 1570 & 56.01 & 153.01 & 84.02 & & & & \\
\hline & & li & 58.13 & 177 & 909.05 & 1082.01 & 1539.02 & 57.02 & JStauch & & & & & 487.01 \\
\hline & & & & & & & & 926.25 & & & & & & \\
\hline \multirow{2}{*}{ RG/FK 58.01} & \multirow{2}{*}{ smat } & re & 58.14 & 158 & 197.02 & 1578 & & 58.05 & 57.05 & 383 & & & & \\
\hline & & li & 913.18 & 5.01 & 308.01 & 1495 & 77.03 & 58.01 & 65.03 & 306 & & & & \\
\hline \multirow{3}{*}{$\begin{array}{l}\text { RG/FK } 58.03 \\
\text { (M13) }\end{array}$} & \multirow{3}{*}{$\begin{array}{l}\text { sjuv- } \\
\text { fad }\end{array}$} & re & & & & & 526.01 & 65.01 & 533.02 & 411.02 & \multirow{3}{*}{233.01} & & & \\
\hline & & li & 610 & & & & & 58.03 & 387 & 415 & & & & \\
\hline & & & 913.03 & & & & & & & & & & & \\
\hline \multirow{6}{*}{$\begin{array}{l}\mathrm{RG} / \mathrm{FK} / \mathrm{KS} \\
58.08 \text { (M7) }\end{array}$} & \multirow{6}{*}{ inf II } & & & & & & & & & 84.01 & & & \multirow{6}{*}{$\begin{array}{l}910.01 \\
\text { pp } 3.01\end{array}$} & \\
\hline & & & & & & & & & & 56.04 & & & & \\
\hline & & $\mathrm{re}$ & 926.03 & E 26 & 237.04 & E 16 & 926.04 & 58.08 & E 32 & 3190.22 & & & & 929.02 \\
\hline & & li & 179.01 & 1079.02 & 1080.01 & 928.03 & & 906.08 & 220 & 182.01 & & & & \\
\hline & & & & & & & & & & 176.02 & & & & \\
\hline & & & & & & & & & & 3190.32 & & & & \\
\hline
\end{tabular}


Fortsetzung Tabelle 11: Übersicht über die Zuordnungen der Knochen aus der Lichtensteinhöhle zu Individuen.

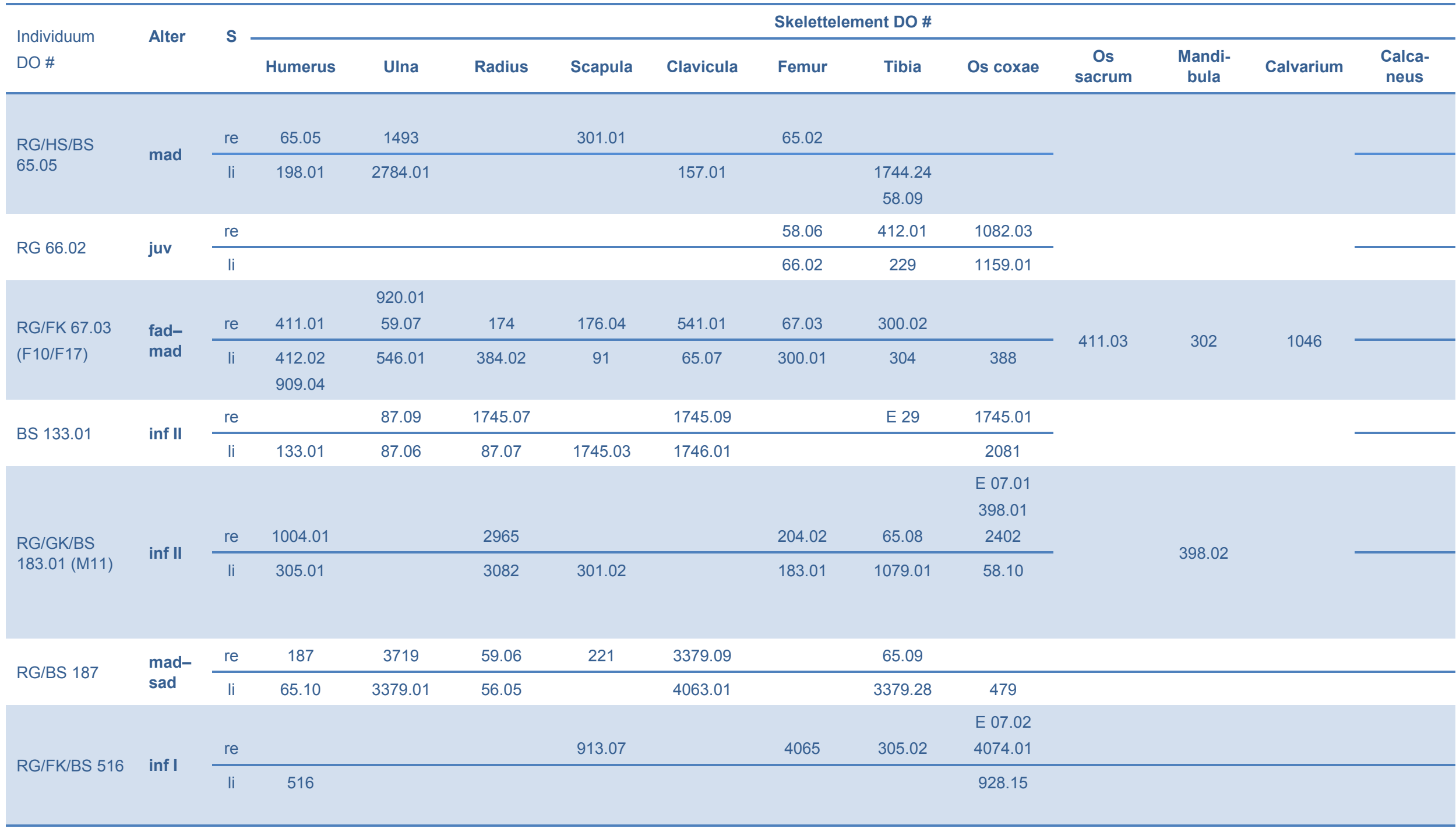


Fortsetzung Tabelle 11: Übersicht über die Zuordnungen der Knochen aus der Lichtensteinhöhle zu Individuen.

\begin{tabular}{|c|c|c|c|c|c|c|c|c|c|c|c|c|c|c|}
\hline \multirow{2}{*}{$\begin{array}{l}\text { Individuum } \\
\text { DO \# }\end{array}$} & \multirow{2}{*}{ Alter } & \multirow{2}{*}{$\mathbf{s}$} & \multicolumn{12}{|c|}{ Skelettelement DO \# } \\
\hline & & & Humerus & Ulna & Radius & Scapula & Clavicula & Femur & Tibia & Os coxae & $\begin{array}{l}\text { Os } \\
\text { sacrum }\end{array}$ & $\begin{array}{l}\text { Mandi- } \\
\text { bula }\end{array}$ & Calvarium & $\begin{array}{l}\text { Calca- } \\
\text { neus }\end{array}$ \\
\hline \multirow{3}{*}{$\begin{array}{l}\text { FK/RG/HS/ BS } \\
901.01 \\
\text { (M18/F16) }\end{array}$} & \multirow{3}{*}{ fmat } & re & 914.01 & 533.01 & 147 & 399 & 1474 & 3715 & & 20 & \multirow{3}{*}{145.06} & & \multirow{3}{*}{ R 2} & \\
\hline & & li & 930.01 & 477 & & 1752 & 1158.01 & 901.01 & 921.03 & 4.03 & & & & \\
\hline & & & & & & & & & 935.01 & & & & & \\
\hline \multirow{2}{*}{$\begin{array}{l}\text { FK/RG/HS } \\
902.01 \text { (M10) }\end{array}$} & \multirow{2}{*}{$\operatorname{mad}$} & re & 413.01 & 256.01 & 101 & 5.02 & & 58.02 & 186 & 154 & \multirow{2}{*}{155} & \multirow{2}{*}{480.01} & & \\
\hline & & li & OF 1 & 935.02 & 28 & & 237.05 & 902.01 & 66.01 & & & & & \\
\hline \multirow{3}{*}{$\begin{array}{l}\mathrm{FK} / \mathrm{HS} / \mathrm{RG} / \mathrm{BS} \\
903.01\end{array}$} & \multirow{3}{*}{ fad } & & & & & & & & & 2058 & \multirow{3}{*}{1946} & & & \\
\hline & & re & 1585.03 & & & 920.02 & 933.01 & 900.01 & 901.03 & 2062 & & & & \\
\hline & & li & & & & & 929.01 & $\begin{array}{c}903.01 \\
58.07\end{array}$ & 906.02 & 1750 & & & & \\
\hline \multirow{3}{*}{$\begin{array}{l}\mathrm{FK} / \mathrm{RG} / \mathrm{HS} / \mathrm{BS} \\
903.02\end{array}$} & \multirow{3}{*}{$\operatorname{mad}$} & & & & & & & 58.04 & & & & & & \\
\hline & & re & & & & & & 903.02 & 1774.05 & & & & & \\
\hline & & li & & 928.08 & & & & 87.11 & 3380.08 & & & & & \\
\hline \multirow{2}{*}{$\begin{array}{l}\mathrm{FK} / \mathrm{RG} / \mathrm{JS} \\
904.04\end{array}$} & \multirow{2}{*}{ inf I } & re & 904.01 & 904.02 & 917.02 & 1156 & & 904.04 & 904.05 & & & & & \\
\hline & & li & & & & 180.01 & & 915.02 & 7075.02 & 913.06 & & & & \\
\hline \multirow{2}{*}{$\begin{array}{l}\text { FK/RG } 905.01 \\
\text { (M14) }\end{array}$} & \multirow{2}{*}{ fad } & re & & 176.03 & & & 394.01 & 904.03 & 905.02 & & & & \multirow{2}{*}{918.01} & \\
\hline & & li & 901.02 & & 59.05 & 914.03 & 886.01 & 905.01 & & & & & & \\
\hline \multirow{3}{*}{$\begin{array}{l}\text { FK/RG/BS } \\
907.01\end{array}$} & \multirow{3}{*}{$\inf I$} & & & & & & & & & 1921 & & & & \\
\hline & & re & 1745.08 & 277.01 & & 907.03 & & & & 87.15 & & & & \\
\hline & & li & 1494 & & & & & 907.01 & & & & & & \\
\hline
\end{tabular}


Fortsetzung Tabelle 11: Übersicht über die Zuordnungen der Knochen aus der Lichtensteinhöhle zu Individuen.

\begin{tabular}{|c|c|c|c|c|c|c|c|c|c|c|c|c|c|c|}
\hline \multirow{2}{*}{$\begin{array}{l}\text { Individuum } \\
\text { DO \# }\end{array}$} & \multirow{2}{*}{ Alter } & \multirow{2}{*}{$\mathbf{s}$} & \multicolumn{12}{|c|}{ Skelettelement DO \# } \\
\hline & & & Humerus & Ulna & Radius & Scapula & Clavicula & Femur & Tibia & Os coxae & $\begin{array}{c}\text { Os } \\
\text { sacrum }\end{array}$ & $\begin{array}{l}\text { Mandi- } \\
\text { bula }\end{array}$ & Calvarium & $\begin{array}{l}\text { Calca- } \\
\text { neus }\end{array}$ \\
\hline \multirow{2}{*}{$\begin{array}{l}\text { RG/FK } 1076 \\
\text { (M1) }\end{array}$} & \multirow{2}{*}{ smat } & re & 1573 & 1147 & 393.01 & & 1064 & 67.01 & 201 & 6495 & & \multirow{2}{*}{1172.01} & \multirow{2}{*}{1485} & \\
\hline & & li & 1492 & 1539.01 & 1576 & 34 & & 1076 & 1065 & 1956 & & & & \\
\hline \multirow{2}{*}{$\begin{array}{l}\text { RG/FK/BS } \\
1078 \text { (F13) }\end{array}$} & \multirow{2}{*}{$\begin{array}{l}\text { smat- } \\
\text { sen }\end{array}$} & re & 204.01 & 510.01 & 389 & 1819 & 305.03 & 385 & 303.01 & 408 & & \multirow{2}{*}{1078} & & \\
\hline & & li & 414.01 & 202 & 204.03 & 409 & & 1044 & 523.01 & 911.01 & & & & 4033.01 \\
\hline \multirow{2}{*}{ BS 1102 (M2) } & \multirow{2}{*}{$\begin{array}{l}\text { mma- } \\
\text { smat }\end{array}$} & re & 2108 & 2034 & 4559 & 3601 & 3640 & 3605 & & 3973 & \multirow{2}{*}{3643} & \multirow{2}{*}{3644} & & \\
\hline & & li & 3670 & 4495 & 2519 & 2056 & 3981.01 & 1102 & 87.12 & & & & & \\
\hline \multirow{3}{*}{$\begin{array}{l}\text { BS/RG } 1103 \\
\text { (F14) }\end{array}$} & \multirow{3}{*}{ mad } & re & 3675 & 4015 & 4311.01 & 3717 & & 5518 & 3380.06 & 3619 & & \multirow{3}{*}{4309} & & \\
\hline & & li & 3745 & 4324.01 & 4323.01 & 2066 & 3379.12 & 1103 & 5522 & 2025 & & & & \\
\hline & & & & & & & & & & 179.02 & & & & \\
\hline \multirow{3}{*}{$\begin{array}{l}\text { BS/RG } 1176 \\
\text { (F18) }\end{array}$} & \multirow{3}{*}{$\begin{array}{l}\text { sad- } \\
\text { fmat }\end{array}$} & & & & 197.03 & & & & & & \multirow{3}{*}{3701} & \multirow{3}{*}{2133} & \multirow{3}{*}{1176} & \\
\hline & & re & 1496 & 58.18 & 542.01 & 1970 & 3379.10 & 200 & 386 & 3716 & & & & \\
\hline & & li & 6458 & & & 3380.07 & & 199 & 384.01 & 3657 & & & & \\
\hline \multirow{4}{*}{$\begin{array}{l}\text { BS/RG/FK } \\
1247 \text { (F7) }\end{array}$} & \multirow{4}{*}{ inf II } & & & & & & & & & 933.03 & & \multirow{4}{*}{1247} & \multirow{4}{*}{65.06} & \\
\hline & & re & 6495 & 4049 & 3998 & 4005.01 & 3997.01 & 1928 & 1745.10 & 41 & & & & \\
\hline & & li & & & 3987 & 3814 & 3794 & 1206.01 & 1188 & 926.01 & & & & \\
\hline & & & & & & & & & & 933.05 & & & & \\
\hline \multirow{2}{*}{ HS/GK 1461} & \multirow{2}{*}{ fjuv } & re & & & 3288.03 & & & & 1455 & N 965.05 & & & & \\
\hline & & li & & & 1461 & & & & 3157 & N 959.03 & & & & \\
\hline \multirow{2}{*}{$\begin{array}{l}\mathrm{HS} / \mathrm{BS} \\
1467.01\end{array}$} & \multirow{2}{*}{$\inf I$} & re & & & & & & & & & & & & \\
\hline & & li & 1467.01 & 1636 & & & 1543.01 & & 327 & & & & & \\
\hline
\end{tabular}


Fortsetzung Tabelle 11: Übersicht über die Zuordnungen der Knochen aus der Lichtensteinhöhle zu Individuen.

\begin{tabular}{|c|c|c|c|c|c|c|c|c|c|c|c|c|c|c|}
\hline \multirow{2}{*}{$\begin{array}{l}\text { Individuum } \\
\text { DO \# }\end{array}$} & \multirow{2}{*}{ Alter } & \multirow{2}{*}{$\mathbf{s}$} & \multicolumn{12}{|c|}{ Skelettelement DO \# } \\
\hline & & & Humerus & Ulna & Radius & Scapula & Clavicula & Femur & Tibia & Os coxae & $\begin{array}{c}\text { Os } \\
\text { sacrum }\end{array}$ & $\begin{array}{l}\text { Mandi- } \\
\text { bula }\end{array}$ & Calvarium & $\begin{array}{l}\text { Calca- } \\
\text { neus }\end{array}$ \\
\hline \multirow{4}{*}{$\begin{array}{l}\mathrm{HS} / \mathrm{GK} / \mathrm{BS} \\
1471\end{array}$} & \multirow{4}{*}{ juv } & & 2915 & & & & & 1457 & & & & & & \\
\hline & & re & 2942.01 & & & & N 969.08 & 1548.11 & 3297 & N 968.07 & & & & \\
\hline & & li & 3380 & & & & & 1471 & 1547.02 & & & & & \\
\hline & & & & & & & & N 969.10 & & & & & & \\
\hline \multirow{2}{*}{$\begin{array}{l}\text { RG/BS/DS } \\
1482(M 3)\end{array}$} & \multirow{2}{*}{ mmat } & re & 2601 & 1246 & 1171 & 4016.01 & 2786 & 1186 & 1069 & 1572 & \multirow{2}{*}{1082.02} & \multirow{2}{*}{1482} & \multirow{2}{*}{6525} & \\
\hline & & li & 1183 & 1826.01 & 1944 & 3801 & 1223.01 & 1911 & 321 & 1475 & & & & \\
\hline \multirow{3}{*}{$\begin{array}{l}\text { RG/BS } 1500 \\
(F 2)\end{array}$} & \multirow{3}{*}{ sad } & re & 1398.01 & 325.01 & 323.02 & & & 1827.01 & 319 & 653.01 & & & & \\
\hline & & li & 1035 & 2125 & 6463 & 196.01 & & 1500 & 1919 & 56.03 & & & & 2642 \\
\hline & & & & & & & & & & 563.01 & & & & \\
\hline \multirow{2}{*}{$\begin{array}{l}\text { HS/GK } \\
1547.01\end{array}$} & \multirow{2}{*}{ inf I } & re & E 13 & 2966 & & & & & 1744.35 & & & & & \\
\hline & & li & 1775.03 & 3000,23 & 3000,22 & 2644.01 & & & 1547.01 & & & & & \\
\hline \multirow{2}{*}{$\begin{array}{l}\text { HS/GK } \\
1547.03\end{array}$} & \multirow{2}{*}{ sjuv } & re & 1547.03 & & & & & E 04 & 3299 & & & & & \\
\hline & & li & & & E 24 & & 1744.10 & & 3300 & N 968.06 & & & & \\
\hline \multirow{2}{*}{$\begin{array}{l}\mathrm{HS} / \mathrm{GK} \\
1548.01\end{array}$} & \multirow{2}{*}{ fjuv } & re & 1775.04 & N 969.06 & 2593.01 & N 964.03 & 1744.09 & E 01 & 1548.01 & & & & & \\
\hline & & li & 1462 & 1774.01 & 1463 & & & E 02 & 1548.02 & & & & & \\
\hline \multirow{2}{*}{$\begin{array}{l}\text { HS/GK } \\
1585.03(F 19)^{*}\end{array}$} & \multirow{2}{*}{ sen } & re & 1585.03 & 2552 & N 969.03 & N 968.02 & 2729.01 & 2579 & E 06 & & & & & \\
\hline & & li & N 968.04 & N 969.04 & 2591.02 & N 968.03 & N 969.07 & 1585.07 & N 969.05 & 2578 & & & & 1585.04 \\
\hline \multirow{4}{*}{$\begin{array}{l}\text { BS/FK/GK/ HS } \\
1745.02\end{array}$} & \multirow{4}{*}{ inf II } & & & & & & & & & 2707 & & & & \\
\hline & & re & & & & 1548.06 & 2629 & & 913.17 & 4238 & & & & \\
\hline & & li & & 2641.02 & 2964.01 & & 2373 & 3622 & & 1745.02 & & & & \\
\hline & & & & & & & & & & 2067 & & & & \\
\hline
\end{tabular}

* Zu diesem Individuum gehören noch die Fibula re DO 1775.02 und die Fibula li DO E 27 
Fortsetzung Tabelle 11: Übersicht über die Zuordnungen der Knochen aus der Lichtensteinhöhle zu Individuen.

\begin{tabular}{|c|c|c|c|c|c|c|c|c|c|c|c|c|c|c|}
\hline \multirow{2}{*}{$\begin{array}{l}\text { Individuum } \\
\text { DO \# }\end{array}$} & \multirow{2}{*}{ Alter } & \multirow{2}{*}{$\mathbf{s}$} & \multicolumn{12}{|c|}{ Skelettelement DO \# } \\
\hline & & & Humerus & Ulna & Radius & Scapula & Clavicula & Femur & Tibia & Os coxae & $\begin{array}{c}\text { Os } \\
\text { sacrum }\end{array}$ & $\begin{array}{l}\text { Mandi- } \\
\text { bula }\end{array}$ & Calvarium & $\begin{array}{c}\text { Calca- } \\
\text { neus }\end{array}$ \\
\hline \multirow{2}{*}{$\begin{array}{l}\text { RG/BS } 1905 \\
\text { (M9) }\end{array}$} & \multirow{2}{*}{$\begin{array}{l}\text { sad- } \\
\text { fmat }\end{array}$} & re & 1917 & & & 483.01 & 1751.02 & 1905 & 1084 & & \multirow{2}{*}{3726} & \multirow{2}{*}{2749} & \multirow{2}{*}{1473} & \\
\hline & & li & 1948 & & 1958 & 1751.01 & 1223.02 & 1916 & 1484 & 65.04 & & & & \\
\hline \multirow{5}{*}{$\begin{array}{l}\text { BS/FK } 2030.01 \\
(M 6)\end{array}$} & \multirow{5}{*}{ inf II } & & & & & & & & & 2102 & & \multirow{5}{*}{2111.01} & \multirow{5}{*}{ R 3} & \\
\hline & & & & & & & & & & E 10 & & & & \\
\hline & & re & 2009 & 2460 & 2106 & 2101 & 5216 & 2061 & 447 & 1746.03 & & & & \\
\hline & & li & 3630 & 2380 & 2105 & 2068 & & 2030.01 & 3379.13 & 2522 & & & & \\
\hline & & & & & & & & & 3379.05 & 929.28 & & & & \\
\hline \multirow{2}{*}{ BS 2263 (M15) } & \multirow{2}{*}{$\inf I I$} & re & & & & & & & & & \multirow{2}{*}{\multicolumn{2}{|c|}{2263}} & & \\
\hline & & li & & & & & & & & & & & & \\
\hline \multirow{4}{*}{$\begin{array}{l}\text { GK/HS/RG } \\
2588 \text { (F15) }\end{array}$} & \multirow{4}{*}{$\begin{array}{l}\text { sjuv- } \\
\text { fad }\end{array}$} & & & & & & & N 965.01 & & & & \multirow{4}{*}{2589} & & \\
\hline & & re & N 965.02 & 965.04 & N 965.03 & & & 3379.29 & 2588 & & & & & \\
\hline & & li & N 964.02 & 959.01 & 1744.06 & 2414.03 & & N 964.01 & 191.01 & & & & & \\
\hline & & & 1744.08 & & & & & & & & & & & \\
\hline \multirow{2}{*}{$\begin{array}{l}\text { KS } 3190.11 \\
\text { (F20) }\end{array}$} & \multirow[t]{2}{*}{ inf II } & re & & & & & & & & & & \multirow{2}{*}{3190.11} & & \\
\hline & & li & & & & & & & & & & & & \\
\hline \multirow{5}{*}{ BS $3628(F 3)$} & \multirow{5}{*}{ inf II } & & & & & & & & & 4568 & & \multirow{5}{*}{2388} & \multirow{5}{*}{$\begin{array}{l}1746.06 \\
1746.05\end{array}$} & \\
\hline & & re & 2255.03 & 2255.01 & 2255.02 & 2094.01 & 2092 & 4374 & 3628 & 2520 & & & & \\
\hline & & li & 2364 & 2441 & 2395 & 2029 & 2420 & 4372 & 3474 & 3981.02 & & & & \\
\hline & & & & & & & & & & 2565 & & & & \\
\hline & & & & & & & & & & 2485.02 & & & & \\
\hline
\end{tabular}


Fortsetzung Tabelle 11: Übersicht über die Zuordnungen der Knochen aus der Lichtensteinhöhle zu Individuen.

\begin{tabular}{|c|c|c|c|c|c|c|c|c|c|c|c|c|c|c|}
\hline \multirow{2}{*}{$\begin{array}{l}\text { Individuum } \\
\text { DO \# }\end{array}$} & \multirow{2}{*}{ Alter } & \multirow{2}{*}{$\mathbf{S}$} & \multicolumn{12}{|c|}{ Skelettelement DO \# } \\
\hline & & & Humerus & Ulna & Radius & Scapula & Clavicula & Femur & Tibia & Os coxae & $\begin{array}{c}\text { Os } \\
\text { sacrum }\end{array}$ & $\begin{array}{l}\text { Mandi- } \\
\text { bula }\end{array}$ & Calvarium & $\begin{array}{l}\text { Calca- } \\
\text { neus }\end{array}$ \\
\hline \multirow{2}{*}{ BS 3695 (F4) } & \multirow{2}{*}{$\begin{array}{l}\text { mmat- } \\
\text { smat }\end{array}$} & re & 4013 & 3702 & 3695 & & 4060.01 & & & 3615 & \multirow{2}{*}{3609} & \multirow{2}{*}{4078} & \multirow{2}{*}{5516} & \\
\hline & & li & 3662 & 3667 & 4062 & 4017.01 & 4061.01 & 3727 & 320 & 3475 & & & & \\
\hline \multirow{2}{*}{$\begin{array}{l}\text { BS } 3706 \\
\text { (F5/F11) }\end{array}$} & \multirow{2}{*}{$\begin{array}{l}\text { mmat- } \\
\text { smat }\end{array}$} & re & 3661 & 3538.01 & 3740 & & 1195 & 3990 & 3720 & 3600 & \multirow{2}{*}{2078.01} & \multirow{2}{*}{3713} & \multirow{2}{*}{3706} & \\
\hline & & li & 4014 & 4317.01 & 4318.01 & 1180 & & 3756 & 3672 & 3620 & & & & \\
\hline \multirow{2}{*}{ BS/FK $3714^{* *}$} & \multirow{2}{*}{ mad } & re & 87.08 & 3665 & 87.10 & & 3674 & 4077 & 3658 & & & & & \\
\hline & & li & 3714 & 4070 & 3744 & & 4316.01 & & 913.02 & & & & & \\
\hline \multirow{3}{*}{$\begin{array}{l}\text { BS/FK } 3742 \\
(\mathrm{~F} 9)^{\star \star \star}\end{array}$} & \multirow{3}{*}{ fjuv } & re & 925.01 & E 19 & 929.05 & & & 3379.02 & 3654 & 4025 & & \multirow{3}{*}{3746} & \multirow{3}{*}{3705} & \\
\hline & & li & & E 20 & & & & 3742 & 3729 & 3743 & & & & \\
\hline & & & & & & & & & 4022.01 & & & & & \\
\hline \multirow{2}{*}{$\begin{array}{l}\text { BS/RG } 3748 \\
\text { (F8) }\end{array}$} & \multirow{2}{*}{$\begin{array}{l}\text { fad- } \\
\text { mad }\end{array}$} & re & 5521 & 323.01 & 5598 & 3986.01 & 3841.01 & 3635 & 3748 & 87.13 & \multirow{2}{*}{1179} & & \multirow{2}{*}{3631} & \\
\hline & & li & 3664 & 1189 & 4342.01 & 5592 & 3993.01 & & 5533 & 1603 & & & & 3841.03 \\
\hline \multirow{2}{*}{ BS 3757 (M8) } & \multirow{2}{*}{$\begin{array}{l}\text { inf I- } \\
\text { inf II }\end{array}$} & re & 3971 & 2309.02 & 2064 & & 1098 & 4361.01 & 3703 & 3626 & & \multirow{2}{*}{4003} & \multirow{2}{*}{3757} & \\
\hline & & li & 2389 & & 2057 & 2098 & 1834.01 & 3808 & 327.02 & 5603 & & & & \\
\hline \multirow{5}{*}{$\begin{array}{l}\mathrm{BS} / \mathrm{RG} / \mathrm{FK} / \mathrm{HS} \\
3886 \text { (M16) }\end{array}$} & \multirow{5}{*}{$\begin{array}{l}\text { inf I- } \\
\text { inf II }\end{array}$} & & & & & & & & & 1744.32 & & & \multirow{5}{*}{3886} & \\
\hline & & & & & & & & & & 931.03 & & & & \\
\hline & & re & & 4046 & 3856.01 & 3379.11 & & & & 3792 & & & & \\
\hline & & li & 5403 & 5192 & 5424 & 3881.01 & & 3793 & 3788.01 & & & & & \\
\hline & & & & & & & & 1150.01 & & & & & & \\
\hline
\end{tabular}

** Zu diesem Individuum gehört noch der Metacarpale DO 2431

*** Zu diesem Individuum gehört noch die Patella DO 4460 
Fortsetzung Tabelle 11: Übersicht über die Zuordnungen der Knochen aus der Lichtensteinhöhle zu Individuen.

\begin{tabular}{|c|c|c|c|c|c|c|c|c|c|c|c|c|c|c|}
\hline \multirow{2}{*}{$\begin{array}{l}\text { Individuum } \\
\text { DO \# }\end{array}$} & \multirow{2}{*}{ Alter } & \multirow{2}{*}{$\mathbf{s}$} & \multicolumn{12}{|c|}{ Skelettelement DO \# } \\
\hline & & & Humerus & Ulna & Radius & Scapula & Clavicula & Femur & Tibia & Os coxae & $\begin{array}{c}\text { Os } \\
\text { sacrum }\end{array}$ & $\begin{array}{l}\text { Mandi- } \\
\text { bula }\end{array}$ & Calvarium & $\begin{array}{l}\text { Calca- } \\
\text { neus }\end{array}$ \\
\hline \multirow{3}{*}{$\begin{array}{l}\text { BS/FK } 4008 \\
\text { (M5) }\end{array}$} & \multirow{3}{*}{ fad } & & & & & & & & 2096 & & & \multirow{3}{*}{3380.01} & \multirow{3}{*}{908} & \\
\hline & & re & 4767 & 2060 & 4008 & 3652 & & 3752 & E 5.02 & 4001 & & & & \\
\hline & & li & 5503.01 & 5597 & 4079 & 4004.01 & 4315.01 & & 3704 & 3666 & & & & \\
\hline \multirow{2}{*}{$\begin{array}{l}\text { BS/GK } \\
4310.01\end{array}$} & \multirow{2}{*}{$\begin{array}{l}\text { inf I- } \\
\text { inf II }\end{array}$} & re & 4058 & 2399 & 4310.01 & 3810 & & 2918 & E 31 & 3380.03 & & & & \\
\hline & & li & 3812 & 2442 & 3850 & & & & & 3660 & & & & \\
\hline \multirow{3}{*}{ BS 5517 (F6) } & \multirow{3}{*}{ sjuv } & re & 3710 & 4052 & 4007 & 5663 & 4318.02 & 3728 & 3669 & 3379.08 & & \multirow{3}{*}{3709} & \multirow{3}{*}{5517} & \\
\hline & & li & 3994 & 3621 & 3379.03 & 4026 & & 3750 & 3707 & 3982 & & & & 4032.01 \\
\hline & & & & & & & & & 4326.01 & & & & & \\
\hline \multirow{3}{*}{ JS 7043.01} & \multirow{3}{*}{ finf I } & & & & & & & & & 7030.07 & & \multirow{3}{*}{7227.03} & \multirow{3}{*}{$\begin{array}{l}7043.01 \\
7270.10\end{array}$} & \\
\hline & & re & 7043.02 & & 7043.03 & 7043.07 & 7043.05 & 7030.06 & 6982 & 7052.02 & & & & \\
\hline & & li & 7227.02 & 6987.01 & 7052.01 & 7043.06 & 7043.04 & 6962 & 7339 & 7030.08 & & & & \\
\hline \multirow{2}{*}{ JS 7075.01} & \multirow{2}{*}{ mad } & re & 7230 & & & 7156.01 & 7227.01 & & & 6983 & & \multirow{2}{*}{7060} & \multirow{2}{*}{7075.01} & \\
\hline & & li & & & & 7231 & & & 7058 & & & & & \\
\hline \multirow{4}{*}{ FK/KS E 11} & \multirow{4}{*}{$\begin{array}{l}\text { inf II- } \\
\text { fjuv }\end{array}$} & re & E 11 & E 23 & 3190.01 & 923.01 & & E OF 1 & 913.01 & E 08 & & & & \\
\hline & & li & E 12 & & 909.03 & 33 & 914.02 & E 03 & E 30 & E 09 & & & & \\
\hline & & & & & & & & & & 103.03 & & & & \\
\hline & & & & & & & & & & 905.04 & & & & \\
\hline
\end{tabular}


Fortsetzung Tabelle 11: Übersicht über die Zuordnungen der Knochen aus der Lichtensteinhöhle zu Individuen.

\begin{tabular}{|c|c|c|c|c|c|c|c|c|c|c|c|c|c|c|}
\hline \multirow{2}{*}{$\begin{array}{l}\text { Individuum } \\
\text { DO \# }\end{array}$} & \multirow{2}{*}{ Alter } & \multirow{2}{*}{ s } & \multicolumn{12}{|c|}{ Skelettelement DO \# } \\
\hline & & & Humerus & Ulna & Radius & Scapula & Clavicula & Femur & Tibia & Os coxae & $\begin{array}{c}\text { Os } \\
\text { sacrum }\end{array}$ & $\begin{array}{l}\text { Mandi- } \\
\text { bula }\end{array}$ & Calvarium & $\begin{array}{l}\text { Calca- } \\
\text { neus }\end{array}$ \\
\hline \multirow{2}{*}{ E 33 (M12) } & \multirow{2}{*}{ inf II } & re & & & & & & & & & \multirow{2}{*}{\multicolumn{2}{|c|}{ E 33}} & & \\
\hline & & li & & & & & & & & & & & & \\
\hline \multirow{2}{*}{ E 37 (F21) } & \multirow{2}{*}{ inf II } & re & & & & & & & & & & \multirow{2}{*}{\multicolumn{2}{|c|}{ E 37}} & \\
\hline & & li & & & & & & & & & & & & \\
\hline \multirow{4}{*}{$\begin{array}{l}\text { HS/GK } \\
\text { N } 957.01\end{array}$} & \multirow{4}{*}{ inf II } & & & & & & & E 28 & & 1544.16 & & & & \\
\hline & & re & 1774.02 & E 21 & 1547.04 & 2917 & N 957.01 & 1544.14 & & N 957.02 & & & & \\
\hline & & li & N 968.05 & E 22 & 1547.05 & & & & 3182 & 1544.15 & & & & \\
\hline & & & & & & & & & & N 959.04 & & & & \\
\hline \multirow{2}{*}{$\begin{array}{l}\mathrm{BS} / \mathrm{FK} / \mathrm{RG} / \mathrm{HS} / \\
\mathrm{GK} / \mathrm{KS} \\
\mathrm{N} 962.01\end{array}$} & \multirow{2}{*}{ inf II } & re & & & E 25 & & N 969.09 & 2103 & 4047 & & & & & \\
\hline & & li & & 3190.14 & N 962.01 & 915.04 & & & 2088 & 307.02 & & & & \\
\hline \multirow{2}{*}{$\begin{array}{l}\text { RG/FK R } 1 \\
\text { (F12) }\end{array}$} & \multirow{2}{*}{$\begin{array}{l}\text { sad- } \\
\text { fmat }\end{array}$} & re & & 410 & 1537.01 & & 906.01 & 67.02 & & & & & \multirow{2}{*}{ R 1} & \\
\hline & & li & & 126.01 & 1571 & & & & & & & & & \\
\hline
\end{tabular}

DO = Dorste, $\mathrm{BS}=$ Berndsaal, FK = Fiddikluft, GK = Grabkammer, HS = Horstspalte, $\mathrm{JS}=$ Jensschluf, $\mathrm{KS}=\mathrm{Kathrinsspalte}, \mathrm{RG}=\mathrm{Reinhardsgrotte}, \mathrm{S}=\mathrm{Seite}$, re = rechts, li = links 


\subsection{Pathologische Befunde und andere Auffälligkeiten}

Eine systematische Erfassung von Pathologien war aufgrund der Gipssinterschicht auf vielen der Knochen nicht möglich. Die Sinterschicht war teilweise so kompakt mit der Knochenoberfläche verbunden, dass eine Entfernung stellenweise gar nicht möglich war oder mit einer Zerstörung der Knochenintegrität einhergegangen wäre. Zudem war es oft nicht möglich, aufgefundene Veränderungen an den dislozierten Knochen einem bestimmten Individuum zuzuordnen. Deshalb konnten Pathologien, insbesondere Erkrankungen der Zähne und des Zahnhalteapparates sowie der Gebissstatus, nur in Einzelfällen erfasst werden.

Aufgefunden und fotografisch dokumentiert wurden zum einen auffällige Abrasionsgrade der Zähne (siehe Abb. 22-24). Des Weiteren gab es einige Fälle von Karies (siehe Abb. 24) sowie Zahnstein (siehe Abb. 25). An einigen Kieferknochen wurde leichte Parodontose festgestellt (siehe Abb. 22, 25 und 26). In der Maxilla des Calvariums DO 5516 befand sich eine recht große Zyste, welche vermutlich durch einen entzündlichen Prozess verursacht wurde (siehe Abb. 27).

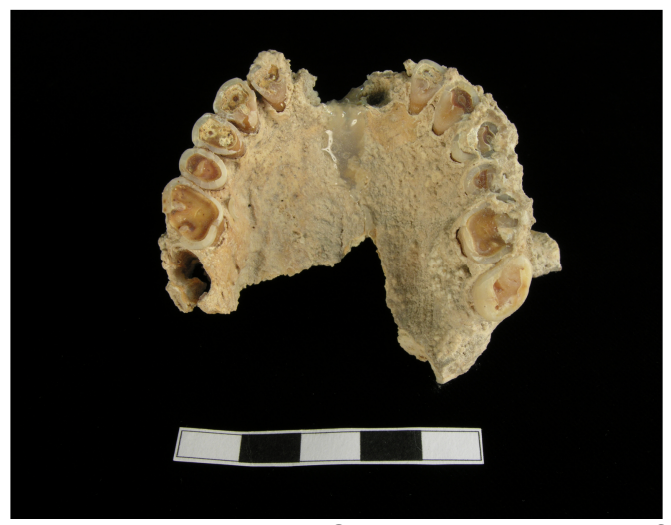

Abb. 22: Maxilla DO 90; Zähne bis auf Dentin abgekaut, Paradontose.

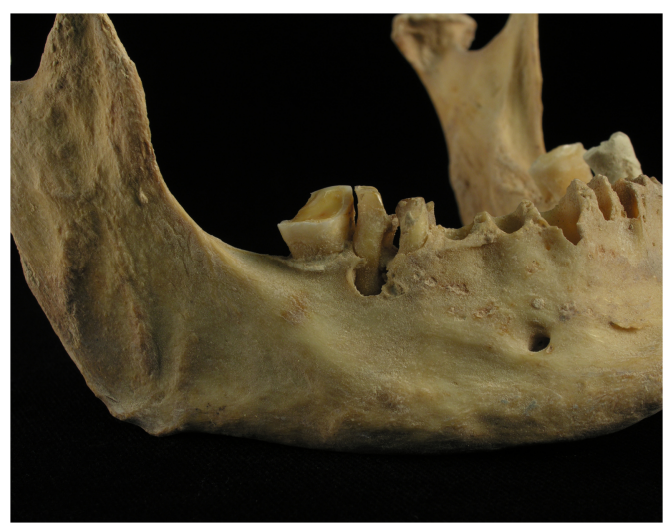

Abb. 24: Mandibula DO 1172.01; bei 36 nur noch Wurzel vorhanden, vermutlich kariöser Verlust der Krone.

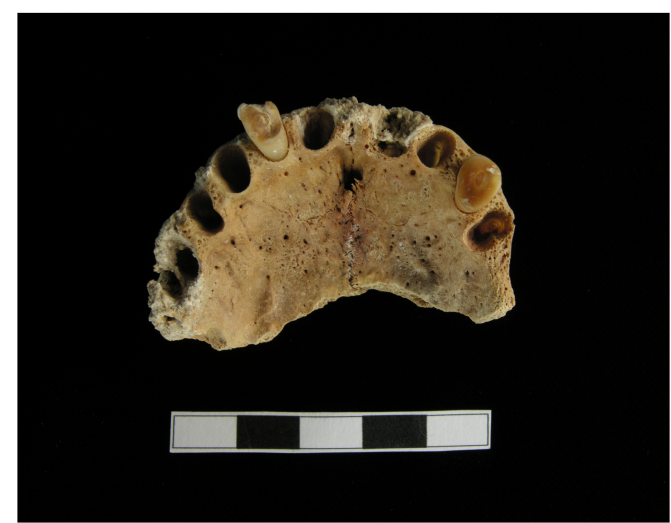

Abb. 23: Maxilla DO 1075.02; Zähne mit extremem Abrasionsgrad.

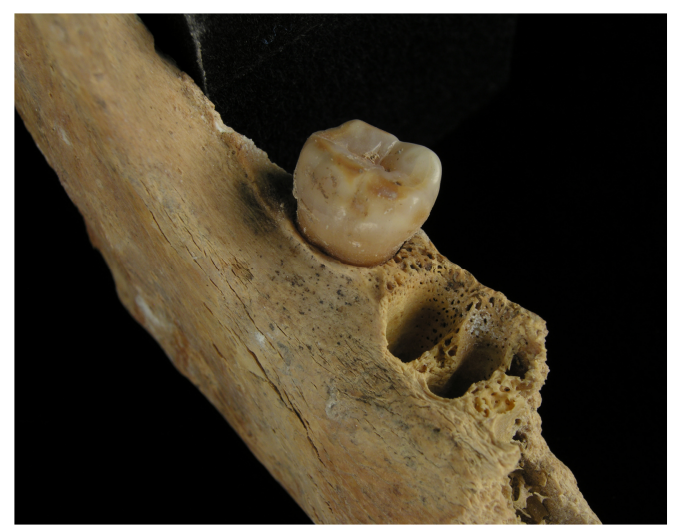

Abb. 25: Mandibula DO 87.01 mit leichter Parodontose im Molarenbereich. 


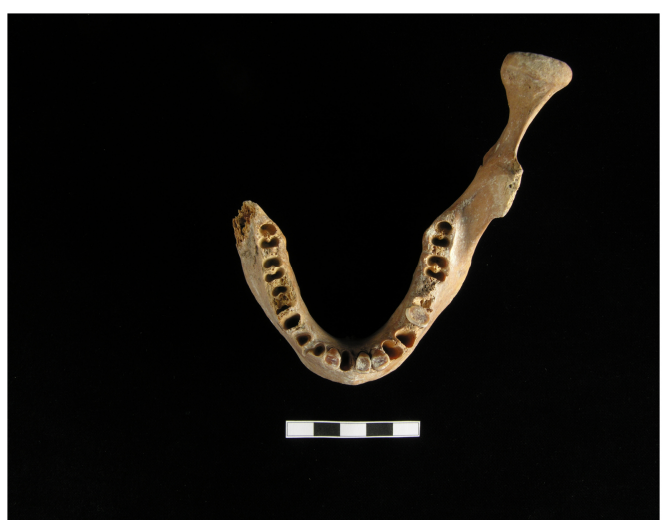

Abb. 26: Mandibula DO 193 mit Parodontose und wahrscheinlich Zahnstein.

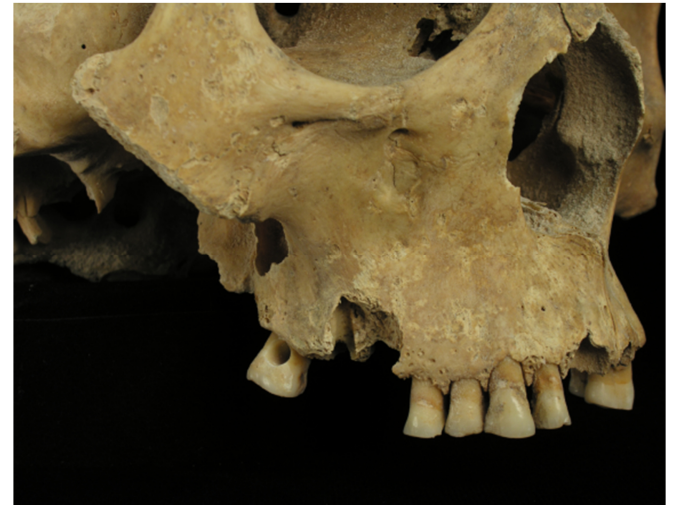

Abb. 27: Calvarium DO 5516 mit Zyste in der Maxilla.

Neben Auffälligkeiten der Zähne und des Zahnhalteapparates stellen degenerative Veränderungen bei der Begutachtung von (prä-) historischen Skelettserien einen häufig auftretenden Befund dar (Ortner und Putschar 1985). Veränderungen der Gelenke treten durch Ermüdungserscheinungen des Gelenkknorpels altersbedingt regulär auf, wobei es schwierig sein kann, diese in jedem Fall von pathologischen Veränderungen zu differenzieren (Herrmann et al. 1990). Bei den Knochen aus der Lichtensteinhöhle wurden an einer Reihe von Wirbeln Knochenneubildungen festgestellt (siehe Abb. 2837). Das Spektrum reichte hierbei von leichter Randleistenbildung (z.B. DO 325.16, Abb. 32) über extreme Randleistenbildung (z.B. DO 1072.02, Abb. 33) bis hin zur Ausbildung von knöchernen Überbrückungen zwischen mehreren Wirbeln (z.B. DO 3648, Abb. 37).

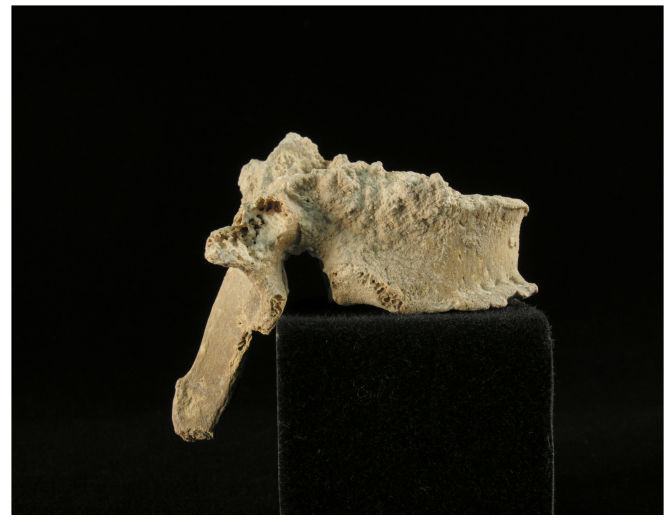

Abb. 28: Vertebra thoracica DO 87.16 mit Randleisten.

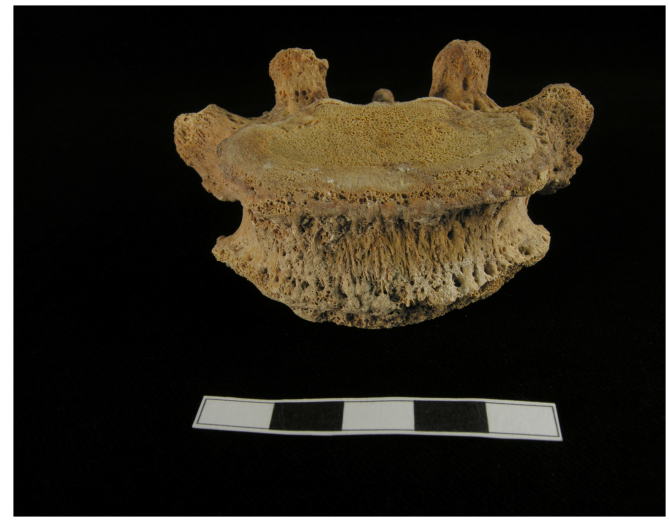

Abb. 29: Vertebra lumbalis DO 156 mit Randleisten. 


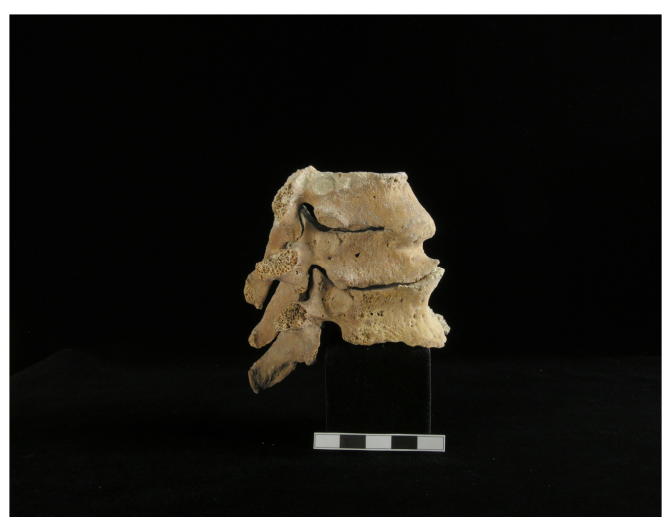

Abb. 30: Vertebra thoracica DO 157.04 mit Randleisten, zwei Wirbel knöchern verbunden.

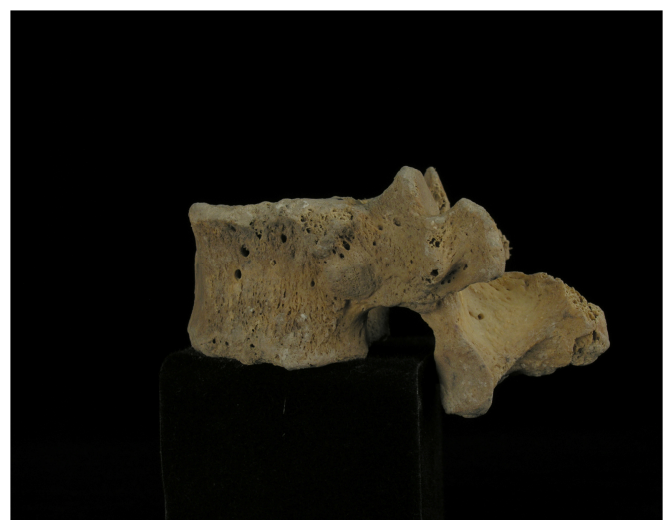

Abb. 32: Vertebra thoracica DO 325.16 mit Randleisten.

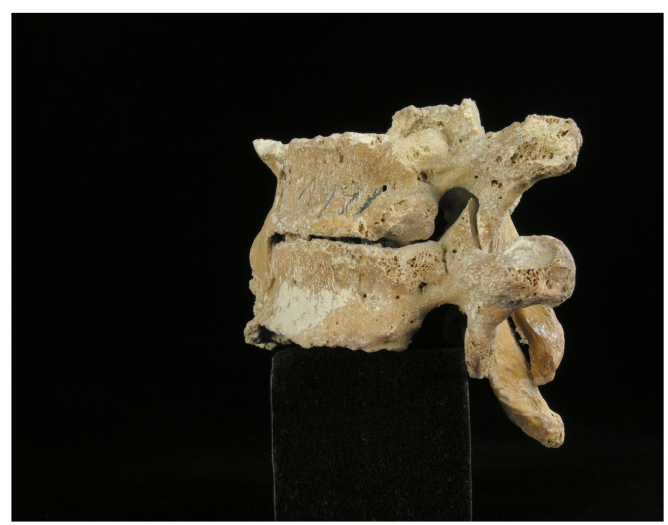

Abb. 34: Vertebra thoracica DO $1491 \mathrm{mit}$ Randleisten und knöcherner Überbrückung.

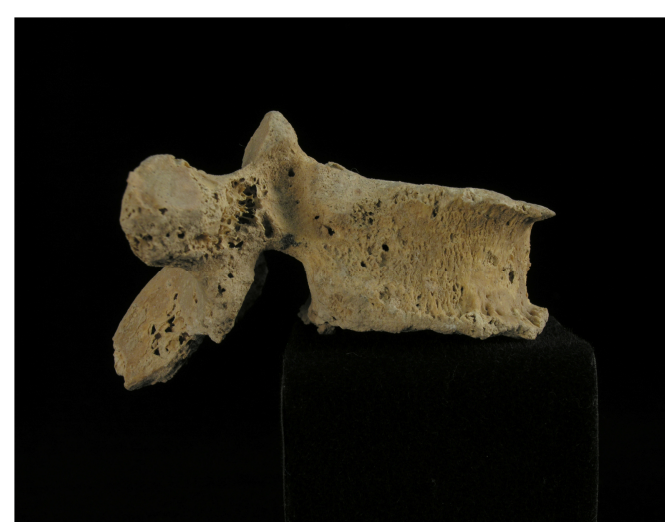

Abb. 31: Vertebra thoracica DO 325.13 mit Randleisten.

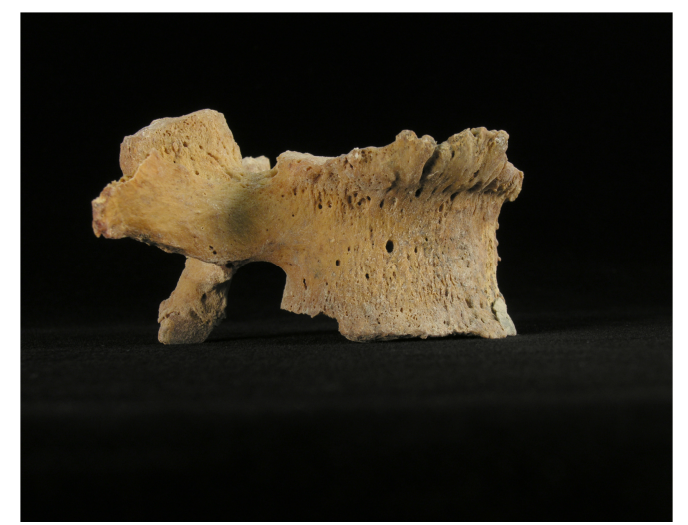

Abb. 33: Vertebra lumbalis DO 1072.02 mit extremen Randleisten.

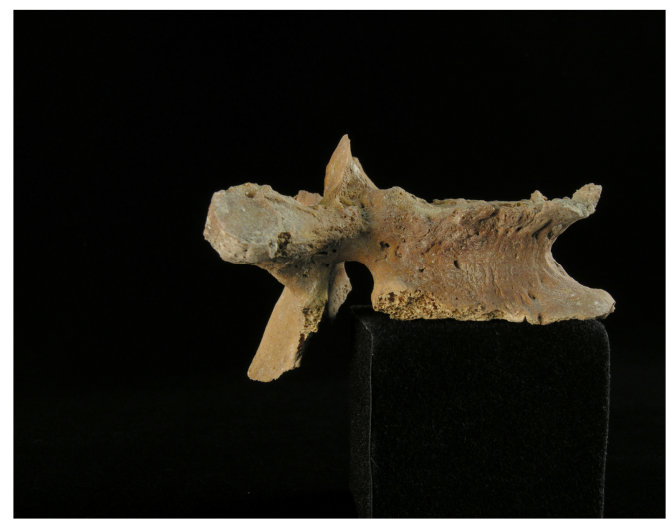

Abb. 35: Vertebra thoracica DO 1524.03 mit extremen Randleisten. 


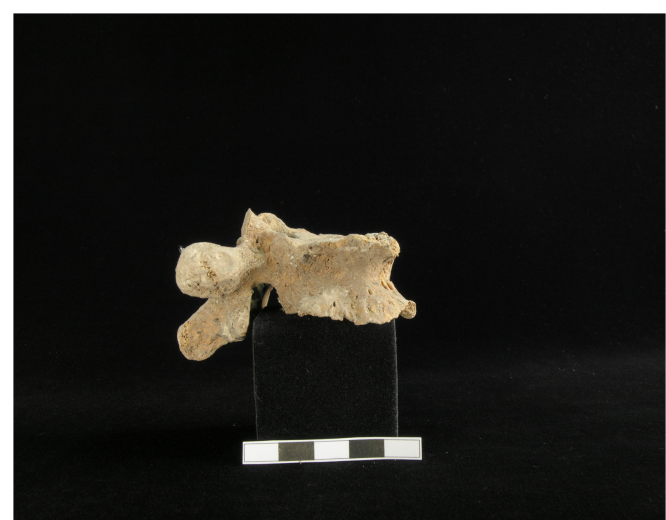

Abb. 36: Vertebra lumbalis DO 1568 mit Randleisten.

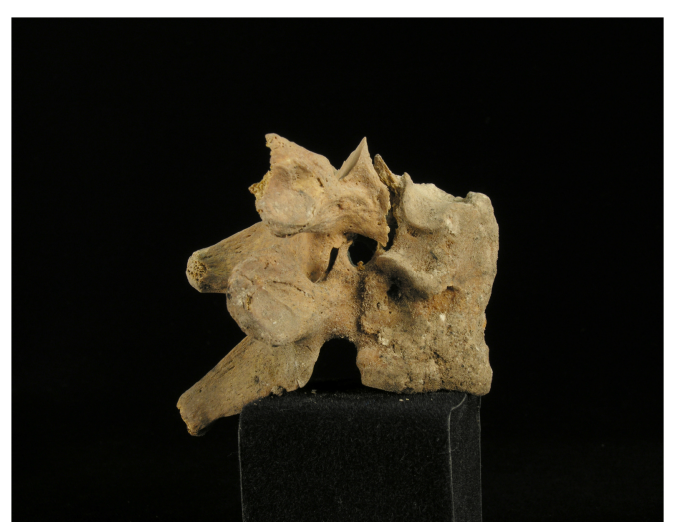

Abb. 37: Vertebra thoracica DO 3648 mit extremen Randleisten und knöcherner Überbrückung.

Neben den Veränderungen an verschiedenen Wirbeln wurden auch an anderen Skelettelementen Knochenneubildungen aufgefunden, welche vermutlich auf degenerative Prozesse zurückzuführen sind. So wurden Randleisten in Einzelfällen auch an einem Phalanx proximalis ossa manus (Abb. 38), einer Patella (Abb. 39), am Acetabulum eines Os coxae (Abb. 40), an der Incisura trochlearis einer Ulna (Abb. 41) und an der Cavitas glenoidalis einer Scapula (Abb. 42) dokumentiert. Eine knöcherne Überbrückung an einem Manubrium zur Costa (Abb. 43) ist vermutlich ebenfalls durch degenerative Prozessen bedingt.

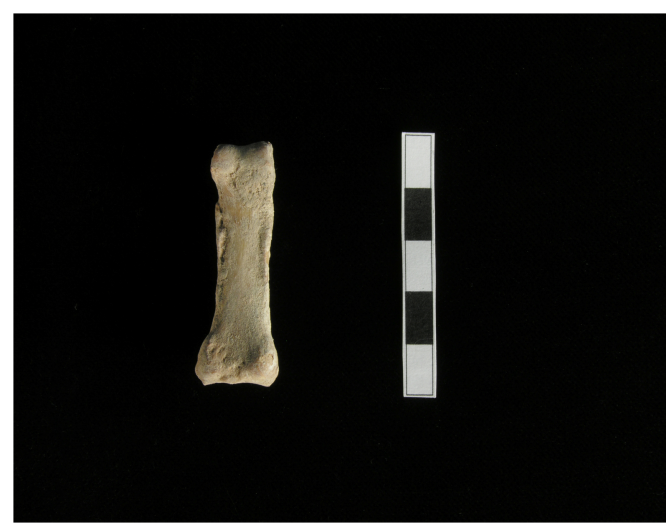

Abb. 38: Phalanx proximalis ossa manus DO 151.01 mit Randleisten.

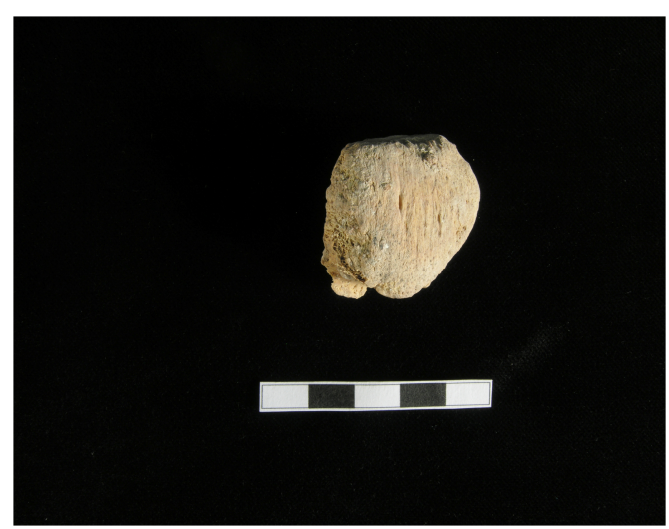

Abb. 39: Patella DO 219.02 mit Randleistenbildung an der Gelenkfläche. 


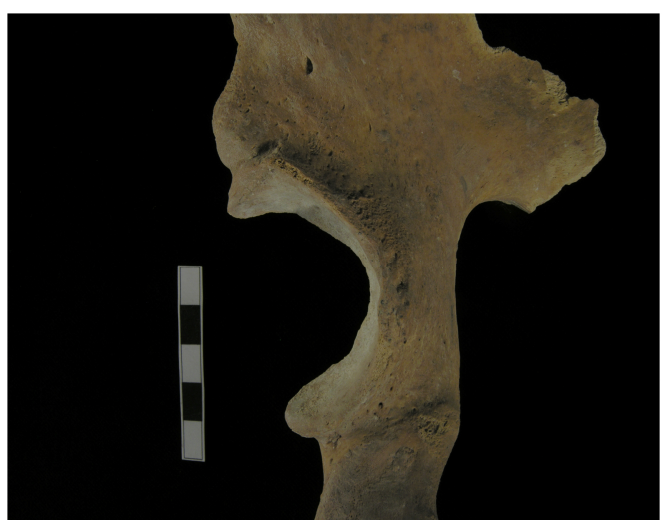

Abb. 40: Os coxae DO 306 mit Randleistenbildung am Acetabulum.

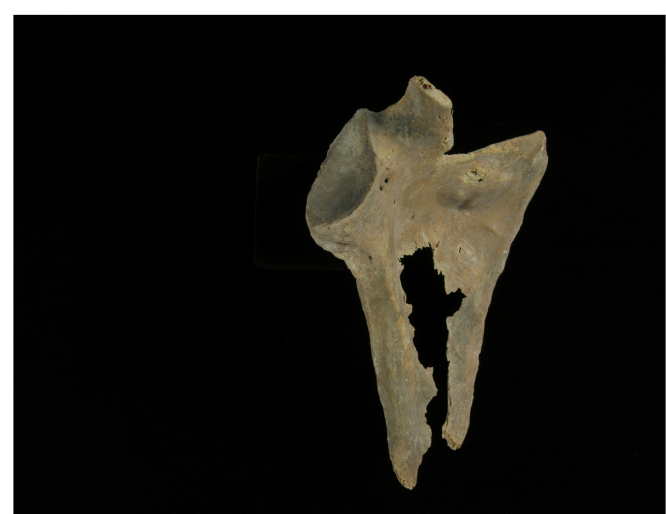

Abb. 42: Scapula DO 3652 mit Randleistenbildung an der Cavitas glenoidalis und eingesunkene Gelenkfläche.

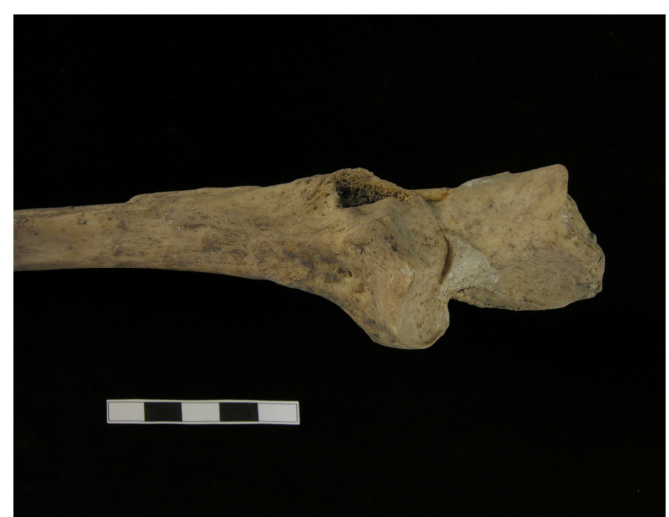

Abb. 41: Ulna DO 1246 mit Randleistenbildung um die Incisura trochlearis.



Abb. 43: Manubrium DO 1486.03 mit knöcherner Überbrückung zur Costa.

Abgesehen von den degenerativen Veränderungen wurden lediglich Einzelfälle von weiteren Auffälligkeiten an den Knochen aus der Lichtensteinhöhle festgestellt. So wies ein einzelner Wirbel Impressionen von Schmorl'schen Knorpelknötchen auf (Abb. 44). Ein kleines Osteom am Os frontale des Calvariums DO 5516 stellt ebenso einen Einzelbefund dar (Abb. 45).

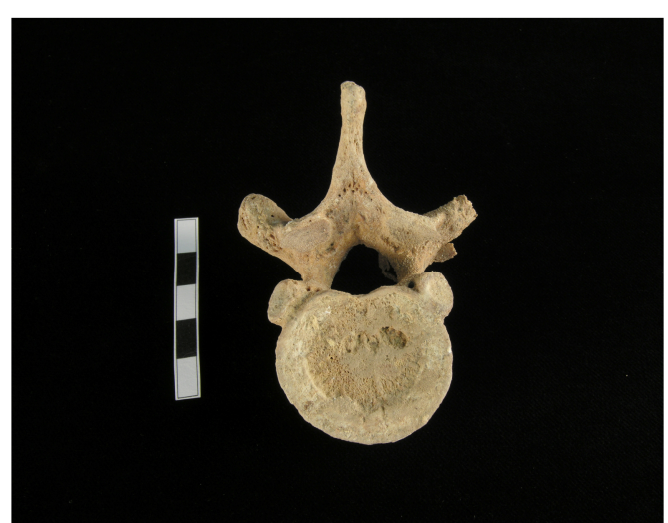

Abb. 44: Vertebra thoracica DO 219.02; caudal mit Schmorl'schen Knorpelknötchen.

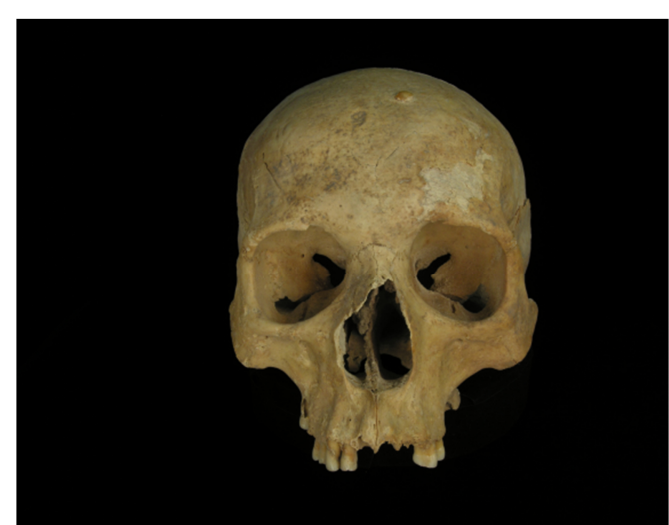

Abb. 45: Calvarium DO 5516 mit Osteom auf dem Os frontale. 
Zeichen von Infektionskrankheiten fehlen nahezu vollständig an den untersuchten Skelettelementen. An einer Clavicula wurde eine kleinräumige periostale Reaktion festgestellt, welche auf eine lokale Entzündung zurückzuführen sein könnte (Abb. 46). Das distale Ende der Tibia DO 153.01 weist eine Knochenauflagerung auf, welche eventuell auch als Reaktion auf einen Entzündungsprozesses entstanden sein könnte (Abb. 47).

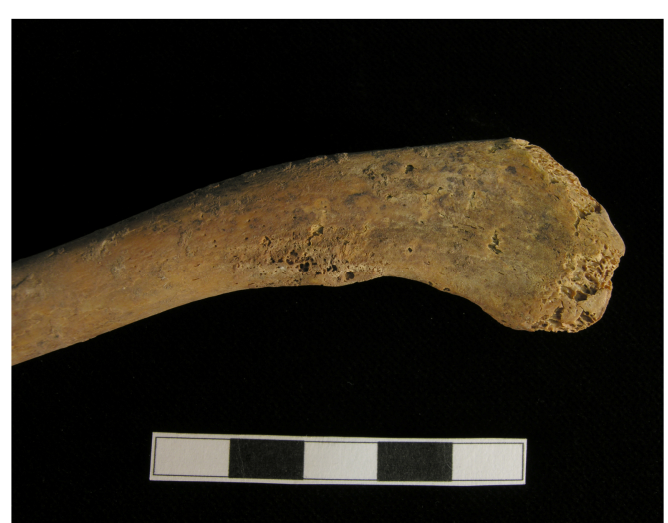

Abb. 46: Clavicula DO 4315.01; anterioracromial mit kleinräumiger periostaler Reaktion.

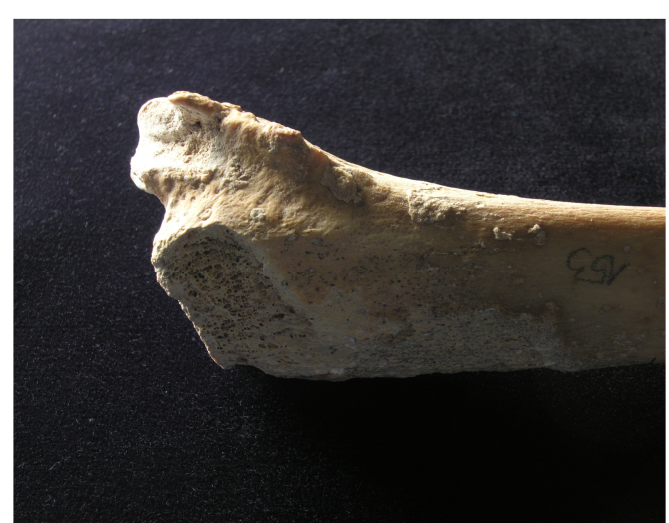

Abb. 47: Tibia DO 153.01; posteriormedial mit Knochenauflagerungen.

Ebenfalls nahezu fehlend sind Spuren von Gewalteinwirkungen an den Knochen aus der Lichtensteinhöhle. Die wenigen aufgefundenen traumatischen Veränderungen sind weitestgehend vermutlich durch Alltagsunfälle verursacht worden. Dokumentiert werden konnten verheilte Frakturen an einer Clavicula (Abb. 48), einer rechten Costa (Abb. 49), einer linken Costa (Abb. 50) und einem Os metacarpale (Abb. 51). In allen Fällen waren die Frakturen zum Todeszeitpunkt bereits gut verheilt, wie die Spuren der Kallusbildung belegen. Umfangreichere Traumata durch Einwirkung von stumpfer oder scharfer Gewalt, wie sie im Zuge von kriegerischen Handlungen zu erwarten wären, fehlen an den Überresten vollkommen. 


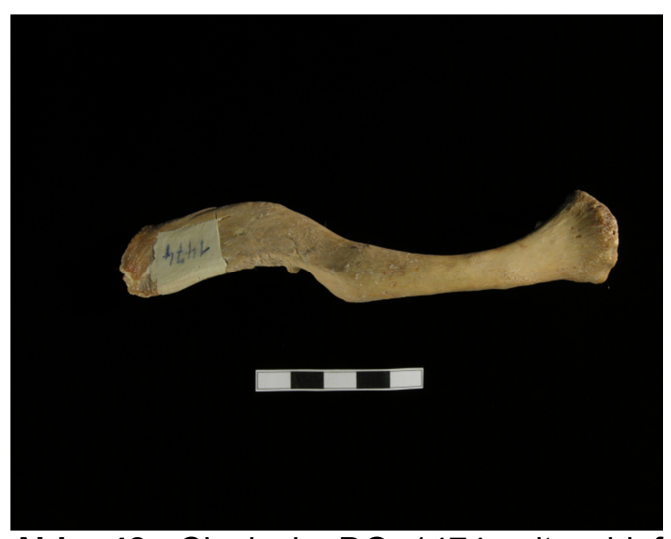

Abb. 48: Clavicula DO 1474 mit schief verheilter Fraktur.

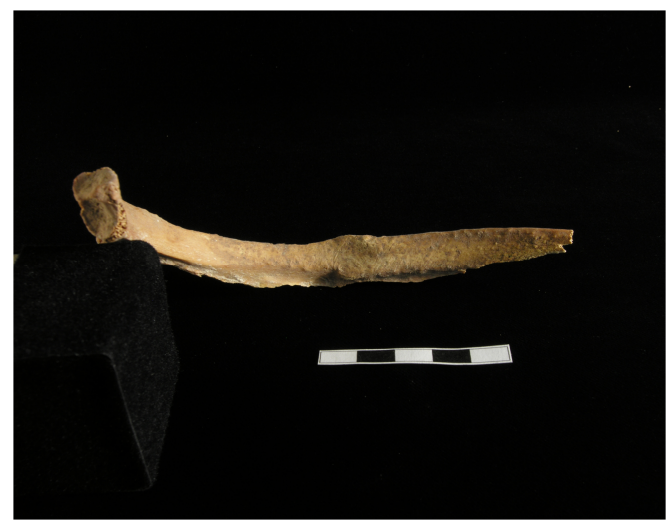

Abb. 50: Costa DO 157.06 mit verheilter Fraktur.

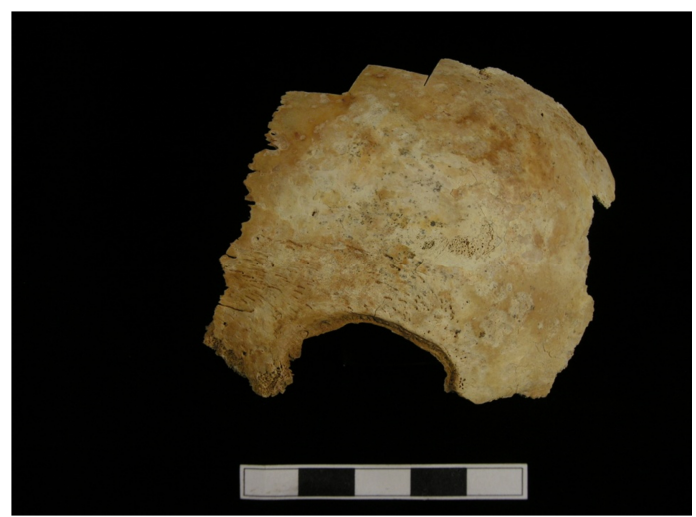

Abb. 52: Calottenfragment DO 78.01 mit verheilter Trepanation (Foto von Schilz 2006).

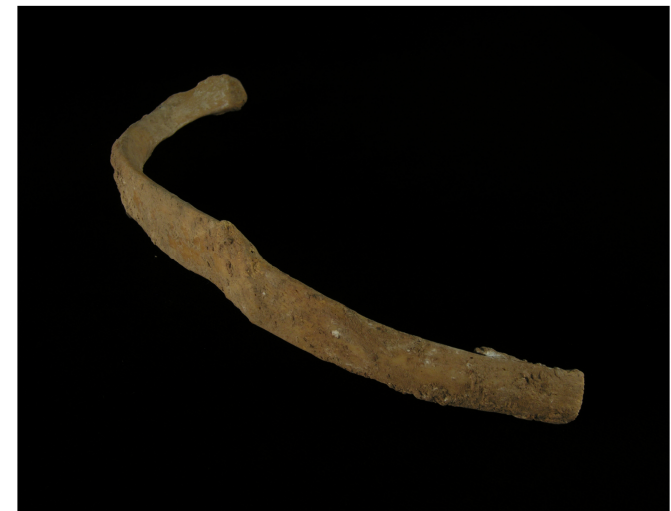

Abb. 49: Costa DO 1194 mit verheilter Fraktur.

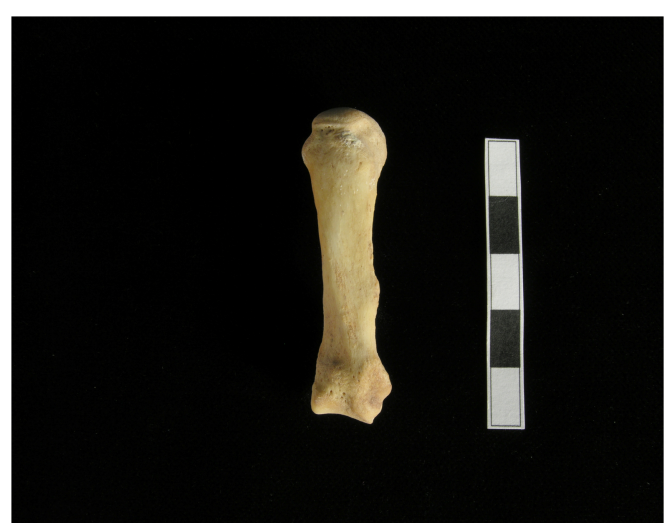

Abb. 51: Os metacarpale V DO 263.01 mit Deformation.

Eine besondere Form des Traumas findet sich an einem Calottenfragment eines 810jährigen Kindes. Dieses Calottenfragment DO 78.01 (Abb. 52) weist eine Trepanation auf. Deutliche Heilungsspuren, in Form eines Wiederverschlusses der Diploe durch Knochenneubildungen, zeigen, dass diese intentionale Eröffnung des Hirnschädels zumindest über einen gewissen Zeitraum überlebt wurde. Die Ursache für diesen

Eingriff dürfte vermutlich nicht in einer Verletzung des Schädels gelegen haben - z.B. zum Druckabbau nach einer intracranialen Blutung - da sich zumindest an dem vorhandenen Fragment keinerlei weitere Verletzungsspuren finden. Dass sich solche Spuren am nicht aufgefundenen Rest des Calvariums finden würden, kann jedoch natürlich nicht ausgeschlossen werden. Es kommen aber auch andere Gründe für die 
Schädeleröffnung infrage, wie z.B. psychische Auffälligkeiten, Migräne oder auch epileptische Anfälle.

Hinweise auf Fehl- oder Mangelernährung finden sich i.d.R. nicht an den Knochen aus der Lichtensteinhöhle. Lediglich in zwei Fällen wurde eine schwach ausgeprägte Cribra orbitalia beobachtet (Abb. 53 und 54), welche auf einen Eisenmangel dieser Individuen hinweist.

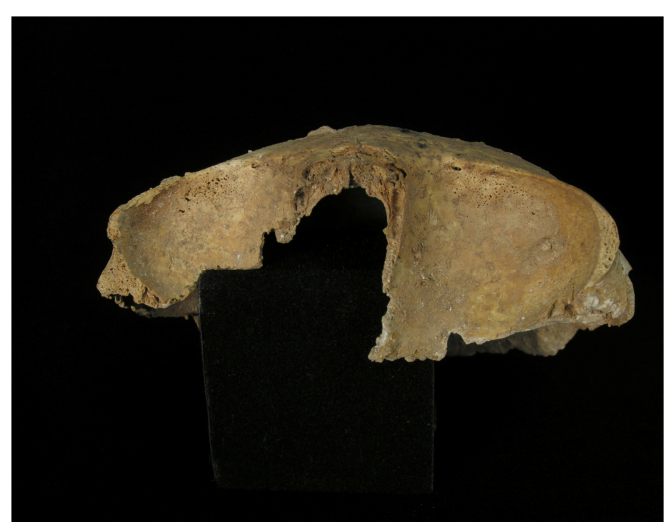

Abb. 53: Os frontale DO 531 mit schwacher Cribra orbitalia.

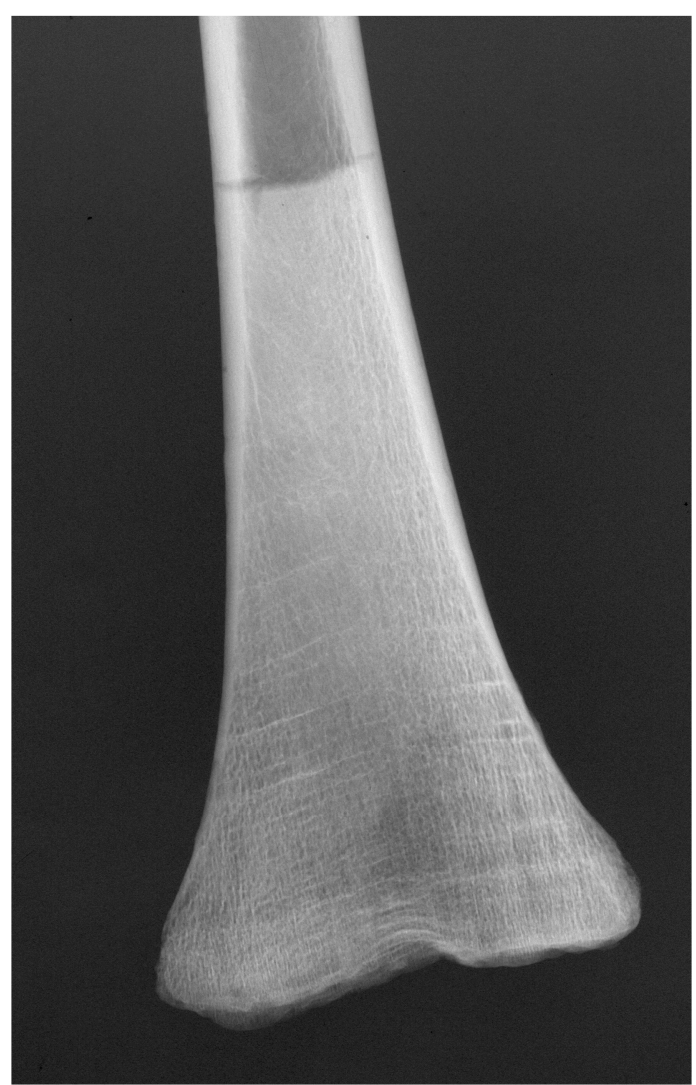

Abb. 55: Röntgenbild des linken Femurs DO 2030.01 mit Harris-Linien im distalen Diaphysenende (Foto aus Schilz 2006).

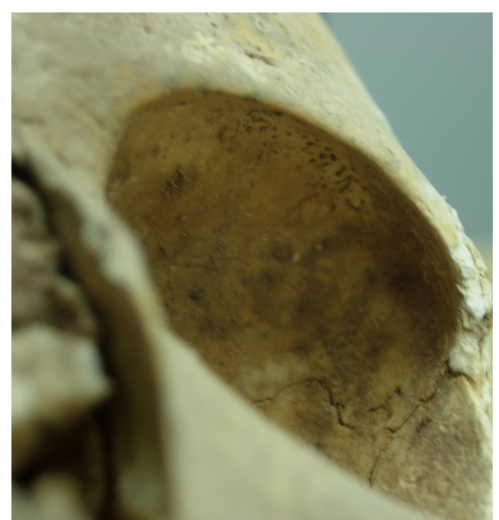

Abb. 54: Schädel DO 3757 mit schwacher Cribra orbitalia (Foto von Schilz 2006).

Um einen Einzelfall handelt es sich bei den im Röntgenbild nachgewiesenen Harris-Linien im linken Femur DO 2030.01 eines Individuums der Altersklasse Infans II (Abb. 55). Diese im Röntgenbild sichtbaren Strukturverdichtungen des Knochengewebes in Form von parallel zur Epiphysenfuge verlaufenden Linien resultieren aus einer verstärkten Wiederaufnahme des Knochenwachstums nach einer Phase des gehemmten Knochenwachstums. Als Ursache hierfür kommt jegliche Form von Stress infrage, wie z.B. Mangelernährung, Infektionskrankheiten aber auch starker psychischer Stress. 
Neben den pathologisch und degenerativ bedingten Veränderungen wurden an den Knochen aus der Lichtensteinhöhle auch einige weitere Auffälligkeiten festgestellt, welche den sogenannten Diskreta zuzuordnen sind. Hierbei handelt es sich um kleinräumige anatomische Varianten, welche i.d.R. genetischen Ursprungs sind. Hierzu ist z.B. die Anlage zusätzlicher Foramina zu rechnen, wie es für die Ulna DO 3667 mit einem doppelt angelegten Foramen nutritium der Fall ist (Abb. 56). An einem Humerus (DO 3675) wurde ein Foramen supratrochleare vorgefunden (Abb. 57).

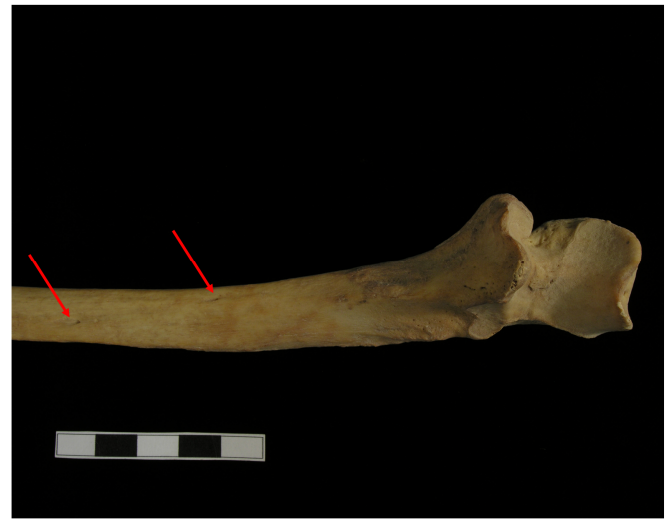

Abb. 56: Ulna DO 3667 mit doppelt angelegtem Foramen nutricium (mit Pfeilen markiert).

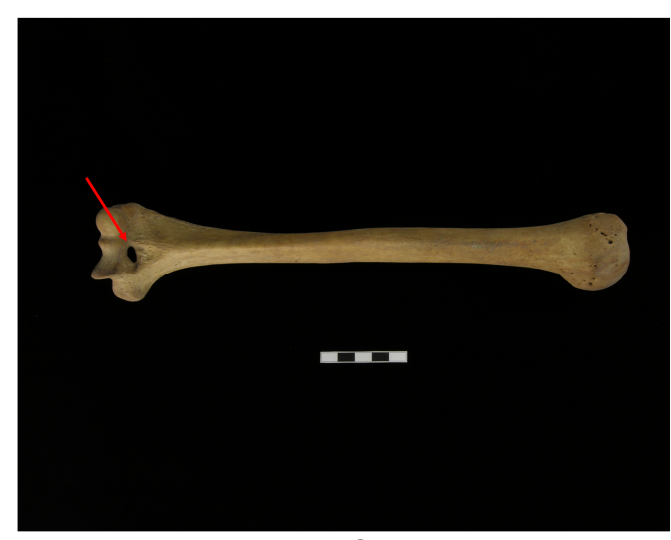

Abb. 57: Humerus DO 3675 mit Foramen supratrochleare (mit Pfeil markiert).

Ebenso zu den Diskreta zählen kleine zusätzliche Knocheninseln in den Nahtbereichen der Schädelcalotte, welche als Wormsche Knochen bezeichnet werden (Herrmann et al. 1990). Ist ein solcher Nahtknochen in erweiterter Form im Bereich des Aufeinandertreffens der Sutura sagittalis und der Sutura lambdoidea ausgeprägt wird er differenzierend als Os lambda bezeichnet (Herrmann et al. 1990). Beide Ausprägungen von Nahtknochen waren an jeweils einem der Calvarien aus der Lichtensteinhöhle vorhanden (siehe Abb. 58 und 59).

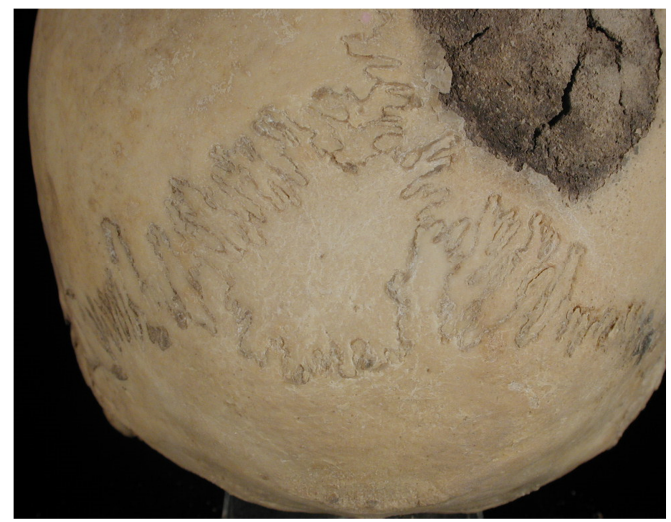

Abb. 58: Calvarium DO 3706 mit Os lambda (Foto von Schilz 2006).

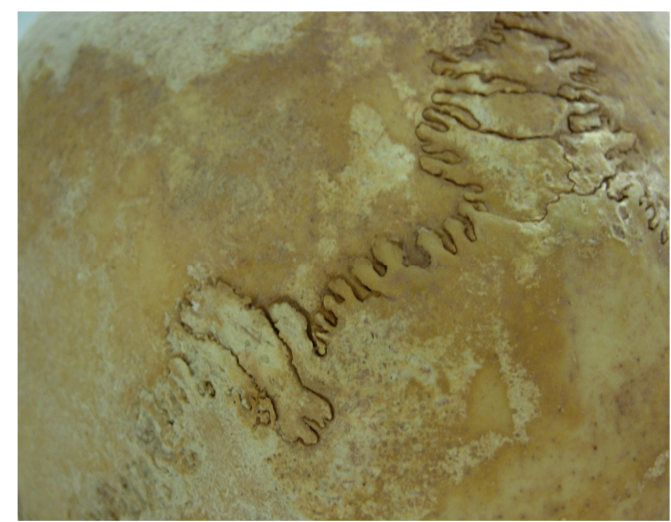

Abb. 59: Wormsche Knochen in der Sutura lambdoidea des Calvariums DO 1046 (Foto von Schilz 2006). 
Weitere am untersuchten Skelettmaterial auftretende Diskreta waren eine persistierenden Sutura metopica am Viscerocranium DO E 37 (Abb. 60) und einige Fälle von Gefäßimpressionen im Os frontale (siehe Abb. 61-65).

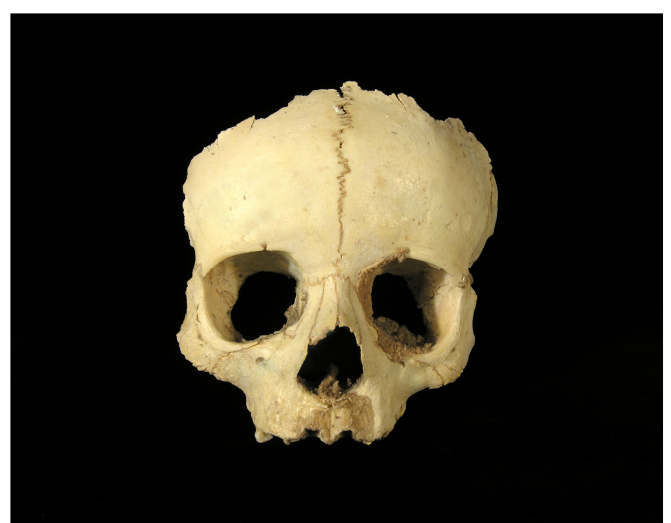

Abb. 60: Viscerocranium DO E 37 mit persistierender Sutura metopica.

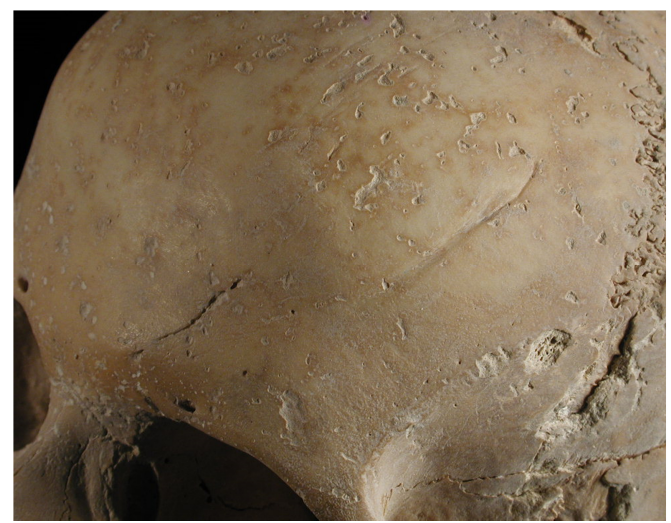

Abb. 62: Gefäßimpression links am Os frontale des Calvarium DO 3631 (Foto von Schilz 2006).

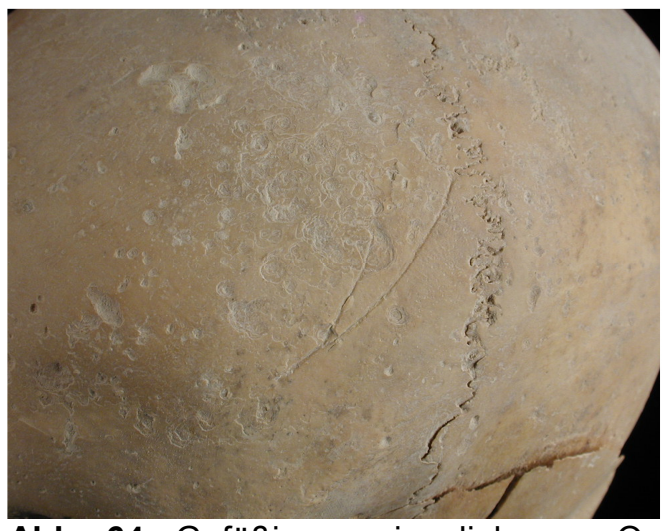

Abb. 64: Gefäßimpression links am Os frontale des Calvarium DO 5517 (Foto von Schilz 2006).

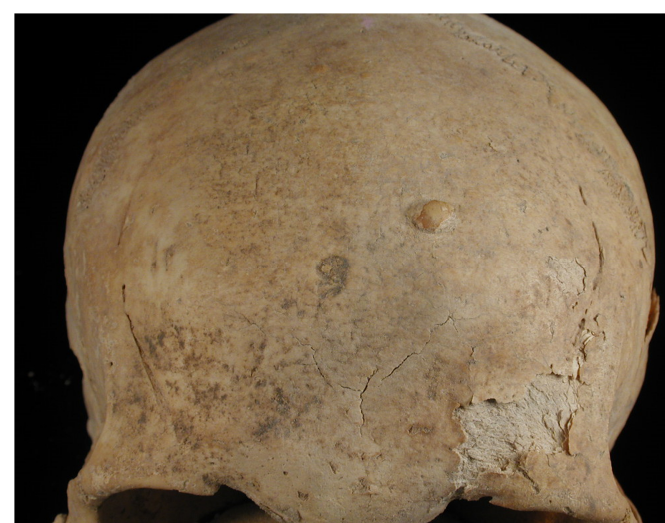

Abb. 61: Gefäßimpressionen beidseitig am Os frontale des Calvarium DO 5516 (Foto von Schilz 2006).

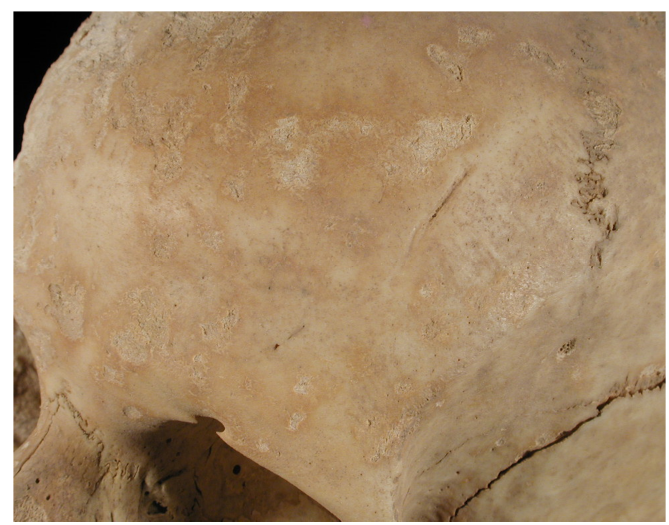

Abb. 63: Gefäßimpression links am Os frontale des Calvarium DO 3706 (Foto von Schilz 2006).



Abb. 65: Gefäßimpression links am Os frontale des Calvarium DO 6525 (Foto von Schilz 2006). 


\subsection{Altersverteilung}

Die Altersdiagnosen für die Individuen aus der Lichtensteinhöhle, welche auf die erste Sichtprüfung hin eindeutig in die subadulten Altersklassen einzuordnen waren, wurden überwiegend mit morphologischen Methoden vorgenommen. Hierbei wurde die Größe der Knochen und der Status der Knochenobliteration berücksichtigt. Für einige der subadulten Individuen wurde zudem der Zahnstatus im Röntgenbild begutachtet (Schilz 2006). Zudem wurde für einige der subadulten Individuen eine mikroskopische Begutachtung des Entwicklungsstatus der Knochenbinnenstruktur an Knochendünnschliffen vorgenommen.

Die Altersdiagnose für die Individuen aus der Lichtensteinhöhle, welche aufgrund eines vollständigen Anschlusses aller Epiphysen in die Altersklassen Adultas, Maturitas oder Senilis einzuordnen waren, wurde mittels histologischer Methoden vorgenommen. Für 23 dieser Individuen wurden Dünnschnitte der Langknochenkompakta beurteilt, für drei der Individuen wurden die Zuwachsringe im Zahnzement ausgezählt und für fünf Individuen wurden beide histologische Methoden angewendet.

Bei der abschließenden Bestimmung des Alters wurden die morphologischen, histologischen und radiologischen Ergebnisse für einige der Individuen aus vorhergehenden Arbeiten an dem Fundkomplex aus der Lichtensteinhöhle berücksichtigt (Schultes 2000, Schilz, 2006, Schiel 2008, Jungk 2008, Hollerbuhl 2009, Schubert 2009, Brandt 2010). Die Ergebnisse der Altersbestimmung sind der Tabelle 11 (Seiten 69-77) zu entnehmen. Die Altersverteilung für die Population aus der Lichtensteinhöhle findet sich in Tabelle 12 und ist zudem in Abb. 66 grafisch dargestellt. Wurde für ein Individuum festgestellt, dass es sich im Übergangsbereich von einer Altersklasse in die nächste befand, oder konnte die Altersdiagnose aufgrund nicht beurteilbarer Merkmale nicht ganz genau erfolgen, wurde das Alter mit Angaben wie z.B. „sad-fmat“ beschrieben. Individuen mit einer solchen Altersangabe wurden jeweils mit dem Wert 0,5 zu beiden der in der Beschreibung vorkommenden Altersklassen gezählt. 
Tabelle 12: Übersicht über die Sterbealterverteilung der Individuen aus der Lichtensteinhöhle.

\begin{tabular}{lcccc}
\hline Altersklasse & gesamt & weiblich & männlich & nd \\
\hline inf I & 8 & 2 & 5 & 1 \\
\hline inf II & 15 & 5 & 10 & - \\
fjuv & 4 & 1 & 3 & - \\
\hline juv & 2 & 1 & 1 & - \\
sjuv & 3 & 2,5 & 0,5 & - \\
fad & 5 & 2,5 & 2,5 & - \\
mad & 8,5 & 5,5 & 3 & - \\
\hline sad & 3 & 2,5 & 0,5 & - \\
fmat & 2,5 & 2 & 0,5 & - \\
mmat & 2,5 & 1 & 1,5 & - \\
\hline smat & 4,5 & 3 & 1,5 & - \\
\hline sen & 2 & 2 & - & - \\
\hline nd = nicht determiniert. & & &
\end{tabular}

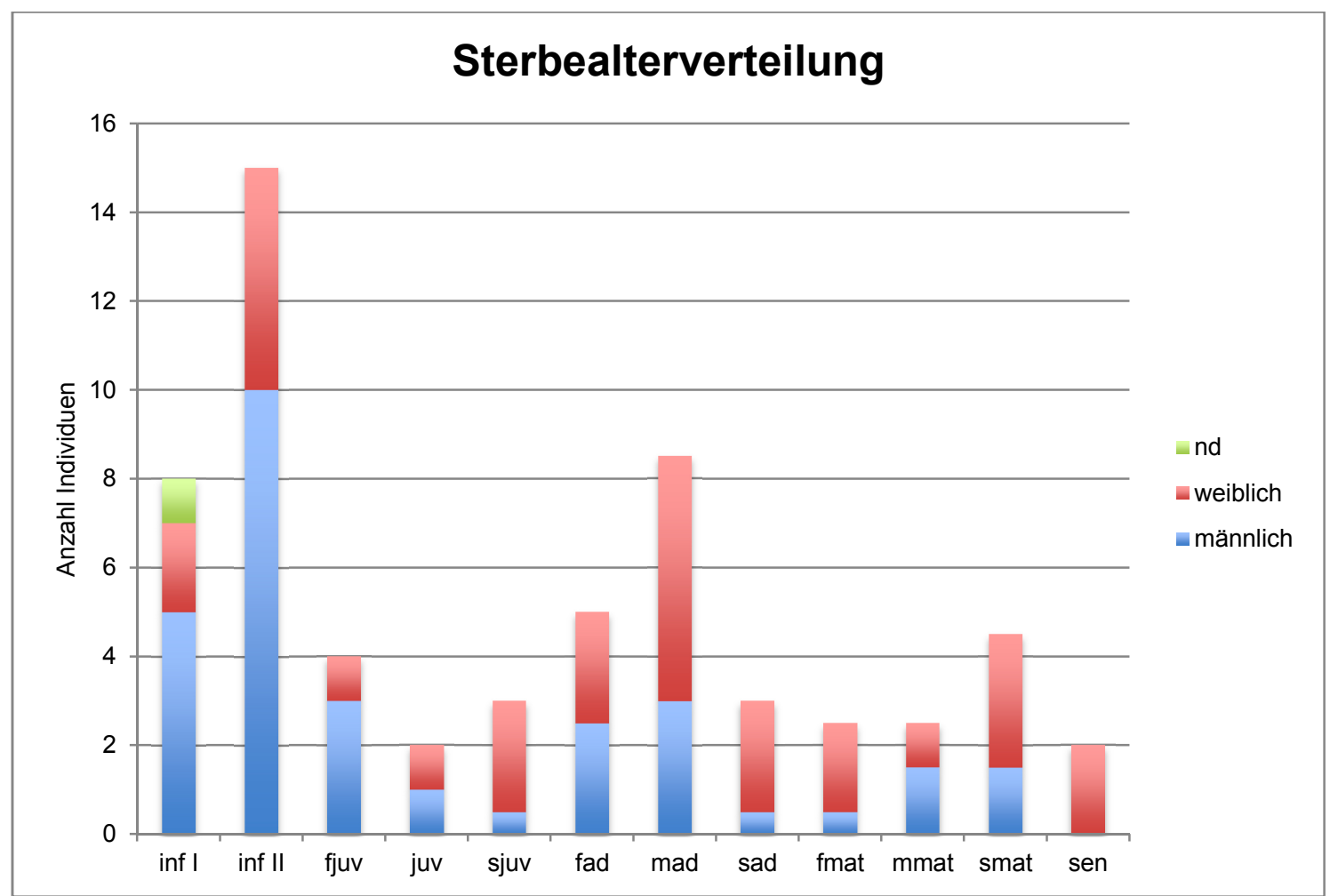

Abb. 66: Grafische Darstellung der Sterbealterverteilung der Individuen aus der Lichtensteinhöhle. nd = nicht determiniert.

Bei der Sterbealterverteilung (Abb. 11) fällt auf, dass insbesondere Individuen der Altersklasse Infans II in besonders hoher Zahl in der Höhle aufgefunden wurden. Dies spiegelt sich - wie aus der auf Basis der Altersverteilung errechneten Sterbetafel (Tabelle 13) hervorgeht - in einer erhöhten Sterbewahrscheinlichkeit und einer extrem niedrigeren mittleren Lebenserwartung für jüngere Individuen wider. 
Die grundlegenden Sterblichkeitsverhältnisse weisen jedoch Übereinstimmungen mit zeitstellungsgleichen Leichenbrandserien (Schutkowski und Hummel 1990) auf (Abb. 67). Die größten Ähnlichkeiten finden sich zu den Friedhöfen Neumünster-Faldera (800-500 v. Chr.) und Neumünster-Tungendorf A (800-550 v. Chr.).

Tabelle 13: Sterbetafel für die Individuen aus der Lichtensteinhöhle.

\begin{tabular}{lcccccccc}
\hline Altersklasse $\mathrm{x}$ & $\mathrm{a}$ & $\mathrm{D}_{\mathrm{x}}$ & $\mathrm{d}_{\mathrm{x}}$ & $\mathrm{I}_{\mathrm{x}}$ & $\mathrm{q}_{\mathrm{x}}$ & $\mathrm{L}_{\mathrm{x}}$ & $\mathrm{T}_{\mathrm{x}}$ & $\mathrm{e}_{\mathrm{x}}$ \\
\hline infans I & 6 & 8 & 133,3 & 1000,0 & 0,1 & 5600,0 & 22691,7 & 22,7 \\
infans II & 6 & 15 & 250,0 & 866,7 & 0,3 & 4450,0 & 17091,7 & 19,7 \\
juvenil & 6 & 9,0 & 150,0 & 616,7 & 0,2 & 3250,0 & 12641,7 & 20,5 \\
frühadult & 7 & 5,0 & 83,3 & 466,7 & 0,2 & 2975,0 & 9391,7 & 20,1 \\
mitteladult & 7 & 8,5 & 141,7 & 383,3 & 0,4 & 2187,6 & 6416,7 & 16,7 \\
\hline spätadult & 7 & 3,0 & 50,0 & 241,7 & 0,2 & 1516,7 & 4229,2 & 17,5 \\
frühmatur & 7 & 2,5 & 41,7 & 191,7 & 0,2 & 1195,8 & 2712,5 & 14,2 \\
\hline mittelmatur & 7 & 2,5 & 41,7 & 150,0 & 0,3 & 904,2 & 1516,7 & 10,1 \\
spätmatur & 7 & 4,5 & 75,0 & 108,3 & 0,7 & 495,8 & 612,5 & 5,7 \\
\hline senil & 7 & 2,0 & 33,3 & 33,3 & 1,0 & 116,7 & 116,7 & 3,5 \\
\hline Summe & $\mathbf{6 7}$ & $\mathbf{6 0}$ & $\mathbf{1 . 0 0 0 , 0}$ & & & $22.691,6667$ & & \\
\hline
\end{tabular}

a: Umfang der Altersklasse in Jahren; $\mathbf{D}_{\mathbf{x}}$ : Anzahl der in $\mathbf{x}$ gestorbenen Individuen; $\mathbf{d}_{\mathbf{x}}$ : relative Anzahl der in $\mathrm{x}$ gestorbenen Individuen; $\mathrm{I}_{\mathbf{x}}$ : relative Anzahl der Überlebenden in $\mathrm{x}$; $\mathbf{q}_{\mathbf{x}}$ : Sterbewahrscheinlichkeit in $\mathbf{x} ; \mathbf{L}_{\mathbf{x}}$ : Anzahl der insgesamt gelebten Jahre zwischen $\mathbf{x}$ und $\mathrm{x}+1 ; \mathbf{T}_{\mathbf{x}}$ : Anzahl der insgesamt noch zu lebenden Jahre; $\mathbf{e}_{\mathbf{x}}$ : mittlere Lebenserwartung in $\mathrm{x}$.

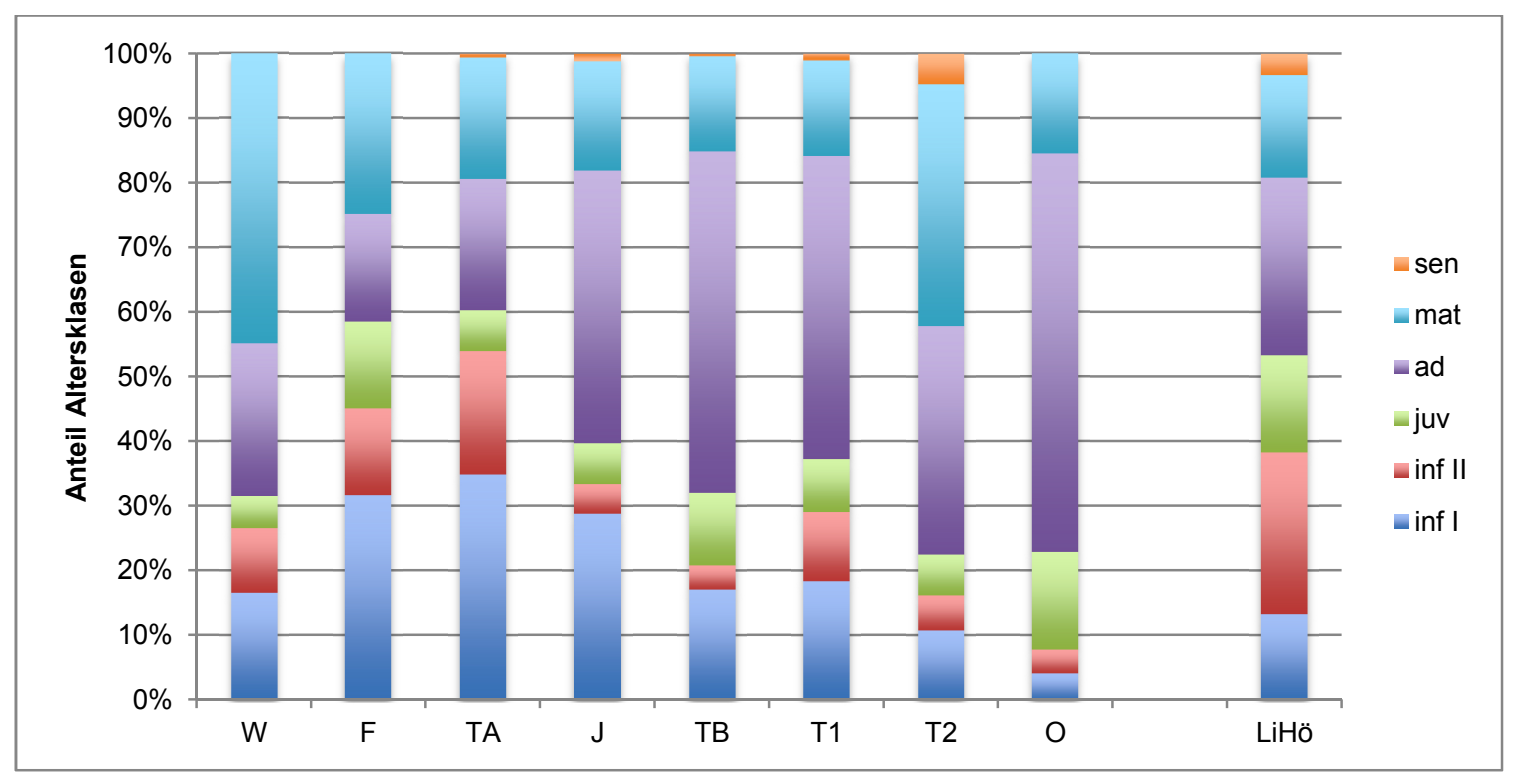

Abb. 67: Vergleich der Sterbealterverteilung der Individuen aus der Lichtensteinhöhle (LiHö) mit denen verschiedener Leichenbrandserien. $W=$ Wahlstedt, 900-600 v. Chr.; $F=$ NeumünsterFaldera, 800-500 v. Chr.; TA = Neumünster-Tungendorf A, 800-550 v. Chr.; J = Jevenstedt, 550-200 v. Chr.; TB = Neumünster-Tungendorf B, 550-50 v. Chr.; T1 = Groß-Timmendorf 1, 550-200 v. Chr.; T2 = Groß-Timmendorf 2, 500-50 v. Chr.; O = Owschlag, 500-50 v. Chr. 


\subsection{Geschlechtsverteilung}

Die Geschlechtsbestimmung für die Individuen aus der Lichtensteinhöhle erfolgte vor allem genetisch mit Hilfe des in der Hepta- und Dekaplex PCR enthaltenen Amelogenin-Markers (siehe Tabelle 15, Seiten 96-98). Soweit vorhanden und beurteilbar wurden morphologische Kriterien mit berücksichtigt. Die Ergebnisse der Geschlechtsbestimmung sind der Tabelle 11 (Seiten 69-77) zu entnehmen.

Insgesamt ist die Geschlechtsverteilung in etwa ausgeglichen (siehe Tabelle 14 und Abb. 68). Betrachtet man jedoch die Geschlechtsverteilung differenziert für subadulte (Abb. 69) und erwachsene Individuen (Abb. 70) ist auffällig, dass sich unter den subadulten deutlich mehr männliche Individuen befinden, während dieses Verhältnis bei den erwachsenen Individuen genau umgekehrt ist.

Tabelle 14: Übersicht über die Geschlechtsverteilung der Individuen aus der Lichtensteinhöhle.

\begin{tabular}{lccc}
\hline Geschlecht & $\begin{array}{c}\text { Anzahl Individuen } \\
\text { gesamt }\end{array}$ & $\begin{array}{c}\text { Anzahl Individuen } \\
\text { subadult }\end{array}$ & $\begin{array}{c}\text { Anzahl Individuen } \\
\text { erwachsen }\end{array}$ \\
\hline weiblich & 30 & 11,5 & 18,5 \\
männlich & 29 & 19,5 & 9,5 \\
nd & 1 & 1 & - \\
\hline nd = nicht determiniert. & &
\end{tabular}

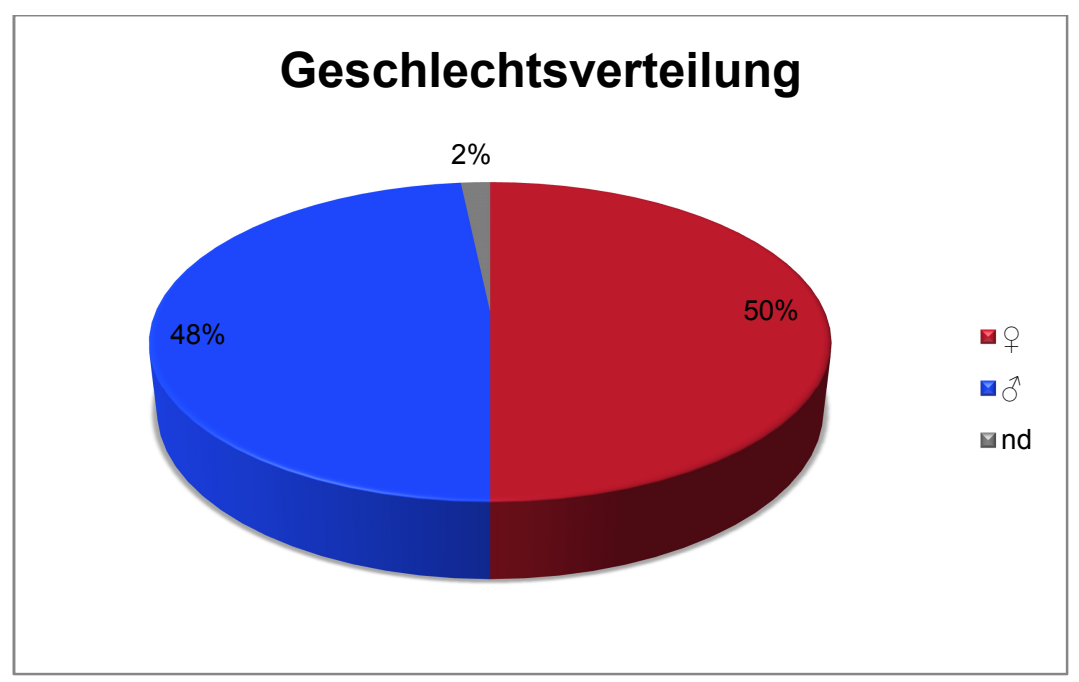

Abb. 68: Grafische Darstellung der Geschlechtsverteilung über alle Altersklassen der Individuen aus der Lichtensteinhöhle. nd = nicht determiniert. 


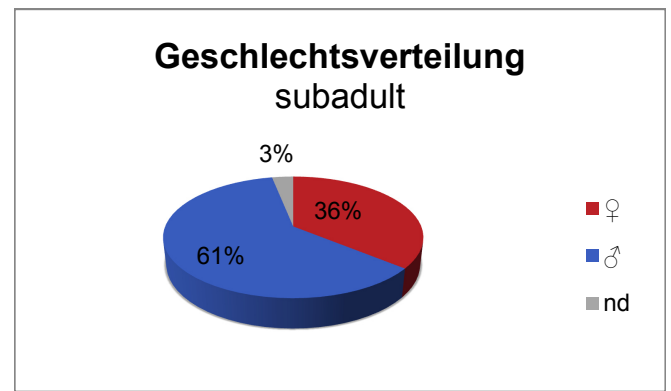

Abb. 69: Grafische Darstellung der Geschlechtsverteilung der subadulten Individuen aus der Lichtensteinhöhle. $\mathrm{nd}=$ nicht determiniert.

\section{Geschlechtsverteilung erwachsen}

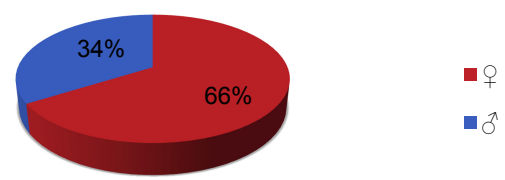

Abb. 70: Grafische Darstellung der Geschlechtsverteilung der erwachsenen Individuen aus der Lichtensteinhöhle. $\mathrm{nd}=$ nicht determiniert.

Der Vergleich der Geschlechtsverteilung in der Population aus der Lichtensteinhöhle mit denen in Populationen ähnlicher Zeitstellungen (Schutkowski und Hummel 1990) (Abb. 71) zeigt grundsätzlich Ähnlichkeiten mit den Leichenbrandserien der jüngeren Bronzezeit auf. Bei an Leichenbrand erhobenen Daten für die Geschlechtsverteilung ist jedoch zu berücksichtigen, dass Geschlechtsbestimmungen an Leichenbränden nur bei größerem Geschlechtsdimorphismus zuverlässig möglich sind und es somit zu fehlerhaften Bestimmungen des Geschlechts kommen kann, sobald die Robustizitätsunterschiede zwischen den Geschlechtern wenig ausgeprägt sind.

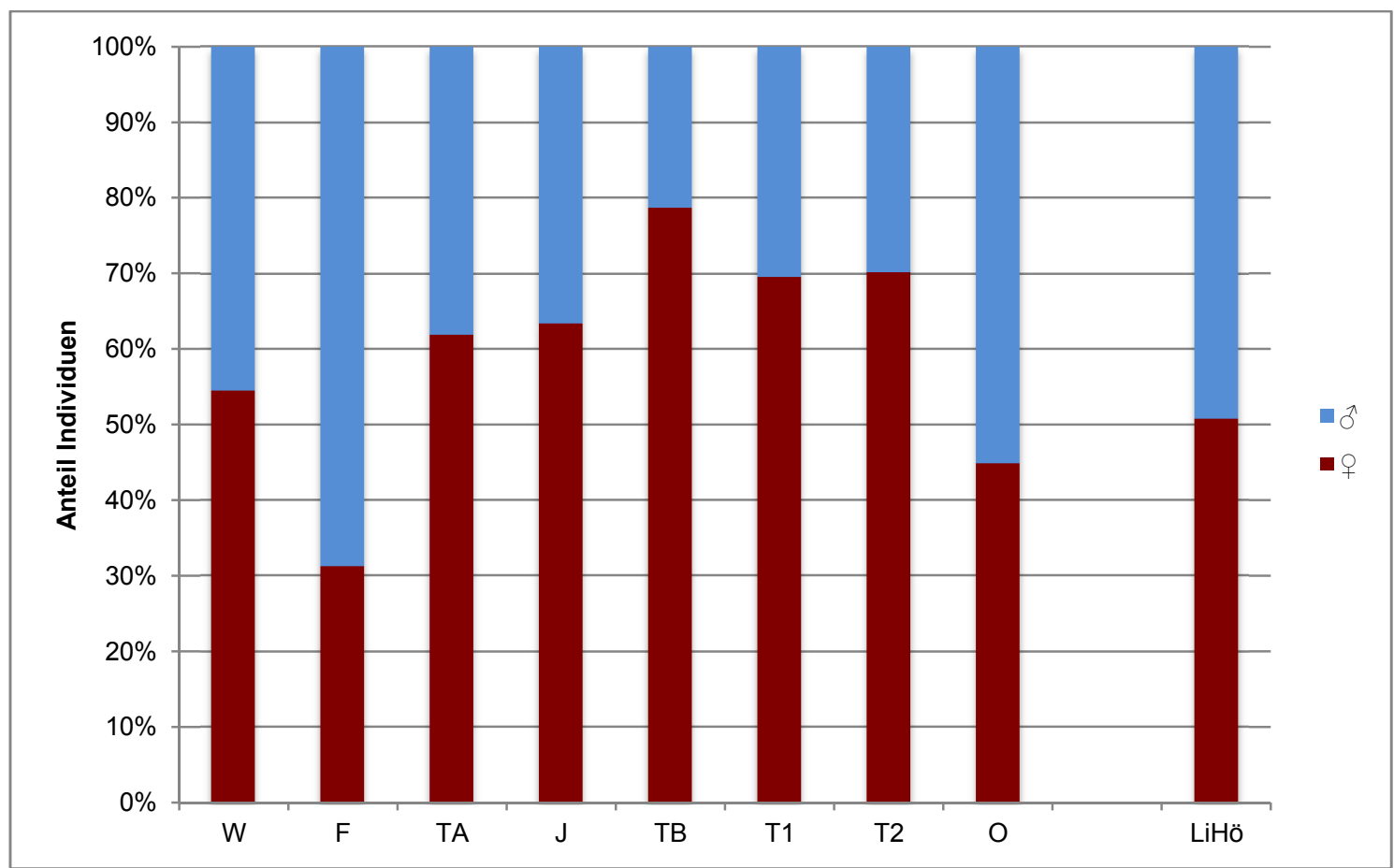

Abb. 71: Vergleich der Geschlechtsverteilung der Individuen aus der Lichtensteinhöhle (LiHö) mit denen verschiedener Leichenbrandserien. $W=$ Wahlstedt, 900-600 v. Chr.; $F=$ Neumünster-Faldera, 800-500 v. Chr.; TA = Neumünster-Tungendorf A, 800-550 v. Chr.; $\mathrm{J}=$ Jevenstedt, 550-200 v. Chr.; TB = Neumünster-Tungendorf B, 550-50 v. Chr.; T1 = GroßTimmendorf 1, 550-200 v. Chr.; T2 = Groß-Timmendorf 2, 500-50 v. Chr.; O = Owschlag, 50050 v. Chr. 


\subsection{Genetische Typisierungsergebnisse}

\subsubsection{Autosomale STRs}

So wie der Erhaltungszustand der Knochen sehr variabel war, variierte auch die aus den untersuchten Knochen extrahierte DNA stark bezüglich der Erhaltungsqualität bzw. des Degradierungsgrades. Abb. 72 zeigt exemplarisch den Amplifikationserfolg für einige stark degradierte DNA-Proben und eine recht gut erhaltene (DO E 11). Für Proben mit guter DNA-Erhaltung konnten konstant gute Amplifikationserfolge erzielt werden (siehe Abb. 73).

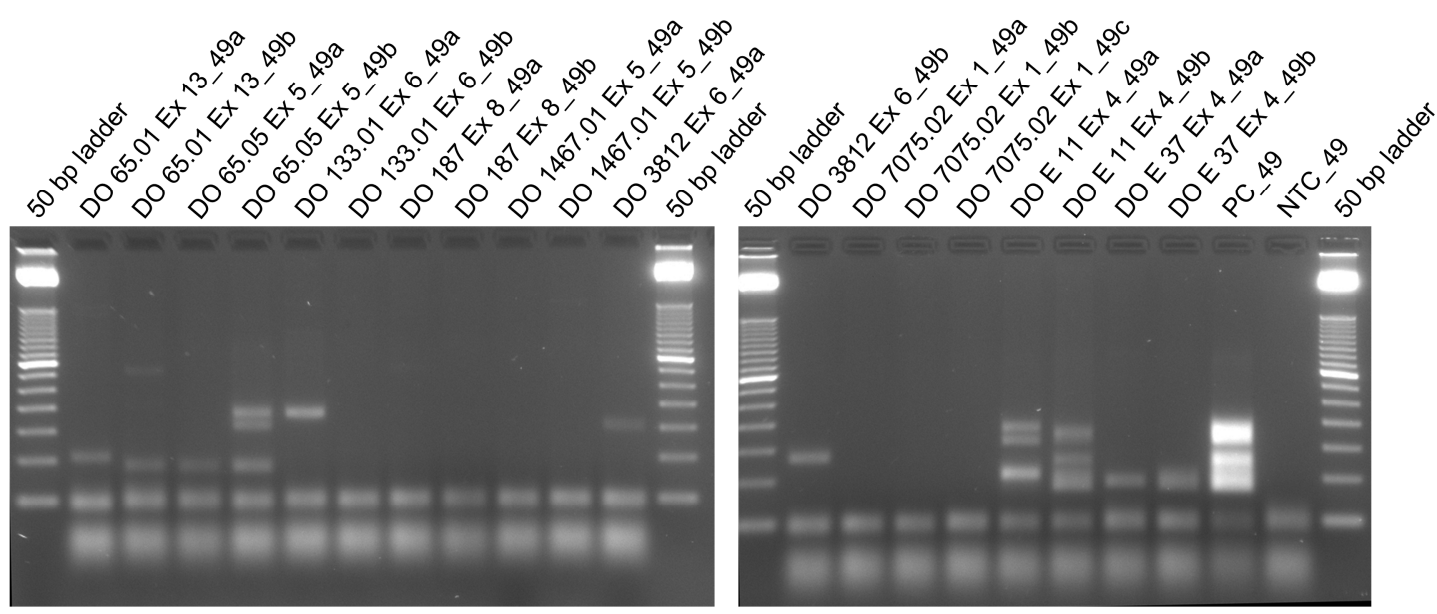

Abb. 72: Agarosegelfoto einer Amplifikation mit dem Heptaplex Kit (PCR 49) zur Analyse autosomaler STRs mit eher durchschnittlichem bis schlechtem Amplifikationserfolg. 50 bp ladder $=$ Längenstandard, $\mathrm{PC}=$ positive control, NTC $=$ no template control .

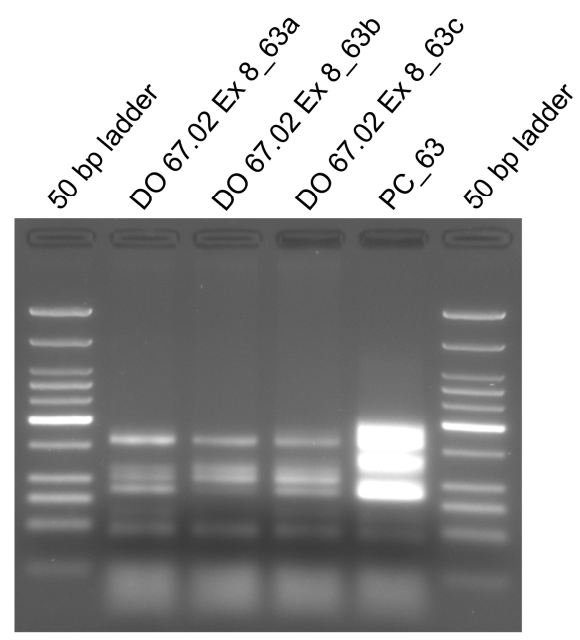

Abb. 73: Agarosegelfoto einer Amplifikation mit dem Heptaplex Kit (PCR 63) zur Analyse autosomaler STRs mit recht gutem Amplifikationserfolg. 50 bp ladder $=$ Längenstandard, $\mathrm{PC}=$ positive control . 
Einige sehr gut erhaltene Proben wiesen einen so guten DNA-Erhalt auf, dass über alle untersuchten Fragmentlängen hinweg annähernd gleichmäßig große Mengen PCR Produkt generiert werden konnten. Die Elektropherogramme der Fragmentlängenanalyse mittels Kapillarelektrophorese zeigten für solche Proben ein Bild wie es der Ergebnisqualität von Rezentproben entspricht (siehe exemplarisch Probe DO 7075.01 Ex 1 aus PCR 28 in Abb. 74 A). Zunehmende Grade der DNA-Degradierung äußerten sich vor allem in einer Abnahme der Produktintensitäten längerer DNA-Fragmente. Abb. 74 B zeigt exemplarisch das Elektropherogramm der Fragmentlängenanalyse einer Amplifikation mit dem Heptaplex Kit zur Analyse autosomaler STRs für die Probe DO 107 Ex 1 aus PCR 4. Es ist deutlich zu sehen, dass für die längeren STR-Systeme (D5S818, FGA, D18S51 und D21S11) wesentlich geringere Produktmengen entstanden sind als für die STR-Systeme TH01 und D13S317 und den Amelogenin-Marker, welche sehr kurze Fragmentlängen aufweisen. Bei einigen Proben war die DNA-Degradierung so weit fortgeschritten, dass die längeren Fragmente nicht durchgängig in ausreichendem Maße amplifiziert wurden, um die Detektionsgrenze in der Kapillarelektrophorese zu überschreiten. Ein Beispiel hierfür ist in Abb. $74 \mathrm{C} \mathrm{im}$ Elektropherogramm einer Fragmentlängenanalyse für die Probe DO 58.04 Ex 7 PCR 11 zu sehen. Hier wurden nur die kurzen Marker mit guten Produktmengen amplifiziert, während für die längeren Systeme gar keine Produkte mehr detektiert werden konnten. 

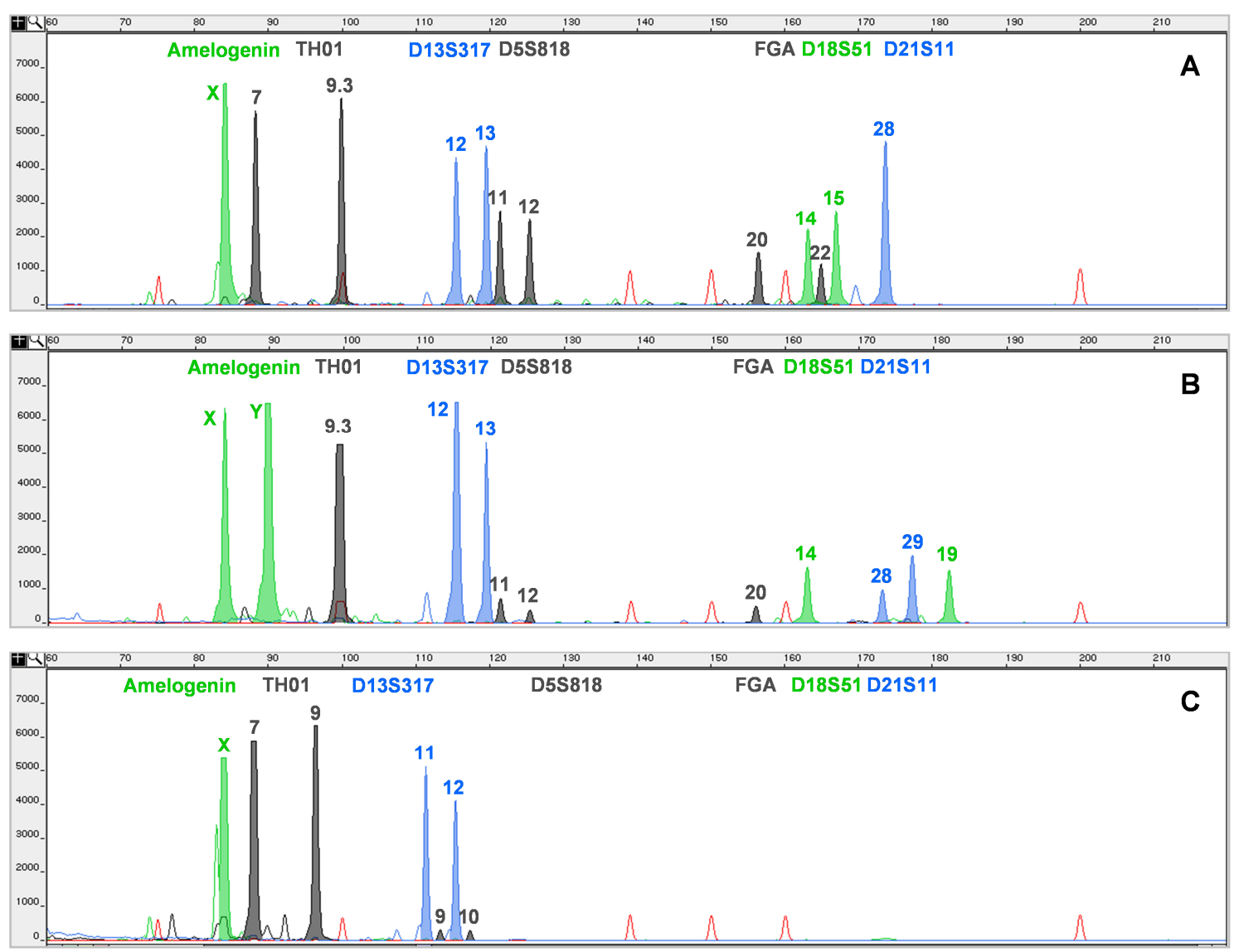

Abb. 74: Elektropherogramme der Fragmentlängenanalyse von drei mit dem Heptaplex Kit zur Analyse autosomaler STRs amplifizierten Proben. Während das Ergebnis für die Probe DO 7075.01 Ex 1 aus PCR 28 (A) quasi die Qualität von Rezentproben hat, sind bei der Probe DO 107 Ex 1 aus PCR 4 (B) Anzeichen leichter Degradierung in Form von mit der Fragmentlänge abnehmenden Produktmengen zu sehen. Bei der Probe DO 58.04 Ex 7 PCR 11 (C) ist für die längeren Fragmente die Produktmenge unter der Nachweisgrenze geblieben.

Mit Abschluss der durchgeführten Analysen liegen - unter Berücksichtigung aller Ergebnisse aus dieser und vorhergehenden Arbeiten - insgesamt für 40 der untersuchten Individuen vollständige genetische Fingerabdrücke vor. Für 7 Individuen ist der Typisierungserfolg mit 78-92\% erfolgreich typisierten autosomalen STR-Systemen immer noch als recht gut einzustufen. Ebenfalls für 7 Individuen war mit 57-71 \% erfolgreich typisierten autosomalen STR-Systemen ein mittlerer Typisierungserfolg zu verzeichnen und 5 Individuen wiesen mit lediglich 28-50\% erfolgreich typisierten autosomalen STR-Systemen einen eher schlechten Typisierungserfolg auf.

In Tabelle 15 sind die genetischen Typisierungsergebnisse der autosomalen STRs für die Individuen aus der Lichtensteinhöhle tabellarisch zusammengefasst. Hierbei handelt es sich um sogenannte Konsensusgenotypen, d.h. es wurden für jedes Individuum mehrere Analysen durchgeführt und die Ergebnisse der Einzelanalysen zusammengeführt. Die Einzeltypisierungsergebnisse finden sich auf der beigefügten CD (Lichtensteinhöhle Einzeltypisierungen autosomale STRs.xls). 
Tabelle 15: Konsensusgenotypen für die autosomalen STRs.

\begin{tabular}{|c|c|c|c|c|c|c|c|c|c|c|c|c|c|c|c|c|}
\hline Individuum [DO \#] & Amelo & D3S1358 & VWA & FGA & D8S1179 & D21S11 & D18S51 & D5S818 & D13S317 & D7S820 & CSF1PO & TH01 & D16S539 & D2S1338 & D19S433 & D9S1120 \\
\hline FK/HS/RG 35 (M4) & $X / Y$ & $15 / 17$ & $16 / 17$ & $20 / 25$ & $10 / 14$ & $28 / 29$ & $14 / 19$ & $11 / 12$ & $12 / 13$ & $11 / 12$ & $12 /-$ & 9.3/- & $12 / 13$ & $23 / 24$ & $13 / 14$ & $16 / 17$ \\
\hline FK/RG/BS 38 (F1) & $\mathrm{X} /-$ & $16 /-$ & $16 /-$ & $20 / 21$ & $8 / 15$ & $28 / 29$ & $12 / 18$ & $9 / 11$ & $11 / 13$ & $9 / 12$ & $11 / 13$ & $7 / 9.3$ & $12 / 13$ & $17 /-$ & 13/- & $15 / 16$ \\
\hline $\begin{array}{l}\text { RG/FK } 57.02 \\
\text { (M17/M19) }\end{array}$ & $X / Y$ & $15 / 17$ & $16 / 18$ & $23 / 25$ & $10 / 13$ & $28 / 29$ & $14 / 15$ & $12 / 13$ & $8 / 13$ & $10 / 12$ & $10 / 12$ & $7 / 9.3$ & $12 / 13$ & $16 / 23$ & 13/15.2 & 16/- \\
\hline RG/FK 58.01 & $\mathrm{X} /-$ & $15 / 16$ & $17 / 19$ & $20 /-$ & 14/- & $29 / 30$ & $16 / 19$ & 10/11 & $12 / 14$ & $11 / 13$ & & $7 / 9.3$ & $12 / 13$ & 24/- & $14 / 15$ & $16 / 17$ \\
\hline RG/FK 58.03 (M13) & $X / Y$ & $15 / 18$ & $16 / 18$ & $21 / 25$ & 13/- & $29 / 30$ & $16 / 20$ & $11 /-$ & $8 / 13$ & $10 / 11$ & $10 / 12$ & $6 / 8$ & $11 / 12$ & $(17) / 19$ & $13 / 15$ & $16 / 17$ \\
\hline RG/FK/KS 58.08 (M7) & $X / Y$ & $14 / 15$ & $17 / 18$ & $24 / 25$ & 10/11 & $29 / 30$ & $13 / 18$ & $12 /-$ & $8 / 12$ & 10/11 & 10/- & $6 / 8$ & $(11) / 13$ & $-/$ & $13 / 14$ & $16 /(17)$ \\
\hline RG/HS/BS 65.05 & $\mathrm{X} /-$ & $(15) /(16)$ & $17 /-$ & $20 /(24)$ & $(12) /(14)$ & $29 /(30)$ & $(16) /(19)$ & $11 /(13)$ & $12 /(14)$ & $-1-$ & & $7 / 9.3$ & $-1-$ & $-/-$ & $(14) /(15)$ & $-/-$ \\
\hline RG 66.02 & $\mathrm{X} /-$ & $15 / 16$ & $17 /(18)$ & $20 / 25$ & $13 /(14)$ & $28 / 29$ & $14 / 16$ & $11 / 12$ & $8 / 12$ & $10 / 11$ & & $9.3 /-$ & $(9) / 12$ & $(23) /(24)$ & $14 / 15.2$ & $16 /-$ \\
\hline $\begin{array}{l}\text { RG/FK } 67.03 \\
\text { (F10/F17) }\end{array}$ & X/- & $15 / 16$ & 16/- & $22 / 24$ & $13 / 15$ & $28 / 30.2$ & $16 / 17$ & $9 / 12$ & $9 / 13$ & $8 / 12$ & $11 / 12$ & $6 / 9.3$ & $9 / 12$ & $20 / 23$ & $12 / 13$ & $(16) /(18)$ \\
\hline BS 133.01 & $X / Y$ & $14 / 15$ & $17 / 18$ & $(20) / 21$ & $(11) /(15)$ & $(28) / 29$ & $(16) /(18)$ & $-/-$ & $-/-$ & $(11) / 12$ & $-/-$ & $8 / 9.3$ & $11 / 12$ & $(17) /-$ & 15/- & $16 /(17)$ \\
\hline $\begin{array}{l}\text { RG/GK/BS } 183.01 \\
\text { (M11) }\end{array}$ & $X / Y$ & $14 / 16$ & $14 / 19$ & $(22) / 24$ & $13 /(16)$ & 29/32.2 & $13 / 15$ & 10/- & $8 / 11$ & 10/- & $-1-$ & $6 / 9.3$ & $11 / 12$ & 20/- & $13 / 14$ & $15 / 17$ \\
\hline RG/BS 187 & $\mathrm{X} /-$ & $14 /-$ & 14/- & $22 / 23$ & $13 / 15$ & 29/- & $12 / 14$ & $11 / 13$ & $12 / 14$ & (10)- & & $6 / 9.3$ & (9)/- & $-/-$ & 15/- & $-/-$ \\
\hline RG/FK/BS 516 & $\mathrm{X} /-$ & $16 /-$ & $(17) /-$ & $(25) /-$ & $-/-$ & $(27) /(28)$ & $-1-$ & $(9) /-$ & $(11) /(13)$ & $8 / 9$ & & $(7) /(9.3)$ & $12 /-$ & $(16) /-$ & $13 / 15$ & $16 /-$ \\
\hline $\begin{array}{l}\text { FK/RG/HS/BS } 901.01 \\
\text { (M18/F16) }\end{array}$ & $\mathrm{X} /-$ & $16 / 18$ & $15 / 18$ & $21 /-$ & $12 / 13$ & $30 / 33.2$ & $15 / 16$ & $12 /-$ & $8 / 12$ & $10 / 14$ & - & $9 / 9.3$ & $12 / 14$ & $16 / 24$ & $13 / 14$ & $14 / 18$ \\
\hline $\begin{array}{l}\text { FK/RG/HS } 902.01 \\
\text { (M10) }\end{array}$ & $X / Y$ & $14 / 15$ & 13/15 & $22 / 24$ & 13/- & $31.2 / 32.2$ & $10 / 12$ & $12 /-$ & $9 / 13$ & 9/- & 10/11 & $6 / 9.3$ & $11 / 12$ & $19 / 20$ & 13/13.2 & $13 / 16$ \\
\hline FK/HS/RG/BS 903.01 & $\mathrm{X} /-$ & $15 / 16$ & $17 / 18$ & $21 / 24$ & $8 / 13$ & $29 / 30$ & $14 / 17$ & $11 /-$ & 8/- & $9 / 12$ & $-1-$ & $6 / 9.3$ & $12 /-$ & $17 / 20$ & $13 / 15$ & $15 /(16)$ \\
\hline FK/RG/HS/BS 903.02 & $\mathrm{X} /-$ & $16 / 17$ & $(14) / 17$ & $22 /-$ & $12 /(13)$ & 30/- & $-1-$ & $-1-$ & $11 / 12$ & $-1-$ & $10 / 11$ & $7 / 9$ & $12 /-$ & $(19) /(21)$ & $13 /(15)$ & $-1-$ \\
\hline FK/RG/JS 904.04 & $-1-$ & $-1-$ & $-1-$ & $(19) /(24)$ & $-/$ & $(31) /(32.2)$ & $-1-$ & $(12) /-$ & $(9) /-$ & $-1-$ & & $(7) /-$ & $-1-$ & - & $17 /-$ & $-1-$ \\
\hline FK/RG 905.01 (M14) & $X / Y$ & $15 /-$ & 16/- & $20 / 22$ & $12 / 13$ & $29 / 31.2$ & $18 / 19$ & $11 / 12$ & $8 / 11$ & $10 / 12$ & $10 / 12$ & $7 / 9$ & 9/11 & $17 /-$ & $12 / 15$ & $15 / 16$ \\
\hline FK/RG/BS 907.01 & $X / Y$ & $15 / 17$ & $(15) / 16$ & $21 /-$ & 8/(15) & $28 / 30$ & $14 / 20$ & $11 /-$ & $8 / 13$ & 9/- & & $6 / 9.3$ & $12 / 13$ & $(17) /(20)$ & $15 / 17$ & 16/- \\
\hline RG/FK 1076 (M1) & $X / Y$ & $15 / 17$ & $15 / 16$ & $21 / 25$ & $12 / 13$ & $30.2 / 33.2$ & $14 / 20$ & $10 / 12$ & $11 / 13$ & $7 / 8$ & 10/- & $9.3 /-$ & $11 / 12$ & $(17) / 18$ & $13 / 15$ & 16/- \\
\hline
\end{tabular}


Fortsetzung Tabelle 15: Konsensusgenotypen für die autosomalen STRs.

\begin{tabular}{|c|c|c|c|c|c|c|c|c|c|c|c|c|c|c|c|c|}
\hline Individuum [DO \#] & Amelo & D3S1358 & VWA & FGA & D8S1179 & D21S11 & D18S51 & D5S818 & D13S317 & D7S820 & CSF1PO & TH01 & D16S539 & D2S1338 & D19S433 & D9S1120 \\
\hline RG/FK/BS 1078 (F13) & $\mathrm{X} /-$ & 16/- & $15 / 17$ & $21 /-$ & 13/- & 27/- & 13/- & $9 / 12$ & $11 / 12$ & $8 / 11$ & $10 / 11$ & $9.3 /-$ & $11 / 12$ & $16 / 19$ & 15/- & 16/- \\
\hline BS 1102 (M2) & $X / Y$ & $15 / 16$ & $16 /-$ & $20 / 21$ & $12 / 15$ & $29 / 33.2$ & $14 / 18$ & $9 / 10$ & $11 /-$ & $7 / 9$ & $10 / 13$ & $7 / 9.3$ & $11 / 13$ & 17/- & 13/- & 16/- \\
\hline BS/RG 1103 (F14) & $\mathrm{X} /-$ & $14 / 16$ & $14 / 15$ & $23 / 24$ & $11 / 14$ & $28 / 30$ & $12 / 15$ & $11 / 12$ & $12 / 13$ & $12 /-$ & $11 /-$ & $6 / 9.3$ & $10 / 13$ & $18 / 25$ & $13 / 15$ & $15 /-$ \\
\hline BS/RG 1176 (F18) & $\mathrm{X} /-$ & $15 / 16$ & $14 / 17$ & $19 / 24$ & $14 / 15$ & $28 / 29$ & $14 / 16$ & $10 / 12$ & $10 / 11$ & 11/- & $10 / 12$ & $7 / 9$ & $11 / 12$ & $22 / 24$ & 14/- & $16 /-$ \\
\hline BS/RG/FK 1247 (F7) & $\mathrm{X} /-$ & $15 / 16$ & $17 /-$ & $22 / 25$ & $11 / 13$ & $29 / 32.2$ & $15 / 17$ & $12 /-$ & $8 / 12$ & $8 / 10$ & $11 / 12$ & $8 / 9.3$ & $12 / 13$ & 19/- & 14/- & $16 / 17$ \\
\hline HS/GK 1461 & $X /(Y)$ & $16 /(17)$ & $-/-$ & $-/-$ & $(13) /-$ & $-1-$ & $(12) /(14)$ & $(10) /(11)$ & $11 / 12$ & $9 /(12)$ & & $6 / 9.3$ & 9/11 & $(17) /-$ & 13/- & $-1-$ \\
\hline HS/BS 1467.01 & $X / Y$ & $(18) /-$ & $-1-$ & $-1-$ & $(11) /-$ & $27 /(29)$ & $(13) /-$ & $-1-$ & $(8) / 11$ & & $-1-$ & & $(12) /-$ & $-1-$ & $(16) /-$ & \\
\hline HS/GK/BS 1471 & $X / Y$ & $15 / 16$ & $(16) /(18)$ & $(20) /(24)$ & 8/(14) & $28 / 29$ & $(13) /(20)$ & $12 /-$ & $11 / 13$ & $10 / 12$ & $-1-$ & $9 / 9.3$ & $11 / 12$ & 18/- & $15 / 15.2$ & $16 / 18$ \\
\hline RG/BS/DS 1482 (M3) & $X / Y$ & $16 / 18$ & $17 / 19$ & $21 / 22$ & 13/- & $30.2 / 32.2$ & $15 / 17$ & $11 / 12$ & $12 /-$ & $8 / 11$ & $11 / 13$ & 9.3/- & $12 / 13$ & $18 / 19$ & $14 / 15$ & $16 /(17)$ \\
\hline RG/BS 1500 (F2) & $\mathrm{X} /-$ & $16 / 18$ & $17 / 18$ & $20 / 21$ & $13 / 14$ & $28 / 30$ & $12 / 15$ & $11 / 12$ & $11 / 12$ & $10 / 13$ & $11 / 13$ & $6 / 9.3$ & $11 /-$ & $19 / 25$ & $13 / 14.2$ & $16 / 17$ \\
\hline HS/GK 1547.01 & $\mathrm{X} /-$ & $-1-$ & $-1-$ & 20/- & $-1-$ & $(29) /(31)$ & $(13) /-$ & $(10) / 12$ & $(11) / 12$ & $-1-$ & & 9.3/- & $-1-$ & $-1-$ & $-1-$ & $-1-$ \\
\hline HS/GK 1547.03 & $\mathrm{X} /-$ & $(15) / 16$ & $(15) /(16)$ & $(19) /(20)$ & $(14) /-$ & $(29) /-$ & 20/- & $(10) /-$ & $11 / 13$ & $10 / 12$ & & $9 / 9.3$ & $11 / 12$ & $(25) /-$ & $15 /-$ & $17 / 18$ \\
\hline HS/GK 1548.01 & $X / Y$ & $15 / 16$ & $(15) /(16)$ & $20 / 21$ & $-1-$ & $27 / 28$ & $13 / 14$ & $9 / 10$ & $11 / 13$ & $(8) /(9)$ & & $9.3 /-$ & $12 /-$ & $-1-$ & $(13) /-$ & $-1-$ \\
\hline HS/GK 1585.03 (F19) & $\mathrm{X} /-$ & $15 / 17$ & $14 / 18$ & $20 / 24$ & $12 / 14$ & $30.2 / 31$ & $14 / 15$ & $10 / 12$ & $10 / 11$ & $10 / 11$ & $11 / 13$ & $(6) / 9$ & $12 / 13$ & $(23) /(25)$ & $14 / 15$ & $14 / 16$ \\
\hline $\begin{array}{l}\text { BS/FK/GK/HS } \\
1745.02\end{array}$ & $\mathrm{X} /-$ & 16/- & $16 / 18$ & 21/- & $14 / 15$ & $28 / 29$ & $12 / 14$ & 9/11 & $11 / 12$ & $7 / 10$ & $-/$ & $9.3 /-$ & 11/- & $(17) /(25)$ & $13 / 14.2$ & $16 / 17$ \\
\hline RG/BS 1905 (M9) & $X / Y$ & $16 / 19$ & $14 / 16$ & $21 / 23$ & 13/- & $27 / 32.2$ & $12 / 14$ & $12 /-$ & $11 / 14$ & $10 / 13$ & $10 / 11$ & $6 / 7$ & 13/- & $16 /(25)$ & $13 / 16.2$ & $14 / 17$ \\
\hline BS/FK 2030.01 (M6) & $X / Y$ & $16 /-$ & $17 / 18$ & $21 / 24$ & $10 / 12$ & $29 / 30.2$ & $16 / 18$ & $10 / 13$ & $12 / 13$ & 9/- & $-/-$ & $7 / 9$ & $12 / 14$ & $17 / 19$ & $13 / 16.2$ & 15/- \\
\hline BS 2263 (M15) & $X / Y$ & $(15) / 16$ & $-/-$ & $22 / 24$ & $13 / 14$ & $-/-$ & $16 / 18$ & $12 / 13$ & $(11) / 12$ & $(7) /(8)$ & $-/-$ & $(9.3) /-$ & $-/-$ & $-/-$ & $-/-$ & $-/-$ \\
\hline GK/HS/RG 2588 (F15) & $\mathrm{X} /-$ & $15 / 16$ & $14 / 15$ & $22 / 24$ & 13/- & $28 / 30$ & $13 / 15$ & $11 / 12$ & $11 / 12$ & $10 / 11$ & $-/-$ & $7 / 9.3$ & $8 / 11$ & $17 / 20$ & $13 / 14$ & 16/- \\
\hline KS 3190.11 (F20) & $\mathrm{X} /-$ & 16/- & $16 /-$ & $-1-$ & $-/-$ & $-/-$ & $-/-$ & $-/-$ & $11 / 12$ & $-1-$ & $11 /-$ & & & & & \\
\hline BS 3628 (F3) & $\mathrm{X} /-$ & $15 / 16$ & $16 / 17$ & $20 / 21$ & $13 / 15$ & $30 / 33.2$ & $14 / 15$ & 9/11 & $11 /-$ & $7 / 10$ & 13/- & $7 / 9.3$ & $11 / 13$ & $17 / 19$ & 13/- & 16/- \\
\hline BS 3695 (F4) & $\mathrm{X} /-$ & $15 / 18$ & $14 / 17$ & $20 / 25$ & $11 / 15$ & $29 / 30$ & $14 / 15$ & $12 /-$ & $8 / 11$ & $10 / 12$ & $11 / 12$ & $6 / 8$ & 13/- & $-1-$ & $(13) / 14$ & $(16) /(18)$ \\
\hline BS 3706 (F5/F11) & $\mathrm{X} /-$ & 18/- & $17 / 19$ & $21 / 23$ & $12 / 15$ & $28 / 29$ & 16/- & $12 /-$ & $8 / 9$ & 10/- & $10 / 11$ & 9/9.3 & $12 / 13$ & $24 / 25$ & $13 / 14$ & $15 / 16$ \\
\hline
\end{tabular}


Fortsetzung Tabelle 15: Konsensusgenotypen für die autosomalen STRs.

\begin{tabular}{|c|c|c|c|c|c|c|c|c|c|c|c|c|c|c|c|c|}
\hline Individuum [DO \#] & Amelo & D3S1358 & VWA & FGA & D8S1179 & D21S11 & D18S51 & D5S818 & D13S317 & D7S820 & CSF1PO & TH01 & D16S539 & D2S1338 & D19S433 & D9S1120 \\
\hline BS/FK 3714 & $X / Y$ & $15 / 16$ & 17/- & $21 / 23$ & $10 / 14$ & $27 / 30$ & $13 / 17$ & $11 / 12$ & $11 / 12$ & $8 / 11$ & $-1-$ & $6 / 7$ & $11 / 12$ & $(17) / 25$ & $14 / 16.2$ & $(15) / 17$ \\
\hline BS/FK 3742 (F9) & $X /-$ & $14 / 16$ & $13 / 14$ & $24 /-$ & $11 / 13$ & $29 / 32.2$ & $12 / 15$ & $10 / 13$ & $8 / 10$ & $9 / 10$ & $10 / 12$ & $9.3 /-$ & $11 / 12$ & $20 / 24$ & $13.2 / 15$ & $15 / 17$ \\
\hline BS/RG 3748 (F8) & $\mathrm{X} /-$ & $18 /-$ & $14 / 17$ & $21 / 25$ & $11 / 13$ & $30 / 30.2$ & $15 / 17$ & $12 /-$ & $8 / 12$ & $10 / 11$ & $11 / 13$ & $6 / 9.3$ & $(11) / 12$ & $19 /(26)$ & $14 / 15$ & $16 / 17$ \\
\hline BS 3757 (M8) & $X / Y$ & $17 / 18$ & $17 / 18$ & $21 / 25$ & $10 / 11$ & $24.2 / 30.2$ & $12 / 17$ & $10 / 12$ & $10 / 12$ & $9 / 11$ & $12 / 13$ & $6 / 9.3$ & $(11) /(12)$ & $-/-$ & $(14) /-$ & $(17) /-$ \\
\hline $\begin{array}{l}\text { BS/RG/FK/HS } 3886 \\
\text { (M16) }\end{array}$ & $X / Y$ & $17 / 18$ & $14 / 17$ & $24 / 25$ & $10 / 13$ & $29 / 30.2$ & $12 / 15$ & $10 / 12$ & $8 / 10$ & $8 / 11$ & $11 / 12$ & $6 / 9.3$ & $11 / 12$ & $19 / 20$ & $13 / 14$ & $17 /-$ \\
\hline BS/FK 4008 (M5) & $X / Y$ & $15 / 17$ & $16 / 19$ & $20 / 25$ & $10 / 14$ & $28 / 30$ & $15 / 19$ & $11 / 13$ & $8 / 14$ & $10 / 13$ & $10 / 12$ & $7 / 9.3$ & $12 / 13$ & $16 / 24$ & $13 / 15$ & $16 /-$ \\
\hline BS/GK 4310.01 & $X / Y$ & $-/-$ & $-1-$ & $25 /-$ & $(10) /-$ & $30.2 / 33.2$ & $(10) /-$ & $(11) /(13)$ & $11 /(12)$ & $-1-$ & $-1-$ & $6 / 9.3$ & $-1-$ & $-1-$ & $(13) /-$ & $-1-$ \\
\hline BS 5517 (F6) & $\mathrm{X} /-$ & $16 / 18$ & $17 /-$ & $21 / 25$ & $12 / 13$ & $29 / 32.2$ & $16 / 17$ & $11 / 12$ & $9 / 12$ & $8 / 10$ & $10 / 13$ & 9/9.3 & $12 / 13$ & $19 / 25$ & $14 /-$ & $15 / 17$ \\
\hline JS 7043.01 & $X / Y$ & $15 / 18$ & $15 / 17$ & $21 / 22$ & 13/- & $31.2 /-$ & $15 / 17$ & $12 /-$ & 8/- & $11 /(14)$ & & $6 / 9$ & $11 / 13$ & $24 /(25)$ & $14 / 16$ & $13 / 16$ \\
\hline JS 7075.01 & $\mathrm{X} /-$ & $16 / 18$ & $17 / 18$ & $20 / 22$ & $12 / 13$ & $28 /-$ & $14 / 15$ & $11 / 12$ & $12 / 13$ & $10 / 11$ & & $7 / 9.3$ & $9 / 12$ & $20 / 25$ & 14/18.2 & $13 / 16$ \\
\hline FK/KS E 11 & $X / Y$ & $16 /-$ & $(15) /-$ & $(22) /(25)$ & $-/-$ & $(29) /-$ & $16 /-$ & (13)/- & $-/-$ & - & & 9.3/- & $(11) /(12)$ & - & $(13) /-$ & $-1-$ \\
\hline E 33 (M12) & $X / Y$ & $15 / 18$ & $16 / 18$ & $20 / 21$ & $12 / 13$ & $30 / 33.2$ & $15 / 18$ & $9 / 11$ & $11 /-$ & $9 /(13)$ & $13 /-$ & $7 / 9.3$ & $11 / 13$ & $17 /(25)$ & $13 /-$ & $(16) / 17$ \\
\hline E 37 (F21) & $X / Y$ & $(14) / 16$ & $16 /-$ & $22 / 24$ & $15 /-$ & $(29) /-$ & $-/-$ & $(10) /(11)$ & $8 /(13)$ & $(8) /-$ & $(10) /-$ & 9.3/- & - & $-/-$ & $(15) /-$ & $-/-$ \\
\hline HS/GK N 957.01 & $X /(Y)$ & $-/-$ & $-1-$ & $-/$ & $-/-$ & $-/-$ & $-/$ & $(12) /-$ & $(9) /(10)$ & & $(10) /(13)$ & $(6) /(9.3)$ & $-/-$ & $-/-$ & $(13) /-$ & $-/-$ \\
\hline $\begin{array}{l}\text { BS/FK/RG/HS/GK/KS } \\
\text { N } 962.01\end{array}$ & $\mathrm{X} /-$ & $-1-$ & $-1-$ & $(22) /-$ & $(13) /-$ & $(29) /(32.2)$ & $(14) / 16$ & $(10) / 11$ & $(9) / 13$ & -1 & & $7 /(9.3)$ & & & & \\
\hline RG/FK R 1 (F12) & $\mathrm{X} /-$ & $16 /-$ & $14 / 17$ & $21 /-$ & 13/- & $29 / 33.2$ & $16 / 17$ & $9 / 12$ & $11 / 12$ & $11 / 12$ & $10 / 11$ & 9.3/- & $11 / 12$ & $19 / 21$ & $15 /-$ & $16 /-$ \\
\hline
\end{tabular}




\title{
4.5.2 Gonosomale STRs
}

In dieser Arbeit wurden für 21 Individuen Analysen Y-chromosomaler STRs durchgeführt. Bei zwei Individuen mit unsicheren Ergebnissen bezüglich des Amelogenin-Markers (DO RG 66.02 und DO FK/RG/HS/BS 903.02), bei denen jedoch vermutet wurde, dass es sich um weibliche Individuen handelt, dienten die Analysen als Prüfinstrument, ob dies tatsächlich der Fall war. Für beide Individuen wurden keine Ychromosomalen Marker amplifiziert, was die Eingangsvermutung unterstützt.

Insgesamt blieb der Amplifikationserfolg leicht hinter dem der autosomalen STRs zurück. Allerdings zeigte sich auch bei der Amplifikation Y-chromosomaler STRs probenabhängig ein sehr variabler Amplifikationserfolg. So ist z.B. im Agarosegelfoto in Abb. 75 eine Probe mit nahezu perfekten Ergebnissen (DO 5403) zu sehen, einige Proben mit mittelmäßigem (z.B. DO E 11) und eine Reihe von Proben mit sehr schlechtem (z.B. DO 1461) Amplifikationserfolg.

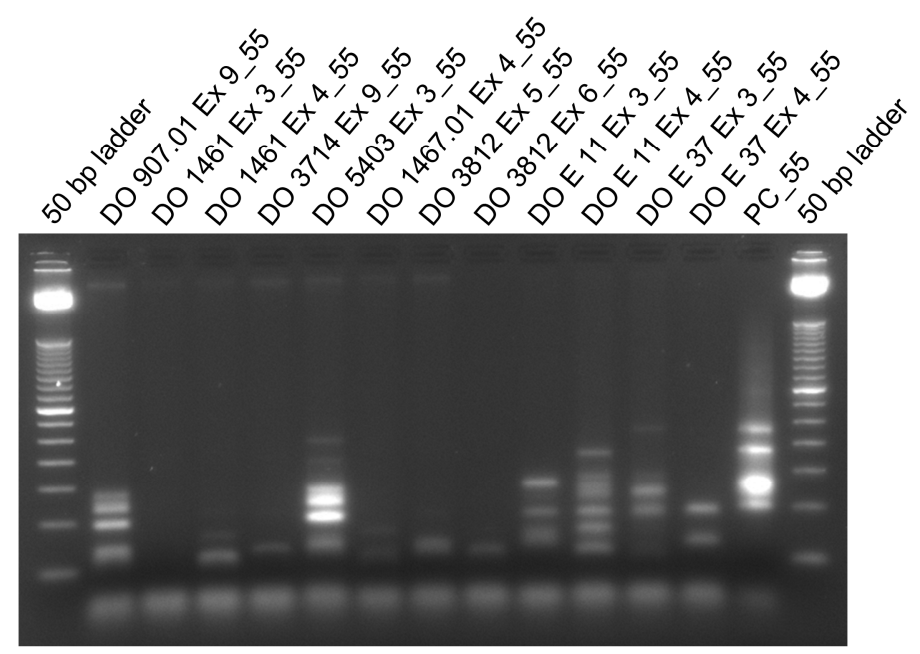

\begin{abstract}
Abb. 75: Agarosegelfoto einer Amplifikation mit dem Y-Dekaplex Kit (PCR 55) zur Analyse Ychromosomaler STRs mit sehr variablem Amplifikationserfolg. $50 \mathrm{bp}$ ladder $=$ Längenstandard, $\mathrm{PC}=$ positive control.
\end{abstract}

Insgesamt konnte - unter Berücksichtigung aller Ergebnisse aus dieser und vorhergehenden Arbeiten - für 13 der 29 männlichen Individuen ein vollständiger YHaplotyp generiert werden. Für 2 Individuen ist der Typisierungserfolg mit $90 \%$ erfolgreich typisierten Y-chromosomalen STR-Systemen immer noch als recht gut einzustufen, für 5 Individuen mit 54-72\% als mittelgut und für 6 Individuen mit lediglich 27-45 \% als eher schlecht. Für zwei männliche Individuen konnte kein einziges Y-chromosomales STR-System amplifiziert werden.

In Tabelle 16 sind die genetischen Typisierungsergebnisse Y-chromosomaler STRs für die Individuen aus der Lichtensteinhöhle tabellarisch zusammengefasst. Auch hier 
handelt es sich um Konsensusgenotypen. Die Einzeltypisierungsergebnisse finden sich auf der beigefügten CD (Lichtensteinhöhle Einzeltypisierungen Y-chromosomale STRs und $m t D N A . x l s)$.

Auf Basis der Ergebnisse für die Y-chromosomalen STRs konnte für 20 Individuen ein eindeutiger Haplotyp bestimmt werden (siehe Tabelle 17). Bei zwei Individuen (DO FK/RG/BS 907.01 und DO E 37 (F21)) war es nicht ganz sicher, ob sie zur Gruppe der Individuen mit dem Haplotypen Y1 oder zu der mit dem Haplotypen Y6 gehören. Diese beiden Haplotypen unterscheiden sich nur in einem einzigen STR-System, welches bei diesen beiden Individuen nicht sicher bestimmt werden konnte. Für 7 Individuen waren die Ergebnisse nicht ausreichend, um einen eindeutigen Haplotyp zu definieren. 
Tabelle 16: Konsensushaplotypen für die Y-chromosomalen STRs.

\begin{tabular}{|c|c|c|c|c|c|c|c|c|c|c|c|c|c|}
\hline Individuum [DO \#] & Amelo & DYS19 & DYS385 & DYS389 I & DYS389 II & DYS390 & DYS391 & DYS392 & DYS393 & DYS437 & DYS438 & DYS439 & Y-Haplotyp \\
\hline FK/HS/RG 35 (M4) & $X / Y$ & 16 & $13-17$ & 12 & 28 & 24 & 11 & 11 & 13 & 15 & 10 & 11 & Y 6 \\
\hline FK/RG/BS 38 (F1) & $\mathrm{X} /-$ & & & & & & & & & & & & 우 \\
\hline RG/FK 57.02 (M17/M19) & $X / Y$ & (16) & 13-17 & 12 & 28 & 24 & 11 & 11 & 13 & 15 & 10 & 11 & Y 6 \\
\hline RG/FK 58.01 & $\mathrm{X} /-$ & & & & & & & & & & & & 우 \\
\hline RG/FK 58.03 (M13) & $X / Y$ & 16 & 13-17 & 12 & 28 & 25 & 11 & 11 & 13 & 15 & 10 & 11 & Y 1 \\
\hline RG/FK/KS 58.08 (M7) & $X / Y$ & 16 & 13-17 & 12 & 28 & 25 & 11 & 11 & 13 & 15 & 10 & 11 & Y1 \\
\hline RG/HS/BS 65.05 & $\mathrm{X} /-$ & & & & & & & & & & & & 우 \\
\hline RG 66.02 & $\mathrm{X} /-$ & & & & & & & & & & & & 우 \\
\hline RG/FK 67.03 (F10/F17) & $\mathrm{X} /-$ & & & & & & & & & & & & 우 \\
\hline BS 133.01 & $X / Y$ & - & $-\cdots$ & - & - & - & - & - & - & - & - & (11) & n.d. \\
\hline RG/GK/BS 183.01 (M11) & $X / Y$ & (15) & - - - & (13) & - & - & 11 & 11 & 13 & (15) & 11 & 11 & Y 7 \\
\hline RG/BS 187 & $\mathrm{X} /-$ & & & & & & & & & & & & 우 \\
\hline RG/FK/BS 516 & $\mathrm{X} /-$ & & & & & & & & & & & & 우 \\
\hline FK/RG/HS/BS 901.01 (M18/F16) & $\mathrm{X} /-$ & & & & & & & & & & & & 우 \\
\hline FK/RG/HS 902.01 (M10) & $X / Y$ & 15 & $11-(13)$ & 13 & 30 & 25 & 11 & 11 & 13 & 14 & 11 & 11 & Y 5 \\
\hline FK/HS/RG/BS 903.01 & $\mathrm{X} /-$ & & & & & & & & & & & & 우 \\
\hline FK/RG/HS/BS 903.02 & $\mathrm{X} /-$ & & & & & & & & & & & & 우 \\
\hline FK/RG/JS 904.04 & $-/-$ & & & & & & & & & & & & \\
\hline FK/RG 905.01 (M14) & $X / Y$ & 15 & (13)- - & 12 & - & 25 & 11 & 11 & 13 & 14 & 10 & 11 & Y 8 \\
\hline FK/RG/BS 907.01 & $X / Y$ & 16 & 13-17 & 12 & - & - & 11 & 11 & 13 & - & 10 & 11 & Y 1 o. Y 6 \\
\hline RG/FK 1076 (M1) & $X / Y$ & 16 & 13-17 & 12 & 28 & 25 & 11 & 11 & 13 & 15 & 10 & 11 & Y1 \\
\hline RG/FK/BS 1078 (F13) & $\mathrm{X} /-$ & & & & & & & & & & & & 우 \\
\hline BS 1102 (M2) & $X / Y$ & 16 & 13- - & 12 & 28 & 25 & 11 & - & 13 & 15 & 10 & 11 & Y 1 \\
\hline BS/RG 1103 (F14) & $\mathrm{X} /-$ & & & & & & & & & & & & 우 \\
\hline
\end{tabular}


Fortsetzung Tabelle 16: Konsensushaplotypen für die Y-chromosomalen STRs.

\begin{tabular}{|c|c|c|c|c|c|c|c|c|c|c|c|c|c|}
\hline Individuum [DO \#] & Amelo & DYS19 & DYS385 & DYS389 I & DYS389 II & DYS390 & DYS391 & DYS392 & DYS393 & DYS437 & DYS438 & DYS439 & Y-Haplotyp \\
\hline BS/RG 1176 (F18) & $\mathrm{X} /-$ & & & & & & & & & & & & 우 \\
\hline BS/RG/FK 1247 (F7) & $\mathrm{X} /-$ & & & & & & & & & & & & 우 \\
\hline HS/GK 1461 & $X /(Y)$ & - & (15)- - & - & - & - & (9) & (14) & - & - & (11) & - & n.d. \\
\hline HS/BS 1467.01 & $X / Y$ & - & -- & - & - & - & - & - & - & - & - & - & n.d. \\
\hline HS/GK/BS 1471 & $X / Y$ & (14) & (13)-14 & - & (29) & - & (10) & - & 13 & - & 12 & - & Y 10 \\
\hline RG/BS/DS 1482 (M3) & $X / Y$ & 15 & 13-17 & 12 & 27 & 25 & 11 & 11 & 13 & 15 & 10 & 11 & Y 2 \\
\hline RG/BS 1500 (F2) & $\mathrm{X} /-$ & & & & & & & & & & & & 우 \\
\hline HS/GK 1547.01 & $\mathrm{X} /-$ & & & & & & & & & & & & 우 \\
\hline HS/GK 1547.03 & $\mathrm{X} /-$ & & & & & & & & & & & & 우 \\
\hline HS/GK 1548.01 & $X / Y$ & - & $(17)--$ & 12 & - & - & 9 & - & $13-15$ & - & - & (11) & Y 9 \\
\hline HS/GK 1585.03 (F19) & $\mathrm{X} /-$ & & & & & & & & & & & & 우 \\
\hline BS/FK/GK/HS 1745.02 & $\mathrm{X} /-$ & & & & & & & & & & & & 우 \\
\hline RG/BS 1905 (M9) & $X / Y$ & 14 & $11-14$ & 13 & 29 & 23 & 11 & 13 & 13 & 15 & 12 & 12 & Y 3 \\
\hline BS/FK 2030.01 (M6) & $X / Y$ & 15 & $13-17$ & 12 & 27 & 25 & 11 & 11 & 13 & 15 & 10 & 11 & Y 2 \\
\hline BS 2263 (M15) & $X / Y$ & - & --- & (13) & (29) & - & (11) & - & - & - & - & (13) & Y 11 \\
\hline GK/HS/RG 2588 (F15) & $\mathrm{X} /-$ & & & & & & & & & & & & 우 \\
\hline KS 3190.11 (F20) & X/- & & & & & & & & & & & & 우 \\
\hline BS 3628 (F3) & $X /-$ & & & & & & & & & & & & 우 \\
\hline BS 3695 (F4) & X/- & & & & & & & & & & & & 우 \\
\hline BS 3706 (F5/F11) & $\mathrm{X} /-$ & & & & & & & & & & & & 우 \\
\hline BS/FK 3714 & $X / Y$ & (14) & -- & 12 & - & - & - & - & - & - & 10 & - & n.d. \\
\hline BS/FK 3742 (F9) & $\mathrm{X} /-$ & & & & & & & & & & & & 우 \\
\hline BS/RG 3748 (F8) & $\mathrm{X} /-$ & & & & & & & & & & & & 우 \\
\hline BS 3757 (M8) & $X / Y$ & 16 & $13-17$ & 12 & 28 & 25 & 11 & 11 & 13 & 15 & 10 & 11 & Y 1 \\
\hline
\end{tabular}


Fortsetzung Tabelle 16: Konsensushaplotypen für die Y-chromosomalen STRs.

\begin{tabular}{|c|c|c|c|c|c|c|c|c|c|c|c|c|c|}
\hline Individuum [DO \#] & Amelo & DYS19 & DYS385 & DYS389 I & DYS389 II & DYS390 & DYS391 & DYS392 & DYS393 & DYS437 & DYS438 & DYS439 & Y-Haplotyp \\
\hline BS/RG/FK/HS 3886 (M16) & $X / Y$ & (16) & $13-17$ & 12 & 28 & 25 & 11 & 11 & 13 & 15 & 10 & 11 & Y 1 \\
\hline BS/FK 4008 (M5) & $X / Y$ & 16 & $13-17$ & 12 & 28 & 24 & 11 & 11 & 13 & 15 & 10 & 11 & Y 6 \\
\hline BS/GK 4310.01 & $X / Y$ & - & -- & 12 & - & - & - & (9) & - & - & (10) & (11) & n.d. \\
\hline BS 5517 (F6) & $\mathrm{XI}-$ & & & & & & & & & & & & 우 \\
\hline JS 7043.01 & $X / Y$ & 16 & $13-17$ & 12 & 28 & 25 & 11 & 11 & 13 & 15 & 10 & 11 & Y 1 \\
\hline JS 7075.01 & $\mathrm{X} /-$ & & & & & & & & & & & & 우 \\
\hline FK/KS E 11 & $X / Y$ & - & -- & 12 & - & - & (11) & 11 & - & - & - & 11 & n.d. \\
\hline E 33 (M12) & $X / Y$ & 17 & (13)-(17) & 12 & (28) & - & 11 & - & - & - & 10 & 11 & Y 4 \\
\hline E 37 (F21) & $X / Y$ & (16) & 17- - & - & - & - & (11) & 11 & (13) & - & 10 & 11 & Y 1 o. Y 6 \\
\hline HS/GK N 957.01 & $\mathrm{X} /(\mathrm{Y})$ & & & & & & & & & & & & \\
\hline BS/FK/RG/HS/GK/KS N 962.01 & $\mathrm{X} /-$ & & & & & & & & & & & & 우 \\
\hline RG/FK R 1 (F12) & $\mathrm{X} /-$ & & & & & & & & & & & & 우 \\
\hline
\end{tabular}


Für jeden Y-Haplotyp wurde mittels des online nutzbaren haplogroup predictors (http://www.hprg.com/hapest5/, Athey 2006), welcher auf Basis der Allelfrequenzen der Y-chromosomalen STRs die wahrscheinlichste Y-chromosomale Haplogruppe berechnet, die jeweilige Haplogruppe bestimmt (siehe Tabelle 17).

Tabelle 17: Übersicht über die Y-Haplotypenzugehörigkeit und die abgeleiteten Y-Haplogruppen

\begin{tabular}{|c|c|c|}
\hline Haplotyp & Individuen [DO \#] & $\begin{array}{l}\text { Haplogruppe } \\
\text { (\% Wahrscheinlichkeit) }\end{array}$ \\
\hline \multirow{7}{*}{ Y 1} & RG/FK 58.03 (M13) & $12 \mathrm{~b}(100)$ \\
\hline & RG/FK/KS 58.08 (M7) & $12 \mathrm{~b}(100)$ \\
\hline & RG/FK 1076 (M1) & $12 \mathrm{~b}(100)$ \\
\hline & BS 1102 (M2) & $\mathrm{I} 2 \mathrm{~b}(100)$ \\
\hline & BS 3757 (M8) & $\mathrm{I} 2 \mathrm{~b}(100)$ \\
\hline & BS/RG/FK/HS 3886 (M16) & $\mathrm{I} 2 \mathrm{~b}(100)$ \\
\hline & JS 7043.01 & $12 \mathrm{~b}(100)$ \\
\hline \multirow{2}{*}{ Y 2} & RG/BS/DS 1482 (M3) & $\mathrm{I} 2 \mathrm{~b}(100)$ \\
\hline & BS/FK 2030.01 (M6) & $12 \mathrm{~b}(100)$ \\
\hline Y 3 & RG/BS 1905 (M9) & $\mathrm{R} 1 \mathrm{~b}(100)$ \\
\hline Y 4 & E 33 (M12) & I2b $(99,9)$ \\
\hline Y 5 & FK/RG/HS 902.01 (M10) & $\mathrm{R} 1 \mathrm{a}(100)$ \\
\hline \multirow{3}{*}{ Y 6} & FK/HS/RG 35 (M4) & $\mathrm{I} 2 \mathrm{~b}(100)$ \\
\hline & RG/FK 57.02 (M17/M19) & $\mathrm{I} 2 \mathrm{~b}(100)$ \\
\hline & BS/FK 4008 (M5) & $\mathrm{I} 2 \mathrm{~b}(100)$ \\
\hline Y 7 & RG/GK/BS 183.01 (M11) & n.d. \\
\hline Y 8 & FK/RG 905.01 (M14) & I2b $(97,8)$ \\
\hline Y 9 & HS/GK 1548.01 & n.d. \\
\hline Y 10 & HS/GK/BS 1471 & n.d. \\
\hline Y 11 & BS 2263 (M15) & n.d. \\
\hline \multirow{2}{*}{ Y 1 o. Y 6} & FK/RG/BS 907.01 & $\mathrm{I} 2 \mathrm{~b}(99.9)$ \\
\hline & E 37 (F21) & n.d. \\
\hline \multirow{7}{*}{ n.d. } & BS 133.01 & n.d. \\
\hline & HS/GK 1461 & n.d. \\
\hline & HS/BS 1467.01 & n.d. \\
\hline & BS/FK 3714 & n.d. \\
\hline & BS/GK 4310.01 & n.d. \\
\hline & FK/KS E 11 & n.d. \\
\hline & HS/GK N 957.01 & n.d. \\
\hline
\end{tabular}


Für einige Knochen, bei denen aufgrund einzelner Nachweise eines Y-chromosomalen Signals des Amelogenin-Markers in Kombination mit überwiegend auf ein weibliches Individuum hinweisenden Ergebnissen, die molekulargenetische Geschlechtszuordnung nicht ganz eindeutig war, wurden Amplifikationen mit einem PCR System vorgenommen, welches sowohl Y-chromosomale als auch X-chromosomale STRs amplifiziert (sogenannte SexMultiplex). Mit Hilfe dieser Amplifikationen konnte über heterozygote Ergebnisse für die X-chromosomalen Marker die Diagnose „weiblich“ in fünf Fällen eindeutig bestätigt werden. Bei den aufgetretenen Y-chromosomalen Signalen für den Amelogenin-Marker muss es sich also um Produkte aus Minimalkontaminationen durch vorherige, männliche Bearbeiter oder aus den Reaktionsgefäßen handeln. Die Ergebnisse der Amplifikationen mit dem SexMultiplex Kit finden sich in Tabelle 18. Aus einer vorhergehenden Arbeit (Schmidt 2004) liegen zudem Ergebnisse für weitere X-chromosomale STRs vor, welche in Tabelle 19 aufgeführt sind.

Tabelle 18: Ergebnisse der Amplifikationen gonosomaler STRs mit dem SexMultiplex Kit.

\begin{tabular}{|c|c|c|c|c|c|c|c|c|c|}
\hline $\begin{array}{l}\text { Individuum } \\
\text { [DO \#] }\end{array}$ & Fund $\mathrm{Nr}$. & Element & Extrakt & PCR & Amelo & $\begin{array}{l}\text { DYS } \\
391\end{array}$ & $\begin{array}{l}\text { DYS } \\
392\end{array}$ & $\begin{array}{l}\text { DXS } \\
6789\end{array}$ & $\begin{array}{l}\text { DXS } \\
9898\end{array}$ \\
\hline \multirow{4}{*}{$\begin{array}{l}\text { FK/RG/HS/BS } \\
901.01 \\
\text { (M18/F16) }\end{array}$} & DO 914.01 & Hu re & Ex 4 & VSE 25 & $\mathrm{X} /-$ & - & - & $-/$ & $11 / 13$ \\
\hline & DOR 2 & Calv & $\mathrm{b} / \mathrm{Ex} \mathrm{IVa} / \mathrm{Ex} \mathrm{IVb}$ & VSE 25 & $\mathrm{X} /-$ & - & - & 19/- & $11 / 13$ \\
\hline & DOR 2 & Calv & Ex IVb/Ex 2 & VSE 25 & $\mathrm{X} /-$ & - & - & $-1-$ & $11 / 13$ \\
\hline & Konsensus & & & & $x / X$ & - & - & $(19) /-$ & $11 / 13$ \\
\hline \multirow{4}{*}{$\begin{array}{l}\text { RG/FK/BS } \\
1078 \text { (F13) }\end{array}$} & DO 204.01 & Hu re & Ex 2 & VSE 25 & $\mathrm{X} /-$ & - & - & 20/- & $8.3 / 11$ \\
\hline & DO 1044 & Fe li & ExII & VSE 25 & $\mathrm{X} /-$ & - & - & $-1-$ & $8.3 / 11$ \\
\hline & DO 1078 & Mand & Ex 2 & VSE 25 & $X /-$ & - & - & $20 / 21$ & $8.3 / 11$ \\
\hline & Konsensus & & & & $x / X$ & - & - & $20 /(21)$ & $8.3 / 11$ \\
\hline \multirow{3}{*}{ HS/GK 1461} & DO 1461 & Ra li & Ex 3 & VSE 50 & X/- & - & - & $-1-$ & $8.3 /-$ \\
\hline & DO 1461 & Ra li & Ex 4 & VSE 50 & $\mathrm{X} /-$ & - & - & $-1-$ & $-1-$ \\
\hline & Konsensus & & & & $\mathrm{X} /-$ & - & - & $-1-$ & $(8.3) /-$ \\
\hline \multirow{3}{*}{$\begin{array}{l}\text { BS/FK/GK/HS } \\
1745.02\end{array}$} & DO 3622 & Fe li & Ex 3 & VSE 50 & $\mathrm{X} /-$ & - & - & $21 /-$ & $12 /-$ \\
\hline & DO 3622 & Feli & Ex 4 & VSE 50 & $X /-$ & - & - & $21 / 23$ & $8.3 /-$ \\
\hline & Konsensus & & & & $X / X$ & - & - & $21 /(23)$ & $(8.3) /(12)$ \\
\hline BS/FK 3714 & DO 3714 & Hu li & Ex 9 & VSE 50 & $\mathrm{X} /-$ & - & - & $24 /-$ & $8.3 /-$ \\
\hline \multirow{3}{*}{$\begin{array}{l}\text { BS/FK } 3742 \\
\text { (F9) }\end{array}$} & DO 3742 & Fe li & $\mathrm{A} / \mathrm{E} \times 1$ & VSE 25 & $\mathrm{X} /-$ & - & - & $20 / 21$ & $8.3 / 13$ \\
\hline & DO 3746 & Mand & Ex I/Ex III & VSE 25 & $\mathrm{X} /-$ & - & (13) & 20/- & $(8.3) / 13$ \\
\hline & Konsensus & & & & $x / X$ & - & - & $20 /(21)$ & $8.3 / 13$ \\
\hline \multirow{3}{*}{$\begin{array}{l}\text { RG/FK R } 1 \\
\text { (F12) }\end{array}$} & DO 67.02 & Fe re & Ex 8 & & $X /-$ & - & - & 20/- & $-1-$ \\
\hline & DO 67.02 & Fe re & Ex 8 & VSE 64a & $\mathrm{X} /-$ & - & - & $(20) /-$ & $11 / 12$ \\
\hline & Konsensus & & & VSE 64b & $X / X$ & - & - & $20 /-$ & $(11) /(12)$ \\
\hline
\end{tabular}


Tabelle 19: Konsensusgenotypen für X-chromosomale STRs (aus Schmidt 2004).

\begin{tabular}{|c|c|c|c|c|c|c|c|c|c|}
\hline $\begin{array}{l}\text { Individuum } \\
\text { [DO \#] }\end{array}$ & Fund Nr. & Element & $\begin{array}{l}\text { DXS } \\
7424\end{array}$ & $\begin{array}{c}\text { GATA } \\
\text { 172D05 }\end{array}$ & $\begin{array}{l}\text { DXS } \\
9898\end{array}$ & $\begin{array}{l}\text { DXS } \\
6800\end{array}$ & $\begin{array}{l}\text { DXS } \\
6789\end{array}$ & $\begin{array}{l}\text { DXS } \\
101\end{array}$ & Bearbeiter \\
\hline FK/RG/BS 38 (F1) & DO 26 & Fe li & $15 / 16$ & $5 / 9$ & $8.3 / 11$ & $16 / 17$ & $15 / 21$ & $19 / 23$ & Schmidt \\
\hline $\begin{array}{l}\text { RG/FK } 58.03 \\
\text { (M13) }\end{array}$ & DO 58.03 & Fe li & 15 & 10 & 13 & 16 & 21 & 24 & Schmidt \\
\hline $\begin{array}{l}\text { RG/GK/BS } 183.01 \\
\text { (M11) }\end{array}$ & DO 183.01 & Fe li & 14 & (5) & (13) & 15 & 20 & - & Schmidt \\
\hline $\begin{array}{l}\text { FK/RG/HS } 902.01 \\
\text { (M10) }\end{array}$ & DO 902.01 & Fe li & 16 & 5 & 11 & 18 & 20 & 23 & Schmidt \\
\hline FK/RG/BS 907.01 & DO 907.01 & Fe li & - & - & 12 & 15 & - & 19 & Schmidt \\
\hline RG/FK 1076 (M1) & DO 1076 & Fe li & 16 & 9 & 8.3 & (18) & 24 & (25) & Schmidt \\
\hline $\begin{array}{l}\text { RG/FK/BS } 1078 \\
\text { (F13) }\end{array}$ & DO 1044 & Fe li & $13 / 17$ & $7 / 9$ & $8.3 / 11$ & $15 / 20$ & $20 / 21$ & $23 / 25$ & Schmidt \\
\hline BS 1102 (M2) & DO 1102 & Fe li & 16 & 9 & 8.3 & 17 & 21 & 19 & Schmidt \\
\hline BS/RG 1103 (F14) & DO 1103 & Fe li & $15 /-$ & $-1-$ & $12 / 13$ & $18 / 18$ & $20 /(20)$ & $(24) / 28$ & Schmidt \\
\hline $\begin{array}{l}\text { BS/RG/FK } 1247 \\
\text { (F7) }\end{array}$ & DO 1206.01 & Fe li & $14 / 16$ & $9 / 11$ & $11 / 12$ & $(15) / 18$ & $20 /(20)$ & $24 /-$ & Schmidt \\
\hline $\begin{array}{l}\text { RG/BS/DS } 1482 \\
\text { (M3) }\end{array}$ & DO 1911 & Fe li & 16 & 9 & 12 & 15 & 20 & 25 & Schmidt \\
\hline RG/BS 1500 (F2) & DO 1500 & Fe li & $14 / 15$ & $7 / 10$ & $12 / 14$ & $15 /-$ & $15 / 23$ & $24 /(24)$ & Schmidt \\
\hline $\begin{array}{l}\text { HS/GK } 1585.03 \\
\text { (F19) }\end{array}$ & DO 1585.07 & Fe li & $(15) / 17$ & $7 /(7)$ & 8.3/- & $15 /-$ & $-/-$ & $-/-$ & Schmidt \\
\hline $\begin{array}{l}\text { BS/FK } 2030.01 \\
\text { (M6) }\end{array}$ & DO 2030.01 & Fe li & 15 & 10 & 8.3 & 15 & 21 & 24 & Schmidt \\
\hline $\begin{array}{l}\text { GK/HS/RG } 2588 \\
\text { (F15) }\end{array}$ & DO 2589 & Mand & $16 / 19$ & $9 / 10$ & $8.3 / 8.3$ & $15 / 18$ & $20 / 21$ & $20 / 24$ & Schmidt \\
\hline BS 3628 (F3) & DO 2388 & Mand & $14 / 16$ & $5 / 9 / 10$ & $8.3 / 12$ & $17 / 20$ & $21 / 23$ & $19 / 24$ & Schmidt \\
\hline BS 3706 (F5/F11) & DO 3756 & Fe li & $11 / 15$ & $10 / 11$ & $8.3 / 14$ & $19 / 20$ & $20 / 22$ & $18 / 24$ & Schmidt \\
\hline BS/FK 3742 (F9) & DO 3742 & Fe li & $13 / 15$ & $7 / 10$ & $8.3 / 13$ & $15 /-$ & $20 / 21$ & $27 /-$ & Schmidt \\
\hline BS 5517 (F6) & DO 3750 & Fe li & $15 / 16$ & 9/- & $12 / 14$ & $15 / 19$ & $20 / 22$ & $18 / 25$ & Schmidt \\
\hline RG/FK R 1 (F12) & DO R 1 & Calv & $13 / 16$ & $9 / 10$ & $11 / 12$ & $15 / 20$ & $20 / 20$ & $20 / 25$ & Schmidt \\
\hline
\end{tabular}




\subsubsection{Mitochondriale HVR I und HVR II}

In dieser Arbeit konnte für 33 Individuen ein Abschnitt der mitochondrialen HVR I und für 27 Individuen ein Abschnitt der mitochondrialen HVR II amplifiziert und sequenziert werden. Der Amplifikationserfolg ist insgesamt als sehr gut einzuordnen. In der Regel konnten große Produktmengen generiert werden, lediglich für einen kleinen Teil der Proben waren die Signale etwas schwächer oder blieben unter der Nachweisgrenze (siehe Agarosegelfoto Abb. 76).

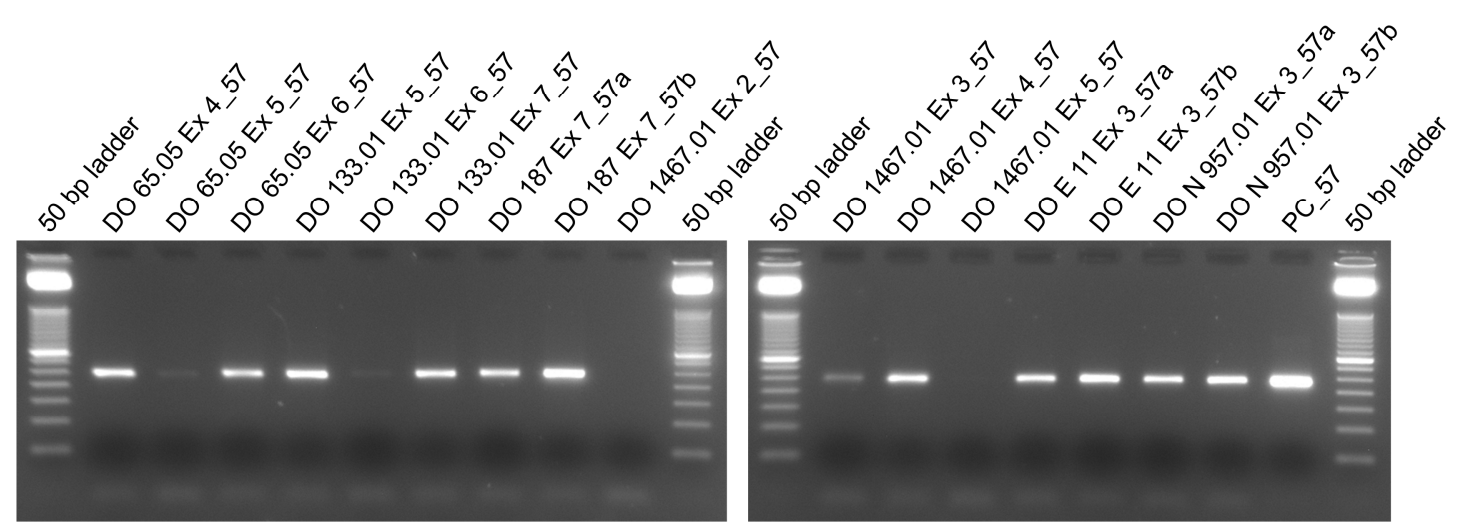

Abb. 76: Agarosegelfoto einer Amplifikation der mitochondrialen HVR I (PCR 57) mit überwiegend sehr gutem Amplifikationserfolg. $50 \mathrm{bp}$ ladder $=$ Längenstandard, $\mathrm{PC}=$ positive control.

Wie nach den Fotos der Agarosegele $\mathrm{zu}$ erwarten war, brachte die SangerSequenzierung zumeist saubere, gut lesbare Sequenzen. Nur in wenigen Fällen wurden an einzelnen Basenpositionen Doppelausprägungen von $\mathrm{C}$ und $\mathrm{T}$ ( $=\mathrm{Y}$ nach dem IUB Code) oder $\mathrm{A}$ und $\mathrm{G}$ (= $\mathrm{R}$ nach dem IUB Code $)$ detektiert. Da diese Doppelausprägungen nicht systematisch an immer derselben Stelle in jeder Amplifikation für einen bestimmten Knochen vorkamen, sondern sporadisch an verschiedenen Basenpositionen auftraten, handelt es sich hierbei vermutlich um keine echten Heteroplasmien, sondern um Degradierungsartefakte aufgrund von Desaminierungen. Alternativ könnten die Doppelausprägungen auch auf Coamplifikationen von Minimalkontamination aus den Reaktionsgefäßen zurückzuführen sein.

Insgesamt konnte - unter Berücksichtigung aller Ergebnisse aus dieser und vorhergehenden Arbeiten - für 59 der 60 Individuen der mitochondriale Haplotyp bestimmt werden. Nur bei der Probe des Individuums DO HS/BS 1467.01 war die 
Degradierung der DNA so weit fortgeschritten, dass keine sauberen Sequenzen generiert werden konnten und der Haplotyp nicht bestimmt werden konnte.

Mit Hilfe des online verfügbaren mtDNA-Baumes (PhyloTree, http://www.phylotree.org, rCRS-oriented version of Build 17, van Oven und Kayser 2009) und eines darauf basierenden, online verfügbaren Programms zur automatischen Klassifizierung von mt-Haplogruppen (https://haplogrep.uibk.ac.at/) wurde für jeden ermittelten Haplotyp die Haplogruppenzugehörigkeit bestimmt. Dies war für 58 der 59 erfolgreich typisierten Individuen eindeutig möglich. Lediglich für das Individuum FK/RG/JS 904.04 konnte nicht genau determiniert werden, ob der ermittelte Haplotyp in die Haplogruppe H3d oder in die Haplogruppe H4alal einzuordnen ist.

In Tabelle 20 sind die genetischen Typisierungsergebnisse der Sequenzierung der untersuchten Abschnitte der HVR I und HVR II für die Individuen aus der Lichtensteinhöhle tabellarisch zusammengefasst. Auch hier handelt es sich um Konsensushaplotypen. Die Einzeltypisierungsergebnisse finden sich auf der beigefügten CD (Lichtensteinhöhle Einzeltypisierungen Y-chromosomale STRs und mtDNA.xls). In Tabelle 21 findet sich eine Übersicht der jeweiligen Haplogruppenzugehörigkeit. Da in der Arbeit von Schilz (2006) die Haplogruppenzugehörigkeit noch nicht so detailliert bestimmt werden konnte und daher dort noch teilweise andere Haplogruppennamen verwendet wurden, sind diese dort mit aufgeführt. 
Tabelle 20: Konsensushaplotypen für die mitochondrialen HVRs.

\begin{tabular}{|c|c|c|c|c|c|c|c|c|c|c|c|c|c|c|c|c|c|c|c|c|c|c|c|c|c|c|c|c|c|c|c|c|c|c|c|c|c|c|c|c|c|c|c|c|c|c|c|c|c|}
\hline Indi & 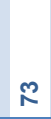 & ๓ & \& & เి & ูู & w & & $\stackrel{8}{\stackrel{2}{2}}$ & $\bar{\sim}$ & & ্ָ & มี & ֻ & ๙̊ำ & वें & กั่ & $\frac{\bar{n}}{m}$ & & 동 & & & & & & & & 趈 & $\begin{array}{l}0 \\
0 \\
0\end{array}$ & : & $\frac{\infty}{0}$ & $\frac{\sigma}{0}$ & : & స్ํ & 웡 & & : & & డั่ & ণิ & & స్ํำ & ஜֶ. & $\stackrel{8}{\circ}$ & ஜ્ఠ & గ & $\begin{array}{l}\text { 苞 } \\
\stackrel{0}{0}\end{array}$ & & 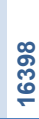 & $\begin{array}{l}\text { mt- } \\
\text { Haplo- } \\
\text { gruppe }\end{array}$ \\
\hline rCRS & $A$ & A & $\bar{T}$ & C & $\bar{T}$ & G & 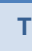 & $T$ & A & G & $\bar{T}$ & c & $A$ & $\mathrm{C}$ & - & - & - & G & A & c & c & A & $A$ & $T$ & G & $T$ & $\overline{G A}$ & $\bar{A} T$ & $T A$ & $T$ & c & $T$ & C & $T$ & $\mathrm{C}$ & C & C & C & C & $\mathrm{C}$ & A & G & $T$ & $T$ & $A$ & C & $\bar{T}$ & G & \\
\hline FK/HS/RG 35 (M4) & - & - & - & - & - & - & - & - & - & - & - & - & G & - & - & - & C & & & & - & - & • & - & - & - & $\cdot$. & - $\cdot$ & - $\cdot$ & - & - & - & - & • & - & - & - & - & • & - & - & - & 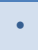 & & & & & & $\mathrm{H} \# 5$ \\
\hline FK/RG/BS 38 (F1) & $\cdot$ & - & - & • & C & - & - & - & - & - & - & • & G & • & • & • & C & & - & - & • & • & • & - & - & • & - & • $\cdot$ & $\cdot \cdot$ & • & • & - & - & • & • & - & $\cdot$ & • & • & • & • & $\cdot$ & 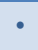 & & & & & & $\mathrm{H} \# 1$ \\
\hline RG/FK 57.02 (M17 & • & - & - & - & - & • & - & - & - & - & C & • & G & - & - & - & C & & & & - & - & • & - & - & - & - $\cdot$ & - $\cdot$ & • $\cdot$ & - & - & - & - & - & • & - & - & - & - & $\cdot$ & - & $\cdot$ & - & - & - & $\cdot$ & - & - & H6 \#1 \\
\hline RG/FK 58.01 & $\cdot$ & • & • & • & • & - & • & - & - & • & • & $\cdot$ & G & - & - & • & C & - & • & - & - & $\cdot$ & • & - & $\cdot$ & - & - & • $\cdot$ & $\cdot \cdot$ & • & - & • & • & • & • & - & - & • & • & • & • & $\cdot$ & $\cdot$ & • & $\cdot$ & $\cdot$ & • & • & $\mathrm{H} \# 5$ \\
\hline RG/FK 58.03 (M13) & G & $\cdot$ & • & - & • & • & - & - & • & $\cdot$ & - & $\cdot$ & G & - & $\cdot$ & - & C & - & - & - & $\cdot$ & - & • & c & - & - & - $\cdot$ & - $\cdot$ & • $\cdot$ & - & - & - & • & • & • & • & • & - & $\mathrm{T}$ & $T$ & - & • & - & - & • & $\cdot$ & - & - & T2 \\
\hline RG/FK/KS 58.08 (M7) & $\cdot$ & - & • & - & - & • & - & - & - & - & - & - & G & - & C & C & C & & • & - & • & • & • & - & - & - & - . & - $\cdot$ & • $\cdot$ & - & - & • & - & - & • & - & • & • & - & • & - & • & - & - & $\cdot$ & $\cdot$ & - & • & H \#7 \\
\hline RG/HS/BS 65.05 & • & - & - & - & - & • & • & - & - & - & - & - & G & - & - & - & C & - & • & - & - & - & - & - & - & - & - $\cdot$ & - $\cdot$ & • $\cdot$ & - & - & - & - & • & - & - & - & - & - & $\cdot$ & - & $\cdot$ & Y & • & - & $\cdot$ & - & - & $\mathrm{H} \# 5$ \\
\hline RG 66.02 & - & - & - & - & - & • & • & • & • & - & - & - & G & $\cdot$ & $\cdot$ & - & C & - & • & - & - & - & • & - & $\cdot$ & - & - $\cdot$ & - $\cdot$ & • $\cdot$ & - & - & - & - & • & • & - & - & - & • & $\cdot$ & - & $\cdot$ & - & • & • & $\cdot$ & - & • & H \#5 \\
\hline RG/FK 67.0 & G & • & • & - & - & • & • & • & - & - & - & $\cdot$ & G & • & C & - & C & & & & - & • & • & C & - & - & - $\cdot$ & • $\cdot$ & • $\cdot$ & - & - & - & • & • & • & - & - & - & $\mathrm{T}$ & $T$ & - & $\cdot$ & C & & & & & & T2b \#2 \\
\hline BS 133.01 & G & $\cdot$ & $\cdot$ & $\mathrm{T}$ & • & • & - & • & - & • & - & - & G & - & • & $\cdot$ & C & - & • & - & $\cdot$ & G & $\cdot$ & • & - & - & $\cdot \cdot$ & - $\cdot$ & $\cdot \cdot$ & (C) & & & & (C) & • & $\mathrm{T}$ & • & • & - & • & • & $\cdot$ & . & - & • & $\cdot$ & • & - & U5b \\
\hline RG/GK/BS 183.01 (M11) & (G) & - & - & $\mathrm{T}$ & - & • & - & • & • & - & - & - & G & - & - & - & C & & & & - & • & • & - & $\cdot$ & - & - $\cdot$ & - $\cdot$ & • $\cdot$ & - & - & - & - & - & • & - & - & - & - & $\cdot$ & - & $\cdot$ & - & & & & & & U3 \\
\hline RG/BS 187 & G & $\cdot$ & $\cdot$ & • & $\cdot$ & • & - & • & • & - & $\cdot$ & - & G & $\cdot$ & $\cdot$ & $\cdot$ & C & - & • & - & • & - & • & - & $\cdot$ & - & - $\mathrm{c}$ & G $\mathrm{C}$ & $c \cdot$ & • & - & C & • & - & • & • & - & • & • & $\cdot$ & • & $\cdot$ & • & • & • & $\cdot$ & • & • & H1a1c \\
\hline RG/FK/ & $\cdot$ & $\cdot$ & $\cdot$ & - & $\cdot$ & • & • & • & • & - & $\cdot$ & - & G & $\cdot$ & $\cdot$ & $\cdot$ & C & - & - & - & - & - & • & - & - & - & - $\cdot$ & - $\cdot$ & • $\cdot$ & $\cdot$ & - & $\cdot$ & - & • & $\cdot$ & - & - & • & - & $\cdot$ & G & $\cdot$ & $\cdot$ & - & $\cdot$ & $\cdot$ & - & • & $\mathrm{H}_{3}$ \\
\hline $\begin{array}{l}\mathrm{FK} / \mathrm{RG} / \mathrm{HS} / \mathrm{B} \\
\text { (M18/F16) }\end{array}$ & G & - & - & - & - & - & C & - & - & - & - & - & G & - & C & C & C & & & & - & - & - & c & - & - & $A$. & - $\cdot$ & - $\cdot$ & - & - & - & - & - & - & - & - & - & $\mathrm{T}$ & $\mathrm{T}$ & - & - & C & & & & & & 2b \#3 \\
\hline FK/RG/HS 902.01 (M10) & & & & & & • & - & - & • & - & $\cdot$ & • & G & $\cdot$ & C & $\cdot$ & C & & $\cdot$ & - & - & $\cdot$ & $\cdot$ & C & $\cdot$ & - & - $\cdot$ & • $\cdot$ & $\cdot \cdot$ & - & $\cdot$ & $\cdot$ & $\cdot$ & $\cdot$ & $\cdot$ & $\cdot$ & - & $\cdot$ & $\mathrm{T}$ & $\mathrm{T}$ & $\cdot$ & $\cdot$ & C & $\cdot$ & $\cdot$ & $\cdot$ & - & $\cdot$ & T2b \#2 \\
\hline FK/HS/RG/BS 903.01 & $\cdot$ & $\cdot$ & $\cdot$ & - & $\cdot$ & • & • & • & - & $\cdot$ & $\cdot$ & $\cdot$ & G & • & $\cdot$ & - & C & - & - & - & - & $\cdot$ & - & - & - & - & - . & - • & • $\cdot$ & - & • & - & • & • & - & - & - & - & • & • & - & $\cdot$ & - & - & • & • & - & • & $\mathrm{H} \# 5$ \\
\hline FK/RG/H & G & - & - & $\mathrm{T}$ & • & • & - & • & - & - & - & • & G & - & • & • & C & - & • & • & • & • & • & • & - & • & - & - • & • $\cdot$ & C & $\mathrm{T}$ & - & • & • & - & $T$ & - & - & • & • & • & • & - & • & • & • & - & A & U $5 \mathrm{~b} 2 \mathrm{a} 2$ \\
\hline FK/RG/JS 904.04 & (G) & - & - & - & - & - & $\bullet^{\bullet}$ & - & - & - & - & - & G & . & - & - & $C$ & - & - & ${ }^{\circ}$ & - & - & - & - & - & Y & - $\cdot$ & - & - & - & - & - & - & - & - & - & - & - & - & - & - & - & - & • & - & - & - & • & $\begin{array}{l}\text { H3d o. } \\
\text { H4a1a1 }\end{array}$ \\
\hline FK/RG 905.01 (M14) & • & - & • & - & • & • & - & - & • & - & • & • & G & • & • & • & C & & • & - & - & • & • & - & $\cdot$ & - & - $\cdot$ & - $\cdot$ & • $\cdot$ & - & • & - & • & • & • & - & - & $\cdot$ & • & • & - & $\cdot$ & C & - & • & $\cdot$ & - & • & H5 \#1 \\
\hline FK/RG/BS 907.01 & - & - & - & - & - & • & - & • & - & - & - & - & G & - & $\cdot$ & - & C & - & • & - & - & - & - & - & $\cdot$ & - & - $\cdot$ & • $\cdot$ & • $\cdot$ & - & - & • & - & • & - & - & - & $\cdot$ & - & • & - & $\cdot$ & - & • & - & $\cdot$ & - & - & $\mathrm{H} \# 5$ \\
\hline RG/FK 1076 (M1) & $\cdot$ & G & • & - & C & - & - & • & - & - & - & $\cdot$ & G & • & $\cdot$ & • & C & & & & • & $\cdot$ & • & - & • & - & - & • $\cdot$ & $\cdot \cdot$ & - & - & - & - & • & • & - & - & • & - & • & • & • & • & & & & & & $\mathrm{H} \# 3$ \\
\hline
\end{tabular}


Fortsetzung Tabelle 20: Konsensushaplotypen für die mitochondrialen HVRs.

\begin{tabular}{|c|c|c|c|c|c|c|c|c|c|c|c|c|c|c|c|c|c|c|c|c|c|c|c|c|c|c|c|c|c|c|c|c|c|c|c|c|c|c|c|c|c|c|c|}
\hline liv & 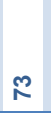 & ๓ & $\stackrel{4}{1}$ & & 논 & & & & & & ปี & & & & & ळ్ల & : & & & & & & & & & & $\frac{\infty}{0}$ & $\frac{\sigma}{\circ}$ & 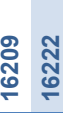 & & ֻٕ & & & & 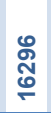 & & & & $\stackrel{0}{\stackrel{0}{0}}$ & $\begin{array}{l}\text { 芯 } \\
\stackrel{0}{0}\end{array}$ & 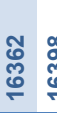 & ㄴ & $\begin{array}{l}\text { mt- } \\
\text { Haplo- } \\
\text { gruppe }\end{array}$ \\
\hline rCRS & A & A & $\mathrm{T}$ & C & $T$ & $G \quad T$ & $T T$ & A & G & $\mathbf{T}$ & C & A & C & - & - & G & $A$ & c & C & $A A$ & $\mathbf{T}$ & G & $\mathbf{T}$ & G & A 1 & $A$ & $T$ & C T & $T$ & $T$ & C & C & C C & C $\mathrm{C}$ & $\mathbf{C}$ & A & G T & $T \quad T$ & A & C & $T$ & G & \\
\hline RG/FK/BS 1078 (F13) & • & - & - & - & - & - $\bullet$ & - $\bullet$ & - & - & • & • & G & • & - & - $\mathrm{C}$ & & & & - & • $\cdot$ & • & - & - & $\cdot$ & • & - & - & $\cdot \cdot$ & - $\cdot$ & $\cdot$ & - & - & • $\cdot$ & $\cdot \cdot$ & $\cdot$ & G & $\cdot \cdot$ & & & & & & H39 \\
\hline BS 1102 (M2) & • & - & - & - & c & - $\cdot$ & • $\cdot$ & - & - & - & $\cdot$ & G & - & - & - $\mathrm{C}$ & & $\cdot$ & - & • & - $\cdot$ & • & • & - & • & • & - & - & $\cdot \cdot$ & - $\cdot$ & • & - & - & $\cdot \cdot$ & $\cdot \cdot$ & • & • & $\cdot \cdot$ & - & & & & & $\mathrm{H} \# 1$ \\
\hline BS/RG 1103 (F14) & G & - & - & - & • & - $\cdot$ & • $\cdot$ & - & - & • & $T$ & G & $\mathrm{T}$ & - & - $\mathrm{C}$ & & • & - & $\mathrm{T}$ & • $\cdot$ & c & $\cdot$ & - & A & - & . & • & $\cdot \cdot$ & - $\mathrm{T}$ & • & $T$ & - & - $\cdot$ & • $\cdot$ & • & - & • & - & & & & & J1b1a1 \\
\hline BS/RG 1176 (F18) & G & $\cdot$ & $\cdot$ & - & C & - 0 & $c \cdot$ & - & - & - & - & G & - & - & - $\mathrm{C}$ & & & & - & - $\cdot$ & 0 & • & - & - & - & - & • & - $\cdot$ & - $\cdot$ & • & - & $\cdot$ & - $\cdot$ & • $\cdot$ & • & - & • & - & & & & & U \#1 \\
\hline BS/RG/FK 1247 (F7 & G & $\cdot$ & - & $T$ & • & • $\bullet$ & - $\cdot$ & - & - & • & • & G & - & - & - $\mathrm{C}$ & & $\cdot$ & - & • & $G \cdot$ & - & • & - & • & - & - & C & $T \cdot$ & - $\cdot$ & C & $\cdot$ & $\mathrm{T}$ & - $\cdot$ & • $\cdot$ & $\cdot$ & $\cdot$ & - $\cdot$ & - & & & & & U5b \\
\hline HS/GK 1461 & G & $\cdot$ & - & - & - & $A \cdot$ & - $\cdot$ & - & A & - & $\cdot$ & G & $\mathrm{T}$ & - & - $\mathrm{C}$ & $\cdot$ & •. & - & $\mathrm{T}$ & - $\cdot$ & c & • & - & - & - & - & - & - $\cdot$ & - $\cdot$ & - & - & $\cdot$ & - $\cdot$ & • $\cdot$ & • & - & - $\cdot$ & - $\cdot$ & $\cdot$ & - & - & - & J1c \\
\hline HS/BS 1467.01 & $\mathrm{R}$ & - & $Y$ & $\cdot$ & - & - $Y$ & Y Y & • & $\mathrm{R}$ & - & - & G & Y & - & - $\mathrm{C}$ & $\mathrm{R}$ & • & - & - & - $\cdot$ & - & (A) & - & - & - & - & • & - $\cdot$ & - $\cdot$ & - & - & Y & - $\mathrm{Y}$ & r • & • & - & - $\cdot$ & - $\cdot$ & $\mathrm{R}$ & - & - & - & n.d. \\
\hline HS/GK/BS 1471 & • & $\cdot$ & - & - & C & - • & - $\cdot$ & - & - & • & • & G & - & - & - $\mathrm{C}$ & $\cdot$ & $\cdot$ & - & - & - $\cdot$ & - & • & - & • & - & - & $\cdot$ & - $\cdot$ & - $\cdot$ & • & Y & $\cdot$ & - $\cdot$ & $\cdot \cdot$ & $\cdot$ & - & - $\cdot$ & - $\bullet$ & $\cdot$ & • & - & - & H\#1 \\
\hline RG/BS/DS 1482 (M3) & $\cdot$ & $\cdot$ & $\cdot$ & $\cdot$ & $\cdot$ & - $\cdot$ & • $\cdot$ & $\cdot$ & - & $\cdot$ & $\cdot$ & G & - & C & - $\mathrm{C}$ & $\cdot$ & & & $\cdot$ & - $\cdot$ & • & $\cdot$ & • & - & • & - & $\cdot$ & $\cdot \cdot$ & - $\cdot$ & $\cdot$ & $\cdot$ & $\cdot$ & - $\cdot$ & $\cdot \cdot$ & $\cdot$ & $\cdot$ & $\cdot \cdot$ & - & & & & & H2a1 \\
\hline RG/BS & & & & & - & $A \cdot$ & - $\cdot$ & - & A & - & - & G & $\mathrm{T}$ & - & - $\mathrm{C}$ & & $\cdot$ & - & $\mathrm{T}$ & - $\cdot$ & c & $\cdot$ & - & - & - & - & • & - $\cdot$ & - $\cdot$ & $\cdot$ & - & $\cdot$ & - $\cdot$ & $\cdot \cdot$ & • & - & $\cdot \cdot$ & - & & & & & J1c \\
\hline HS/GK 1547.01 & • & $\cdot$ & $\cdot$ & - & • & - $\cdot$ & $\cdot \cdot \cdot$ & - & - & - & $\cdot$ & G & - & $\cdot$ & - $\mathrm{C}$ & $\cdot$ & $\cdot$ & - & $\cdot$ & - $\cdot$ & - & - & - & • & - & - & • & $\cdot \cdot$ & - $\cdot$ & $\cdot$ & • & $\cdot$ & $\cdot \cdot$ & $\cdot \cdot$ & $\cdot$ & G & $\cdot \cdot$ & - $\cdot$ & - & $\cdot$ & • & - & H39 \\
\hline HS/GK 1547.03 & • & $\cdot$ & $\cdot$ & - & C & - $\cdot$ & - $\cdot$ & - & - & • & $\cdot$ & G & - & - & - $\mathrm{C}$ & $\cdot$ & $\cdot$ & • & - & • & - & - & - & • & - & - & • & - $\cdot$ & - $\cdot$ & $\cdot$ & - & $\cdot$ & - $\cdot$ & • $\cdot$ & • & $\cdot$ & $\cdot \cdot$ & - $\cdot$ & • & $\cdot$ & - & - & $\mathrm{H} \# 1$ \\
\hline HS/GK 1548.01 & $\cdot$ & $\cdot$ & $\cdot$ & • & • & - $\cdot$ & $\cdot \cdot \cdot$ & $\cdot$ & - & $\cdot$ & $\cdot$ & G & - & $\cdot$ & - $\mathrm{C}$ & $\cdot$ & $\cdot$ & • & $\cdot$ & • & • & $\cdot$ & • & - & - & - & $\cdot$ & $\cdot \cdot$ & - $\cdot$ & $\cdot$ & $\cdot$ & $\cdot$ & - $\cdot$ & $\cdot \cdot$ & $\cdot$ & G & $\cdot \cdot$ & - $\cdot$ & $\cdot$ & $\cdot$ & - & $\cdot$ & H39 \\
\hline $\mathrm{HS} / \mathrm{G}$ & $\cdot$ & $\cdot$ & $\cdot$ & $\cdot$ & $\cdot$ & • $\cdot$ & $\cdot \cdot$ & $\cdot$ & - & $\cdot$ & $\cdot$ & G & - & C & $C \mathrm{C}$ & & & & - & - & • & $\cdot$ & • & $\cdot$ & $\cdot$ & - & $\cdot$ & $\cdot \cdot$ & - $\cdot$ & $\cdot$ & $\cdot$ & $\cdot$ & $\cdot$ & $\cdot \cdot$ & $\cdot$ & $\cdot$ & $\cdot \mathrm{C}$ & C & & & & & H5 \#2 \\
\hline BS/FK/GK/HS 1745.02 & G & - & - & - & - & $A \cdot$ & - $\cdot$ & - & A & - & - & G & $\mathrm{T}$ & - & - $\mathrm{C}$ & $\cdot$ & $\cdot$ & - & $\mathrm{T}$ & • & C & • & - & - & - & - & • & - $\cdot$ & - $\cdot$ & • & - & - & - $\cdot$ & • $\cdot$ & • & - & $\cdot \cdot$ & - $\cdot$ & - & - & - & - & J1c \\
\hline RG/BS 1905 (M9) & $\cdot$ & $\cdot$ & $\cdot$ & - & - & - $\cdot$ & $\cdot \cdot$ & $\cdot$ & - & - & $\cdot$ & G & - & c & - $\mathrm{C}$ & & & & $\cdot$ & • & - & $\cdot$ & - & • & - & - & $\cdot$ & $\cdot \cdot$ & - $\cdot$ & $\cdot$ & $T$ & $\cdot$ & - $\cdot$ & • $\cdot$ & • & - & - $\cdot$ & - & & & & & H7a1 \\
\hline BS/FK 2030.01 (M6) & $\cdot$ & $\cdot$ & $\cdot$ & - & C & - $\cdot$ & • $\cdot$ & $\cdot$ & - & - & $\cdot$ & G & • & - & - $\mathrm{C}$ & & $\cdot$ & • & - & • & • & $\cdot$ & - & • & • & - & $\cdot$ & - $\cdot$ & - $\cdot$ & • & - & $\cdot$ & - $\cdot$ & • $\cdot$ & $\cdot$ & $\cdot$ & $\cdot \cdot$ & - $\cdot$ & $\cdot$ & $\cdot$ & - & $\cdot$ & $\mathrm{H} \# 1$ \\
\hline BS 22 & G & $\cdot$ & $\cdot$ & $\cdot$ & $\cdot$ & $A \cdot$ & $\cdot \cdot$ & - & A & - & $\cdot$ & G & T & - & - $\mathrm{C}$ & & & & $\mathrm{T}$ & • & C & $\cdot$ & - & - & $\cdot$ & - & $\cdot$ & $\cdot \cdot$ & - $\cdot$ & $\cdot$ & $\cdot$ & $\cdot$ & - $\cdot$ & $\cdot \cdot$ & $\cdot$ & $\cdot$ & $\cdot \cdot$ & - & & & & & J1 \\
\hline GK/HS/RG 2588 (F15) & G & $\cdot$ & $\cdot$ & - & C & - $\cdot$ & $\cdot \cdot$ & C & - & - & $\cdot$ & G & - & C & C $\mathrm{C}$ & & G & • & - & • & • & C & - & - & $\cdot$ & - $\mathrm{C}$ & C & $\cdot \cdot$ & - $\cdot$ & $\cdot$ & $\cdot$ & $\cdot$ & - $\cdot$ & $\cdot \cdot$ & $\cdot$ & $\cdot$ & $\cdot \cdot$ & - $\cdot$ & $\cdot$ & $\cdot$ & C & $\cdot$ & U2e1 \\
\hline KS 3190.11 (F20) & $\cdot$ & $\cdot$ & - & • & - & - $\cdot$ & $\cdot \cdot$ & - & - & - & $\cdot$ & G & - & - & - $\mathrm{C}$ & & & & • & - & • & • & • & - & - & - & • & - $\cdot$ & - $\cdot$ & $\cdot$ & $\cdot$ & $\cdot$ & - $\cdot$ & $\cdot \cdot$ & • & G & $\cdot \cdot$ & • & & & & & H39 \\
\hline BS 36 & G & $\cdot$ & - & $\cdot$ & $\cdot 1$ & $A \cdot$ & $\cdot \cdot$ & - & A & - & $\cdot$ & G & $\mathrm{T}$ & - & - $\mathrm{C}$ & & $\cdot$ & • & $\mathrm{T}$ & • & C & - & - & $\cdot$ & - & - & $\cdot$ & - $\cdot$ & - $\cdot$ & • & $\cdot$ & $\cdot$ & - $\cdot$ & • $\cdot$ & • & $\cdot$ & $\cdot \cdot$ & - $\cdot$ & $\cdot$ & $\cdot$ & - & $\cdot$ & J1c \\
\hline BS 3 & G & $\cdot$ & - & $\mathrm{T}$ & • & - $\cdot$ & - $\cdot$ & - & - & - & $\cdot$ & G & - & • & - $\mathrm{C}$ & & & & - & G & - & • & - & - & - & - & C & $\mathrm{T} \cdot$ & - $\cdot$ & C & $\cdot$ & $\mathrm{T}$ & - $\cdot$ & • $\cdot$ & • & $\cdot$ & $\cdot \cdot$ & - $\bullet$ & $\cdot$ & $\cdot$ & - & - & $5 b$ \\
\hline BS 3706 (F5/F11) & G & - & $\cdot$ & - & - & - $\cdot$ & 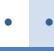 & - & 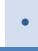 & 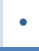 & - & G & - & - & - $\mathrm{C}$ & & $\cdot$ & - & 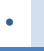 & - & - & 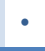 & 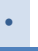 & - & - & - & - & - $\cdot$ & - $\cdot$ & 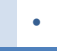 & $\cdot$ & $\cdot$ & - $\cdot$ & - $\mathrm{T}$ & $\mathrm{T}$ & $\cdot$ & - $\mathrm{c}$ & C & & & & & T2b \#1 \\
\hline
\end{tabular}


Fortsetzung Tabelle 20: Konsensushaplotypen für die mitochondrialen HVRs.

\begin{tabular}{|c|c|c|c|c|c|c|c|c|c|c|c|c|c|c|c|c|c|c|c|c|c|c|c|c|c|c|c|c|c|c|c|c|c|c|c|c|c|c|c|c|c|c|}
\hline Individuum [DO \#] & & & $\stackrel{2}{+2}$ & ڤ్ & & & ஜ & & & & & & & & & & & & & & o & & & & & & 恶 & 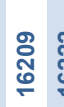 & 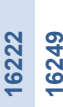 & है & กิ & : & స్ ญั & 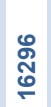 & & 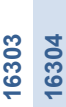 & ?ָ & 융 & & & & $\begin{array}{l}\text { mt- } \\
\text { Haplo- } \\
\text { gruppe }\end{array}$ \\
\hline rCRS & A & A & $\mathrm{T}$ & C T & $T C$ & $\mathbf{T}$ & $T$ & A & G & $T$ & c & c & - & - & - & G & A & ( & $\mathrm{A}$ & A & $\mathbf{T}$ & G T & G & A & $T$ & A & C & $\mathrm{T}$ & C T & - $c$ & c & C c & C C & c & A C & G $T$ & $T$ & A & C T & $T G$ & $\mathrm{~g}$ & \\
\hline BS/FK 3714 & • & - & - & - $\cdot$ & • & - & - & - & $\cdot$ & - & • & 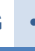 & c & - & C & - & - & . & - $\cdot$ & - & - & - $\cdot$ & - & - & - & • & - & - & - $\cdot$ & - & $\cdot$ & $\cdot \cdot$ & - $\cdot$ & $\cdot$ & $\cdot$ & $\cdot \cdot$ & - & $\cdot$ & $\mathrm{T} \cdot$ & - & • & H2a1 \\
\hline BS/FK 3742 (F9) & G & - & • & $\mathrm{T} \cdot$ & • & - & - & - & • & - & - $c$ & 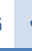 & • & - & C & & - & 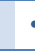 & - $\cdot$ & - & - & • $\cdot$ & - & - & - & - . & - & • & - • & $\cdot$ & • & - • & - $\cdot$ & $\cdot$ & - & - $\cdot$ & & & & & & U3 \\
\hline BS/RG 3748 (F8) & G & • & - & $\mathrm{T} \cdot$ & • $\cdot$ & - & - & • & $\cdot$ & - & - $c$ & - & • & • & C & & & . & G & - & - & $\cdot$ & - & - & - & - $c$ & $T$ & - & - $\mathrm{C}$ & • & $\mathrm{T}$ & - • & - $\cdot$ & $\cdot$ & - & - $\cdot$ & & & & & & U5b \\
\hline BS 3757 (M8) & G & - & - & $\mathrm{T} \cdot$ & • $\cdot$ & - & - & • & - & - & • & 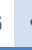 & $\bullet$ & - & C & & - & . & - $\mathrm{G}$ & - & • & $\cdot$ & - & - & - & - $\mathrm{c}$ & $T$ & - & - $\mathrm{C}$ & • & $\mathrm{T}$ & - $\cdot$ & - $\cdot$ & $\cdot$ & - & - $\cdot$ & $\cdot$ & - & • $\cdot$ & - $\cdot$ & • & U5b \\
\hline $\begin{array}{l}\text { BS/RG/FK/HS } 3 \\
\text { (M16) }\end{array}$ & G & - & - & $\mathrm{T} \cdot$ & • & - & - & - & - & - & - $\mathrm{c}$ & - & - & - & C & - & - & . & - $\mathrm{G}$ & - & - & - & - & - & - & - $\mathrm{c}$ & $T$ & - & - $\mathrm{C}$ & • & $\mathrm{T}$ & - • & - $\cdot$ & • & - & - $\cdot$ & - & - & - $\cdot$ & - & - & U5b \\
\hline BS/FK 4008 (M5) & $\cdot$ & $\cdot$ & $\cdot$ & - $\cdot$ & • $\cdot$ & - & $\cdot$ & $\cdot$ & $\cdot$ & $\cdot$ & - & s & • & - & C & & & s & $\cdot$ & $\cdot$ & $\cdot$ & $\cdot \cdot$ & • & $\cdot$ & - & - . & $\cdot$ & $\cdot$ & - $\bullet$ & $\cdot$ & $\cdot$ & $\cdot \cdot$ & - $\cdot$ & $\cdot$ & $\cdot \cdot$ & $\cdot \cdot$ & & & & & & $\mathrm{H} \# 5$ \\
\hline BS/GK 4310.01 & G & - & - & $\mathrm{T} \cdot$ & • $\cdot$ & - & - & - & - & - & & & & & & & - & te & - $\mathrm{G}$ & • & - & - & - & - & - & - & & & - $\mathrm{C}$ & . & $\mathrm{T}$ & - $\cdot$ & - $\cdot$ & • & - & - $\cdot$ & $\cdot$ & - & $\cdot \cdot$ & - $\cdot$ & • & U5b \\
\hline BS 5517 (F6) & G & $\cdot$ & $\cdot$ & - $\cdot$ & • $\cdot$ & - & $\cdot$ & $\cdot$ & $\cdot$ & • & • & 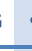 & • & - & C & & - & ( & - $\cdot$ & • & C & $\cdot \cdot$ & - & - & - & - & $\cdot$ & - & - $\cdot$ & • & - & - $\cdot$ & - $\mathrm{T}$ & $\mathrm{T}$ & - & - $\mathrm{C}$ & & & & & & $\mathrm{T} 2 \mathrm{~b} \# 1$ \\
\hline JS 7043.01 & $\cdot$ & $\cdot$ & $\cdot$ & - $\mathrm{c}$ & $c$ & - & $\cdot$ & $\cdot$ & $\cdot$ & C & - & 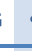 & c & - & C & • & - & t & $\cdot$ & $\cdot$ & $\cdot$ & $\cdot$ & • & $\cdot$ & $\cdot$ & - & $\cdot$ & $\cdot$ & - $\cdot$ & $\cdot$ & • & $\cdot \cdot$ & - $\cdot$ & $\cdot$ & $\cdot \cdot$ & $\cdot \cdot$ & $\cdot$ & $\cdot$ & $\cdot c$ & c $\cdot$ & • & H6 \#3 \\
\hline JS 7075.01 & $\cdot$ & $\cdot$ & $\cdot$ & - $\cdot$ & • & - & $\cdot$ & $\cdot$ & $\cdot$ & $\cdot$ & - & 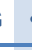 & C & - & C & $\cdot$ & - & 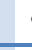 & $\cdot$ & $\cdot$ & $\cdot$ & $\cdot \cdot$ & • & $\cdot$ & $\cdot$ & - & $\cdot$ & $\cdot$ & - $\cdot$ & • & - & $\mathrm{T} \cdot$ & - $\cdot$ & $\cdot$ & $\cdot \cdot$ & $\cdot \cdot$ & • & $\cdot$ & $\cdot \cdot$ & - $\cdot$ & • & $\mathrm{H}^{*}$ \\
\hline FK/KS E 11 & $\cdot$ & $\cdot$ & $\cdot$ & - $\cdot$ & • $\cdot$ & - & $\cdot$ & $\cdot$ & $\cdot$ & $\cdot$ & - & s & • & - & C & $\cdot$ & - & s. & - $\cdot$ & $\cdot$ & $\cdot$ & $\cdot$ & • & $\cdot$ & $\cdot$ & - & $\cdot$ & $\cdot$ & - $\bullet$ & • & $\cdot$ & $\cdot \cdot$ & - $\cdot$ & $\cdot$ & G & $\cdot \cdot$ & • & • & $\cdot \cdot$ & - $\cdot$ & • & H39 \\
\hline E 33 (M12) & G & - & - & - $\cdot$ & - $A$ & - & - & $\cdot$ & A & • & - & $T$ & • & - & C & & & 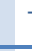 & $T \cdot$ & • & C & $\cdot \cdot$ & - & - & - & - & $\cdot$ & - & - $\cdot$ & $\cdot$ & - & $\cdot \cdot$ & - $\cdot$ & • & - & - $\cdot$ & & & & & & J1c \\
\hline E 37 (F21) & $\cdot$ & • & - & - $\cdot$ & • $\cdot$ & - & - & • & $\cdot$ & - & - & ( & • & - & C & & & 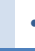 & - $\cdot$ & - & $\cdot$ & $\cdot$ & - & - & - & - & - & - & - • & · & • & - • & - $\cdot$ & $\cdot$ & - & - $\cdot$ & & & & & & $\mathrm{H} \# 5$ \\
\hline HS/GK N 957.01 & G & - & - & - $\cdot$ & - A & - & - & - & A & - & - $c$ & 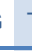 & • & - & C & - & - & 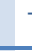 & - & • & C & $\cdot$ & - & - & $\bullet$ & - & - & $\cdot$ & - $\cdot$ & • & - & - $\cdot$ & - $\cdot$ & • & - & - $\cdot$ & $\cdot$ & - & $\cdot \cdot$ & - $\cdot$ & • & J1c \\
\hline $\begin{array}{l}\text { BS/FK/RG/HS/GK/KS } \\
\text { N } 962.01\end{array}$ & • & - & - & - & • & - & - & - & - & - & • & & c & - & C & 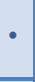 & - & & - & c & - & - & - & - & C & - & - & - & - $\cdot$ & - • & - & - & - $\cdot$ & - & - & - $\cdot$ & - C & - & - $\cdot$ & - $\cdot$ & - & HV6a \\
\hline RG/FK R 1 (F12) & • & • & $\cdot \cdot$ & - $\cdot$ & • & - & - & $t$ & $\cdot$ & $\bullet$ & - $c$ & 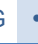 & 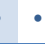 & - & 0 & & & & . & 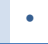 & 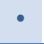 & $\cdot$ & 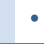 & - & 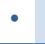 & - & $\cdot$ & $\cdot$ & - $\bullet$ & • & $\cdot$ & $\cdot \cdot$ & - $\cdot$ & $\cdot$ & G & - • & & & & & & H39 \\
\hline
\end{tabular}


Tabelle 21: Übersicht über die mt-Haplogruppenzugehörigkeit.

\begin{tabular}{|c|c|c|}
\hline Haplogruppe & Individuen [DO \#] & Name der Haplogruppe bei Schilz (2006) \\
\hline H1a1c & RG/BS 187 & \\
\hline \multirow{2}{*}{ H2a1 } & RG/BS/DS $1482(\mathrm{M} 3)$ & \multirow{2}{*}{$\mathrm{H} \# 8$} \\
\hline & BS/FK 3714 & \\
\hline H3d o. H4a1a1 & FK/RG/JS 904.04 & \\
\hline H5 \#1 & FK/RG 905.01 (M14) & $\mathrm{H} \# 9$ \\
\hline H5 \#2 & HS/GK 1585.03 (F19) & $\mathrm{H} \# 4$ \\
\hline H6 \#1 & RG/FK 57.02 (M17/M19) & $\mathrm{H} \# 10$ \\
\hline H6 \#3 & JS 7043.01 & \\
\hline H7a1 & RG/BS 1905 (M9) & $\mathrm{H} \# 6$ \\
\hline \multirow{7}{*}{ H39 } & RG/FK/BS 516 & \multirow{7}{*}{$\mathrm{H} \# 2$} \\
\hline & RG/FK/BS 1078 (F13) & \\
\hline & HS/GK 1547.01 & \\
\hline & HS/GK 1548.01 & \\
\hline & KS 3190.11 (F20) & \\
\hline & FK/KS E 11 & \\
\hline & RG/FK R 1 (F12) & \\
\hline $\mathrm{H}^{*}$ & JS 7075.01 & \\
\hline HV6a & BS/FK/RG/HS/GK/KS N 962.01 & \\
\hline \multirow{5}{*}{ H\#1 } & FK/RG/BS 38 (F1) & \multirow{5}{*}{$\mathrm{H} \# 1$} \\
\hline & BS 1102 (M2) & \\
\hline & HS/GK/BS 1471 & \\
\hline & HS/GK 1547.03 & \\
\hline & BS/FK 2030.01 (M6) & \\
\hline $\mathrm{H} \# 3$ & RG/FK 1076 (M1) & $\mathrm{H} \# 3$ \\
\hline \multirow{8}{*}{ H \#5 } & $\mathrm{FK} / \mathrm{HS} / \mathrm{RG} 35$ (M4) & \multirow{8}{*}{$\mathrm{H} \# 5$} \\
\hline & RG/FK 58.01 & \\
\hline & RG/HS/BS 65.05 & \\
\hline & RG 66.02 & \\
\hline & FK/HS/RG/BS 903.01 & \\
\hline & FK/RG/BS 907.01 & \\
\hline & BS/FK 4008 (M5) & \\
\hline & E 37 (F21) & \\
\hline H \#7 & RG/FK/KS 58.08 (M7) & $\mathrm{H} \# 7$ \\
\hline \multirow{7}{*}{ J1c } & HS/GK 1461 & \multirow{7}{*}{$J^{*}$} \\
\hline & RG/BS $1500(F 2)$ & \\
\hline & BS/FK/GK/HS 1745.02 & \\
\hline & BS 2263 (M15) & \\
\hline & BS 3628 (F3) & \\
\hline & E 33 (M12) & \\
\hline & HS/GK N 957.01 & \\
\hline J1b1a1 & BS/RG 1103 (F14) & J1b1 \\
\hline T2 & RG/FK 58.03 (M13) & n.d. \#1 \\
\hline \multirow{2}{*}{ T2b \#1 } & BS 3706 (F5/F11) & \multirow{2}{*}{$\mathrm{T} 2 \mathrm{~b} \# 1$} \\
\hline & BS 5517 (F6) & \\
\hline \multirow{2}{*}{ T2b \#2 } & RG/FK 67.03 (F10/F17) & \multirow{2}{*}{$\mathrm{T} 2 \mathrm{~b} \# 2$} \\
\hline & FK/RG/HS 902.01 (M10) & \\
\hline T2b \#3 & FK/RG/HS/BS 901.01 (M18/F16) & $\mathrm{T} 2 \mathrm{~b} \# 3$ \\
\hline
\end{tabular}


Fortsetzung Tabelle 21: Übersicht über die mt-Haplogruppenzugehörigkeit.

\begin{tabular}{lll}
\hline Haplogruppe & Individuen & Name der Haplogruppe bei Schilz (2006) \\
\hline U2e1 & GK/HS/RG 2588 (F15) & U(2) \\
U3 & RG/GK/BS 183.01 (M11) & U2 \\
& BS/FK 3742 (F9) & \\
& BS 133.01 & \\
& BS/RG/FK 1247 (F7) U5b & \\
U5b & BS 3695 (F4) & \\
& BS/RG 3748 (F8) & \\
& BS 3757 (M8) & \\
& BS/RG/FK/HS 3886 (M16) & \\
U5b2a2 & BS/GK 4310.01 & U \#1 \\
\hline U \#1 & FK/RG/HS/BS 903.02 \\
\hline n.d. & BS/RG 1176 (F18) & \\
\hline
\end{tabular}




\section{Ableitungen aus den Datensätzen}

\subsection{Verwandtschaftsrekonstruktion}

Ausgangsbasis für die Verwandtschaftsrekonstruktion stellte der in der Arbeit von Schilz (2006) veröffentlichte Stammbaum für die $40 \mathrm{zu}$ diesem Zeitpunkt bekannten Individuen dar, welcher für 28 der Individuen Verwandtschaftsbeziehungen untergliedert in mehrere Kernfamilien - aufzeigte (siehe Abb. 11, S. 15).

Für die weitere Verwandtschaftsanalyse wurde zunächst ein Screening mit dem Programm DNA·VIEW (mit freundlicher Unterstützung von Dr. Charles H. Brenner, Consulting in Forensic Mathematics, CA USA) durchgeführt. Zusätzlich wurde der genetische Fingerabdruck jedes Individuums mit dem jedes anderen Individuums abgeglichen und ausgezählt, in wie vielen von wie vielen vergleichbaren Systemen (= für beide jeweils gerade verglichenen Individuen liegen Daten vor) die beiden jeweils verglichenen Individuen ein gleiches Allel aufweisen. Hieraus wurde für jeden paarweisen Vergleich ein Quotient gebildet, welcher ein Maß für die genetische Nähe darstellt. Im Falle von direkter Eltern-Kind-Verwandtschaft wird ein Quotient von 1 (= teilen sich in allen Systemen je ein Allel) erwartet. Es wurde jedoch berücksichtigt, dass auch Individuen, die nicht den eigentlich notwendigen Quotient von 1 aufweisen, evtl. direkt verwandt sein können, da das eigentlich passende Allel durch degradierungsbedingtes allelic dropout ausgefallen sein könnte. Für jedes Individuum wurde nun die Kreuztabelle nach absteigendem Quotient sortiert und zur Prüfung der aufgezeigten möglichen Verwandtschaftsbeziehungen die Daten der jeweiligen Individuen noch einmal genau miteinander verglichen. Hierbei wurden neben den Daten für die autosomalen STRs auch die Y-chromosomalen und mitochondrialen Haplotypen miteinbezogen.

Für Individuen, für die keine direkten Verwandtschaftsbeziehungen aufgedeckt werden konnte, wurde nach möglicher Verwandtschaft innerhalb der Familiengruppen über die mitochondrialen und Y-chromosomalen Haplotypen geschaut. Wenn möglich wurde für Alternativszenarien mit Hilfe des Programms familias (http://www.familias.name/) geprüft, welche die jeweils wahrscheinlichere Variante ist. So ist es z.B. für das Individuum DO BS/FK 3714 mit einer posterior probability von 0,6776 wahrscheinlicher, dass es sich um einen Onkel des Individuums DO RG/BS/DS 1482 (M3) handelt, als dass die beiden Individuen Brüder sind (posterior probability 0,3223). Ebenso ist z.B. das Individuum DO BS/GK 4310.01 mit einer posterior probability von 0,7345 wahrscheinlicher ein Neffe des Individuums BS 3695 (F4) als ein Bruder 
(posterior probability 0,2654). Allerdings war die Arbeit mit dem Programm familias nicht durchgängig möglich, da mit diesem Programm nur mit vollständigen genetischen Fingerabdrücken unter Angabe von zwei Allelen pro STR gearbeitet werden kann. Eine solche Angabe war aber nicht immer möglich, da bei recht schlechter Ergebnislage nicht sicher bestimmt werden konnte, an welchen Stellen wirklich ein homozygotes Ergebnis real war und an welchen Stellen eigentlich ein heterozygoter Genotyp vorlag und das zweite Allel lediglich aufgrund von allelic dropout nicht nachgewiesen werden konnte.

Im Zuge der Verwandtschaftsanalyse konnten nahezu alle Verwandtschaftsbeziehungen, die bereits im Stammbaum von Schilz (2006) definiert wurden, bestätigt werden. Eine Änderung ergab sich nur für das Indiviuum F21 (neuer Name: DO E 37 (F21)). Zum einen handelt es sich bei diesem Individuum um ein männliches und nicht um ein weibliches Individuum, zum anderen ergab sich eine wahrscheinlichere Verwandtschaftsbeziehung innerhalb des Familienzweiges der Individuen mit dem mitochondrialen Haplotypen H \#5.

Für drei der Individuen, die bei Schilz (2006) benannt wurden, aber nicht in den Stammbaum integriert werden konnten, konnte aufgezeigt werden, dass die diese Individuen repräsentierenden Skelettelemente mit anderen von Schilz untersuchten Skelettelementen zusammen von einem Individuum stammen. So stammen die Knochen, welche die Individuen F10 und F17 repräsentieren, von einem Individuum (neuer Name: DO RG/FK 67.03 (F10/F17)), ebenso die Knochen, welche die Individuen M17 und M19 repräsentieren (neuer Name: DO RG/FK 57.02 (M17/M19)) und auch die Knochen, welche die Individuen M18 und F16 repräsentieren (neuer Name: DO FK/RG/HS/BS 901.01 (M18/F16)), wobei es sich bei letzterem um ein weibliches Individuum handelt.

Für die Individuen M7 (neuer Name: DO RG/FK/KS 58.08 (M7)) und M13 (neuer Name: DO RG/FK 58.03 (M13)), die ebenfalls bereits bei Schilz (2006) benannt wurden, aber nicht in den Stammbaum integriert werden konnten, war dies nun möglich. Somit verblieben von den zwölf bei Schilz nicht in den Stammbaum integrierten Individuen sieben separat.

Insgesamt kamen 24 neu aufgefundene Individuen hinzu. Hiervon wiesen 17 einen mitochondrialen Haplotyp auf, der bereits bei zuvor bekannten Individuen nachgewiesen wurde. Sechs der neu aufgefundenen Individuen wiesen mitochondriale 
Haplotypen auf, die keines der anderen Individuen teilte. Für ein Individuum konnte der mitochondriale Haplotyp nicht bestimmt werden.

Mit den 24 zusätzlichen Individuen kamen neun direkte Eltern-Kind-Beziehungen hinzu. So konnte z.B. ein Individuum identifiziert werden, welches im Stammbaum von Schilz (2006) bereits anonym benannt wurde (die Mutter der Individuen M4 und M5 mit dem mitochondrialen Haplotypen H \#5). Dieses Individuum (DO RG/FK 58.01) ist nicht nur eindeutig die Mutter von den Individuen DO FK/HS/RG 35 (M4) und DO BS/FK 4008 (M5) sondern zudem auch von dem ebenfalls neu identifizierten Individuum DO RG 66.02. Ein weiteres Beispiel einer neu aufgedeckten direkten Eltern-Kind-Beziehung ist die Elternschaft der Individuen DO RG/BS 1500 (F2) und DO BS 1102 (M2) zu dem Individuum DO BS/FK/GK/HS 1745.02.

Insgesamt konnten alle 17 neu hinzugekommenen Individuen mit bereits bekannten mitochondrialen Haplotypen über diese und über die auf Basis der autosomalen STRs ermittelte genetische Nähe in den Stammbaum integriert werden. Eines der sechs Individuen mit singulär auftretendem mitochondrialen Haplotyp (Individuum DO JS 7043.01) war durch den Nachweis des Y-chromosomalen Haplotypen Y1 und durch die auf Basis der autosomalen STRs ermittelte genetische Nähe ebenfalls integrierbar.

Somit konnten insgesamt für 47 der 60 Individuen Verwandtschaftsbeziehungen rekonstruiert werden, während 13 Individuen separat verblieben. Der um die neu hinzugekommenen Individuen erweiterte Stammbaum umfasst 6 Generationen und ist in Abb. 77 (folgende Seite) dargestellt.

Es ist allerdings zu beachten, dass es sich bei diesem Stammbaum lediglich um einen nach dem Parsimonieprinzip sehr wahrscheinlichen handelt, aber dass prinzipiell noch andere Stammbäume möglich wären. Tatsächlich scheint dieser Stammbaum in einigen Aspekten den archäologischen Fakten zu widersprechen (persönliche Mitteilung Dr. Stefan Flindt). Aus der Stratigrafie und der Verteilung der archäologischen Artefakte gibt es Indizien, dass die Individuen, deren Überreste im Jensschluf gefunden wurden, als erstes in der Höhle abgelegt wurden. Des Weiteren gibt es Hinweise, dass im Folgenden zunächst nur die hinteren Teile der Höhle (Grabkammer, Horstspalte, Fiddikluft und Reinhardsgrotte) für die Knochenablage genutzt wurden, während der Berndsaal für rituelle Handlungen genutzt wurde, was aus dem Brandschichtenhorizont in letzterem hervorgeht. Erst später wurde begonnen, auch im Berndsaal Knochen abzulegen, so dass also die Individuen, deren Knochen dort aufgefunden wurden, in den späteren Generationen des Stammbaums zu finden sein müssten. 


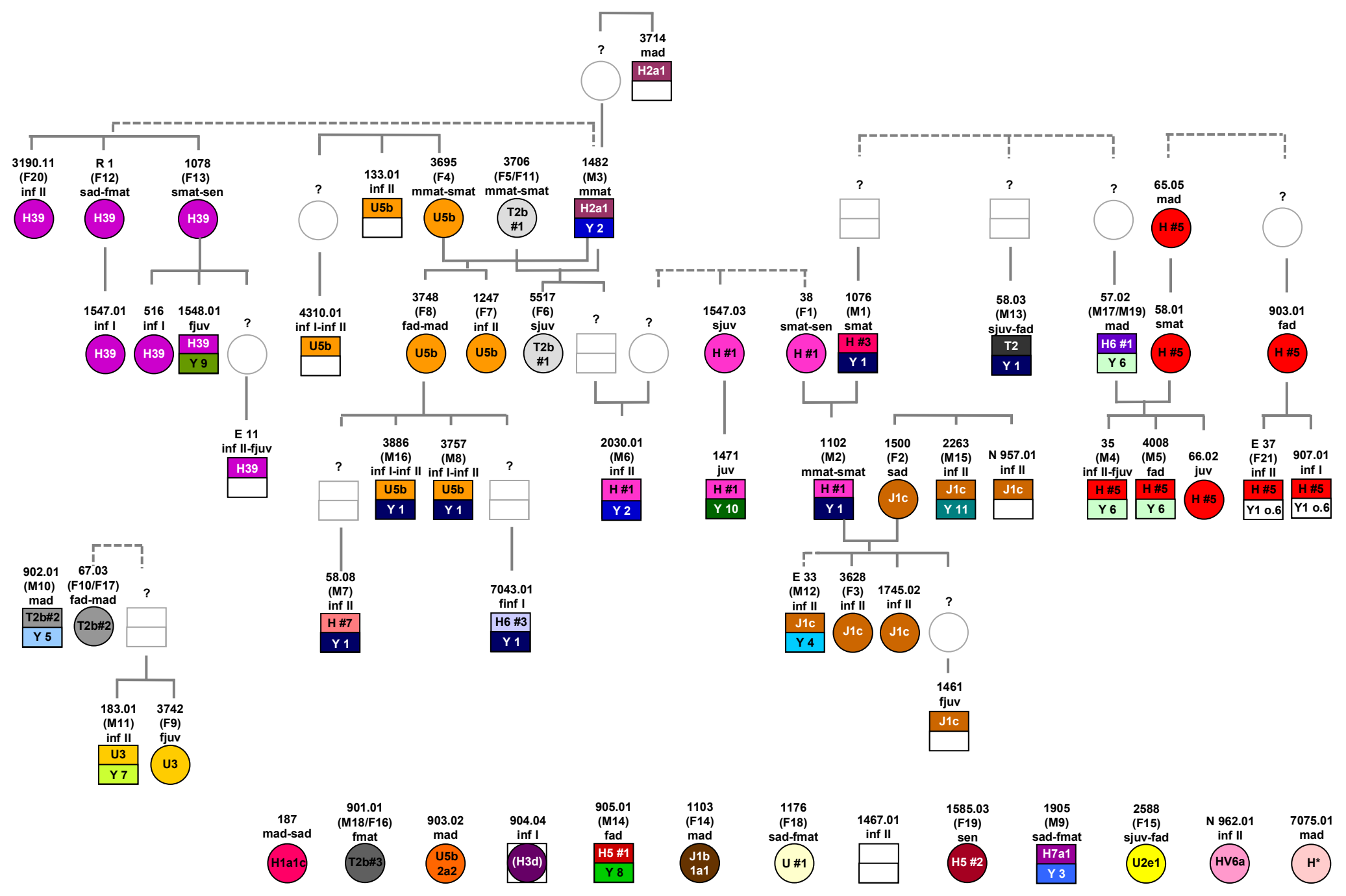

Abb. 77: Stammbaum für die Individuen aus der Lichtensteinhöhle. Männliche Individuen sind durch ein zweigeteiltes Quadrat symbolisiert. Im oberen Abschnitt ist der mitochondriale Haplotyp des jeweiligen Individuums angegeben, im unteren Abschnitt der Y-chromosomale Haplotyp. Weibliche Individuen sind durch einen Kreis symbolisiert, in dem der mitochondriale Haplotyp vermerkt ist. Gleiche Farben stehen für gleiche Haplotypen. 
Aufgrund dieser archäologisch basierten Indizien wurde der nach dem biologischen Parsimonieprinzip erstellten Stammbaum in Hinblick auf den Auffindeort der Knochen der jeweiligen Individuen betrachtet. Zum einen fiel auf, dass die Mitglieder der verschiedenen, durch die mitochondrialen Haplotypen und die Nachweise direkter Verwandtschaft definierten, Familiengruppen i.d.R. in den gleichen Höhlenabschnitten aufgefunden wurden. Unter der Annahme, dass die im Berndsaal lokalisierten Individuen die späteren Generationen repräsentieren, ist davon auszugehen, dass die verschiedenen Familiengruppen nicht zeitglich kontinuierlich eingebracht wurden, sondern dass sie zeitversetzt in der Höhle bestattet wurden. Zudem wird für drei der Individuen (DO RG/FK/KS 58.08 (M7), DO JS 7043.01, DO E 33 (M12) und DO HS/GK 1461) eine alternative Positionierung im Stammbaum nahegelegt. So weist zwar z.B. das Individuum DO JS 7043.01 die größte genetische Nähe zu den Individuen des Familienzweiges aus dem Berndsaal mit dem mitochondrialen Haplotypen U5b auf, da dieses Individuum jedoch im Jensschluf aufgefunden wurde, müssen die Überreste deutlich früher in die Höhle gelangt sein als die der Individuen aus dem Berndsaal.

Unter Berücksichtigung der stratigrafischen und archäologischen Indizien ergibt sich ein Alternativstammbaum, welcher in Abb. 78 (folgende Seite) dargestellt ist. Dieser Stammbaum ist nach dem biologischen Parsimonieprinzip zwar deutlich unwahrscheinlicher, da an zwei Stellen über mehrere Generationen nicht in der Höhle aufgefundene Individuen zur Verknüpfung der verschiedenen Familiengruppen angenommen werden müssen, welcher Stammbaum jedoch letzten Endes der prähistorischen Realität am nächsten kommt, ist nicht eindeutig zu sagen. 

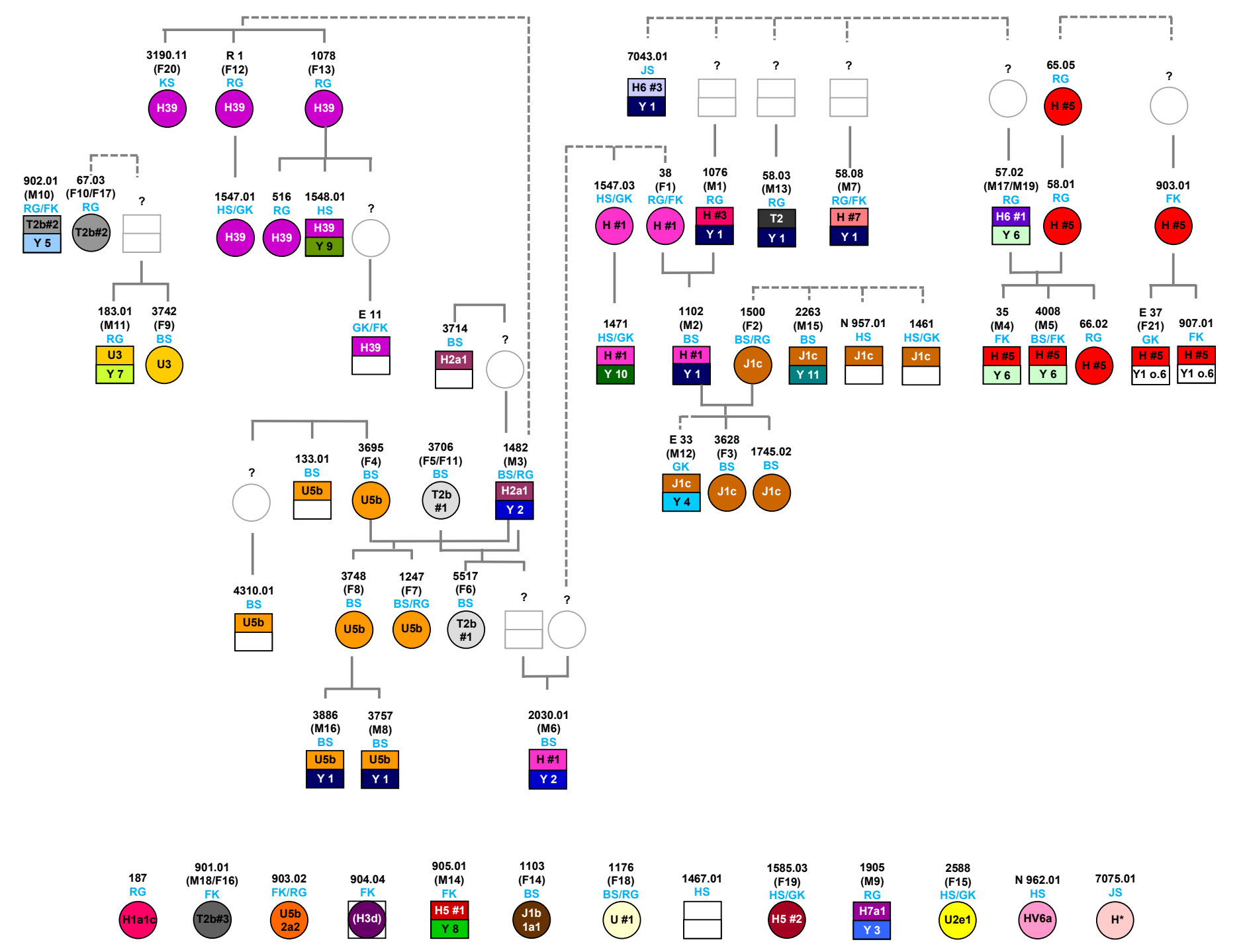

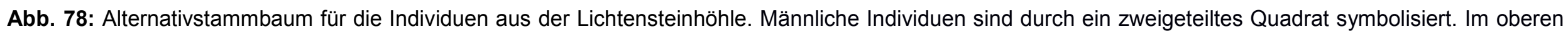

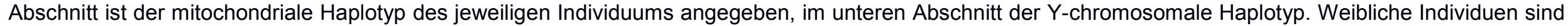
durch einen Kreis symbolisiert, in dem der mitochondriale Haplotyp vermerkt ist. Gleiche Farben stehen für gleiche Haplotypen. 


\subsection{Matri- vs. Patrilokalität}

Über die Betrachtung der Variabilität mitochondrialer und Y-chromosomaler Haplotypen lassen sich Hinweise auf das Residenzverhalten - und damit auf die sozialen Strukturen - einer Bevölkerung gewinnen, da sich über Generationen ausgeübte Muster im Partnermobilitätsverhalten im Genpool einer Bevölkerung niederschlagen. Grundsätzlich gibt es zwei Formen des Residenzverhaltens, Matri- und Patrilokalität. Während in maternalen Gesellschaften die Frauen an ihrem Geburtsort verbleiben und mit Männern von außerhalb, welche ihren Geburtsort verlassen, Reproduktionsgemeinschaften bilden, ist es in paternalen Gesellschaften genau andersherum (Levi-Strauss 1981).

Durch ein maternales Residenzverhalten kommt es zu einem extrem geringen Eintrag mitochondrialer DNA, während ein ständiger Eintrag Y-chromosomaler Sequenzen stattfindet. Daher ist in Gesellschaften mit maternalem Residenzverhalten die Variabilität mitochondrialer Marker im Vergleich zu der Variabilität Y-chromosomaler Marker deutlich geringer. In Gesellschaften mit paternalem Residenzverhalten ist die Sachlage entsprechend genau umgekehrt und die Variabilität Y-chromosomaler Marker deutlich geringer als die Variabilität mitochondrialer Marker (Salem et al. 1996, Oota et al. 2001).

Hinweis auf ein maternales Residenzverhalten in einer Gesellschaft kann zusätzlich darüber gewonnen werden, wenn in den weiblichen Individuen der Bevölkerung die mitochondriale Variabilität deutlich geringer ist als die in den männlichen Individuen (Gerstenberger 2002). Die Frauen bleiben vor Ort und es ziehen nur wenige zu, so dass immer dieselben, wenigen mt-Haplotypen vererbt werden, wohingegen mit jeder neuen Generation Männer mit neuen mt-Haplotypen zuziehen und die Männer, die einen vorhandenen mt-Haplotypen geerbt haben, kontinuierlich wegziehen. In paternalen Gesellschaften hingegen wird eine ähnliche Variabilität der mitochondrialen Haplotpyen in beiden Geschlechtern erwartet, da männliche Individuen durch die maternale Vererbung das Bild der Müttergeneration widerspiegeln.

Für die Individuen aus der Lichtensteinhöhle konnte für 20 männliche Individuen sowohl der mitochondriale als auch der Y-chromosomale Haplotyp bestimmt werden (siehe Tabelle 22). Dabei fanden sich unter den 20 Individuen 15 verschiedene mitochondriale und 11 verschiedenen Y-chromosomale Haplotypen. 
Tabelle 22: Zusammenstellung der männlichen Individuen aus der Lichtensteinhöhle, für die sowohl der mitochondriale als auch der Ychromosomale Haplotyp bekannt ist.

\begin{tabular}{|c|c|c|c|}
\hline Individuum & Geschlecht & Haplotyp mt & Haplotyp Y \\
\hline DO BS 1102 (M2) & $\mathrm{m}$ & $\mathrm{H} \# 1$ & Y 1 \\
\hline DO HS/GK/BS 1471 & $\mathrm{~m}$ & $\mathrm{H} \# 1$ & Y 10 \\
\hline DO BS/FK 2030.01 (M6) & $\mathrm{m}$ & $\mathrm{H} \# 1$ & Y 2 \\
\hline DO RG/FK 1076 (M1) & $\mathrm{m}$ & $\mathrm{H} \# 3$ & Y 1 \\
\hline DO FK/HS/RG 35 (M4) & $\mathrm{m}$ & $\mathrm{H} \# 5$ & Y 6 \\
\hline DO BS/FK 4008 (M5) & $\mathrm{m}$ & $\mathrm{H} \# 5$ & Y 6 \\
\hline DO RG/FK/KS 58.08 (M7) & $\mathrm{m}$ & $\mathrm{H} \# 7$ & Y 1 \\
\hline DO RG/BS/DS 1482 (M3) & $\mathrm{m}$ & $\mathrm{H} 2 \mathrm{a} 1$ & Y 2 \\
\hline DO HS/GK 1548.01 & $\mathrm{~m}$ & $\mathrm{H} 39$ & Y 9 \\
\hline DO FK/RG 905.01 (M14) & $\mathrm{m}$ & $\mathrm{H} 5$ \#1 & Y 8 \\
\hline DO RG/FK 57.02 (M17/M19) & $\mathrm{m}$ & $\mathrm{H} 6$ \#1 & Y 6 \\
\hline DO JS 7043.01 & $\mathrm{~m}$ & $\mathrm{H} 6$ \#3 & Y 1 \\
\hline DO RG/BS 1905 (M9) & $\mathrm{m}$ & $\mathrm{H} 7 \mathrm{a} 1$ & Y 3 \\
\hline DO BS 2263 (M15) & $\mathrm{m}$ & $\mathrm{J} 1 \mathrm{C}$ & Y 11 \\
\hline DO E 33 (M12) & $\mathrm{m}$ & J1C & Y 4 \\
\hline DO RG/FK 58.03 (M13) & $\mathrm{m}$ & $\mathrm{T} 2$ & Y 1 \\
\hline DO FK/RG/HS 902.01 (M10) & $\mathrm{m}$ & $\mathrm{T} 2 \mathrm{~b} \# 2$ & Y 5 \\
\hline DO RG/GK/BS 183.01 (M11) & $\mathrm{m}$ & U3 & Y 7 \\
\hline DO BS 3757 (M8) & $\mathrm{m}$ & U5b & Y 1 \\
\hline \multirow[t]{2}{*}{ DO BS 3886 (M16) } & $\mathrm{m}$ & U5b & Y 1 \\
\hline & & 15 & 11 \\
\hline
\end{tabular}

$\mathrm{m}=$ männlich.

Der Vergleich der Diversität der mitochondrialen und Y-chromosomalen Haplotypen in den männlichen Individuen zeigt also, dass diese für die mitochondrialen etwas größer ist (siehe Abb. 79). Dies kann als Hinweis auf eine mögliche Patrilokalität der Individuen aus der Lichtensteinhöhle gedeutet werden.

Betrachtet man die Variabilität der mitochondrialen Haplotypen im Geschlechtervergleich, so kommen bei 28 männlichen Individuen 15 verschiedene Haplotypen vor und bei 30 weiblichen Individuen 17 verschiedene. D.h. die Variabilität der mitochondrialen Haplotypen ist in beiden Geschlechtern annähernd gleich (siehe Abb. 80). Hieraus ergibt sich kein Hinweis auf das Vorliegen einer Gesellschaft mit maternalem Residenzverhalten. Die beobachteten Verhältnisse würden jedoch für eine Gesellschaft mit paternalem Residenzverhalten genau so erwartet. 
In $20 \curvearrowright$ Individuen

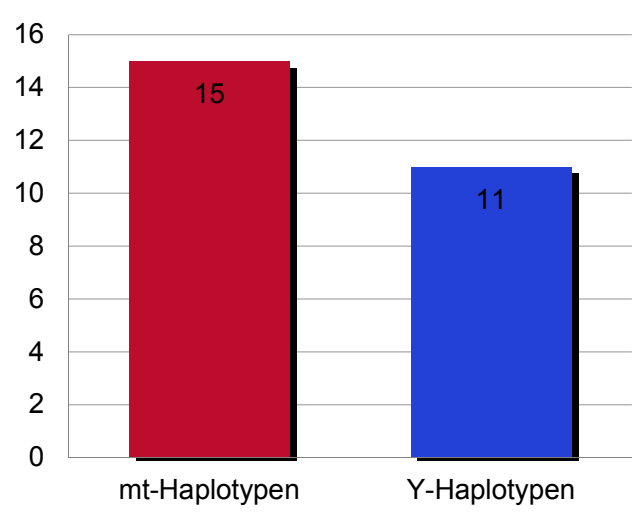

Abb. 79: Vergleich der Diversität der mitochondrialen und Y-chromosomalen Haplotypen unter den männlichen Individuen aus der Lichtensteinhöhle.

\section{Variabilität mt-Haplotypen}

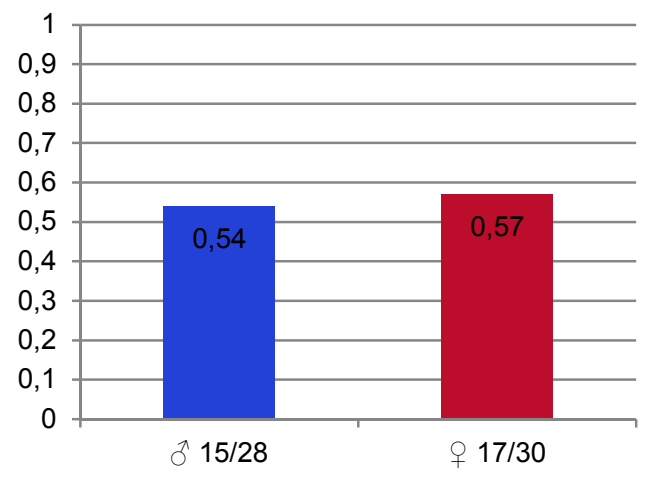

Abb. 80: Vergleich der Variabilität der mtHaplotypen in den männlichen und weiblichen Individuen aus der Lichtensteinhöhle.

\subsection{Hinweise auf die regionale Einordnung}

Um globale aber auch regionale Besiedlungsgeschichte nachzuvollziehen sowie die regionale Herkunft einzelner Individuen oder gesamter Populationen aufzuklären, bedient man sich der Analyse väterlicher und mütterlicher Familienlinien. Die hierfür verwendeten DNA-Abschnitte sind haploid und weisen eine uniparentale Vererbung auf. Die väterlichen Linien werden mit Hilfe Y-chromosomaler Sequenzen untersucht, während die mütterlichen Linien anhand mitochondrialer DNA analysiert werden. Die hierbei verwendeten Marker sind selektionsneutral, hochpolymorph und verändern sich infolge fehlender Rekombination nur durch Mutation. Grundsätzlich weisen die Mitglieder einer Familie denselben Haplotyp - d.h. dieselben Polymorphismen - auf. Die sogenannten Haplogruppen umfassen mehrere miteinander eng verwandte Haplotypen, die einige Polymorphismen teilen. Ihre Frequenzverteilung über die Kontinente ermöglicht es, Besiedlungsbewegungen nachzuvollziehen (Roewer et al. 2005, Deguilloux et al. 2011, Nikitin et al. 2012).

Die mitochondrialen Haplogruppen werden mittels der Analyse von SNPs bestimmt, wobei es bei europäischen Haplogruppen genügt, die beiden hypervariablen Regionen (HVR I und HVR II) des mitochondrialen Genoms zu untersuchen. Da die mitochondrialen Haplogruppen innerhalb Europas jedoch sehr ähnlich verteilt sind (Simoni 2000, Richards et al. 2002), ist bei der Ermittlung der geografischen Herkunft innerhalb Europas die Zuhilfenahme von Y-chromosomalen Haplogruppen von besonderer Bedeutung. 
Auch die Y-Haplogruppen werden anhand von SNPs ermittelt. Zusätzlich dazu kann ein Y-chromosomaler Haplotyp mit Hilfe von sich auf dem Chromosom befindenden STRSystemen gebildet werden. Aufgrund der hochpolymorphen Eigenschaften der STRs besitzt dieser Haplotyp eine höhere Auflösung als der aus SNPs bestehende Haplotyp. Zwischen beiden Arten von Haplotypen besteht ein Zusammenhang, der es ermöglicht, die SNP-Haplogruppe unter Einsatz der STR-Daten zu berechnen (Athey 2005).

Für die Individuen aus der Lichtensteinhöhle wurden sowohl mt-Haplogruppen als auch Y-Haplogruppen analysiert, wobei die Y-Haplogruppen mittels des Haplogroup Predictors (www.hprg.com) von den Y-chromosomalen STR-Haplotypen abgeleitet wurden. Abb. 81 und Abb. 82 zeigen die jeweilige Verteilung der mitochondrialen und Y-chromosomalen Haplogruppen für die Individuen aus der Lichtensteinhöhle.

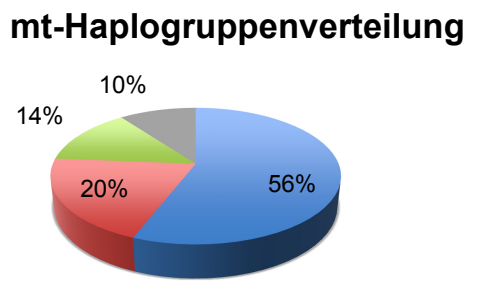

Abb. 81: Prozentuale Anteile der in den Individuen aus der Lichtensteinhöhle vertretenen mitochondrialen GroßHaplogruppen.

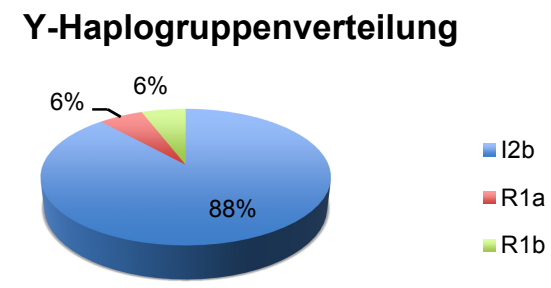

Abb. 82: Prozentuale Anteile der in den Individuen aus der Lichtensteinhöhle vertretenen Y-chromosomalen Haplogruppen.

Bezüglich der mitochondrialen Haplogruppen ist auffällig, dass lediglich vier $(\mathrm{H}, \mathrm{U}, \mathrm{J}$ und T) der neun europäischen Haupt-Haplogruppen (H, I, J, K, T, U, V, W und X) vertreten sind. Dies kann jedoch durchaus auf die Verwandtschaft der Individuen untereinander zurückgeführt werden. Die vertretenen Haplogruppen fallen mit ihren Frequenzverhältnissen in den Range für rezente europäische Populationen (Torroni et al. 1996, Wiesbauer et al. 2006).

Bei Betrachtung der Y-chromosomalen Haplogruppen ergibt sich ein ganz anderes Bild. Es fallen deutliche Abweichungen zu rezenten Haplogruppenfrequenzen europäischer Populationen auf. Das heutige Europa wird hauptsächlich durch zwei Subhaplogruppen der Haplogruppe R dominiert. Hierbei kommt die Haplogruppe R1b mit sehr hohen Frequenzen im westlichen Europa vor, die Haplogruppe R1a dominiert im östlichen Europa (Myres 2011, Roewer 2005, Underhill 2010). Lediglich drei der Ychromosomalen Haplotypen aus der Lichtensteinhöhle lassen sich der Haplogruppe R1b 
zuordnen und zwei der Haplogruppe R1a. Die Mehrheit der Y-chromosomalen Haplotypen fällt jedoch in die Gruppe I2b, welche im heutigen Europa selten ist und über deren Entstehungs- und Verbreitungsgeschichte wenig bekannt ist. Diese Diskrepanz zu heutigen Verteilungsmustern kann natürlich wiederum ein in der Verwandtschaft begründeter Fehler sein. Es finden sich jedoch immerhin fünf verschiedene Haplotypen der Haplogruppe I2b, was ein Hinweis darauf sein könnte, dass es sich bei der Haplogruppe I2b um eine sehr alte, ursprüngliche, zentraleuropäische Haplogruppe handelt und die bronzezeitlichen Individuen durch diese Haplogruppe geprägt sind, bevor eine Verdrängung durch Populationen der Haplogruppen R1a und R1b stattfand.

Die Frequenzen der für die Individuen aus der Lichtensteinhöhle ermittelten Ychromosomalen Haplotypen in der Rezentbevölkerung wurden über die Y Chromosome Haplotype Reference Database (www.yhrd.com) bestimmt und finden sich in Tabelle 23. Sie geben insgesamt keine eindeutige Tendenz an, viele der Haplotypen finden sich weltweit in verschiedenen Metapopulationen. Alle Haplotypen sind jedoch in der eurasischen Metapopulation zu finden. 
Tabelle 23: Frequenzen der Y-chromosomalen Haplotypen aus der Lichtensteinhöhle in Rezentpopulationen.

\begin{tabular}{|c|c|c|c|}
\hline Haplotyp & Allelanzahl & Haplogruppe & Frequenz \\
\hline Y1 & 9 & $12 \mathrm{~b}$ & $\begin{array}{l}5,065 \times 10^{-5} \text { (eurasische Metapopulation) } \\
6,656 \times 10^{-5} \text { (admixed Metapopulation) }\end{array}$ \\
\hline Y2 & 9 & $12 b$ & $1,688 \times 10^{-5}$ (eurasische Metapopulation) \\
\hline Y3 & 12 & $\mathrm{R} 1 \mathrm{~b}$ & $\begin{array}{l}5,874 \times 10^{-3} \text { (eurasische Metapopulation) } \\
1,567 \times 10^{-2} \text { (australian aboriginal Metapopulation) } \\
2,533 \times 10^{-3} \text { (afrikanische Metapopulation) } \\
1,372 \times 10^{-3} \text { (native american Metapopulation) } \\
3,565 \times 10^{-3} \text { (eskimo aleut Metapopulation) } \\
3,840 \times 10^{-3} \text { (admixed Metapopulation) }\end{array}$ \\
\hline Y4 & 6 & $12 b$ & $\begin{array}{l}1,520 \times 10^{-4} \text { (eurasische Metapopulation) } \\
1,915 \times 10^{-4} \text { (afrikanische Metapopulation) }\end{array}$ \\
\hline Y5 & 9 & $\mathrm{R} 1 \mathrm{a}$ & $\begin{array}{l}1,182 \times 10^{-4} \text { (eurasische Metapopulation) } \\
4,496 \times 10^{-5} \text { (ostasiatische Metapopulation) } \\
1,585 \times 10^{-3} \text { (eskimo aleut Metapopulation) }\end{array}$ \\
\hline Y6 & 12 & $12 b$ & $1,001 \times 10^{-4}$ (eurasische Metapopulation) \\
\hline Y7 & 5 & $\mathrm{R} 1 \mathrm{a}$ & $\begin{array}{l}3,337 \times 10^{-5} \text { (eurasische Metapopulation) } \\
1,870 \times 10^{-4} \text { (ostasiatische Metapopulation) } \\
4,221 \times 10^{-4} \text { (afrikanische Metapopulation) } \\
3,241 \times 10^{-4} \text { (afro-asiatische Metapopulation) } \\
9,143 \times 10^{-5} \text { (admixed Metapopulation) }\end{array}$ \\
\hline Y8 & 6 & $12 \mathrm{~b}$ & $\begin{array}{l}6,785 \times 10^{-4} \text { (eurasische Metapopulation) } \\
4,380 \times 10^{-5} \text { (ostasiatische Metapopulation) } \\
5,744 \times 10^{-4} \text { (afrikanische Metapopulation) } \\
1,585 \times 10^{-3} \text { (eskimo aleut Metapopulation) } \\
2,021 \times 10^{-4} \text { (afro-asiatische Metapopulation) } \\
1,997 \times 10^{-4} \text { (admixed Metapopulation) }\end{array}$ \\
\hline Y9 & 4 & & $\begin{array}{l}6,305 \times 10^{-4} \text { (eurasische Metapopulation) } \\
1,477 \times 10^{-3} \text { (ostasiatische Metapopulation) } \\
1,555 \times 10^{-3} \text { (afrikanische Metapopulation) } \\
1,102 \times 10^{-3} \text { (native american Metapopulation) } \\
2,293 \times 10^{-3} \text { (afro-asiatische Metapopulation) } \\
1,462 \times 10^{-3} \text { (admixed Metapopulation) }\end{array}$ \\
\hline Y10 & 7 & $\mathrm{R} 1 \mathrm{~b}$ & $\begin{array}{l}1,274 \times 10^{-4} \text { (eurasische Metapopulation) } \\
1,624 \times 10^{-4} \text { (admixed Metapopulation) }\end{array}$ \\
\hline Y11 & 4 & $\mathrm{R} 1 \mathrm{~b}$ & $\begin{array}{l}1,750 \times 10^{-2} \text { (eurasische Metapopulation) } \\
4,717 \times 10^{-3} \text { (ostasiatische Metapopulation) } \\
5,352 \times 10^{-2} \text { (australian aboriginal Metapopulation) } \\
1,270 \times 10^{-2} \text { (afrikanische Metapopulation) } \\
1,157 \times 10^{-2} \text { (native american Metapopulation) } \\
1,902 \times 10^{-2} \text { (eskimo aleut Metapopulation) } \\
3,668 \times 10^{-3} \text { (afro-asiatische Metapopulation) } \\
2,916 \times 10^{-2} \text { (admixed Metapopulation) }\end{array}$ \\
\hline
\end{tabular}




\section{Ergebnisse vorheriger und begleitender Forschungsarbeiten zur Lichtensteinhöhle}

In der Abteilung Historische Anthropologie und Humanökologie des Johann-FriedrichBlumenbach-Institutes für Zoologie und Anthropologie der Universität Göttingen wurden seit Beginn der Ausgrabungen über die Jahre hinweg zahlreiche Examensarbeiten angefertigt, welche die Knochen aus der Lichtensteinhöhle als Untersuchungsgegenstand hatten. Insgesamt wurden 7 Dissertationen, 24 Diplomarbeiten, 2 Magisterarbeiten, 7 Staatsexamensarbeiten, 3 Masterarbeiten und 7 Bachelorarbeiten geschrieben. In einem Teil der Arbeiten wurden die Knochen aus der Lichtensteinhöhle vor allem wegen ihres außergewöhnlichen Alters in Verbindung mit gutem DNA-Erhalt lediglich als Referenzmaterial z.B. für die Methodenentwicklung herangezogen. Andere Arbeiten hingegen verfolgten konkrete Zielsetzungen bezüglich der genetischen Ausstattung und/oder der Lebensumstände der Individuen aus der Lichtensteinhöhle. Diese Arbeiten werden im Folgenden kurz zusammengefasst. Eine vollständige Auflistung aller Examensarbeiten in denen Material aus der Lichtensteinhöhle verwendet wurde, findet sich im Anhang A (Kapitel 10.2).

\subsection{Körperhöhenschätzung}

Informationen zur Körperhöhe (prä-) historischer Individuen sind in der historischen Anthropologie nicht nur als Individualdatum von Interesse, sondern vor allem auch zur Charakterisierung von Populationen. Im Populationsvergleich können dann Hinweise auf z.B. den Ernährungszustand oder den sozialen Stand einer Population gewonnen werden. So nimmt die Körpergröße in Populationen mit guten Lebensbedingungen und einem hohen sozialen Stand zu (Knußmann 1996).

Die Körperhöhe wird mittels osteometrischer Methoden über das vermessen verschiedener Langknochen mit anschließender linearer Regressionsanalyse ermittelt (Pearson 1899, Breitinger 1937, Rother 1978, Herrmann et al. 1990). Oberthür (2010) nutzte hierfür für die Individuen aus der Lichtensteinhöhle die Formeln von Pearson, da sie am besten für Populationen aus Zeiten vor Einsetzen der säkularen Akzeleration geeignet sind. Die ermittelten Körperhöhen für erwachsene Frauen und Männer aus der Lichtensteinhöhle sind den Tabellen 24 und 25 zu entnehmen. 
Tabelle 24: Übersicht über die Körperhöhe erwachsener Frauen aus der Lichtensteinhöhle.

\begin{tabular}{|c|c|c|c|}
\hline Individuum & Fund $\mathrm{Nr}$. & Körperhöhe [cm] & Skelettelement(e) \\
\hline \multirow{2}{*}{ DO FK/RG/BS 38 (F1) } & $\mathrm{DO} 26+\mathrm{DO} 27$ & \multirow{2}{*}{$161,4 \pm 3,1$} & \multirow{2}{*}{$\varnothing$ Femur + Tibia } \\
\hline & DO 26 + DO 39 & & \\
\hline DO RG/FK 58.01 & DO 58.01 + DO 65.03 & $156,7 \pm 3,1$ & Femur + Tibia \\
\hline DO RG/FK 67.03 (F10/F17) & DO 300.01 + DO 304 & $155,1 \pm 3,1$ & Femur + Tibia \\
\hline DO RG/FK/BS 1078 (F13) & DO 1044 + DO 303.01 & $157,2 \pm 3,1$ & Femur + Tibia \\
\hline \multirow{2}{*}{ DO BS/RG 1103 (F14) } & DO 1103 + DO 5522 & \multirow{2}{*}{$157,1 \pm 3,1$} & \multirow{2}{*}{$\varnothing$ Femur + Tibia } \\
\hline & DO 5518 + DO 5522 & & \\
\hline DO BS/RG 1176 (F18) & DO 200 & $162,9 \pm 3,3$ & Femur re \\
\hline DO RG/BS 1500 (F2) & DO 1827.01 + DO 1919 & $160,9 \pm 3,1$ & Femur + Tibia \\
\hline \multirow{2}{*}{ DO HS/GK 1585.03 (F19) } & DO 2579 + DO N 969.05 & \multirow{2}{*}{$150,5 \pm 3,1$} & \multirow{2}{*}{$\varnothing$ Femur + Tibia } \\
\hline & DO 2579 + DO E 06 & & \\
\hline \multirow{2}{*}{ DO GK/HS/RG 2588 (F15) } & DO 1744.06 & \multirow{2}{*}{$153,3 \pm 4,1$} & \multirow{2}{*}{$\varnothing$ Radius } \\
\hline & DO N 965.03 & & \\
\hline DO BS 3695 (F4) & DO 3695 & $165,8 \pm 4,1$ & Radius re \\
\hline \multirow{2}{*}{ DO BS 3706 (F5/F11) } & DO 3756 + DO 3720 & \multirow{2}{*}{$150,2 \pm 3,1$} & \multirow{2}{*}{$\varnothing$ Femur + Tibia } \\
\hline & DO 3990 + DO 3720 & & \\
\hline \multirow{2}{*}{ DO BS/RG 3748 (F8) } & DO 3635 + DO 3748 & \multirow{2}{*}{$166,2 \pm 3,1$} & \multirow{2}{*}{$\varnothing$ Femur + Tibia } \\
\hline & DO 3635 + DO 5533 & & \\
\hline DO BS/FK 4008 (M5) & DO 2096 & $170,0 \pm 3,5$ & Tibia re \\
\hline \multicolumn{4}{|c|}{ Durchschnittliche Körperhöhe Frauen: $158,1 \mathrm{~cm}$} \\
\hline
\end{tabular}

Tabelle 25: Übersicht über die Körperhöhe erwachsener Männer aus der Lichtensteinhöhle.

\begin{tabular}{|c|c|c|c|}
\hline Individuum & Fund Nr. & Körperhöhe [cm] & Skelettelement(e) \\
\hline DO RG/FK 57.02 (M17/M19) & DO 153.01 & $166,7 \pm 3,5$ & Tibia re \\
\hline DO FK/RG/HS 902.01 (M10) & DO 66.01 & $173,1 \pm 3,5$ & Tibia li \\
\hline DO RG/FK 1076 (M1) & $\begin{array}{l}\text { DO } 1076 \text { + DO } 1065 \\
\text { DO } 67.01 \text { + DO } 201\end{array}$ & $171,1 \pm 3,0$ & $\varnothing$ Femur + Tibia \\
\hline DO BS 1102 (M2) & $\begin{array}{l}\text { DO } 1102 \\
\text { DO } 3605\end{array}$ & $172,8 \pm 3,3$ & $\varnothing$ Femur \\
\hline DO RG/BS/DS 1482 (M3) & $\begin{array}{l}\text { DO } 1911 \text { + DO } 321 \\
\text { DO } 1186 \text { + DO } 1069\end{array}$ & $173,4 \pm 3,0$ & $\varnothing$ Femur + Tibia \\
\hline DO RG/BS 1905 (M9) & $\begin{array}{l}\text { DO } 1916 \text { + DO } 1484 \\
\text { DO } 1905 \text { + DO } 1084\end{array}$ & $168,8 \pm 3,0$ & $\varnothing$ Femur + Tibia \\
\hline DO BS/FK 3714 & DO 4077 & $163,1 \pm 3,3$ & Femur re \\
\hline DO BS/FK 4008 (M5) & DO 2096 & $170,0 \pm 3,5$ & Tibia re \\
\hline
\end{tabular}


Die ermittelten durchschnittlichen Körperhöhen von 158,1 cm für Frauen und von $169,8 \mathrm{~cm}$ für Männer passen zu den, durch Untersuchung von bronzezeitlichen Bevölkerungen gewonnenen, Erkenntnissen von Schultz (1994), nach denen in der Bronzezeit Männer Körperhöhen zwischen 169,5 cm und 170,4 cm erreichten und Frauen eine mittlere Körperhöhe von $160 \mathrm{~cm}$.

Auch im Vergleich mit rekonstruierten Körperhöhen aus Leichenbrandserien Norddeutschlands vergleichbarer und angrenzender Zeitstellungen (Schutkowski und Hummel 1990) (Abb. 83) zeigen die Individuen aus der Lichtensteinhöhle vergleichbare Charakteristika. Insbesondere fällt auf, dass der in den Leichenbrandserien für die Jüngere Bronzezeit und beginnende Eisenzeit typische, deutliche Geschlechtsdimorphismus auch in der Lichtensteinhöhle ausgeprägt ist.

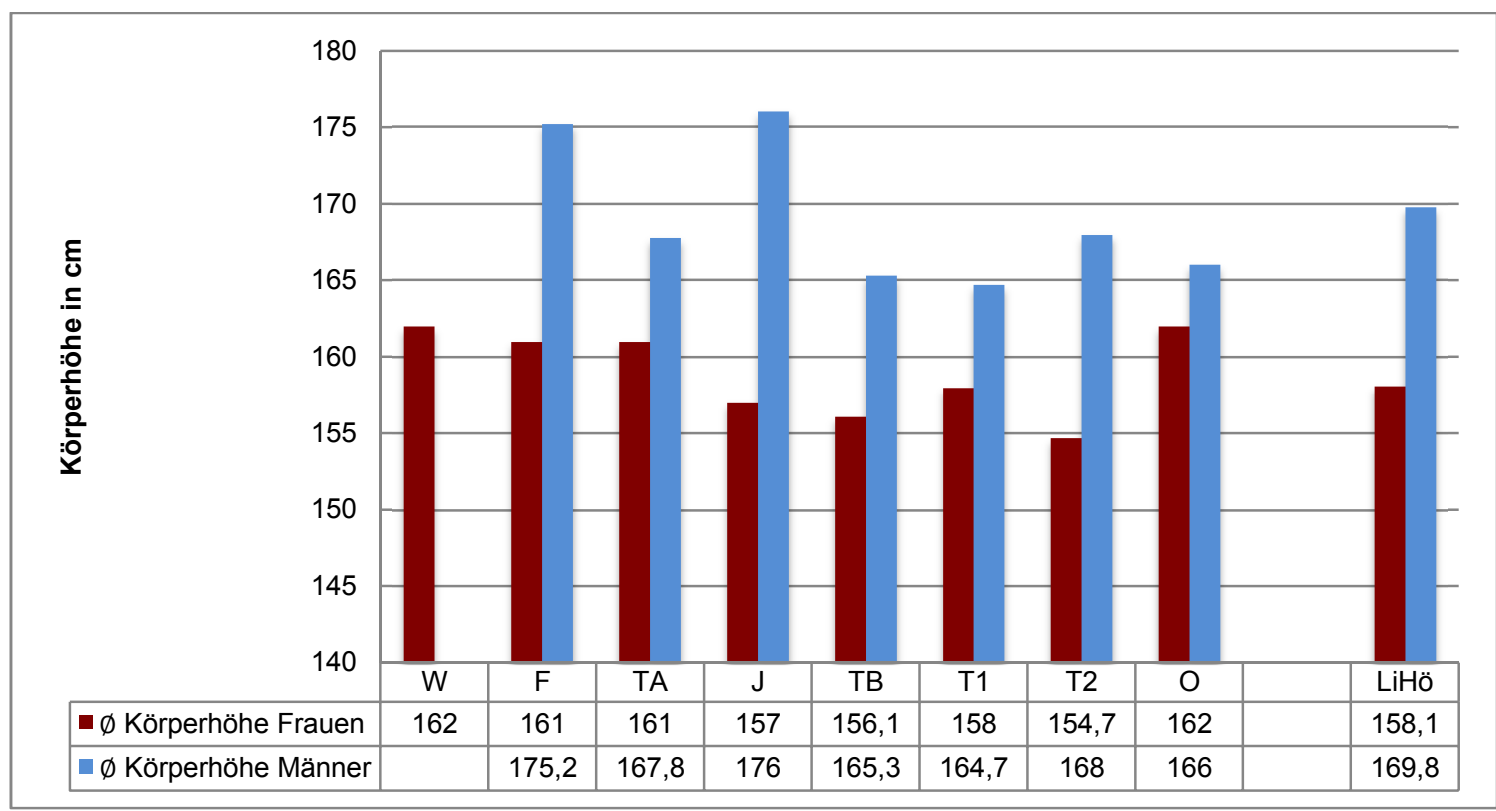

Abb. 83: Vergleich der durchschnittlichen Körperhöhen der Individuen aus der Lichtensteinhöhle ( $\mathrm{LiHö)} \mathrm{mit} \mathrm{denen} \mathrm{verschiedener} \mathrm{Leichenbrandserien.} \mathrm{W}=$ Wahlstedt, 900 600 v. Chr.; $F=$ Neumünster-Faldera, $800-500$ v. Chr.; TA $=$ Neumünster-Tungendorf A, 800550 v. Chr.; $\mathrm{J}=$ Jevenstedt, 550-200 v. Chr.; TB = Neumünster-Tungendorf B, 550-50 v. Chr.; $\mathrm{T} 1=$ Groß-Timmendorf 1, 550-200 v. Chr.; T2 = Groß-Timmendorf 2, 500-50 v. Chr.; $\mathrm{O}=$ Owschlag, $500-50 \mathrm{v}$. Chr. 


\subsection{Immungenetische Eigenschaften}

\subsubsection{Interleukine}

Die Interleukine IL6 und IL10 gehören als Zytokine zu den Botenstoffen des Immunsystems. Sie sorgen, mit anderen Botenstoffen zusammen, über ein Gleichgewicht zwischen inflammatorischen und antiinflammatorischen Reaktionen, dafür, dass das Immunsystem den Organismus schützen kann ohne ihn zu schädigen (Mocellin et al 2004). Sowohl im IL6 codierenden Gen, als auch im IL10 codierenden, wurden SNPs beschrieben, welche die Genexpression und damit auch den Zytokinspiegel und den Verlauf und Ausgang von Infektionskrankheiten beeinflussen (Turner et al. 1997, Fishman et al. 1998, Crawley et al. 1999, Trevilatto et al. 2003).

Die verschiedenen Ausprägungen der SNPs wurden in verschiedenen Studien mit Dispositionen für zahlreiche Erkrankungen in Verbindung gebracht. So wird für SNPs im IL6 Gen ein Zusammenhang hergestellt mit z.B. neonatalen Infektionen (WojsykBanaszak et al. 2005), juveniler rheumatoider Arthritis (Fishman et al. 1998), Artherosklerose (Giacconi et al. 2004), Diabetes Typ I und Typ II (Kristiansen et al. 2003, Huth et al. 2006) oder auch der Langlebigkeit (Bonafe et al. 2001, Wang et al. 2001, Christiansen et al. 2004, Giacconi et al. 2004). Für SNPs im IL10 Gen wurde ein Zusammenhang hergestellt mit z.B. Herz-Kreislauf-Erkrankungen (van den Beggelaar et al. 2004), Tuberkulose (Scola et al. 2003), Spontanaborten (van den Biggelaar et al. 2004) und auch der Langlebigkeit (Lio et al. 2004, Naumova et al. 2004).

In zwei Diplomarbeiten (Puder 2005, Suray 2007) und einem Dissertationsprojekt (Pepperl 2008) wurden SNPs im IL6 und IL10 Gen und einige weitere immungenetische Marker (IL4, IL4R $\alpha$, TLR2, TLR4) unter anderem an 35 Individuen aus der Lichtensteinhöhle untersucht. Ziel dabei war es, Erkenntnisse über die Auswirkungen von Veränderungen der Pathogenbelastung in der Umwelt auf die immungenetische Ausstattung europäischer Bevölkerungen zu erhalten.

Die Ergebnisse (siehe Tabelle 26) ergaben keinen signifikanten Unterschied der Allelfrequenzen der prähistorischen zu rezenten Populationen, was darauf hindeutet, dass das veränderte epidemiologische Geschehen der letzten 3.000 Jahre sich weniger stark als vermutet auf die immungenetischen Ausstattung ausgewirkt hat (Pepperl 2008). 
Tabelle 26: Konsensusgenotypen für immungenetisch relevante SNPs in Genen für verschiedene Interleukine (ILs) und toll like receptors (TLRs).

\begin{tabular}{|c|c|c|c|c|c|c|c|c|c|c|c|c|c|c|}
\hline Individuum [DO \#] & Fund Nr. & Element & IL6-174 & IL10-1082 & IL10-819 & IL10-592 & IL10-1087 & IL10-2849 & TLR_753 & TLR_299 & TLR_399 & IL4-524 & IL4Ra576 & Bearbeiter \\
\hline FK/HS/RG 35 (M4) & $\begin{array}{l}\text { DO } 35 \\
\text { DO } 900.03\end{array}$ & $\begin{array}{l}\text { Fe li } \\
\text { Calv }\end{array}$ & $(\mathrm{G}) /(\mathrm{C})$ & $-1-$ & $-1-$ & $-1-$ & $-1-$ & $(\mathrm{A}) /-$ & (G)/- & $-1-$ & (C)/- & $-1-$ & $(\mathrm{A}) /-$ & Suray, Pepperl \\
\hline FK/RG/BS 38 (F1) & $\begin{array}{l}\text { DO } 26 \\
\text { DO } 38\end{array}$ & $\begin{array}{l}\text { Fe li } \\
\text { Mand }\end{array}$ & $\mathrm{G} /(\mathrm{C})$ & $A / G$ & $\mathrm{C} / \mathrm{C}$ & $\mathrm{C} / \mathrm{C}$ & $G /(A)$ & $\mathrm{G} / \mathrm{A}$ & G/G & $\mathrm{A} / \mathrm{A}$ & $\mathrm{C} /(\mathrm{T})$ & $-1-$ & $\mathrm{G} / \mathrm{A}$ & Suray, Pepperl \\
\hline $\begin{array}{l}\text { RG/FK } 57.02 \\
\text { (M17/M19) }\end{array}$ & $\begin{array}{l}\text { DO } 57.02 \\
\text { DO } 153.01\end{array}$ & $\begin{array}{l}\text { Feli } \\
\text { Ti re }\end{array}$ & $(\mathrm{G}) / \mathrm{C}$ & (A)/- & (C)/- & $-1-$ & $\mathrm{A} /-$ & $(\mathrm{G}) / \mathrm{A}$ & G/- & $-1-$ & $\mathrm{C} /-$ & $\mathrm{C} /-$ & (G)/A & Suray, Pepperl \\
\hline RG/FK 58.03 (M13) & DO 58.03 & Feli & G/G & & & & $A /-$ & $\mathrm{G} / \mathrm{A}$ & G/G & $A /-$ & $\mathrm{C} / \mathrm{C}$ & (C)/- & $A /-$ & Pepperl \\
\hline RG/FK/KS 58.08 (M7) & $\begin{array}{l}\text { DO } 910.01 \\
\text { DO } 3.01\end{array}$ & $\begin{array}{l}\text { Calv } \\
\mathrm{pp}\end{array}$ & $\mathrm{G} / \mathrm{C}$ & & & & $\mathrm{G} / \mathrm{A}$ & $(\mathrm{G}) / \mathrm{A}$ & G/G & A/- & $\mathrm{C} / \mathrm{C}$ & $\mathrm{C} /-$ & $\mathrm{G} / \mathrm{A}$ & Pepperl \\
\hline RG/FK 67.03 (F10/F17) & $\begin{array}{l}\text { DO } 300.01 \\
\text { DO } 302 \\
\text { DO } 1046\end{array}$ & $\begin{array}{l}\text { Fe li } \\
\text { Mand } \\
\text { Calv }\end{array}$ & $\mathrm{G} /(\mathrm{C})$ & & & & G/G & $\mathrm{G} / \mathrm{A}$ & $\mathrm{G} /(\mathrm{A})$ & $\mathrm{A} / \mathrm{A}$ & $\mathrm{C} / \mathrm{C}$ & $\mathrm{C} / \mathrm{C}$ & $\mathrm{G} / \mathrm{A}$ & Pepperl \\
\hline $\begin{array}{l}\text { RG/GK/BS } 183.01 \\
\text { (M11) }\end{array}$ & DO 183.01 & Fe li & (C)/- & $-1-$ & $-1-$ & $(\mathrm{A}) /-$ & (A)/- & $(G) /(A)$ & (G)/- & $-1-$ & (C)/- & $-/$ & (A)/- & Suray, Pepperl \\
\hline $\begin{array}{l}\text { FK/RG/HS/BS } 901.01 \\
\text { (M18/F16) }\end{array}$ & $\begin{array}{l}\text { DO } 900.01 \\
\text { DO R } 2\end{array}$ & $\begin{array}{l}\text { Fe li } \\
\text { Calv }\end{array}$ & (C)/- & & & & $\mathrm{A} /-$ & $(G) /(A)$ & G/- & $(A) /(G)$ & C/- & (C)/- & $\mathrm{A} /-$ & Pepperl \\
\hline $\begin{array}{l}\text { FK/RG/HS } 902.01 \\
\text { (M10) }\end{array}$ & $\begin{array}{l}\text { DO } 902.01 \\
\text { DO } 480.01\end{array}$ & $\begin{array}{l}\text { Fe li } \\
\text { Mand }\end{array}$ & $\mathrm{C} /-$ & & & & G/A & $\mathrm{A} /-$ & G/G & $A / G$ & $\mathrm{C} / \mathrm{C}$ & $\mathrm{C} / \mathrm{C}$ & $\mathrm{G} / \mathrm{A}$ & Pepperl \\
\hline FK/RG 905.01 (M14) & DO 905.01 & Fe li & $-/-$ & & & & $-/-$ & $(G) /(A)$ & $(\mathrm{G}) /-$ & $-/-$ & $-/-$ & (C)/- & $(G) /-$ & Pepperl \\
\hline RG/FK 1076 (M1) & $\begin{array}{l}\text { DO } 1076 \\
\text { DO } 1172.01\end{array}$ & $\begin{array}{l}\text { Fe li } \\
\text { Mand }\end{array}$ & $\mathrm{G} / \mathrm{C}$ & $\mathrm{A} / \mathrm{A}$ & $\mathrm{C} / \mathrm{T}$ & $\mathrm{C} / \mathrm{A}$ & $\mathrm{A} /-$ & $\mathrm{G} / \mathrm{A}$ & $G /(A)$ & (A)/- & $\mathrm{C} / \mathrm{C}$ & (C)/- & $\mathrm{G} / \mathrm{A}$ & Suray, Pepperl \\
\hline RG/FK/BS 1078 (F13) & DO 1044 & Fe li & $-/-$ & $\mathrm{A} / \mathrm{A}$ & $\mathrm{C} / \mathrm{T}$ & $\mathrm{C} /(\mathrm{A})$ & $-/-$ & (A)/- & $(\mathrm{G}) /-$ & $-/-$ & (C)/- & (C)/- & $(A) /-$ & Suray, Pepperl \\
\hline BS 1102 (M2) & DO 1102 & Fe li & $\mathrm{G} /(\mathrm{C})$ & $A /(G)$ & $\mathrm{C} /-$ & $\mathrm{C} /-$ & $-/-$ & $\mathrm{A} /-$ & $\mathrm{G} /(\mathrm{A})$ & $\mathrm{A} /-$ & $\mathrm{C} /-$ & $-/-$ & $\mathrm{A} /-$ & Suray, Pepperl \\
\hline BS/RG 1103 (F14) & $\begin{array}{l}\text { DO } 1103 \\
\text { DO } 4309\end{array}$ & $\begin{array}{l}\text { Fe li } \\
\text { Mand }\end{array}$ & $\mathrm{C} / \mathrm{C}$ & & & & $\mathrm{A} / \mathrm{A}$ & $\mathrm{G} / \mathrm{A}$ & $\mathrm{G} /(\mathrm{A})$ & $\mathrm{A} / \mathrm{A}$ & $\mathrm{C} / \mathrm{C}$ & $\mathrm{C} /-$ & $\mathrm{G} / \mathrm{A}$ & Pepperl \\
\hline BS/RG 1176 (F18) & DO 1176 & Calv & (G)/- & & & & $(\mathrm{G}) /(\mathrm{A})$ & $-1-$ & (G)/- & (A)/- & (C)/- & (C)/- & (A)/- & Pepperl \\
\hline BS/RG/FK 1247 (F7) & $\begin{array}{l}\text { DO } 1206.01 \\
\text { DO } 1247\end{array}$ & $\begin{array}{l}\text { Fe li } \\
\text { Mand }\end{array}$ & (C)/- & $(A) /(G)$ & $\mathrm{C} / \mathrm{T}$ & $\mathrm{C} /(\mathrm{A})$ & $\mathrm{G} / \mathrm{A}$ & $(G) /(A)$ & $-1-$ & $\mathrm{A} /-$ & (C)/- & (C)/- & $A /-$ & Suray, Pepperl \\
\hline RG/BS/DS 1482 (M3) & DO 1911 & Feli & $\mathrm{C} / \mathrm{C}$ & A/- & (C)/T & (C)/(A) & $(\mathrm{A}) /-$ & $\mathrm{G} / \mathrm{A}$ & G/G & $\mathrm{A} /-$ & $\mathrm{C} / \mathrm{C}$ & (C)/- & $\mathrm{A} /-$ & Suray, Pepperl \\
\hline
\end{tabular}


Fortsetzung Tabelle 26: Konsensusgenotypen für immungenetisch relevante SNPs in Genen für verschiedene Interleukine (ILs) und toll like receptors (TLRs).

\begin{tabular}{|c|c|c|c|c|c|c|c|c|c|c|c|c|c|c|}
\hline Individuum [DO \#] & Fund $\mathrm{Nr}$. & Element & IL6-174 & IL10-1082 & IL10-819 & IL10-592 & IL10-1087 & IL10-2849 & TLR_753 & TLR_299 & TLR_399 & IL4-524 & IL4Ra576 & Bearbeiter \\
\hline RG/BS 1500 (F2) & DO 1500 & Fe li & $\mathrm{G} /(\mathrm{C})$ & (A)/- & $-/-$ & $-/-$ & $-/-$ & $(\mathrm{G}) /(\mathrm{A})$ & $(\mathrm{G}) /-$ & (A)/- & (C)/- & $-1-$ & (G)/A & Suray, Pepperl \\
\hline HS/GK 1585.03 (F19) & DO 1585.04 & Calc li & $\mathrm{G} / \mathrm{C}$ & & & & $-/-$ & (G)/A & G/- & $-/-$ & $\mathrm{C} /-$ & $-/-$ & $A /-$ & Pepperl \\
\hline RG/BS 1905 (M9) & DO 1916 & Feli & G/G & & & & $(G) /-$ & $\mathrm{G} / \mathrm{A}$ & G/G & A/- & $\mathrm{C} / \mathrm{C}$ & (C)/- & $\mathrm{A} /-$ & Pepperl \\
\hline BS/FK 2030.01 (M6) & DO 2030.01 & Fe li & $-/-$ & & & & $(G) /(A)$ & $(G) /(A)$ & $(G) /-$ & (G)/- & (C)/- & (C)/- & $-1-$ & Pepperl \\
\hline GK/HS/RG 2588 (F15) & DO 2589 & Mand & $-1-$ & & & & $-1-$ & $(G) /(A)$ & G/- & A/- & $\mathrm{C} /-$ & -- & $(\mathrm{G}) / \mathrm{A}$ & Pepperl \\
\hline KS 3190.11 (F20) & DO 3190.11 & Mand & $-/-$ & & & & $-1-$ & $(G) /(A)$ & $-1-$ & $-1-$ & $-1-$ & -- & $\mathrm{A} /-$ & Pepperl \\
\hline BS 3628 (F3) & $\begin{array}{l}\text { DO } 1746.05 \\
\text { DO } 1746.06\end{array}$ & Calv & $\mathrm{C} /-$ & $A / G$ & $\mathrm{C} / \mathrm{T}$ & $\mathrm{C} / \mathrm{A}$ & $-1-$ & (A)/- & G/G & $\mathrm{A} /-$ & $\mathrm{C} / \mathrm{C}$ & (C)/- & $\mathrm{G} / \mathrm{A}$ & Suray, Pepperl \\
\hline BS 3695 (F4) & $\begin{array}{l}\text { DO } 4078 \\
\text { DO } 5516\end{array}$ & $\begin{array}{l}\text { Mand } \\
\text { Calv }\end{array}$ & $\mathrm{C} /(\mathrm{G})$ & G/G & $\mathrm{C} / \mathrm{C}$ & $\mathrm{C} / \mathrm{C}$ & $\mathrm{G} / \mathrm{G}$ & $\mathrm{G} / \mathrm{A}$ & G/G & $\mathrm{A} / \mathrm{A}$ & $\mathrm{C} /-$ & (C)/- & $\mathrm{A} / \mathrm{A}$ & Suray, Pepperl \\
\hline BS 3706 (F5/F11) & $\begin{array}{l}\text { DO } 3756 \\
\text { DO } 3713 \\
\text { DO } 3706\end{array}$ & $\begin{array}{l}\text { Fe li } \\
\text { Mand } \\
\text { Calv }\end{array}$ & $(\mathrm{G}) / \mathrm{C}$ & G/G & $\mathrm{C} / \mathrm{C}$ & $\mathrm{C} / \mathrm{C}$ & (G)/- & $\mathrm{G} / \mathrm{A}$ & G/G & $\mathrm{A} /-$ & $\mathrm{C} / \mathrm{C}$ & $\mathrm{C} /-$ & A/- & Suray, Pepperl \\
\hline BS/FK 3742 (F9) & $\begin{array}{l}\text { DO } 3742 \\
\text { DO } 3746 \\
\text { DO } 3705\end{array}$ & $\begin{array}{l}\text { Fe li } \\
\text { Mand } \\
\text { Calv }\end{array}$ & $\mathrm{G} / \mathrm{C}$ & $-1-$ & (C)/- & (C)/- & $\mathrm{G} / \mathrm{A}$ & $\mathrm{G} / \mathrm{A}$ & G/G & $A / A$ & $\mathrm{C} / \mathrm{C}$ & $\mathrm{C} /-$ & $\mathrm{G} / \mathrm{A}$ & Suray, Pepperl \\
\hline BS/RG 3748 (F8) & DO 3631 & Calv & $\mathrm{C} /-$ & $A / G$ & $\mathrm{C} / \mathrm{T}$ & C/A & $\mathrm{G} / \mathrm{A}$ & $(G) /(A)$ & G/G & $\mathrm{A} / \mathrm{A}$ & $\mathrm{C} /-$ & $\mathrm{C} / \mathrm{C}$ & $\mathrm{A} / \mathrm{A}$ & Suray, Pepperl \\
\hline BS 3757 (M8) & $\begin{array}{l}\text { DO } 3757 \\
\text { DO } 4003\end{array}$ & Calv & $\mathrm{C} / \mathrm{C}$ & $A / G$ & $\mathrm{C} / \mathrm{T}$ & $\mathrm{C} / \mathrm{A}$ & $(G) /(A)$ & G/- & G/G & (A)/- & $\mathrm{C} / \mathrm{C}$ & (C)/- & $(\mathrm{A}) /-$ & Suray, Pepperl \\
\hline BS 3886 (M16) & DO 3886 & $\mathrm{pp}$ & $\mathrm{G} / \mathrm{C}$ & $\mathrm{A} / \mathrm{G}$ & $\mathrm{C} / \mathrm{T}$ & $\mathrm{C} / \mathrm{A}$ & $\mathrm{G} / \mathrm{A}$ & $\mathrm{G} / \mathrm{A}$ & G/G & $\mathrm{A} / \mathrm{A}$ & $\mathrm{C} / \mathrm{C}$ & $\mathrm{C} / \mathrm{C}$ & $\mathrm{A} / \mathrm{A}$ & Suray, Pepperl \\
\hline BS/FK 4008 (M5) & $\begin{array}{l}\text { DO } 3380.01 \\
\text { DO } 908\end{array}$ & $\begin{array}{l}\text { Mand } \\
\text { Calv }\end{array}$ & $-/$ & $A / G$ & $C /(T)$ & $\mathrm{C} /(\mathrm{A})$ & $-1-$ & (A)/- & $-1-$ & $-1-$ & $-/-$ & $-/$ & (A)/- & Suray, Pepperl \\
\hline BS 5517 (F6) & $\begin{array}{l}\text { DO } 3750 \\
\text { DO } 3709 \\
\text { DO } 5517\end{array}$ & $\begin{array}{l}\text { Fe li } \\
\text { Mand } \\
\text { Calv }\end{array}$ & $\mathrm{C} /-$ & $(\mathrm{A}) / \mathrm{G}$ & $\mathrm{C} /(\mathrm{T})$ & $\mathrm{C} /(\mathrm{A})$ & $\mathrm{G} / \mathrm{A}$ & (A)/- & G/- & $\mathrm{A} / \mathrm{A}$ & $\mathrm{C} /-$ & $\mathrm{C} / \mathrm{C}$ & $\mathrm{A} / \mathrm{A}$ & Suray, Pepperl \\
\hline E 33 (M12) & DOE 33 & Mand & $-/-$ & $A / G$ & $\mathrm{C} / \mathrm{T}$ & $\mathrm{C} / \mathrm{A}$ & $-1-$ & (A)/- & $(\mathrm{G}) /-$ & $-1-$ & (C)/- & $-1-$ & $(A) /-$ & Suray, Pepperl \\
\hline E 37 (F21) & DO E37 & Calv & -- & $-1-$ & -- & $-1-$ & -- & (A)/- & $-/-$ & (A)/- & $-/-$ & $-1-$ & (A)/- & Suray, Pepperl \\
\hline RG/FK R 1 (F12) & DO R 1 & Calv & $\mathrm{C} / \mathrm{C}$ & $A / A$ & $\mathrm{C} / \mathrm{T}$ & $\mathrm{C} / \mathrm{A}$ & $\mathrm{A} /-$ & $\mathrm{G} / \mathrm{A}$ & G/G & $\mathrm{A} /-$ & $\mathrm{C} / \mathrm{C}$ & $-1-$ & $\mathrm{A} /-$ & Suray, Pepperl \\
\hline
\end{tabular}




\subsubsection{CCR5}

Anfang der 90er Jahre wurde die medizinische Forschung im Zusammenhang mit der AIDS-Forschung auf eine 32 bp Deletions-Variante des Gens für den Cystein-Cystein linked Chemokin-Rezeptor 5 (CCR5) aufmerksam (z.B. Dragic et al. 1996). Die $\Delta 32$ Variante bewirkt eine unvollständige Genexpression wodurch - bei homozygotem Vorliegen des $\Delta 32$-Allels - der Oberflächenrezeptor nicht auf der Zelloberfläche ausgeprägt ist. Dies führt dazu, dass Träger des HI-Virus gegen einen Ausbruch der AIDS-Erkrankung immun sind (z.B. Dean et al. 1996). Bei heterozygoten Trägern des $\Delta 32$-Allels ist die Zahl der Oberflächenrezeptoren vermindert und eine akute AIDSErkrankung beginnt häufig erst verzögert (Rappaport et al. 1997). Homozygote Träger sind ansonsten unauffällig, was dafür spricht, dass die normalen Funktionen dieses Oberflächenrezeptors von anderen Rezeptoren übernommen werden können (Lederman et al. 2006). Seit Entdeckung der Mutation wurde jedoch auch mit dem Verlauf diverser anderer Erkrankungen ein Zusammenhang hergestellt. Hierzu gehören z.B. eine schnelle Erholung von Hepatits B (Thio et al. 2006), ein verzögerter Beginn von Schizophrenie-Erkrankung (Rasmussen et al. 2006) und ein milderer Krankheitsverlauf bei rheumatischer Arthritis (Garred et al. 1998, Zapico et al. 2000).

In der Verteilung der Frequenz der $\Delta 32$ Mutation in eurasischen Populationen findet sich ein starkes Nord-Süd-Gefälle, während die Mutation in nicht europäisch stämmigen Populationen vollkommen fehlt (Martinson et al. 1997, Libert et al. 1998). Dies wurde als Hinweis auf eine Entstehung durch ein singuläres Mutationsereignis nach Abspaltung der kaukasischen von der afrikanischen Entwicklungslinie gedeutet (Dean et al. 1996, Stephens et al. 1998). Schätzungen des Alters der Mutation reichen von 700 (Stephens et al. 1998) bis 5.000 (Sabeti et al. 2005) Jahre. Diese Schätzungen beruhen auf Untersuchungen des Ausmaßes an Mutations- und Rekombinationsereignissen an Genloci, welche in starkem linkage disequlibrium mit dem CCR5 Locus stehen. Dies ist für die Dinukleotid-STRs IRI 3.1 und IRI 3.2 gegeben. Die Kenntnis eines sogenannten ancient haplotype für diese Marker, der gekoppelt mit dem $\Delta 32-$ Allel vererbt wird, ermöglicht die o.g. Untersuchungen (Galvani und Novembre 2005, Hummel et al. 2005).

Die genetischen Marker CCR5, IRI 3.1 und IRI 3.2 wurden in zwei Examensarbeiten für insgesamt 43 Individuen aus der Lichtensteinhöhle analysiert (Bertermann 2004, Mazanec 2010) um evtl. weitere Hinweise auf das Alter der $\Delta 32$ Mutation zu erlangen. Die Typisierungsergebnisse finden sich in Tabelle 27. 
Für das $\Delta 32$-Allel wurde eine Frequenz von 11,3\% festgestellt (Mazanec 2010), was ungefähr der heutigen durchschnittlichen Frequenz in Eurasien von 10 \% (Martinson et al. 1997) entspricht. Die Ergebnisse deuten darauf hin, dass in den vergangenen 3.000 Jahren kein starker Selektionsdruck auf die Mutation gewirkt hat, was die bisherigen Altersschätzungen eher unwahrscheinlich macht (Mazanec 2010). Eine neue Abschätzung des Alters war nicht möglich, da durch die Ergebnisse der STR-Marker IRI 3.1 und IRI 3.2 die bisherige Definition des ancient haplotypes in Frage gestellt wurde. Die für den Marker IRI 3.1 ermittelte Abweichung um eine repeat unit zwischen der bronzezeitlichen und der rezenten Population deutet jedoch auf ein relativ hohes Alter des Mutationsereignisses hin.

Tabelle 27: Konsenusgenotypen des Markers CCR5, sowie der STRs IRI 3.1 und IRI 3.2.

\begin{tabular}{|c|c|c|c|c|c|c|}
\hline Individuum [DO \#] & Fund Nr. & Element & CCR5 & IRI 3.1 & IRI 3.2 & Bearbeiter \\
\hline FK/HS/RG 35 (M4) & $\begin{array}{l}\text { DO } 35 \\
\text { DO } 900.03\end{array}$ & $\begin{array}{l}\text { Fe li } \\
\text { Calv }\end{array}$ & $w t /-$ & $((112) /((116))$ & $-1-$ & Mazanec \\
\hline FK/RG/BS 38 (F1) & DO 26 & Fe li & $w t / w t$ & $114 / 122$ & $165 / 169$ & Bertermann \\
\hline RG/FK 57.02 (M17/M19) & DO 153.01 & Tire & $w t /(w t)$ & $(((12)) /((116))$ & $145 /((157))$ & Mazanec \\
\hline RG/FK 58.01 & DO 58.01 & Fe li & $w t /-$ & $((114)) /((118))$ & $((139)) /((163))$ & Mazanec \\
\hline RG/FK 58.03 (M13) & DO 58.03 & Fe li & $w t / w t$ & $112 /-$ & $145 /-$ & $\begin{array}{l}\text { Bertermann } \\
\text { Mazanec }\end{array}$ \\
\hline RG/FK/KS 58.08 (M7) & DO 58.08 & Fe re & $w t /-$ & $-1-$ & $-1-$ & Mazanec \\
\hline RG 66.02 & DO 66.02 & Fe li & wt/- & $(112) /-$ & $145 /((169))$ & Mazanec \\
\hline RG/FK 67.03 (F10/F17) & $\begin{array}{l}\text { DO } 300.01 \\
\text { DO } 67.03\end{array}$ & $\begin{array}{l}\text { Fe li } \\
\text { Fe re }\end{array}$ & $w t / w t$ & $106 / 118$ & $((159)) /-$ & $\begin{array}{l}\text { Bertermann } \\
\text { Mazanec }\end{array}$ \\
\hline RG/GK/BS 183.01 (M11) & DO 183.01 & Fe li & $w t / \Delta 32$ & $108 / 116$ & $151 /((161))$ & $\begin{array}{l}\text { Bertermann } \\
\text { Mazanec }\end{array}$ \\
\hline $\begin{array}{l}\text { FK/RG/HS/BS } 901.01 \\
\text { (M18/F16) }\end{array}$ & DO 901.01 & Fe li & $w t /(w t)$ & $((110)) /-$ & $-1-$ & Mazanec \\
\hline FK/RG/HS 902.01 (M10) & DO 902.01 & Fe li & $w t / \Delta 32$ & $108 / 116$ & $151 / 171$ & Bertermann \\
\hline FK/HS/RG/BS 903.01 & DO 903.01 & Fe li & $w t /-$ & $-1-$ & $((161)) /-$ & Mazanec \\
\hline FK/RG/HS/BS 903.02 & DO 903.02 & Fe re & $w t /-$ & $-1-$ & $-1-$ & Mazanec \\
\hline FK/RG/JS 904.04 & DO 904.05 & Ti re & $-1-$ & $-1-$ & $-1-$ & Mazanec \\
\hline FK/RG 905.01 (M14) & $\begin{array}{l}\text { DO } 901.02 \\
\text { DO } 905.01\end{array}$ & $\begin{array}{l}\text { Hu li } \\
\text { Fe li }\end{array}$ & $w t / w t$ & $120 /-$ & $(((155)) /((165))$ & Mazanec \\
\hline FK/RG/BS 907.01 & DO 907.01 & Fe li & $w t /(w t)$ & $(((106)) /((114))$ & $(139) /((159))$ & Mazanec \\
\hline RG/FK 1076 (M1) & DO 1076 & Fe li & $w t /-$ & $114 / 118$ & $139 / 159$ & Bertermann \\
\hline RG/FK/BS 1078 (F13) & $\begin{array}{l}\text { DO } 1044 \\
\text { DO } 385\end{array}$ & $\begin{array}{l}\text { Fe li } \\
\text { Fe re }\end{array}$ & $w t / w t$ & $(112) / 118$ & $((139)) /(157)$ & $\begin{array}{l}\text { Bertermann } \\
\text { Mazanec }\end{array}$ \\
\hline BS 1102 (M2) & DO 1102 & Fe li & $w t / w t$ & $114 / 118$ & $161 / 169$ & Bertermann \\
\hline BS/RG 1103 (F14) & DO 1103 & Fe li & $w t / \Delta 32$ & $106 / 118$ & $151 / 161$ & Bertermann \\
\hline BS/RG 1176 (F18) & $\begin{array}{l}\text { DO } 199 \\
\text { DO } 2133\end{array}$ & $\begin{array}{l}\text { Fe li } \\
\text { Mand }\end{array}$ & $w t / \Delta 32$ & $118 /-$ & $151 / 159$ & $\begin{array}{l}\text { Bertermann } \\
\text { Mazanec }\end{array}$ \\
\hline BS/RG/FK 1247 (F7) & $\begin{array}{l}\text { DO } 1928 \\
\text { DO } 1247\end{array}$ & $\begin{array}{l}\text { Fe re } \\
\text { Mand }\end{array}$ & $\mathrm{wt} /((\Delta 32))$ & $112 /-$ & $139 / 165$ & Mazanec \\
\hline HS/GK 1461 & DO 3157 & Tili & $w t / w t$ & $114 /-$ & $139 / 159$ & Mazanec \\
\hline
\end{tabular}


Fortsetzung Tabelle 27: Konsenusgenotypen des Markers CCR5, sowie der STRs IRI 3.1 und IRI 3.2 .

\begin{tabular}{|c|c|c|c|c|c|c|}
\hline Individuum [DO \#] & Fund $\mathrm{Nr}$. & Element & CCR5 & IRI 3.1 & IRI 3.2 & Bearbeiter \\
\hline HS/GK/BS 1471 & DO 1457 & Fe re & $w t /((\Delta 32))$ & $(122) /-$ & $((159)) /(165)$ & Mazanec \\
\hline RG/BS/DS 1482 (M3) & DO 1911 & Fe li & $w t /(\Delta 32)$ & $112 /-$ & $139 /((159))$ & $\begin{array}{l}\text { Bertermann } \\
\text { Mazanec }\end{array}$ \\
\hline RG/BS 1500 (F2) & DO 1500 & Feli & $w t / w t$ & $106 / 112$ & $139 / 153$ & Bertermann \\
\hline HS/GK 1547.01 & DO 1547.01 & Ti li & $-/-$ & $-/-$ & $-/-$ & Mazanec \\
\hline HS/GK 1547.03 & DO 3299 & Ti re & $w t / w t$ & $106 / 114$ & $-/-$ & Mazanec \\
\hline HS/GK 1548.01 & DO 1548.01 & Ti re & $w t / w t$ & $112 / 122$ & $-1-$ & Mazanec \\
\hline HS/GK 1585.03 (F19) & $\begin{array}{l}\text { DO N } 968.04 \\
\text { DO } 1585.07\end{array}$ & $\begin{array}{l}\text { Hu li } \\
\text { Fe li }\end{array}$ & $w t / w t$ & $116 /-$ & $161 /-$ & Mazanec \\
\hline BS/FK/GK/HS 1745.02 & DO 1745.02 & Cox li & wt/wt & $106 / 112$ & $((149)) / 169$ & Mazanec \\
\hline RG/BS 1905 (M9) & $\begin{array}{l}\text { DO } 1917 \\
\text { DO } 1948 \\
\text { DO } 1916\end{array}$ & $\begin{array}{l}\text { Hu re } \\
\text { Hu li } \\
\text { Fe li }\end{array}$ & wt/wt & $114 /-$ & $139 / 173$ & $\begin{array}{l}\text { Bertermann } \\
\text { Mazanec }\end{array}$ \\
\hline BS/FK 2030.01 (M6) & DO 2030.01 & Fe li & $w t / w t$ & $112 / 122$ & $((139)) /((165))$ & $\begin{array}{l}\text { Bertermann } \\
\text { Mazanec }\end{array}$ \\
\hline GK/HS/RG 2588 (F15) & DO 2588 & Tire & $w t / w t$ & $112 / 120$ & $(139) / 165$ & Mazanec \\
\hline BS 3628 (F3) & DO 4374 & Fe re & $w t /(w t)$ & $106 / 118$ & $((151)) /(159)$ & Mazanec \\
\hline BS 3695 (F4) & DO 3727 & Fe li & $-1-$ & $-1-$ & $((171)) /-$ & Mazanec \\
\hline BS 3706 (F5/F11) & DO 3756 & Fe li & wt/- & $114 / 118$ & $159 /-$ & Bertermann \\
\hline BS/FK 3742 (F9) & DO 3742 & Fe li & $w t / \Delta 32$ & $108 / 118$ & $161 /-$ & Bertermann \\
\hline BS/RG 3748 (F8) & $\begin{array}{l}\text { DO } 5521 \\
\text { DO } 3635\end{array}$ & $\begin{array}{l}\text { Hu re } \\
\text { Fe re }\end{array}$ & $w t / w t$ & $112 /-$ & $139 / 169$ & Mazanec \\
\hline BS 3757 (M8) & DO 3757 & Calv & $w t / w t$ & $(112) /((118))$ & $(139) /-$ & Mazanec \\
\hline BS/FK 4008 (M5) & $\begin{array}{l}\text { DO } 3752 \\
\text { DO } 3380.01\end{array}$ & $\begin{array}{l}\text { Fe re } \\
\text { Mand }\end{array}$ & $w t /(w t)$ & $112 /-$ & $-/-$ & Mazanec \\
\hline BS/GK 4310.01 & DO 3812 & Hu li & wt/- & $-1-$ & $(((145)) /-$ & Mazanec \\
\hline BS 5517 (F6) & DO 3750 & Fe li & $w t / w t$ & $((114)) /-$ & $-/-$ & $\begin{array}{l}\text { Bertermann } \\
\text { Mazanec }\end{array}$ \\
\hline
\end{tabular}

\subsubsection{Rhesusfaktor}

Das Rhesus Blutgruppensystem wurde Ende der 1930er Jahre entdeckt (Wiener 1946). Grundlage sind zwei Rhesus-Proteine - RhCE und RhD - die auf der Erythrozytenmembran exprimiert werden (Agre und Cartron 1991). Diese beiden Proteine werden durch zwei gleichnamige Gene codiert welche auf 1p34.1-p36 in direkter Nähe zueinander mit entgegengesetzter Orientierung und einer Homologie von 93,8 \% zueinander lokalisiert sind (Chérif-Zahar et al. 1991, Okuda et al. 1999, Okuda et al. 2000, Wagner und Flegel 2000,). Es wird vermutet, dass das RHD-Gen aus einer Duplikation des RHCE-Gens hervorgegangen ist (Le van Kim et al. 1992, Wagner und Flegel 2002). Das Alter dieser Duplikation wird auf 8-11 Millionen Jahre vor Heute geschätzt (Cartron 1994, Matassi et al. 1999). 
Bei einem geringen Anteil der weltweiten Bevölkerung fehlt jedoch das RhD Protein. Während dies für ca. $15 \%$ aller Europäer und 3-5\% der Afrikaner der Fall ist, sind nahezu alle Asiaten rhesuspositiv (Daniels et al. 2002). Ursache für das Fehlen des Proteins ist meist das komplette Fehlen des RHD-Gens (Colin et al. 1991). Wann dieser sekundäre Verlust aufgetreten ist, ist allerdings bislang unbekannt.

Der Rhesusstatus einer Person ist zum einen in der Transfusionsmedizin relevant, da es bei Transfusionen mit nicht kompatiblem Blut bei rhesusnegativen Personen zur Antikörperbildung kommt. Bei erneuter Transfusion mit rhesuspositivem Blut kommt es zur Immunantwort, die zur Hämolyse führt, welche tödlich verlaufen kann (Cartron 1994, Avent und Reid 2000). Wegen dieses immungenetischen Mechanismus ist der Rhesusstatus auch in der Gynäkologie relevant. Bekommt eine rhesusnegative Frau ein rhesuspositives Kind, kommt es durch fetale Erythrozyten, die in den Kreislauf der Mutter gelangen, zur Antikörperbildung. Wird sie erneut mit einem rhesuspositiven Kind schwanger, kommt es zu einer Abwehrreaktion, die mit hoher Wahrscheinlichkeit einen Abort verursachen kann. Inzwischen sind Behandlungsmethoden zur Unterdrückung der Immunreaktion etabliert. In Zeiten vor diesen Behandlungsmöglichkeiten war es für rhesusnegative Frauen nahezu unmöglich mit homozygot rhesuspositiven Männern mehr als ein Kind zu bekommen.

Da ein rhesusnegativer Status also für Frauen einen reproduktiven Nachteil bedeutet, stellt sich die Frage, wie sich die RHD negative Variante stabil in der Bevölkerung erhalten konnte. Hierfür wird z.B. ein Heterozygotenvorteil vermutet (z.B. Novotna et al. 2008). Genaue Mechanismen hierfür sind aber noch nicht umfassend bekannt.

Bei Betrachtung des Stammbaumes von Schilz (2006) für die Individuen aus der Lichtensteinhöhle schien es, als ob nur relativ wenige Kinder pro Elternpaar vorhanden waren. Eine Untersuchung des Rhesusstatus an 37 Individuen aus der Lichtensteinhöhle (Rohlf 2011) sollte zeigen, ob hierfür evtl. ein hoher Anteil an rhesusnegativen Frauen mit rhesuspositiven Männern als Reproduktionspartner ursächlich sein kann. Zudem sollte über die Feststellung der Frequenz des rhesusnegativen bzw. rhesuspositiven Status in der Population aus der Lichtensteinhöhle untersucht werden, ob sich die heutigen Frequenzen im Vergleich dazu evtl. durch selektiven Druck verändert haben.

Für die Untersuchungen wurde zunächst ein neues Analysesystem entwickelt, da bereits bekannte Systeme nicht für die Analyse von aDNA geeignet schienen. Das entwickelte System amplifiziert zwei RHD-spezifische Intronsequenzen, welche bei RHCE fehlen. Wegen der Möglichkeit des Ausbleibens dieser Signale aufgrund von allelic dropout 
und nicht aufgrund eines rhesusnegativen Status wurden zwei Kontrollfragmente mit größeren Fragmentlängen integriert, welche sowohl im RHCE-Gen als auch im RHDGen vorhanden sind. Bei rhesusnegativem Status wird also bei der Agarosegelelektrophorese ein Zwei-Banden-Muster erwartet und bei rhesuspositivem Status ein Vier-Banden-Muster.

Durch die Typisierungsergebnisse (siehe Tabelle 28) konnte ausgeschlossen werden, dass ein erhöhtes Vorkommen von rhesusnegativen Frauen mit homozygot rhesuspositiven Männern als Reproduktionspartnern der Grund für die relative „Kinderarmut“ ist. Die Frequenz des rhesusnegativen Status unterscheidet sich mit ungefähr 18,75\% nicht signifikant von der in der heutigen deutschen Bevölkerung $(17,29 \%)$. Somit scheint in den letzten 3.000 Jahren kein starker Selektionsdruck auf dieses Merkmal gewirkt zu haben (Rohlf 2011).

Tabelle 28: Konsensusgenotypen des Rhesusfaktors D.

\begin{tabular}{|c|c|c|c|c|c|c|c|c|}
\hline Individuum [DO \#] & Fund $\mathrm{Nr}$. & Element & RhDCE3 & RhD4 & RhDCE9 & RhD1 & $\begin{array}{c}\text { RhD } \\
\text { Konsenus }\end{array}$ & Bearbeiter \\
\hline FK/HS/RG 35 (M4) & DO 35 & Fe li & $x$ & - & $x$ & - & (RhD negativ) & Rohlf \\
\hline FK/RG/BS 38 (F1) & $\begin{array}{l}\text { DO } 39 \\
\text { DO } 38\end{array}$ & $\begin{array}{l}\text { Ti re } \\
\text { Mand }\end{array}$ & $x$ & $x$ & $x$ & $x$ & RhD positiv & Rohlf \\
\hline $\begin{array}{l}\text { RG/FK } 57.02 \\
\text { (M17/M19) }\end{array}$ & DO 153.01 & Ti re & $x$ & $x$ & $x$ & $x$ & RhD positiv & Rohlf \\
\hline RG/FK 58.03 (M13) & DO 58.03 & Fe li & $x$ & $x$ & $x$ & $x$ & RhD positiv & Rohlf \\
\hline RG 66.02 & DO 66.02 & Fe li & $(\mathrm{X})$ & - & - & - & nd & Rohlf \\
\hline $\begin{array}{l}\text { RG/FK } 67.03 \\
\text { (F10/F17) }\end{array}$ & DO 300.01 & Feli & $x$ & $x$ & $x$ & $x$ & RhD positiv & Rohlf \\
\hline $\begin{array}{l}\text { RG/GK/BS } 183.01 \\
\text { (M11) }\end{array}$ & DO 204.02 & Fe re & - & - & - & - & nd & Rohlf \\
\hline $\begin{array}{l}\text { FK/RG/HS/BS } 901.01 \\
\text { (M18/F16) }\end{array}$ & DO 901.01 & Fe li & $x$ & $x$ & $x$ & $x$ & RhD positiv & Rohlf \\
\hline $\begin{array}{l}\text { FK/RG/HS } 902.01 \\
\text { (M10) }\end{array}$ & DO 902.01 & Fe li & $x$ & $(\mathrm{X})$ & $x$ & $(X)$ & nd & Rohlf \\
\hline FK/HS/RG/BS 903.01 & DO 903.01 & Fe li & $(\mathrm{X})$ & $(X)$ & $(X)$ & $(\mathrm{X})$ & nd & Rohlf \\
\hline FK/RG 905.01 (M14) & $\begin{array}{l}\text { DO } 901.02 \\
\text { DO } 905.01\end{array}$ & $\begin{array}{l}\text { Hu li } \\
\text { Fe li }\end{array}$ & $x$ & $x$ & $x$ & $x$ & RhD positiv & Rohlf \\
\hline FK/RG/BS 907.01 & DO 907.01 & Fe li & $x$ & $x$ & $x$ & $x$ & RhD positiv & Rohlf \\
\hline RG/FK 1076 (M1) & DO 1076 & Fe li & $x$ & $x$ & $x$ & $x$ & RhD positiv & Rohlf \\
\hline RG/FK/BS 1078 (F13) & $\begin{array}{l}\text { DO } 1044 \\
\text { DO } 385\end{array}$ & $\begin{array}{l}\text { Fe li } \\
\text { Fe re }\end{array}$ & $x$ & $(-)$ & $x$ & $(-)$ & (RhD negativ) & Rohlf \\
\hline BS 1102 (M2) & DO 1102 & Fe li & $x$ & $x$ & $x$ & $x$ & RhD positiv & Rohlf \\
\hline BS/RG 1103 (F14) & DO 1103 & Fe li & $x$ & $x$ & $x$ & $x$ & RhD positiv & Rohlf \\
\hline BS/RG 1176 (F18) & DO 199 & Fe li & $x$ & $x$ & $x$ & $x$ & RhD positiv & Rohlf \\
\hline
\end{tabular}


Fortsetzung Tabelle 28: Konsensusgenotypen des Rhesusfaktors D.

\begin{tabular}{|c|c|c|c|c|c|c|c|c|}
\hline Individuum [DO \#] & Fund Nr. & Element & RhDCE3 & RhD4 & RhDCE9 & RhD1 & $\begin{array}{c}\text { RhD } \\
\text { Konsenus }\end{array}$ & Bearbeiter \\
\hline BS/RG/FK 1247 (F7) & $\begin{array}{l}\text { DO } 1206.01 \\
\text { DO } 1928 \\
\text { DO } 1247\end{array}$ & $\begin{array}{l}\text { Fe li } \\
\text { Fe re } \\
\text { Mand }\end{array}$ & $\mathrm{x}$ & $x$ & $x$ & $x$ & RhD positiv & Rohlf \\
\hline HS/GK 1461 & DO 3157 & Ti li & $x$ & - & $x$ & $x$ & (RhD positiv) & Rohlf \\
\hline HS/GK/BS 1471 & DO 1471 & Fe li & $x$ & $x$ & $x$ & $x$ & RhD positiv & Rohlf \\
\hline RG/BS/DS 1482 (M3) & DO 1911 & Fe li & $\mathrm{x}$ & $x$ & $x$ & $\mathrm{X}$ & RhD positiv & Rohlf \\
\hline RG/BS 1500 (F2) & DO 1827.01 & Fe re & $x$ & $x$ & $x$ & $x$ & RhD positiv & Rohlf \\
\hline HS/GK 1547.03 & DO 3299 & Ti re & $x$ & $x$ & $x$ & $x$ & RhD positiv & Rohlf \\
\hline HS/GK 1548.01 & DO 1548.01 & Ti re & $x$ & $x$ & $x$ & $x$ & RhD positiv & Rohlf \\
\hline HS/GK 1585.03 (F19) & $\begin{array}{l}\text { DO N } 968.04 \\
\text { DO } 1585.07\end{array}$ & $\begin{array}{l}\text { Hu li } \\
\text { Fe li }\end{array}$ & $x$ & $x$ & $x$ & $x$ & RhD positiv & Rohlf \\
\hline $\begin{array}{l}\text { BS/FK/GK/HS } \\
1745.02\end{array}$ & DO 3622 & Fe li & $x$ & - & $(X)$ & $(\mathrm{X})$ & nd & Rohlf \\
\hline RG/BS 1905 (M9) & $\begin{array}{l}\text { DO } 1917 \\
\text { DO } 1916\end{array}$ & $\begin{array}{l}\text { Hu re } \\
\text { Fe li }\end{array}$ & $x$ & $x$ & $\mathrm{x}$ & $x$ & RhD positiv & Rohlf \\
\hline BS/FK 2030.01 (M6) & DO 2030.01 & Fe li & $x$ & - & $x$ & - & RhD negativ & Rohlf \\
\hline $\begin{array}{l}\text { GK/HS/RG } 2588 \\
\text { (F15) }\end{array}$ & DO 2588 & Ti re & $x$ & - & $x$ & - & RhD negativ & Rohlf \\
\hline BS 3628 (F3) & DO 4374 & Fe re & $x$ & - & $x$ & - & (RhD negativ) & Rohlf \\
\hline BS 3695 (F4) & DO 4013 & Hu re & $x$ & $x$ & $x$ & $x$ & RhD positiv & Rohlf \\
\hline BS 3706 (F5/F11) & DO 3756 & Fe li & $x$ & $x$ & $x$ & $x$ & RhD positiv & Rohlf \\
\hline BS/FK 3742 (F9) & DO 3742 & Fe li & $x$ & $x$ & $x$ & $x$ & RhD positiv & Rohlf \\
\hline BS/RG 3748 (F8) & $\begin{array}{l}\text { DO } 5521 \\
\text { DO } 3635\end{array}$ & $\begin{array}{l}\text { Hu re } \\
\text { Fe re }\end{array}$ & $x$ & $x$ & $x$ & $x$ & RhD positiv & Rohlf \\
\hline BS 3757 (M8) & DO 3757 & Calv & $\mathrm{x}$ & $x$ & $x$ & $x$ & RhD positiv & Rohlf \\
\hline BS/FK 4008 (M5) & $\begin{array}{l}\text { DO } 4767 \\
\text { DO } 3752 \\
\text { DO } 2096 \\
\text { DO } 908\end{array}$ & $\begin{array}{l}\text { Hu re } \\
\text { Fe re } \\
\text { Ti re } \\
\text { Calv }\end{array}$ & $x$ & $x$ & $x$ & $(X)$ & (RhD positiv) & Rohlf \\
\hline BS 5517 (F6) & DO 3750 & Fe li & $x$ & - & $x$ & - & RhD negativ & Rohlf \\
\hline
\end{tabular}

\subsubsection{AB0}

Neben dem Rhesus-System ist das AB0 Blutguppensystem eines der wichtigsten. Die zugrundeliegenden genetischen Marker, welche die AB0 Blutgruppen determinieren, wurden von Yamamoto et al. (1990) beschrieben. Die AB0 Blutgruppengene finden sich auf 9q34 (Yip 2002, Daniels 2005) und bestehen aus mind. 7 Exons mit einem codierenden Bereich von über $18 \mathrm{~kb}$ genomischer DNA. Die Diversität der AB0-Allele ist hauptsächlich auf eine Reihe von Punktmutationen zurückzuführen. Bei Studien der verschiedenen blutgruppenbestimmenden Sequenzvariationen dieses Locus wurden mittlerweile über 100 Allele identifiziert, die meisten sind allerdings sehr seltene Allele (Ferri et al. 2004). 
Die AB0-Gene codieren eine Glykosyltransferase, die im Falle der Blutgruppe A NAcetyl D-Galactosamin und bei der Blutgruppe B D-Galactose auf die Blutproteine und Lipide überträgt. So entstehen die A- und B-Antigene. Dem Blutgruppe-0-Phänotyp liegt ein inaktives Glycosyltransferasegen zugrunde so dass das inaktive H-Antigen exprimiert wird. Zusätzlich zu den Antigenen tragen zwei Antikörper zur Bildung des Blutgruppenphänotyps bei. Bei der Vererbung der AB0-Allele verhalten sich A und B untereinander kodominant, jedoch dominant gegenüber 0 .

Die verschiedenen AB0 Blutgruppenvarianten finden sich in allen Populationen weltweit, allerdings mit teilweise sehr unterschiedlichen Frequenzen. Als Ursache für die Frequenzunterschiede kommen Einflüsse durch z.B bottleneck-Situationen oder founder-Effekte in Frage, aber auch Selektionsdrücke durch Assoziationen mit Krankheiten, welche die Reproduktionsfähigkeit beeinflussen. So haben z.B. Träger der Blutgruppe 0 ein erhöhtes Risiko schwerer Infektionskrankheiten, da einige Pathogene Antigene aufweisen, die dem körpereigenen H-Antigen stark ähneln und somit vom Immunsystem nicht erkannte werden (z.B. Glass et al. 1985, Swerdlow et al. 1994, Hennesy et al. 2003). Einige Studien weisen auf einen möglichen Selektionsdruck gegen die Blutgruppe 0 durch Epidemien von Vibrio cholerae (Glass et al. 1985, Swerdlow et al. 1994, Lagos et al. 1995, Tacket et al. 1995) oder E. coli (van Loon et al. 1991, Blackwell et al. 2002) hin.

Untersuchungen an historischen Populationen würden die Möglichkeit beinhalten, Hinweisen auf angenommene Selektionsdrücke eine zeitliche Dimension hinzuzufügen. Benachteiligungen von Trägern bestimmter Blutgruppen im Zusammenhang mit bestimmten Infektionskrankheiten wie z.B. Pest oder Cholera würden prüfbar. Zudem könnten durch diachrone Vergleiche auch Hinweise auf Besiedlungsbewegungen und andere populationsgenetische Ereignisse wie z.B. genetische Flaschenhälse oder genetische Drift möglich.

Ursprünglich wurde versucht, die Blutgruppen auch an stark degradiertem biologischem Material mittels serologischer Tests festzustellen (Boyd und Boyd 1933, Kirst et al. 1971, Borgognini-Tarli 1980). Es konnte jedoch später gezeigt werden, dass dies wenig praktikabel ist, da eingewanderte Mikroorganismen den AB0-Antigenen ähnelnde Stoffe abgeben können, die zu falschen serologischen Ergebnissen führen (z.B. Berg et al. 1983). Durch die Arbeit von Yamamoto et al. (1990) und weitere Studien (z.B. Lee und Chang 1992, Fukumori et al. 1995, Nishimukai et al. 1996, Grunnet et al. 2000, 
Ringel et al. 2000, Yip 2002) wurde die genetische Feststellung der Blutgruppen an historischem Material möglich (siehe auch Hummel et al. 2002, Schmidt 2004).

In diesem Projekt wurde ein minisequencing System zur Bestimmung der AB0 Blutgruppen über die Analyse von vier SNPs entwickelt (siehe Kap. 3.2.3 Entwicklung molekulargenetischer Analysesysteme). Mit Hilfe dieser SNPs ist es möglich die Allele A, B, 01, 01v und $02 \mathrm{zu}$ bestimmen. Zur Authentifizierung der Ergebnisse der biallelischen Marker findet eine simultane Amplifikation von 3 autosomalen STRs statt (siehe auch Georges et al. 2012).

Insgesamt konnte für 25 Individuen aus der Lichtensteinhöhle die AB0-Blutgruppe bestimmt werden (siehe Tabelle 31, folgende Seite). Tabelle 29 und Tabelle 30 zeigen die für die Individuen aus der Lichtensteinhöhle ermittelten Frequenzdaten im Vergleich mit denen für eine Stichprobe aus über 600.000 Blutspendern in Deutschland (Wagner et. al. 1995). Die für die bronzezeitlichen Individuen ermittelten Allel- und Phänotypenhäufigkeiten weisen keine Besonderheiten auf und ähneln denen rezenter mitteleuropäischer Populationen.

Tabelle 29: Prozentuale Verteilung der AB0 Blutgruppenallele.

\begin{tabular}{|c|c|c|c|c|}
\hline Allel & Anzahl & $\begin{array}{r}\text { Alle } \\
\text { Lichte }\end{array}$ & $\begin{array}{l}\text { quenz } \\
\text { einhöhle }\end{array}$ & $\begin{array}{c}\text { Allelfrequenz } \\
\text { Rezentpopulation }\end{array}$ \\
\hline A & 15 & & $30 \%$ & $27,9 \%$ \\
\hline B & 3 & & $6 \%$ & $8,1 \%$ \\
\hline 01 & 21 & $42 \%$ & \multirow{3}{*}{$64 \%$} & \multirow{3}{*}{$64 \%$} \\
\hline $01 v$ & 9 & $18 \%$ & & \\
\hline 02 & 2 & $4 \%$ & & \\
\hline
\end{tabular}

Tabelle 30: Prozentuale Verteilung der AB0 Blutgruppen.

\begin{tabular}{lccc}
\hline Phänotyp & Anzahl & $\begin{array}{c}\text { Blutgruppenfrequenz } \\
\text { Lichtensteinhöhle }\end{array}$ & $\begin{array}{c}\text { Blutgruppenfrequenz } \\
\text { Rezentpopulation }\end{array}$ \\
\hline A & 13 & $52 \%$ & $43,26 \%$ \\
B & 3 & $12 \%$ & $10,71 \%$ \\
$\mathbf{0}$ & 9 & $36 \%$ & $41,21 \%$ \\
AB & 0 & $0 \%$ & $4,82 \%$ \\
\hline
\end{tabular}


Tabelle 31: Konsensusgenotypen zur AB0-Blutgruppen-Bestimmung.

\begin{tabular}{|c|c|c|c|c|c|c|c|c|c|}
\hline Individuum [DO \#] & Fund Nr. & Element & 802 & 796 & 297 & 261 & $\begin{array}{l}\text { Geno- } \\
\text { typ }\end{array}$ & $\begin{array}{l}\text { Phäno- } \\
\text { typ }\end{array}$ & Bearbeiter \\
\hline FK/HS/RG 35 (M4) & DO 35 & Fe li & $\mathrm{C} / \mathrm{C}$ & $\mathrm{C} / \mathrm{C}$ & $\mathrm{A} / \mathrm{A}$ & $(G) / A$ & (A)01 & A & Seidenberg \\
\hline FK/RG/BS 38 (F1) & DO 39 & Ti re & $\mathrm{C} / \mathrm{C}$ & $\mathrm{C} / \mathrm{C}$ & $\mathrm{A} / \mathrm{A}$ & $\mathrm{G} / \mathrm{A}$ & $\mathrm{A} 01$ & A & Seidenberg \\
\hline RG/FK 57.02 (M17/M19) & DO 153.01 & Ti re & $\mathrm{C} / \mathrm{C}$ & C/A & $\mathrm{G} / \mathrm{A}$ & $\mathrm{G} / \mathrm{A}$ & B01 & B & Seidenberg \\
\hline RG/FK 58.03 (M13) & DO 58.03 & Fe li & $\mathrm{C} / \mathrm{C}$ & $\mathrm{C} / \mathrm{C}$ & $\mathrm{G} / \mathrm{A}$ & $\mathrm{G} / \mathrm{A}$ & A01v & A & Seidenberg \\
\hline RG/FK 67.03 (F10/F17) & DO 300.01 & Fe li & $\mathrm{C} / \mathrm{C}$ & $\mathrm{C} / \mathrm{C}$ & $\mathrm{A} / \mathrm{A}$ & $\mathrm{G} / \mathrm{A}$ & $\mathrm{A} 01$ & A & Seidenberg \\
\hline $\begin{array}{l}\text { FK/RG/HS/BS } 901.01 \\
\text { (M18/F16) }\end{array}$ & DO 901.01 & Fe li & $\mathrm{C} / \mathrm{C}$ & $\mathrm{C} / \mathrm{C}$ & $\mathrm{G} / \mathrm{A}$ & $(G) / A$ & (A)01v & A & Seidenberg \\
\hline FK/RG 905.01 (M14) & $\begin{array}{l}\text { DO } 901.02 \\
\text { DO } 905.01\end{array}$ & $\begin{array}{l}\text { Huli } \\
\text { Fe li }\end{array}$ & $\mathrm{C} / \mathrm{C}$ & $\mathrm{C} /(\mathrm{A})$ & $A /-$ & $A /-$ & (B)01 & B & Seidenberg \\
\hline FK/RG/BS 907.01 & DO 907.01 & Fe li & $\mathrm{C} / \mathrm{C}$ & $\mathrm{C} /-$ & $\mathrm{A} / \mathrm{A}$ & $\mathrm{G} / \mathrm{A}$ & $\mathrm{A} 01$ & A & Seidenberg \\
\hline RG/FK 1076 (M1) & DO 1076 & Fe li & $\mathrm{C} / \mathrm{C}$ & $\mathrm{C} / \mathrm{C}$ & $A /-$ & $\mathrm{G} / \mathrm{A}$ & $\mathrm{A}(01)$ & A & Seidenberg \\
\hline RG/FK/BS 1078 (F13) & DO 1044 & Fe li & $\mathrm{C} / \mathrm{C}$ & $\mathrm{C} / \mathrm{C}$ & $\mathrm{A} / \mathrm{A}$ & G/G & AA & A & Seidenberg \\
\hline BS 1102 (M2) & DO 1102 & Fe li & $\mathrm{C} / \mathrm{C}$ & $\mathrm{C} / \mathrm{C}$ & $\mathrm{A} / \mathrm{A}$ & G/G & AA & A & Seidenberg \\
\hline BS/RG 1103 (F14) & DO 1103 & Fe li & $\mathrm{C} / \mathrm{C}$ & $\mathrm{C} / \mathrm{C}$ & $\mathrm{G} / \mathrm{A}$ & $\mathrm{G} / \mathrm{A}$ & A01v & A & Seidenberg \\
\hline BS/RG 1176 (F18) & DO 199 & Fe li & $\mathrm{C} / \mathrm{C}$ & $\mathrm{C} / \mathrm{C}$ & $\mathrm{A} / \mathrm{A}$ & $\mathrm{A} / \mathrm{A}$ & 0101 & 0 & Seidenberg \\
\hline BS/RG/FK 1247 (F7) & DO 1206.01 & Fe li & C/- & $\mathrm{C} /-$ & $(A) /-$ & $(\mathrm{A}) /-$ & $(0101)$ & 0 & Seidenberg \\
\hline RG/BS/DS 1482 (M3) & DO 1911 & Fe li & $\mathrm{C} / \mathrm{C}$ & $\mathrm{C} / \mathrm{C}$ & $\mathrm{A} / \mathrm{A}$ & $\mathrm{A} / \mathrm{A}$ & 0101 & 0 & Seidenberg \\
\hline RG/BS 1500 (F2) & DO 1827.01 & Fe re & $\mathrm{C} /-$ & $\mathrm{C} /(\mathrm{A})$ & $G /(A)$ & $(G) / A$ & (B01) & B & Seidenberg \\
\hline HS/GK 1585.03 (F19) & DO 1585.03 & Hu re & $\mathrm{C} / \mathrm{T}$ & $\mathrm{C} / \mathrm{C}$ & $\mathrm{G} / \mathrm{G}$ & $\mathrm{G} / \mathrm{A}$ & 01v02 & 0 & Seidenberg \\
\hline RG/BS 1905 (M9) & DO 1917 & Hu re & $\mathrm{C} / \mathrm{C}$ & $\mathrm{C} / \mathrm{C}$ & $(G) / A$ & $\mathrm{G} / \mathrm{A}$ & $(\mathrm{A} 01 \mathrm{v})$ & A & Seidenberg \\
\hline BS/FK 2030.01 (M6) & DO 2030.01 & Fe li & $\mathrm{C} / \mathrm{C}$ & $\mathrm{C} / \mathrm{C}$ & $\mathrm{A} / \mathrm{A}$ & $\mathrm{G} / \mathrm{A}$ & $\mathrm{A} 01$ & A & Seidenberg \\
\hline GK/HS/RG 2588 (F15) & DO 2588 & Ti re & $\mathrm{C} / \mathrm{T}$ & $\mathrm{C} / \mathrm{C}$ & $\mathrm{G} / \mathrm{G}$ & $\mathrm{G} / \mathrm{A}$ & 01v02 & 0 & Seidenberg \\
\hline BS 3695 (F4) & DO 4013 & Hu re & $\mathrm{C} / \mathrm{C}$ & $\mathrm{C} / \mathrm{C}$ & $(G) / A$ & $\mathrm{~A} / \mathrm{A}$ & $01(01 v)$ & 0 & Seidenberg \\
\hline BS 3706 (F5/F11) & DO 3756 & Fe li & $\mathrm{C} / \mathrm{C}$ & $\mathrm{C} / \mathrm{C}$ & $\mathrm{G} / \mathrm{A}$ & $\mathrm{A} / \mathrm{A}$ & $0101 \mathrm{v}$ & 0 & Seidenberg \\
\hline BS/FK 3742 (F9) & DO 3742 & Fe li & $\mathrm{C} / \mathrm{C}$ & $\mathrm{C} / \mathrm{C}$ & $\mathrm{G} / \mathrm{A}$ & $\mathrm{G} / \mathrm{A}$ & A01v & A & Seidenberg \\
\hline BS/RG 3748 (F8) & DO 3635 & Fe re & $\mathrm{C} / \mathrm{C}$ & $\mathrm{C} / \mathrm{C}$ & $\mathrm{A} / \mathrm{A}$ & $\mathrm{A} / \mathrm{A}$ & 0101 & 0 & Seidenberg \\
\hline BS 5517 (F6) & DO 3994 & Hu li & $\mathrm{C} / \mathrm{C}$ & $\mathrm{C} / \mathrm{C}$ & $\mathrm{A} / \mathrm{A}$ & $\mathrm{A} / \mathrm{A}$ & 0101 & 0 & Seidenberg \\
\hline
\end{tabular}

\subsection{Genetisch determinierte Erkrankungen}

\subsubsection{Cystische Fibrose}

Unter den Individuen aus der Lichtensteinhöhle sind sehr viele Individuen der Altersklasse Infans II zu finden. Dies kann als ungewöhnlich angesehen werden, da nach UN Modellpopulation dies die Altersklasse mit der geringsten Sterbewahrscheinlichkeit ist (United Nations 1955). Es konnten keine Hinweise auf ein vermehrtes Vorkommen von Gewalteinwirkungen, die zum Tode hätten führen können, für Individuen dieser Altersklasse festgestellt werden. Als Todesursache könnten jedoch z.B. auch genetisch bedingte Erkrankungen in Frage kommen, welche zum Tode im Kindesalter führen und keine Spuren am Skelett hinterlassen. Um eine solche 
Erbkrankheit handelt es sich bei der Cystischen Fibrose (auch als Mukoviszidose bekannt), welche mit einer Heterozygotenrate von 1:23 eine der häufigsten Erbkrankheiten ist und ohne moderne Behandlungsmethoden im Kindesalter zum Tode führt.

In $70 \%$ der Fälle Cystischer Fibrose ist eine 3 bp-Deletion $(\Delta F 508)$ im Gen für das Cystische-Fibrose-Transmembran-Regulator (CFTR) Protein krankheitsverursachend (Kerem et al. 1989, Riordan et al.1989). Das Alter der Mutation wird auf 11.000 bis 52.000 Jahre geschätzt (Morral et al. 1994, Dawson und Frossard 2000, Wiuf 2001). Bei Vorliegen der $\Delta$ F508-Mutation kommt es zur Bildung eines defekten Proteins, welches sofort abgebaut wird. Das Fehlen des Proteins führt $\mathrm{zu}$ einer reduzierten Flüssigkeitssekretion in exokrinen Drüsen mit schwerwiegenden Folgen für den gesamten Organismus (Cheng et al. 1990, Southern 1997). Bei heterozygotem Status für die Mutation ist die Symptomatik nur schwach ausgeprägt, so dass häufig ein Überleben bis ins reproduktionsfähige Alter möglich ist (Johansen et al. 1991, Rodman et al. 2004). Da beim Vorliegen des homozygoten Status der Mutation i.d.R. die Zeugung von Nachwuchs ausgeschlossen ist, aber die Mutation trotzdem mit hoher Frequenz verbreitet ist, wurde ein Heterozygotenvorteil angenommen (Hansson 1988) und inzwischen auch belegt. So leiden heterozygote Träger der $\Delta$ F508-Mutation z.B. bei Durchfallerkrankungen - z.B. bei $V$. cholerae oder E. coli Infektionen - nicht so schnell an Dehydrierung und haben somit bessere Überlebenschancen (Hansson 1988, Rodman 1991, Cheng 1990, Gabriel et al. 1994, Southern 1997). Auch beim Kontakt mit Typhuserregern haben heterozygote $\Delta$ F508-Träger durch eine verzögerte Erkrankung und einen milderen Krankheitsverlauf einen Vorteil bzw. eine höhere Überlebenschance (Pier et al. 1998, van de Vosse et al. 2005).

Es wurden 33 Individuen aus der Lichtensteinhöhle auf das Vorliegen der $\Delta$ F508Mutation untersucht (Scholten 2006). Für keines der Individuen konnte ein $\Delta$ F508-Allel für das CFTR-Gen nachgewiesen werden sondern für alle Individuen homozygot das Wildtypallel (siehe Tabelle 32). Aufgrund der Allelfrequenz von 0,022 (Kerem et al. 1989) in kaukasischer Bevölkerung würde man eigentlich für die untersuchte Stichprobengröße mindestens ein bis zwei heterozygote Individuen erwarten. Die Abweichung zur erwarteten Frequenz ist am wahrscheinlichsten vor allem auf die verwandtschaftlichen Beziehungen unter den Individuen zurückzuführen. Jedoch ist nicht auszuschließen, dass die $\Delta$ F508-Mutation vor 3.000 Jahren noch mit sehr viel 
geringerer Frequenz auftrat und erst in jüngerer Vergangenheit durch positiven Selektionsdruck in Fällen von Heterozygotie angereichert wurde.

Tabelle 32: Konsensusgenotypen für den Marker $\Delta \mathrm{F} 508$.

\begin{tabular}{|c|c|c|c|c|}
\hline Individuum [DO \#] & Fund Nr. & Element & $\Delta \mathrm{F} 508$ & Bearbeiter \\
\hline FK/HS/RG 35 (M4) & DO 900.03 & Calv & $w t / w t$ & Scholten \\
\hline FK/RG/BS 38 (F1) & DO 152 & Calv & $w t / w t$ & Scholten \\
\hline RG/FK 58.03 (M13) & DO 58.03 & Fe li & $w t / w t$ & Scholten \\
\hline RG/FK/KS 58.08 (M7) & DO 910.01 & Calv & $w t / w t$ & Scholten \\
\hline RG/FK 67.03 (F10/F17) & $\begin{array}{l}\text { DO } 300.01 \\
\text { DO } 1046\end{array}$ & $\begin{array}{l}\text { Fe li } \\
\text { Calv }\end{array}$ & $w t / w t$ & Scholten \\
\hline RG/GK/BS 183.01 (M11) & DO 183.01 & Fe li & wt/- & Scholten \\
\hline FK/RG/HS/BS 901.01 (M18/F16) & DO R 2 & Calv & $w t / w t$ & Scholten \\
\hline FK/RG/HS 902.01 (M10) & DO 902.01 & Fe li & $w t / w t$ & Scholten \\
\hline FK/RG 905.01 (M14) & DO 918.01 & Calv & $w t / w t$ & Scholten \\
\hline RG/FK 1076 (M1) & DO 1485 & Calv & $w t / w t$ & Scholten \\
\hline RG/FK/BS 1078 (F13) & DO 1078 & Mand & $w t / w t$ & Scholten \\
\hline BS 1102 (M2) & DO 3644 & Mand & $w t / w t$ & Scholten \\
\hline BS/RG 1103 (F14) & DO 4309 & Mand & $w t / w t$ & Scholten \\
\hline BS/RG 1176 (F18) & DO 1176 & Calv & $w t / w t$ & Scholten \\
\hline BS/RG/FK 1247 (F7) & DO 65.06 & Calv & $w t / w t$ & Scholten \\
\hline RG/BS/DS 1482 (M3) & DO 1482 & Mand & $w t / w t$ & Scholten \\
\hline RG/BS 1500 (F2) & DO 1500 & Fe li & $w t / w t$ & Scholten \\
\hline HS/GK 1585.03 (F19) & DO 1585.04 & Calc li & $w t / w t$ & Scholten \\
\hline RG/BS 1905 (M9) & $\begin{array}{l}\text { DO } 2749 \\
\text { DO } 1473\end{array}$ & $\begin{array}{l}\text { Mand } \\
\text { Calv }\end{array}$ & $w t / w t$ & Scholten \\
\hline BS/FK 2030.01 (M6) & $\begin{array}{l}\text { DO } 447 \\
\text { DO R } 3\end{array}$ & $\begin{array}{l}\text { Ti re } \\
\text { Calv }\end{array}$ & wt/- & Scholten \\
\hline BS 2263 (M15) & DO 2263 & Mand & $w t / w t$ & Scholten \\
\hline GK/HS/RG 2588 (F15) & DO 2589 & Mand & $w t / w t$ & Scholten \\
\hline BS 3628 (F3) & DO 1746.06 & Calv & $w t / w t$ & Scholten \\
\hline BS 3695 (F4) & $\begin{array}{l}\text { DO } 4078 \\
\text { DO } 5516\end{array}$ & $\begin{array}{l}\text { Mand } \\
\text { Calv }\end{array}$ & $w t / w t$ & Scholten \\
\hline BS 3706 (F5/F11) & $\begin{array}{l}\text { DO } 3713 \\
\text { DO } 3706\end{array}$ & $\begin{array}{l}\text { Mand } \\
\text { Calv }\end{array}$ & $w t /-$ & Scholten \\
\hline BS/FK 3742 (F9) & $\begin{array}{l}\text { DO } 3746 \\
\text { DO } 3705\end{array}$ & $\begin{array}{l}\text { Mand } \\
\text { Calv }\end{array}$ & $w t / w t$ & Scholten \\
\hline BS/RG 3748 (F8) & DO 3631 & Calv & $w t / w t$ & Scholten \\
\hline BS 3757 (M8) & DO 3757 & Calv & $w t / w t$ & Scholten \\
\hline BS 3886 (M16) & DO 3886 & $\mathrm{pp}$ & $w t / w t$ & Scholten \\
\hline BS/FK 4008 (M5) & DO 908 & Calv & $w t / w t$ & Scholten \\
\hline BS 5517 (F6) & $\begin{array}{l}\text { DO } 3709 \\
\text { DO } 5517\end{array}$ & $\begin{array}{l}\text { Mand } \\
\text { Calv }\end{array}$ & $w t / w t$ & Scholten \\
\hline E 33 (M12) & DO E 33 & Mand & $w t / w t$ & Scholten \\
\hline RG/FK R 1 (F12) & DO R 1 & Calv & $w t / w t$ & Scholten \\
\hline
\end{tabular}




\subsubsection{Hämochromatose}

In Populationen europäischer Abstammung ist die klassische hereditäre Hämochromatose (Typ I) mit einer Homozygotenrate von 1:400 die häufigste autosomal rezessive Erbkrankheit (Mayer 1992). Im Rahmen des Krankheitsbildes kommt es zu einer erhöhten Resorption von Eisen im Dünndarm, was zu pathologischer Eisenspeicherung mit Gewebeschädigung und Verschlechterung von Organfunktionen führt. Betroffene Organe sind hierbei vor allem die Leber, die Bauchspeicheldrüse, das Herz und die Hypophyse (Mayer 1992). Infolge der pathologischen Eisenspeicherung kann es zu Leberzirrhosen, Kardiomyopathien, Hypogonadismus, Hyperpigmentierung oder auch Arthritis kommen (Mayer 1992, Camaschella 2005). Zur Symptommanifestation kommt es jedoch erst bei Einlagerung von 20-40 g Eisen (Renz-Polster et al. 2004), weshalb die Krankheit oft erst im Lebensalter von 40-60 Jahren auftritt. Bei Frauen kommt es i.d.R. deutlich später als bei Männern zu Symptomen - oft erst postmenopausal - und der Krankheitsverlauf ist weniger schwer, da es durch Menstruation, Schwangerschaft und Laktation zur zusätzlichen Eisenverwertung kommt (Mayer 1992).

Die hereditäre Hämochromatose ist auf zwei Punktmutationen im HFE (High Iron Fe) Gen auf dem kurzen Arm des Chromosoms 6 zurückzuführen (Mayer 1992). Durch das homozygote Vorliegen der C282Y (G zu A Transition an Position 845) wird die Krankheit ausgelöst. Es herrscht jedoch eine unvollständige Penetranz, deren Ursache bislang noch unklar ist, da der genaue Pathomechanismus noch nicht vollständig aufgeklärt ist (Bradley et al. 1996, Steiner und von Ahsen 2005). Die zweite Punktmutation H63D (C zu G Transversion an Position 187) führt auch bei homozygoter Ausprägung alleine nicht zur Erkrankung sondern nur im compoundheterozygoten Zustand mit der C282Y Mutation.

Das Alter der Mutation C282Y im HFE-Gen wird auf ca. 1300 Jahre (Lucotte 1998) bzw. 2000 Jahre (Ajioka und Kushner 2002) geschätzt. Über das Alter der H63D Mutation ist nichts bekannt. Um mehr über das Alter der Mutationen zu erfahren, wurde geprüft, ob sie in den vor 3.000 Jahren verstorbenen Individuen aus der Lichtensteinhöhle bereits vorkamen. Gerade in (prä-)historischen Populationen könnte für die Varianten im HFE-Gen ein Heterozygotenvorteil gegeben gewesen sein, da evtl. Mangelphasen mit verminderter Eisenzufuhr besser überstanden werden konnten. Insbesondere Frauen waren evtl. resistenter gegen einen zu hohen Eisenverlust durch Menstruation, Schwangerschaft und Laktation (Lucotte 1998). 
Mit Hilfe eines RFLP-basierten Analysesystems wurden die beiden Mutationen für 32 Individuen aus der Lichtensteinhöhle untersucht (Krause 2006). Es wurden keine Träger der krankheitsauslösenden Genotypen aufgefunden, beide Mutationen wurden jedoch nachgewiesen (siehe Tabelle 33). Somit konnte bewiesen werden, dass die Mutationen deutlich älter sind, als von Ajioka und Kushner (2002) angenommen. Eine genauere zeitliche Einordnung konnte auf Basis der gewonnenen Daten allerdings nicht erfolgen. Die ermittelte Heterozygotenhäufigkeit ähnelt der heutiger Populationen, was auf einen niedrigen Selektionsdruck schließen lässt. 
Tabelle 33: Konsensusgenotypen der Marker C282Y und H63D im Hämochromatosegen.

\begin{tabular}{|c|c|c|c|c|c|}
\hline Individuum [DO \#] & Fund Nr. & Element & C282Y & H63D & Bearbeiter \\
\hline FK/HS/RG 35 (M4) & DO 900.03 & Calv & G/G & $\mathrm{C} / \mathrm{C}$ & Krause \\
\hline FK/RG/BS 38 (F1) & $\begin{array}{l}\text { DO } 38 \\
\text { DO } 152\end{array}$ & $\begin{array}{l}\text { Mand } \\
\text { Calv }\end{array}$ & G/G & C/G & Krause \\
\hline RG/FK 58.03 (M13) & DO 58.03 & Fe li & $\mathrm{G} / \mathrm{G}$ & $\mathrm{C} / \mathrm{C}$ & Krause \\
\hline RG/FK/KS 58.08 (M7) & $\begin{array}{l}\text { DO } 910.01 \\
\text { DO } 929.02\end{array}$ & $\begin{array}{l}\text { Calv } \\
\text { Calc li }\end{array}$ & $\mathrm{G} / \mathrm{G}$ & $\mathrm{C} / \mathrm{C}$ & Krause \\
\hline RG/FK 67.03 (F10/F17) & $\begin{array}{l}\text { DO } 300.01 \\
\text { DO } 1046\end{array}$ & $\begin{array}{l}\text { Fe li } \\
\text { Calv }\end{array}$ & G/G & C/G & Krause \\
\hline RG/GK/BS 183.01 (M11) & DO 183.01 & Fe li & $-/-$ & $\mathrm{C} /-$ & Krause \\
\hline FK/RG/HS/BS 901.01 (M18/F16) & DO R 2 & Calv & G/G & $\mathrm{C} / \mathrm{C}$ & Krause \\
\hline FK/RG/HS 902.01 (M10) & DO 902.01 & Fe li & $\mathrm{G} / \mathrm{A}$ & $\mathrm{C} / \mathrm{C}$ & Krause \\
\hline FK/RG 905.01 (M14) & DO 918.01 & Calv & $\mathrm{G} / \mathrm{G}$ & $\mathrm{C} / \mathrm{C}$ & Krause \\
\hline RG/FK 1076 (M1) & $\begin{array}{l}\text { DO } 1076 \\
\text { DO } 1485\end{array}$ & $\begin{array}{l}\text { Fe li } \\
\text { Calv }\end{array}$ & $\mathrm{G} / \mathrm{G}$ & $\mathrm{C} /-$ & Krause \\
\hline RG/FK/BS 1078 (F13) & DO 1078 & Mand & $\mathrm{G} / \mathrm{G}$ & $\mathrm{C} / \mathrm{C}$ & Krause \\
\hline BS 1102 (M2) & DO 3644 & Mand & G/- & C/G & Krause \\
\hline BS/RG 1103 (F14) & DO 4309 & Mand & $\mathrm{G} / \mathrm{G}$ & $\mathrm{C} / \mathrm{C}$ & Krause \\
\hline BS/RG 1176 (F18) & $\begin{array}{l}\text { DO } 2133 \\
\text { DO } 1176\end{array}$ & $\begin{array}{l}\text { Mand } \\
\text { Calv }\end{array}$ & $\mathrm{G} / \mathrm{A}$ & $\mathrm{C} / \mathrm{C}$ & Krause \\
\hline BS/RG/FK 1247 (F7) & DO 65.06 & Calv & $\mathrm{G} / \mathrm{G}$ & $\mathrm{C} /-$ & Krause \\
\hline RG/BS/DS 1482 (M3) & $\begin{array}{l}\text { DO } 1911 \\
\text { DO } 1482\end{array}$ & $\begin{array}{l}\text { Fe li } \\
\text { Mand }\end{array}$ & $\mathrm{G} / \mathrm{G}$ & $\mathrm{C} / \mathrm{C}$ & Krause \\
\hline RG/BS 1500 (F2) & $\begin{array}{l}\text { DO } 1500 \\
\text { DO } 319\end{array}$ & $\begin{array}{l}\text { Fe li } \\
\text { Ti re }\end{array}$ & $\mathrm{G} / \mathrm{G}$ & $\mathrm{C} /-$ & Krause \\
\hline HS/GK 1585.03 (F19) & DO 1585.04 & Calc li & $\mathrm{G} / \mathrm{G}$ & $\mathrm{C} / \mathrm{C}$ & Krause \\
\hline RG/BS 1905 (M9) & $\begin{array}{l}\text { DO } 2749 \\
\text { DO } 1473\end{array}$ & $\begin{array}{l}\text { Mand } \\
\text { Calv }\end{array}$ & G/G & $\mathrm{C} /(\mathrm{G})$ & Krause \\
\hline BS/FK 2030.01 (M6) & DO 2030.01 & Fe li & $\mathrm{G} / \mathrm{G}$ & $\mathrm{G} / \mathrm{G}$ & Krause \\
\hline BS 2263 (M15) & DO 2263 & Mand & $-1-$ & $-1-$ & Krause \\
\hline GK/HS/RG 2588 (F15) & $\begin{array}{l}\text { DO } 2588 \\
\text { DO } 2589\end{array}$ & $\begin{array}{l}\text { Ti re } \\
\text { Mand }\end{array}$ & $\mathrm{G} / \mathrm{G}$ & $\mathrm{C} /-$ & Krause \\
\hline BS 3628 (F3) & DO 1746.06 & Calv & $\mathrm{G} / \mathrm{G}$ & $C / G$ & Krause \\
\hline BS 3695 (F4) & $\begin{array}{l}\text { DO } 4078 \\
\text { DO } 5516\end{array}$ & $\begin{array}{l}\text { Mand } \\
\text { Calv }\end{array}$ & $\mathrm{G} / \mathrm{G}$ & C/G & Krause \\
\hline BS 3706 (F5/F11) & DO 3706 & Calv & G/G & $\mathrm{G} / \mathrm{G}$ & Krause \\
\hline BS/FK 3742 (F9) & $\begin{array}{l}\text { DO } 3654 \\
\text { DO } 3746 \\
\text { DO } 3705\end{array}$ & $\begin{array}{l}\text { Ti re } \\
\text { Mand } \\
\text { Calv }\end{array}$ & $\mathrm{G} / \mathrm{G}$ & $\mathrm{C} /-$ & Krause \\
\hline BS/RG 3748 (F8) & DO 3631 & Calv & $\mathrm{G} / \mathrm{G}$ & C/G & Krause \\
\hline BS 3886 (M16) & DO 3886 & $\mathrm{pp}$ & $\mathrm{G} / \mathrm{G}$ & $\mathrm{G} / \mathrm{G}$ & Krause \\
\hline BS/FK 4008 (M5) & DO 908 & Calv & $\mathrm{G} / \mathrm{G}$ & $\mathrm{C} / \mathrm{C}$ & Krause \\
\hline BS 5517 (F6) & $\begin{array}{l}\text { DO } 3709 \\
\text { DO } 5517 \\
\text { DO } 4032.01\end{array}$ & $\begin{array}{l}\text { Mand } \\
\text { Calv } \\
\text { Calc li }\end{array}$ & $\mathrm{G} / \mathrm{G}$ & $C / G$ & Krause \\
\hline E 33 (M12) & DO E 33 & Mand & $-1-$ & $-1-$ & Krause \\
\hline RG/FK R 1 (F12) & DO R 1 & Calv & $\mathrm{G} / \mathrm{G}$ & $\mathrm{C} / \mathrm{C}$ & Krause \\
\hline
\end{tabular}




\subsection{Laktosetoleranz und Subsistenzstrategien}

Laktosetoleranz bezeichnet den Zustand, auch im Erwachsenenalter Laktose problemlos verdauen zu können. Hierfür ist die Aktivität des Enzyms Laktase notwendig, welches das Disaccharid Laktose in Glucose und Galaktose aufspaltet. Evolutionär gesehen ist der Phänotyp der Laktoseintoleranz der ursprüngliche Zustand. Die Fähigkeit Laktose verdauen zu können geht nach Entwöhnung von der Muttermilch rasch verloren, damit gesichert ist, dass diese als Ressource für die nächste Nachkommenschaft zur Verfügung steht. Bei Laktoseintoleranz nimmt die Laktaseaktivität nach der Entwöhnung von der Muttermilch rasch um 75-90 \% (Cuatrecasas et al. 1965, Kretchmer 1971, Sahi 1994, Swallow 2003, Matthews et al. 2005) und über die gesamte Lebensspanne kontinuierlich weiter (Swagerty et al. 2002) ab. Laktoseintoleranz äußert sich vor allem in Flatulenzen und abdominalen Schmerzen aber auch Diarrhö oder Übelkeit und Erbrechen nach dem Konsum von Milch (Swagerty et al. 2002). Die Symptome wurden bereits bei den Römern (Ingram et al. 2009) und auch von Hippokrates (Matthews et al. 2005) beschrieben. Abzugrenzen ist die Laktoseintoleranz von der Milcheiweißallergie, bei der eine allergische Reaktion auf die in der Milch enthaltenen Proteine stattfindet (Crittenden und Bennett 2005).

Die Fähigkeit oder Unfähigkeit bis ins Erwachsenenalter Milch zu verdauen ist genetisch bedingt (Sahi et al. 1973, Sahi 1974). Im Jahre 1988 wurde das Laktase (LCT) Gen auf 2q21 lokalisiert (Kruse et al. 1988, Mantei et al. 1988). Es gibt eine genetische Variante, bei der die Abnahme der Laktaseexpression ausbleibt, so dass weiterhin Milch als Nahrungsquelle genutzt werden kann. Ursache für die Unterschiede liegen nicht in der Gensequenz selber (Boll et al. 1991) sondern in der transkriptionellen Regulation (Harvey et al. 1995, Naim 2001, Olds und Sibley 2003).

Seit 2002 sind zwei mit der Laktosetoleranz bzw. -intoleranz korrelierte SNPs bekannt (G/A -22018 und C/T -13910), welche upstream des LCT Gens lokalisiert sind (Enattah et al. 2002). Hierbei weist der C/T -13910 Polymorphismus die stärkere Korrelation auf. Bei homozygotem Vorliegen des C-Allels kommt es zur Laktoseintoleranz, beim heterozygoten Status oder beim homozygoten Vorliegen des TAllels zur Laktosetoleranz.

Insgesamt weisen ca. 65 \% der Weltbevölkerung einen laktoseintoleranten Phänotyp auf (Sahi 1994). Allerdings variieren die Frequnzen der Laktosetoleranz weltweit (Flatz 1987, Swallow 2003). Innerhalb Europas z.B. ist ein Nord-Süd-Gradient ausgeprägt, mit einem besonders hohen prozentualen Anteil laktosetoleranter Menschen in Nordeuropa. 
Zur Verbreitung der Laktosetoleranz gibt es verschiedene Theorien (Simoons 1970, Bayless et al. 1971, McCracken 1971, Flatz und Rotthauwe 1973, Vesa et al. 2000, Aoki 2001, Burger et al. 2007, Gerbault et al. 2009). Momentan wird als wahrscheinlichste Theorie angesehen (Holden und Mace 1997), dass die Verbreitung der Laktosetolernz durch positive Selektion im Zuge der Neotlithischen Revolution (= Übergang vom Nomadentum zur Sesshaftwerdung 12.000 bis 10.000 Jahre v. Chr.) stattfand (Simoons 1970, Cavalli-Sforza 1990, Vesa et al. 2000). Der Konsum von Milch wurde erst mit der Domestikation von Nutztieren möglich, es ist also wahrscheinlich, dass die Laktosetoleranz mit der kulturellen Nutzung der Milchviehwirtschaft auftrat (Itan et al. 2009). Es gibt eine ganze Reihe von Schätzungen zum Alter der C/T -13910 Mutation (Bersaglieri et al. 2004, Coelho et al. 2005, Enattah 2005, Burger et al. 2007, Enattah et al. 2007).

Die Untersuchungen des C/T -13910 Polymorphismus an historischen Populationen könnte zum einen helfen, den Entstehungszeitpunkt näher einzugrenzen. Zum anderen könnten auch Informationen über bestimmte Populationen gewonnen werden, inwieweit sie Milch als Nahrungsquelle genutzt haben könnten. In zwei Examensarbeiten wurde der C/T -13910 Polymorphismus für insgesamt 47 Individuen aus der Lichtensteinhöhle mittels eines PCR/RFLP-basierten Systems untersucht (Fulge 2005, Seebode 2010). Die Typisierungsergebnisse sind in Tabelle 34 dargestellt. Die ermittelten Allelfrequenzen zeigen eine Zunahme des T-Allels von der Bronzezeit bis in die Gegenwart und der anhand dieser Frequenzen errechnete Selektionskoeffizient von 0,02 ermöglicht die Schätzung eines Entstehungszeitraumes der Laktosetoleranz auf 11.225 bis 13.470 Jahre vor heute, was den allgemein angenommen Zeitrahmen stützt und mit Modellen in Hinblick auf die Verbreitung der Milchviehwirtschaft koinzidiert. 
Tabelle 34: Konsensusgenotypen zur Untersuchung auf Laktosetoleranz.

\begin{tabular}{|c|c|c|c|c|c|}
\hline Individuum [DO \#] & Fund $\mathrm{Nr}$. & Element & 2q21LCT-13910 & Phänotpy & Bearbeiter \\
\hline FK/HS/RG 35 (M4) & $\begin{array}{l}\text { DO } 35 \\
\text { DO } 900.03\end{array}$ & $\begin{array}{l}\text { Fe li } \\
\text { Calv }\end{array}$ & $\mathrm{C} /-$ & intolerant & $\begin{array}{l}\text { Fulge } \\
\text { Seebode }\end{array}$ \\
\hline FK/RG/BS 38 (F1) & $\begin{array}{l}\text { DO } 26 \\
\text { DO } 38\end{array}$ & $\begin{array}{l}\text { Fe li } \\
\text { Mand }\end{array}$ & $\mathrm{C} / \mathrm{C}$ & intolerant & $\begin{array}{l}\text { Fulge } \\
\text { Seebode }\end{array}$ \\
\hline RG/FK 57.02 (M17/M19) & DO 57.02 & Fe li & $\mathrm{C} / \mathrm{T}$ & tolerant & Fulge \\
\hline RG/FK 58.01 & DO 58.01 & Fe li & $\mathrm{C} / \mathrm{T}$ & tolerant & Fulge \\
\hline RG/FK 58.03 (M13) & DO 58.03 & Fe li & $\mathrm{C} / \mathrm{T}$ & tolerant & Fulge \\
\hline RG/FK/KS 58.08 (M7) & DO 58.08 & Fe re & $-1-$ & & Seebode \\
\hline RG 66.02 & DO 58.06 & Fe re & $\mathrm{C} / \mathrm{T}$ & tolerant & Fulge \\
\hline RG/FK 67.03 (F10/F17) & DO 300.01 & Fe li & $\mathrm{C} / \mathrm{C}$ & intolerant & Fulge \\
\hline RG/GK/BS 183.01 (M11) & DO 183.01 & Fe li & $\mathrm{C} / \mathrm{T}$ & tolerant & Fulge \\
\hline RG/FK/BS 516 & DO 516 & Hu li & $-1-$ & & Seebode \\
\hline FK/RG/HS/BS 901.01 (M18/F16) & DO 901.01 & Fe li & $\mathrm{C} / \mathrm{T}$ & tolerant & $\begin{array}{l}\text { Fulge } \\
\text { Seebode }\end{array}$ \\
\hline FK/RG/HS 902.01 (M10) & DO 902.01 & Fe li & $\mathrm{C} / \mathrm{T}$ & tolerant & Fulge \\
\hline FK/HS/RG/BS 903.01 & DO 903.01 & Fe li & $\mathrm{T} / \mathrm{T}$ & tolerant & Fulge \\
\hline FK/RG/HS/BS 903.02 & DO 58.04 & Fe re & $\mathrm{C} / \mathrm{T}$ & tolerant & Fulge \\
\hline FK/RG/JS 904.04 & DO 904.05 & Tire & (C)/- & & Seebode \\
\hline FK/RG 905.01 (M14) & $\begin{array}{l}\text { DO } 905.01 \\
\text { DO } 901.02\end{array}$ & $\begin{array}{l}\text { Fe li } \\
\text { Hu li }\end{array}$ & $\mathrm{C} / \mathrm{T}$ & tolerant & $\begin{array}{l}\text { Fulge } \\
\text { Seebode }\end{array}$ \\
\hline FK/RG/BS 907.01 & DO 907.01 & Fe li & $\mathrm{C} / \mathrm{C}$ & intolerant & Fulge \\
\hline RG/FK 1076 (M1) & DO 1076 & Fe li & $\mathrm{C} / \mathrm{C}$ & intolerant & Fulge \\
\hline RG/FK/BS 1078 (F13) & $\begin{array}{l}\text { DO } 1044 \\
\text { DO } 385\end{array}$ & $\begin{array}{l}\text { Fe li } \\
\text { Fe re }\end{array}$ & $\mathrm{C} / \mathrm{T}$ & tolerant & $\begin{array}{l}\text { Fulge } \\
\text { Seebode }\end{array}$ \\
\hline BS 1102 (M2) & DO 1102 & Fe li & $\mathrm{C} / \mathrm{C}$ & intolerant & Fulge \\
\hline BS/RG 1103 (F14) & DO 1103 & Fe li & $\mathrm{C} /(\mathrm{T})$ & tolerant & $\begin{array}{l}\text { Fulge } \\
\text { Seebode }\end{array}$ \\
\hline BS/RG 1176 (F18) & DO 199 & Fe li & $\mathrm{C} / \mathrm{T}$ & tolerant & Fulge \\
\hline BS/RG/FK 1247 (F7) & $\begin{array}{l}\text { DO } 1206.01 \\
\text { DO } 1928 \\
\text { DO } 1247\end{array}$ & $\begin{array}{l}\text { Fe li } \\
\text { Fe re } \\
\text { Mand }\end{array}$ & $\mathrm{C} / \mathrm{T}$ & tolerant & $\begin{array}{l}\text { Fulge } \\
\text { Seebode }\end{array}$ \\
\hline HS/GK 1461 & DO 3157 & Ti li & $-/-$ & & Seebode \\
\hline HS/BS 1467.01 & DO 1467.01 & Hu li & $-1-$ & & Seebode \\
\hline HS/GK/BS 1471 & DO 1471 & Fe li & $\mathrm{C} / \mathrm{T}$ & tolerant & Fulge \\
\hline RG/BS/DS 1482 (M3) & DO 1911 & Fe li & $\mathrm{C} / \mathrm{T}$ & tolerant & Fulge \\
\hline RG/BS 1500 (F2) & $\begin{array}{l}\text { DO } 1500 \\
\text { DO } 1827.01\end{array}$ & $\begin{array}{l}\text { Fe li } \\
\text { Fe re }\end{array}$ & $\mathrm{C} / \mathrm{T}$ & tolerant & Fulge \\
\hline HS/GK 1547.01 & $\begin{array}{l}\text { DO } 3000,22 \\
\text { DO } 1775.03 \\
\text { DO } 1547.01\end{array}$ & $\begin{array}{l}\text { Ra li } \\
\text { Hu li } \\
\text { Ti li }\end{array}$ & $-/-$ & & Seebode \\
\hline HS/GK 1547.03 & DO 3299 & Ti re & $-/-$ & & Seebode \\
\hline HS/GK 1548.01 & DO 1548.01 & Ti re & $\mathrm{C} / \mathrm{C}$ & intolerant & Seebode \\
\hline HS/GK 1585.03 (F19) & $\begin{array}{l}\text { DO N } 968.04 \\
\text { DO } 1585.07\end{array}$ & $\begin{array}{l}\text { Hu li } \\
\text { Fe li }\end{array}$ & $\mathrm{C} / \mathrm{C}$ & intolerant & $\begin{array}{l}\text { Fulge } \\
\text { Seebode }\end{array}$ \\
\hline BS/FK/GK/HS 1745.02 & DO 1745.02 & Cox li & $\mathrm{C} / \mathrm{C}$ & intolerant & Seebode \\
\hline RG/BS 1905 (M9) & $\begin{array}{l}\text { DO } 1917 \\
\text { DO } 1916\end{array}$ & $\begin{array}{l}\text { Hu re } \\
\text { Fe li }\end{array}$ & $\mathrm{C} / \mathrm{C}$ & intolerant & $\begin{array}{l}\text { Fulge } \\
\text { Seebode }\end{array}$ \\
\hline
\end{tabular}


Fortsetzung Tabelle 34: Konsensusgenotypen zur Untersuchung auf Laktosetoleranz.

\begin{tabular}{|c|c|c|c|c|c|}
\hline Individuum [DO \#] & Fund $\mathrm{Nr}$. & Element & 2q21LCT-13910 & Phänotpy & Bearbeiter \\
\hline BS/FK 2030.01 (M6) & $\begin{array}{l}\text { DO } 2030.01 \\
\text { DO } 2111.01\end{array}$ & $\begin{array}{l}\text { Fe li } \\
\text { Mand }\end{array}$ & $\mathrm{C} /(\mathrm{T})$ & tolerant & $\begin{array}{l}\text { Fulge } \\
\text { Seebode }\end{array}$ \\
\hline GK/HS/RG 2588 (F15) & $\begin{array}{l}\text { DO } 2588 \\
\text { DO } 2589\end{array}$ & $\begin{array}{l}\text { Ti re } \\
\text { Mand }\end{array}$ & $\mathrm{C} / \mathrm{C}$ & intolerant & $\begin{array}{l}\text { Fulge } \\
\text { Seebode }\end{array}$ \\
\hline BS 3628 (F3) & $\begin{array}{l}\text { DO } 4374 \\
\text { DO } 2388\end{array}$ & $\begin{array}{l}\text { Fe re } \\
\text { Mand }\end{array}$ & $\mathrm{C} / \mathrm{T}$ & tolerant & $\begin{array}{l}\text { Fulge } \\
\text { Seebode }\end{array}$ \\
\hline BS 3695 (F4) & $\begin{array}{l}\text { DO } 3727 \\
\text { DO } 5516\end{array}$ & $\begin{array}{l}\text { Fe li } \\
\text { Calv }\end{array}$ & $\mathrm{C} / \mathrm{T}$ & tolerant & $\begin{array}{l}\text { Fulge } \\
\text { Seebode }\end{array}$ \\
\hline BS 3706 (F5/F11) & DO 3756 & Fe li & $\mathrm{C} / \mathrm{C}$ & intolerant & Fulge \\
\hline BS/FK 3742 (F9) & DO 3742 & Fe li & $\mathrm{C} / \mathrm{C}$ & intolerant & Fulge \\
\hline BS/RG 3748 (F8) & $\begin{array}{l}\text { DO } 5521 \\
\text { DO } 3635\end{array}$ & $\begin{array}{l}\text { Hu re } \\
\text { Fe re }\end{array}$ & $\mathrm{C} / \mathrm{T}$ & tolerant & Seebode \\
\hline BS 3757 (M8) & DO 3757 & Calv & $\mathrm{C} /(\mathrm{T})$ & tolerant & Seebode \\
\hline BS/FK 4008 (M5) & $\begin{array}{l}\text { DO } 3752 \\
\text { DO } 908\end{array}$ & $\begin{array}{l}\text { Fe re } \\
\text { Calv }\end{array}$ & $\mathrm{C} / \mathrm{C}$ & intolerant & Seebode \\
\hline BS/GK 4310.01 & DO 3812 & Hu li & $-/-$ & & Seebode \\
\hline BS 5517 (F6) & DO 3750 & Feli & $\mathrm{C} / \mathrm{T}$ & tolerant & Fulge \\
\hline BS/FK/RG/HS/GK/KS N 962.01 & DO N962.01 & Ra li & $\mathrm{T} /-$ & tolerant & Seebode \\
\hline RG/FK R 1 (F12) & DO R 1 & Calv & $\mathrm{C} / \mathrm{C}$ & intolerant & Fulge \\
\hline
\end{tabular}

\subsection{Pigmentierung}

Die Rekonstruktion der Pigmentierung der Haare, der Haut und der Augen (sogenannte external visible characteristics, EVCs) mittels genetischer Analysen ist insbesondere in der Forensik von großem Interesse (Schmidt und Hummel 2007, Zaumsegel et al. 2007, Graham 2008, Kayser und Schneider 2009, Liu et al. 2009). Die Kenntnis über die individuelle Ausprägung dieser Merkmale kann beispielsweise bei der Identifikation vermisster Personen oder von Opfern einer Naturkatastrophe helfen. Auch in der Aufklärung von Kriminalfällen würden neue Perspektiven eröffnet, wenn es möglich wäre, über eine rein genetische Spur Hinweise auf das äußere Erscheinungsbild eines Täters zu erlangen (Grimes et al. 2001). Allerdings steht dies vorerst noch im Konflikt mit der deutschen Gesetzgebung, welche besagt, dass nur genetische Marker untersucht werden dürfen, welche nicht codierend sind und keine Auskunft über phänotypische Eigenschaften einer Person geben (StPO $§ 81 \mathrm{e}$ Molekulargenetische Untersuchungen). Einzige Ausnahme hierbei ist eine Geschlechtsfeststellung mittels genetischer Analysen. Inwieweit sich die Gesetzeslage an die sich entwickelnden Möglichkeiten anpassen darf und wird, muss umfassend hinterfragt und geprüft werden und bleibt daher abzuwarten. 
In der prähistorischen und historischen Anthropologie ist die molekulargenetische Rekonstruktion der EVCs vor allem im musealen Kontext von besonders großer Bedeutung. Mittels genetischer Analysen könnte so ein realistischeres und lebendigeres Bild (prä-) historischer Populationen oder bestimmter historischer Persönlichkeiten generiert werden. Die Farbgebung plastischer Rekonstruktionen wäre nicht mehr abhängig von der Vorstellung des jeweiligen Künstlers oder von Zeitgeist und Ideologie, sondern könnte nahe der tatsächlichen Realität gestaltet werden.

Haut- Haar- und Augenfarbe variieren weltweit in ihren Verteilungen. Die größte Variabilität - und die höchste Frequenz hellerer Pigmentierung - findet sich hierbei bei europäisch-stämmigen Menschen (Frost 2006, Frudakis 2008). Die Unterschiede in der Pigmentierung korrelieren mit klimatischen Bedingungen (Barsh 2003). Eine hellere Pigmentierung stellt vermutlich eine evolutionäre Anpassung an eine geringere Sonneneinstrahlung dar, im Zusammenhang mit dem Vitamin D- und Kalziumstoffwechsel (Jablonski 2004, Parra 2007). Es wird vermutet, dass eine adaptive Aufhellung der Haut zweimal unabhängig in Europa sowie in Ostasien entstanden ist (McEvoy et al. 2006, Norton et al. 2007).

Die Pigmentierung der Haut, der Haare und der Iris des Auges ist abhängig vom Mengenverhältnis und der Verteilung der beiden Melaninarten Eumelanin und Phäomelanin sowie von Dichte, Größe und Form der Melanozyten (Szabo 1967, Toda et al. 1972, Sturm und Frudakis 2004, Quevedo und Holstein 2006, Lin und Fisher 2007). Die genetischen Hintergründe sind komplex - unter vermuteter Beteiligung von über 120 verschiedenen Genen - und bis heute nicht vollständig aufgeklärt (Rouzaud et al. 2005). Mittels genomweiter Assoziationsstudien (GWAS) konnten mehrere Gene und SNPs gefunden werden, die mit der der phänotypischen Ausprägung der Haar- bzw. der Augenfarbe im Zusammenhang stehen (Sulem et al. 2007, Eiberg et al. 2008, Han et al. 2008, Kayser et al. 2008, Sulem et al. 2008, Erikson et al. 2010, Branicki et al. 2011, Walsh et al. 2011).

Für die Bestimmung der Haarfarbe wurde im Rahmen einer Examensarbeit (Schücker 2012) ein SBE-basiertes Multiplex-Analysesystem entwickelt. Das System amplifiziert simultan sieben haarfarbenassoziierte SNPs sowie drei STRs, die der Authentifizierung dienen. Mit dem neu entwickelten Analysesystem wurde für 23 Individuen aus der Lichtensteinhöhle die wahrscheinlichste Haarfarbe bestimmt. Ausgewählt wurden 23 Individuen, die in vorangegangenen Analysen durch überwiegend gute DNA-Erhaltung 
aufgefallen waren. Aufgrund dieser Auswahl gelang es, die SNP-Genotypen aller untersuchten Individuen zu bestimmen (Ergebnisse siehe Tabelle 35 und 37).

Die Augenfarbe derselben 23 Individuen wurde mittels Typisierung mit der sogenannten IrisPlex (Walsh et al. 2011) bestimmt (Krause 2012). Diese Multiplex-SBE amplifiziert sechs mit der Augenfarbe assoziierte SNPs. Das System wurde ebenfalls gezielt auch für die Anwendbarkeit auf degradierte DNA entwickelt und dient der Differenzierung blauer und brauner Augenfarben. Von den 23 untersuchten Individuen konnte für 13 die Augenfarbe mit einer Exaktheit der Vorhersagewahrscheinlichkeit von $90 \%$ bestimmt werden (Ergebnisse siehe Tabelle 36 und 38).

Tabelle 35: Prozentuale Verteilung der Haarfarben.

\begin{tabular}{llll}
\hline Haarfarbe & \multicolumn{2}{l}{ Anzahl } & Anteil \\
\hline blond & 2 & 7 & $30,4 \%$ \\
dunkelblond & 5 & & $17,4 \%$ \\
\hline div. rötlich & 4 & 4 & $26,1 \%$ \\
$\begin{array}{l}\text { dunkelblond-braun } \\
\text { hellbraun }\end{array}$ & 3 & 6 & \\
dunkel & 3 & & $26,1 \%$ \\
dunkelbraun-schwarz & 5 & 6 & \\
\hline
\end{tabular}

Tabelle 36: Prozentuale Verteilung der Augenfarben.

\begin{tabular}{lccc}
\hline Augenfarbe & Anzahl & \multicolumn{2}{c}{ Anteil } \\
\hline blau & 8 & & $35 \%$ \\
intermediate-blau & 2 & $8 \%$ & $43 \%$ \\
intermediate-braun & 8 & $35 \%$ & \\
braun & 5 & & $22 \%$ \\
\hline
\end{tabular}


Tabelle 37: Konsensusgenotypen zur Haarfarben-Bestimmung und abgeleitete Haarfarben.

\begin{tabular}{|c|c|c|c|c|c|c|c|c|c|c|c|c|}
\hline Individuum [DO \#] & Fund $\mathrm{Nr}$. & Element & $\begin{array}{c}\text { f rs } \\
1805005\end{array}$ & $\begin{array}{c}\text { f rs } \\
1805007\end{array}$ & $\begin{array}{c}r \text { rs } \\
1805008\end{array}$ & $\begin{array}{c}r \text { rs } \\
1393350\end{array}$ & $\begin{array}{c}\text { f r r } \\
12896399\end{array}$ & $\begin{array}{c}\mathrm{rrs} \\
28777\end{array}$ & $\begin{array}{c}\text { r rs } \\
12913832\end{array}$ & $\begin{array}{c}r r s \\
16891982\end{array}$ & Haarfarbe & Bearbeiter \\
\hline FK/RG/BS 38 (F1) & DO 39 & Ti re & G/G & $\mathrm{C} / \mathrm{C}$ & G/G & $\mathrm{C} /-$ & $\mathrm{G} / \mathrm{T}$ & $\mathrm{T} / \mathrm{T}$ & $\mathrm{Cl}-$ & $\mathrm{C} /-$ & dunkelblond & Schücker \\
\hline RG/FK 57.02 (M17/M19) & DO 57.02 & Fe li & G/G & $\mathrm{C} /-$ & G/G & $\mathrm{C} / \mathrm{C}$ & $\mathrm{G} / \mathrm{T}$ & $\mathrm{T} / \mathrm{T}$ & $\mathrm{C} / \mathrm{T}$ & $\mathrm{C} / \mathrm{C}$ & dunkelblond & Schücker \\
\hline RG/FK 58.03 (M13) & DO 58.03 & Fe li & $\mathrm{G} / \mathrm{T}$ & $\mathrm{C} / \mathrm{T}$ & G/G & $\mathrm{C} / \mathrm{T}$ & $\mathrm{T} / \mathrm{T}$ & $\mathrm{T} / \mathrm{T}$ & $\mathrm{C} / \mathrm{T}$ & $\mathrm{C} / \mathrm{C}$ & dunkelblond-braun (rötl.) & Schücker \\
\hline FK/RG/HS/BS 901.01 (M18/F16) & DO 901.01 & Fe li & G/G & $\mathrm{C} / \mathrm{C}$ & G/G & $\mathrm{C} / \mathrm{C}$ & G/G & $\mathrm{T} / \mathrm{T}$ & $\mathrm{C} / \mathrm{C}$ & $\mathrm{C} / \mathrm{C}$ & dunkel & Schücker \\
\hline FK/RG/HS 902.01 (M10) & DO 902.01 & Fe li & G/G & $\mathrm{C} / \mathrm{C}$ & G/G & $\mathrm{C} / \mathrm{C}$ & $\mathrm{T} / \mathrm{T}$ & $T / T$ & $\mathrm{C} / \mathrm{T}$ & $\mathrm{C} / \mathrm{C}$ & blond & Schücker \\
\hline RG/FK 1076 (M1) & DO 1076 & Fe li & $\mathrm{G} / \mathrm{T}$ & $\mathrm{C} / \mathrm{C}$ & G/G & $\mathrm{C} / \mathrm{T}$ & G/G & $\mathrm{T} / \mathrm{T}$ & $\mathrm{C} / \mathrm{T}$ & $\mathrm{C} / \mathrm{C}$ & hellbraun & Schücker \\
\hline RG/FK/BS 1078 (F13) & DO 1044 & Fe li & G/G & $\mathrm{C} / \mathrm{C}$ & G/G & $\mathrm{C} / \mathrm{C}$ & G/G & $T / T$ & $\mathrm{C} / \mathrm{T}$ & $\mathrm{C} /-$ & dunkel & Schücker \\
\hline BS 1102 (M2) & DO 3670 & Hu li & $\mathrm{G} /(\mathrm{T})$ & $\mathrm{C} /(\mathrm{T})$ & G/G & $\mathrm{C} / \mathrm{C}$ & $\mathrm{G} / \mathrm{T}$ & $\mathrm{T} / \mathrm{T}$ & $\mathrm{C} / \mathrm{T}$ & $\mathrm{C} / \mathrm{C}$ & dunkelblond (rötl.) & Schücker \\
\hline BS/RG 1103 (F14) & DO 1103 & Fe li & G/G & $\mathrm{C} / \mathrm{C}$ & G/G & $\mathrm{C} / \mathrm{C}$ & G/G & $T / T$ & $\mathrm{C} / \mathrm{T}$ & $\mathrm{C} / \mathrm{C}$ & dunkel & Schücker \\
\hline BS/RG 1176 (F18) & DO 199 & Feli & G/G & $\mathrm{C} / \mathrm{T}$ & G/G & $\mathrm{C} / \mathrm{C}$ & $\mathrm{G} / \mathrm{G}$ & $\mathrm{T} / \mathrm{T}$ & $\mathrm{C} / \mathrm{C}$ & $\mathrm{C} / \mathrm{C}$ & dunkel (rötl.) & Schücker \\
\hline BS/RG/FK 1247 (F7) & DO 6495 & Hu re & G/G & $\mathrm{C} / \mathrm{C}$ & G/G & $\mathrm{C} / \mathrm{T}$ & $\mathrm{G} / \mathrm{T}$ & $\mathrm{T} / \mathrm{T}$ & $\mathrm{C} / \mathrm{C}$ & $\mathrm{C} / \mathrm{C}$ & dunkelblond-braun & Schücker \\
\hline RG/BS/DS 1482 (M3) & DO 1911 & Fe li & $\mathrm{G} / \mathrm{T}$ & $\mathrm{C} /-$ & G/G & $\mathrm{C} / \mathrm{C}$ & $\mathrm{G} / \mathrm{T}$ & $\mathrm{T} / \mathrm{T}$ & $\mathrm{C} / \mathrm{T}$ & $\mathrm{C} / \mathrm{C}$ & dunkelblond & Schücker \\
\hline RG/BS 1500 (F2) & DO 1827.01 & Fe re & G/G & $\mathrm{C} / \mathrm{C}$ & G/- & $\mathrm{C} / \mathrm{C}$ & $\mathrm{G} / \mathrm{T}$ & $\mathrm{T} / \mathrm{T}$ & $\mathrm{C} / \mathrm{C}$ & $\mathrm{G} / \mathrm{C}$ & dunkelbraun-schwarz & Schücker \\
\hline HS/GK 1585.03 (F19) & DO 1585.03 & Hu re & G/G & $\mathrm{C} / \mathrm{C}$ & G/G & $\mathrm{C} / \mathrm{C}$ & $\mathrm{G} / \mathrm{T}$ & $\mathrm{T} / \mathrm{T}$ & $\mathrm{C} / \mathrm{C}$ & $\mathrm{C} / \mathrm{C}$ & dunkelblond & Schücker \\
\hline RG/BS 1905 (M9) & DO 1917 & Hu re & $\mathrm{G} / \mathrm{T}$ & $\mathrm{C} / \mathrm{C}$ & G/G & $\mathrm{C} / \mathrm{C}$ & $\mathrm{G} / \mathrm{T}$ & $T / T$ & $\mathrm{C} / \mathrm{T}$ & $\mathrm{C} / \mathrm{C}$ & dunkelblond & Schücker \\
\hline BS/FK 2030.01 (M6) & DO 2030.01 & Fe li & G/G & $\mathrm{C} / \mathrm{C}$ & G/G & $\mathrm{C} / \mathrm{C}$ & $\mathrm{T} / \mathrm{T}$ & $\mathrm{T} / \mathrm{T}$ & $\mathrm{C} / \mathrm{T}$ & $\mathrm{C} / \mathrm{C}$ & blond & Schücker \\
\hline GK/HS/RG 2588 (F15) & DO 2588 & Ti re & G/G & $\mathrm{C} / \mathrm{T}$ & G/G & $\mathrm{C} /-$ & $\mathrm{G} / \mathrm{T}$ & $\mathrm{G} / \mathrm{T}$ & $\mathrm{C} / \mathrm{C}$ & $\mathrm{G} / \mathrm{C}$ & dunkelbraun-schwarz (rötl.) & Schücker \\
\hline BS 3706 (F5/F11) & DO 3756 & Fe li & G/G & $\mathrm{C} / \mathrm{C}$ & G/G & $\mathrm{C} / \mathrm{T}$ & $\mathrm{G} / \mathrm{T}$ & $\mathrm{T} / \mathrm{T}$ & $\mathrm{T} / \mathrm{T}$ & $\mathrm{C} / \mathrm{C}$ & hellbraun & Schücker \\
\hline BS/FK 3714 & DO 3714 & Huli & G/G & $\mathrm{C} / \mathrm{C}$ & G/G & $\mathrm{C} / \mathrm{T}$ & $\mathrm{G} / \mathrm{T}$ & $\mathrm{T} / \mathrm{T}$ & $\mathrm{C} / \mathrm{T}$ & $\mathrm{C} / \mathrm{C}$ & hellbraun & Schücker \\
\hline BS/FK 3742 (F9) & DO 3742 & Fe li & $\mathrm{G} / \mathrm{G}$ & $\mathrm{C} / \mathrm{C}$ & G/- & $\mathrm{C} / \mathrm{C}$ & G/G & $\mathrm{T} / \mathrm{T}$ & $\mathrm{C} / \mathrm{T}$ & $\mathrm{C} / \mathrm{C}$ & dunkel & Schücker \\
\hline BS/RG 3748 (F8) & DO 5521 & Hu re & $\mathrm{G} / \mathrm{T}$ & $\mathrm{C} / \mathrm{C}$ & G/G & $\mathrm{C} / \mathrm{T}$ & $\mathrm{T} / \mathrm{T}$ & $\mathrm{T} / \mathrm{T}$ & $\mathrm{C} / \mathrm{T}$ & $\mathrm{C} / \mathrm{C}$ & dunkelblond-braun & Schücker \\
\hline BS/FK 4008 (M5) & DO 2096 & Ti re & G/G & $\mathrm{C} / \mathrm{C}$ & G/G & $\mathrm{C} / \mathrm{T}$ & $\mathrm{T} / \mathrm{T}$ & $\mathrm{T} / \mathrm{T}$ & $\mathrm{C} / \mathrm{C}$ & $\mathrm{C} / \mathrm{C}$ & dunkelblond-braun & Schücker \\
\hline BS 5517 (F6) & DO 3710 & Hu re & G/G & $\mathrm{C} /-$ & G/G & $\mathrm{C} / \mathrm{C}$ & G/G & $\mathrm{T} / \mathrm{T}$ & $\mathrm{T} / \mathrm{T}$ & $\mathrm{C} / \mathrm{C}$ & dunkel & Schücker \\
\hline
\end{tabular}


Tabelle 38: Konsensusgenotypen zur Augenfarben-Bestimmung und abgeleitete Augenfarben.

\begin{tabular}{|c|c|c|c|c|c|c|c|c|c|c|c|c|c|}
\hline Individuum [DO \#] & Fund Nr. & Element & $\begin{array}{c}r \text { rs } \\
1800407\end{array}$ & $\begin{array}{c}f r s \\
16891982\end{array}$ & $\begin{array}{c}r \text { rs } \\
12203592\end{array}$ & $\begin{array}{c}r \text { rs } \\
12913832\end{array}$ & $\begin{array}{c}\mathrm{rrs} \\
1393350\end{array}$ & $\begin{array}{c}f \text { rs } \\
12896399\end{array}$ & Blue & $\begin{array}{l}\text { Inter- } \\
\text { mediate }\end{array}$ & Brown & Augenfarbe & Bearbeiter \\
\hline FK/RG/BS 38 (F1) & DO 39 & Ti re & $\mathrm{C} / \mathrm{C}$ & G/G & $\mathrm{G} / \mathrm{A}$ & $\mathrm{C} / \mathrm{C}$ & $\mathrm{C} / \mathrm{C}$ & $\mathrm{G} / \mathrm{T}$ & 0,9315 & 0,04985 & 0,01867 & blau & Krause \\
\hline RG/FK 57.02 (M17/M19) & DO 57.02 & Feli & $\mathrm{C} / \mathrm{C}$ & G/G & G/G & $\mathrm{C} / \mathrm{T}$ & $\mathrm{C} / \mathrm{C}$ & $G / T$ & 0,1511 & 0,1317 & 0,7173 & braun & Krause \\
\hline RG/FK 58.03 (M13) & DO 58.03 & Feli & $\mathrm{C} / \mathrm{T}$ & G/G & G/G & $\mathrm{C} / \mathrm{T}$ & $\mathrm{C} / \mathrm{T}$ & $T / T$ & 0,5032 & 0,2106 & 0,2862 & intermediate-blau & Krause \\
\hline FK/RG/HS/BS 901.01 (M18/F16) & DO 901.01 & Fe li & $\mathrm{C} / \mathrm{C}$ & G/G & G/G & $\mathrm{C} / \mathrm{C}$ & $\mathrm{C} / \mathrm{C}$ & G/G & 0,8788 & 0,06716 & 0,054 & blau & Krause \\
\hline FK/RG/HS 902.01 (M10) & DO 902.01 & Fe li & $\mathrm{C} / \mathrm{C}$ & G/G & $\mathrm{G} / \mathrm{A}$ & $\mathrm{C} / \mathrm{T}$ & $\mathrm{C} / \mathrm{C}$ & $T / T$ & 0,3165 & 0,1933 & 0,4902 & intermediate-braun & Krause \\
\hline RG/FK 1076 (M1) & DO 1076 & Fe li & $\mathrm{C} / \mathrm{T}$ & G/- & G/- & $\mathrm{C} / \mathrm{T}$ & $\mathrm{C} / \mathrm{C}$ & G/- & 0,2098 & 0,2587 & 0,5315 & intermediate-braun & Krause \\
\hline RG/FK/BS 1078 (F13) & DO 1044 & Feli & $\mathrm{C} / \mathrm{T}$ & G/G & G/G & $\mathrm{C} / \mathrm{T}$ & $\mathrm{C} / \mathrm{C}$ & G/G & 0,2098 & 0,2587 & 0,5315 & intermediate-braun & Krause \\
\hline BS 1102 (M2) & DO 3670 & Hu li & $\mathrm{C} / \mathrm{T}$ & G/G & $\mathrm{G} / \mathrm{A}$ & $\mathrm{C} / \mathrm{T}$ & $\mathrm{C} / \mathrm{C}$ & $\mathrm{G} / \mathrm{T}$ & 0,3718 & 0,3211 & 0,3072 & intermediate-blau & Krause \\
\hline BS/RG 1103 (F14) & DO 1103 & Feli & $\mathrm{C} / \mathrm{T}$ & G/G & G/G & $\mathrm{C} / \mathrm{T}$ & $\mathrm{C} / \mathrm{C}$ & G/- & 0,2098 & 0,2587 & 0,5315 & intermediate-braun & Krause \\
\hline BS/RG 1176 (F18) & DO 199 & Feli & $\mathrm{C} / \mathrm{C}$ & G/G & $\mathrm{G} /(\mathrm{A})$ & $\mathrm{C} /-$ & $\mathrm{C} / \mathrm{C}$ & $\mathrm{G} / \mathrm{G}$ & 0,8788 & 0,06716 & 0,054 & blau & Krause \\
\hline BS/RG/FK 1247 (F7) & DO 6495 & Hu re & $\mathrm{C} / \mathrm{C}$ & G/G & G/- & $\mathrm{C} / \mathrm{T}$ & $\mathrm{C} / \mathrm{T}$ & $\mathrm{G} / \mathrm{T}$ & 0,9399 & 0,3816 & 0,02193 & blau & Krause \\
\hline RG/BS/DS 1482 (M3) & DO 1911 & Feli & $\mathrm{C} / \mathrm{C}$ & G/G & $\mathrm{G} / \mathrm{A}$ & $\mathrm{C} / \mathrm{T}$ & $\mathrm{C} / \mathrm{C}$ & $\mathrm{G} / \mathrm{T}$ & 0,2186 & 0,209 & 0,5724 & intermediate-braun & Krause \\
\hline RG/BS 1500 (F2) & DO 1827.01 & Fe re & $\mathrm{C} / \mathrm{C}$ & $\mathrm{G} / \mathrm{C}$ & $\mathrm{G} / \mathrm{A}$ & $\mathrm{C} / \mathrm{C}$ & $\mathrm{C} / \mathrm{C}$ & $\mathrm{G} / \mathrm{T}$ & 0,9902 & 0,005518 & 0,004315 & blau & Krause \\
\hline HS/GK 1585.03 (F19) & DO 1585.03 & Hu re & $\mathrm{C} / \mathrm{C}$ & G/G & G/G & $\mathrm{C} /-$ & $\mathrm{C} /-$ & $\mathrm{G} / \mathrm{T}$ & 0,9215 & 0,04498 & 0,03349 & blau & Krause \\
\hline RG/BS 1905 (M9) & DO 1917 & Hu re & $\mathrm{C} /-$ & G/G & G/G & $\mathrm{C} / \mathrm{T}$ & $\mathrm{C} / \mathrm{C}$ & $\mathrm{G} / \mathrm{T}$ & 0,1511 & 0,1317 & 0,7173 & braun & Krause \\
\hline BS/FK 2030.01 (M6) & DO 2030.01 & Fe li & $\mathrm{C} / \mathrm{C}$ & G/G & $\mathrm{G} / \mathrm{A}$ & $\mathrm{C} / \mathrm{T}$ & $\mathrm{C} /-$ & $\mathrm{T} / \mathrm{T}$ & 0,3165 & 0,1933 & 0,4902 & intermediate-braun & Krause \\
\hline GK/HS/RG 2588 (F15) & DO 2588 & Ti re & $\mathrm{C} / \mathrm{C}$ & $\mathrm{G} / \mathrm{C}$ & $G /(A)$ & $\mathrm{C} /(\mathrm{T})$ & $\mathrm{C} /(\mathrm{T})$ & $\mathrm{G} / \mathrm{T}$ & 0,9872 & 0,005018 & 0,007801 & blau & Krause \\
\hline BS 3706 (F5/F11) & $\begin{array}{l}\text { DO } 3756 \\
\text { DO } 3706\end{array}$ & $\begin{array}{l}\text { Fe li } \\
\text { Calv }\end{array}$ & $\mathrm{C} / \mathrm{T}$ & G/G & G/G & $T / T$ & $\mathrm{C} / \mathrm{T}$ & $G / T$ & 0,007226 & 0,08456 & 0,9082 & braun & Krause \\
\hline BS/FK 3714 & DO 3714 & Hu li & $\mathrm{C} /(\mathrm{T})$ & G/G & G/G & $\mathrm{C} / \mathrm{T}$ & $\mathrm{C} /-$ & $\mathrm{G} / \mathrm{T}$ & 0,3044 & 0,2397 & 0,4559 & intermediate-braun & Krause \\
\hline BS/FK 3742 (F9) & DO 3742 & Feli & $\mathrm{C} / \mathrm{C}$ & G/G & G/G & $\mathrm{C} / \mathrm{T}$ & C/- & G/G & 0,09621 & 0,1313 & 0,7725 & braun & Krause \\
\hline BS/RG 3748 (F8) & DO 5521 & Hu re & $\mathrm{C} / \mathrm{C}$ & G/G & $\mathrm{G} / \mathrm{A}$ & $\mathrm{C} / \mathrm{T}$ & $\mathrm{C} / \mathrm{T}$ & (G)/T & 0,2876 & 0,2287 & 0,4836 & intermediate-braun & Krause \\
\hline BS/FK 4008 (M5) & DO 2096 & Tire & $\mathrm{C} /-$ & G/G & G/G & $\mathrm{C} / \mathrm{C}$ & $\mathrm{C} / \mathrm{T}$ & $T / T$ & 0,9618 & 0,02494 & 0,01327 & blau & Krause \\
\hline BS 5517 (F6) & $\begin{array}{l}\text { DO } 3710 \\
\text { DO } 3750\end{array}$ & $\begin{array}{l}\text { Hu re } \\
\text { Feli }\end{array}$ & $\mathrm{C} / \mathrm{T}$ & G/G & $\mathrm{G} / \mathrm{A}$ & $T / T$ & $\mathrm{C} / \mathrm{C}$ & G/G & 0,004814 & 0,1163 & 0,8789 & braun & Krause \\
\hline
\end{tabular}




\subsection{Dopamin Rezeptor D4 VNTR und Risikoverhalten}

Beim Botenstoff Dopamin handelt es sich um einen Neurotransmitter, der u.a. im Belohnungssystem des Gehirns eine Rolle spielt (Young 1959, Spanagel und Weiss 1999, Peterson 2005). Es sind fünf verschiedene Typen von Dopamin-Rezeptoren bekannt. Im Fokus der Verhaltensforschung befindet sich insbesondere der Dopamin Rezeptor D4 (DRD4), der auf Chromosom 11p15.5 codiert ist und dessen Gen aus 4 Exons besteht (Gelernter et al. 1992).

Im Exon 3 des Gens für den Dopamin Rezeptor D4 befindet sich ein 48 bp VNTR mit den Allelen 2-11, wobei das Allel 4 weltweit gesehen das häufigste Allel ist, gefolgt von Allel 7 und Allel 2 und 3 (Ding et al. 2002). Laut einer Vielzahl genetischer Assoziationsstudien ist das Allel 7 des VNTRs im Exon 3 des DRD4-Gens mit Verhaltensauffälligkeiten von erhöhtem Risikoverhalten oder dem sogenannten „,novelty seeking“ (z.B. Chen et al. 1999, Metthews und Butler 2011) bis hin zu verschiedenen psychischen Erkrankungen wie z.B. ADHS (LaHoste et al. 1996, Swanson et al. 2000) assoziiert. Es gibt Vermutungen, dass in hunter-gatherer Populationen das Allel 7, und somit eine erhöhte Risikobereitschaft, einen Vorteil bedeutete und daher dieses Allel dort mit besonders hohen Frequenzen vorkommt, während in niedergelassenen Bevölkerungen eine erhöhte Risikobereitschaft eher einen Nachteil darstellt und daher das Allel 7 mit eher niedrigen Frequenzen vorkommt (Ding et al 2002, Rodrigues et al. 2010). Untersuchungen des DRD4 VNTRs an (prä-) historischen Populationen könnten einen interessanten neuen Blickwinkel eröffnen. Vielleicht könnte es - nach Vorliegen ausreichender Mengen an gesicherten Daten - sogar irgendwann möglich werden, über die Frequenzen der DRD4 Allele Hinweis auf die Lebensform einer unbekannten historischen Bevölkerung zu erlangen.

Für die Analyse des 48 bp VNTRs im Exon 3 des DRD4 Genes wurde daher in einer Examensarbeit ein Analysesystem entwickelt, welches zur Analyse alter DNA geeignet ist (Blume 2012). Mit diesem Analysesystem werden in einer Duplex PCR der VNTR mit Fragmentlängen von 211-643 bp (Allel 2-11) und ein Kontrollfragment mit 519 bp amplifiziert. Das relativ lange Kontrollfragment wurde integriert um bei Amplifikation nur eines VNTR-Allels mit relativ großer Sicherheit ableiten zu können, dass es sich tatsächlich um einen Homozygoten Genotyp handelt.

Die Ergebnisse für 20 Kontrollproben zeigten Allelfrequenzen von $65 \%$ für das Allel 4, $20 \%$ für das Allel 7 und jeweils 7,5\% für die Allele 2 und 3 (Blume 2012). Dies entspricht den Allelfrequenzen, wie sie für eine rezente europäische Population zu 
erwarten sind (Chang et al. 1996). Von den Individuen aus der Lichtensteinhöhle wurden sieben mit sehr gutem DNA-Erhalt untersucht. Sechs dieser Individuen weisen mindestens ein Allel 4 auf. Für zwei der Individuen wurde das Allel 2 nachgewiesen und für jeweils ein Individuum die Allele 3 und 7 (Tabelle 39). Die Stichprobe ist zwar zu klein um eine Prädisposition für erhöhte Risikobereitschaft innerhalb der Population gänzlich auszuschließen, aber die Häufigkeit der verschiedenen Allele scheint doch eher auf eine „niedergelassene“ Population hinzuweisen.

Tabelle 39: Konsensusgenotypen des VNTRs im Dopamin Rezeptor D4 (DRD4) Gen.

\begin{tabular}{lllcc}
\hline Individuum [DO \#] & Fund Nr. & Element & VNTR & Bearbeiter \\
\hline FK/RG/HS/ BS 901.01 (M18/F16) & DO 901.01 & Fe li & $4 /(7)$ & Blume \\
\hline FK/RG/HS 902.01 (M10) & DO 480.01 & Mand & $2 /-$ & Blume \\
\hline RG/FK 1076 (M1) & DO 201 & Ti re & $4 /-$ & Blume \\
\hline BS/RG 1176 (F18) & DO 2133 & Mand & $2 / 4$ & Blume \\
\hline BS/RG/FK 1247 (F7) & DO 6495 & Hu re & $4 /-$ & Blume \\
\hline RG/BS/DS 1482 (M3) & DO 1911 & Fe li & $4 /-$ & Blume \\
\hline BS/RG/FK/HS 3886 (M16) & DO 3886 & Pp & $3 / 4$ & Blume \\
\hline
\end{tabular}

\subsection{Auswertung von Streumustern, Färbung und Textur der Knochen sowie des Amplifikationserfolges}

Mit der Frage, ob es sich bei dem Fundort Lichtensteinhöhle um einen Primär- oder Sekundärbestattungsplatz handelt, beschäftigten sich vier Bachelorarbeiten, welche statistische Auswertungen verschiedener Merkmale beinhalteten. Es wurde geprüft, ob sich ein signifikanter Zusammenhang zwischen Knochenfarbe (Merkes 2010), Knochenoberflächentextur (Knorre 2010) oder DNA-Erhaltung (Blume 2010) mit der Individuenzugehörigkeit oder mit dem Auffindeort in der Höhle herstellen lässt. Zudem wurden die Streumuster der Knochen statistisch analysiert (Zeidler 2010).

Für die Analyse der Streumuster (Zeidler 2010) wurden jeweils alle Knochen eines Individuums im Quandrantenplan kartiert und die Distanzen zueinander als Streuung in Form von Maßzahlen erfasst. Zudem wurde geprüft, ob es Verteilungsmuster in Bezug auf das Geschlecht, die Vollständigkeit oder auch die Lage eines Individuums in einem bestimmten Höhlenabschnitt gibt.

Unter Einbeziehung aller Höhlenabschnitte ergab sich ein Streuungsgrad von $70 \%$. Allerdings variierte der Streuungsgrad in den verschiedenen Höhlenkammern teilweise. So ist der Streuungsgrad in Reinhardsgrotte und Berndsaal mit 74 \% bzw. 75 \% nahezu 
gleich, jedoch in der Fiddikluft mit $79 \%$ noch etwas höher. Insgesamt konnten Variationen des Streuungsgrades zwischen $54 \%$ und $96 \%$ für die Individuen ermittelt werden. Ein Verteilungsmuster konnte weder in Bezug auf das Geschlecht noch die Vollständigkeit oder die Lage in einem bestimmten Höhlenabschnitt festgestellt werden. Es zeigte sich lediglich, dass die Knochen im Berndsaal über einen größeren Bereich des Höhlenabschnittes streuen, wohingegen sie in Fiddikluft und Reinhardsgrotte auf vergleichsweise kleinen Flächen am Rand der Höhlenabschnitte zu finden waren. Es wurde angenommen, dass es sich, wenn die Knochen eines Individuums über mehrere Höhlenabschnitte sehr stark streuen, wahrscheinlich eher um einen Sekundärbestattungsplatz handelt. Unter dieser Annahme deuten die Hinweise auf eine massive Umlagerung darauf hin, dass Sekundärbestattungen tatsächlich wahrscheinlicher anzunehmen sind als Primärbestattungen.

Grundgedanke hinter der Auswertung der Merkmale Färbung, Oberflächentextur und DNA-Degradierung war, dass die Knochen, wenn ein Körper an seinem primären Bestattungsort verweste und erst dann die Knochen in der Höhle verstreut wurden, die Knochen eines Individuums sich bezüglich der Merkmalsausprägung ähneln sollten, da das Liegemilieu am primären Bestattungsort außerhalb der Höhle über einen längeren Zeitraum gleichmäßig eingewirkt haben dürfte. Die Feststellung eines signifikanten Zusammenhangs mit der Individuenzugehörigkeit würde also eher dafür sprechen, dass die Lichtensteinhöhle als Sekundärbestattungort genutzt wurde.

Für die Prüfung auf einen Zusammenhang zwischen der Färbung der Knochen und der Individuenzugehörigkeit oder dem Auffindeort wurden die Knochen begutachtet und ihre jeweilige Farbe in sieben Kategorien eingeordnet (Merkes 2010). Hierbei wurde sowohl die generelle Helligkeit als auch Farbstiche in eher gelbliche, orangene oder bräunliche Tönung berücksichtigt. Insgesamt wurden 387 Knochen von 44 Individuen unabhängig begutachtet. Im Rahmen der Begutachtung wurde auch auf möglicherweise vorhandene Nagespuren oder Spuren von Pflanzenwurzeln geachtet. Die statistischen Tests ergaben sowohl für einen Zusammenhang mit der Individuenzugehörigkeit als auch mit dem Auffindeort signifikante Ergebnisse. Für den Zusammenhang mit dem Auffindeort wurde das höhere Signifikanzniveau erzielt. Dies würde nach der oben genannten Grundannahme eher für einen Primärbestattungsort sprechen. Nagespuren konnten keine an den Knochen gefunden werden, es gab jedoch einen Fall einer feinen Pflanzenwurzel an einem der begutachteten Knochen. 
Für die Prüfung auf einen Zusammenhang zwischen der Oberflächentextur der Knochen und der Individuenzugehörigkeit oder dem Auffindeort wurden 342 Skelettelemente von 36 Individuen begutachtet und nach fünf Kategorien klassifiziert (Knorre 2010). Die einzelnen Stufen reichten von „Vollständig ohne Oberflächenläsionen“ bis hin zu „Größere Knochenbereiche fehlend und schwere Oberflächenläsionen“. Neben den möglichen Zusammenhängen mit Auffindeort und Individuenzugehörigkeit wurde auch auf einen möglichen Zusammenhang mit der Art des Skelettelements getestet. Alle geprüften Zusammenhänge waren signifikant, wobei eine aufsteigend höhere Signifikanz in der Reihenfolge „Zusammenhang mit Individuenzugehörigkeit“, „Zusammenhang mit Art des Skelettelements“ und „Zusammenhang mit dem Auffindeort“ festgestellt wurde. Die höchste Signifikanz für den Zusammenhang mit dem Auffindeort weist ebenfalls eher in die Richtung dass die Lichtensteinhöhle als primärer Bestattungsplatz genutzt wurde.

Für die Prüfung auf einen Zusammenhang zwischen der DNA-Degradierung der Knochen und der Individuenzugehörigkeit oder dem Auffindeort wurden die Ergebnisse der genetischen Fingerabdrücke für 113 Skelettelemente von 31 Individuen ausgewertet (Blume 2010). Als Maß für einen sehr guten DNA-Erhalt bzw. eine fortgeschrittene DNA-Degradierung wurde der Amplifikationserfolg bzw. die Vollständigkeit der genetischen Profile in Prozent herangezogen. Es wurde ein signifikanter Zusammenhang des Amplifikationserfolges mit der Individuenzugehörigkeit festgestellt, während der Zusammenhang mit dem Auffindeort nicht signifikant war. Diese Sachlage spricht unter der oben formulierten Annahme eher für einen Sekundärbestattungsort. 


\subsection{Entomologische Untersuchungen}

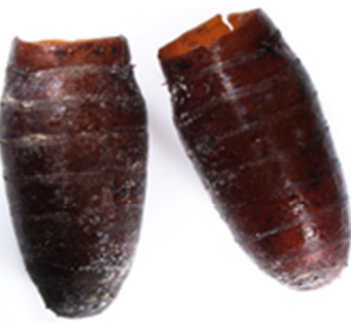

Abb. 84: In der Lichtensteinhöhle aufgefundene Fliegen-Exuvien.

In der Lichtensteinhöhle wurde neben menschlichen und tierischen Knochen, Pflanzenresten und archäologischen Artefakten auch eine größere Anzahl von Fliegen-Exuvien gefunden (Abb. 84).

Eine morphologische Prüfung unter dem Binokular ergab, dass es sich durchgängig um die Exuvien von einer einzigen Art handelte (pers. Mitteilung A. Scholten). Die morphologische Artbestimmung ergab, dass die Exuvien von der Fliegenart Calliphora vicina stammen (pers. Mitteilung A. Scholten). Dies wurde durch eine genetische Bestimmung über die Sequenzierung eines Abschnittes des 28S-Gens gestützt (mit freundlicher Unterstützung durch P. von Grumbkow; zur Methodik siehe auch Büsse et al. 2012), welche in dieselbe Richtung weist (siehe auch Abb. 85).

\begin{tabular}{|c|c|c|c|c|c|c|c|c|c|c|}
\hline 1710 & 1720 & 1730 & 1740 & 1750 & 1760 & 1770 & 1780 & 1790 & 1800 & \\
\hline \multicolumn{11}{|c|}{ 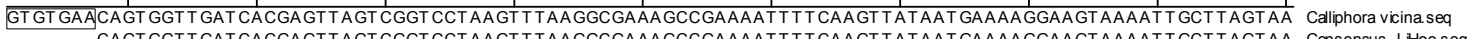 } \\
\hline$\cdots$ CAGT & TCACC & GTCG & AGTT & GAAAC & AATT & TTTAT & AAGG & AATTC & GTAA & \multirow{2}{*}{ Consensus_LiHoe.seq } \\
\hline 1810 & 1820 & 1830 & 1840 & 1850 & 1860 & 1870 & 1880 & 1890 & 1900 & \\
\hline $\begin{array}{l}\text { TAAACACT TG } \\
\text { TAAACACTTG }\end{array}$ & $\begin{array}{l}\text { TIG } \\
\text { TTG }\end{array}$ & $\begin{array}{l}1 \\
\mathrm{AGG} \\
\mathrm{GGGG}\end{array}$ & & & & & & & & $\begin{array}{l}\text { Calliphora vicina.seq } \\
\text { Consensus_LiHoe.seq }\end{array}$ \\
\hline
\end{tabular}

Abb. 85: Alignment einer aus einer Exuvie aus der Lichtensteinhöhle gewonnenen DNASequenz für einen Abschnittes des 28S-Gens und einer Referenzsequenz der Spezies Calliphora vicina. 


\section{Gesamtinterpretation und Diskussion}

\subsection{Demografische Struktur der Population aus der Lichtensteinhöhle}

\section{Individuenzahl}

Die Knochen aus der Lichtensteinhöhle wurden nahezu durchgängig disloziert aufgefunden, weshalb die Anzahl bestatteter Individuen nicht direkt ersichtlich war. Über das Auszählen der vorhandenen Exemplare der verschiedenen Skelettelemente konnte über das am häufigsten vorkommende Element - in diesem Fall die rechte Tibia - eine Mindestindividuenzahl von 51 ermittelt werden. Das Auszählen der verschiedenen Skelettelemente wurde jedoch dadurch erschwert, dass die Knochen zum Teil fragmentiert vorlagen und nur in Einzelfällen die Fragmente wieder aneinandergefügt werden konnten. Bei einer solchen Sachlage besteht die Gefahr, dass, wenn jedes Knochenfragment als separater Knochen in die Zählung mit eingeht, die Knochenanzahl überschätzt wird. Dies wurde dadurch umgangen, dass nur ganze Knochen und Fragmente, welche mindestens die Hälfte eines Knochens repräsentieren, in die Zählung mit einflossen.

Bereits über die ersten molekulargenetischen Arbeiten an den Knochen konnten - über Analysen der genetischen Fingerabdrücke - in einigen Fällen einzelne Knochen als von demselben Individuum stammend einander zugeordnet werden (Schultes 1997, Schultes 2000, Schilz 2006). Dies konnte über Reihenuntersuchungen des genetischen Fingerabdruckes an Humeri (Mußlick 2005), Radii (Gaertner 2005), Tibiae (Croll 2005) und Calcanei (Klingner 2005) und über morphologische Zuordnungen (Jungk 2008, Schiel 2008, Hollerbuhl 2009, Schubert 2009) mit weiteren, stichprobenartigen, genetischen Überprüfungen (Becker 2011) umfassend weitergeführt werden. Während die molekulargentisch basierten Zuordnungen eine sehr große Sicherheit besitzen, ist bei den morphologischen Zuordnungen die Zuordnungssicherheit sehr variabel. Bei Individuen, die durch Alters-, Größen- oder Robustizitätsmerkmale eine Einzigartigkeit aufweisen, kann auch bei den morphologischen Zuordnungen eine recht große Sicherheit erreicht werden, gibt es mehrere Individuen mit ähnlichen Charakteristika, nimmt die Zuordnungssicherheit jedoch deutlich ab. Grundsätzlich wurde bei den morphologischen Zuordnungen in Zweifelsfällen nach dem Parsimonieprinzip vorgegangen, wonach es wahrscheinlicher ist, dass ein Knochen oder Knochenfragment $\mathrm{zu}$ einem bereits definierten Individuum gehört, bei dem dieser Knochen fehlt, als dass der Knochen ein zusätzliches, separates Individuum darstellt. Nach Abschluss der Zuordnung der Knochen $\mathrm{zu}$ Individuen mittels morphologischer und 
molekulargenetischer Untersuchungen ergab sich eine Individuenzahl von 60. Auffällig ist jedoch, dass für lediglich zwei Individuen alle bei den Zuordnungen berücksichtigten Knochen - die Langknochen der Extremitäten und die Skelettelemente des Schulterund Beckengürtels - zugeordnet werden konnten.

Ableitungen bezüglich der Größe der Lebendpopulation sind generell schwierig (Grupe et al. 2015) und gerade in diesem Fall nicht sinnvoll, da es Hinweise darauf gibt, dass es sich bei den Bestattungen in der Lichtensteinhöhle um eine Sonderbestattung handelt (s.u. Kapitel 7.2 Nutzungsdauer und Nutzungsart der Lichtensteinhöhle).

\section{Alters- und Gechlechtsverteilung}

Die Geschlechtsverteilung und die Sterbealterverteilung stellen zwei der paläodemografischen Hauptparameter dar, aus denen die Bevölkerungszusammensetzung, die Sterblichkeitsverhältnisse und grundlegende Lebensbedingungen abgeleitet werden können.

Das Geschlechterverhältnis unter den Individuen aus der Lichtensteinhöhle ist insgesamt betrachtet mit 29 männlichen Individuen und 30 weiblichen Individuen (für 1 Individuum war das Geschlecht nicht bestimmbar) ausgewogen, was den Verhältnissen in zeitstellungsähnlichen Leichenbrandserien entspricht (Schutkowski und Hummel 1990). Betrachtet man jedoch die Geschlechterverhältnisse separat für die subadulten Individuen und die erwachsenen Individuen, so fällt auf, dass unter den subadulten ein höherer Anteil (61\%) an männlichen Individuen zu finden ist und entsprechend unter den erwachsenen ein höherer Anteil (66 \%) an weiblichen Individuen. Dies ist nicht unerwartet, da sich Erbkrankheiten, welche auf dem X-Chromosom codiert sind, in den ersten Lebensjahren bei männlichen Individuen manifestieren und sich - da viele dieser Krankheiten häufig tödlich verlaufen - in Form einer leichten Übersterblichkeit männlicher Individuen in den sehr jungen Altersklassen auswirken. Im Erwachsenenalter hingegen sind Frauen durch Schwangerschaften und Geburten einem erhöhten Mortalitätsrisiko ausgesetzt.

Im Gegensatz zur Geschlechtsverteilung weist die für die Individuen aus der Lichtensteinhöhle ermittelte Altersverteilung einige nicht zu erwartende Auffälligkeiten auf. Zwar stimmen die grundlegenden Sterblichkeitsverhältnisse mit denen zeitstellungsgleicher Leichenbrandserien überein (Schutkowski und Hummel 1990), jedoch weisen die Individuen der Altersklasse Infans II eine deutlich erhöhte Sterblichkeit auf. Grundsätzlich wäre jedoch eine erhöhte Sterblichkeit eher für 
Individuen der Altersklasse Infans I zu erwarten, da diese z.B. aufgrund ihres noch nicht vollständig entwickelten Immunsystems anfälliger für Infektionskrankheiten sind.

Für dieses Ungleichgewicht der Sterblichkeit innerhalb der subadulten Altersklassen gibt es weder durch eine eventuelle erbliche Belastung der Population mit genetischen Varianten, welche eine erhöhte Sterblichkeit im Infans II mit sich bringen (siehe Kapitel 6.3 Genetisch determinierte Erkrankungen), noch durch ein vermehrtes Unfallrisiko für diese Altersklasse, welches über ein erhöhtes Vorkommen von Traumata abgebildet würde (siehe Kapitel 4.2 Pathologische Befunde und andere Auffälligkeiten), eine Erklärung. Daher liegt die Vermutung nahe, dass es sich hier um eine verschobene Abbildung der Sterblichkeit aufgrund der Bestattungsform handeln könnte. So könnten z.B. Individuen der Altersklasse Infans I an einem anderen Ort gesondert bestattet worden sein, wogegen jedoch spricht, dass mehrere Individuen dieser Altersklasse vorhanden sind. Des Weiteren gibt es deutliche Hinweise darauf, dass es sich bei der Lichtensteinhöhle um einen Sekundärbestattungsplatz handelt (s.u. Kapitel 7.2 Nutzungsdauer und Nutzungsart der Lichtensteinhöhle). In diesem Fall könnte es sein, dass die Skelettreste der Individuen der Altersklasse Infans I aufgrund ihrer Grazilität schneller stark degradiert waren und daher zum Zeitpunkt, an dem eine Umbettung in die Höhle erfolgen sollte nicht mehr vorhanden waren.

Weiterhin fällt bei Betrachtung der Sterbealterverteilung auf, dass es im frühen bis mittleren Adultas nicht nur zu einem deutlichen Anstieg der Mortalität bei Frauen kommt, was sich problemlos mit den Risiken aus Schwangerschaft und Geburt erklären lässt, sondern auch bei Männern. Dies wäre durch ein erhöhtes Unfallrisiko oder durch Einflüsse von gewalttätigen Konflikten zu erklären, jedoch gibt es aufgrund des Fehlens $\mathrm{zu}$ erwartender Traumata (siehe Kapitel 4.2 Pathologische Befunde und andere Auffälligkeiten) keine Hinweise auf entsprechende Ursachen. Eine mögliche Erklärung wäre natürlich die Auswirkung von Verletzungen, welche nicht am Knochen manifest werden, wie z.B. eine Sepsis im Zusammenhang mit größeren Wunden.

Die Population aus der Lichtensteinhöhle weist eine insgesamt für die Zeitstellung typische, niedrige durchschnittliche Lebenserwartung zu Beginn des Lebens auf. Auffällig ist jedoch, dass Individuen, die die Risiken der sub- und frühadulten Altersklassen erfolgreich überwunden hatten, tatsächlich auch hohe Lebensalter (spätmatur und senil) erreicht haben. Vor diesem Hintergrund betrachtet, kann die Tatsache, dass nur wenige - und meist nur schwach ausgeprägte - degenerative Veränderungen an den Knochen nachweisbar waren, als Hinweis darauf gewertet 
werden, dass das Leben der in der Lichtensteinhöhle bestatteten Menschen nicht von übermäßig harter, Verschleiß fördernder Arbeit geprägt war.

\section{Körperhöhe}

Die Körperhöhe der erwachsenen Individuen aus der Lichtensteinhöhle wurde mit Hilfe osteometrischer Methoden durch Vermessen der Langknochen mit anschließender Berechnung mittels Regressionsformeln ermittelt (Oberthür 2010). Dies war nicht für alle Individuen möglich, da nicht für alle intakte Langknochen vorhanden waren bzw. nicht entfernbare Reste der Sinterschicht das exakte Vermessen verhinderten. Die ermittelten durchschnittlichen Körperhöhen von 158,1 cm für Frauen und von 169,8 cm für Männer fallen in den für bronzezeitliche Populationen zu erwartenden Bereich (Schutkowski und Hummel 1990, Schultz 1994). Dies kann dahingehend interpretiert werden, dass die in der Lichtensteinhöhle Bestatteten zu Lebzeiten unter den für die Bronzezeit üblichen Ernährungsbedingungen gelebt haben und in den Wachstumsphasen nicht kontinuierlichem Stress ausgesetzt waren.

\section{Degenerative Erscheinungen und Pathologien}

Pathologische Veränderungen am Skelettmaterial können nicht nur Hinweise bezüglich individueller Biografien geben sondern ermöglichen, in der Gesamtheit betrachtet, auch Ableitungen zur Krankheitsbelastung der gesamten Population oder - im Zusammenhang mit Infektionen - auch zu hygienischen Bedingungen. Frakturen und Traumata können, bei gehäuftem Auftreten, ein Indiz für Kampfhandlungen sein. Degenerative Veränderungen an den Knochen können Hinweise auf die Arbeitsbelastung und, damit verknüpft, auf den sozialen Stand geben. Ebenso hinterlassen längere Hunger- oder sonstige Mangelperioden Spuren am Skelettmaterial aus denen diese rekonstruiert werden können.

Eine systematische Untersuchung pathologischer und degenerativer Veränderungen war für die Individuen aus der Lichtensteinhöhle aufgrund des dislozierten Vorliegens der Skelettelemente und der teilweise nicht zu entfernenden Reste der Gipssinterschicht nicht möglich. Insgesamt wurden jedoch nur wenige Auffälligkeiten an den einzelnen Knochen festgestellt.

Es konnten keine Spuren von Verletzungen dokumentiert werden, die offensichtlich todesursächlich waren. Lediglich in Fällen wie z.B. einer großen Zyste in der Maxilla (siehe Abb. 27 Kapitel 4.2 Pathologische Befunde und andere Auffälligkeiten), welche 
von einem Entzündungsprozess herrührt, kann nicht ausgeschlossen werden, dass es zu einer Sepsis mit Todesfolge gekommen sein könnte. Hierbei handelt es sich jedoch um Einzelfälle.

Die wenigen Brüche, von denen sich Spuren an einzelnen Knochen fanden, waren gut verheilt und lassen sich unproblematisch mit Alltagsunfällen in Einklang bringen. Hinweise auf kriegerische Auseinandersetzungen waren nicht am Skelettmaterial zu finden.

Degenerative Veränderungen fanden sich in Form von Randleisten vor allem an einigen Wirbeln. Hierbei handelte es sich um leichte Knochenneubildungen bis hin zu extremer Randleistenbildung mit knöchernen Überbrückungen zwischen mehreren Wirbeln. Aber auch an anderen Skelettelementen ließen sich in Einzelfällen Randleisten feststellen, so z.B. an einem Phalanx proximalis ossa manus, einer Patella, am Acetabulum eines Os coxae, an der Incisura trochlearis einer Ulna und an der Cavitas glenoidalis einer Scapula. Eine knöcherne Überbrückung an einem Manubrium zur Costa ist vermutlich ebenfalls durch degenerative Prozesse bedingt. Insgesamt wurden jedoch relativ wenige degenerative Veränderungen vorgefunden angesichts der Tatsache, dass sich unter den 60 Individuen immerhin sieben Individuen im Altersbereich mittelmatur bis senil fanden. Dies kann als Hinweis darauf gewertet werden, dass die Individuen aus der Lichtensteinhöhle zu Lebzeiten nicht mit schwerer körperlicher Arbeit kontfrontiert waren.

Hinweise auf Mangelernährung finden sich ebenfalls nur in Einzelfällen an den Skelettelementen aus der Lichtensteinhöhle. So wurde nur ein einziger Fall von Harris Linien als Hinweis auf die Wiederaufnahme des Wachstums nach einer Stress- oder Mangelperiode im Röntgenbild offenbar und es konnten nur zwei leichte Fälle von Cribra orbitalia als Hinweis auf Eisenmangel oder Anämie dokumentiert werden. Das Fehlen von Hinweisen auf Nährstoffmangel spricht dafür, dass die Population durchgängig einen guten Zugang zu Nahrungsressourcen hatte und keinen Mangel litt. Um einen interessanten Einzelfall handelt es sich bei einer Trepanation im Os parietale eines subadulten Individuums. Die Tatsache, dass diese intentionale Schädelöffnung längerfristig überlebt wurde - wie aus den Heilungsspuren an der Diploe hervorgeht könnte ein Hinweis auf eine recht fortgeschrittene medizinische Versorgung sein. 


\section{Verwandtschaft und genetische Ausstattung}

Über Analysen der genetischen Fingerabdrücke und der mitochondrialen sowie Ychromosomalen Haplotypen ließen sich für 47 der 60 Individuen Verwandtschaftsbeziehungen rekonstruieren, welche einen Familienstammbaum mit sechs Generationen ergaben. Die 13 Individuen, welche nicht in den Stammbaum integriert werden konnten, könnten dennoch einen verwandtschaftlichen Bezug zu den übrigen Individuen besitzen, wobei die biologisch verbindenden Nachkommen lediglich nicht in der Höhle bestattet wurden. Bei dem in Abb. 77 (Seite 117) dargestellten Stammbaum handelt es sich um den nach dem Parsimonieprinzip wahrscheinlichsten Stammbaum. Es kann jedoch nicht ausgeschlossen werden, dass in einigen Fällen die weniger parsiomonische Lösung den tatsächlichen Verhältnissen entspricht. Insbesondere für die Individuen, für die nur recht schlechte genetische Ergebnisse erzielt werden konnten, ist es durchaus möglich, dass aufgrund der fehlenden Daten Verwandtschaftsbeziehungen übersehen bzw. genetische Ähnlichkeiten fehlinterpretiert wurden. Die Auswertung der Diversität der mitochondrialen und Y-chromosomalen Haplotypen ergab Hinweise darauf, dass es sich bei der Populaiton aus der Lichtensteinhöhle um eine patrilokale Gesellschaft handelte.

Die Ergebnisse der weiteren genetischen Analysen verschiedener genetischer Marker zeichnen das Bild einer Population, welche sich in der immungenetischen Ausstattung nicht wesentlich von heutigen mitteleuropäischen Populationen unterscheidet. Es konnte keine erhöhte Belastung mit Erbkrankheiten wie der Cystischen Fibrose (Scholten 2006) oder der Hereditären Hämochromatose (Krause 2006) festgestellt werden. Für den Laktosetoleranzmarker C/T -13910 konnte eine Zunahme der Frequenz des TAllels von der Bronzezeit bis in die Gegenwart nachgewiesen werden (Seebode 2010). Jedoch war das T-Allel auch in der Population aus der Lichtensteinhöhle bereits so weit etabliert, dass davon ausgegangen werden kann, dass Milch einen regulären Bestandteil der Nahrung dargestellt haben dürfte. Die Rekonstruktion der phänotypischen Merkmale Haar- und Augenfarbe mittels genetischer Analysen (Krause 2012, Schücker 2012) ergab ebenfalls ein Bild, welches sich nicht grundlegend von heutigen mitteleuropäischen Populationen unterscheidet.

\section{Zusammenfassung der demografischen Charakteristika}

Zusammenfassend lässt sich festhalten, dass die menschlichen Überreste aus der Lichtensteinhöhle von 60 Individuen stammen, welche sich zu gleichen Teilen auf beide 
Geschlechter verteilen. Bei der Altersverteilung ist auffällig, dass es einen Überschuss an - vor allem männlichen - Infans II Individuen gibt und weniger Infans I Individuen als erwartet vorhanden sind. Die Bestatteten stellen einen Familienclan dar, welcher sich aus mehreren Kernfamilien zusammensetzt und es handelt sich sehr wahrscheinlich um eine patrilokale Gesellschaft. Es wurden keine Hinweise auf andauernde Mangelernährung oder andere Stressfaktoren gefunden, was, zusammen mit den für bronzezeitliche Populationen normalen durchschnittlichen Körperhöhen und nur wenigen degenerativen Veränderungen an den Skelettelementen, dafür spricht, dass es durchgängig guten Zugang zu Nahrungsressourcen und keinen Zwang zu harter körperlicher Arbeit gab. Eventuell könnte es sich bei den in der Lichtensteinhöhle bestatteten Individuen um sozial höhergestellte Personen handeln. Hinweise auf kriegerische Auseinandersetzungen sind am aufgefundenen Skelettmaterial ebenfalls nicht feststellbar. Die genetische Ausstattung und das phänotypische Erscheinungsbild der Individuen aus der Lichtensteinhöhle ist weitestgehend recht nahe an den Verhältnissen in heutigen mitteleuropäischen Populationen.

\subsection{Nutzungsdauer und Nutzungsart der Lichtensteinhöhle}

Hinweise auf die Nutzungsdauer eines Bestattungsplatzes lassen sich am besten aus der Anzahl der vertretenen Generationen ableiten. Der Stammbaum für die Individuen aus der Lichtensteinhöhle umfasst sechs Generationen. Geht man von einer durchschnittlichen Generationendauer von 20 Jahren aus, so ergibt dies einen Nutzungszeitraum von 120 Jahren. Dies korrespondiert sehr gut mit den Ergebnissen der archäologischen Datierungen, nach denen eine Nutzung vom 10. Jh. v. Chr. bis ins 9. Jh. v. Chr. hinein erfolgte (Flindt und Hummel 2014).

Die Frage nach der Nutzungsart der Lichtensteinhöhle ist etwas schwieriger zu beantworten. Während anfänglich, direkt nach der Entdeckung der fundtragenden Teile der Höhle, davon ausgegangen wurde, dass es sich um eine Opferhöhle handelt, konnte diese Theorie bereits durch die Arbeiten von Schultes (2000) und Schilz (2006) als höchst unwahrscheinlich verworfen werden. Das ausgewogenen Geschlechterverhältnis, die Tatsache, dass Individuen aller Altersklassen repräsentiert waren, das Fehlen von todesursächlichen Verletzungsspuren und die nachgewiesenen Verwandtschaftsbeziehungen wiesen eindeutig darauf hin, dass es sich bei der Höhle um einen Bestattungsplatz handelte. Im Rahmen der Zuordnungen der disloziert aufgefundenen 
Skelettelemente zu Individuen (Jungk 2008, Schiel 2008, Hollerbuhl 2009, Schubert 2009) zeigte sich, dass sich die Skelettelemente eines Individuums zum Teil in verschiedenen Höhlenabschnitten befanden und dass bei nahezu allen Individuen entweder einzelne Skelettelemente oder ganze Gruppen von Skelettelementen verschiedener anatomischer Regionen fehlten. Dies warf die Frage auf, ob die Höhle eventuell nicht als primärer Bestattungsplatz sondern Sekundärbestattungsplatz in der Sonderform eines Beinhauses (Ossuar) genutzt wurde. Dass die fehlenden Knochen innerhalb der Höhle komplett vergangen sein könnten, erscheint unwahrscheinlich angesichts der guten Erhaltungsbedingungn innerhalb der Höhle und angesichts der Tatsache, dass auch größere Skelettelemente - wie z.B. Femora - und nicht nur kleine spongiöse Knochen - wie z.B. Rippen oder Wirbel - fehlten. Schon allein die Tatsache, dass die Skelettelemente nahezu durchgängig nicht mehr im anatomischen Verband vorgefunden wurden, könnte als Hinweis auf sekundäre Bestattungen in der Höhle gewertet werden, wobei natürlich nicht ausgeschlossen werden kann, dass die Knochen nach dem Verwesungsprozess der Weichgewebe innerhalb der Höhle lediglich zur Seite geräumt wurden, um Platz für weitere Bestattungen oder rituelle Handlungen zu schaffen.

Ein weiterer Hinweis, dass es sich tatsächlich um einen Sekundärbestattungsplatz handeln könnte, ergibt sich aus der ungewöhnlichen Altersverteilung mit einer scheinbar erhöhten Sterblichkeit von Individuen der Altersklasse Infans II bzw. einer Unterrepräsentanz von Individuen der Altersklasse Infans I. Bei einer primären Erdbestattung an einem Ort außerhalb der Höhle mit einer zeremoniellen Umbettung nach einer gewissen Zeitspanne könnten die sehr kleinen und grazilen Knochen von Infans I Individuen häufig bereits so weit vergangen gewesen sein, dass sie nicht mehr bei den Umbettungen berücksichtigt werden konnten.

Um der Frage nach dem praktizierten Bestattungsmodus weiter nachzugehen, wurden in begleitenden Arbeiten statistische Analysen von Mustern in der Färbung der Knochen, der oberflächlichen Degradierung und Textur der Knochenoberfläche sowie der DNADegradierung durchgeführt. Desweiteren wurde die Streuung der Knochen, welche jeweils einander $\mathrm{zu}$ einem Individuum zugeordnet worden waren, statistisch ausgewertet. Die Ergebnisse dieser statistischen Auswertungen waren nicht ganz eindeutig. Die Auswertung der Färbung (Merkes 2010) und der Oberflächentextur (Knorre 2010) ergab einen höheren signifikanten Zusammenhang der Merkmalsausprägung mit dem genauen Auffindeort innerhalb der Höhle als mit der 
Zugehörigkeit $\mathrm{zu}$ einem bestimmten Individuum, was eher für einen primären Bestattungsplatz sprechen würde. Allerdings war auch der Zusammenhang mit der Individuenzugehörigkeit statistisch signifikant. Die Auswertung der DNA-Degradierung (Blume 2010) hingegen ergab einen statistisch signifikanten Zusammenhang nur mit der Zugehörigkeit der Skelettelemente zu bestimmten Individuen, was eher auf einen sekundären Bestattungsplatz hinweist.

Eventuell könnte die Färbung und die Oberflächentextur tatsächlich sowohl vom primären Bestattungsort als auch der sekundären Lage innerhalb der Höhle beeinflusst worden sein. Da diese beiden Merkmale durch den direkten Kontakt mit dem Boden sehr direkt und unmittelbar beeinflusst werden, könnten in stärkerem Maße beide Umgebungen einen deutlichen Einfluß gehabt haben. Die DNA-Erhaltung hingegen könnte in größerem Maße von der primären Umgebung außerhalb der Höhle beeinflusst worden sein, während die konkrete Lage innerhalb der Höhle nur noch deutlich weniger Einfluß hatte, da die Erhaltungsbedingungen innerhalb der Höhle prinzipiell eher gut waren und die DNA in der Tiefe des Knochens nicht so unmittelbar beeinflußt wird. Bei einer solchen Interpretation würden die Ergebnisse der Auswertung aller drei Merkmale die Theorie, dass es sich bei der Lichtensteinhöhle um einen Sekundärbestattungsplatz handelt, unterstützen.

Bezüglich der Streuungsgrade der Knochen eines jeweiligen Individuums wurde angenommen, dass es sich, wenn die Knochen über mehrere Höhlenabschnitte sehr stark streuen, wahrscheinlich eher um einen Sekundärbestattungsplatz handelt (Zeidler 2010). Die Untersuchungen ergaben hohe Streuungsgrade, was auf massive Umlagerungen der Knochen hinweist und damit unter der obigen Annahme darauf hin deutet, dass Sekundärbestattungen tatsächlich wahrscheinlicher anzunehmen sind als Primärbestattungen.

Bei der Begutachtung und Klassifikation der Knochenfärbung wurde auch auf möglicherweise vorhandene Nagespuren und Spuren von Pflanzenwurzeln geachtet. Hierbei wurden an einem der Knochen kleine Reste einer Pflanzenwurzel und Abdrücke des weiteren Verlaufs der Wurzel auf der Knochenoberfläche gefunden (Merkes 2010). Da es im Inneren der Höhle keinen Pflanzenbewuchs gab, ist dies als weiterer Hinweis auf eine primäre Bestattung an einem anderen Ort zu werten.

Weitere Hinweise wurden aus der Analyse der in der Lichtensteinhöhle aufgefundenen Fliegen-Exuvien erhofft. Mittels morphologischer und genetischer Analysen konnten die Exuvien als durchgängig von der Art Calliphora vicina stammend identifiziert 
werden (pers. Mitteilung A. Scholten, pers. Mitteilung P. von Grumbkow). Dies ist eine der ersten Fliegenarten, welche eine Leiche besiedeln (Defilippo et al. 2013), allerdings verpuppen sich diese Fliegen nur bei Temperaturen von mindestens ca. $5^{\circ} \mathrm{C}$ (Davies und Ratcliffe 1994). Da es in der Höhle also über weite Strecken des Jahres eigentlich für die Fliegen der Spezies Calliphora vicina für eine Verpuppung zu kalt gewesen sein dürfte, scheint deren Identifikation zunächst ebenfalls die Theorie, dass es sich bei der Lichtensteinhöhle um einen Sekundärbestattungsplatz handelt, zu unterstützen. Allerdings könnte es während der Nutzung des Berndsaals für rituelle Handlungen durch die Feuerstellen zwischenzeitlich in der gesamten Höhle deutlich wärmer gewesen sein. Zudem müssen die Fliegenlarven bzw. Pupparien nicht zwangsläufig aus den menschlichen Überresten stammen. Eventuell könnten sie auch mit vielleicht schon befallenen Tierfleisch-Opfergaben in die Höhle gelangt sein. Die Ergebnisse der entomologischen Untersuchungen sind also nur schwer als Argument in eine bestimmte Richtung festzulegen.

Insgesamt betrachtet gibt es jedoch genügend Hinweise dahingehend, dass es sich bei der Lichtensteinhöhle höchst wahrscheinlich um einen Sekundärbestattungsplatz handelt. Unter dieser Annahme könnte auch erklärt werden, warum es an einigen Stellen des biologisch-parsimonischen Stammbaums scheinbar einen Konflikt der Generationenfolge mit der aus der archäologischen Stratigrafie abgeleiteten Bestattungsreihenfolge gibt. Handelt es sich tatsächlich um Sekundärbestattungen, so müssen die Individuen nicht zwangsläufig in der tatsächlichen Sterbereihenfolge in die Höhle verbracht worden sein. Ältere Generationen könnten auch nach jüngeren bestattet worden sein.

Allerdings würden bei einer solchen Sachlage wiederum die Schätzungen zur Nutzungsdauer der Höhle relativiert. Wenn die Individuen nicht in den „natürlichen“ Sterbeabständen eingebracht wurden, sondern zu nicht nachvollziehbaren Zeitpunkten kleinere oder größere Gruppen von Individuen an den sekundären Bestattungsplatz umgebettet wurden, kann nicht mehr von der Generationenzahl auf die Nutzungsdauer der Höhle gechlossen werden. Nichtsdestotrotz bleiben natürlich bezüglich der Antwort auf die Frage nach der Nutzungsdauer die archäologischen Fakten aus der Einordnung der aufgefundenen Bronzen und Tonscherben bestehen, was wiederum zeigt, wie wichtig die interdisziplinäre archäologische und anthropologische Analyse und Interpretation (prä-) historischer Fundstätten wie der Lichtensteinhöhle ist. 


\section{Zusammenfassung}

Bei der Lichtensteinhöhle handelt es sich um eine Klufthöhle im Nordwesthang des Berges Lichtenstein in den Harzausläufern. Im anthropogenen Teil der Höhle, welcher aus mehreren, durch Engstellen verbundenen Höhlenkammern besteht, wurden größere Mengen disoloziert vorliegender, menschlicher und tierischer Knochen sowie ein breites Spektrum von archäologischen Artefakten aus Bronze und anderen Materialien gefunden. Über die archäologischen Funde konnte eine Datierung ins 10.-9. Jh. v. Chr. erfolgen. Die Funde waren mit einer Schicht aus Gipssinter überzogen, welche, gemeinsam mit den vorherrschenden konstant niedrigen Temperaturen einen herausragend guten Erhaltungszustand der Knochen und der enthaltenen aDNA bewirkte. Die Menschenknochen aus der Lichtensteinhöhle wurden nach ihrer Bergung in kontinuierlich durchgeführten Grabungskampagnen in eine Kühlkammer in der Abteilung Historische Anthropologie und Humanökologie des Johann-FriedrichBlumenbach-Institutes für Zoologie und Anthropologie der Georg August Universität Göttingen verbracht. Seither wurden umfangreiche Forschungsarbeiten zu diversen Fragestellungen an den Knochen vorgenommen.

Eine der zentralen Fragestellungen zu Beginn der Forschung zur Lichtensteinhöhle war, ob es sich um eine Opferstätte oder einen Bestattungsplatz handelt. Während ganz zu Beginn ersteres vermutet wurde, konnte über den Nachweis eines ausgewogenen Geschlechterverhältnisses, einer Altersverteilung über alle Altersklassen und von, molekulargenetisch rekonstruierten, verwandtschaftlichen Beziehungen zwischen einigen Individuen die Nutzung als Bestattungsplatz als deutlich wahrscheinlicher angenommen werden. Die folgende umfangreiche Verwandtschaftsrekonstruktion für die $\mathrm{zu}$ diesem Zeitpunkt identifizierten 40 Individuen ergab den Stammbaum eines Familienclans, welcher in verschiedene Kernfamilien substrukturiert war. Über begleitende Reihenuntersuchungen verschiedener Skelettelemente und morphologische Zuordnungen von Skelettelementen zu Individuen wurde zum einen deutlich, dass Knochen von deutlich mehr Individuen als den bislang identifizierten 40 Individuen in der Höhle waren. Des Weiteren wurde deutlich, dass für nahezu alle Individuen jeweils einige der bei den Zuordnungen berücksichtigten Knochen - Langknochen der Extremitäten, Knochen des Schulter- und Beckengürtels sowie craniale Elemente nicht in der Höhle auffindbar waren. Eine der möglichen Ursachen für das Fehlen von Skelettelementen wäre, dass es sich bei der Höhle nicht um einen Primär- sondern um einen Sekundärbestattungsplatz handelt. 
Im aktuell durchgeführten Forschungsprojekt wurden die Zuordnungen der dislozierten Knochen zu Individuen, unter Verwendung morphologischer und molekulargenetischer Methoden, zu Ende geführt. Es konnten insgesamt 60 Individuen über einen individuellen genetischen Fingerabdruck identifiziert werden. Auch nach Abschluss der Zuordnungen der Knochen $\mathrm{zu}$ Individuen konnten nur zwei der Individuen als vollständig vermerkt werden, wohingegen für die Mehrheit wenige bis viele Knochen fehlten. Die Dokumentation der pathologischen Veränderungen und sonstiger Auffälligkeiten am Skelettmaterial zeigte einige wenige Fälle degenerativer Veränderungen an vorwiegend Wirbeln auf. Daraus wurde geschlossen, dass die in der Lichtensteinhöhle bestatteten Menschen nicht übermäßig hart körperlich gearbeitet haben. Spuren von massiver Gewalteinwirkung gab es nicht. Einige wenige gut verheilte Frakturen an Rippen oder Schlüsselbein lassen sich problemlos mit Alltagsunfällen in Verbindung bringen. Somit ist es unwahrscheinlich, dass die bestattete Population in kriegerische Auseinandersetzungen involviert war. Spuren von Mangel- oder Stressphasen gab es nur in Einzelfällen - zwei Fälle von Cribra orbitalia und ein Fall von Harris Linien - was darauf hin deutet, dass die Bestatteten zu Lebzeiten kontinuierlichen Zugang zu ausreichenden Nahrungsressourcen hatten.

Das Geschlechterverhältnis war mit 30 weiblichen und 29 männlichen Individuen (nur für ein Individuum konnte das Geschlecht nicht bestimmt werden) ausgewogen. Die Altersverteilung entsprach mit einem Sterbegipfel im Kindesalter und einem weiteren im früheren Erwachsenenalter in den Grundzügen der für eine historische Population zu erwartenden. Während Kinder häufig anfälliger für Infektionen sind, bringt das frühere Erwachsenenalter ein höheres Sterberisiko für Frauen durch Schwangerschaft und Geburt mit sich. Allerdings war bei der Sterbealterverteilung auffällig, dass innerhalb der Infans Altersklassen nicht wie erwartet die höchste Sterblichkeit im Infans I lag, sondern im Infans II. Eine mögliche Erklärung hierfür ist, dass jüngere Kinder an einem separaten Ort bestattet wurden. Eine weitere Erklärungsmöglichkeit ist, dass tatsächlich Sekundärbestattungen praktiziert wurden und die sehr kleinen, fragilen Knochen der Infans I Individuen zum Zeitpunkt der Umbettungen bereits vergangen waren.

Die molekulargenetischen Analysen der genetischen Fingerabdrücke sowie der mitochondraialen und Y-chromosomalen Haplotypen für alle neu identifizierten Inividuen mit anschließender Verwandtschaftsrekonstruktion ergab einen nach dem Parsimonieprinzip wahrscheinlichsten, erweiterten Stammbaum, in dem für 47 der 60 Individuen entweder direkte Verwandtschaft oder aber Verwandtschaft in mütterlicher 
oder väterlicher Familienlinie belegt ist. Der Stammbaum umfasst insgesamt sechs Generationen, was - bei einer angenommenen Generationendauer von 20 Jahren - einer Nutzungsdauer von 120 Jahren entspricht. Dies passt gut zum archäologisch ermittelten Nutzungszeitraum vom 10. Jh. v. Chr bis ins 9. Jh. v. Chr.. Die Auswertung der Diversität der mitochondrialen und Y-chromosomalen Haplotypen ergab Hinweise auf eine patrilokale Gesellschaftsform.

In begleitenden Arbeiten wurden diverse weitere genetische Marker untersucht. Die Analysen ergaben, dass sich in vielerlei Hinsicht - z.B. bezüglich der immungenetischen Ausstattung oder bezüglich der genetischen Marker, welche das äußere Erscheinungsbild beeinflussen - die grundsätzliche genetische Ausstattung in den letzten 3.000 Jahren nicht grundlegend geändert hat. Die statistischen Analysen verschiedener Merkmale, wie die Färbung oder Oberflächentextur der Knochen bzw. der Grad der DNA-Degradierung, ergaben zwar nicht ganz eindeutige Ergebnisse, ingesamt betrachtet liefern sie jedoch weitere Hinweise in die Richtung, dass es sich bei der Lichtensteinhöhle tatsächlich um einen Sekundärbestattungsplatz handeln dürfte. 


\section{Literatur}

Acsádi G, Nemeskéri J (1970) History of human life span and mortality. Akademiai Kiado, Budapest

Agre P, Cartron JP (1991) Molecular biology of the Rh antigens. Blood 78:551-563

Ajioka RS, Kushner JP (2002) Hereditary Hemochromatosis. Seminar in Hematology 39:235241

Allentoft ME et al. (2015) Population genomics of Bronze Age Eurasia. Nature 522:167-172. doi:10.1038/nature14507

Alonso A, Andelinovic S, Martín P et al. (2001) DNA typing from skeletal remains: Evaluation of multiplex and megaplex STR systems on DNA isolated from bone and teeth samples. CMJ 42:260-266

Amory S, Huel R, Bilić A, Loreille O, Parsons TJ (2012) Automatable full demineralization DNA extraction procedure from degraded skeletal remains. Forensic Sci Int Genet 6:398406

Amtsblatt der Europäischen Gemeinschaften ENTSCHLIESSUNG DES RATES vom 25. Juni 2001 über den Austausch von DNS-Analyseergebnissen (2001/C 187/01)

Amtsblatt der Europäischen Union ENTSCHLIESSUNG DES RATES vom 30. November 2009 über den Austausch von DNS-Analyseergebnissen (2009/C 296/01)

Aoki K (2001) Theoretical and empirical aspects of gene-culture coevolution. Theor Popul Biol 59:253-261

Asamura H, Fujimori S, Ota M, Fukushima H (2007) MiniSTR multiplex system based on non-CODIS loci for analysis of degraded DNA samples. Forensic Sci Int 173:7-15

Assis S, Keenleyside A, Santos AL, Alves Cardoso F (2015) Bone Diagenesis and its Implication for Disease Diagnosis: The Relevance of Bone Microstructure Analysis for the Study of Past Human Remains. Microsc Microanal 21:805-825

Athey TW (2005) Haplogroup Prediction from Y-STR Values Using an Allele-Frequency Approach. J Genet Geneal 1:1-7

Athey TW (2006) Haplogroup Prediction from Y-STR Values Using a Bayesian-AlleleFrequency Approach. J Genet Geneal 2:34-39

Avent ND, Reid ME (2000)The Rh blood group system: a review. Blood 95:375-387

Barsh GS (2003) What controls variation in human skin color? PLoS Biol 1:19-22

Bayless TM, Paige DM, Ferry GD (1971) Lactose intolerance and milk drinking habits. Gastroenterology 60:605-608

Becker M (2011) Molekulargenetiche Überprüfung morphologischer Zuordnungen von isolierten Skelettelementen aus der bronzezeitlichen Lichtensteinhöhle. Diplomarbeit, Universität Göttingen

Berg S, Bertozzi B, Meier R, Mendritzki S (1983) omparative methodological contribution and critical observations on the interpretation of blood group determinations of mummies and skeletal remains. Anthropol Anz 41:1-19

Bersaglieri T, Sabeti PC, Patterson N, Vanderploeg T, Schaffner SF, Drake JA, Rhodes M, Reich DE, Hirschhorn JN (2004) Genetic signatures of strong recent positive selection at the lactase gene. Am J Hum Genet 71:1111-1120

Bertermann U (2004) Alte STR-Haplotypen und delta32 ccr5 - Untersuchungen zur Datierungsfrage einer immunologisch relevanten Mutation an Skelettfunden der Lichtensteinhöhle und des Frankenbergquartiers. Staatsexamensarbeit, Universität Göttingen 
Blackwell C, Dundas S, James V, Mackenzie D, Brown J, Alkout A, Todd W, Elton R, Weir D (2002) Blood group and susceptibility to disease caused by Escherichia coli O157. The Journal of Infectious Diseases 185:393-396

Blume A (2010) Zur Frage der Nutzung der Lichtensteinhöhle als Primär- oder Sekundärbestattungsplatz - Prüfung des DNA-Erhalts auf Abhängigkeit von in situ-Lage und Individuenzugehörigkeit genetisch analysierter Skelettelemente. Bachelorarbeit, Universität Göttingen

Blume A (2012) Prehistoric risk behavior: Development of an analysis system for the $48 \mathrm{bp}$ variable number of tandem repeats polymorphism of the human dopamine receptor D4 (DRD4) applicable to aDNA. Masterarbeit, Universität Göttingen

Boll W, Wagner P, Mantei N (1991) Structure of the chromosomal gene and cDNAs coding for lactase-phlorizin hydrolase in humans with adult-type hypolactasia or persistence of lactase. Am J Hum Gnet 48:889-902

Bonafe M, Olivieri F, Cavallone L, Giovagnetti S, Marchegiani F, Cardelli M, Pieri C, Marra M, Antonicelli R, Lisa R, Rizzo MR, Paolisso G, Monti D, Franceschi C (2001) A gender-dependent genetic predisposition to produce high levels of IL-6 is detrimental for longevity. Eur J Immunol 31:2357-2361

Borgognini-Tarli SM (1980) Blood group determination on medieval bone samples (XI A.D.) from gava market (Hungary). Anthrop Contemp 3:351-354

Bouakaze C, Keyser C, Crubézi E, Montagnon D, Ludes B (2009) Pigment phenotype and biogeographical ancestry from ancient skeletal remains: inferences from multiplexed autosomal SNP analysis. Int J Lega Med 123:315-325

Boyd WC, Boyd LC (1933) Blood grouping by means of preserved muscle. Science 78:578

Bradley LA, Haddow JE, Palomaki GE (1996) Population screening for hemochromatosis: A unifying analysis of published intervention trials. J Med Screen 3:178-184

Bramanti B, Sineo L, Vianello M, Caramelli D, Hummel S, Chiarelli B, Herrmann B (2000) The selective advantage of cystic fibrosis heterozygotes tested by aDNA analysis: a preliminary investigation. Int J Anthropol 15:255-262

Brandt A (2010) Untersuchung der Mikrostruktur der Femurkompakta mit dem Ziel der Altersdiagnose und der Dokumentation hypermineralisierter Linien am prähistorischen Skelettkollektiv der Lichtensteinhöhle. Bachelorarbeit, Universität Göttingen

Branicki W, Liu F, Duijn K, Draus-Barini J, Pośpiech E, Walsh S, Kupiec T, WojasPelcA, Kayser M (2011) Model-based prediction of human hair color using DNA variants. Hum Genet 129: 443-454

Breitinger E (1937) Zur Berechnung der Körperhöhe aus den langen gleidmaßenknochen. Anthropol Anz 14:249-274

Brothwell DR (1972) Digging up bones: The excavation, treatment and study of human skeletal remains. Trustees of the British Museum, London

Burger J, Hummel S, Herrmann B, Henke W (1999) DNA preservation: A microsatelliteDNA study on ancient skeletal remains. Electrophoresis 20:1722-1728

Burger J, Kirchner M, Bramanti B, Haak W, Thomas MG (2007) Absence of the lactasepersistence-associated allele in early Neolithic Europeans. PNAS 104:3736-3741

Büsse S, von Grumbkow P, Hummel S, Shah DN, Tachamo Shah RD, Li J, Zhang X, Yoshizawa K, Wedmann S, Hörnschemeyer T (2012) Phylogeographic Analysis Elucidates the Influence of the Ice Ages on the Disjunct Distribution of Relict Dragonflies in Asia. PLoS ONE 7:e38132.

Butler JM, Shen Y, McCord BR (2003) The development of reduced size STR amplicons as tools for analysis of degraded DNA. J Forensic Sci 48:1054-1064 
Butler JM (2005) Forensic DNA Typing - Biology, Technology, and Genetics of STR Markers. Second ed. Elsevier

Butler JM (2015) U.S. initiatives to strengthen forensic science \& international standards in forensic DNA. Forensic Science International: Genetics 18:4-20

Camaschella C (2005) Understandin iron homeostasis through genetic analysis of hemochromatosis and related disorders. Blood 106:3710-3717

Campos PF, Craig OE, Turner-Walker G, Peacock E, Willerslev E, Gilbert MT (2012) DNA in ancient bone - Where is it located and how should we extract it? Ann Anat 194:7-16

Capelli C, Tschentscher F, Pascali VL (2003) "Ancient" protocols for the crime scene? Similarities and differences between forensic genetics and ancient DNA analysis. Forensic Sience International 131:59-64

Cartron JP (1994) Defining the Rh blood group antigens. Biochemistry and molecular genetics. Blood Rev 8:199-212

Cavalli-Sforza LL (1990) Cultural transmission and nutrition. World Rev Nutr Diet 63: 35-48

Chang FM, Kidd JR, Livak KJ, Pakstis AJ, Kidd KK (1996) The world-wide distribution of allel frequencies at the human dopamine D4 receptor locus. Human Genetics 98:91-101

Chen CS, Burton M, Greenberger E, Dmitrieva J (1999) Population migration and the variation of dopamine D4 receptor (DRD4) allele frequencies around the globe. Evolution and Human Behavior 20:309-324

Cheng SH, Gregory RJ, Marshall J, Paul S, Souza DW, White GA, O'Riordan CR, Smith AE (1990) Defective intracellular transport and processing of CFTR is the molecular basis of most cystic fibrosis. Cell 63:827-834

Chérif-Zahar B, Mattei MG, Le Van Kim C, Bailly P, Cartron JP, Colin Y (1991) Localization of the human $\mathrm{Rh}$ blood group gene structure to chromosome region $1 \mathrm{p} 34.3-$ 1 p36.1 by in situ hybridization. Hum Genet $86: 398-400$

Christiansen L, Bathum L, Andersen-Ranberg K, Jeune B, Christensen K (2004) Modest implication of inteleukin-6 promoter polymorphisms in longevity. Mech Ageing Dev 125:391-395.

Cieslak M, Pruvost M, Benecke N, Hofreiter M, Morales A, Reissmann M, Ludwig A (2010) Origin and history of mitochondrial DNA lineages in domestic horses. PLoS One 5:e15311

Coble MD, Butler JM (2005) Characterization of new miniSTR loci to aid analysis of degraded DNA. J Forensic Sci 50:43-53

Coelho M, Luiselli D, Bertorelle G, Lopes AI, Seixas S, Destro-Bisol G, Rocha J (2005) Microsatellite variation and evolution of human lactase persistence. Hum Genet 117:329339

Colin Y, Chérif-Zahar B, van Kim C, Raynal V, van Huffel V, Cartron JP (1991) Genetic basis of the RhD-positive and $\mathrm{RhD}$-negative blood group polymorphism as determined by Southern analysis. Blood 78:2747-2752

Cooper A und Poinar HN (2000) Ancient DNA: Do it right or not al all. Science 289:1139 Faerman M, Nebel A, Filon D et al. (2000) Trans-Atlantic slave trade and sickle cell anemia studied by DNA analysis. Vortrag auf der V. International Ancient DNA Conference, Manchester, Juli 2000

Crawley E, Kay R, Sillibourne J, Patel P, Hutchinson I, Woo P (1999) Polymorphic haplotypes of the interleukin-10 5' flanking region determine variable interleukin-10 transcription and are associated with particular phenotypes of juvenile rheumatoid arthritis. Arthritis Rheum 42:1101-1108 
Crittenden RG, Bennett LE (2005) Cow's milk allergy: a complex disorder. J Am Coll Nutr 24:582S-591S

Croll S (2005) Fingerprinting an Tibiae aus der Lichtensteinhöhle - Molekulargenetische Analysen von short tandem repeats zur Aufdeckung von Verteilungsmustern isoliert vorliegender Skelettelemente aus einer bronzezeitlichen gestörten Fundsituation. Diplomarbeit, Universität Göttingen

Cuatrecasas P, Lockwood DH, Caldwell JR (1965) Lactase defeciency in the adult. A common occuranc. Lancet 2:14-18

Daniels G (2002) Human blood groups. $2^{\text {nd }}$ edition, Blackwell Science, Malden MA

Daniels G (2005) The molecular genetics of blood group polymorphism. Transpl Immunol 14: $143-153$

Davies L, Ratcliffe GG (1994) Development rates of some pre-adult stages in blowflies with reference to low temperatures. Medical and Veterinary Entomology 8:245-254

Dawson KP, Frossard PM (2000) The geographic distribution of cystic fibrosis mutations gives clues about population origins. Eur J Pediatr 159:496-499

Dean M, Carringtin M, Winkler C, Huttley GA, Smith MW, Allikmets R, Goedert JJ, Buchbinder SP, Vittinghoff E, Gomperts E, Donfield S, Vlahov D, Kaslow R, Saah A, Rinaldo C, Detels R, O'Brien SJ (1996) Genetic Restriction of HIV-1 Infection and Progression to AIDS by a Deletion Allele of the CKR5 Structural Gene. Science 27 (273): 1856-1862

Defilippo F, Bonilauri P, Dottori M (2013) Effect of Temperature on Six Different Developmental Landmarks within the Pupal Stage of the Forensically Important Blowfly Calliphora vicina (Robineau-Desvoidy) (Diptera: Calliphoridae). J Forensic Sci 58:1554 1557

Deguilloux MF, Pemonge, MH, Dubut V, Hughes S, Hänni C, Chollet L, Conte E, Murail P (2011) Human ancient and extant mtDNA from the Gambier Islands (French polynesia): Evidence for an early Melanesian maternal contribution and new perspectives into the settlement of easternmost Polynesia. Am J Phys Anthropol 144 (2): 248-257

Di Bernardo G, Del Gaudio S, Galderisi U, Cascino A, Cipollaro M (2009) Ancient DNA and family relationships in a Pompeian house. Ann Hum Genet 73:429-437

Dieffenbach CW, Lowe TMJ, Dveksler GS (1993) General concepts for PCR primer design. PCR Methods Appl 3:30e37

Ding YC, Chi HG, Grady DL, Morishima A, Kidd JR, Kidd KK, Flodma P, Spencer A, Schuck S, Swason JM, Zhang YP, Moyzis RK (2002) Evidence of positive selection acting at the human dopamine receptor D4 gene locus. PNAS 99:309-314

Doran GH, Dickel DN, Ballinger WE, Agee OF, Laipis PJ, Hauswirth WW (1986) Anatomical, cellular and molecular analysis of 8,000-yr-old human brain tissue from the Windover archaeological site. Nature 323:803-806

Dragic T, Litwin V, Allaway GP, Martin SR, Huang Y, Nagashima KA, Cayanan C, Maddon PJ, Koup RA, Moore JP, Paxton WA (1996) HIV-1 entry into CD4+ cells is mediated by the chemokine receptor CC-CKR-5. Nature 381:667-673

Edwards CJ, Bollongino R, Scheu A, Chamberlain A, Tresset A, Vigne JD, Baird JF, Larson G, Ho SY, Heupink TH, Shapiro B, Freeman AR, Thomas MG, Arbogast RM, Arndt B, Bartosiewicz L, Benecke N, Budja M, Chaix L, Choyke AM, Coqueugniot E, Döhle HJ, Göldner H, Hartz S, Helmer D, Herzig B, Hongo H, Mashkour M, Ozdogan M, Pucher E, Roth G, Schade-Lindig S, Schmölcke U, Schulting RJ, Stephan E, Uerpmann HP, Vörös I, Voytek B, Bradley DG, Burger J (2007) Mitochondrial DNA analysis shows a Near Eastern Neolithic origin for domestic 
cattle and no indication of domestication of European aurochs. Proc Biol Sci 274:13771385

Eiberg H, Troelson J, Nielsen M, Mikkelsen A, Mengel-From J, Kjaer KW, Hansen L (2008) Blue eye color in humans may be caused by a perfectly associated founder mutation in a regulatory element located within the HERC2 gene inhibiting OCA2 expression. Hum Genet 123 (2): 177-187

Enattah NS, Sahi T, Savilahti E, Terwilliger JD, Peltonen L, Järvelä I (2002) Identification of a variant associated with adult-type hypolactasia. Nat Genet 30:233-237

Enattah NS (2005) Molecular genetics of lactase persistence. Diss. University Helsinki

Enattah NS, Trudeau A, Pimenoff V, Maiuri L, Auricchio S, Greco L, Rossi M, Lentze M, Seo JK, Rahgozar S, Kahlil I, Alifrangis M, Natah S, Groop L, Shatt N, Kozlov A, Verschubskaya G, Comas D, Bulayeva K, Mehdi SQ, Terwilliger JD, Sahi T, Savilahti E, Perola M, Sajantila A, Jarvela I, Peltonen L (2007) Evidence of stillongoing convergence evolution of the lactase persistence T-13910 alleles in humans. Am J Hum Genet 81:615-625

Erikson N, Macpherson JM, Tung JY, Hon LS, Naughton B, Saxonov S, Avey L, Wojcicki A, Pe'er I, Mountain J (2010) Web-based, participant-driven studies yield novel genetic associations for common traits. PLoS Genet 6: e1000993

Faerman M, Nebel A, Filon D, Thomas MG, Bradman N, Ragsdale BD, Schultz M, Oppenheim A (2000) From a dry bone to a genetic portrait: a case study of sickle cell anemia. Am J Phys Anthropol 111:153-63

Fehren-Schmitz L (2008) Molekularanthropologische Untersuchungen zur präkolumbischen Besiedlungsgeschichte des südlichen Perus am Beispiel der Palpa-Region. Dissertation, Universität Göttingen

Fehren-Schmitz L, Warnberg O, Reindel M, Seidenberg V, Isla J, Tomasto E, Hummel S, Herrmann B (2011) Diachronic investigations of mitochondrial and Y-chromosomal genetic markers in pre-Columbian Andean Highlanders from South Peru. Annals of Human Genetics 75:266-283

Ferri G, Bini C, Ceccardi S, Pelotti S (2004) AB0 genotyping by minisequencing analysis. Transfusion 44: 943-944

Fishman D, Faulds G, Jeffery R, Mohamed-Ali V, Yudkin JS, Humphries S, Woo P (1998) The effect of novel polymorphisms in the interleukin-6 (IL-6) gene on IL-6 transcription and plasma IL-6 levels, and an association with systemic-onset juvenile chronic arthritis. J Clin Invest. 102:1369-1376

Flatz G, Rotthauwe HW (1973) Evidence against Nutrtional Adaption of Tolerance to Lactose. Humangenetik 13:118-125

Flatz G (1987) Genetics of lactose digestion in humans. Adv Hum Genet 16:1-77

Flindt S (1996) Die Lichtensteinhöhle bei Osterode, Landkreis Osterode am Harz - Eine Opferhöhle der jüngeren Bronzezeit im Gipskarst des südwestlichen Harzrandes Forschungsgeschichte und erste Grabungsergebnisse. Die Kunde N.F. 47:435-466

Flindt S (1998) Die Lichtensteinhöhle. In: Flindt S, Leiber C (Hrsg.) Kulthöhlen und Menschenopfer im Harz, Ith und Kyffhäuser. Verlag Jörg Mitzkat, Holzminden, S. 50-80

Flindt S, Haßmann H, Malek K (2012) Ausgrabungen in der Lichtensteinhöhle bei Osterode am Harz abgeschlossen. Berichte zur Denkmalpflege in Niedersachsen 2/2012: 84-89

Flindt S, Hummel S, Seidenberg V, Schoon R, Wolf G, Haßmann H, Saile T (2013) Die Lichtensteinhöhle. Ein "irregulärer" Ort mit menschlichen Skelettresten aus der Urnenfelderzeit - Vorbericht über die Ausgrabungen der Jahre 1993-2011. In: N. MüllerScheeß1 (Hrsg.) "Irreguläre" Bestattungen in der Urgeschichte: Norm, Ritual, Strafe ...? 
Akten der Internationale Tagung in Frankfurt a. M. vom 3. bis 5. Februar 2012. Kolloquien zur Vor-und Frühgeschichte 19:347-364

Flindt S, Hummel S (2014) Die Lichtensteinhöhle - Bestattungsplatz einer Großfamilie aus der Bronzezeit. Publikation des HöhlenErlebnisZentrum Iberger Tropfsteinhöhle - Ein Museum des Landkreises Osterode am Harz. Bad Grund 2014

Frischalowski M, Seidenberg V, Grosskopf B, Wulf FW, Hummel S (2015) Molekulargenetische Untersuchung des Verwandtschaftsverhältnisses von möglichen Mutter-Kind-Bestattungen aus dem frühneuzeitlichen Eldagsen. Nachrichten aus Niedersachsens Urgeschichte 84:193-206

Frost P (2006) European hair and eye color: A case of frequency dependent sexual selection? Evol Hum Behav 27:85-103

Frudakis TN (2008) Molecular photofitting: predicting ancestry and phenotype using DNA. Elsevier Academic Press, Burlington

Fukumori Y, Ohnoki S, Shibata H, Yamaguchi H, Nishimukai H (1995) Genotyping of ABO blood groups by PCR and RFLP analysis of 5 nucleotide positions. Int J Legal Med 107:179-182

Fulge M (2005) Laktosetoleranz in der bronzezeitlichen Lichtensteinhöhle Molekulargenetischer Nachweis des Polymorphismus C/T 13910 an prähistorischer DNA. Staatsexamensarbeit, Universität Göttingen

Gabriel SE, Brigman KN, Koller BH, Boucher RC, Stutts MJ (1994) Cystic fibrosis heterozygote resistance to cholera toxin in the cystic fibrosis mouse model. Science 266: 107-109

Gaertner S (2005) Fingerprinting an bronzezeitlichen Ossa radii - Molekulargenetische Analysen von short tandem repeats zur Aufdeckung von Verteilungsmustern isoliert vorliegender Skelettelemente aus einer gestörten Fundsituation. Staatsexamensarbeit, Universität Göttingen

Galvani A, Novembre J (2005) The evolutionary history of the CCR5- $\Delta 32$ HIV-resistance mutation. Microbes and Infection 7: 302-309

Gamba C, Fernández E, Tirado M, Pastor F, Arroyo-Pardo E (2011) Brief communication: Ancient nuclear DNA and kinship analysis: the case of a medieval burial in San Esteban Church in Cuellar (Segovia, Central Spain). Am J Phys Anthropol 144:485-491

Garred P, Madsen HO, Petersen J, Marquart H, Hansen TM, Freiesleben Sørensen S, Volck B, Svejgaard A, Andersen V (1998) CC chemokine receptor 5 polymorphism in rheumatoid arthritis. Journal of Rheumatology 25: 1462-1465

Gelernter J, Kennedy JL, van Tol HHM, Civelli O, Kidd KK (1992) The D4 dopamine receptor (DRD4) maps to distal 11p close to HRAS. Genomics 13:208-210

Georges L, Seidenberg V, Hummel S, Fehren-Schmitz L (2012) Molecular Characterization of ABO Blood Group Frequencies in Pre-Columbian Peruvian Highlanders. Am J Phys Anthropol 149:242-249

Gerbault P, Moret C, Currat M, Sanchez-Mazas A (2009) Impact of selection and demography on the diffusion of lactase persistence. PLoS One 4:6369

Gerstenberger J, Hummel S, Herrmann B (2002) Reconstruction of residence patterns through genetic typing of skeletal remains of an early medieval population. Ancient Biomolecules 4:25-31

Giacconi R, Cipriano C, Albanese F, Boccoli G, Saba V, Olivieri F, Franceschi C, Mocchegiani E (2004) The $-174 \mathrm{G} / \mathrm{C}$ polymorphism of IL6 is useful to screen old subjects at risk for atherosclerosis or to reach successful ageing. Exp Gerontol 39:621628 
Gilbert MTP, Djurhuus D, Melchior L, Lynnerup N, Worobey M, Wilson AS, Andreasen C, Dissing J (2007) mtDNA From Hair and Nail Clarifies the Genetic Relationship of the 15th Century Qilakitsoq Inuit Mummies. Am J Phys Anthropol 133:847-853

Gill P, Fereday L, Morling N, Schneider PM (2006) The evolution of DNA databasesRecommendations for new European STR loci. Forensic Science International 156:242244

Glass RI, Holmgren J, Haley CE, Khan MR, Svennerholm A, Stoll BJ, Hossain KMB, Black RE, Yunus M, Barua D (1985) Predisposition for cholera of individuals with 0 blood group. Am J Epidemiol 121:791-796

Graham EA (2008) DNA reviews: predicting phenotype. Forensic Sci Med Pathol 4:196-199

Gravlund P, Aaris-Sørensen K, Hofreiter M, Meyer M, Bollback JP, Noe-Nygaard N (2012) Ancient DNA extracted from Danish aurochs (Bos primigenius): Genetic diversity and preservation. Ann Anat 194:103-111

Green RE, Krause J, Briggs AW, Maricic T, Stenzel U, Kircher M, Patterson N, Li H, Zhai W, Fritz MH, Hansen NF, Durand EY, Malaspinas AS, Jensen JD, MarquesBonet T, Alkan C, Prüfer K, Meyer M, Burbano HA, Good JM, Schultz R, AximuPetri A, Butthof A, Höber B, Höffner B, Siegemund M, Weihmann A, Nusbaum C, Lander ES, Russ C, Novod N, Affourtit J, Egholm M, Verna C, Rudan P, Brajkovic D, Kucan Z, Gusic I, Doronichev VB, Golovanova LV, Lalueza-Fox C, de la Rasilla M, Fortea J, Rosas A, Schmitz RW, Johnson PL, Eichler EE, Falush D, Birney E, Mullikin JC, Slatkin M, Nielsen R, Kelso J, Lachmann M, Reich D, Pääbo S (2010) A draft sequence of the Neandertal genome. Science 328:710-722

Grimes EA, Noake PJ, Dixon L, Urquhart A (2001) Sequence polymorphism in the human melanocortin 1 receptor gene as an indicator of the red hair phenotype. Forensic Sci Int 122:124-129

Großkopf B (1990) Individualaltersbestimmung mit Hilfe von Zuwachsringen im Zement bodengelagerter menschlicher Zähne. Z Rechtsmed 103:351-359

Großkopf B (2004) Leichenbrand - Biologisches und kulturhistorisches Quellenmaterial zur Rekonstruktion vor- und frühgeschichtlicher Populationen und ihrer Funeralpraktiken. Dissertation, Universität Leipzig.

Grubwieser P, Mühlmann R, Berger B, Niederstätter H, Pavlic M, Parson W (2006) A new "miniSTR-multiplex" displaying reduced amplicon lengths for the analysis of degraded DNA. Int J Legal Med 120:115-120.

Grumbkow von P, Zipp A, Seidenberg V, Fehren-Schmitz L, Kempf VAJ, Groß U, Hummel S (2011) Evidence of Bartonella quintana infections in skeletons of a historical mass grave in Kassel, Germany. Am J Phys Anthropol 146:148-151

Grumbkow von P (2013) Das Leben in der napoleonischen Armee - interdisziplinäre Untersuchung eines Massengrabs aus Kassel, Hessen. Dissertation, Universität Göttingen

Grunnet N, Steffensen R, Bennett EP, Clausen H (2000) Evaluation of histo-blood group $\mathrm{ABO}$ genotyping in a Danish population: frequency of a novel $\mathrm{O}$ allele defined as $\mathrm{O} 2$. Vox Sang 67:210-215

Grupe G (2007) Taphonomic and diagenetic processes. In: Handbook of Paleoanthropology, Henke W, Tattersall I, Hardt T (Eds.) pp. 241-259. Springer-Verlag, Berlin Heidelberg

Grupe G, Harbeck M, McGlynn GC (2015) Prähistorische Anthropologie. Springer, Berlin, Heidelberg

Haack K (1999) Detektion von aDNA-Sequenzen mit über 300 bp Länge aus menschlichem bodengelagerten Skelettmaterial. Diplomarbeit, Universität Göttingen 
Haak W, Forster P, Bramanti B, Matsumura S, Brandt G, Tänzer M, Villems R, Renfrew C, Gronenborn D, Alt KW, Burger J (2005) Ancient DNA from the first European farmers in 7500-year-old Neolithic sites. Science 310:1016-1018

Haak W, Brandt G, de Jong HN, Meyer C, Ganslmeier R, Heyd V, Hawkesworth C, Pike AW, Meller H, Alt KW (2008) Ancient DNA, Strontium isotopes, and osteological analyses shed light on social and kinship organization of the Later Stone Age. Proc Natl Acad Sci USA 105:18226-18231

Haak W et al. (2015) Massive migration from the steppe was a source for Indo-European languages in Europe. Nature 522:207-211. doi:10.1038/nature14317

Hagelberg E, Sykes B, Hedges R (1989) Ancient bone DNA amplified. Nature 342:485

Han J, Kraft P, Nan H, Guo Q, Chen C, Qureshi A, Hankinson SE, Hu FB, Duffy DL, Zhao ZZ, Martin NG, Montgomery GW, Hayward NK, Thomas G, Hoover RN, Chanock S, Hunter DJ (2008) A genome-wide association study identifies novel alleles associated with hair color and pigmentation. PLoS Genet 4:e1000074

Hansen HE, Gürtler H (1983) HLA Types of Mummified Eskimo Bodies From the 15th Century. Am J Phys Anthropol 61:447-452

Hansson G (1988) Cystic fibrosis and chloride-secreting diarrhea. Nature 333:711

Hares DR (2015) Selection and implementation of expanded CODIS core loci in the United States. Forensic Sci. Int. Genet. 17:33-34

Harvey CB, Pratt WS, Islam I, Whitehouse DB, Swallow DM (1995) DNA polymorphisms in the lactase gene. Linkage disequilibrium across the 70-kb region. Eur J Hum Genet 3:27-41

Hennesy EP, Green AD, Connor MP, Darby R, MacDonald P (2003) Norwalk virus infection and disease is associated with $\mathrm{ABO}$ histo-blood group type. J Infect Dis 188:176-177

Herrmann B, Grupe G, Hummel S, Piepenbrink H, Schutkowski H (1990) Prähistorische Anthropologie: Leitfaden der Feld- und Labormethoden. Springer Verlag, Berlin, Heidelberg

Hill CR, Kline MC, Coble MD, Butler JM (2008) Characterization of 26 miniSTR loci for improved analysis of degraded DNA samples. J Forensic Sci 53:73-80

Hofreiter M, Serre D, Poinar HN et al. (2001) Ancient DNA. Nat Rev Genet 2:353-359

Hofreiter M, Paijmans JLA, Goodchild H, Speller CF, Barlow A, Fortes GG, Thomas JA, Ludwig A, Collins MJ (2014) The future of ancient DNA: Technical advances and conceptual shifts. Bioessays 37:284-293. DOI 10.1002/bies.201400160

Holden C, Mace R (1997) Phylogenetic analysis oft he evolution of lactase digestion in adults. Hum boil 69:605-628

Hollerbuhl T (2009) Identifikation und Zuordnung prähistorischer menschlicher Skelettelemente aus dem Bernd-Saal der Lichtensteinhöhle anhand morphologischer und molekulargenetischer Kriterien. Diplomarbeit, Universität Göttingen

Hughes-Stamm SR, Ashton KJ, van Daal A (2011) Assessment of DNA degradation and the genotyping success of highly degraded samples. Int J Legal Med 125:341-348

Hummel S, Herrmann B (1991) Y-chromosome-specific DNA amplified in ancient human bone. Naturwissenschaften 78:266-267

Hummel S, Schmidt D, Kahle M, Herrmann B (2002) ABO blood group genotyping of ancient DNA by PCR-RFLP. Int J Legal Med 116:327-333

Hummel S (2003) Ancient DNA Typing. Methods, Strategies, and Applications. Springer, New York, Berlin, Heidelberg 
Hummel S, Schmidt D, Kremeyer B, Herrmann B, Oppermann M (2005) Detection of the CCR5-Delta32 HIV resistance gene in Bronze Age skeletons. Genes Immun 6:371-374

Huth C, Heid IM, Vollmert C, Gieger C, Grallert H, Wolford JK, Langer B, Thorand B, Klopp N, Hamid YH, Pedersen O, Hansen T, Lyssenko V, Groop L, Meisinger C, Döring A, Löwel H, Lieb W, Hengstenberg C, Rathmann W, Martin S, Stephens JW, Ireland H, Mather H, Miller GJ, Stringham HM, Boehnke M, Tuomilehto J, Boeing H, Möhlig M, Spranger J, Pfeiffer A, Wernstedt I, Niklason A, LopézBermejo A, Fernandez-Real JM, Hanson RL, Gallart L, Vendrell J, Tsiavou A, Hatziagelaki E, Humphries SE, Wichmann HE, Herder C, Illig T (2006) IL6 gene promoter polymorphisms and type 2 diabetes: joint analysis of individual participants' data from 21 studies. Diabetes 55:2915-2921

Ingram CJE, Mulcare CA, Itan Y, Thomas MG, Swallow DM (2009) Lactose digestion and the evolutionary genetics of lactase persistence. Hum Genet 124:579-591

Ishida Y, Roca AL, Fratpietro S, Greenwood AD (2012) Successful Genotyping of Microsatellites in the Woolly Mammoth. J Hered 103:459-464

Itan Y, Powell A, Beaumont MA, Burger J, Thomas MG (2009) The origins of lactase persistence in Europe. PLoS Comput Biol 5:e10000491

Jablonski NG (2004) The evolution of human skin and skin color. Annu Rev Anthropol 33:585-623

Johansen HK, Nir M, Hoiby N, Koch C, Schwartz M (1991) Severity of cystic fibrosis in patients homozygous and heterozygous for delta F508 mutation. Lancet 337:631-634

Jungk A (2008) Identifikation und Zuordnung von prähistorischen menschlichen Skelettelementen der oberen Extremität aus zwei Abschnitten der Lichtensteinhöhle. Staatsexamensarbeit, Universität Göttingen

Kayser M, Liu F, Janssens AC, Rivadeneira F, Lao O, van Duijn K, Vermeulen M, Arp P, Jhamai MM, van Ijcken WF, den Dunnen JT, Heath S, Zelenika D, Despriet DD, Klaver CC, Vingerling JR, de Jong PT, Hofman A, Aulchenko YS, Uitterlinden AG, Oostra BA, van Duijn CM (2008) Three genome-wide association studies and a linkage analysis identify HERC2 as a human iris color gene. Am J Hum Genet 82:411-423

Kayser M, Schneider PM (2009) DNA-based prediction of human externally visible characteristiks in forensics: Motivations, scientific challenges, and ethical considerations. Forensic Sci Int Genet 3:154-161

Kempe S, Vladi F (1988) Die Lichtenstein-Höhle. Eine präholozäne Gerinnehöhle im Gips und Stätte urgeschichtlicher Menschenopfer am Südwestrand des Harzes (Gemarkung Dorste, Landkreis Osterode). Heimatblätter für den süd-westlichen Harzrand 44:1-12

Kerem B, Rommens J, Buchanan JA, Markiewicz D, Cox TK, Chakravarti A, Buchwald M, Tsui LC (1989) Identification of the Cystic Fibrosis Gene: Genetic Analysis. Science 245: $1073-1080$

Kircher M (2012) Analysis of high-throughput ancient DNA sequencing data. Methods Mol Biol 840:197-228

Kirst R, Lukie M, Richter C, Schuebert W (1971) Über die AB0-Blutgruppeneigenschaften der Fingernägel. Forum Kriminalistik 3:76-80

Klingner S (2005) Fingerprinting an Calcanei aus der Lichtensteinhöhle - Molekulargenetische Analysen von short tandem repeats zur Aufdeckung von Verteilungsmustern isoliert vorliegender Skelettelemente aus einer bronzezeitlich gestörten Fundsituation. Diplomarbeit, Universität Göttingen

Knorre K (2010) Zur Frage der Nutzung der Lichtensteinhöhle als Primär- oder Sekundärbestattungsplatz - Untersuchung von Dekompositionserscheinungen an ausgewählten menschlichen Skelettelementen. Bachelorarbeit, Universität Göttingen 
Knußmann R (1996) Vergleichende Biologie des Menschen. Lehrbuch der Anthropologie und Humangenetik. Gustav Fischer Verlag, Stuttgart

Krause I (2012) Reconstruction of the iris pigmentation from individuals of a Bronze Age archeological site. Masterarbeit, Universität Göttingen

Krause S (2006) Genetische Analysen zur Bestimmung der Allelfrequenz von C28Y/H63D (erbliche Eisenspeicherkrankheit) an Skelettelementen eines bronzezeitlichen Fundkomplexes. Diplomarbeit, Universität Göttingen

Kretchmer N (1971) Lactose and Lactase - a historical perspective. Gastroenterology 61:805813

Kristiansen OP, Nolsøe RL, Larsen L, Gjesing AM, Johannesen J, Larsen ZM, Lykkesfeldt AE, Karlsen AE, Pociot F, Mandrup-Poulsen T; DIEGG; DSGD (2003) Association of a functional 17beta-estradiol sensitive IL6-174G/C promoter polymorphism with early-onset type 1 diabetes in females. Hum Mol Genet 12:11011110

Kruse TA, Bolund L, Grzeschik KH, Ropers HH, Sjöström H, Norén O, Mantei N, Semenza G (1988) The human lactase-phlorizin hydrolase gene is located on chromosome 2. FEBS Lett 240:123-126

Lacan M, Keyser C, Ricaut FX, Brucato N, Duranthon F, Guilaine J, Crubézy E, Ludes B (2011) Ancient DNA reveals male diffusion through the Neolithic Mediterranean route. Proc Natl Acad Sci USA 108:9788-9791

Lagos R, Avendano A, Prado V, Horwitz I, Wassermann S, Losonsky G, Cryz S Jr., Kaper JB, Levine MM (1995) Attenuated live cholera vaccine strain CVD 103-HgR elicits significantly higher serum vibriocidal antibody titers in persons of blood group $\mathrm{O}$. Infect Immun 63:707-709

LaHoste GJ, Swanson JM, Wigal SB, Glabe C, Wigal T, King N, Kennedy JL (1996) Dopamine D4 receptor gene polymorphism is associated with attention deficit hyperactivity disorder. Molecular Psychiatry 61:87-92

Lalueza-Fox C, Gilbert MT (2011) Paleogenomics of archaic hominins. Curr Biol 21:R1002R1009

Larcombe LA, Nickerson P, Hoppa RD Matheson C (2005) Detection of a single nucleotide polymorphism in the IL-6 promoter region of ancient nuclear DNA. Infect Genet Evol $5: 117-122$

Larson G, Albarella U, Dobney K, Rowley-Conwy P, Schibler J, Tresset A, Vigne JD, Edwards CJ, Schlumbaum A, Dinu A, Balaçsescu A, Dolman G, Tagliacozzo A, Manaseryan N, Miracle P, Van Wijngaarden-Bakker L, Masseti M, Bradley DG, Cooper A (2007) Ancient DNA, pig domestication, and the spread of the Neolithic into Europe. Proc Natl Acad Sci USA 104:15276-15281

Ledermann MM, Penn-Nicholson A, Cho M, Mosier D (2006) Biology of CCR5 and Its Role in HIV Infection and Treatment. Journal of the American Medical Association 296: 815826

Lee JC, Chang JG (1992) ABO genotyping by polymerase chain reaction. J Forensic Sci 37:1269-1275

Le van Kim C, Mouro I, Chérif-Zahar B, Raynal V, Cherrier C, Cartron JP, Colin Y (1992) Molecular cloning and primary structure of the human blood group RhD polypeptide. PNAS 89:10925-10929

Levi-Strauss C (Hrsg.) (1981) Die elementaren Strukturen der Verwandtschaft. Suhrkamp, Frankfurt a.M. 
Libert F, Cochaux P, Beckman G, Samson M, Aksenova M, Cao A, Czeizel A, Claustres M, de la Rúa C, Ferrari M, Ferrec C, Glover G, Grinde B, Güran S, Kucinskas V, Lavinha J, Mercier B, Ogur G, Peltonen L, Rosatelli C (1998) The $\Delta$ ccr5 mutation conferring protection against HIV-1 in Caucasian populations has a single and recent origin in Northeastern Europe. Human Molecular Genetics 7 (3): 399-406

Lin JY, Fisher DE (2007) Melanocyte biology and skin pigmentation. Nature 445:843-850

Lio D, Candore G, Crivello A, Scola L, Colonna-Romano G, Cavallone L, Hoffmann E, Caruso M, Licastro F, Caldarera CM, Branzi A, Franceschi C, Caruso C (2004) Opposite effects of interleukin 10 common gene polymorphisms in cardiovascular diseases and in successful ageing: genetic background of male centenarian is protective against coronary heart disease. J Med Genet 41:790-794

Liu F, van Duijn K, Vingerling JR, Hofman A, Uitterlinden AG, Janssens AC, Kayser M (2009) Eye color and the prediction of complex phenotypes from genotypes. Curr Biol 19:R192-R193

Lucotte G (1998) Celtic Origin of the C282Y Mutation of Hemochromatosis. Blood Cells Maolecules and Diseases 24:433-438

Malmström H, Vretemark M, Tillmar A, Durling MB, Skoglund P, Gilbert MT, Willerslev E, Holmlund G, Götherström A (2012) Finding the founder of Stockholm A kinship study based on Y-chromosomal, autosomal and mitochondrial DNA. Ann Anat 194:138-145

Mantei N, Villa M, Enzler T, Wacker H, Boll W, James P, Hunziker W, Semenza G (1988) Complete primary structure of human and rabbit lactase-phlorizin hydrolase: implications for biosynthesis, membrane anchoring and evolution of the enzyme. EMBO J 7:27052713

Marjanović D, Durmić-Pašić A, Kovačević L, Avdić J, Džehverović M, Haverić S, Ramić J, Kalamujić B, Bilela LL, Škaro V, Projić P, Bajrović K, Drobnič K, Davoren J., Primorac D (2009) Identification of skeletal remains of communist armed forces victims during and after World War II: combined Y-chromosome short tandem repeat (STR) and miniSTR approach. Croat Med J 50:296-304

Martin R, Saller K (1959) Lehrbuch der Anthropologie. Fischer, Stuttgart

Martinson JJ, Chapman NH, Rees DC, Liu YT, Clegg JB (1997) Global distribution of the CCR5 gene 32-basepair deletion. Nature Genetics Vol. 16:100-103

Matassi G, Chérif-Zahar B, Pesole G, Raynal V, Cartron JP (1999) The Members of the RH Gene Family (RH50 and RH30) Followed Different Evolutionary Pathways. J Mol Evol 48:151-159

Matheson CD, Vernon KK, Lahti A, Fratpietro R, Spigelman M, Gibson S, Greenblatt CL, Donoghue HD, Zissu B (2009) Molecular exploration of the first-century Tomb of the Shroud in Akeldama, Jerusalem. PLoS One 4:e8319

Matthews SB, Waud JP, Roberts AG, Cambpell AK (2005) Systemic lactose intolerance: a new perspective on an old problem. Postgrad Med J 81:167-173

Mayer JF (1992) Metabolische und sozialmedizinische Gesichtspunkte der Hämochromatose. Dissertation, Würzburg

Mazanec J (2010) Die Lichtensteinhöhle als genetisches Archiv - Untersuchung des Markers delta32ccr5 an den bronzezeitlichen Individuen. Diplomarbeit, Universität Göttingen

McCracken RD (1971) Lactase deficiency: an example of dietary evolution. Curr Anthropol 12:479-517 
McEvoy B Beleza S, Shriver MD (2006) The genetic architecture of normal variation in human pigmentation: an evolutionary perspective and model. Hum Mol Genet 15:R176R181

Merkes M (2010) Zur Frage der Nutzung der Lichtensteinhöhle als Primär- oder Sekundärbestattungsplatz - Klassifizierung und Bewertung der Oberflächentextur ausgewählter menschlicher Skelettelemente. Bachelorarbeit, Universität Göttingen

Metthews LJ, Butler PM (2011) Novelty-Seeking DRD4 Polymorphism are Associated with Human Migration Distance Out-of-Africa After Controlling for Neutral Population Gene Structure. Am J Phys Anthropol 145:382-389

Mocellin S, Marincola F, Rossi CR, Nitti D, Lise M (2004) The multifaceted relationship between IL-10 and adaptive immunity: putting together the pieces of a puzzle. Cytokine \& Growth Factor Reviews 15:61-76

Morral N, Bertranpetit J, Estivill X, Nunes V, Casals T, Gimenez J, Reis A, VaronMateeva R, Macek M Jr., Kalaydjieva L, Angelicheva D, Dancheva R, Romeo G, Russo MP, Garnerone S, Restagno G, Ferrari M, Magnani C, Claustres M, Desgeorges M, Schwartz M, Schwarz M, Dallapiccola B, Novelli G, Ferec C, de Arce M, Nemeti M, Kere J, Anvret M, Dahl N, Kadasi L (1994) The origin of the major cystic fibrosis mutation $(\Delta \mathrm{F} 508)$ in European populations. Nature Genetics 7:169-175

Mulero JJ, Wei Chang C, Lagacé RE, Wang DY, Bas JL, McMahon TP, Hennessy LK (2008) Development and validation of the AmpFeSTR ${ }^{\circ}$ MiniFiler ${ }^{\mathrm{TM}}$ PCR amplification kit: a miniSTR multiplex for the analysis of degraded and/or PCR inhibited DNA. J Forensic Sci 53:838-852

Müller B (2002) Design einer Multiplex-PCR zur Typisierung von Y-STR Haplotypen aus degradierter DNA. Diplomarbeit, Universität Göttingen

Mußlick D (2005) Fingerprinting an Humeri aus der Lichtensteinhöhle - Molekulargenetische Analysen an short tandem repeats zur Aufdeckung von Verteilungsmustern isoliert vorliegender Skelettelemente aus einer bronzezeitlich gestörten Fundsituation. Diplomarbeit, Universität Göttingen

Myres NM, Rootsi S, Lin AA, Järve M, King RJ, Kutuev I, Cabrera VM, Khusnutdinova EK, Pshenichnov A, Yunusbayev B, Balanovsky O, Balanovska E, Rudan P, Baldovic M, Herrera RJ, Chiaroni J, Di Cristofaro J, Villems R, Kivisild T, Underhill PA (2011) A major Y-chromosome haplogroup R1b Holocene era founder effect in Central and Western Europe. Europ J Hum Genet 19: 95-101

Naim HY (2001) Molecular and cellular aspects and regulation of intestinal lactase-phlorizin hydrolase. Histol Histopathol 16:553-561

Naumova E, Mihaylova A, Ivanova M, Michailova S, Penkova K, Baltadjieva D (2004) Immunological markers contributing to successful aging in Bulgarians. Exp Geront 39:637-644

Nikitin AG, Newton JR, Potekhina ID (2012) Mitochondrial haplogroup C in ancient mitochondrial DNA from Ukraine extends the presence of East Eurasian genetic lineages in Neolithic Central and Eastern Europe. J Hum Genet 57: 610-612

Nishimukai H, Fukumori Y, Okiura T, Yuasa I, Shinomiya T, Ohnoki S, Shibata H, Vogt U (1996) Genotyping of the ABO blood group system: analysis of nucleotide position 802 by PCR-RFLP and the distribution of ABO genotypes in a German population. Int $\mathrm{J}$ Legal Med 109:90-93

Norton HL, Kittles RA, Parra E, McKeigue P, Mao X, Cheng K, Canfield VA, Bradley DG, McEvoy B, Shriver MD (2007) Genetic evidence for the convergent evolution of light skin in Europeans and East Asians. Mol Biol Evol 24:710-722 
Novotná M, Havlíček J, Smith AP, Kolbeková P, Skallovč A, Klose J, Gašová Z, Písačka M, sechovská M, Flegr J (2008) Toxoplasma and reaction time: role of toxoplasmosis in the origin, preservation and geographical dit'stribution of Rh blood group polymorphism. Parasitology 135:1253-1261

Oberthür R (2010) Rekonstruktion der Körperhöhe aus Maßen der Langknochen von Individuen des prähistorischen Skelettkollektives der Lichtensteinhöhle. Bachelorarbeit, Universität Göttingen

Okuda H, Suganuma H, Tsudo N, Omi T, Iwamoto S, Kajii E (1999) Sequence Analysis of the Spacer Region between the RHD and RHCE Genes. Biochem Biophys Res Commun 263:378-383

Okuda H, Suganuma H, Kamesaki T, Kumada M, Tsudo N, Omi T, Iwamoto S, Kajii E (2000) Analysis of Nucleotide Substitutions, Gaps, and Recombination Events between RHD and RHCE Genes Through Complete Sequencing. Biochem Biophys Res Commun 274:670-683

Olds LC, Sibley E (2003) Lactase persistence DNA variation enhances lactase promoter activity in vitro: functional role as a cis regulatory element. Hum Mol Genet 12:23332340

Oota H, Settheetham-Ishida W, Tiwawech D, Ishida T, Stoneking M (2001) Human mtDNA and y-chromosome variation is correlated with matrilocal versus patrilocal residence. Nat Genet 29:20-21

Ortner DJ, Putschar WG (1985) Identification of pathological conditions in human skeletal remains. Smithsonian Inst. Press, Washington

Otto M (2007) Mitochondriale Haplotypen in einer rezenten Bevölkerung des Harzvorlandes. Staatsexamensarbeit, Universität Göttingen

Oven van M, Kayser M (2009) Updated comprehensive phylogenetic tree of global human mitochondrial DNA variation. Hum Mutat 30:E386-E394

Parra EJ (2007) Human pigmentation variation: evolution, genetic basis, and implications for public health. Am J Phys Anthropol 45:85-105

Pearson K (1899) Mathematical contributions of the theory of evolution. V. On the reconstruction of the stature of prehistoric races. Phil Transact R Soc London. Ser A Vol 192: $169-245$

Pepperl J (2008) Immungenetische Marker im Wandel der Zeit. Molekulargenetische Analyse von single nucleotide Polymorphismen immungenetischer Rezeptoren und Interleukine in historischen Bevölkerungen. Dissertation, Universität Göttingen

Peterson RL (2005) The neuroscience of investing: fMRI oft he reward system. Brain Res Bull 67:391-397

Pfister D (2008) Entwicklung einer Multiplex-PCR zur Typisierung der STR-Marker FGA, SE33, TH01, D18S51 und D21S11 in stark degradiertem forensischem und archäologischem Probenmaterial. Diplomarbeit, Universität Göttingen

Pier GB, Grout M, Zaidi T, Meluleni G, Mueschenborn SS, Banting G, Ratcliff R, Evans MJ, Colledge WH (1998) Salmonella typhi uses CFTR to enter intestinal epithelial cells. Nature 393:79-82

Puder Y (2005) Molekulargenetische Identifikation der Allelhäufigkeit eines immungenetischen Markers der IL-6-Promotorregion bei bronzezeitlichen Individuen aus Mitteleuropa. Diplomarbeit, Universität Göttingen

Purps J et al. (2014) A global analysis of Y-chromosomal haplotype diversity for 23 STR loci. Forensic Science International: Genetics 12:12-23 
Püschel K, Bauerochse A, Fuhrmann A, Hummel S, Jopp E, Kettner A, Lockemann U, Metzler A, Schmidt D, Schmidt KD (2005) Rechtsmedizin, Anthropologie und Archäologie. Ein „vermisstes“ Mädchen entpuppt sich als über 2700 Jahre alte Moorleiche. Rechtsmed 15: 202-205

Quevedo WC, Holstein TJ (2006) General Biology of Mammalian Pigmentation. In: Nordlund JJ, Boissy RE, Hearing VJ, King RA, Ortonne JP (Hrsg.) The pigmentary system: Physiology and Pathophysiology. Blackwell, Oxford

Rappaport J, Cho YY, Hendel H, Schwartz EJ, Schachter F, Zagury JF (1997) 32 bp CCR5 gene deletion and resistance to fast progression in HIV-1 infected hetero-zygotes. Lancet 349: 922-923

Rasmussen H, Timm S, Wang AG, Søeby K, Lublin H, Fenger M, Hemmingsen R, Werge T (2006) Association Between the CCR5 32-bp Deletion Allele and Late Onset of Schizophrenia. American Journal of Psychiatry 163: 507-511

Renz-Polster H, Krautzig S, Braun J (2004) Basislehrbuch Innere Medizin. Urban fischer, Münschen, Jena

Richards M, Macaulay V, Torroni A, Bandelt HJ (2002) In search of geographical patterns in European mitochondrial DNA. Am J Hum Genet 71: 1168-1174

Riesen M (2007) Y-chromosomale Haplotypen in einer rezenten Bevölkerung des Harzvorlandes. Staatsexamensarbeit, Universität Göttingen

Ringel PF, Weiler G, Bein G (2000) Errors in ABO typing of blood stains using PCR. Int J Legal Med 113:352-355

Riordan J, Rommens J, Kerem B, Alon N, Rozmahel R, Grzelczak Z, Zielenski J, Lok S, Plavsic N, Chou JL, Drumm ML, Iannuzzi MC, Collins FS, Tsui LC (1989) Identification of the Cystic Fibrosis Gene: Cloning and Charakterization of the Complementary DNA. Science 245:1066-1073

Rodman D, Polis J, Heltshe S, Sontag M, Chacon C (2004) Late Diagnosis Defines a Unique Population of Long-term Survivors of Cystic Fibrosis. American Journal of Respiratory and Critical Care Medicine 171:621-626

Rodrigues LT, Callegari-Javques SM, Petzl-Erler ML, Tsuneto L, Salzano FM, Hutz H (2010) Dopamine Receptor D4 Allele Distribution in Amerindians: A Reflection of Past Behavior Differences? Am J Phys Anthropol 143:458-464

Roewer L, Croucher PJP, Willuweit S, Lu TT, Kayser M, Lessig R., De Knijff P, Jobling MA, Tyler Smith C, Krawczak M. (2005) Signature of recent historical events in the European Y-chromosomal STR haplotype distribution. Hum Genet1 16 (4): 279-91

Rogaev EI, Grigorenko AP, Moliaka YK, Faskhutdinova G, Goltsov A, Lahti A, Hildebrandt C, Kittler EL, Morozova I (2009) Genomic identification in the historical case of the Nicholas II royal family. Proc Natl Acad Sci USA 106:5258-5263

Rohlf J (2011) Molekularenetische Typisierung von der Rhesusfaktor D-Eigenschaften in bronzezeitlichen Individuen der Lichtensteinhöhle. Diplomarbeit, Universität Göttingen

Rother P (1978) Zur Rekonstruktion der Körpergröße. In: Hunger H, Leopold D (Hrsg.) Identifikation. Springer-Verlag, Berlin, Heidelberg, New York

Rouzaud F, Kadekaro AL, Abdel-Malek ZA, Hearing VJ (2005) MC1R and the response of melanocytes to ultraviolet radiation. Mutat Res 571:133-152

Sabeti PC, Walsh E, Schaffner SF, Varilly P, Fry B, Hutcheson HB, Cullen M, Mikkelsen TS, Roy J, Patterson N, Cooper R, Reich D, Altshuler D, O'Brien S, Lander ES (2005) The Case for Selection at CCR5- 432 . PLoS Biology 3: e378

Sahi T, Isokoski M, Jussila J, Launiala K, Pyörälä K (1973) Recessive inheritance of adulttype lactose malabsorption. Lancet 2:823-826 
Sahi T (1974) the inheritance of selective adult-type lactose malabsorption. Scand J Gastroenterology 30:1-73

Sahi T (1994) Genetics and epidemiology of adult-type hypolactasia. Scand J Gastroenterol Suppl 202:7-20

Salem AH, Badr FM, Gaballah MF, Pääbo S (1996) The genetics of traditional living: ychromosomal and mitochondrial lineages in the Sinai Peninsula. Am J Hum Genet 59:741-743

Sampietro ML, Lao O, Caramelli D, Lari M, Pou R, Martí M, Bertranpetit J, Lalueza-Fox C (2007) Palaeogenetic evidence supports a dual model of Neolithic spreading into Europe. Proc Biol Sci 274:2161-2167

Schiel M (2008) Identifikation und Zuordnung von prähistorischen menschlichen Skelettelementen aus zwei Abschnitten der Lichtensteinhöhle. Bachelorarbeit, Universität Göttingen

Schilz F (2006) Molekulargenetische Verwandtschaftsanalyse am prähistorischen Skelettkollektiv der Lichtensteinhöhle. Dissertation, Universität Göttingen

Schmidt D (2004) Entwicklung neuer Markersysteme für die ancient DNA-Analyse Erweiterung des molekulargenetischen Zugangs zu kultur- und sozialgeschichtlichen Fragestellungen der prähistorischen Anthropologie. Dissertation, Universität Göttingen

Schmidt D, Hummel S (2007) DNA-Analysen in der forensischen Fallarbeit. In: Herrmann B, Saternus KS (Hrsg.) Biologische Spurenkunde - Kriminalbiologie. Springer Verlag, Berlin, Heidelberg, New York

Schneider PM (2009) Expansion of the European Standard Set of DNA Database Loci- the Current Situation. Profiles in DNA, März 2009, www.promega.com

Scholten A (2006) Genetische Analysen zur Bestimmung der Allelfrequenz von $\Delta$ F508 an menschlichen Skelettelementen eines bronzezeitlichen Fundkomplexes. Diplomarbeit, Universität Göttingen

Schoon R (2010) Gefunden an einem besonderen Ort - zu den Überresten von Tieren aus der Lichtensteinhöhle. Arch. Niedersachsen 13:47-51

Schubert J (2009) Identifikation und Zuordnung prähistorischer menschlicher Skelettelemente aus der Reinhardsgrotte und der Fiddi-Kluft der Lichtensteinhöhle anhand morphologischer und molekulargenetischer Kriterien. Diplomarbeit, Universität Göttingen

Schücker K (2012) Analyses of hair pigmentation of human remains from the Bronze Age. Masterarbeit, Universität Göttingen

Schultes T (1997) Zuordnung isolierter Skelettelemente mittels Typisierung von alter DNA. Diplomarbeit, Universität Göttingen

Schultes T (2000) Typisierung alter DNA zur Rekonstruktion von Verwandtschaft in einem bronzezeitlichen Skelettkollektiv. Dissertation, Universität Göttingen

Schultz M (1994) Leben, Krankheit und Tod - Skelettfunde als Spiegel der Lebensbedingungen. In: Jockenhövel A, Kubach W (Hrsg) Bronzezeit in Deutschland. C. Konrad Theiss Verlag GmbH \& Co., Stuttgart: S 15-17

Schutkowski H, Hummel S (1991) Vorgeschichtliche Bevölkerungen in Schleswig-Holstein Leichenbranduntersuchungen von Urnenfriedhöfen Mittel- und Ostholsteins im diachronen Vergleich. Sonderdruck aus Offa, Berichte und Mitteilungen zur Urgeschichte, Frühgeschichte und Mittelalterarchäologie Band 48, Karl Wachholtz Verlag Neumünster 
Scola L, Crivello A, Marino V, Gioia V, Serauto A, Candore G, Colonna-Romano G, Caruso C, Lio D (2003) IL-10 and TNF- $\alpha$ polymorphsisms in a sample of Sicilian patients affected by tuberculosis: implication for ageing and life span expectancy. Mech Ageing Dev 124:569-572

Seebode C (2010) Die Lichtensteinhöhle als genetisches Archiv - Untersuchung des Laktosetoleranzmarkers C/T 13910 an den bronzezeitlichen Individuen. Diplomarbeit, Universität Göttingen

Seidenberg V, Schilz F, Pfister D, Georges L, Fehren-Schmitz L, Hummel S (2012) A new miniSTR heptaplex system for genetic fingerprinting of ancient DNA from archaeological human bone. Journal of Archaeological Science 39:3224-3229

Senge T, Madea B, Junge A, Rothschild MA, Schneider P (2011) STRs, miniSTRs and SNPs - a comparative study for typing degraded DNA. Leg Med 13:68-74

Simoni L, Calafell F, Pettener D, Bertranpetit J, Barbujani G (2000) Geographic patterns of mtDNA diversity in Europe. Am J Hum Genet 66:262-278

Simoons FJ (1970) Primary adult lactose intolerance and the milking habit: a problem in biological and cultural interrelations. II A culture historical hypothesis. Am J Dig Dis 15: 695-710

Söchtig J (2009) Entwicklung von molekulargenetischen Analysesystemen zur Rekonstruktion der Pigmentierung von Augen und Haaren. Diplomarbeit, Universität Göttingen

Southern KW (1997) $\Delta$ F508 in cystic fibrosis: willing but not able. Arch Dis Child 76:278282

Spanagel R, Weiss F (1999) The dopamine hypothesis of reward: past and current status. Trends Neurosci. 22:521-527

Stauch J (2005) Die Lichtensteinhöhle im Harz - Archäologisch-anthropologische Untersuchungen anhand isolierter Skelettreste eines Individuums mit Trepanation aus einem bronzezeitlichen Skelttkollektiv. Magisterarbeit, Universität Göttingen

Steiner M, von Ahsen N (2005) Den Verdacht auf eine hereditäre Hämochromatose früh und nichtinvasiv bestätigen. Klinikarzt 34:61-65

Stephens J C, Reich DE, Goldstein DB, Shin HD, Smith MW, Carrington M, Winkler C, Huttley GA, Allikmets R, Schriml L, Gerrard B, Malasky M, Ramos MD, Morlot S, Tzetis M, Oddoux C, di Giovine FS, Nasioulas G, Chandler D, Aseev M (1998) Dating the Origin of the CCR5- $\triangle 32$ AIDS-Resistance Allele by the Coalescence of Haplotypes. American Journal of Human Genetics 62: 1507-1515

Stoneking M, Krause J (2011) Learning about human population history from ancient and modern genomes. Nat Rev Genet 12:603-614

Sturm RA, Frudakis TN (2004) Eye colour: portals into pigmentation genes and ancestry. Trends Genet 20:327-332

Sulem P, Gudbjartsson DF, Stacey SN, Helgason A, Rafnar T, Magnusson KP, Manolescu A, Karason A, Palsson A, Thorleifsson G, Jakobsdottir M, Steinberg S, Pálsson S, Jonasson F, Sigurgeirsson B, Thorisdottir K, Ragnarsson R, Benediktsdottir KR, Aben KK, Kiemeney LA, Olafsson JH, Gulcher J, Kong A, Thorsteinsdottir U, Stefansson K (2007) Genetic determinants of hair, eye and skin pigmentation in Europeans. Nat Genet 39:1443-1452

Sulem P, Gudbjartsson DF, Stacey SN, Helgason A, Rafnar T, JakobsdottirM,Steinberg S, Gudjonsson SA, Palsson A, Thorleifsson G, Pálsson S, Jonasson F, Sigurgeirsson B, Thorisdottir K, Ragnarsson R, Benediktsdottir, Aben KK, Vermeulen SH, Goldstein AM, Tucker MA, Kiemeney LA, Olafsson JH, Gulcher J, Kong A, Thorsteinsdottir U, Stefansson K (2008) Two newly identified genetic determinants of pigmentation in Europeans. Nat Genet 40:835-837 
Suray D (2007) Interleukin-10-Haplotypen eines bronzezeitlichen Skelettkollektivs aus dem Harzer Vorland. Diplomarbeit, Universität Göttingen

Svensson E, Götherström A (2008) Temporal fluctuations of Y-chromosomal variation in Bos taurus. Biol Lett 4:752-754

Swagerty DL, Walling AD, Klein RM (2002) Lactose intolerance. American Family Physicians 65:1845-1850

Swallow DM (2003) Genetics of lactase persistence and lactose intolerance. Annu Rev Genet $37: 197-219$

Swanson JM, Flodman P, Kennedy J, Spence MA, Moyzis R, Schuck S, Murias M, Moriarity J, Barr C, Smith M, Posner M (2000) Dopamine genes and ADHS. Neuroscience and Biobehavioral Reviews 24:21-25

Swerdlow DL, Mintz ED, Rodriguez M, Tejada E, Ocampo C, Espejo L, Barrett TJ, Petzelt J, Bean NH, Seminario L, Tauxe RV (1994) Severe life-threatening cholera associated with blood group $\mathrm{O}$ in Peru: implications for the Latin American Epidemic. J Infect Dis 170:468-472

Szabo G (1967) Photobiology of melanogenesis: cytological aspects with reference to differences in racial coloration. Advances in biology of skin. In: Montagna W, Hu F (eds) The Pigmentary System. Pergamon Press, New York pp 369-379

Tacket CO, Losonsky G, Nataro JP, Wassermann SS, Cryz SJ, Edelman R, Levine MM (1995) Extension of the volunteer challenge modelt o study South American cholera in a population of volunteers predominantly with blood group antigen O. Trans R Soc Trop Med Hyg 89:75-77

Tariverdian G, Buselmaier W (2004) Humangenetik. 3. Auflage. Springer, New York, Berlin, Heidelberg

Templeton JEL, Brotherton PM, Llamas B, Soubrier J, Haak W, Cooper A, Austin JJ (2013) DNA capture and next-generation sequencing can recover whole mitochondrial genomes from highly degraded samples for human identification. Investigative Genetics 4:26-38. DOI: $10.1186 / 2041-2223-4-26$

Thio C, Astemborski J, Bashirova A, Mosbruger T, Greer S, Witt MD, Goedert JJ, Margaret Hilgartner M, Majeske A, O'Brien SJ, Thomas DL, Carrington M (2006) Genetic Protection against Hepatitis B Virus Conferred by CCR5 32 : Evidence that CCR5 Contributes to Viral Persistence. Journal of Virology 81 (2): 441-445

Tilford CA et al. (2001) A physical map of the human Y chromosome. Nature 409:943-945

Toda K, Pathak MA, Parrish JA, Fitzpatrick TB, Quevedo WC Jr. (1972) Alteration of racial differences in melanosome distribution in human epidermis after exposure to ultraviolet light. Nat New Biol 236:143-145

Torroni A, Huoponen K, Francalacci P, Petrozzi M, Morelli L, Scozzari R, Obinu D, Savontaus ML, Wallace DC (1996) Classification of European mtDNAs From an Analysis of Three European Populations. Genetics 144: 1835-1850

Trevilatto PC, Scarel-Caminaga RM, de Brito RB Jr., de Souza AP, Line SR (2003) Polymorphism at position -174 of IL-6 gene is associated with susceptibility to chronic periodontitis in a Caucasian Brazilian population. J. Clin Periodontol 30:438-442

Tsangaras K, Greenwood AD (2012) Museums and disease: Using tissue archive and museum samples to study pathogens. Ann Anat 194:58-73

Turner DM, Williams DM, Sankaran D, Lazarus M, Sinnott PJ, Hutchinson IV (1997) An Investigation of polymorphism in the Interleukin-10 gene promoter. Eur J Immunogen $24: 1-8$ 
Underhill PA, Kivisild T (2007) Use of y chromosome and mitochondrial DNA population structure in tracing human migrations. Annu Rev Genet 41:539-564

Underhill PA, Myres NM, Rootsi S, Metspalu M, Zhivotovsky LA, King RJ, Lin AA, Chow CET, Semino O, Battaglia V, Kutuev I, Järve M, Chaubey G, Ayub Q, Mohyuddin A, Mehdi SQ, Sengupta S, Rogaev EI, Khusnutdinova EK, Pshenichnov A, Balanovsky O, Balanovska E, Jeran N, Augustin DH, Baldovic M, Herrera RJ, Thangaraj K, Singh V, Singh L, Majumder P, Rudan P, Primorac D, Villems R, Kivisild T (2010) Separating the post-Glacial coancestry of European and Asian Y chromosomes within haplogroup R1a. Eur J Hum Genet 18: 479-484

United Nations (1955) Age and sex pattern of mortality. Moedl life-tables for underdeveloped countries. United Nations, department of social affairs, population Studies 22. New York

Uytterschaut H (1993) Human bone remodelling and aging. In: Grupe G, Garland AN (eds) Histology of ancient human bone: methods and diagnosis. Seiten 95-109, Springer, Berlin, Heidelberg, New York

Van den Biggelaar AHJ, de Craen AJM, Gussekloo J, Huizinga TWJ, Heijmans BT, Frölich M, Kirkwood TBL, Westendorp RGJ (2004) Inflammation underlying cardiovascular mortality is a late consequence of evolutionary programming. FASEB journal. doi 10.1096/fj.03-1162fje.

van de Vosse E, Ali S, Visser AW, Surjadi C, Widjaja S, Vollaard AM, Dissel JT (2005) Susceptibility to typhoid fever is associated with a polymorphism in the cystic fibrosis transmembrane conductance regulator (CFTR). Hum Genet 118:138-140

van Loon FP, Clemens JD, Sack DA, Rao MR, Ahmed F, Chowdhury S, Harris JR, Ali M, Chakraborty J, Khan MR (1991) ABO blood groups and the risk of darrhea due to enterotoxigenic Escherichia coli. J Infect Dis 163:1243-1246

Vesa TH, Marteau P, Korpela R (2000) Lactose intolerance. J Am Coll Nutr 19: 165-175

Walsh S, Liu F, Ballantyne KN, van Oven M, Lao O, Kayser M (2011a) Irisplex: A sensitive DNA tool for accurate prediction of blue and brown eye colour in the absence of ancestry information. Forensic Sci Int Genet 5:170-180

Wagner FF, Kasulke D, Kerowgan M, Flege WA (1995) Frequencies of the Blood Groups ABO, Rhesus, D Category VI, Kell, and of Clinically Relevant High-Frequency Antigens in South-Western Germany. Infusionsther Transfusionsmed 22:285-290

Wagner FF, Flegel WA (2000) RHD gene deletion occurred in the Rhesus box. Blood 95:3662-3668

Wagner FF, Flegel WA (2002) RHCE represents the ancestral RH position, while RHD is the duplicated gene. Blood 99:2272-2274

Wang XY, Hurme M, Jylhä M, Hervonen A (2001) Lack of association between human longevity and polmorphisms of Il1 cluster, IL6, IL10 and TNF- $\alpha$ genes in Finnish nonagenarians. Mech Ageing Dev 123:29-38

Wiener AS (1946) The Rh System in the Chimpanzee. Science 104:578-579

Wiesbauer M, Meierhofer D, Mayr JA, Sperl W, Paulweber B, Kofler B (2006) Multiplex primer extension analysis for rapid detection of major European mitochondrial haplogroups. Electrophoresis 27: 3864-3868

Wiuf C (2001) Do $\Delta$ F508 heterozygotes have a selective advantage? Genet Res Camb 78:4147

Wojsyk-Banaszak I, Seremak-Mrozikiewicz A, Szczapa J, Drews K, Zandecka-Dziubak J, Mrozikiewicz PM (2005) The significance of $-174 \mathrm{G} / \mathrm{C}$ polymorphism of the gene coding for interleukin-6 in neonatal infections. Ginekol Pol 76:127-134 
Yamamoto FI, Clausen H, White T, Marken J, Hakomori SI (1990) Molecular genetic basis of the histo-blood group ABO system. Nature 345: 229-233

Yip SP (2002) Sequence variation at the AB0 locus. Ann Hum Genet 66:1-27

Young PT (1959) The role of affective processes in learning and motivation. Psychological Review 66:104-125

Zapico I, Coto E, Rodríguez A, Alvarez C, Torre JC, Alvarez V (2000) CCR5 (chemokine rezeptor-5) DNA-polymorphism influences the severity of rheumatoid arthritis. Genes and Immunity 1: 288-289

Zaumsegel D, Rothschild M, Schneider PM (2007) SNPs for the analysis of human pigmentation genes - A comparative study. Forensic Sci Int Genet Supplement Series $1: 554-556$

Zeidler S (2010) Zur Frage der Nutzung der Lichtensteinhöhle als Primär- oder Sekundärbestattungsplatz - Eine Analyse des Verteilungsmusters und Streuungsgrad innerhalb der Höhle. Bachelorarbeit, Universität Göttingen 


\section{Anhang A}

\subsection{Datenblätter zu den Individuen aus der Lichtensteinhöhle}

Auf den folgenden Seiten findet sich für jedes der identifizierten Individuen eine Zusammenfassung aller für das jeweilige Individuum ermittelten Daten. In der obersten kleinen Tabelle auf jeder Seite sind die Allelausprägungen der autosomalen STRs (=genetischer Fingerabdruck) aufgeführt; in der Tabelle darunter die der Ychromosomalen STRs (= Y-Haplotyp) und die wahrscheinliche Y-Haplogruppe. In der nächsten Zeile findet sich die ermittelte mitochondriale Haplogruppenzugehörigkeit.

Die dritte kleine Tabelle zeigt, welche Skelettelemente dem jeweiligen Individuum zugeordnet werden konnten. In den Zeilen darunter ist neben der Körperhöhe und dem Geschlecht auch das Alter des jeweiligen Individuums angegeben, wobei die Methode der Altersdiagnose benannt wird (Morphologie, Knochen- bzw. Zahnhistologie) und die Fundnummer des Knochens aufgeführt wird, an dem die Altersbestimmung vorgenommen wurde.

Im untersten Teil jedes Datenblattes sind alle weiteren untersuchten genetischen Marker, ggf. die jeweiligen Typisierungsergebnisse, sowie der/die Bearbeiter/in zusammengestellt. Die hier aufgeführten Marker sind im Einzelnen: AB0-Blutgruppen, Augenfarbe, der immungenetische Marker CCR5 und die damit gekoppelten STRs IRI 3.1 und 3.2, der mit der Krankheit Mukoviszidose in Zusammenhang stehende Marker $\Delta \mathrm{F} 508$, die mit der Eisenspeicherkrankheit Hämochromatose assoziierten Marker C82Y und H63D, die immungenetischen Interleukin-Marker IL6-174, IL101082, IL10-819, IL10-592, IL101078, IL10-2849, IL4-524 und IL4-Ra576, sowie die Toll-like Rezeptor-Marker TLR2_753, TLR, TLR4_299, und TLR4_399, der über die Laktoseverträglichkeit Aufschluss gebende Marker C/T 13910 (Lac) der Rhesus D Status und ein VNTR im DRD4 Gen, welcher mit Risikobereitschaft assoziiert wird. 
DO FK/HS/RG 35 (M4)

\begin{tabular}{|c|c|c|c|c|c|c|c|c|c|c|c|c|c|c|c|}
\hline Amelo & D3S1358 & VWA & FGA & D8S1179 & D21S11 & D18S51 & D5S818 & D13S317 & D7S820 & CSF1PO & TH01 & D16S539 & D2S1338 & D19S433 & D9S1120 \\
\hline$X / Y$ & $15 / 17$ & $16 / 17$ & $20 / 25$ & $10 / 14$ & $28 / 29$ & $14 / 19$ & $11 / 12$ & $12 / 13$ & $11 / 12$ & $12 /-$ & $9.3 /-$ & $12 / 13$ & $23 / 24$ & $13 / 14$ & $16 / 17$ \\
\hline
\end{tabular}

\begin{tabular}{|c|c|c|c|c|c|c|c|c|c|c|c|}
\hline DYS19 & DYS385 & DYS389 I & DYS389 II & DYS390 & DYS391 & DYS392 & DYS393 & DYS437 & DYS438 & DYS439 & Y6 \\
\hline \hline 16 & $13-17$ & 12 & 28 & 24 & 11 & 11 & 13 & 15 & 10 & 11 & I2b (100) \\
\hline
\end{tabular}

$\mathrm{mt}$

H \#5

\begin{tabular}{|c|c|c|c|c|c|c|c|c|c|c|c|c|}
\hline \multirow{2}{*}{$\mathbf{s}$} & \multicolumn{12}{|c|}{ Skelettelement } \\
\hline & Humerus & Ulna & Radius & Scapula & Clavicula & Femur & Tibia & Os coxae & Os sacrum & Mandibula & Calvarium & Calcaneus \\
\hline re & 58.16 & & 66.04 & E 15 & & & 107 & 928.04 & & & & \\
\hline li & 934.01 & & & & & 35 & 32 & $113 / 1850.01$ & & & & \\
\hline
\end{tabular}

Alter:

inf II-fjuv (Histologie Knochen; DO 35)

\section{Körperhöhe:}

Geschlecht:

\begin{tabular}{|l|c|c|l|}
\hline FundNr & Marker & Ausprägung & Bearbeiter \\
\hline \hline DO 35 & AB0-Blutgruppe & $($ A $) 01$ & Seidenberg \\
\hline & Augenfarbe & & \\
\hline $\begin{array}{l}\text { DO 35; } \\
\text { DO 900.03 }\end{array}$ & CCR5 & wt/- & Mazanec \\
\hline $\begin{array}{l}\text { DO 35; } \\
\text { DO 900.03 }\end{array}$ & IRI 3_1 & $((112)) /((116))$ & Mazanec \\
\hline $\begin{array}{l}\text { DO 35; } \\
\text { DO 900.03 }\end{array}$ & IRI 3_2 & $-/-$ & Mazanec \\
\hline DO 900.03 & $\Delta$ F508 & wt/wt & Scholten \\
\hline Haarfarbe & & \\
\hline DO 900.03 & C82Y & G/G & Krause \\
\hline
\end{tabular}

\begin{tabular}{|l|c|c|l|}
\hline FundNr & Marker & Ausprägung & Bearbeiter \\
\hline \hline DO 900.03 & H63D & C/C & Krause \\
\hline $\begin{array}{l}\text { DO 35; } \\
\text { DO 900.03 }\end{array}$ & IL6-174 & (G)/(C) & Pepperl \\
\hline $\begin{array}{l}\text { DO 35; } \\
\text { DO 900.03 }\end{array}$ & IL10-1082 & $-/-$ & Suray \\
\hline $\begin{array}{l}\text { DO 35; } \\
\text { DO 900.03 }\end{array}$ & IL10-819 & - -- & Suray \\
\hline $\begin{array}{l}\text { DO 35; } \\
\text { DO 900.03 }\end{array}$ & IL10-592 & $-/-$ & Suray \\
\hline $\begin{array}{l}\text { DO 35; } \\
\text { DO 900.03 }\end{array}$ & IL10-1087 & - -- & Pepperl \\
\hline $\begin{array}{l}\text { DO 35; } \\
\text { DO 900.03 }\end{array}$ & IL10-2849 & (A)/- & Pepperl \\
\hline $\begin{array}{l}\text { DO 35; } \\
\text { DO 900.03 }\end{array}$ & TLR2_753 & (G)/- & Pepperl \\
\hline
\end{tabular}

\begin{tabular}{|l|c|c|l|}
\hline FundNr & Marker & Ausprägung & Bearbeiter \\
\hline \hline $\begin{array}{l}\text { DO 35; } \\
\text { DO 900.03 }\end{array}$ & TLR4_299 & - -- & Pepperl \\
\hline $\begin{array}{l}\text { DO 35; } \\
\text { DO 900.03 }\end{array}$ & TLR4_399 & (C)/- & Pepperl \\
\hline $\begin{array}{l}\text { DO 35; } \\
\text { DO 900.03 }\end{array}$ & IL4-524 & $-/-$ & Pepperl \\
\hline $\begin{array}{l}\text { DO 35; } \\
\text { DO 900.03 }\end{array}$ & IL4-Ra576 & (A)/- & Pepperl \\
\hline $\begin{array}{l}\text { DO 35; } \\
\text { DO 900.03 }\end{array}$ & Lac & C/- (intolerant) & $\begin{array}{l}\text { Fulge } \\
\text { Seebode }\end{array}$ \\
\hline DO 35 & Rhesus D & (negativ) & Rohlf \\
\hline & DRD4 & & \\
\hline
\end{tabular}


DO FK/RG/BS 38 (F1)

\begin{tabular}{|c|c|c|c|c|c|c|c|c|c|c|c|c|c|c|c|}
\hline Amelo & D3S1358 & VWA & FGA & D8S1179 & D21S11 & D18S51 & D5S818 & D13S317 & D7S820 & CSF1PO & TH01 & D16S539 & D2S1338 & D19S433 & D9S1120 \\
\hline$X /-$ & $16 /-$ & $16 /-$ & $20 / 21$ & $8 / 15$ & $28 / 29$ & $12 / 18$ & 9/11 & $11 / 13$ & 9/12 & $11 / 13$ & $7 / 9.3$ & $12 / 13$ & 17/- & $13 /-$ & $15 / 16$ \\
\hline
\end{tabular}

\begin{tabular}{|l|l|l|l|l|l|l|l|l|l|l|l|}
\hline DYS19 & DYS385 & DYS389 I & DYS389 II & DYS390 & DYS391 & DYS392 & DYS393 & DYS437 & DYS438 & DYS439 & \\
\hline \hline & & & & & & & & & & & \\
\hline
\end{tabular}

mt:

H \#1

\begin{tabular}{|c|c|c|c|c|c|c|c|c|c|c|c|c|}
\hline \multirow{2}{*}{$\mathbf{s}$} & \multicolumn{12}{|c|}{ Skelettelement } \\
\hline & Humerus & Ulna & Radius & Scapula & Clavicula & Femur & Tibia & Os coxae & Os sacrum & Mandibula & Calvarium & Calcaneus \\
\hline re & 97 & & & & 4359.01 & 105 & 39 & 57.03 & & 38 & 152 & \\
\hline
\end{tabular}

Alter: smat-sen (Histologie Knochen; DO 26)

Körperhöhe: 161,4 \pm 3,1 cm

Geschlecht:

\begin{tabular}{|l|c|c|l|}
\hline FundNr & Marker & Ausprägung & Bearbeiter \\
\hline \hline DO 39 & AB0-Blutgruppe & A01 & Seidenberg \\
\hline DO 39 & Augenfarbe & blau & Krause \\
\hline DO 26 & CCR5 & wt/wt & Bertermann \\
\hline DO 26 & IRI 3_1 & $114 / 122$ & Bertermann \\
\hline DO 26 & IRI 3_2 & $165 / 169$ & Bertermann \\
\hline DO 152 & $\Delta$ F508 & wt/wt & Scholten \\
\hline DO 39 & Haarfarbe & dunkelblond & Schücker \\
\hline $\begin{array}{l}\text { DO 38; } \\
\text { DO 152 }\end{array}$ & C82Y & G/G & Krause \\
\hline
\end{tabular}

\begin{tabular}{|l|c|c|l|}
\hline FundNr & Marker & Ausprägung & Bearbeiter \\
\hline \hline $\begin{array}{l}\text { DO 38; } \\
\text { DO 152 }\end{array}$ & H63D & C/G & Krause \\
\hline $\begin{array}{l}\text { DO 26; } \\
\text { DO 38 }\end{array}$ & IL6-174 & G/(C) & Pepperl \\
\hline $\begin{array}{l}\text { DO 26; } \\
\text { DO 38 }\end{array}$ & IL10-1082 & A/G & Suray \\
\hline $\begin{array}{l}\text { DO 26; } \\
\text { DO 38 }\end{array}$ & IL10-819 & C/C & Suray \\
\hline $\begin{array}{l}\text { DO 26; } \\
\text { DO 38 }\end{array}$ & IL10-592 & C/C & Suray \\
\hline $\begin{array}{l}\text { DO 26; } \\
\text { DO 38 }\end{array}$ & IL10-1087 & G/(A) & Pepperl \\
\hline $\begin{array}{l}\text { DO 26; } \\
\text { DO 38 }\end{array}$ & IL10-2849 & G/A & Pepperl \\
\hline $\begin{array}{l}\text { DO 26; } \\
\text { DO 38 }\end{array}$ & TLR2_753 & G/G & Pepperl \\
\hline
\end{tabular}

\begin{tabular}{|l|c|c|l|}
\hline FundNr & Marker & Ausprägung & Bearbeiter \\
\hline \hline $\begin{array}{l}\text { DO 26; } \\
\text { DO 38 }\end{array}$ & TLR4_299 & A/A & Pepperl \\
\hline $\begin{array}{l}\text { DO 26; } \\
\text { DO 38 }\end{array}$ & TLR4_399 & C/(T) & Pepperl \\
\hline $\begin{array}{l}\text { DO 26; } \\
\text { DO 38 }\end{array}$ & IL4-524 & $-/-$ & Pepperl \\
\hline $\begin{array}{l}\text { DO 26; } \\
\text { DO 38 }\end{array}$ & IL4-Ra576 & G/A & Pepperl \\
\hline $\begin{array}{l}\text { DO 26; } \\
\text { DO 38 }\end{array}$ & Lac & C/C (intolerant) & $\begin{array}{l}\text { Fulge } \\
\text { Seebode }\end{array}$ \\
\hline $\begin{array}{l}\text { DO 38; } \\
\text { DO 39 }\end{array}$ & Rhesus D & positiv & Rohlf \\
\hline & DRD4 & & \\
\hline
\end{tabular}


DO RG/FK 57.02 (M17/M19)

\begin{tabular}{|c|c|c|c|c|c|c|c|c|c|c|c|c|c|c|c|}
\hline Amelo & D3S1358 & VWA & FGA & D8S1179 & D21S11 & D18S51 & D5S818 & D13S317 & D7S820 & CSF1PO & TH01 & D16S539 & D2S1338 & D19S433 & D9S1120 \\
\hline$X / Y$ & $15 / 17$ & $16 / 18$ & $23 / 25$ & $10 / 13$ & $28 / 29$ & $14 / 15$ & $12 / 13$ & $8 / 13$ & $10 / 12$ & $10 / 12$ & $7 / 9.3$ & $12 / 13$ & $16 / 23$ & $13 / 15.2$ & $16 /-$ \\
\hline
\end{tabular}

\begin{tabular}{|c|c|c|c|c|c|c|c|c|c|c|c|c|}
\hline DYS19 & DYS385 & DYS389 I & DYS389 II & DYS390 & DYS391 & DYS392 & DYS393 & DYS437 & DYS438 & DYS439 & \multirow{2}{*}{ Y6 } & \multirow{2}{*}{ I2b (100 } \\
\hline (16) & $13-17$ & 12 & 28 & 24 & 11 & 11 & 13 & 15 & 10 & 11 & & \\
\hline
\end{tabular}

mt:

H6 \#1

\begin{tabular}{|c|c|c|c|c|c|c|c|c|c|c|c|c|}
\hline \multirow{2}{*}{$\mathbf{s}$} & \multicolumn{12}{|c|}{ Skelettelement } \\
\hline & Humerus & Ulna & Radius & Scapula & Clavicula & Femur & Tibia & Os coxae & Os sacrum & Mandibula & Calvarium & Calcaneus \\
\hline re & OF 2 & $\begin{array}{l}66.03 / \\
58.17\end{array}$ & 1827.02 & 1580 & 1570 & 56.01 & 153.01 & $481 / 84.02$ & & & & \\
\hline li & 58.13 & 177 & 909.05 & 1082.01 & 1539.02 & $\begin{array}{l}57.021 \\
926.25\end{array}$ & JStauch & & & & & 487.01 \\
\hline
\end{tabular}

Alter: $\quad \operatorname{mad}($ Histologie Knochen; DO 57.02)

Körperhöhe: $166,7 \pm 3,5 \mathrm{~cm}$



Geschlecht:

\begin{tabular}{|l|c|c|l|}
\hline FundNr & Marker & Ausprägung & Bearbeiter \\
\hline \hline DO 153.01 & AB0-Blutgruppe & B01 & Seidenberg \\
\hline DO 57.02 & Augenfarbe & braun & Krause \\
\hline DO 153.01 & CCR5 & wt/(wt) & Mazanec \\
\hline DO 153.01 & IRI 3_1 & $((112)) /((116))$ & Mazanec \\
\hline DO 153.01 & IRI 3_2 & $145 /((157))$ & Mazanec \\
\hline & $\Delta$ F508 & & \\
\hline DO 57.02 & Haarfarbe & dunkelblond & Schücker \\
\hline & C82Y & & \\
\hline
\end{tabular}

\begin{tabular}{|l|c|c|l|}
\hline FundNr & Marker & Ausprägung & Bearbeiter \\
\hline \hline & H63D & & \\
\hline $\begin{array}{l}\text { DO 57.02; } \\
\text { DO 153.01 }\end{array}$ & IL6-174 & (G)/C & Pepperl \\
\hline $\begin{array}{l}\text { DO 57.02; } \\
\text { DO 153.01 }\end{array}$ & IL10-1082 & (A)/- & Suray \\
\hline $\begin{array}{l}\text { DO 57.02; } \\
\text { DO 153.01 }\end{array}$ & IL10-819 & (C)/- & Suray \\
\hline $\begin{array}{l}\text { DO 57.02; } \\
\text { DO 153.01 }\end{array}$ & IL10-592 & $-/-$ & Suray \\
\hline $\begin{array}{l}\text { DO 57.02; } \\
\text { DO 153.01 }\end{array}$ & IL10-1087 & A/- & Pepperl \\
\hline $\begin{array}{l}\text { DO 57.02; } \\
\text { DO 153.01 }\end{array}$ & IL10-2849 & (G)/A & Pepperl \\
\hline $\begin{array}{l}\text { DO 57.02; } \\
\text { DO 153.01 }\end{array}$ & TLR2_753 & G/- & Pepperl \\
\hline
\end{tabular}

\begin{tabular}{|l|c|c|l|}
\hline FundNr & Marker & Ausprägung & Bearbeiter \\
\hline \hline $\begin{array}{l}\text { DO 57.02; } \\
\text { DO 153.01 }\end{array}$ & TLR4_299 & $-/-$ & Pepperl \\
\hline $\begin{array}{l}\text { DO 57.02; } \\
\text { DO 153.01 }\end{array}$ & TLR4_399 & C/- & Pepperl \\
\hline $\begin{array}{l}\text { DO 57.02; } \\
\text { DO 153.01 }\end{array}$ & IL4-524 & C/- & Pepperl \\
\hline $\begin{array}{l}\text { DO 57.02; } \\
\text { DO 153.01 }\end{array}$ & IL4-Ra576 & (G)/A & Pepperl \\
\hline DO 57.02 & Lac & C/T (tolerant) & Fulge \\
\hline DO 153.01 & Rhesus D & positiv & Rohlf \\
\hline & DRD4 & & \\
\hline
\end{tabular}


DO RG/FK 58.01

\begin{tabular}{|c|c|c|c|c|c|c|c|c|c|c|c|c|c|c|c|}
\hline Amelo & D3S1358 & VWA & FGA & D8S1179 & D21S11 & D18S51 & D5S818 & D13S317 & D7S820 & CSF1PO & TH01 & D16S539 & D2S1338 & D19S433 & D9S1120 \\
\hline X/- & $15 / 16$ & $17 / 19$ & $20 /-$ & 14/- & $29 / 30$ & $16 / 19$ & $10 / 11$ & $12 / 14$ & $11 / 13$ & & $7 / 9.3$ & $12 / 13$ & $24 /-$ & $14 / 15$ & $16 / 17$ \\
\hline
\end{tabular}

\begin{tabular}{|l|l|l|l|l|l|l|l|l|l|l|l|}
\hline DYS19 & DYS385 & DYS389 I & DYS389 II & DYS390 & DYS391 & DYS392 & DYS393 & DYS437 & DYS438 & DYS439 & \\
\hline \hline & & & & & & & & & & & \\
\hline
\end{tabular}

mt:

H \#5

\begin{tabular}{|c|c|c|c|c|c|c|c|c|c|c|c|c|}
\hline \multirow{2}{*}{$\mathbf{s}$} & \multicolumn{12}{|c|}{ Skelettelement } \\
\hline & Humerus & Ulna & Radius & Scapula & Clavicula & Femur & Tibia & Os coxae & Os sacrum & Mandibula & Calvarium & Calcaneus \\
\hline re & 58.14 & 158 & 197.02 & 1578 & & 58.05 & 57.05 & 383 & & & & \\
\hline li & 913.18 & 5.01 & 308.01 & 1495 & 77.03 & 58.01 & 65.03 & 306 & & & & \\
\hline
\end{tabular}

Alter: $\quad$ smat (Histologie Knochen; DO 58.01)

Körperhöhe: 156,7 $\pm 3,1 \mathrm{~cm}$

Geschlecht:

\begin{tabular}{|l|c|c|l|}
\hline FundNr & Marker & Ausprägung & Bearbeiter \\
\hline \hline & AB0-Blutgruppe & & \\
\hline & Augenfarbe & & \\
\hline DO 58.01 & CCR5 & wt/- & Mazanec \\
\hline DO 58.01 & IRI 3_1 & $((114)) /((118))$ & Mazanec \\
\hline DO 58.01 & IRI 3_2 & $((139)) /((163))$ & Mazanec \\
\hline & LF508 & & \\
\hline & Haarfarbe & & \\
\hline & C82Y & & \\
\hline
\end{tabular}

\begin{tabular}{|l|c|c|c|}
\hline FundNr & Marker & Ausprägung & Bearbeiter \\
\hline \hline & H63D & & \\
\hline & IL6-174 & & \\
\hline & IL10-1082 & & \\
\hline & IL10-819 & & \\
\hline & IL10-592 & & \\
\hline & IL10-1087 & & \\
\hline & IL10-2849 & & \\
\hline & TLR2_753 & & \\
\hline
\end{tabular}

\begin{tabular}{|l|c|l|l|}
\hline FundNr & Marker & Ausprägung & Bearbeiter \\
\hline \hline & TLR4_299 & & \\
\hline & TLR4_399 & & \\
\hline & IL4-524 & & \\
\hline & IL4-Ra576 & & \\
\hline DO 58.01 & Lac & C/T (tolerant) & Fulge \\
\hline & Rhesus D & & \\
\hline & DRD4 & & \\
\hline
\end{tabular}

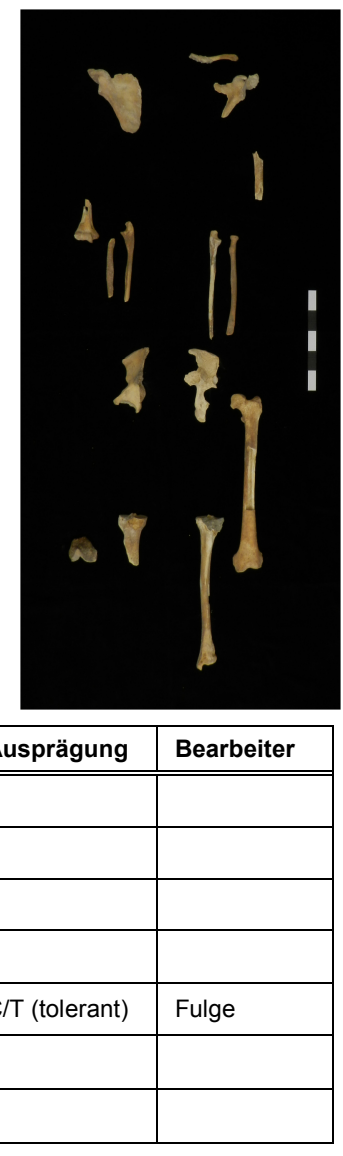


DO RG/FK 58.03 (M13)

\begin{tabular}{|c|c|c|c|c|c|c|c|c|c|c|c|c|c|c|c|}
\hline Amelo & D3S1358 & VWA & FGA & D8S1179 & D21S11 & D18S51 & D5S818 & D13S317 & D7S820 & CSF1PO & TH01 & D16S539 & D2S1338 & D19S433 & D9S1120 \\
\hline$X / Y$ & $15 / 18$ & $16 / 18$ & $21 / 25$ & 13/- & $29 / 30$ & $16 / 20$ & $11 /-$ & $8 / 13$ & 10/11 & $10 / 12$ & $6 / 8$ & $11 / 12$ & $(17) / 19$ & $13 / 15$ & $16 / 17$ \\
\hline
\end{tabular}

\begin{tabular}{|c|c|c|c|c|c|c|c|c|c|c|c|c|}
\hline DYS19 & DYS385 & DYS389 I & DYS389 II & DYS390 & DYS391 & DYS392 & DYS393 & DYS437 & DYS438 & DYS439 & \multirow{2}{*}{ Y 1} & \multirow{2}{*}{ I2b (100) } \\
\hline 16 & 13-17 & 12 & 28 & 25 & 11 & 11 & 13 & 15 & 10 & 11 & & \\
\hline
\end{tabular}

mt:

T2

\begin{tabular}{|c|c|c|c|c|c|c|c|c|c|c|c|c|}
\hline \multirow{2}{*}{$\mathbf{s}$} & \multicolumn{12}{|c|}{ Skelettelement } \\
\hline & Humerus & Ulna & Radius & Scapula & Clavicula & Femur & Tibia & Os coxae & Os sacrum & Mandibula & Calvarium & Calcaneus \\
\hline re & & & & & 526.01 & 65.01 & 533.02 & 411.02 & & & & \\
\hline li & $610 / 913.03$ & & & & & 58.03 & 387 & 415 & & & & \\
\hline
\end{tabular}

Alter: $\quad$ sjuv-fad (Histologie Knochen; DO 58.03)

Körperhöhe:

Geschlecht:

\begin{tabular}{|l|c|c|l|}
\hline FundNr & Marker & Ausprägung & Bearbeiter \\
\hline \hline DO 58.03 & AB0-Blutgruppe & A01v & Seidenberg \\
\hline DO 58.03 & Augenfarbe & intermediate-blau & Krause \\
\hline DO 58.03 & CCR5 & wt/wt & $\begin{array}{l}\text { Bertermann } \\
\text { Mazanec }\end{array}$ \\
\hline DO 58.03 & IRI 3_1 & $112 /-$ & $\begin{array}{l}\text { Bertermann } \\
\text { Mazanec }\end{array}$ \\
\hline DO 58.03 & IRI 3_2 & $145 /-$ & $\begin{array}{l}\text { Bertermann } \\
\text { Mazanec }\end{array}$ \\
\hline DO 58.03 & DF508 & wt/wt & Scholten \\
\hline DO 58.03 & Haarfarbe & dunkelblond-braun (rötl.) & Schücker \\
\hline DO 58.03 & C82Y & G/G & Krause \\
\hline
\end{tabular}

\begin{tabular}{|l|c|c|l|}
\hline FundNr & Marker & Ausprägung & Bearbeiter \\
\hline \hline DO 58.03 & H63D & C/C & Krause \\
\hline DO 58.03 & IL6-174 & G/G & Pepperl \\
\hline & IL10-1082 & & \\
\hline & IL10-819 & & \\
\hline & IL10-592 & & \\
\hline DO 58.03 & IL10-1087 & A/A & Pepperl \\
\hline DO 58.03 & IL10-2849 & G/A & Pepperl \\
\hline DO 58.03 & TLR2_753 & G/G & Pepperl \\
\hline
\end{tabular}

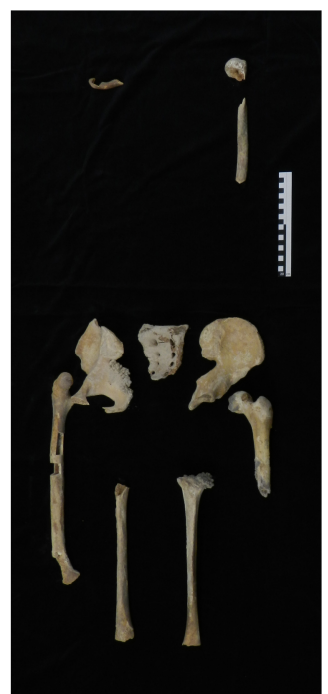

\begin{tabular}{|l|c|c|l|}
\hline FundNr & Marker & Ausprägung & Bearbeiter \\
\hline \hline DO 58.03 & TLR4_299 & A/A & Pepperl \\
\hline DO 58.03 & TLR4_399 & C/C & Pepperl \\
\hline DO 58.03 & IL4-524 & C/- & Pepperl \\
\hline DO 58.03 & IL4-Ra576 & A/A & Pepperl \\
\hline DO 58.03 & Lac & C/T (tolerant) & Fulge \\
\hline DO 58.03 & Rhesus D & positiv & Rohlf \\
\hline & DRD4 & & \\
\hline
\end{tabular}


DO RG/FK/KS 58.08 (M7)

\begin{tabular}{|c|c|c|c|c|c|c|c|c|c|c|c|c|c|c|c|}
\hline Amelo & D3S1358 & VWA & FGA & D8S1179 & D21S11 & D18S51 & D5S818 & D13S317 & D7S820 & CSF1PO & TH01 & D16S539 & D2S1338 & D19S433 & D9S1120 \\
\hline$X / Y$ & $14 / 15$ & $17 / 18$ & $24 / 25$ & $10 / 11$ & $29 / 30$ & $13 / 18$ & $12 /-$ & $8 / 12$ & $10 / 11$ & $10 /-$ & $6 / 8$ & $(11) / 13$ & $-1-$ & $13 / 14$ & $16 /(17)$ \\
\hline
\end{tabular}

\begin{tabular}{|c|c|c|c|c|c|c|c|c|c|c|c|c|}
\hline DYS19 & DYS385 & DYS389 I & DYS389 II & DYS390 & DYS391 & DYS392 & DYS393 & DYS437 & DYS438 & DYS439 & \multirow{2}{*}{ Y1 } & \multirow{2}{*}{$\mathbf{I 2 b}(100)$} \\
\hline 16 & 13-17 & 12 & 28 & 25 & 11 & 11 & 13 & 15 & 10 & 11 & & \\
\hline
\end{tabular}

mt:

H \#7

\begin{tabular}{|c|c|c|c|c|c|c|c|c|c|c|c|c|}
\hline \multirow{2}{*}{$\mathbf{s}$} & \multicolumn{12}{|c|}{ Skelettelement } \\
\hline & Humerus & Ulna & Radius & Scapula & Clavicula & Femur & Tibia & Os coxae & Os sacrum & Mandibula & Calvarium & Calcaneus \\
\hline re & 926.03 & E 26 & 237.04 & E 16 & 926.04 & 58.08 & E 32 & $84.01 / 56.04 / 3190.22$ & & & \multirow{2}{*}{$\begin{array}{l}910.01 \\
\text { pp } 3.01\end{array}$} & 929.02 \\
\hline li & 179.01 & 1079.02 & 1080.01 & 928.03 & & 906.08 & 220 & $\begin{array}{c}182.01 / 176.02 / \\
3190.32\end{array}$ & & & & \\
\hline
\end{tabular}

Alter:

inf II (Morphologie/Zahnstatus; ca. 10 Jahre)

Körperhöhe:

Geschlecht:

\begin{tabular}{|l|c|c|l|}
\hline FundNr & Marker & Ausprägung & Bearbeiter \\
\hline \hline & AB0-Blutgruppe & & \\
\hline DO 58.08 & Augenfarbe & & \\
\hline DO 58.08 & IRI 3_1 & $-/-$ & Mazanec \\
\hline DO 58.08 & IRI 3_2 & $-/-$ & Mazanec \\
\hline DO 910.01 & AF508 & wt/wt & Scholten \\
\hline & Haarfarbe & & \\
\hline $\begin{array}{l}\text { DO 910.01; } \\
\text { DO 929.02 }\end{array}$ & C82Y & G/G & Krause \\
\hline
\end{tabular}

\begin{tabular}{|l|c|c|l|}
\hline FundNr & Marker & Ausprägung & Bearbeiter \\
\hline \hline $\begin{array}{l}\text { DO 910.01; } \\
\text { DO 929.02 }\end{array}$ & H63D & C/C & Krause \\
\hline $\begin{array}{l}\text { DO 3.01; } \\
\text { DO 910.01 }\end{array}$ & IL6-174 & G/C & Pepperl \\
\hline & IL10-1082 & & \\
\hline & IL10-819 & & \\
\hline $\begin{array}{l}\text { DO 3.01; } \\
\text { DO 910.01 }\end{array}$ & IL10-592 & & \\
\hline $\begin{array}{l}\text { DO 3.01; } \\
\text { DO 910.01 }\end{array}$ & IL10-2849 & G/A & Pepperl \\
\hline $\begin{array}{l}\text { DO 3.01; } \\
\text { DO 910.01 }\end{array}$ & TLR2_753 & G/G & Pepperl \\
\hline
\end{tabular}

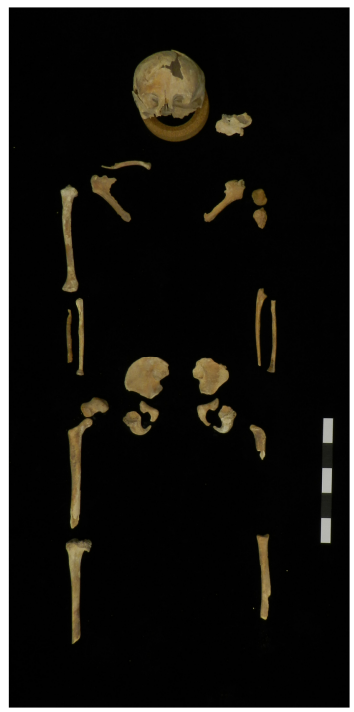

\begin{tabular}{|l|c|c|l|}
\hline FundNr & Marker & Ausprägung & Bearbeiter \\
\hline \hline $\begin{array}{l}\text { DO 3.01; } \\
\text { DO 910.01 }\end{array}$ & TLR4_299 & A/A & Pepperl \\
\hline $\begin{array}{l}\text { DO 3.01; } \\
\text { DO 910.01 }\end{array}$ & TLR4_399 & C/C & Pepperl \\
\hline $\begin{array}{l}\text { DO 3.01; } \\
\text { DO 910.01 }\end{array}$ & IL4-524 & C/C & Pepperl \\
\hline $\begin{array}{l}\text { DO 3.01; } \\
\text { DO 910.01 }\end{array}$ & IL4-Ra576 & G/A & Pepperl \\
\hline DO 58.08 & Lac & $-/-$ & Seebode \\
\hline & Rhesus D & & \\
\hline & DRD4 & & \\
\hline
\end{tabular}


DO RG/HS/BS 65.05

\begin{tabular}{|c|c|c|c|c|c|c|c|c|c|c|c|c|c|c|c|}
\hline Amelo & D3S1358 & VWA & FGA & D8S1179 & D21S11 & D18S51 & D5S818 & D13S317 & D7S820 & CSF1PO & TH01 & D16S539 & D2S1338 & D19S433 & D9S1120 \\
\hline $\mathrm{X} /-$ & $(15) /(16)$ & 17/- & $20 /(24)$ & $(12) /(14)$ & $29 /(30)$ & $(16) /(19)$ & $11 /(13)$ & $12 /(14)$ & $-/-$ & & $7 / 9.3$ & $-/-$ & $-/-$ & $(14) /(15)$ & $-1-$ \\
\hline
\end{tabular}

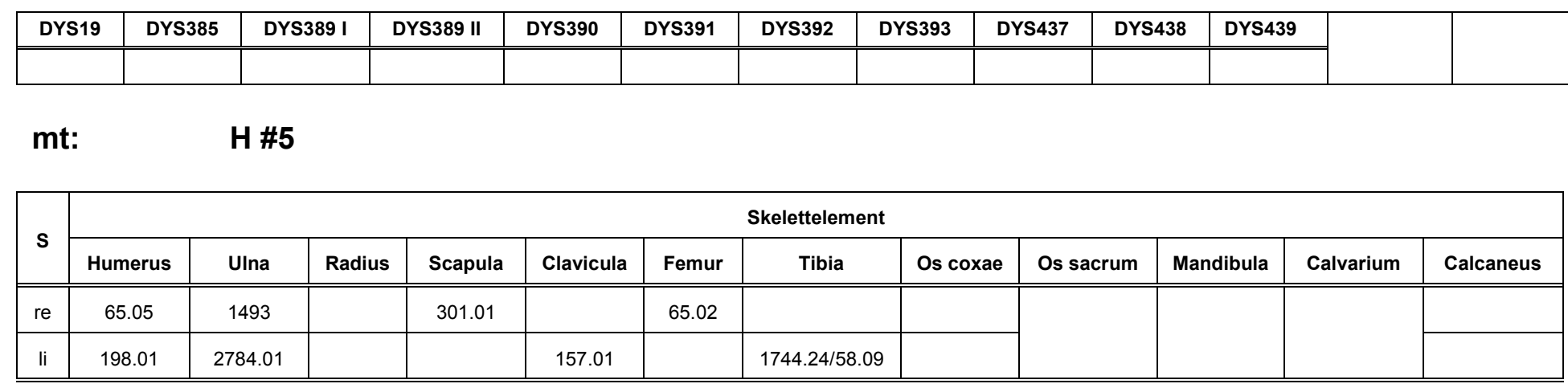

Alter: $\quad$ mad (Histologie Knochen; DO 65.05)

\section{Körperhöhe:}

Geschlecht:

\begin{tabular}{|l|c|l|l|}
\hline FundNr & Marker & Ausprägung & Bearbeiter \\
\hline \hline & AB0-Blutgruppe & & \\
\hline & Augenfarbe & & \\
\hline & CCR5 & & \\
\hline & IRI 3_1 & & \\
\hline & IRI 3_2 & & \\
\hline & SF508 & & \\
\hline & Haarfarbe & & \\
\hline & C82Y & & \\
\hline
\end{tabular}

\begin{tabular}{|l|c|l|l|}
\hline FundNr & Marker & Ausprägung & Bearbeiter \\
\hline \hline & H63D & & \\
\hline & IL6-174 & & \\
\hline & IL10-1082 & & \\
\hline & IL10-819 & & \\
\hline & IL10-592 & & \\
\hline & IL10-1087 & & \\
\hline & IL10-2849 & & \\
\hline & TLR2_753 & & \\
\hline
\end{tabular}

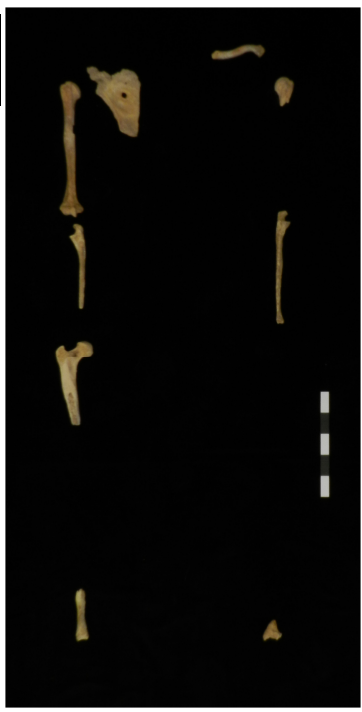

\begin{tabular}{|l|c|l|l|}
\hline FundNr & Marker & Ausprägung & Bearbeiter \\
\hline \hline & TLR4_299 & & \\
\hline & TLR4_399 & & \\
\hline & IL4-524 & & \\
\hline & IL4-Ra576 & & \\
\hline & Lac & & \\
\hline & Rhesus D & & \\
\hline & DRD4 & & \\
\hline
\end{tabular}


DO RG 66.02

\begin{tabular}{|c|c|c|c|c|c|c|c|c|c|c|c|c|c|c|c|}
\hline Amelo & D3S1358 & VWA & FGA & D8S1179 & D21S11 & D18S51 & D5S818 & D13S317 & D7S820 & CSF1PO & TH01 & D16S539 & D2S1338 & D19S433 & D9S1120 \\
\hline$X /-$ & $15 / 16$ & $17 /(18)$ & $20 / 25$ & $13 /(14)$ & $28 / 29$ & $14 / 16$ & $11 / 12$ & $8 / 12$ & 10/11 & & $9.3 /-$ & (9)/12 & $(23) /(24)$ & $14 / 15.2$ & $16 /-$ \\
\hline
\end{tabular}

\begin{tabular}{|l|l|l|l|l|l|l|l|l|l|l|l|}
\hline DYS19 & DYS385 & DYS389 I & DYS389 II & DYS390 & DYS391 & DYS392 & DYS393 & DYS437 & DYS438 & DYS439 & \\
\hline \hline & & & & & & & & & & & \\
\hline
\end{tabular}

mt:

H \#5

\begin{tabular}{|c|c|c|c|c|c|c|c|c|c|c|c|c|}
\hline \multirow{2}{*}{$\mathbf{s}$} & \multicolumn{12}{|c|}{ Skelettelement } \\
\hline & Humerus & Ulna & Radius & Scapula & Clavicula & Femur & Tibia & Os coxae & Os sacrum & Mandibula & Calvarium & Calcaneus \\
\hline re & & & & & & 58.06 & 412.01 & 1082.03 & & & & \\
\hline li & & & & & & 66.02 & 229 & 1159.01 & & & & \\
\hline
\end{tabular}

Alter: $\quad$ juv (Histologie Knochen; DO 58.06)

\section{Körperhöhe:}

Geschlecht:

\begin{tabular}{|l|c|c|l|}
\hline FundNr & Marker & Ausprägung & Bearbeiter \\
\hline \hline & AB0-Blutgruppe & & \\
\hline & Augenfarbe & & \\
\hline DO 66.02 & CCR5 & wt/- & Mazanec \\
\hline DO 66.02 & IRI 3_1 & $(112) /-$ & Mazanec \\
\hline DO 66.02 & IRI 3_2 & $145 /((169))$ & Mazanec \\
\hline & $\Delta$ F508 & & \\
\hline & Haarfarbe & & \\
\hline & C82Y & & \\
\hline
\end{tabular}

\begin{tabular}{|l|c|c|c|}
\hline FundNr & Marker & Ausprägung & Bearbeiter \\
\hline \hline & H63D & & \\
\hline & IL6-174 & & \\
\hline & IL10-1082 & & \\
\hline & IL10-819 & & \\
\hline & IL10-592 & & \\
\hline & IL10-1087 & & \\
\hline & IL10-2849 & & \\
\hline & TLR2_753 & & \\
\hline
\end{tabular}

\begin{tabular}{|l|c|c|l|}
\hline FundNr & Marker & Ausprägung & Bearbeiter \\
\hline \hline & TLR4_299 & & \\
\hline & TLR4_399 & & \\
\hline & IL4-524 & & \\
\hline & IL4-Ra576 & & \\
\hline DO 58.06 & Lac & C/T (tolerant) & Fulge \\
\hline DO 66.02 & Rhesus D & nd & Rohlf \\
\hline & DRD4 & & \\
\hline
\end{tabular}


DO RG/FK 67.03 (F10/F17)

\begin{tabular}{|c|c|c|c|c|c|c|c|c|c|c|c|c|c|c|c|}
\hline Amelo & D3S1358 & VWA & FGA & D8S1179 & D21S11 & D18S51 & D5S818 & D13S317 & D7S820 & CSF1PO & TH01 & D16S539 & D2S1338 & D19S433 & D9S1120 \\
\hline $\mathrm{X} /-$ & $15 / 16$ & 16/- & $22 / 24$ & $13 / 15$ & $28 / 30.2$ & $16 / 17$ & $9 / 12$ & $9 / 13$ & $8 / 12$ & 11/12 & $6 / 9.3$ & $9 / 12$ & $20 / 23$ & $12 / 13$ & $(16) /(18)$ \\
\hline
\end{tabular}

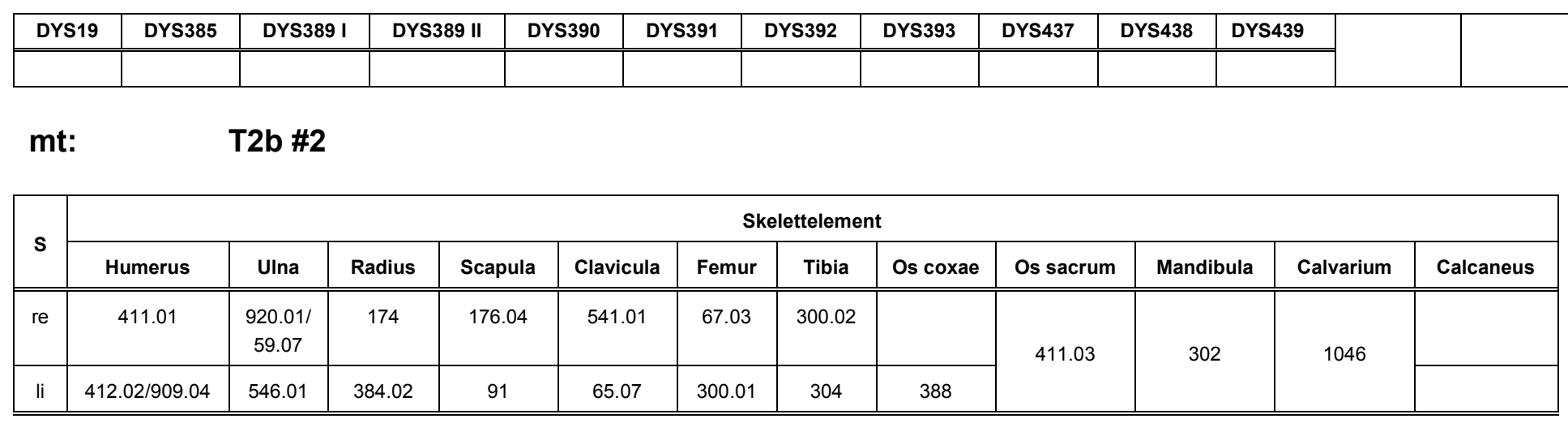

Alter: $\quad$ fad-mad (Histologie Knochen; DO 300.01)

Körperhöhe: $155,1 \pm 3,1 \mathrm{~cm}$

Geschlecht: $\uparrow$

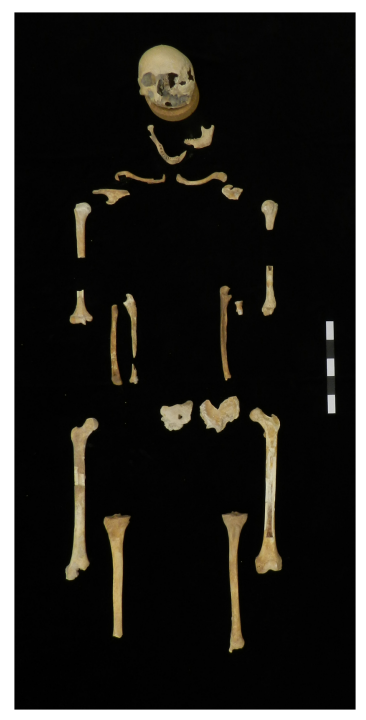

\begin{tabular}{|l|c|c|l|}
\hline FundNr & Marker & Ausprägung & Bearbeiter \\
\hline \hline DO 300.01 & $\begin{array}{c}\text { AB0- } \\
\text { Blutgruppe }\end{array}$ & A01 & Seidenberg \\
\hline Augenfarbe & & \\
\hline $\begin{array}{l}\text { DO 67.03; } \\
\text { DO 300.01 }\end{array}$ & CCR5 & wt/wt & $\begin{array}{l}\text { Bertermann } \\
\text { Mazanec }\end{array}$ \\
\hline $\begin{array}{l}\text { DO 67.03; } \\
\text { DO 300.01 }\end{array}$ & IRI 3_1 & $106 / 118$ & $\begin{array}{l}\text { Bertermann } \\
\text { Mazanec }\end{array}$ \\
\hline $\begin{array}{l}\text { DO 67.03; } \\
\text { DO 300.01 }\end{array}$ & IRI 3_2 & $((159)) /-$ & $\begin{array}{l}\text { Bertermann } \\
\text { Mazanec }\end{array}$ \\
\hline $\begin{array}{l}\text { DO 300.01; } \\
\text { DO 1046 }\end{array}$ & $\Delta F 508$ & wt/wt & Scholten \\
\hline $\begin{array}{l}\text { DO 300.01; } \\
\text { DO 1046 }\end{array}$ & C82Y & G/G & Krause \\
\hline
\end{tabular}

\begin{tabular}{|l|c|c|l|}
\hline FundNr & Marker & Ausprägung & Bearbeiter \\
\hline \hline DO 300.01; DO 1046 & H63D & C/G & Krause \\
\hline $\begin{array}{l}\text { DO 300.01; DO 302; } \\
\text { DO 1046 }\end{array}$ & IL6-174 & G/(C) & Pepperl \\
\hline & IL10-1082 & & \\
\hline & IL10-819 & & \\
\hline $\begin{array}{l}\text { DO 300.01; DO 302; } \\
\text { DO 1046 }\end{array}$ & IL10-592 & & \\
\hline $\begin{array}{l}\text { DO 300.01; DO 302; } \\
\text { DO 1046 }\end{array}$ & IL10-2849 & G/G & Pepperl \\
\hline $\begin{array}{l}\text { DO 300.01; DO 302; } \\
\text { DO 1046 }\end{array}$ & TLR2_753 & G/(A) & Pepperl \\
\hline
\end{tabular}

\begin{tabular}{|l|c|c|l|}
\hline FundNr & Marker & Ausprägung & Bearbeiter \\
\hline \hline $\begin{array}{l}\text { DO 300.01; DO 302; } \\
\text { DO 1046 }\end{array}$ & TLR4_299 & A/A & Pepperl \\
\hline $\begin{array}{l}\text { DO 300.01; DO 302; } \\
\text { DO 1046 }\end{array}$ & TLR4_399 & C/C & Pepperl \\
\hline $\begin{array}{l}\text { DO 300.01; DO 302; } \\
\text { DO 1046 }\end{array}$ & IL4-524 & C/C & Pepperl \\
\hline $\begin{array}{l}\text { DO 300.01; DO 302; } \\
\text { DO 1046 }\end{array}$ & IL4-Ra576 & G/A & Pepperl \\
\hline DO 300.01 & Lac & $\begin{array}{c}\text { C/C } \\
\text { (intolerant) }\end{array}$ & Fulge \\
\hline DO 300.01 & Rhesus D & positiv & Rohlf \\
\hline & DRD4 & & \\
\hline
\end{tabular}


DO BS 133.01

\begin{tabular}{|c|c|c|c|c|c|c|c|c|c|c|c|c|c|c|c|}
\hline Amelo & D3S1358 & VWA & FGA & D8S1179 & D21S11 & D18S51 & D5S818 & D13S317 & D7S820 & CSF1PO & TH01 & D16S539 & D2S1338 & D19S433 & D9S1120 \\
\hline$X / Y$ & $14 / 15$ & $17 / 18$ & $(20) / 21$ & $(11) /(15)$ & $(28) / 29$ & $(16) /(18)$ & $-/-$ & $-1-$ & $(11) / 12$ & $-1-$ & $8 / 9.3$ & $11 / 12$ & $(17) /-$ & $15 /-$ & $16 /(17)$ \\
\hline
\end{tabular}

\begin{tabular}{|c|c|c|c|c|c|c|c|c|c|c|c|}
\hline DYS19 & DYS385 & DYS389 I & DYS389 II & DYS390 & DYS391 & DYS392 & DYS393 & DYS437 & DYS438 & DYS439 & n.d. \\
\hline \hline- & - & - & - & - & - & - & - & - & - & $(11)$ & \\
\hline
\end{tabular}

\section{mt: U5b}

\begin{tabular}{|c|c|c|c|c|c|c|c|c|c|c|c|c|}
\hline \multirow{2}{*}{$\mathbf{s}$} & \multicolumn{12}{|c|}{ Skelettelement } \\
\hline & Humerus & Ulna & Radius & Scapula & Clavicula & Femur & Tibia & Os coxae & Os sacrum & Mandibula & Calvarium & Calcaneus \\
\hline re & & 87.09 & 1745.07 & & 1745.09 & & E 29 & 1745.01 & & & & \\
\hline li & 133.01 & 87.06 & 87.07 & 1745.03 & 1746.01 & & & 2081 & & & & \\
\hline
\end{tabular}

Alter: $\quad$ inf II (Morphologie)

\section{Körperhöhe:}

Geschlecht:

\begin{tabular}{|l|c|l|l|}
\hline FundNr & Marker & Ausprägung & Bearbeiter \\
\hline \hline & AB0-Blutgruppe & & \\
\hline & Augenfarbe & & \\
\hline & CCR5 & & \\
\hline & IRI 3_1 & & \\
\hline & IRI 3_2 & & \\
\hline & DF508 & & \\
\hline & Haarfarbe & & \\
\hline & C82Y & & \\
\hline
\end{tabular}

\begin{tabular}{|l|c|c|c|}
\hline FundNr & Marker & Ausprägung & Bearbeiter \\
\hline \hline & H63D & & \\
\hline & IL6-174 & & \\
\hline & IL10-1082 & & \\
\hline & IL10-819 & & \\
\hline & IL10-592 & & \\
\hline & IL10-1087 & & \\
\hline & IL10-2849 & & \\
\hline & TLR2_753 & & \\
\hline
\end{tabular}

\begin{tabular}{|l|c|l|l|}
\hline FundNr & Marker & Ausprägung & Bearbeiter \\
\hline \hline & TLR4_299 & & \\
\hline & TLR4_399 & & \\
\hline & IL4-524 & & \\
\hline & IL4-Ra576 & & \\
\hline & Lac & & \\
\hline & Rhesus D & & \\
\hline & DRD4 & & \\
\hline
\end{tabular}

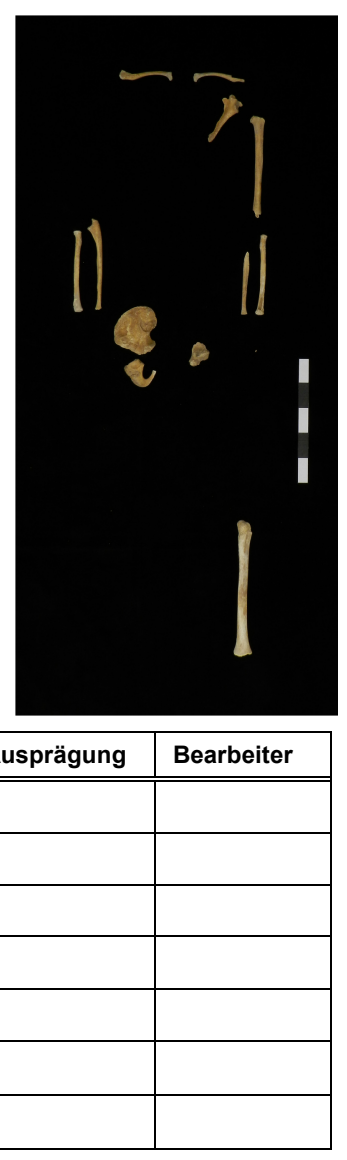


DO RG/GK/BS 183.01 (M11)

\begin{tabular}{|c|c|c|c|c|c|c|c|c|c|c|c|c|c|c|c|}
\hline Amelo & D3S1358 & VWA & FGA & D8S1179 & D21S11 & D18S51 & D5S818 & D13S317 & D7S820 & CSF1PO & TH01 & D16S539 & D2S1338 & D19S433 & D9S1120 \\
\hline$X / Y$ & $14 / 16$ & $14 / 19$ & $(22) / 24$ & $13 /(16)$ & $29 / 32.2$ & $13 / 15$ & 10/- & $8 / 11$ & 10/- & $-/-$ & $6 / 9.3$ & $11 / 12$ & $20 /-$ & $13 / 14$ & $15 / 17$ \\
\hline
\end{tabular}

\begin{tabular}{|c|c|c|c|c|c|c|c|c|c|c|c|}
\hline DYS19 & DYS385 & DYS389 I & DYS389 II & DYS390 & DYS391 & DYS392 & DYS393 & DYS437 & DYS438 & DYS439 & Y 7 \\
\hline \hline$(15)$ & -- & $(13)$ & - & - & 11 & 11 & 13 & $(15)$ & 11 & 11 & R1a (30,6) \\
\hline
\end{tabular}

mt:

U3

\begin{tabular}{|c|c|c|c|c|c|c|c|c|c|c|c|c|}
\hline \multirow{2}{*}{$\mathbf{s}$} & \multicolumn{12}{|c|}{ Skelettelement } \\
\hline & Humerus & Ulna & Radius & Scapula & Clavicula & Femur & Tibia & Os coxae & Os sacrum & Mandibula & Calvarium & Calcaneus \\
\hline re & 1004.01 & & 2965 & & & 204.02 & 65.08 & $\begin{array}{c}\text { E 07.01/ } \\
398.01 / 2402\end{array}$ & & 398.02 & & \\
\hline li & 305.01 & & 3082 & 301.02 & & 183.01 & 1079.01 & 58.10 & & & & \\
\hline
\end{tabular}

Alter:

inf II (Histologie Knochen; DO 183.01)

Körperhöhe:

Geschlecht: $ぇ$

\begin{tabular}{|c|c|c|c|}
\hline FundNr & Marker & Ausprägung & Bearbeiter \\
\hline & AB0-Blutgruppe & & \\
\hline & Augenfarbe & & \\
\hline DO 183.01 & CCR5 & $\mathrm{wt} / \Delta 32$ & $\begin{array}{l}\text { Bertermann } \\
\text { Mazanec }\end{array}$ \\
\hline DO 183.01 & IRI 3_1 & 108/116 & $\begin{array}{l}\text { Bertermann } \\
\text { Mazanec }\end{array}$ \\
\hline DO 183.01 & IRI 3_2 & $151 /((161))$ & $\begin{array}{l}\text { Bertermann } \\
\text { Mazanec }\end{array}$ \\
\hline \multirow[t]{2}{*}{ DO 183.01} & $\Delta \mathrm{F} 508$ & $w t /-$ & Scholten \\
\hline & Haarfarbe & & \\
\hline DO 183.01 & $\mathrm{C} 82 \mathrm{Y}$ & $-/$ & Krause \\
\hline
\end{tabular}

\begin{tabular}{|l|c|c|l|}
\hline FundNr & Marker & Ausprägung & Bearbeiter \\
\hline \hline DO 183.01 & H63D & C/- & Krause \\
\hline DO 183.01 & IL6-174 & (C)/- & Pepperl \\
\hline & IL10-1082 & $-/-$ & Suray \\
\hline & IL10-819 & - -- & Suray \\
\hline DO 183.01 & IL10-592 & (A)/- & Suray \\
\hline DO 183.01 & IL10-1087 & (A)/- & Pepperl \\
\hline DO 183.01 & IL10-2849 & (G)/(A) & Pepperl \\
\hline DO 183.01 & TLR2_753 & (G)/- & Pepperl \\
\hline
\end{tabular}

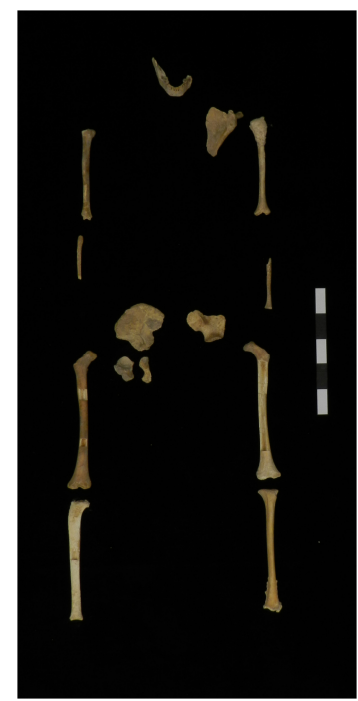

\begin{tabular}{|l|c|c|l|}
\hline FundNr & Marker & Ausprägung & Bearbeiter \\
\hline \hline & TLR4_299 & $-/-$ & Pepperl \\
\hline DO 183.01 & TLR4_399 & (C)/- & Pepperl \\
\hline & IL4-524 & $-/-$ & Pepperl \\
\hline DO 183.01 & IL4-Ra576 & (A)/- & Pepperl \\
\hline DO 183.01 & Lac & C/T (tolerant) & Fulge \\
\hline DO 204.02 & Rhesus D & nd & Rohlf \\
\hline & DRD4 & & \\
\hline
\end{tabular}


DO RG/BS 187

\begin{tabular}{|c|c|c|c|c|c|c|c|c|c|c|c|c|c|c|c|}
\hline Amelo & D3S1358 & VWA & FGA & D8S1179 & D21S11 & D18S51 & D5S818 & D13S317 & D7S820 & CSF1PO & TH01 & D16S539 & D2S1338 & D19S433 & D9S1120 \\
\hline $\mathrm{X} / \mathrm{-}$ & $14 /-$ & $14 /-$ & $22 / 23$ & $13 / 15$ & $29 /-$ & $12 / 14$ & $11 / 13$ & $12 / 14$ & (10)/- & & $6 / 9.3$ & (9)/- & $-1-$ & $15 /-$ & $-1-$ \\
\hline
\end{tabular}

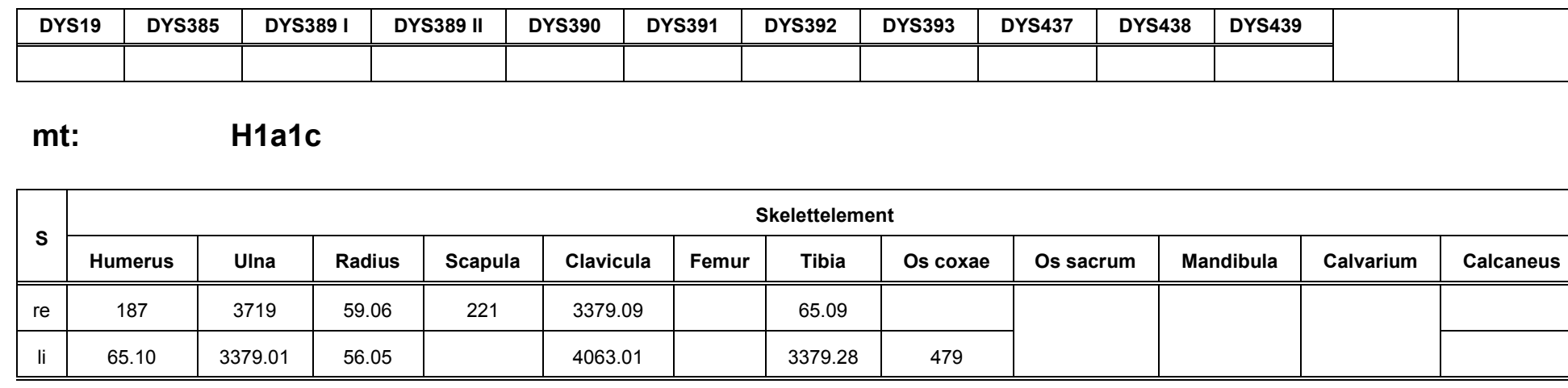

Alter: $\quad$ mad-sad (Histologie Knochen; DO 187)

Körperhöhe:

Geschlecht:

\begin{tabular}{|l|c|l|l|}
\hline FundNr & Marker & Ausprägung & Bearbeiter \\
\hline \hline & AB0-Blutgruppe & & \\
\hline & Augenfarbe & & \\
\hline & CCR5 & & \\
\hline & IRI 3_1 & & \\
\hline & IRI 3_2 & & \\
\hline & SF508 & & \\
\hline & Haarfarbe & & \\
\hline & C82Y & & \\
\hline
\end{tabular}

\begin{tabular}{|l|c|c|c|}
\hline FundNr & Marker & Ausprägung & Bearbeiter \\
\hline \hline & H63D & & \\
\hline & IL6-174 & & \\
\hline & IL10-1082 & & \\
\hline & IL10-819 & & \\
\hline & IL10-592 & & \\
\hline & IL10-1087 & & \\
\hline & IL10-2849 & & \\
\hline & TLR2_753 & & \\
\hline
\end{tabular}

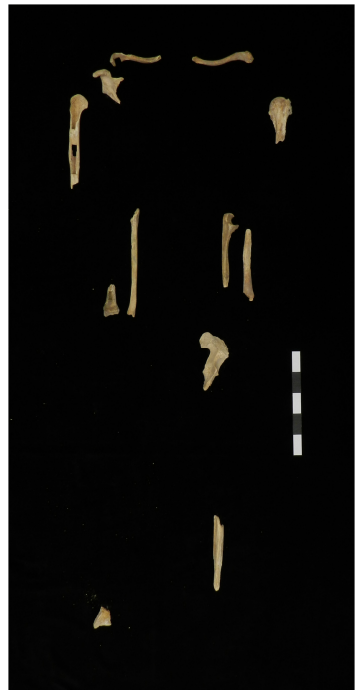

\begin{tabular}{|l|c|l|l|}
\hline FundNr & Marker & Ausprägung & Bearbeiter \\
\hline \hline & TLR4_299 & & \\
\hline & TLR4_399 & & \\
\hline & IL4-524 & & \\
\hline & IL4-Ra576 & & \\
\hline & Lac & & \\
\hline & Rhesus D & & \\
\hline & DRD4 & & \\
\hline
\end{tabular}


DO RG/FK/BS 516

\begin{tabular}{|c|c|c|c|c|c|c|c|c|c|c|c|c|c|c|c|}
\hline Amelo & D3S1358 & VWA & FGA & D8S1179 & D21S11 & D18S51 & D5S818 & D13S317 & D7S820 & CSF1PO & TH01 & D16S539 & D2S1338 & D19S433 & D9S1120 \\
\hline $\mathrm{X} /-$ & $16 /-$ & (17)/- & $(25) /-$ & $-1-$ & $(27) /(28)$ & $-1-$ & $(9) /-$ & $(11) /(13)$ & $8 / 9$ & & $(7) /(9.3)$ & $12 /-$ & $(16) /-$ & $13 / 15$ & $16 /-$ \\
\hline
\end{tabular}

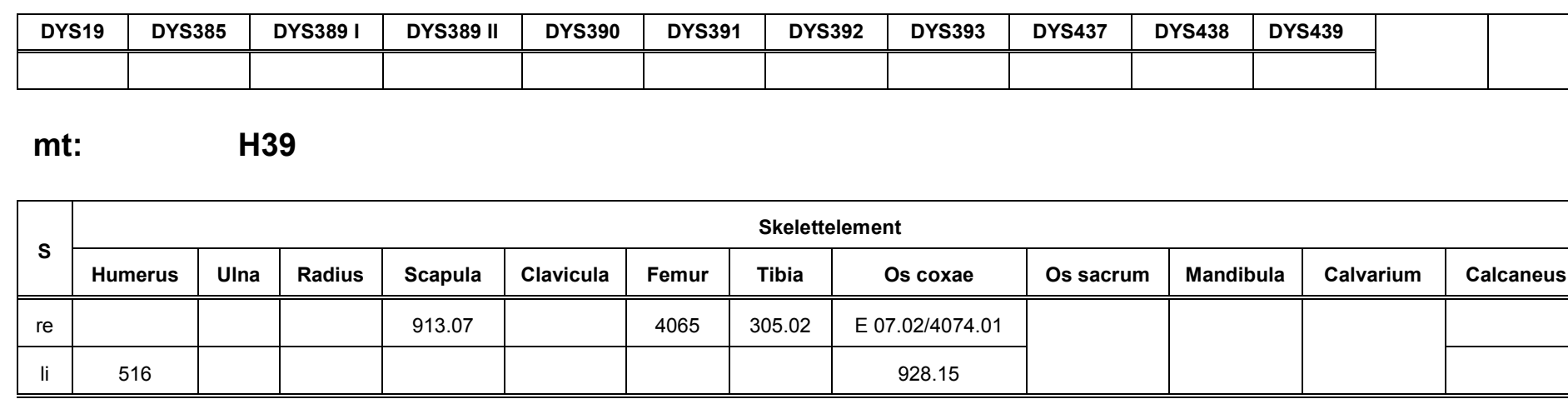

Alter: $\quad$ inf I (Morphologie)

Körperhöhe:

Geschlecht:

\begin{tabular}{|l|c|l|l|}
\hline FundNr & Marker & Ausprägung & Bearbeiter \\
\hline \hline & AB0-Blutgruppe & & \\
\hline & Augenfarbe & & \\
\hline & CCR5 & & \\
\hline & IRI 3_1 & & \\
\hline & IRI 3_2 & & \\
\hline & AF508 & & \\
\hline & Haarfarbe & & \\
\hline & C82Y & & \\
\hline
\end{tabular}

\begin{tabular}{|l|c|l|l|}
\hline FundNr & Marker & Ausprägung & Bearbeiter \\
\hline \hline & H63D & & \\
\hline & IL6-174 & & \\
\hline & IL10-1082 & & \\
\hline & IL10-819 & & \\
\hline & IL10-592 & & \\
\hline & IL10-1087 & & \\
\hline & IL10-2849 & & \\
\hline & TLR2_753 & & \\
\hline
\end{tabular}

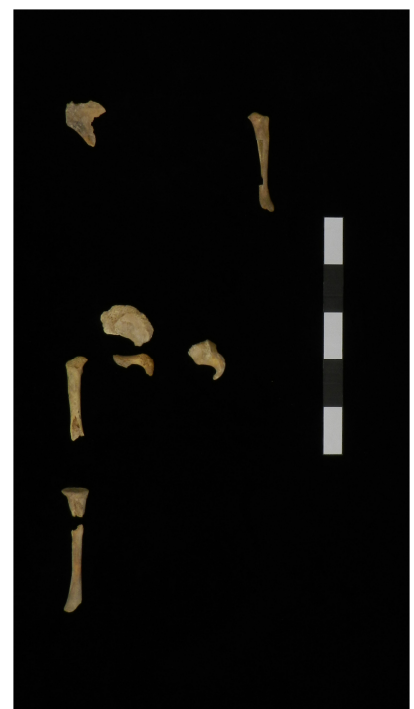

\begin{tabular}{|l|c|c|l|}
\hline FundNr & Marker & Ausprägung & Bearbeiter \\
\hline \hline & TLR4_299 & & \\
\hline & TLR4_399 & & \\
\hline & IL4-524 & & \\
\hline & IL4-Ra576 & & \\
\hline DO 516 & Lac & $-/-$ & Seebode \\
\hline & Rhesus D & & \\
\hline & DRD4 & & \\
\hline
\end{tabular}


DO FK/RG/HS/BS 901.01 (M18/F16)

\begin{tabular}{|c|c|c|c|c|c|c|c|c|c|c|c|c|c|c|c|}
\hline Amelo & D3S1358 & VWA & FGA & D8S1179 & D21S11 & D18S51 & D5S818 & D13S317 & D7S820 & CSF1PO & TH01 & D16S539 & D2S1338 & D19S433 & D9S1120 \\
\hline X/- & $16 / 18$ & $15 / 18$ & $21 /-$ & $12 / 13$ & $30 / 33.2$ & $15 / 16$ & $12 /-$ & $8 / 12$ & $10 / 14$ & -1- & $9 / 9.3$ & $12 / 14$ & $16 / 24$ & $13 / 14$ & $14 / 18$ \\
\hline
\end{tabular}

\begin{tabular}{|l|l|l|l|l|l|l|l|l|l|l|l|}
\hline DYS19 & DYS385 & DYS389 I & DYS389 II & DYS390 & DYS391 & DYS392 & DYS393 & DYS437 & DYS438 & DYS439 & \\
\hline \hline & & & & & & & & & & & \\
\hline
\end{tabular}

$\mathrm{mt}$

T2b \#3

\begin{tabular}{|c|c|c|c|c|c|c|c|c|c|c|c|c|}
\hline \multirow{2}{*}{ s } & \multicolumn{12}{|c|}{ Skelettelement } \\
\hline & Humerus & Ulna & Radius & Scapula & Clavicula & Femur & Tibia & Os coxae & Os sacrum & Mandibula & Calvarium & Calcaneus \\
\hline re & 914.01 & 533.01 & 147 & 399 & 1474 & 3715 & & 20 & \multirow{2}{*}{145.06} & & \multirow{2}{*}{ R2 } & \\
\hline li & 930.01 & 477 & & 1752 & 1158.01 & 901.01 & $921.03 / 935.01$ & 4.03 & & & & \\
\hline
\end{tabular}

Alter: $\quad$ fmat (Histologie Knochen; DO 901.01)

\section{Körperhöhe:}

Geschlecht:

\begin{tabular}{|l|c|c|l|}
\hline FundNr & Marker & Ausprägung & Bearbeiter \\
\hline \hline DO 901.01 & AB0-Blutgruppe & (A)01v & Seidenberg \\
\hline DO 901.01 & Augenfarbe & blau & Krause \\
\hline DO 901.01 & CCR5 & wt/(wt) & Mazanec \\
\hline DO 901.01 & IRI 3_1 & $((110)) /-$ & Mazanec \\
\hline DO 901.01 & IRI 3_2 & $-/-$ & Mazanec \\
\hline DO R 2 & DF508 & wt/wt & Scholten \\
\hline DO 901.01 & Haarfarbe & dunkel & Schücker \\
\hline DO R 2 & C82Y & G/G & Krause \\
\hline
\end{tabular}

\begin{tabular}{|l|c|c|l|}
\hline FundNr & Marker & Ausprägung & Bearbeiter \\
\hline \hline DO R 2 & H63D & C/C & Krause \\
\hline $\begin{array}{l}\text { DO 900.01; } \\
\text { DO R 2 }\end{array}$ & IL6-174 & (C)/- & Pepperl \\
\hline IL10-1082 & IL10-819 & & \\
\hline & IL10-592 & & \\
\hline $\begin{array}{l}\text { DO 900.01; } \\
\text { DO R 2 }\end{array}$ & IL10-1087 & A/- & Pepperl \\
\hline $\begin{array}{l}\text { DO 900.01; } \\
\text { DO R 2 }\end{array}$ & IL10-2849 & (G)/(A) & Pepperl \\
\hline $\begin{array}{l}\text { DO 900.01; } \\
\text { DO R 2 }\end{array}$ & TLR2_753 & G/- & Pepperl \\
\hline
\end{tabular}

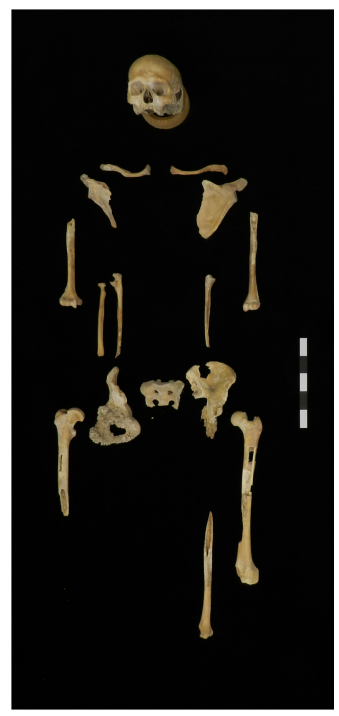

\begin{tabular}{|l|c|c|l|}
\hline FundNr & Marker & Ausprägung & Bearbeiter \\
\hline \hline $\begin{array}{l}\text { DO 900.01; } \\
\text { DO R 2 }\end{array}$ & TLR4_299 & (A)/(G) & Pepperl \\
\hline $\begin{array}{l}\text { DO 900.01; } \\
\text { DO R 2 }\end{array}$ & TLR4_399 & C/C & Pepperl \\
\hline $\begin{array}{l}\text { DO 900.01; } \\
\text { DO R 2 }\end{array}$ & IL4-524 & C/- & Pepperl \\
\hline $\begin{array}{l}\text { DO 900.01; } \\
\text { DO R 2 }\end{array}$ & IL4-Ra576 & A/- & Pepperl \\
\hline DO 901.01 & Lac & C/T (tolerant) & $\begin{array}{l}\text { Fulge } \\
\text { Seebode }\end{array}$ \\
\hline DO 901.01 & Rhesus D & positiv & Rohlf \\
\hline DO 901.01 & DRD4 & $4 /(7)$ & Blume \\
\hline
\end{tabular}


DO FK/RG/HS 902.01 (M10)

\begin{tabular}{|c|c|c|c|c|c|c|c|c|c|c|c|c|c|c|c|}
\hline Amelo & D3S1358 & VWA & FGA & D8S1179 & D21S11 & D18S51 & D5S818 & D13S317 & D7S820 & CSF1PO & TH01 & D16S539 & D2S1338 & D19S433 & D9S1120 \\
\hline$X / Y$ & $14 / 15$ & $13 / 15$ & $22 / 24$ & $13 /-$ & $31.2 / 32.2$ & $10 / 12$ & $12 /-$ & $9 / 13$ & 9/- & $10 / 11$ & $6 / 9.3$ & $11 / 12$ & $19 / 20$ & $13 / 13.2$ & $13 / 16$ \\
\hline
\end{tabular}

\begin{tabular}{|c|c|c|c|c|c|c|c|c|c|c|c|c|}
\hline DYS19 & DYS385 & DYS389 I & DYS389 II & DYS390 & DYS391 & DYS392 & DYS393 & DYS437 & DYS438 & DYS439 & \multirow{2}{*}{ Y 5} & \multirow{2}{*}{ R1a (100) } \\
\hline 15 & 11-(13) & 13 & 30 & 25 & 11 & 11 & 13 & 14 & 11 & 11 & & \\
\hline
\end{tabular}

mt:

T2b \#2

\begin{tabular}{|c|c|c|c|c|c|c|c|c|c|c|c|c|}
\hline \multirow{2}{*}{ S } & \multicolumn{10}{|c|}{ Skelettelement } \\
\cline { 2 - 14 } & Humerus & UIna & Radius & Scapula & Clavicula & Femur & Tibia & Os coxae & Os sacrum & Mandibula & Calvarium & Calcaneus \\
\hline \hline re & 413.01 & 256.01 & 101 & 5.02 & & 58.02 & 186 & 154 & & & & \\
\hline li & OF 1 & 935.02 & 28 & & 237.05 & 902.01 & 66.01 & & 155 & 480.01 & & \\
\hline \hline
\end{tabular}

Alter: $\quad$ mad (Histologie Knochen; DO 902.01/ Histologie Zahn; DO 480.01) Körperhöhe: 173,1 $\pm 3,5 \mathrm{~cm}$ Geschlecht:

\begin{tabular}{|l|c|c|l|}
\hline FundNr & Marker & Ausprägung & Bearbeiter \\
\hline \hline & AB0-Blutgruppe & & \\
\hline DO 902.01 & Augenfarbe & Intermediate-braun & Krause \\
\hline DO 902.01 & CCR5 & wt/A32 & Bertermann \\
\hline DO 902.01 & IRI 3_1 & $108 / 116$ & Bertermann \\
\hline DO 902.01 & IRI 3_2 & $151 / 171$ & Bertermann \\
\hline DO 902.01 & DF508 & wt/wt & Scholten \\
\hline Do 902.01 & Haarfarbe & blond & Schücker \\
\hline DO 902.01 & C82Y & G/A & Krause \\
\hline
\end{tabular}

\begin{tabular}{|l|c|c|l|}
\hline FundNr & Marker & Ausprägung & Bearbeiter \\
\hline \hline DO 902.01 & H63D & C/C & Krause \\
\hline $\begin{array}{l}\text { DO 902.01; } \\
\text { DO 480.01 }\end{array}$ & IL6-174 & C/(G) & Pepperl \\
\hline & IL10-1082 & & \\
\hline & IL10-819 & & \\
\hline $\begin{array}{l}\text { DO 902.01; } \\
\text { DO 480.01 }\end{array}$ & IL10-592 & & \\
\hline $\begin{array}{l}\text { DO 902.01; } \\
\text { DO 480.01 }\end{array}$ & IL10-2849 & G/A & Pepperl \\
\hline $\begin{array}{l}\text { DO 902.01; } \\
\text { DO 480.01 }\end{array}$ & TLR2_753 & G/G & Pepperl \\
\hline
\end{tabular}

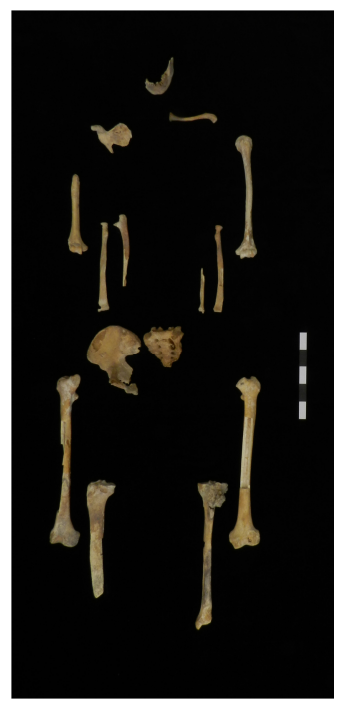

\begin{tabular}{|l|c|c|l|}
\hline FundNr & Marker & Ausprägung & Bearbeiter \\
\hline \hline $\begin{array}{l}\text { DO 902.01; } \\
\text { DO 480.01 }\end{array}$ & TLR4_299 & A/G & Pepperl \\
\hline $\begin{array}{l}\text { DO 902.01; } \\
\text { DO 480.01 }\end{array}$ & TLR4_399 & C/C & Pepperl \\
\hline $\begin{array}{l}\text { DO 902.01; } \\
\text { DO 480.01 }\end{array}$ & IL4-524 & C/C & Pepperl \\
\hline $\begin{array}{l}\text { DO 902.01; } \\
\text { DO 480.01 }\end{array}$ & IL4-Ra576 & G/A & Pepperl \\
\hline DO 902.01 & Lac & C/T /tolerant & Fulge \\
\hline DO 902.01 & Rhesus D & nd & Rohlf \\
\hline DO 480.01 & DRD4 & 2/- & Blume \\
\hline
\end{tabular}


DO FK/HS/RG/BS 903.01

\begin{tabular}{|c|c|c|c|c|c|c|c|c|c|c|c|c|c|c|c|}
\hline Amelo & D3S1358 & VWA & FGA & D8S1179 & D21S11 & D18S51 & D5S818 & D13S317 & D7S820 & CSF1PO & TH01 & D16S539 & D2S1338 & D19S433 & D9S1120 \\
\hline $\mathrm{X} /-$ & $15 / 16$ & 17/18 & $21 / 24$ & $8 / 13$ & $29 / 20$ & $14 / 17$ & $11 /-$ & 8/- & $9 / 12$ & $-1-$ & $6 / 9.3$ & $12 /-$ & $17 / 20$ & $13 / 15$ & $15 /(16)$ \\
\hline
\end{tabular}

\begin{tabular}{|l|l|l|l|l|l|l|l|l|l|l|l|}
\hline DYS19 & DYS385 & DYS389 I & DYS389 II & DYS390 & DYS391 & DYS392 & DYS393 & DYS437 & DYS438 & DYS439 & \\
\hline \hline & & & & & & & & & & & \\
\hline
\end{tabular}

mt: $\quad$ H

\begin{tabular}{|c|c|c|c|c|c|c|c|c|c|c|c|c|}
\hline \multirow{2}{*}{$\mathbf{s}$} & \multicolumn{12}{|c|}{ Skelettelement } \\
\hline & Humerus & Ulna & Radius & Scapula & Clavicula & Femur & Tibia & Os coxae & Os sacrum & Mandibula & Calvarium & Calcaneus \\
\hline re & 1585.03 & & & 920.02 & 933.01 & 900.01 & 901.03 & $2058 / 2062$ & \multirow{2}{*}{1946} & & & \\
\hline $\mathrm{li}$ & & & & & 929.01 & $903.01 / 58.07$ & 906.02 & 1750 & & & & \\
\hline
\end{tabular}

Alter: $\quad$ fad (Histologie Knochen; DO 900.01)

\section{Körperhöhe:}

Geschlecht:

\begin{tabular}{|l|c|c|l|}
\hline FundNr & Marker & Ausprägung & Bearbeiter \\
\hline \hline & AB0-Blutgruppe & & \\
\hline & Augenfarbe & & \\
\hline DO 903.01 & CCR5 & wt/- & Mazanec \\
\hline DO 903.01 & IRI 3_1 & $-/-$ & Mazanec \\
\hline DO 903.01 & IRI 3_2 & $((161)) /-$ & Mazanec \\
\hline & DF508 & & \\
\hline & Haarfarbe & & \\
\hline & C82Y & & \\
\hline
\end{tabular}

\begin{tabular}{|l|c|l|l|}
\hline FundNr & Marker & Ausprägung & Bearbeiter \\
\hline \hline & H63D & & \\
\hline & IL6-174 & & \\
\hline & IL10-1082 & & \\
\hline & IL10-819 & & \\
\hline & IL10-592 & & \\
\hline & IL10-1087 & & \\
\hline & IL10-2849 & & \\
\hline & TLR2_753 & & \\
\hline
\end{tabular}

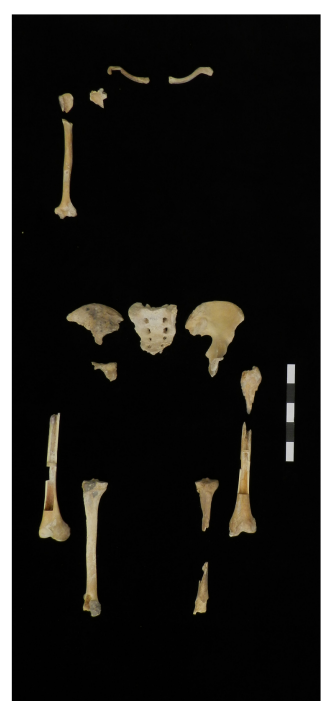

\begin{tabular}{|l|c|c|l|}
\hline FundNr & Marker & Ausprägung & Bearbeiter \\
\hline \hline & TLR4_299 & & \\
\hline & TLR4_399 & & \\
\hline & IL4-524 & & \\
\hline & IL4-Ra576 & & \\
\hline DO 903.01 & Lac & T/T (tolerant) & Fulge \\
\hline DO 903.01 & Rhesus D & nd & Rohlf \\
\hline & DRD4 & & \\
\hline
\end{tabular}


DO FK/RG/HS/BS 903.02

\begin{tabular}{|c|c|c|c|c|c|c|c|c|c|c|c|c|c|c|c|}
\hline Amelo & D3S1358 & VWA & FGA & D8S1179 & D21S11 & D18S51 & D5S818 & D13S317 & D7S820 & CSF1PO & TH01 & D16S539 & D2S1338 & D19S433 & D9S1120 \\
\hline $\mathrm{X} / \mathrm{-}$ & $16 / 17$ & $(14) / 17$ & $22 /-$ & $12 /(13)$ & $30 /-$ & $-1-$ & $-1-$ & $11 / 12$ & $-1-$ & $10 / 11$ & $7 / 9$ & $12 /-$ & $(19) /(21)$ & $13 /(15)$ & $-1-$ \\
\hline
\end{tabular}

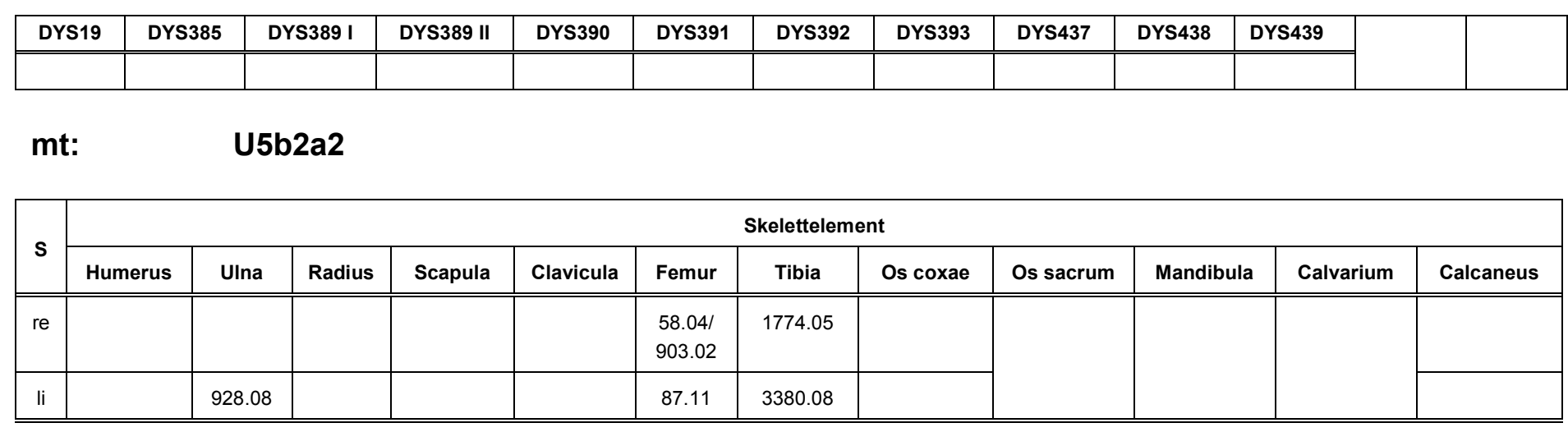

Alter: $\quad$ mad (Histologie Knochen; DO 903.02)

Körperhöhe:

Geschlecht: $\uparrow$

\begin{tabular}{|l|c|c|l|}
\hline FundNr & Marker & Ausprägung & Bearbeiter \\
\hline \hline & AB0-Blutgruppe & & \\
\hline & Augenfarbe & & \\
\hline DO 903.02 & CCR5 & wt/- & Mazanec \\
\hline DO 903.02 & IRI 3_1 & $-/-$ & Mazanec \\
\hline DO 903.02 & IRI 3_2 & $-/-$ & Mazanec \\
\hline & DF508 & & \\
\hline & Haarfarbe & & \\
\hline & C82Y & & \\
\hline
\end{tabular}

\begin{tabular}{|l|c|c|c|}
\hline FundNr & Marker & Ausprägung & Bearbeiter \\
\hline \hline & H63D & & \\
\hline & IL6-174 & & \\
\hline & IL10-1082 & & \\
\hline & IL10-819 & & \\
\hline & IL10-592 & & \\
\hline & IL10-1087 & & \\
\hline & IL10-2849 & & \\
\hline & TLR2_753 & & \\
\hline
\end{tabular}

\begin{tabular}{|l|c|l|l|}
\hline FundNr & Marker & Ausprägung & Bearbeiter \\
\hline \hline & TLR4_299 & & \\
\hline & TLR4_399 & & \\
\hline & IL4-524 & & \\
\hline & IL4-Ra576 & & \\
\hline DO 58.04 & Lac & C/T (tolerant) & Fulge \\
\hline & Rhesus D & & \\
\hline & DRD4 & & \\
\hline
\end{tabular}


DO FK/RG/JS 904.04

\begin{tabular}{|c|c|c|c|c|c|c|c|c|c|c|c|c|c|c|c|}
\hline Amelo & D3S1358 & VWA & FGA & D8S1179 & D21S11 & D18S51 & D5S818 & D13S317 & D7S820 & CSF1PO & TH01 & D16S539 & D2S1338 & D19S433 & D9S1120 \\
\hline$-1-$ & $-1-$ & $-1-$ & $(19) /(24)$ & $-1-$ & $(31) /(32.2)$ & $-1-$ & (12)/- & $(9) /-$ & $-1-$ & $-1-$ & $(7) /-$ & $-1-$ & $-1-$ & $17 /-$ & $-1-$ \\
\hline
\end{tabular}

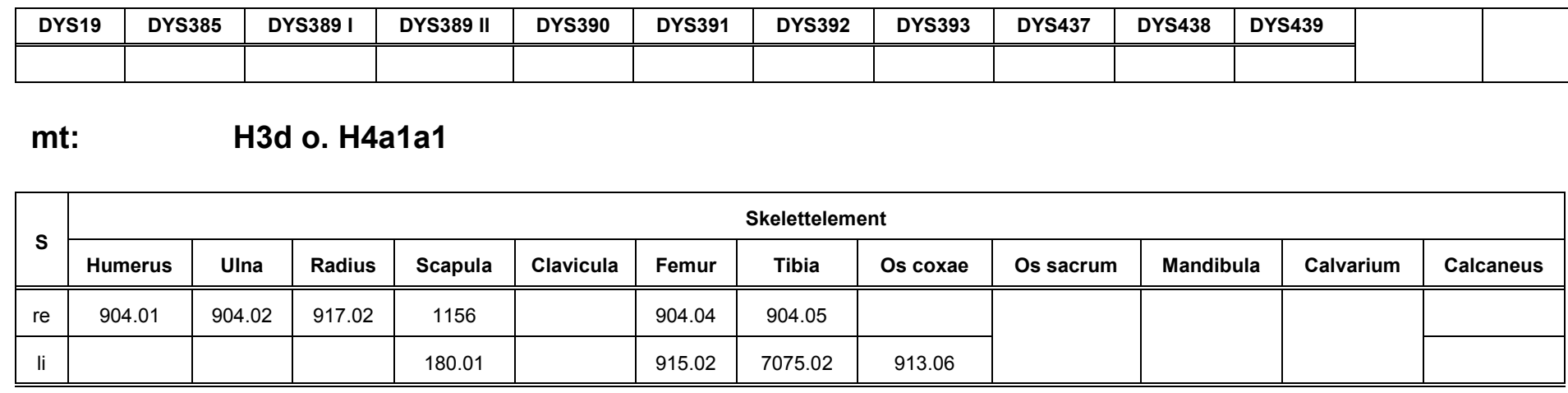

Alter: $\quad \inf I$ (Morphologie)

Körperhöhe:

Geschlecht: n.d.

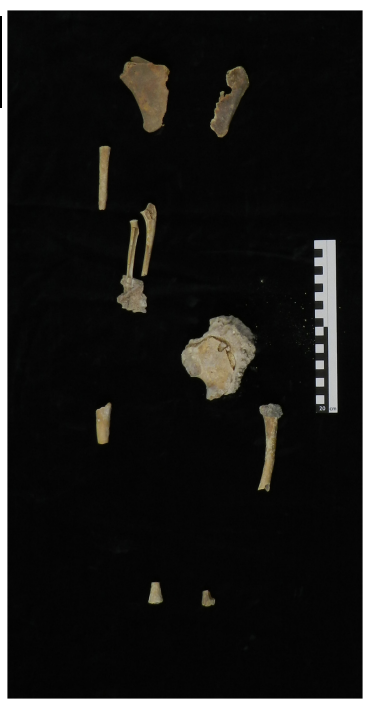

\begin{tabular}{|l|c|c|l|}
\hline FundNr & Marker & Ausprägung & Bearbeiter \\
\hline \hline & AB0-Blutgruppe & & \\
\hline & Augenfarbe & & \\
\hline DO 904.05 & CCR5 & $-/-$ & Mazanec \\
\hline DO 904.05 & IRI 3_1 & $-/-$ & Mazanec \\
\hline DO 904.05 & IRI 3_2 & $-/-$ & Mazanec \\
\hline & DF508 & & \\
\hline & Haarfarbe & & \\
\hline & C82Y & & \\
\hline
\end{tabular}

\begin{tabular}{|l|c|c|c|}
\hline FundNr & Marker & Ausprägung & Bearbeiter \\
\hline \hline & H63D & & \\
\hline & IL6-174 & & \\
\hline & IL10-1082 & & \\
\hline & IL10-819 & & \\
\hline & IL10-592 & & \\
\hline & IL10-1087 & & \\
\hline & IL10-2849 & & \\
\hline & TLR2_753 & & \\
\hline
\end{tabular}

\begin{tabular}{|l|c|c|l|}
\hline FundNr & Marker & Ausprägung & Bearbeiter \\
\hline \hline & TLR4_299 & & \\
\hline & TLR4_399 & & \\
\hline & IL4-524 & & \\
\hline & IL4-Ra576 & & \\
\hline DO 904.05 & Lac & (C)/- & Seebode \\
\hline & Rhesus D & & \\
\hline & DRD4 & & \\
\hline
\end{tabular}


DO FK/RG 905.01 (M14)

\begin{tabular}{|c|c|c|c|c|c|c|c|c|c|c|c|c|c|c|c|}
\hline Amelo & D3S1358 & VWA & FGA & D8S1179 & D21S11 & D18S51 & D5S818 & D13S317 & D7S820 & CSF1PO & TH01 & D16S539 & D2S1338 & D19S433 & D9S1120 \\
\hline$X / Y$ & $15 /-$ & $16 /-$ & $20 / 22$ & $12 / 13$ & $29 / 31.2$ & $18 / 19$ & $11 / 12$ & $8 / 11$ & $10 / 12$ & 10/12 & $7 / 9$ & 9/11 & 17/- & $12 / 15$ & $15 / 16$ \\
\hline
\end{tabular}

\begin{tabular}{|c|c|c|c|c|c|c|c|c|c|c|c|c|}
\hline DYS19 & DYS385 & DYS389 I & DYS389 II & DYS390 & DYS391 & DYS392 & DYS393 & DYS437 & DYS438 & DYS439 & \multirow{2}{*}{ Y 8} & \multirow{2}{*}{ I2b $(97,8)$} \\
\hline 15 & (13)- - & 12 & - & 25 & 11 & 11 & 13 & 14 & 10 & 11 & & \\
\hline
\end{tabular}

mt:

H5 \#1

\begin{tabular}{|c|c|c|c|c|c|c|c|c|c|c|c|c|}
\hline \multirow{2}{*}{$\mathbf{s}$} & \multicolumn{12}{|c|}{ Skelettelement } \\
\hline & Humerus & Ulna & Radius & Scapula & Clavicula & Femur & Tibia & Os coxae & Os sacrum & Mandibula & Calvarium & Calcaneus \\
\hline re & & 176.03 & & & 394.01 & 904.03 & 905.02 & & & & & \\
\hline li & 901.02 & & 59.05 & 914.03 & 886.01 & 905.01 & & & & & & \\
\hline
\end{tabular}

Alter: $\quad$ fad (Histologie Knochen; DO 905.01)

\section{Körperhöhe:}

Geschlecht:

\begin{tabular}{|l|c|c|l|}
\hline FundNr & Marker & Ausprägung & Bearbeiter \\
\hline \hline $\begin{array}{l}\text { DO 901.02; } \\
\text { DO 905.01 }\end{array}$ & AB0-Blutgruppe & $(\mathrm{B}) 01$ & Seidenberg \\
\hline & Augenfarbe & & \\
\hline $\begin{array}{l}\text { DO 901.02; } \\
\text { DO 905.01 }\end{array}$ & CCR5 & wt/wt & Mazanec \\
\hline $\begin{array}{l}\text { DO 901.02; } \\
\text { DO 905.01 }\end{array}$ & IRI 3_1 & $120 /-$ & Mazanec \\
\hline $\begin{array}{l}\text { DO 901.02; } \\
\text { DO 905.01 }\end{array}$ & IRI 3_2 & $((155)) /((165))$ & Mazanec \\
\hline DO 918.01 & $\Delta$ F508 & wt/wt & Scholten \\
\hline & Haarfarbe & & \\
\hline DO 918.01 & C82Y & G/G & Krause \\
\hline
\end{tabular}

\begin{tabular}{|l|c|c|l|}
\hline FundNr & Marker & Ausprägung & Bearbeiter \\
\hline \hline DO 918.01 & H63D & C/C & Krause \\
\hline DO 905.01 & IL6-174 & $-/-$ & Pepperl \\
\hline & IL10-1082 & & \\
\hline & IL10-819 & & \\
\hline & IL10-592 & & \\
\hline DO 905.01 & IL10-1087 & $-/-$ & Pepperl \\
\hline DO 905.01 & IL10-2849 & (G)/(A) & Pepperl \\
\hline DO 905.01 & TLR2_753 & (G)/- & Pepperl \\
\hline
\end{tabular}

\begin{tabular}{|l|c|c|l|}
\hline FundNr & Marker & Ausprägung & Bearbeiter \\
\hline \hline DO 905.01 & TLR4_299 & $-/-$ & Pepperl \\
\hline DO 905.01 & TLR4_399 & $-/-$ & Pepperl \\
\hline DO 905.01 & IL4-524 & (C)/- & Pepperl \\
\hline DO 905.01 & IL4-Ra576 & (G)/- & Pepperl \\
\hline $\begin{array}{l}\text { DO 901.02; } \\
\text { DO 905.01 }\end{array}$ & Lac & C/T (tolerant) & $\begin{array}{l}\text { Fulge } \\
\text { Seebode }\end{array}$ \\
\hline $\begin{array}{l}\text { DO 905.01; } \\
\text { DO 901.02 }\end{array}$ & Rhesus D & positiv & Rohlf \\
\hline & DRD4 & & \\
\hline
\end{tabular}


DO FK/RG/BS 907.01

\begin{tabular}{|c|c|c|c|c|c|c|c|c|c|c|c|c|c|c|c|}
\hline Amelo & D3S1358 & VWA & FGA & D8S1179 & D21S11 & D18S51 & D5S818 & D13S317 & D7S820 & CSF1PO & TH01 & D16S539 & D2S1338 & D19S433 & D9S1120 \\
\hline$X / Y$ & $15 / 17$ & $(15) / 16$ & $21 /-$ & $8 /(15)$ & $28 / 30$ & $14 / 20$ & $11 /-$ & $8 / 13$ & 9/- & $-/-$ & $6 / 9.3$ & $12 / 13$ & $(17) /(20)$ & $15 / 17$ & $16 /-$ \\
\hline
\end{tabular}

\begin{tabular}{|c|c|c|c|c|c|c|c|c|c|c|c|c|}
\hline DYS19 & DYS385 & DYS389 I & DYS389 II & DYS390 & DYS391 & DYS392 & DYS393 & DYS437 & DYS438 & DYS439 & Y1 o. & $\begin{array}{c}\text { I2b } \\
\text { Y 6 }\end{array}$ \\
\hline \hline 16 & $13-17$ & 12 & - & - & 11 & 11 & 13 & - & 10 & 11 & \\
\hline
\end{tabular}

$\mathrm{mt}$

H \#5

\begin{tabular}{|c|c|c|c|c|c|c|c|c|c|c|c|c|}
\hline \multirow{2}{*}{ S } & \multicolumn{9}{|c|}{ Skelettelement } \\
\cline { 2 - 13 } & Humerus & UIna & Radius & Scapula & Clavicula & Femur & Tibia & $\begin{array}{c}\text { Os } \\
\text { coxae }\end{array}$ & $\begin{array}{c}\text { Os } \\
\text { sacrum }\end{array}$ & Mandibula & Calvarium & Calcaneus \\
\hline \hline re & 1745.08 & 277.01 & & 907.03 & & & & $\begin{array}{c}1921 / \\
87.15\end{array}$ & & & & \\
\hline li & 1494 & & & & & 907.01 & & & & & & \\
\hline \hline
\end{tabular}

Alter: $\quad$ inf I (Histologie Knochen; DO 907.01)

Körperhöhe:

Geschlecht:

\begin{tabular}{|l|c|c|l|}
\hline FundNr & Marker & Ausprägung & Bearbeiter \\
\hline \hline DO 907.01 & AB0-Blutgruppe & A01 & Seidenberg \\
\hline & Augenfarbe & & \\
\hline DO 907.01 & CCR5 & wt/(wt) & Mazanec \\
\hline DO 907.01 & IRI 3_1 & $((106)) /((114))$ & Mazanec \\
\hline DO 907.01 & IRI 3_2 & $(139) /((159))$ & Mazanec \\
\hline & $\Delta$ F508 & & \\
\hline & Haarfarbe & & \\
\hline & C82Y & & \\
\hline
\end{tabular}

\begin{tabular}{|l|c|l|l|}
\hline FundNr & Marker & Ausprägung & Bearbeiter \\
\hline \hline & H63D & & \\
\hline & IL6-174 & & \\
\hline & IL10-1082 & & \\
\hline & IL10-819 & & \\
\hline & IL10-592 & & \\
\hline & IL10-1087 & & \\
\hline & IL10-2849 & & \\
\hline & TLR2_753 & & \\
\hline
\end{tabular}

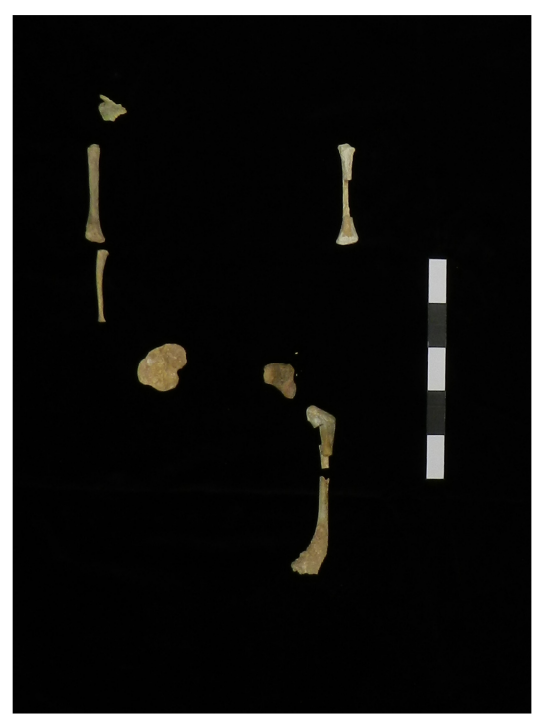

\begin{tabular}{|l|c|c|l|}
\hline FundNr & Marker & Ausprägung & Bearbeiter \\
\hline & TLR4_299 & & \\
\hline & TLR4_399 & & \\
\hline & IL4-524 & & \\
\hline DO 907.01 & IL4-Ra576 & & \\
\hline DO 907.01 & Lac & C/C (intolerant) & Fulge \\
\hline & DResus D & positiv & Rohlf \\
\hline
\end{tabular}


DO RG/FK 1076 (M1)

\begin{tabular}{|c|c|c|c|c|c|c|c|c|c|c|c|c|c|c|c|}
\hline Amelo & D3S1358 & VWA & FGA & D8S1179 & D21S11 & D18S51 & D5S818 & D13S317 & D7S820 & CSF1PO & TH01 & D16S539 & D2S1338 & D19S433 & D9S1120 \\
\hline$X / Y$ & $15 / 17$ & $15 / 16$ & $21 / 25$ & $12 / 13$ & $30.2 / 33.2$ & $14 / 20$ & $10 / 12$ & $11 / 13$ & $7 / 8$ & 10/- & $9.3 /-$ & $11 / 12$ & $(17) / 18$ & $13 / 15$ & $16 /-$ \\
\hline
\end{tabular}

\begin{tabular}{|c|c|c|c|c|c|c|c|c|c|c|c|}
\hline DYS19 & DYS385 & DYS389 I & DYS389 II & DYS390 & DYS391 & DYS392 & DYS393 & DYS437 & DYS438 & DYS439 & Y 1 \\
\hline \hline 16 & $13-17$ & 12 & 28 & 25 & 11 & 11 & 13 & 15 & 10 & 11 & I2b (100) \\
\hline
\end{tabular}

mt:

H \#3

\begin{tabular}{|c|c|c|c|c|c|c|c|c|c|c|c|c|}
\hline \multirow{2}{*}{$\mathbf{s}$} & \multicolumn{12}{|c|}{ Skelettelement } \\
\hline & Humerus & Ulna & Radius & Scapula & Clavicula & Femur & Tibia & Os coxae & Os sacrum & Mandibula & Calvarium & Calcaneus \\
\hline re & 1573 & 1147 & 393.01 & & 1064 & 67.01 & 201 & 6495 & & & & \\
\hline li & 1492 & 1539.01 & 1576 & 34 & & 1076 & 1065 & 1956 & & 19. & 集 & \\
\hline
\end{tabular}

Alter: $\quad$ smat (Histologie Knochen; DO 1076/ Histologie Zahn; M1)

Körperhöhe: $171,1 \pm 3,0 \mathrm{~cm}$

Geschlecht:

\begin{tabular}{|l|c|c|l|}
\hline FundNr & Marker & Ausprägung & Bearbeiter \\
\hline \hline DO 1076 & AB0-Blutgruppe & A(01) & Seidenberg \\
\hline DO 1076 & Augenfarbe & Intermediate-braun & Krause \\
\hline DO 1076 & CCR5 & wt/- & Bertermann \\
\hline DO 1076 & IRI 3_1 & $114 / 118$ & Bertermann \\
\hline DO 1076 & IRI 3_2 & $139 / 159$ & Bertermann \\
\hline DO 1485 & LF508 & wt/wt & Scholten \\
\hline DO 1076 & Haarfarbe & hellbraun & Schücker \\
\hline $\begin{array}{l}\text { DO 1076; } \\
\text { DO 1485 }\end{array}$ & C82Y & G/G & Krause \\
\hline
\end{tabular}

\begin{tabular}{|l|c|c|l|}
\hline FundNr & Marker & Ausprägung & Bearbeiter \\
\hline \hline $\begin{array}{l}\text { DO 1076; } \\
\text { DO 1485 }\end{array}$ & H63D & C/- & Krause \\
\hline $\begin{array}{l}\text { DO 1076; } \\
\text { DO 1172.01 }\end{array}$ & IL6-174 & G/C & Pepperl \\
\hline $\begin{array}{l}\text { DO 1076; } \\
\text { DO 1172.01 }\end{array}$ & IL10-1082 & A/- & Suray \\
\hline $\begin{array}{l}\text { DO 1076; } \\
\text { DO 1172.01 }\end{array}$ & IL10-819 & C/T & Suray \\
\hline $\begin{array}{l}\text { DO 1076; } \\
\text { DO 1172.01 }\end{array}$ & IL10-592 & C/A & Suray \\
\hline $\begin{array}{l}\text { DO 1076; } \\
\text { DO 1172.01 }\end{array}$ & IL10-1087 & A/- & Pepperl \\
\hline $\begin{array}{l}\text { DO 1076; } \\
\text { DO 1172.01 }\end{array}$ & IL10-2849 & G/A & Pepperl \\
\hline $\begin{array}{l}\text { DO 1076; } \\
\text { DO 1172.01 }\end{array}$ & TLR2_753 & G/(A) & Pepperl \\
\hline
\end{tabular}

\begin{tabular}{|l|c|c|l|}
\hline FundNr & Marker & Ausprägung & Bearbeiter \\
\hline \hline $\begin{array}{l}\text { DO 1076; } \\
\text { DO 1172.01 }\end{array}$ & TLR4_299 & (A)/- & Pepperl \\
\hline $\begin{array}{l}\text { DO 1076; } \\
\text { DO 1172.01 }\end{array}$ & TLR4_399 & C/C & Pepperl \\
\hline $\begin{array}{l}\text { DO 1076; } \\
\text { DO 1172.01 }\end{array}$ & IL4-524 & (C)/- & Pepperl \\
\hline $\begin{array}{l}\text { DO 1076; } \\
\text { DO 1172.01 }\end{array}$ & IL4-Ra576 & G/A & Pepperl \\
\hline Do 1076 & Lac & $\begin{array}{c}\text { C/C } \\
\text { (intolerant) }\end{array}$ & Fulge \\
\hline DO 1076 & Rhesus D & positiv & Rohlf \\
\hline DO 201 & DRD4 & 4/- & Blume \\
\hline
\end{tabular}

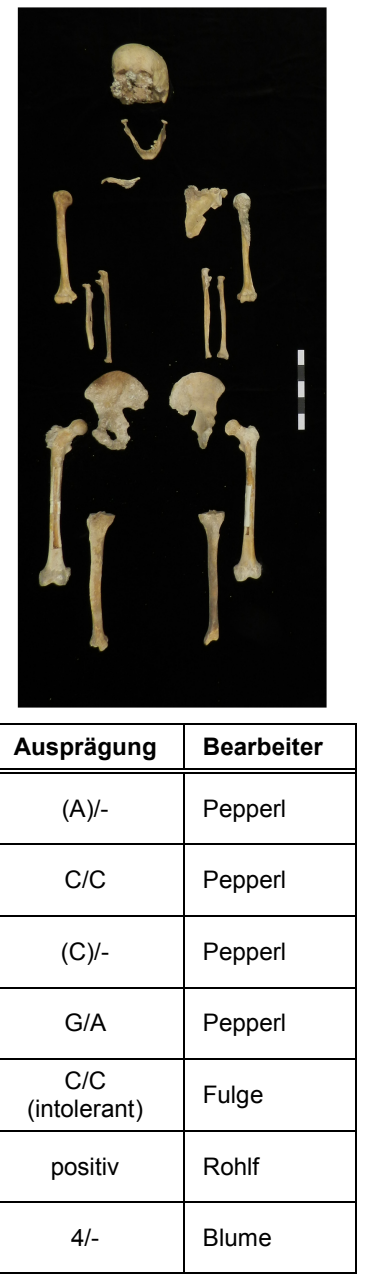


DO RG/FK/BS 1078 (F13)

\begin{tabular}{|c|c|c|c|c|c|c|c|c|c|c|c|c|c|c|c|}
\hline Amelo & D3S1358 & VWA & FGA & D8S1179 & D21S11 & D18S51 & D5S818 & D13S317 & D7S820 & CSF1PO & TH01 & D16S539 & D2S1338 & D19S433 & D9S1120 \\
\hline XI- & 16/- & $\begin{array}{l}15 / 17 \\
\end{array}$ & $21 /-$ & 13/- & $27 /-$ & $13 /-$ & $9 / 12$ & $11 / 12$ & $8 / 11$ & $10 / 11$ & 9.3/- & $11 / 12$ & $16 / 19$ & 15/- & 16/- \\
\hline
\end{tabular}

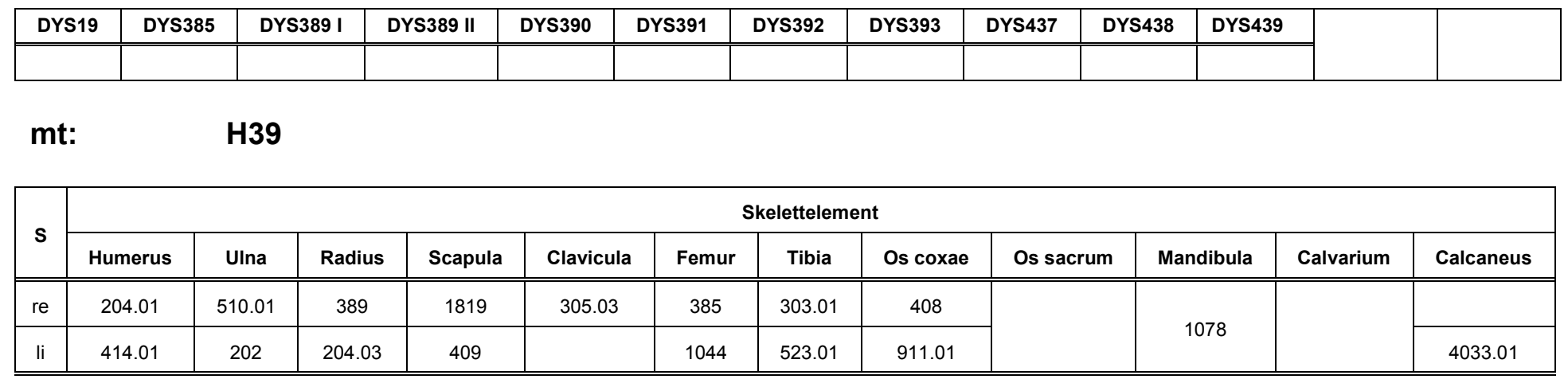

Alter: $\quad$ smat-sen (Histologie Knochen; DO 1044)

Körperhöhe: $157,2 \pm 3,1 \mathrm{~cm}$

Geschlecht:

\begin{tabular}{|l|c|c|l|}
\hline FundNr & Marker & Ausprägung & Bearbeiter \\
\hline \hline DO 1044 & AB0-Blutgruppe & AA & Seidenberg \\
\hline DO 1044 & Augenfarbe & Intermediate-braun & Krause \\
\hline $\begin{array}{l}\text { DO 1044; } \\
\text { DO 385 }\end{array}$ & CCR5 & wt/wt & $\begin{array}{l}\text { Bertermann } \\
\text { Mazanec }\end{array}$ \\
\hline $\begin{array}{l}\text { DO 1044; } \\
\text { DO 385 }\end{array}$ & IRI 3_1 & $(112) / 118$ & $\begin{array}{l}\text { Bertermann } \\
\text { Mazanec }\end{array}$ \\
\hline $\begin{array}{l}\text { DO 1044; } \\
\text { DO 385 }\end{array}$ & IRI 3_2 & $((139)) /(157)$ & $\begin{array}{l}\text { Bertermann } \\
\text { Mazanec }\end{array}$ \\
\hline DO 1078 & AF508 & wt/wt & Scholten \\
\hline DO 1044 & Haarfarbe & dunkel & Schücker \\
\hline DO 1078 & C82Y & G/G & Krause \\
\hline
\end{tabular}

\begin{tabular}{|l|c|c|l|}
\hline FundNr & Marker & Ausprägung & Bearbeiter \\
\hline \hline DO 1078 & H63D & C/C & Krause \\
\hline DO 1044 & IL6-174 & $-/-$ & Pepperl \\
\hline DO 1044 & IL10-1082 & A/- & Suray \\
\hline DO 1044 & IL10-819 & C/T & Suray \\
\hline DO 1044 & IL10-592 & C/(A) & Suray \\
\hline DO 1044 & IL10-1087 & $-/-$ & Pepperl \\
\hline DO 1044 & IL10-2849 & (A)/- & Pepperl \\
\hline DO 1078 & TLR2_753 & (G)/- & Pepperl \\
\hline
\end{tabular}

\begin{tabular}{|l|c|c|l|}
\hline FundNr & Marker & Ausprägung & Bearbeiter \\
\hline \hline DO 1044 & TLR4_299 & $-/-$ & Pepperl \\
\hline DO 1044 & TLR4_399 & (C)/- & Pepperl \\
\hline DO 1044 & IL4-524 & (C)/- & Pepperl \\
\hline DO 1044 & IL4-Ra576 & (A)/- & Pepperl \\
\hline $\begin{array}{l}\text { DO 1044; } \\
\text { DO 385 }\end{array}$ & Lac & C/T (tolerant) & $\begin{array}{l}\text { Fulge } \\
\text { Seebode }\end{array}$ \\
\hline $\begin{array}{l}\text { DO 1044; } \\
\text { DO 385 }\end{array}$ & Rhesus D & (negativ) & Rohlf \\
\hline & DRD4 & & \\
\hline
\end{tabular}


DO BS 1102 (M2)

\begin{tabular}{|c|c|c|c|c|c|c|c|c|c|c|c|c|c|c|c|}
\hline Amelo & D3S1358 & VWA & FGA & D8S1179 & D21S11 & D18S51 & D5S818 & D13S317 & D7S820 & CSF1PO & TH01 & D16S539 & D2S1338 & D19S433 & D9S1120 \\
\hline$X / Y$ & $15 / 16$ & $16 /-$ & $20 / 21$ & $12 / 15$ & $29 / 33.2$ & $14 / 18$ & $9 / 10$ & $11 /-$ & $7 / 9$ & 10/13 & $7 / 9.3$ & $11 / 13$ & $17 /-$ & 13/- & $16 /-$ \\
\hline
\end{tabular}

\begin{tabular}{|c|c|c|c|c|c|c|c|c|c|c|c|c|}
\hline DYS19 & DYS385 & DYS389 I & DYS389 II & DYS390 & DYS391 & DYS392 & DYS393 & DYS437 & DYS438 & DYS439 & \multirow{2}{*}{ Y1 } & \multirow{2}{*}{$\mathbf{I} \mathbf{2 b}(100$} \\
\hline 16 & 13- - & 12 & 28 & 25 & 11 & - & 13 & 15 & 10 & 11 & & \\
\hline
\end{tabular}

mt:

H \#1

\begin{tabular}{|c|c|c|c|c|c|c|c|c|c|c|c|c|}
\hline \multirow{2}{*}{$\mathbf{s}$} & \multicolumn{12}{|c|}{ Skelettelement } \\
\hline & Humerus & Ulna & Radius & Scapula & Clavicula & Femur & Tibia & Os coxae & Os sacrum & Mandibula & Calvarium & Calcaneus \\
\hline re & 2108 & 2034 & 4559 & 3601 & 3640 & 3605 & & 3973 & & & & \\
\hline li & 3670 & 4495 & 2519 & 2056 & 3981.01 & 1102 & 87.12 & & & & & \\
\hline
\end{tabular}

Alter: mmat-smat (Histologie Knochen; DO 1102/ Histologie Zahn; DO 3644)

Körperhöhe: $172,8 \pm 3,3 \mathrm{~cm}$

\section{Geschlecht:}

\begin{tabular}{|l|c|c|l|}
\hline FundNr & Marker & Ausprägung & Bearbeiter \\
\hline \hline DO 1102 & AB0-Blutgruppe & AA & Seidenberg \\
\hline DO 3670 & Augenfarbe & Intermediate-blau & Krause \\
\hline DO 1102 & CCR5 & wt/wt & Bertermann \\
\hline DO 1102 & IRI 3_1 & $114 / 118$ & Bertermann \\
\hline DO 1102 & IRI 3_2 & $161 / 169$ & Bertermann \\
\hline DO 3644 & AF508 & wt/wt & Scholten \\
\hline DO 3670 & Haarfarbe & dunkelblond (rötl.) & Schücker \\
\hline DO 3644 & C82Y & G/- & Krause \\
\hline
\end{tabular}

\begin{tabular}{|l|c|c|l|}
\hline FundNr & Marker & Ausprägung & Bearbeiter \\
\hline \hline DO 3644 & H63D & $\mathrm{C} / \mathrm{G}$ & Krause \\
\hline DO 1102 & IL6-174 & $\mathrm{G} /(\mathrm{C})$ & Pepperl \\
\hline DO 1102 & IL10-1082 & $\mathrm{A} /(\mathrm{G})$ & Suray \\
\hline DO 1102 & IL10-819 & $\mathrm{C} /-$ & Suray \\
\hline DO 1102 & IL10-592 & $\mathrm{C} /-$ & Suray-/- \\
\hline DO 1102 & IL10-1087 & $-/-$ & Pepperl \\
\hline DO 1102 & IL10-2849 & A/- & Pepperl \\
\hline DO 1102 & TLR2_753 & G/(A) & Pepperl \\
\hline
\end{tabular}

\begin{tabular}{|l|c|c|l|}
\hline FundNr & Marker & Ausprägung & Bearbeiter \\
\hline \hline DO 1102 & TLR4_299 & A/- & Pepperl \\
\hline DO 1102 & TLR4_399 & C/- & Pepperl \\
\hline DO 1102 & IL4-524 & $-/-$ & Pepperl \\
\hline DO 1102 & IL4-Ra576 & A/- & Pepperl \\
\hline DO 1102 & Lac & $\begin{array}{c}\text { C/C } \\
\text { (intolerant) }\end{array}$ & Fulge \\
\hline DO 1102 & Rhesus D & positiv & Rohlf \\
\hline & DRD4 & & \\
\hline
\end{tabular}


DO BS/RG 1103 (F14)

\begin{tabular}{|c|c|c|c|c|c|c|c|c|c|c|c|c|c|c|c|}
\hline Amelo & D3S1358 & VWA & FGA & D8S1179 & D21S11 & D18S51 & D5S818 & D13S317 & D7S820 & CSF1PO & TH01 & D16S539 & D2S1338 & D19S433 & D9S1120 \\
\hline XI- & $14 / 16$ & $14 / 15$ & $23 / 24$ & $11 / 14$ & $28 / 30$ & $12 / 15$ & $11 / 12$ & $12 / 13$ & $12 /-$ & $11 /-$ & $6 / 9.3$ & $10 / 13$ & $18 / 25$ & $13 / 15$ & $15 /-$ \\
\hline
\end{tabular}

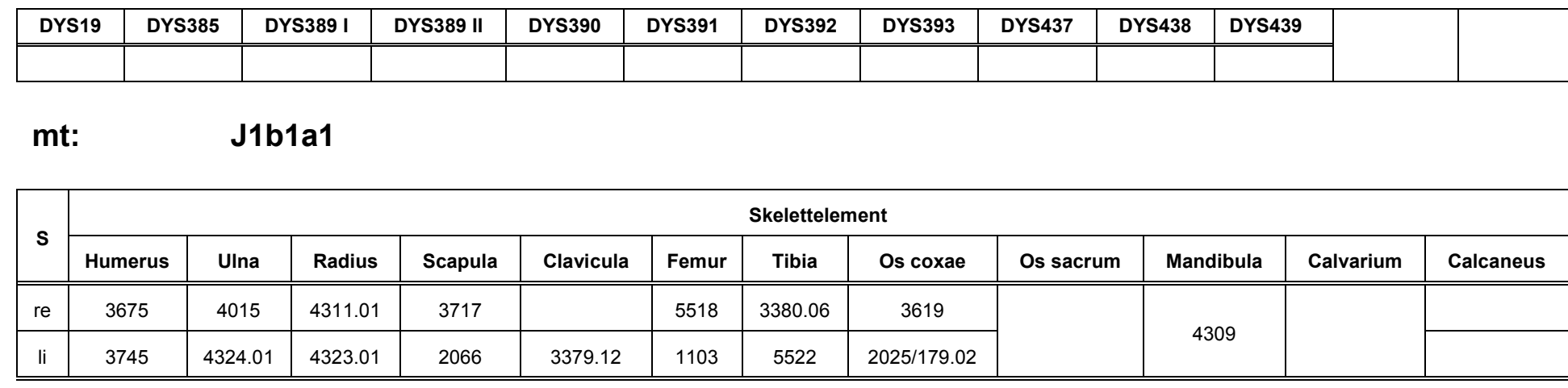

Alter: $\quad$ mad (Histologie Knochen; DO 1103/ Histologie Zahn; DO 4309) Körperhöhe: 157,1 $\pm 3,1 \mathrm{~cm}$

Geschlecht: $\uparrow$

\begin{tabular}{|c|c|c|c|}
\hline FundNr & Marker & Ausprägung & Bearbeiter \\
\hline DO 1103 & AB0-Blutgruppe & A01v & Seidenberg \\
\hline DO 1103 & Augenfarbe & Intermediate-braun & Krause \\
\hline DO 1103 & CCR5 & $w t / \Delta 32$ & Bertermann \\
\hline DO 1103 & IRI 3_1 & $106 / 118$ & Bertermann \\
\hline DO 1103 & IRI 3_2 & $151 / 161$ & Bertermann \\
\hline DO 4309 & $\Delta \mathrm{F} 508$ & $w t / w t$ & Scholten \\
\hline DO 1103 & Haarfarbe & dunkel & Schücker \\
\hline DO 4309 & $\mathrm{C} 82 \mathrm{Y}$ & G/G & Krause \\
\hline
\end{tabular}

\begin{tabular}{|l|c|c|l|}
\hline FundNr & Marker & Ausprägung & Bearbeiter \\
\hline \hline DO 4309 & H63D & C/C & Krause \\
\hline $\begin{array}{l}\text { DO 1103; } \\
\text { DO 4309 }\end{array}$ & IL6-174 & C/C & Pepperl \\
\hline & IL10-1082 & & \\
\hline & IL10-819 & & \\
\hline $\begin{array}{l}\text { DO 1103; } \\
\text { DO 4309 }\end{array}$ & IL10-1087 & A/A & Pepperl \\
\hline $\begin{array}{l}\text { DO 1103; } \\
\text { DO 4309 }\end{array}$ & IL10-2849 & G/A & Pepperl \\
\hline $\begin{array}{l}\text { DO 1103; } \\
\text { DO 4309 }\end{array}$ & TLR2_753 & G/(A) & Pepperl \\
\hline
\end{tabular}

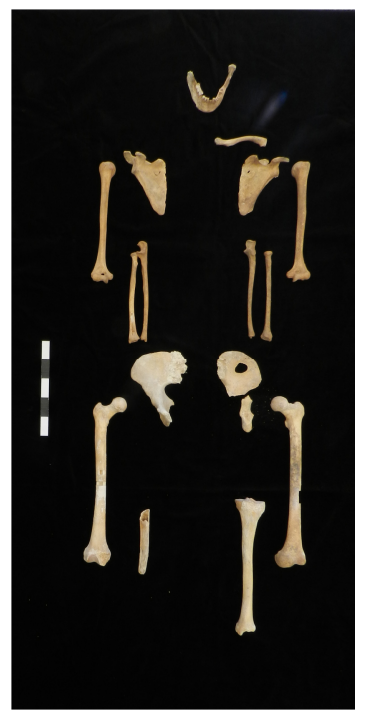

\begin{tabular}{|l|c|c|l|}
\hline FundNr & Marker & Ausprägung & Bearbeiter \\
\hline \hline $\begin{array}{l}\text { DO 1103; } \\
\text { DO 4309 }\end{array}$ & TLR4_299 & A/A & Pepperl \\
\hline $\begin{array}{l}\text { DO 1103; } \\
\text { DO 4309 }\end{array}$ & TLR4_399 & C/C & Pepperl \\
\hline $\begin{array}{l}\text { DO 1103; } \\
\text { DO 4309 }\end{array}$ & IL4-524 & C/- & Pepperl \\
\hline $\begin{array}{l}\text { DO 1103; } \\
\text { DO 4309 }\end{array}$ & IL4-Ra576 & G/A & Pepperl \\
\hline DO 1103 & Lac & C/(T) (tolerant) & $\begin{array}{l}\text { Fulge } \\
\text { Seebode }\end{array}$ \\
\hline DO 1103 & Rhesus D & positiv & Rohlf \\
\hline & DRD4 & & \\
\hline
\end{tabular}


DO BS/RG 1176 (F18)

\begin{tabular}{|c|c|c|c|c|c|c|c|c|c|c|c|c|c|c|c|}
\hline Amelo & D3S1358 & VWA & FGA & D8S1179 & D21S11 & D18S51 & D5S818 & D13S317 & D7S820 & CSF1PO & TH01 & D16S539 & D2S1338 & D19S433 & D9S1120 \\
\hline $\mathrm{X} / \mathrm{-}$ & $15 / 16$ & $14 / 17$ & $19 / 24$ & $14 / 15$ & $28 / 29$ & $14 / 16$ & $10 / 12$ & $10 / 11$ & $11 /-$ & $10 / 12$ & $7 / 9$ & $11 / 12$ & $22 / 24$ & 14/- & $16 /-$ \\
\hline
\end{tabular}

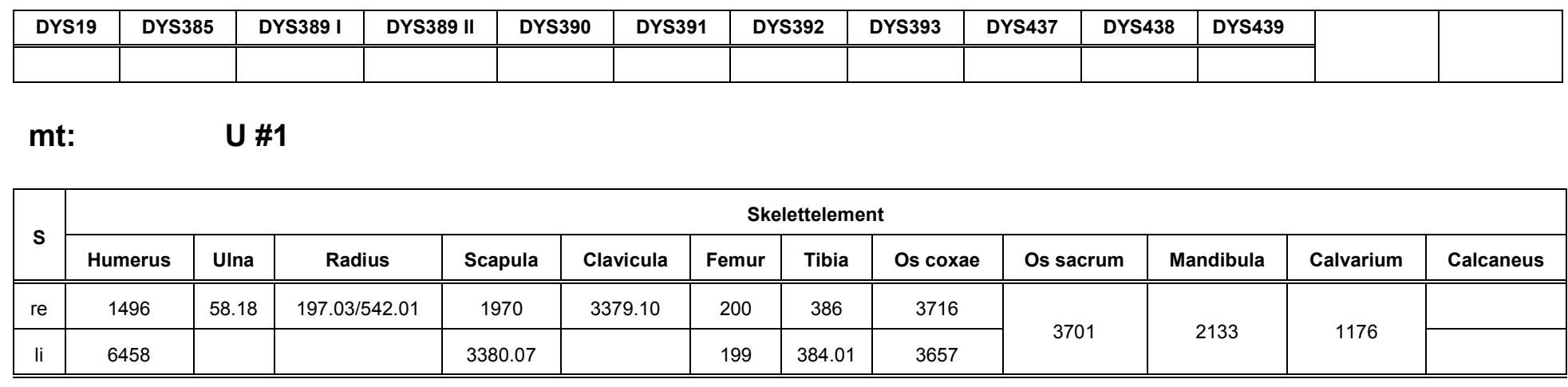

Alter: $\quad$ sad-fmat (Histologie Zahn; F18)

Körperhöhe: $162,9 \pm 3,3 \mathrm{~cm}$

Geschlecht: $\uparrow$

\begin{tabular}{|l|c|c|l|}
\hline FundNr & Marker & Ausprägung & Bearbeiter \\
\hline \hline DO 199 & ABO-Blutgruppe & 0101 & Seidenberg \\
\hline DO 199 & Augenfarbe & blau & Krause \\
\hline $\begin{array}{l}\text { DO 199; } \\
\text { DO 2133 }\end{array}$ & CCR5 & wt/_32 & $\begin{array}{l}\text { Bertermann } \\
\text { Mazanec }\end{array}$ \\
\hline $\begin{array}{l}\text { DO 199; } \\
\text { DO 2133 }\end{array}$ & IRI 3_1 & $118 /-$ & $\begin{array}{l}\text { Bertermann } \\
\text { Mazanec }\end{array}$ \\
\hline $\begin{array}{l}\text { DO 199; } \\
\text { DO 2133 }\end{array}$ & IRI 3_2 & $151 / 159$ & $\begin{array}{l}\text { Bertermann } \\
\text { Mazanec }\end{array}$ \\
\hline DO 1176 & $\Delta$ F508 & wt/wt & Scholten \\
\hline DO 199 & Haarfarbe & dunkel (rötl.) & Schücker \\
\hline $\begin{array}{l}\text { DO 2133; } \\
\text { DO 1176 }\end{array}$ & C82Y & G/A & Krause \\
\hline
\end{tabular}

\begin{tabular}{|l|c|c|l|}
\hline FundNr & Marker & Ausprägung & Bearbeiter \\
\hline \hline $\begin{array}{l}\text { DO 2133; } \\
\text { DO 1176 }\end{array}$ & H63D & C/C & Krause \\
\hline DO 1176 & IL6-174 & (G)/- & Pepperl \\
\hline & IL10-1082 & & \\
\hline & IL10-819 & & \\
\hline & IL10-592 & & \\
\hline DO 1176 & IL10-1087 & (G)/(A) & Pepperl \\
\hline DO 1176 & IL10-2849 & $-/-$ & Pepperl \\
\hline DO 1176 & TLR2_753 & (G)/- & Pepperl \\
\hline
\end{tabular}

\begin{tabular}{|l|c|c|l|}
\hline FundNr & Marker & Ausprägung & Bearbeiter \\
\hline \hline DO 1176 & TLR4_299 & (A)/- & Pepperl \\
\hline DO 1176 & TLR4_399 & (C)/- & Pepperl \\
\hline DO 1176 & IL4-524 & (C)/- & Pepperl \\
\hline DO 1176 & IL4-Ra576 & (A)/- & Pepperl \\
\hline DO 199 & Lac & C/T (tolerant) & Fulge \\
\hline DO 199 & Rhesus D & positiv & Rohlf \\
\hline DO 2133 & DRD4 & 2/4 & Blume \\
\hline
\end{tabular}


DO BS/RG/FK 1247 (F7)

\begin{tabular}{|c|c|c|c|c|c|c|c|c|c|c|c|c|c|c|c|}
\hline Amelo & D3S1358 & VWA & FGA & D8S1179 & D21S11 & D18S51 & D5S818 & D13S317 & D7S820 & CSF1PO & TH01 & D16S539 & D2S1338 & D19S433 & D9S1120 \\
\hline X/- & $15 / 16$ & 17/- & $22 / 25$ & $11 / 13$ & $29 / 32.2$ & $15 / 17$ & $12 /-$ & $8 / 12$ & $8 / 10$ & $11 / 12$ & $8 / 9.3$ & $12 / 13$ & 19/- & 14/- & $16 / 17$ \\
\hline
\end{tabular}

\begin{tabular}{|l|l|l|l|l|l|l|l|l|l|l|l|}
\hline DYS19 & DYS385 & DYS389 I & DYS389 II & DYS390 & DYS391 & DYS392 & DYS393 & DYS437 & DYS438 & DYS439 & \\
\hline \hline & & & & & & & & & & & \\
\hline
\end{tabular}

mt:

U5b

\begin{tabular}{|c|c|c|c|c|c|c|c|c|c|c|c|c|}
\hline \multirow{2}{*}{$\mathbf{s}$} & \multicolumn{12}{|c|}{ Skelettelement } \\
\hline & Humerus & Ulna & Radius & Scapula & Clavicula & Femur & Tibia & Os coxae & Os sacrum & Mandibula & Calvarium & Calcaneus \\
\hline re & 6495 & 4049 & 3998 & 4005.01 & 3997.01 & 1928 & 1745.10 & $933.03 / 41$ & & & & \\
\hline li & & & 3987 & 3814 & 3794 & 1206.01 & 1188 & $926.01 / 933.05$ & & $1<4 !$ & 05.00 & \\
\hline
\end{tabular}

Alter: $\quad$ inf II (Histologie Knochen; DO 1206.01)

Körperhöhe:

Geschlecht:

\begin{tabular}{|l|c|c|l|}
\hline FundNr & Marker & Ausprägung & Bearbeiter \\
\hline \hline DO 1206.01 & $\begin{array}{c}\text { AB0- } \\
\text { Blutgruppe }\end{array}$ & $(0101)$ & Seidenberg \\
\hline DO 6495 & Augenfarbe & blau & Krause \\
\hline $\begin{array}{l}\text { DO 1928; } \\
\text { DO 1247 }\end{array}$ & CCR5 & wt/((D32)) & Mazanec \\
\hline $\begin{array}{l}\text { DO 1928; } \\
\text { DO 1247 }\end{array}$ & IRI 3_1 & $112 /-$ & Mazanec \\
\hline $\begin{array}{l}\text { DO 1928; } \\
\text { DO 1247 }\end{array}$ & IRI 3_2 & $139 / 165$ & Mazanec \\
\hline DO 65.06 & SF508 & wt/wt & Scholten \\
\hline DO 6495 & Haarfarbe & dunkelblond-braun & Schücker \\
\hline DO 65.06 & C82Y & G/G & Krause \\
\hline
\end{tabular}

\begin{tabular}{|l|c|c|l|}
\hline FundNr & Marker & Ausprägung & Bearbeiter \\
\hline \hline DO 65.06 & H63D & C/- & Krause \\
\hline $\begin{array}{l}\text { DO 1247; } \\
\text { DO 1206.01 }\end{array}$ & IL6-174 & (C)/- & Pepperl \\
\hline DO 1247 & IL10-1082 & (A)/(G) & Suray \\
\hline DO 1247 & IL10-819 & C/T & Suray \\
\hline DO 1247 & IL10-592 & C/(A) & Suray \\
\hline $\begin{array}{l}\text { DO 1247; } \\
\text { DO 1206.01 }\end{array}$ & IL10-1087 & G/A & Pepperl \\
\hline $\begin{array}{l}\text { DO 1247; } \\
\text { DO 1206.01 }\end{array}$ & IL10-2849 & (G)/(A) & Pepperl \\
\hline $\begin{array}{l}\text { DO 1247; } \\
\text { DO 1206.01 }\end{array}$ & TLR2_753 & $-/-$ & Pepperl \\
\hline
\end{tabular}

\begin{tabular}{|l|c|c|l|}
\hline FundNr & Marker & Ausprägung & Bearbeiter \\
\hline \hline $\begin{array}{l}\text { DO 1247; } \\
\text { DO 1206.01 }\end{array}$ & TLR4_299 & A/- & Pepperl \\
\hline $\begin{array}{l}\text { DO 1247; } \\
\text { DO 1206.01 }\end{array}$ & TLR4_399 & (C)/- & Pepperl \\
\hline $\begin{array}{l}\text { DO 1247; } \\
\text { DO 1206.01 }\end{array}$ & IL4-524 & (C)/- & Pepperl \\
\hline $\begin{array}{l}\text { DO 1247; } \\
\text { DO 1206.01 }\end{array}$ & IL4-Ra576 & A/- & Pepperl \\
\hline $\begin{array}{l}\text { DO 1206.01 } \\
\text { DO 1928 } \\
\text { DO 1247 }\end{array}$ & Lac & C/T (tolerant) & $\begin{array}{l}\text { Fulge } \\
\text { Seebode }\end{array}$ \\
\hline $\begin{array}{l}\text { DO 1247; } \\
\text { DO 1206.01; } \\
\text { DO 1928 }\end{array}$ & Rhesus D & positiv & Rohlf \\
\hline DO 6495 & DRD4 & 4/- & Blume \\
\hline
\end{tabular}


DO HS/GK 1461

\begin{tabular}{|c|c|c|c|c|c|c|c|c|c|c|c|c|c|c|c|}
\hline Amelo & D3S1358 & VWA & FGA & D8S1179 & D21S11 & D18S51 & D5S818 & D13S317 & D7S820 & CSF1PO & TH01 & D16S539 & D2S1338 & D19S433 & D9S1120 \\
\hline $\mathrm{X} /(\mathrm{Y})$ & $16 /(17)$ & $-1-$ & $-1-$ & (13)/- & $-1-$ & $(12) /(14)$ & $(10) /(11)$ & $11 / 12$ & $9 /(12)$ & & $6 / 9.3$ & 9/11 & (17)/- & $13 /-$ & $-1-$ \\
\hline
\end{tabular}

\begin{tabular}{|c|c|c|c|c|c|c|c|c|c|c|c|}
\hline DYS19 & DYS385 & DYS389 I & DYS389 II & DYS390 & DYS391 & DYS392 & DYS393 & DYS437 & DYS438 & DYS439 & n.d. \\
\hline \hline- & $(15)--$ & - & - & - & $(9)$ & $(14)$ & - & - & $(11)$ & - & \\
\hline
\end{tabular}

$\mathrm{mt}$ :

J1c

\begin{tabular}{|c|c|c|c|c|c|c|c|c|c|c|c|c|}
\hline \multirow{2}{*}{$\mathbf{s}$} & \multicolumn{12}{|c|}{ Skelettelement } \\
\hline & Humerus & Ulna & Radius & Scapula & Clavicula & Femur & Tibia & Os coxae & Os sacrum & Mandibula & Calvarium & Calcaneus \\
\hline re & & & 3288.03 & & & & 1455 & N 965.05 & & & & \\
\hline $\mathrm{li}$ & & & 1461 & & & & 3157 & N 959.03 & & & & \\
\hline
\end{tabular}

Alter: fjuv (Morphologie)

\section{Körperhöhe:}

Geschlecht:

\begin{tabular}{|l|c|c|l|}
\hline FundNr & Marker & Ausprägung & Bearbeiter \\
\hline \hline & AB0-Blutgruppe & & \\
\hline & Augenfarbe & & \\
\hline DO 3157 & CCR5 & wt/wt & Mazanec \\
\hline DO 3157 & IRI 3_1 & $114 /-$ & Mazanec \\
\hline DO 3157 & IRI 3_2 & $139 / 159$ & Mazanec \\
\hline & $\Delta$ F508 & & \\
\hline & Haarfarbe & & \\
\hline & C82Y & & \\
\hline & & &
\end{tabular}

\begin{tabular}{|l|c|c|c|}
\hline FundNr & Marker & Ausprägung & Bearbeiter \\
\hline \hline & H63D & & \\
\hline & IL6-174 & & \\
\hline & IL10-1082 & & \\
\hline & IL10-819 & & \\
\hline & IL10-592 & & \\
\hline & IL10-1087 & & \\
\hline & IL10-2849 & & \\
\hline & TLR2_753 & & \\
\hline
\end{tabular}

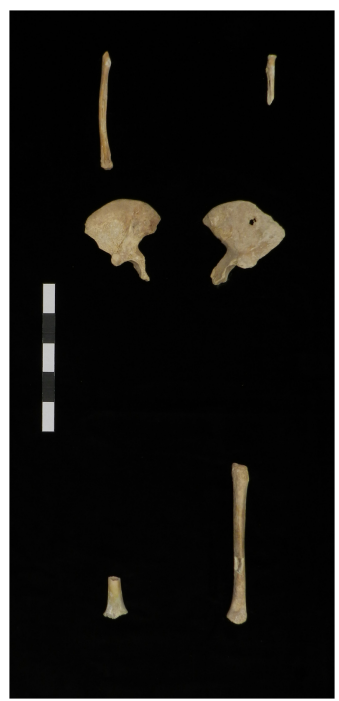

\begin{tabular}{|l|c|c|l|}
\hline FundNr & Marker & Ausprägung & Bearbeiter \\
\hline \hline & TLR4_299 & & \\
\hline & TLR4_399 & & \\
\hline & IL4-524 & & \\
\hline & IL4-Ra576 & & \\
\hline DO 3157 & Lac & $-/-$ & Seebode \\
\hline DO 3157 & Rhesus D & (positiv) & Rohlf \\
\hline & DRD4 & & \\
\hline
\end{tabular}


DO HS/BS 1467.01

\begin{tabular}{|c|c|c|c|c|c|c|c|c|c|c|c|c|c|c|c|}
\hline Amelo & D3S1358 & VWA & FGA & D8S1179 & D21S11 & D18S51 & D5S818 & D13S317 & D7S820 & CSF1PO & TH01 & D16S539 & D2S1338 & D19S433 & D9S1120 \\
\hline$X / Y$ & $(18) /-$ & $-1-$ & $-1-$ & (11)/- & $27 /(29)$ & (13)/- & $-/-$ & $(8) / 11$ & & $-/-$ & $-1-$ & (12)/- & $-1-$ & $(16) /-$ & \\
\hline
\end{tabular}

\begin{tabular}{|c|c|c|c|c|c|c|c|c|c|c|c|}
\hline DYS19 & DYS385 & DYS389 I & DYS389 II & DYS390 & DYS391 & DYS392 & DYS393 & DYS437 & DYS438 & DYS439 & n.d. \\
\hline \hline- & -- & - & - & - & - & - & - & - & - & - & - \\
\hline
\end{tabular}

mt:

n.d.

\begin{tabular}{|c|c|c|c|c|c|c|c|c|c|c|c|c|}
\hline \multirow{2}{*}{$\mathbf{s}$} & \multicolumn{12}{|c|}{ Skelettelement } \\
\hline & Humerus & Ulna & Radius & Scapula & Clavicula & Femur & Tibia & Os coxae & Os sacrum & Mandibula & Calvarium & Calcaneus \\
\hline re & & & & & & & & & & & & \\
\hline li & 1467.01 & 1636 & & & 1543.01 & & 327 & & & & & \\
\hline
\end{tabular}

Alter: $\quad$ inf I (Morphologie)

Körperhöhe:

Geschlecht:

\begin{tabular}{|l|c|l|l|}
\hline FundNr & Marker & Ausprägung & Bearbeiter \\
\hline \hline & AB0-Blutgruppe & & \\
\hline & Augenfarbe & & \\
\hline & CCR5 & & \\
\hline & IRI 3_1 & & \\
\hline & IRI 3_2 & & \\
\hline & SF508 & & \\
\hline & Haarfarbe & & \\
\hline & C82Y & & \\
\hline
\end{tabular}

\begin{tabular}{|l|c|c|c|}
\hline FundNr & Marker & Ausprägung & Bearbeiter \\
\hline \hline & H63D & & \\
\hline & IL6-174 & & \\
\hline & IL10-1082 & & \\
\hline & IL10-819 & & \\
\hline & IL10-592 & & \\
\hline & IL10-1087 & & \\
\hline & IL10-2849 & & \\
\hline & TLR2_753 & & \\
\hline
\end{tabular}

\begin{tabular}{|l|c|c|l|}
\hline FundNr & Marker & Ausprägung & Bearbeiter \\
\hline \hline & TLR4_299 & & \\
\hline & TLR4_399 & & \\
\hline & IL4-524 & & \\
\hline & IL4-Ra576 & & \\
\hline DO 1467.01 & Lac & $-/-$ & Seebode \\
\hline & Rhesus D & & \\
\hline & DRD4 & & \\
\hline
\end{tabular}


DO HS/GK/BS 1471

\begin{tabular}{|c|c|c|c|c|c|c|c|c|c|c|c|c|c|c|c|}
\hline Amelo & D3S1358 & VWA & FGA & D8S1179 & D21S11 & D18S51 & D5S818 & D13S317 & D7S820 & CSF1PO & TH01 & D16S539 & D2S1338 & D19S433 & D9S1120 \\
\hline$X / Y$ & $15 / 16$ & $(16) /(18)$ & $(20) /(24)$ & $8 /(14)$ & $28 / 29$ & $(13) /(20)$ & $12 /-$ & $11 / 13$ & $10 / 12$ & $-/-$ & 9/9.3 & $11 / 12$ & 18/- & $15 / 15.2$ & $16 / 18$ \\
\hline
\end{tabular}

\begin{tabular}{|c|c|c|c|c|c|c|c|c|c|c|c|}
\hline DYS19 & DYS385 & DYS389 I & DYS389 II & DYS390 & DYS391 & DYS392 & DYS393 & DYS437 & DYS438 & DYS439 & \multirow{2}{*}{ Y 10 } \\
\hline \hline$(14)$ & $(13)-14$ & - & $(29)$ & - & $(10)$ & - & 13 & - & 12 & - & R1b (40,8) \\
\hline
\end{tabular}

$\mathrm{mt}$ :

H \#1

\begin{tabular}{|c|c|c|c|c|c|c|c|c|c|c|c|c|}
\hline \multirow{2}{*}{ s } & \multicolumn{12}{|c|}{ Skelettelement } \\
\hline & Humerus & Ulna & Radius & Scapula & Clavicula & Femur & Tibia & Os coxae & Os sacrum & Mandibula & Calvarium & Calcaneus \\
\hline re & $\begin{array}{c}2915 / \\
2942.01\end{array}$ & & & & N 969.08 & $\begin{array}{c}1457 / \\
1548.11\end{array}$ & 3297 & N 968.07 & & & & \\
\hline li & 3380 & & & & & $\begin{array}{c}1471 / \\
\text { N } 969.10\end{array}$ & 1547.02 & & & & & \\
\hline
\end{tabular}

Alter: juv (Morphologie)

Körperhöhe:

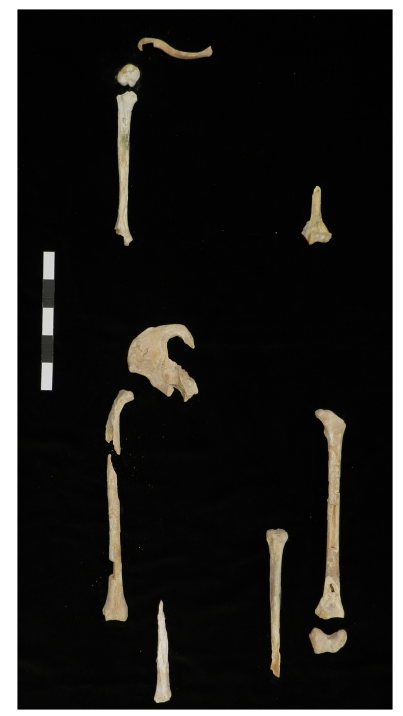

Geschlecht: ภ

\begin{tabular}{|l|c|c|l|}
\hline FundNr & Marker & Ausprägung & Bearbeiter \\
\hline \hline & AB0-Blutgruppe & & \\
\hline & Augenfarbe & & \\
\hline DO 1457 & CCR5 & wt/((432)) & Mazanec \\
\hline DO 1457 & IRI 3_1 & $(122) /-$ & Mazanec \\
\hline DO 1457 & IRI 3_2 & $((159)) /(165)$ & Mazanec \\
\hline & $\Delta$ F508 & & \\
\hline & Haarfarbe & & \\
\hline & C82Y & & \\
\hline
\end{tabular}

\begin{tabular}{|l|c|l|l|}
\hline FundNr & Marker & Ausprägung & Bearbeiter \\
\hline \hline & H63D & & \\
\hline & IL6-174 & & \\
\hline & IL10-1082 & & \\
\hline & IL10-819 & & \\
\hline & IL10-592 & & \\
\hline & IL10-1087 & & \\
\hline & IL10-2849 & & \\
\hline & TLR2_753 & & \\
\hline
\end{tabular}

\begin{tabular}{|l|c|c|l|}
\hline FundNr & Marker & Ausprägung & Bearbeiter \\
\hline \hline & TLR4_299 & & \\
\hline & TLR4_399 & & \\
\hline & IL4-524 & & \\
\hline & IL4-Ra576 & & \\
\hline DO 1471 & Lac & C/T (tolerant) & Fulge \\
\hline DO 1471 & Rhesus D & positiv & Rohlf \\
\hline & DRD4 & & \\
\hline
\end{tabular}


DO RG/BS/DS 1482 (M3)

\begin{tabular}{|c|c|c|c|c|c|c|c|c|c|c|c|c|c|c|c|}
\hline Amelo & D3S1358 & VWA & FGA & D8S1179 & D21S11 & D18S51 & D5S818 & D13S317 & D7S820 & CSF1PO & TH01 & D16S539 & D2S1338 & D19S433 & D9S1120 \\
\hline$X / Y$ & $16 / 18$ & $17 / 19$ & $21 / 22$ & $13 /-$ & $30.2 / 32.2$ & $15 / 17$ & $11 / 12$ & $12 /-$ & $8 / 11$ & $11 / 13$ & $9.3 /-$ & $12 / 13$ & $18 / 19$ & $14 / 15$ & $16 /(17)$ \\
\hline
\end{tabular}

\begin{tabular}{|c|c|c|c|c|c|c|c|c|c|c|c|c|}
\hline DYS19 & DYS385 & DYS389 I & DYS389 II & DYS390 & DYS391 & DYS392 & DYS393 & DYS437 & DYS438 & DYS439 & \multirow{2}{*}{ Y 2} & \multirow{2}{*}{$\mathbf{I} \mathbf{2 b}(99,9)$} \\
\hline 15 & 13-17 & 12 & 27 & 25 & 11 & 11 & 13 & 15 & 10 & 11 & & \\
\hline
\end{tabular}

$\mathrm{mt}$

H2a1

\begin{tabular}{|c|c|c|c|c|c|c|c|c|c|c|c|c|}
\hline \multirow{2}{*}{$\mathbf{s}$} & \multicolumn{12}{|c|}{ Skelettelement } \\
\hline & Humerus & Ulna & Radius & Scapula & Clavicula & Femur & Tibia & Os coxae & Os sacrum & Mandibula & Calvarium & Calcaneus \\
\hline re & 2601 & 1246 & 1171 & 4016.01 & 2786 & 1186 & 1069 & 1572 & \multirow{2}{*}{1082.02} & \multirow{2}{*}{1482} & \multirow{2}{*}{6525} & \\
\hline li & 1183 & 1826.01 & 1944 & 3801 & 1223.01 & 1911 & 321 & 1475 & & & & \\
\hline
\end{tabular}

Alter: $\quad$ mmat (Histologie Knochen; DO 1911)

Körperhöhe: $173,4 \pm 3,0 \mathrm{~cm}$

Geschlecht: $ぇ$

\begin{tabular}{|l|c|c|l|}
\hline FundNr & Marker & Ausprägung & Bearbeiter \\
\hline \hline DO 1911 & ABO-Blutgruppe & 0101 & Seidenberg \\
\hline DO 1911 & Augenfarbe & Intermediate-braun & Krause \\
\hline DO 1911 & CCR5 & wt/(D32) & $\begin{array}{l}\text { Bertermann } \\
\text { Mazanec }\end{array}$ \\
\hline DO 1911 & IRI 3_1 & $112 /-$ & $\begin{array}{l}\text { Bertermann } \\
\text { Mazanec }\end{array}$ \\
\hline DO 1911 & IRI 3_2 & $139 /((159))$ & $\begin{array}{l}\text { Bertermann } \\
\text { Mazanec }\end{array}$ \\
\hline DO 1482 & $\Delta$ F508 & wt/wt & Scholten \\
\hline DO 1911 & Haarfarbe & dunkelblond & Schücker \\
\hline $\begin{array}{l}\text { DO 1911; } \\
\text { DO 1482 }\end{array}$ & C82Y & G/G & Krause \\
\hline
\end{tabular}

\begin{tabular}{|l|c|c|l|}
\hline FundNr & Marker & Ausprägung & Bearbeiter \\
\hline \hline $\begin{array}{l}\text { DO 1911; } \\
\text { DO 1482 }\end{array}$ & H63D & C/C & Krause \\
\hline DO 1911 & IL6-174 & C/C & Pepperl \\
\hline DO 1911 & IL10-1082 & A/- & Suray \\
\hline DO 1911 & IL10-819 & (C)/T & Suray \\
\hline DO 1911 & IL10-592 & (C)/(A) & Suray \\
\hline DO 1911 & IL10-1087 & (A)/- & Pepperl \\
\hline DO 1482 & IL10-2849 & G/A & Pepperl \\
\hline DO 1911 & TLR2_753 & G/G & Pepperl \\
\hline
\end{tabular}

\begin{tabular}{|l|c|c|l|}
\hline FundNr & Marker & Ausprägung & Bearbeiter \\
\hline \hline DO 1911 & TLR4_299 & A/- & Pepperl \\
\hline DO 1911 & TLR4_399 & C/C & Pepperl \\
\hline DO 1911 & IL4-524 & (C)/- & Pepperl \\
\hline DO 1911 & IL4-Ra576 & A/- & Pepperl \\
\hline DO 1911 & Lac & C/T (tolerant) & Fulge \\
\hline DO 1911 & Rhesus D & positiv & Rohlf \\
\hline DO 1911 & DRD4 & 4/- & Blume \\
\hline
\end{tabular}


DO RG/BS 1500 (F2)

\begin{tabular}{|c|c|c|c|c|c|c|c|c|c|c|c|c|c|c|c|}
\hline Amelo & D3S1358 & VWA & FGA & D8S1179 & D21S11 & D18S51 & D5S818 & D13S317 & D7S820 & CSF1PO & TH01 & D16S539 & D2S1338 & D19S433 & D9S1120 \\
\hline X/- & $16 / 18$ & $17 / 18$ & $20 / 21$ & $13 / 14$ & $28 / 30$ & $12 / 15$ & $11 / 12$ & $11 / 12$ & $10 / 13$ & $11 / 13$ & $6 / 9.3$ & $11 /-$ & $19 / 25$ & $13 / 14.2$ & $16 / 17$ \\
\hline
\end{tabular}

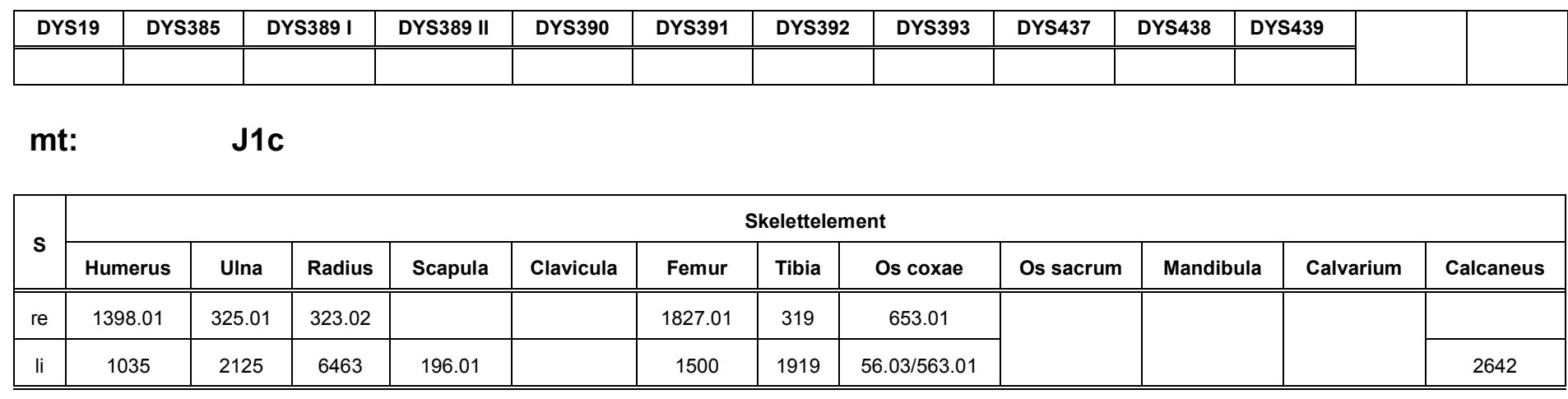

Alter: $\quad$ sad (Histologie Knochen; DO 1500)

Körperhöhe: $160,9 \pm 3,1 \mathrm{~cm}$

Geschlecht: $\uparrow$

\begin{tabular}{|l|c|c|l|}
\hline FundNr & Marker & Ausprägung & Bearbeiter \\
\hline \hline DO 1827.01 & AB0-Blutgruppe & $(B 01)$ & Seidenberg \\
\hline DO 1827.01 & Augenfarbe & blau & Krause \\
\hline DO 1500 & CCR5 & wt/wt & Bertermann \\
\hline DO 1500 & IRI 3_1 & $106 / 112$ & Bertermann \\
\hline DO 1500 & IRI 3_2 & $139 / 153$ & Bertermann \\
\hline DO 1500 & AF508 & wt/wt & Scholten \\
\hline DO 1827.01 & Haarfarbe & dunkelbraun-schwarz & Schücker \\
\hline $\begin{array}{l}\text { DO 1500; } \\
\text { DO 319 }\end{array}$ & C82Y & G/G & Krause \\
\hline
\end{tabular}

\begin{tabular}{|l|c|c|l|}
\hline FundNr & Marker & Ausprägung & Bearbeiter \\
\hline \hline $\begin{array}{l}\text { DO 1500; } \\
\text { DO 319 }\end{array}$ & H63D & C/- & Krause \\
\hline DO 2642 & IL6-174 & G/(C) & Pepperl \\
\hline DO 1500 & IL10-1082 & (A)/- & Suray \\
\hline DO 1500 & IL10-819 & $-/-$ & Suray \\
\hline DO 1500 & IL10-592 & $-/-$ & Suray \\
\hline DO 1500 & IL10-1087 & $-/-$ & Pepperl \\
\hline DO 1500 & IL10-2849 & (G)/(A) & Pepperl \\
\hline DO 1500 & TLR2_753 & (G)/- & Pepperl \\
\hline
\end{tabular}

\begin{tabular}{|l|c|c|l|}
\hline FundNr & Marker & Ausprägung & Bearbeiter \\
\hline \hline DO 1500 & TLR4_299 & (A)/- & Pepperl \\
\hline DO 1500 & TLR4_399 & (C)/- & Pepperl \\
\hline DO 1500 & IL4-524 & $-/-$ & Pepperl \\
\hline DO 1500 & IL4-Ra576 & (G)/A & Pepperl \\
\hline $\begin{array}{l}\text { DO 1500 } \\
\text { DO 1827.01 }\end{array}$ & Lac & C/T (tolerant) & Fulge \\
\hline DO 1827.01 & Rhesus D & positiv & Rohlf \\
\hline & DRD4 & & \\
\hline
\end{tabular}


DO HS/GK 1547.01

\begin{tabular}{|c|c|c|c|c|c|c|c|c|c|c|c|c|c|c|c|}
\hline Amelo & D3S1358 & VWA & FGA & D8S1179 & D21S11 & D18S51 & D5S818 & D13S317 & D7S820 & CSF1PO & TH01 & D16S539 & D2S1338 & D19S433 & D9S1120 \\
\hline X/- & $-1-$ & $-/-$ & $20 /-$ & $-1-$ & $(29) /(31)$ & (13)/- & $(10) / 12$ & $(11) / 12$ & $-1-$ & & 9.3/- & $-1-$ & $-/-$ & $-/-$ & $-/-$ \\
\hline
\end{tabular}

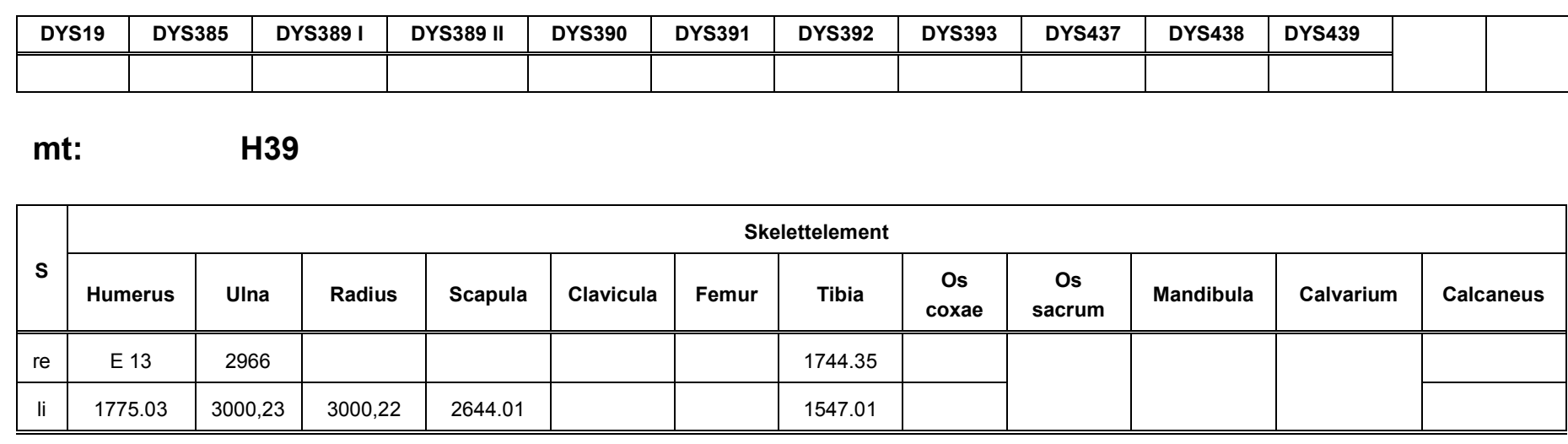

Alter: $\quad$ inf I (Morphologie)

Körperhöhe:

\section{Geschlecht: ?}

\begin{tabular}{|l|c|c|l|}
\hline FundNr & Marker & Ausprägung & Bearbeiter \\
\hline \hline & AB0-Blutgruppe & & \\
\hline & Augenfarbe & & \\
\hline DO 1547.01 & CCR5 & $-/-$ & Mazanec \\
\hline DO 1547.01 & IRI 3_1 & $-/-$ & Mazanec \\
\hline DO 1547.01 & IRI 3_2 & $-/$ & Mazanec \\
\hline & DF508 & & \\
\hline & Haarfarbe & & \\
\hline & C82Y & & \\
\hline
\end{tabular}

\begin{tabular}{|l|c|l|l|}
\hline FundNr & Marker & Ausprägung & Bearbeiter \\
\hline \hline & H63D & & \\
\hline & IL6-174 & & \\
\hline & IL10-1082 & & \\
\hline & IL10-819 & & \\
\hline & IL10-592 & & \\
\hline & IL10-1087 & & \\
\hline & IL10-2849 & & \\
\hline & TLR2_753 & & \\
\hline
\end{tabular}

\begin{tabular}{|l|c|c|l|}
\hline FundNr & Marker & Ausprägung & Bearbeiter \\
\hline \hline & TLR4_299 & & \\
\hline & TLR4_399 & & \\
\hline & IL4-524 & & \\
\hline & IL4-Ra576 & & \\
\hline $\begin{array}{l}\text { DO 3000,22; } \\
\text { DO 1775.03; } \\
\text { DO 1547.01 }\end{array}$ & Lac & $-/-$ & Seebode \\
\hline & Rhesus D & & \\
\hline & DRD4 & & \\
\hline
\end{tabular}


DO HS/GK 1547.03

\begin{tabular}{|c|c|c|c|c|c|c|c|c|c|c|c|c|c|c|c|}
\hline Amelo & D3S1358 & VWA & FGA & D8S1179 & D21S11 & D18S51 & D5S818 & D13S317 & D7S820 & CSF1PO & TH01 & D16S539 & D2S1338 & D19S433 & D9S1120 \\
\hline $\mathrm{X} / \mathrm{-}$ & $(15) / 16$ & $(15) /(16)$ & $(19) /(20)$ & $(14) /-$ & (29)/- & $20 /-$ & (10)/- & $11 / 13$ & $10 / 12$ & & 9/9.3 & $11 / 12$ & $(25) /-$ & $15 /-$ & $17 / 18$ \\
\hline
\end{tabular}

\begin{tabular}{|c|c|c|c|c|c|c|c|c|c|c|c|c|c|c|}
\hline \multicolumn{2}{|c|}{ DYS19 } & DYS385 & \multicolumn{2}{|c|}{ DYS389 I } & DYS389 II & DYS390 & DYS391 & DYS392 & DYS393 & DYS437 & DYS438 & \multicolumn{2}{|c|}{ DYS439 } & \\
\hline \multicolumn{3}{|c|}{ mt: } & \multicolumn{12}{|c|}{ H \#1 } \\
\hline \multirow{2}{*}{$\mathbf{S}$} & \multicolumn{14}{|c|}{ Skelettelement } \\
\hline & Hur & erus & Ulna & Radius & Scapula & Clavicula & Femur & Tibia & Os coxae & Os sacrum & Mandil & & Calvarium & Calcaneus \\
\hline re & & 7.03 & & & & & E 04 & 3299 & & & & & & \\
\hline li & & & & E 24 & & 1744.10 & & 3300 & N 968.06 & & & & & \\
\hline
\end{tabular}

Alter: $\quad$ sjuv (Morphologie)

\section{Körperhöhe:}

Geschlecht:

\begin{tabular}{|l|c|c|l|}
\hline FundNr & Marker & Ausprägung & Bearbeiter \\
\hline \hline & AB0-Blutgruppe & & \\
\hline & Augenfarbe & & \\
\hline DO 3299 & CCR5 & wt/wt & Mazanec \\
\hline DO 3299 & IRI 3_1 & $106 / 114$ & Mazanec \\
\hline DO 3299 & IRI 3_2 & $-/-$ & Mazanec \\
\hline & $\Delta$ F508 & & \\
\hline & Haarfarbe & & \\
\hline & C82Y & & \\
\hline
\end{tabular}

\begin{tabular}{|l|c|c|c|}
\hline FundNr & Marker & Ausprägung & Bearbeiter \\
\hline \hline & H63D & & \\
\hline & IL6-174 & & \\
\hline & IL10-1082 & & \\
\hline & IL10-819 & & \\
\hline & IL10-592 & & \\
\hline & IL10-1087 & & \\
\hline & IL10-2849 & & \\
\hline & TLR2_753 & & \\
\hline
\end{tabular}

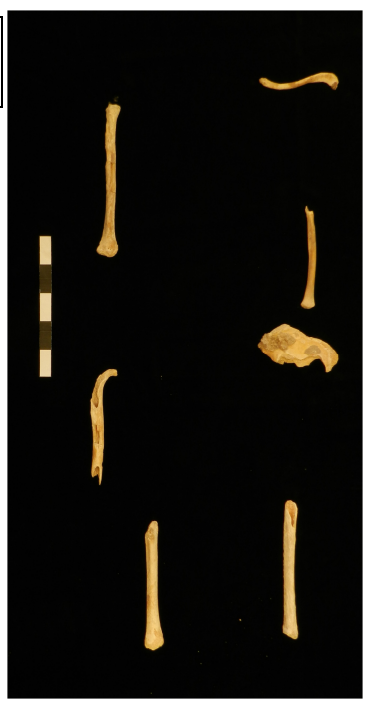

\begin{tabular}{|l|c|c|l|}
\hline FundNr & Marker & Ausprägung & Bearbeiter \\
\hline \hline & TLR4_299 & & \\
\hline & TLR4_399 & & \\
\hline & IL4-524 & & \\
\hline & IL4-Ra576 & & \\
\hline DO 3299 & Lac & $-/-$ & Seebode \\
\hline DO 3299 & Rhesus D & positiv & Rohlf \\
\hline & DRD4 & & \\
\hline
\end{tabular}


DO HS/GK 1548.01

\begin{tabular}{|c|c|c|c|c|c|c|c|c|c|c|c|c|c|c|c|}
\hline Amelo & D3S1358 & VWA & FGA & D8S1179 & D21S11 & D18S51 & D5S818 & D13S317 & D7S820 & CSF1PO & TH01 & D16S539 & D2S1338 & D19S433 & D9S1120 \\
\hline $\bar{X} \mathrm{X} / \mathrm{Y}$ & $215 / 16$ & 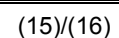 & $20 / 21$ & -1- & $27 / 28$ & $\begin{array}{l}13 / 14 \\
\end{array}$ & $9 / 10$ & $11 / 13$ & 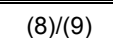 & & (9.3/- & 12/- & -/- & (13)/- & -/- \\
\hline
\end{tabular}

\begin{tabular}{|c|c|c|c|c|c|c|c|c|c|c|c|}
\hline DYS19 & DYS385 & DYS389 I & DYS389 II & DYS390 & DYS391 & DYS392 & DYS393 & DYS437 & DYS438 & DYS439 & \multirow{2}{*}{ Y 9 } \\
\hline \hline- & $(17)--$ & 12 & - & - & 9 & - & $13-15$ & - & - & $(11)$ & \\
\hline
\end{tabular}

mt:

H39

\begin{tabular}{|c|c|c|c|c|c|c|c|c|c|c|c|c|}
\hline \multirow{2}{*}{$\mathbf{s}$} & \multicolumn{12}{|c|}{ Skelettelement } \\
\hline & Humerus & UIna & Radius & Scapula & Clavicula & Femur & Tibia & Os coxae & Os sacrum & Mandibula & Calvarium & Calcaneus \\
\hline re & 1775.04 & N 969.06 & 2593.01 & N 964.03 & 1744.09 & E 01 & 1548.01 & & & & & \\
\hline li & 1462 & 1774.01 & 1463 & & & E 02 & 1548.02 & & & & & \\
\hline
\end{tabular}

Alter: $\quad$ fjuv (Morphologie)

\section{Körperhöhe:}

Geschlecht:

\begin{tabular}{|l|c|c|l|}
\hline FundNr & Marker & Ausprägung & Bearbeiter \\
\hline \hline & AB0-Blutgruppe & & \\
\hline & Augenfarbe & & \\
\hline DO 1548.01 & CCR5 & wt/wt & Mazanec \\
\hline DO 1548.01 & IRI 3_1 & $112 / 122$ & Mazanec \\
\hline DO 1548.01 & IRI 3_2 & $-/-$ & Mazanec \\
\hline & $\Delta$ F508 & & \\
\hline & Haarfarbe & & \\
\hline & C82Y & & \\
\hline
\end{tabular}

\begin{tabular}{|l|c|c|c|}
\hline FundNr & Marker & Ausprägung & Bearbeiter \\
\hline \hline & H63D & & \\
\hline & IL6-174 & & \\
\hline & IL10-1082 & & \\
\hline & IL10-819 & & \\
\hline & IL10-592 & & \\
\hline & IL10-1087 & & \\
\hline & IL10-2849 & & \\
\hline & TLR2_753 & & \\
\hline
\end{tabular}

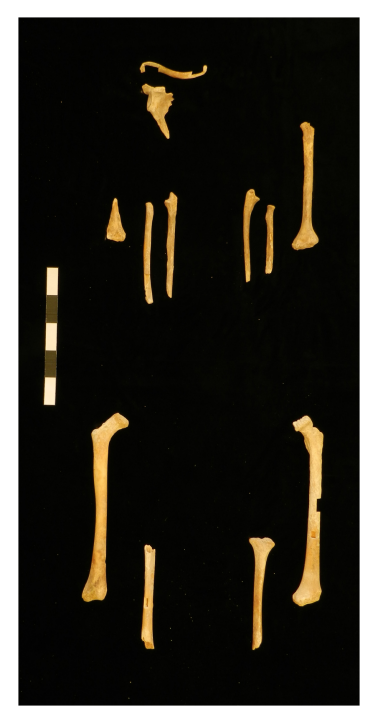

\begin{tabular}{|l|c|c|l|}
\hline FundNr & Marker & Ausprägung & Bearbeiter \\
\hline \hline & TLR4_299 & & \\
\hline & TLR4_399 & & \\
\hline & IL4-524 & & \\
\hline & IL4-Ra576 & & \\
\hline DO 1548.01 & Lac & C/C (intolerant) & Seebode \\
\hline DO 1548.01 & Rhesus D & positiv & Rohlf \\
\hline & DRD4 & & \\
\hline
\end{tabular}


DO HS/GK 1585.03 (F19)

\begin{tabular}{|c|c|c|c|c|c|c|c|c|c|c|c|c|c|c|c|}
\hline Amelo & D3S1358 & VWA & FGA & D8S1179 & D21S11 & D18S51 & D5S818 & D13S317 & D7S820 & CSF1PO & TH01 & D16S539 & D2S1338 & D19S433 & D9S1120 \\
\hline$X /-$ & $15 / 17$ & $14 / 18$ & $20 / 24$ & $12 / 14$ & $30.2 / 31$ & $14 / 15$ & $10 / 12$ & $10 / 11$ & $10 / 11$ & $11 / 13$ & (6)/9 & $12 / 13$ & $(23) /(25)$ & $14 / 15$ & $14 / 16$ \\
\hline
\end{tabular}

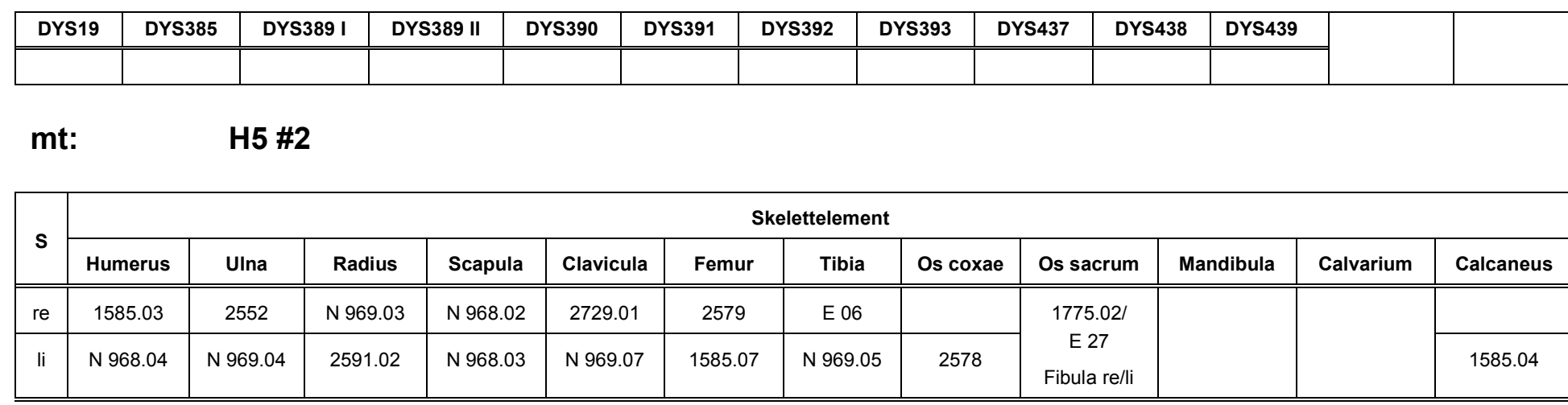

Alter: $\quad$ sen (Histologie Knochen; DO 1585.07)

Körperhöhe: $150,5 \pm 3,1 \mathrm{~cm}$

Geschlecht:

\begin{tabular}{|l|c|c|l|}
\hline FundNr & Marker & Ausprägung & Bearbeiter \\
\hline \hline DO 1585.03 & AB0-Blutgruppe & 01v02 & Seidenberg \\
\hline DO 1585.03 & Augenfarbe & blau & Krause \\
\hline $\begin{array}{l}\text { DO N 968.04; } \\
\text { DO 1585.07 }\end{array}$ & CCR5 & wt/wt & Mazanec \\
\hline $\begin{array}{l}\text { DO N 968.04; } \\
\text { DO 1585.07 }\end{array}$ & IRI 3_1 & $116 /-$ & Mazanec \\
\hline $\begin{array}{l}\text { DO N 968.04; } \\
\text { DO 1585.07 }\end{array}$ & IRI 3_2 & $161 /-$ & Mazanec \\
\hline DO 1585.04 & LF508 & wt/wt & Scholten \\
\hline DO 1585.03 & Haarfarbe & dunkelblond & Schücker \\
\hline DO 1585.04 & C82Y & G/G & Krause \\
\hline
\end{tabular}

\begin{tabular}{|l|c|c|l|}
\hline FundNr & Marker & Ausprägung & Bearbeiter \\
\hline \hline DO 1585.04 & H63D & C/C & Krause \\
\hline DO 1585.04 & IL6-174 & G/C & Pepperl \\
\hline & IL10-1082 & & \\
\hline & IL10-819 & & \\
\hline & IL10-592 & & \\
\hline DO 1585.04 & IL10-1087 & $-/-$ & Pepperl \\
\hline DO 1585.04 & IL10-2849 & (G)/A & Pepperl \\
\hline DO 1585.04 & TLR2_753 & G/- & Pepperl \\
\hline
\end{tabular}

\begin{tabular}{|l|c|c|l|}
\hline FundNr & Marker & Ausprägung & Bearbeiter \\
\hline \hline DO 1585.04 & TLR4_299 & $-/-$ & Pepperl \\
\hline DO 1585.04 & TLR4_399 & C/- & Pepperl \\
\hline DO 1585.04 & IL4-524 & $-/-$ & Pepperl \\
\hline DO 1585.04 & IL4-Ra576 & A/- & Pepperl \\
\hline $\begin{array}{l}\text { DO N 968.04; } \\
\text { DO 1585.07 }\end{array}$ & Lac & $\begin{array}{c}\text { C/C } \\
\text { (intolerant) }\end{array}$ & $\begin{array}{l}\text { Fulge } \\
\text { Seebode }\end{array}$ \\
\hline $\begin{array}{l}\text { DO N 968.04; } \\
\text { DO 1585.07 }\end{array}$ & Rhesus D & positiv & Rohlf \\
\hline & DRD4 & & \\
\hline
\end{tabular}


DO BS/FK/GK/HS 1745.02

\begin{tabular}{|c|c|c|c|c|c|c|c|c|c|c|c|c|c|c|c|}
\hline Amelo & D3S1358 & VWA & FGA & D8S1179 & D21S11 & D18S51 & D5S818 & D13S317 & D7S820 & CSF1PO & TH01 & D16S539 & D2S1338 & D19S433 & D9S1120 \\
\hline $\mathrm{X} / \mathrm{-}$ & $16 /-$ & $16 / 18$ & $21 /-$ & $14 / 15$ & $28 / 29$ & $12 / 14$ & $9 / 11$ & $11 / 12$ & $7 / 10$ & $-/-$ & $9.3 /-$ & $11 /-$ & $(17) /(25)$ & $13 / 14.2$ & $16 / 17$ \\
\hline
\end{tabular}

\begin{tabular}{|l|l|l|l|l|l|l|l|l|l|l|l|}
\hline DYS19 & DYS385 & DYS389 I & DYS389 II & DYS390 & DYS391 & DYS392 & DYS393 & DYS437 & DYS438 & DYS439 & \\
\hline \hline & & & & & & & & & & & \\
\hline
\end{tabular}

mt:

J1c

\begin{tabular}{|c|c|c|c|c|c|c|c|c|c|c|c|c|}
\hline \multirow{2}{*}{$\mathbf{s}$} & \multicolumn{12}{|c|}{ Skelettelement } \\
\hline & Humerus & Ulna & Radius & Scapula & Clavicula & Femur & Tibia & Os coxae & Os sacrum & Mandibula & Calvarium & Calcaneus \\
\hline re & & & & 1548.06 & 2629 & & 913.17 & $2707 / 4238$ & & & & \\
\hline li & & 2641.02 & 2964.01 & & 2373 & 3622 & & $1745.02 / 2067$ & & & & \\
\hline
\end{tabular}

Alter: $\quad$ inf II (Histologie Knochen; DO 3622)

Körperhöhe:

Geschlecht:

\begin{tabular}{|l|c|c|l|}
\hline FundNr & Marker & Ausprägung & Bearbeiter \\
\hline \hline & AB0-Blutgruppe & & \\
\hline & Augenfarbe & & \\
\hline DO 1745.02 & CCR5 & wt/wt & Mazanec \\
\hline DO 1745.02 & IRI 3_1 & $106 / 112$ & Mazanec \\
\hline DO 1745.02 & IRI 3_2 & $((149)) / 169$ & Mazanec \\
\hline & LF508 & & \\
\hline & Haarfarbe & & \\
\hline & C82Y & & \\
\hline
\end{tabular}

\begin{tabular}{|l|c|c|c|}
\hline FundNr & Marker & Ausprägung & Bearbeiter \\
\hline \hline & H63D & & \\
\hline & IL6-174 & & \\
\hline & IL10-1082 & & \\
\hline & IL10-819 & & \\
\hline & IL10-592 & & \\
\hline & IL10-1087 & & \\
\hline & IL10-2849 & & \\
\hline & TLR2_753 & & \\
\hline
\end{tabular}

\begin{tabular}{|l|c|c|l|}
\hline FundNr & Marker & Ausprägung & Bearbeiter \\
\hline \hline & TLR4_299 & & \\
\hline & TLR4_399 & & \\
\hline & IL4-524 & & \\
\hline & IL4-Ra576 & & \\
\hline DO 1745.02 & Lac & C/C (intolerant) & Seebode \\
\hline DO 3622 & Rhesus D & nd & Rohlf \\
\hline & DRD4 & & \\
\hline
\end{tabular}


DO RG/BS 1905 (M9)

\begin{tabular}{|c|c|c|c|c|c|c|c|c|c|c|c|c|c|c|c|}
\hline Amelo & D3S1358 & VWA & FGA & D8S1179 & D21S11 & D18S51 & D5S818 & D13S317 & D7S820 & CSF1PO & TH01 & D16S539 & D2S1338 & D19S433 & D9S1120 \\
\hline$X / Y$ & $16 / 19$ & $14 / 16$ & $21 / 23$ & 13/- & $27 / 32.2$ & $12 / 14$ & $12 /-$ & $11 / 14$ & $10 / 13$ & $10 / 11$ & $6 / 7$ & 13/- & $16 /(25)$ & $13 / 16.2$ & $14 / 17$ \\
\hline
\end{tabular}

\begin{tabular}{|c|c|c|c|c|c|c|c|c|c|c|c|c|}
\hline DYS19 & DYS385 & DYS389 I & DYS389 II & DYS390 & DYS391 & DYS392 & DYS393 & DYS437 & DYS438 & DYS439 & \multirow{2}{*}{ Y 3} & \multirow{2}{*}{ R1b (100) } \\
\hline 14 & 11-14 & 13 & 29 & 23 & $\begin{array}{ll}11 \\
\end{array}$ & 13 & 13 & 15 & 12 & 12 & & \\
\hline
\end{tabular}

mt:

H7a1

\begin{tabular}{|c|c|c|c|c|c|c|c|c|c|c|c|c|}
\hline \multirow{2}{*}{$\mathbf{s}$} & \multicolumn{12}{|c|}{ Skelettelement } \\
\hline & Humerus & Ulna & Radius & Scapula & Clavicula & Femur & Tibia & Os coxae & Os sacrum & Mandibula & Calvarium & Calcaneus \\
\hline re & 1917 & & & 483.01 & 1751.02 & 1905 & 1084 & & \multirow{2}{*}{3726} & \multirow{2}{*}{2749} & \multirow{2}{*}{1473} & \\
\hline li & 1948 & & 1958 & 1751.01 & 1223.02 & 1916 & 1484 & 65.04 & & & & \\
\hline
\end{tabular}

Alter: $\quad$ sad-fmat (Histologie Knochen; DO 1916)

Körperhöhe: $168,8 \pm 3,0 \mathrm{~cm}$

Geschlecht:

\begin{tabular}{|l|c|c|l|}
\hline FundNr & Marker & Ausprägung & Bearbeiter \\
\hline \hline DO 1917 & AB0-Blutgruppe & (A01v) & Seidenberg \\
\hline DO 1917 & Augenfarbe & braun & Krause \\
\hline $\begin{array}{l}\text { DO 1917; } \\
\text { DO 1948; } \\
\text { DO 1916 }\end{array}$ & CCR5 & wt/wt & $\begin{array}{l}\text { Bertermann } \\
\text { Mazanec }\end{array}$ \\
\hline $\begin{array}{l}\text { DO 1917; } \\
\text { DO 1948; } \\
\text { DO 1916 }\end{array}$ & IRI 3_1 & 114/- & $\begin{array}{l}\text { Bertermann } \\
\text { Mazanec }\end{array}$ \\
\hline $\begin{array}{l}\text { DO 1917; } \\
\text { DO 1948; } \\
\text { DO 1916 }\end{array}$ & IRI 3_2 & $139 / 173$ & $\begin{array}{l}\text { Bertermann } \\
\text { Mazanec }\end{array}$ \\
\hline $\begin{array}{l}\text { DO 2749; } \\
\text { DO 1473 }\end{array}$ & AF508 & wt/wt & Scholten \\
\hline DO 1917 & Haarfarbe & dunkelblond & Schücker \\
\hline $\begin{array}{l}\text { DO 2749; } \\
\text { DO 1473 }\end{array}$ & C82Y & G/G & Krause \\
\hline
\end{tabular}

\begin{tabular}{|l|c|c|l|}
\hline FundNr & Marker & Ausprägung & Bearbeiter \\
\hline \hline $\begin{array}{l}\text { DO 2749; } \\
\text { DO 1473 }\end{array}$ & H63D & C/(G) & Krause \\
\hline DO 1916 & IL6-174 & G/G & Pepperl \\
\hline & IL10-1082 & & \\
\hline & IL10-819 & & \\
\hline & IL10-592 & & \\
\hline DO 1916 & IL10-1087 & (G)/- & Pepperl \\
\hline DO 1916 & IL10-2849 & G/A & Pepperl \\
\hline DO 1916 & TLR2_753 & G/G & Pepperl \\
\hline
\end{tabular}

\begin{tabular}{|l|c|c|l|}
\hline FundNr & Marker & Ausprägung & Bearbeiter \\
\hline \hline DO 1916 & TLR4_299 & A/- & Pepperl \\
\hline DO 1916 & TLR4_399 & C/C & Pepperl \\
\hline DO 1916 & IL4-524 & (C)/- & Pepperl \\
\hline DO 1916 & IL4-Ra576 & A/- & Pepperl \\
\hline $\begin{array}{l}\text { DO 1917; } \\
\text { DO 1916 }\end{array}$ & Lac & C/C (intolerant) & $\begin{array}{l}\text { Fulge } \\
\text { Seebode }\end{array}$ \\
\hline $\begin{array}{l}\text { DO 1916; } \\
\text { DO 1917 }\end{array}$ & Rhesus D & positiv & Rohlf \\
\hline & DRD4 & & \\
\hline
\end{tabular}


DO BS/FK 2030.01 (M6)

\begin{tabular}{|c|c|c|c|c|c|c|c|c|c|c|c|c|c|c|c|}
\hline Amelo & D3S1358 & VWA & FGA & D8S1179 & D21S11 & D18S51 & D5S818 & D13S317 & D7S820 & CSF1PO & TH01 & D16S539 & D2S1338 & D19S433 & D9S1120 \\
\hline$X / Y$ & $16 /-$ & $17 / 18$ & $21 / 24$ & $10 / 12$ & $29 / 30.2$ & $16 / 18$ & $10 / 13$ & $12 / 13$ & 9/- & $-1-$ & $7 / 9$ & $12 / 14$ & $17 / 19$ & $13 / 16.2$ & $15 /-$ \\
\hline
\end{tabular}

\begin{tabular}{|c|c|c|c|c|c|c|c|c|c|c|c|c|}
\hline DYS19 & DYS385 & DYS389 I & DYS389 II & DYS390 & DYS391 & DYS392 & DYS393 & DYS437 & DYS438 & DYS439 & \multirow{2}{*}{ Y 2} & \multirow{2}{*}{ I2b $(99,9)$} \\
\hline 15 & 13-17 & 12 & 27 & 25 & 11 & 11 & 13 & 15 & 10 & 11 & & \\
\hline
\end{tabular}

mt:

H \#1

\begin{tabular}{|c|c|c|c|c|c|c|c|c|c|c|c|c|}
\hline \multirow{2}{*}{$\mathbf{s}$} & \multicolumn{12}{|c|}{ Skelettelement } \\
\hline & Humerus & Ulna & Radius & Scapula & Clavicula & Femur & Tibia & Os coxae & Os sacrum & Mandibula & Calvarium & Calcaneus \\
\hline re & 2009 & 2460 & 2106 & 2101 & 5216 & 2061 & 447 & $\begin{array}{c}2102 / \mathrm{E} 10 / \\
1746.03\end{array}$ & & & & \\
\hline li & 3630 & 2380 & 2105 & 2068 & & 2030.01 & $\begin{array}{c}3379.13 / \\
3379.05\end{array}$ & $2522 / 929.28$ & & & & \\
\hline
\end{tabular}

Alter: $\quad$ inf II (Histologie Knochen; DO 2030.01)

Körperhöhe:

Geschlecht: $\Uparrow$

\begin{tabular}{|l|c|c|l|}
\hline FundNr & Marker & Ausprägung & Bearbeiter \\
\hline \hline DO 2030.01 & AB0-Blutgruppe & A01 & Seidenberg \\
\hline DO 2030.01 & Augenfarbe & Intermediate-braun & Krause \\
\hline DO 2030.01 & CCR5 & wt/wt & $\begin{array}{l}\text { Bertermann } \\
\text { Mazanec }\end{array}$ \\
\hline DO 2030.01 & IRI 3_1 & $112 / 122$ & $\begin{array}{l}\text { Bertermann } \\
\text { Mazanec }\end{array}$ \\
\hline DO 2030.01 & IRI 3_2 & $((139)) /((165))$ & $\begin{array}{l}\text { Bertermann } \\
\text { Mazanec }\end{array}$ \\
\hline $\begin{array}{l}\text { DO 447; } \\
\text { DO R 3 }\end{array}$ & AF508 & wt/- & Scholten \\
\hline DO 2030.01 & Haarfarbe & blond & Schücker \\
\hline DO 2030.01 & C82Y & G/G & Krause \\
\hline
\end{tabular}

\begin{tabular}{|l|c|c|l|}
\hline FundNr & Marker & Ausprägung & Bearbeiter \\
\hline \hline DO 2030.01 & H63D & G/G & Krause \\
\hline DO 2030.01 & IL6-174 & $-/-$ & Pepperl \\
\hline & IL10-1082 & & \\
\hline & IL10-819 & & \\
\hline & IL10-592 & & \\
\hline DO 2030.01 & IL10-1087 & (G)/(A) & Pepperl \\
\hline DO 2030.01 & IL10-2849 & (G)/(A) & Pepperl \\
\hline DO 2030.01 & TLR2_753 & (G)/- & Pepperl \\
\hline
\end{tabular}

\begin{tabular}{|l|c|c|l|}
\hline FundNr & Marker & Ausprägung & Bearbeiter \\
\hline \hline DO 2030.01 & TLR4_299 & (G)/- & Pepperl \\
\hline DO 2030.01 & TLR4_399 & (C)/- & Pepperl \\
\hline DO 2030.01 & IL4-524 & (C)/- & Pepperl \\
\hline DO 2030.01 & IL4-Ra576 & $-/-$ & Pepperl \\
\hline $\begin{array}{l}\text { DO 2030.01; } \\
\text { DO 2111.01 }\end{array}$ & Lac & C/(T) (tolerant) & $\begin{array}{l}\text { Fulge } \\
\text { Seebode }\end{array}$ \\
\hline DO 2030.01 & Rhesus D & negativ & Rohlf \\
\hline & DRD4 & & \\
\hline
\end{tabular}


DO BS 2263 (M15)

\begin{tabular}{|c|c|c|c|c|c|c|c|c|c|c|c|c|c|c|c|c|}
\hline Amelo & D3S1358 & VWA & FGA & D8S1179 & D21S11 & D18S51 & D5S818 & D13S317 & D7S820 & CSF1PO & TH01 & D16S539 & D2S1338 & D19S433 & D9S1120 \\
\hline \hline X/Y & $(15) / 16$ & $-/-$ & $22 / 24$ & $13 / 14$ & $-/-$ & $16 / 18$ & $12 / 13$ & $(11) / 12$ & $(7) /(8)$ & $-/-$ & $(9.3) /-$ & $-/-$ & $-/-$ & $-/-$ & $-/-$ & - \\
\hline DYS19 & DYS385 & DYS389 I & DYS389 II & DYS390 & DYS391 & DYS392 & DYS393 & DYS437 & DYS438 & DYS439 & \multirow{2}{*}{ Y 11 } & R1b (55,3) \\
\hline \hline- & -- & $(13)$ & $(29)$ & - & $(11)$ & - & - & - & - & $(13)$ & & \\
\end{tabular}

\section{mt: J1c}

\begin{tabular}{|c|c|c|c|c|c|c|c|c|c|c|c|c|}
\hline \multirow{2}{*}{$\mathbf{s}$} & \multicolumn{12}{|c|}{ Skelettelement } \\
\hline & Humerus & Ulna & Radius & Scapula & Clavicula & Femur & Tibia & Os coxae & Os sacrum & Mandibula & Calvarium & Calcaneus \\
\hline re & & & & & & & & & & & & \\
\hline li & & & & & & & & & & $2 \angle 00$ & & \\
\hline
\end{tabular}

Alter: inf II (Morphologie/ Zahnstatus)

Körperhöhe:

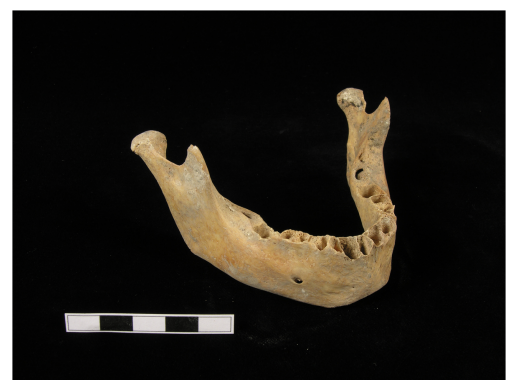

Geschlecht:

\begin{tabular}{|l|c|c|l|}
\hline FundNr & Marker & Ausprägung & Bearbeiter \\
\hline \hline & AB0-Blutgruppe & & \\
\hline & Augenfarbe & & \\
\hline & CCR5 & & \\
\hline & IRI 3_1 & & \\
\hline & IRI 3_2 & & \\
\hline DO 2263 & SF508 & wt/wt & Scholten \\
\hline & Haarfarbe & & \\
\hline DO 2263 & C82Y & $-/-$ & Krause \\
\hline
\end{tabular}

\begin{tabular}{|l|c|c|l|}
\hline FundNr & Marker & Ausprägung & Bearbeiter \\
\hline \hline DO 2263 & H63D & - -- & Krause \\
\hline & IL6-174 & & \\
\hline & IL10-1082 & & \\
\hline & IL10-819 & & \\
\hline & IL10-592 & & \\
\hline & IL10-1087 & & \\
\hline & IL10-2849 & & \\
\hline & TLR2_753 & & \\
\hline
\end{tabular}

\begin{tabular}{|l|c|l|l|}
\hline FundNr & Marker & Ausprägung & Bearbeiter \\
\hline \hline & TLR4_299 & & \\
\hline & TLR4_399 & & \\
\hline & IL4-524 & & \\
\hline & IL4-Ra576 & & \\
\hline & Lac & & \\
\hline & Rhesus D & & \\
\hline & DRD4 & & \\
\hline
\end{tabular}


DO GK/HS/RG 2588 (F15)

\begin{tabular}{|c|c|c|c|c|c|c|c|c|c|c|c|c|c|c|c|}
\hline Amelo & D3S1358 & VWA & FGA & D8S1179 & D21S11 & D18S51 & D5S818 & D13S317 & D7S820 & CSF1PO & TH01 & D16S539 & D2S1338 & D19S433 & D9S1120 \\
\hline $\mathrm{X} /-$ & $15 / 16$ & $14 / 15$ & $22 / 24$ & 13/- & $28 / 30$ & $13 / 15$ & $11 / 12$ & $11 / 12$ & 10/11 & $-1-$ & $7 / 9.3$ & $8 / 11$ & $17 / 20$ & $13 / 14$ & $16 /-$ \\
\hline
\end{tabular}

\begin{tabular}{|l|l|l|l|l|l|l|l|l|l|l|l|}
\hline DYS19 & DYS385 & DYS389 I & DYS389 II & DYS390 & DYS391 & DYS392 & DYS393 & DYS437 & DYS438 & DYS439 & \\
\hline \hline & & & & & & & & & & & \\
\hline
\end{tabular}

mt:

U2e1

\begin{tabular}{|c|c|c|c|c|c|c|c|c|c|c|c|c|}
\hline \multirow{2}{*}{$\mathbf{s}$} & \multicolumn{12}{|c|}{ Skelettelement } \\
\hline & Humerus & Ulna & Radius & Scapula & Clavicula & Femur & Tibia & Os coxae & Os sacrum & Mandibula & Calvarium & Calcaneus \\
\hline $\begin{array}{l}\mathrm{r} \\
\mathrm{e}\end{array}$ & N 965.02 & 965.04 & N 965.03 & & & $\begin{array}{c}\text { N 965.01/ } \\
3379.29\end{array}$ & 2588 & & & \multirow{2}{*}{2589} & & \\
\hline $\mathrm{li}$ & $\begin{array}{c}\text { N 964.02/ } \\
1744.08\end{array}$ & 959.01 & 1744.06 & 2414.03 & & N 964.01 & 191.01 & & & & & \\
\hline
\end{tabular}

Alter:

sjuv-fad (Histologie Zahn; DO 2589)

Körperhöhe: 153,3 \pm 4,1 cm

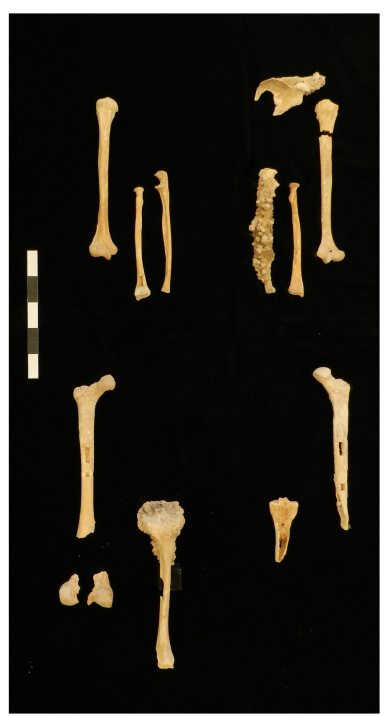

Geschlecht: ?

\begin{tabular}{|l|c|c|l|}
\hline FundNr & Marker & Ausprägung & Bearbeiter \\
\hline \hline DO 2588 & $\begin{array}{c}\text { AB0- } \\
\text { Blutgruppe }\end{array}$ & $01 \mathrm{v02}$ & Seidenberg \\
\hline DO 2588 & Augenfarbe & blau & Krause \\
\hline DO 2588 & CCR5 & wt/wt & Mazanec \\
\hline DO 2588 & IRI 3_1 & $112 / 120$ & Mazanec \\
\hline DO 2588 & IRI 3_2 & $(139) / 165$ & Mazanec \\
\hline DO 2589 & SF508 & wt/wt & Scholten \\
\hline DO 2588 & Haarfarbe & dunkelbraun-schwarz (rötl) & Schücker \\
\hline $\begin{array}{l}\text { DO 2588; } \\
\text { DO 2589 }\end{array}$ & C82Y & G/G & Krause \\
\hline
\end{tabular}

\begin{tabular}{|l|c|c|l|}
\hline FundNr & Marker & Ausprägung & Bearbeiter \\
\hline \hline $\begin{array}{l}\text { DO 2588; } \\
\text { DO 2589 }\end{array}$ & H63D & C/- & Krause \\
\hline DO 2589 & IL6-174 & $-/-$ & Pepperl \\
\hline & IL10-1082 & & \\
\hline & IL10-819 & & \\
\hline & IL10-592 & & \\
\hline DO 2589 & IL10-1087 & $-/-$ & Pepperl \\
\hline DO 2589 & IL10-2849 & (G)/(A) & Pepperl \\
\hline DO 2589 & TLR2_753 & G/- & Pepperl \\
\hline
\end{tabular}

\begin{tabular}{|l|c|c|l|}
\hline FundNr & Marker & Ausprägung & Bearbeiter \\
\hline \hline DO 2589 & TLR4_299 & A/- & Pepperl \\
\hline DO 2589 & TLR4_399 & C/- & Pepperl \\
\hline DO 2589 & IL4-524 & $-/-$ & Pepperl \\
\hline DO 2589 & IL4-Ra576 & (G)/A & Pepperl \\
\hline $\begin{array}{l}\text { DO 2588; } \\
\text { DO 2589 }\end{array}$ & Lac & C/C (intolerant) & $\begin{array}{l}\text { Fulge } \\
\text { Seebode }\end{array}$ \\
\hline DO 2588 & Rhesus D & negativ & Rohlf \\
\hline & DRD4 & & \\
\hline
\end{tabular}


DO KS 3190.11 (F20)

\begin{tabular}{|c|c|c|c|c|c|c|c|c|c|c|c|c|c|c|c|c|}
\hline Amelo & D3S1358 & VWA & FGA & D8S1179 & D21S11 & D18S51 & D5S818 & \multicolumn{2}{|c|}{ D13S317 } & D7S820 & CSF1PO & TH01 & D16S539 & D2S1338 & D19S433 & D9S1120 \\
\hline $\mathrm{X} /-$ & $16 /-$ & $16 /-$ & $-1-$ & $-1-$ & $-1-$ & $-1-$ & $-1-$ & $11 /$ & & $-1-$ & $11 /-$ & & & & & \\
\hline DYS19 & DYS385 & DYS389 I & & 3389 II & DYS390 & DYS391 & DYS392 & DYS393 & & $\mathbf{S 4 3 7}$ & DYS438 & DYS439 & & & & \\
\hline
\end{tabular}

mt:

H39

\begin{tabular}{|c|c|c|c|c|c|c|c|c|c|c|c|c|}
\hline \multirow{2}{*}{$\mathbf{s}$} & \multicolumn{12}{|c|}{ Skelettelement } \\
\hline & Humerus & Ulna & Radius & Scapula & Clavicula & Femur & Tibia & Os coxae & Os sacrum & Mandibula & Calvarium & Calcaneus \\
\hline \multicolumn{13}{|l|}{ re } \\
\hline li & & & & & & & & & & 190.1 & & \\
\hline
\end{tabular}

Alter: $\quad$ inf II (Morphologie/Zahnstatus)

\section{Körperhöhe:}

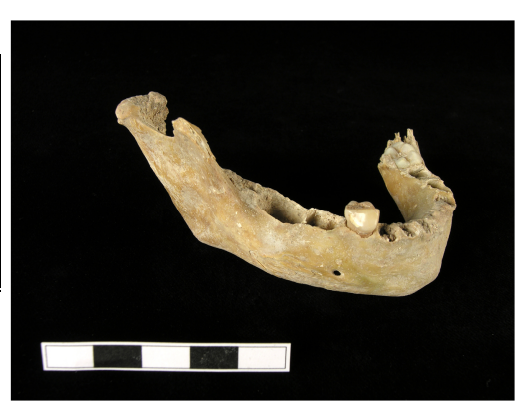

Geschlecht:

\begin{tabular}{|l|c|l|l|}
\hline FundNr & Marker & Ausprägung & Bearbeiter \\
\hline \hline & AB0-Blutgruppe & & \\
\hline & Augenfarbe & & \\
\hline & CCR5 & & \\
\hline & IRI 3_1 & & \\
\hline & IRI 3_2 & & \\
\hline & SF508 & & \\
\hline & Haarfarbe & & \\
\hline & C82Y & & \\
\hline
\end{tabular}

\begin{tabular}{|l|c|c|l|}
\hline FundNr & Marker & Ausprägung & Bearbeiter \\
\hline \hline & H63D & & \\
\hline DO 3190.11 & IL6-174 & $-/-$ & Pepperl \\
\hline & IL10-1082 & & \\
\hline & IL10-819 & & \\
\hline & IL10-592 & & \\
\hline DO 3190.11 & IL10-1087 & $-/-$ & Pepperl \\
\hline DO 3190.11 & IL10-2849 & (G)/(A) & Pepperl \\
\hline DO 3190.11 & TLR2_753 & $-/-$ & Pepperl \\
\hline
\end{tabular}

\begin{tabular}{|l|c|c|l|}
\hline FundNr & Marker & Ausprägung & Bearbeiter \\
\hline \hline DO 3190.11 & TLR4_299 & $-/-$ & Pepperl \\
\hline DO 3190.11 & TLR4_399 & $-/-$ & Pepperl \\
\hline DO 3190.11 & IL4-524 & $-/-$ & Pepperl \\
\hline DO 3190.11 & IL4-Ra576 & A/- & Pepperl \\
\hline & Lac & & \\
\hline & Rhesus D & & \\
\hline & DRD4 & & \\
\hline
\end{tabular}


DO BS 3628 (F3)

\begin{tabular}{|c|c|c|c|c|c|c|c|c|c|c|c|c|c|c|c|}
\hline Amelo & D3S1358 & VWA & FGA & D8S1179 & D21S11 & D18S51 & D5S818 & D13S317 & D7S820 & CSF1PO & TH01 & D16S539 & D2S1338 & D19S433 & D9S1120 \\
\hline$X /-$ & $15 / 16$ & $16 / 17$ & $20 / 21$ & $13 / 15$ & $30 / 33.2$ & $14 / 15$ & $9 / 11$ & $11 /-$ & $7 / 10$ & $13 /-$ & $7 / 9.3$ & $11 / 13$ & $17 / 19$ & $13 /-$ & $16 /-$ \\
\hline
\end{tabular}

\begin{tabular}{|l|l|l|l|l|l|l|l|l|l|l|l|}
\hline DYS19 & DYS385 & DYS389 I & DYS389 II & DYS390 & DYS391 & DYS392 & DYS393 & DYS437 & DYS438 & DYS439 & \\
\hline \hline & & & & & & & & & & & \\
\hline
\end{tabular}

mt:

J1c

\begin{tabular}{|c|c|c|c|c|c|c|c|c|c|c|c|c|}
\hline \multirow{2}{*}{ s } & \multicolumn{12}{|c|}{ Skelettelement } \\
\hline & Humerus & Ulna & Radius & Scapula & Clavicula & Femur & Tibia & Os coxae & Os sacrum & Mandibula & Calvarium & Calcaneus \\
\hline re & 2255.03 & 2255.01 & 2255.02 & 2094.01 & 2092 & 4374 & 3628 & $4568 / 2520$ & & & & \\
\hline li & 2364 & 2441 & 2395 & 2029 & 2420 & 4372 & 3474 & $\begin{array}{c}3981.02 / 2565 / \\
2485.02\end{array}$ & & 2388 & 1746.05 & \\
\hline
\end{tabular}

Alter: $\quad$ inf II (Morphologie/Zahnstatus; ca. 7 Jahre)

\section{Körperhöhe:}

Geschlecht:

\begin{tabular}{|l|c|c|l|}
\hline FundNr & Marker & Ausprägung & Bearbeiter \\
\hline \hline & $\begin{array}{c}\text { AB0- } \\
\text { Blutgruppe }\end{array}$ & & \\
\hline DO 4374 & Augenfarbe & & \\
\hline DO 4374 & IRI 3_1 & $106 / 118$ & Mazanec \\
\hline DO 4374 & IRI 3_2 & $((151)) /(159)$ & Mazanec \\
\hline DO 1746.06 & $\Delta$ F508 & wt/wt & Scholten \\
\hline & Haarfarbe & & \\
\hline DO 1746.06 & C82Y & G/G & Krause \\
\hline
\end{tabular}

\begin{tabular}{|l|c|c|l|}
\hline FundNr & Marker & Ausprägung & Bearbeiter \\
\hline \hline DO 1746.06 & H63D & C/G & Krause \\
\hline $\begin{array}{l}\text { DO 1746.05; } \\
\text { DO 1746.06 }\end{array}$ & IL6-174 & C/- & Pepperl \\
\hline $\begin{array}{l}\text { DO 1746.05; } \\
\text { DO 1746.06 }\end{array}$ & IL10-1082 & A/G & \\
\hline $\begin{array}{l}\text { DO 1746.05; } \\
\text { DO 1746.06 }\end{array}$ & IL10-819 & C/T & \\
\hline $\begin{array}{l}\text { DO 1746.05; } \\
\text { DO 1746.06 }\end{array}$ & IL10-592 & C/A & \\
\hline $\begin{array}{l}\text { DO 1746.05; } \\
\text { DO 1746.06 }\end{array}$ & IL10-1087 & - - & Pepperl \\
\hline $\begin{array}{l}\text { DO 1746.05; } \\
\text { DO 1746.06 }\end{array}$ & IL10-2849 & (A)/- & Pepperl \\
\hline $\begin{array}{l}\text { DO 1746.05; } \\
\text { DO 1746.06 }\end{array}$ & TLR2_753 & G/- & Pepperl \\
\hline
\end{tabular}

\begin{tabular}{|l|c|c|l|}
\hline FundNr & Marker & Ausprägung & Bearbeiter \\
\hline \hline $\begin{array}{l}\text { DO 1746.05; } \\
\text { DO 1746.06 }\end{array}$ & TLR4_299 & A/- & Pepperl \\
\hline $\begin{array}{l}\text { DO 1746.05; } \\
\text { DO 1746.06 }\end{array}$ & TLR4_399 & C/- & Pepperl \\
\hline $\begin{array}{l}\text { DO 1746.05; } \\
\text { DO 1746.06 }\end{array}$ & IL4-524 & (C)/- & Pepperl \\
\hline $\begin{array}{l}\text { DO 1746.05; } \\
\text { DO 1746.06 }\end{array}$ & IL4-Ra576 & G/A & Pepperl \\
\hline $\begin{array}{l}\text { DO 4374; } \\
\text { DO 2388 }\end{array}$ & Lac & C/T (tolerant) & $\begin{array}{l}\text { Fulge } \\
\text { Seebode }\end{array}$ \\
\hline DO 4374 & Rhesus D & (negativ) & Rohlf \\
\hline & DRD4 & & \\
\hline
\end{tabular}


DO BS 3695 (F4)

\begin{tabular}{|c|c|c|c|c|c|c|c|c|c|c|c|c|c|c|c|}
\hline Amelo & D3S1358 & VWA & FGA & D8S1179 & D21S11 & D18S51 & D5S818 & D13S317 & D7S820 & CSF1PO & TH01 & D16S539 & D2S1338 & D19S433 & D9S1120 \\
\hline $\mathrm{X} /-$ & $15 / 18$ & $14 / 17$ & $20 / 25$ & $11 / 15$ & $29 / 30$ & $14 / 15$ & $12 /-$ & $8 / 11$ & $10 / 12$ & $11 / 12$ & $6 / 8$ & $13 /-$ & $-/-$ & (13)/14 & $(16) /(18)$ \\
\hline
\end{tabular}

\begin{tabular}{|l|l|l|l|l|l|l|l|l|l|l|l|}
\hline DYS19 & DYS385 & DYS389 I & DYS389 II & DYS390 & DYS391 & DYS392 & DYS393 & DYS437 & DYS438 & DYS439 & \\
\hline \hline & & & & & & & & & & & \\
\hline
\end{tabular}

$\mathrm{mt}$ :

U5b

\begin{tabular}{|c|c|c|c|c|c|c|c|c|c|c|c|c|}
\hline \multirow{2}{*}{ s } & \multicolumn{12}{|c|}{ Skelettelement } \\
\hline & Humerus & Ulna & Radius & Scapula & Clavicula & Femur & Tibia & Os coxae & Os sacrum & Mandibula & Calvarium & Calcaneus \\
\hline re & 4013 & 3702 & 3695 & & 4060.01 & & & 3615 & \multirow{2}{*}{3609} & \multirow{2}{*}{4078} & \multirow{2}{*}{5516} & \\
\hline li & 3662 & 3667 & 4062 & 4017.01 & 4061.01 & 3727 & 320 & 3475 & & & & \\
\hline
\end{tabular}

Alter: $\quad$ mmat-smat (Histologie Zahn; F4)

Körperhöhe: 165,8 \pm 4,1 cm

Geschlecht:

\begin{tabular}{|l|c|c|l|}
\hline FundNr & Marker & Ausprägung & Bearbeiter \\
\hline \hline DO 4013 & AB0-Blutgruppe & $01(01 \mathrm{v})$ & Seidenberg \\
\hline & Augenfarbe & & \\
\hline DO 3727 & CCR5 & $-/-$ & Mazanec \\
\hline DO 3727 & IRI 3_1 & $-/-$ & Mazanec \\
\hline DO 3727 & IRI 3_2 & $((171)) /-$ & Mazanec \\
\hline $\begin{array}{l}\text { DO 4078; } \\
\text { DO 5516 }\end{array}$ & $\Delta F 508$ & wt/wt & Scholten \\
\hline & Haarfarbe & & \\
\hline $\begin{array}{l}\text { DO 4078; } \\
\text { DO 5516 }\end{array}$ & C82Y & G/G & Krause \\
\hline
\end{tabular}

\begin{tabular}{|l|c|c|l|}
\hline FundNr & Marker & Ausprägung & Bearbeiter \\
\hline \hline $\begin{array}{l}\text { DO 4078; } \\
\text { DO 5516 }\end{array}$ & H63D & C/G & Krause \\
\hline $\begin{array}{l}\text { DO 4078; } \\
\text { DO 5516 }\end{array}$ & IL6-174 & $(\mathrm{G}) / \mathrm{C}$ & Pepperl \\
\hline $\begin{array}{l}\text { DO 4078; } \\
\text { DO 5516 }\end{array}$ & IL10-1082 & G/- & Suray \\
\hline $\begin{array}{l}\text { DO 4078; } \\
\text { DO 5516 }\end{array}$ & IL10-819 & C/- & Suray \\
\hline $\begin{array}{l}\text { DO 4078; } \\
\text { DO 5516 }\end{array}$ & IL10-592 & C/- & Suray \\
\hline $\begin{array}{l}\text { DO 4078; } \\
\text { DO 5516 }\end{array}$ & IL10-1087 & G/G & Pepperl \\
\hline $\begin{array}{l}\text { DO 4078; } \\
\text { DO 5516 }\end{array}$ & IL10-2849 & G/A & Pepperl \\
\hline $\begin{array}{l}\text { DO 4078; } \\
\text { DO 5516 }\end{array}$ & TLR2_753 & G/G & Pepperl \\
\hline
\end{tabular}

\begin{tabular}{|l|c|c|l|}
\hline FundNr & Marker & Ausprägung & Bearbeiter \\
\hline \hline $\begin{array}{l}\text { DO 4078; } \\
\text { DO 5516 }\end{array}$ & TLR4_299 & A/A & Pepperl \\
\hline $\begin{array}{l}\text { DO 4078; } \\
\text { DO 5516 }\end{array}$ & TLR4_399 & C/(T) & Pepperl \\
\hline $\begin{array}{l}\text { DO 4078; } \\
\text { DO 5516 }\end{array}$ & IL4-524 & (C)/- & Pepperl \\
\hline $\begin{array}{l}\text { DO 4078; } \\
\text { DO 5516 }\end{array}$ & IL4-Ra576 & A/A & Pepperl \\
\hline $\begin{array}{l}\text { DO 3727; } \\
\text { DO 5516 }\end{array}$ & Lac & C/T (tolerant) & $\begin{array}{l}\text { Fulge } \\
\text { Seebode }\end{array}$ \\
\hline DO 4013 & Rhesus D & positiv & Rohlf \\
\hline & DRD4 & & \\
\hline
\end{tabular}

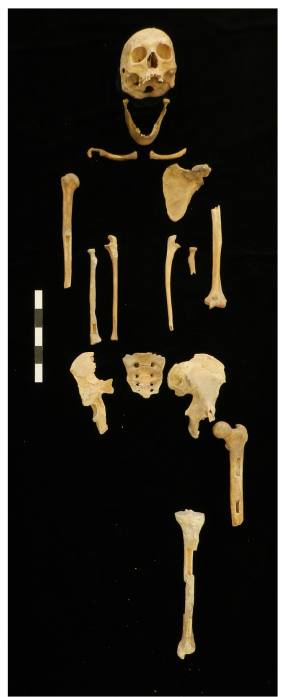


DO BS 3706 (F5/F11)

\begin{tabular}{|c|c|c|c|c|c|c|c|c|c|c|c|c|c|c|c|}
\hline Amelo & D3S1358 & VWA & FGA & D8S1179 & D21S11 & D18S51 & D5S818 & D13S317 & D7S820 & CSF1PO & TH01 & D16S539 & D2S1338 & D19S433 & D9S1120 \\
\hline$X /-$ & $18 /-$ & $17 / 19$ & $21 / 23$ & $12 / 15$ & $28 / 29$ & $16 /-$ & $12 /-$ & $8 / 9$ & $10 /-$ & $10 / 11$ & 9/9.3 & $12 / 13$ & $24 / 25$ & $13 / 14$ & $15 / 16$ \\
\hline
\end{tabular}

\begin{tabular}{|l|l|l|l|l|l|l|l|l|l|l|l|}
\hline DYS19 & DYS385 & DYS389 I & DYS389 II & DYS390 & DYS391 & DYS392 & DYS393 & DYS437 & DYS438 & DYS439 & \\
\hline \hline & & & & & & & & & & & \\
\hline
\end{tabular}

mt:

T2b \#1

\begin{tabular}{|c|c|c|c|c|c|c|c|c|c|c|c|c|}
\hline \multirow{2}{*}{$\mathbf{s}$} & \multicolumn{12}{|c|}{ Skelettelement } \\
\hline & Humerus & Ulna & Radius & Scapula & Clavicula & Femur & Tibia & Os coxae & Os sacrum & Mandibula & Calvarium & Calcaneus \\
\hline re & 3661 & 3538.01 & 3740 & & 1195 & 3990 & 3720 & 3600 & \multirow{2}{*}{2078.01} & \multirow{2}{*}{3713} & \multirow{2}{*}{3706} & \\
\hline li & 4014 & 4317.01 & 4318.01 & 1180 & & 3756 & 3672 & 3620 & & & & \\
\hline
\end{tabular}

Alter: $\quad$ mmat-smat (Histologie Knoche; DO 3756/ Histologie Zahn; DO 3706/ DO 3713)

Geschlecht:

\begin{tabular}{|l|c|c|l|}
\hline FundNr & Marker & Ausprägung & Bearbeiter \\
\hline \hline DO 3756 & $\begin{array}{c}\text { ABO- } \\
\text { Blutgruppe }\end{array}$ & $0101 \mathrm{v}$ & Seidenberg \\
\hline $\begin{array}{l}\text { DO 3756; } \\
\text { DO 3706 }\end{array}$ & Augenfarbe & braun & Krause \\
\hline DO 3756 & CCR5 & wt/- & Bertermann \\
\hline DO 3756 & IRI 3_1 & $114 / 118$ & Bertermann \\
\hline DO 3756 & IRI 3_2 & $159 /-$ & Bertermann \\
\hline $\begin{array}{l}\text { DO 3713; } \\
\text { DO 3706 }\end{array}$ & $\Delta$ F508 & wt/- & Scholten \\
\hline DO 3756 & Haarfarbe & hellbraun & Schücker \\
\hline DO 3706 & C82Y & G/G & Krause \\
\hline
\end{tabular}

Körperhöhe: 150,2 \pm 3,1 cm

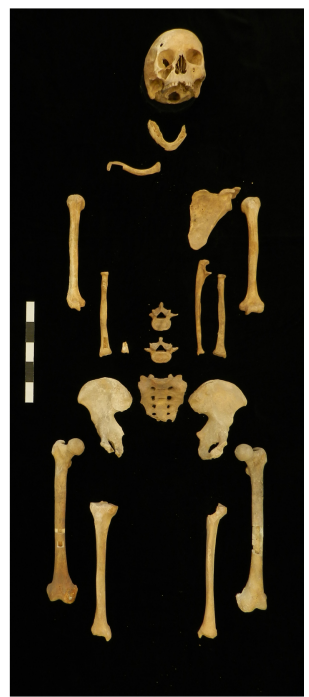

\begin{tabular}{|l|c|c|l|}
\hline FundNr & Marker & Ausprägung & Bearbeiter \\
\hline \hline DO 3706 & H63D & G/G & Krause \\
\hline $\begin{array}{l}\text { DO 3756; DO 3713; } \\
\text { DO 3706 }\end{array}$ & IL6-174 & (G)/C & Pepperl \\
\hline DO 3756 & IL10-1082 & G/- & Suray \\
\hline DO 3756 & IL10-819 & C/- & Suray \\
\hline DO 3756 & IL10-592 & C/- & Suray \\
\hline $\begin{array}{l}\text { DO 3756; DO 3713; } \\
\text { DO 3706 }\end{array}$ & IL10-1087 & (G)/- & Pepperl \\
\hline $\begin{array}{l}\text { DO 3756; DO 3713; } \\
\text { DO 3706 }\end{array}$ & IL10-2849 & G/A & Pepperl \\
\hline $\begin{array}{l}\text { DO 3756; DO 3713; } \\
\text { DO 3706 }\end{array}$ & TLR2_753 & G/G & Pepperl \\
\hline
\end{tabular}

\begin{tabular}{|l|c|c|l|}
\hline FundNr & Marker & Ausprägung & Bearbeiter \\
\hline \hline $\begin{array}{l}\text { DO 3756; DO 3713; } \\
\text { DO 3706 }\end{array}$ & TLR4_299 & A/- & Pepperl \\
\hline $\begin{array}{l}\text { DO 3756; DO 3713; } \\
\text { DO 3706 }\end{array}$ & TLR4_399 & C/C & Pepperl \\
\hline $\begin{array}{l}\text { DO 3756; DO 3713; } \\
\text { DO 3706 }\end{array}$ & IL4-524 & C/- & Pepperl \\
\hline $\begin{array}{l}\text { DO 3756; DO 3713; } \\
\text { DO 3706 }\end{array}$ & IL4-Ra576 & A/- & Pepperl \\
\hline DO 3756 & Lac & $\begin{array}{c}\text { C/C } \\
\text { (intolerant) }\end{array}$ & Fulge \\
\hline DO 3756 & Rhesus D & positiv & Rohlf \\
\hline & DRD4 & & \\
\hline
\end{tabular}


DO BS/FK 3714

\begin{tabular}{|c|c|c|c|c|c|c|c|c|c|c|c|c|c|c|c|}
\hline Amelo & D3S1358 & VWA & FGA & D8S1179 & D21S11 & D18S51 & D5S818 & D13S317 & D7S820 & CSF1PO & TH01 & D16S539 & D2S1338 & D19S433 & D9S1120 \\
\hline$X / Y$ & $15 / 16$ & $17 /-$ & $21 / 23$ & $10 / 14$ & $27 / 30$ & $13 / 17$ & $11 / 12$ & $11 / 12$ & $8 / 11$ & $-1-$ & $6 / 7$ & $11 / 12$ & $(17) / 25$ & $14 / 16.2$ & $(15) / 17$ \\
\hline
\end{tabular}

\begin{tabular}{|c|c|c|c|c|c|c|c|c|c|c|c|}
\hline DYS19 & DYS385 & DYS389 I & DYS389 II & DYS390 & DYS391 & DYS392 & DYS393 & DYS437 & DYS438 & DYS439 & n.d. \\
\hline \hline$(14)$ & -- & 12 & - & - & - & - & - & - & 10 & - & \\
\hline
\end{tabular}

$\mathrm{mt}$

H2a1

\begin{tabular}{|c|c|c|c|c|c|c|c|c|c|c|c|c|}
\hline \multirow{2}{*}{$\mathbf{s}$} & \multicolumn{12}{|c|}{ Skelettelement } \\
\hline & Humerus & Ulna & Radius & Scapula & Clavicula & Femur & Tibia & Os coxae & Os sacrum & Mandibula & Calvarium & Calcaneus \\
\hline re & 87.08 & 3665 & 87.10 & & 3674 & 4077 & 3658 & & 2431 & & & \\
\hline li & 3714 & 4070 & 3744 & & 4316.01 & & 913.02 & & Metacarpus & & & \\
\hline
\end{tabular}

Alter: $\quad$ mad (Histologie Knochen; DO 4077)

Körperhöhe: 163,1 $\pm 3,3 \mathrm{~cm}$

Geschlecht:

\begin{tabular}{|l|c|l|l|}
\hline FundNr & Marker & Ausprägung & Bearbeiter \\
\hline \hline & AB0-Blutgruppe & & \\
\hline DO 3714 & Augenfarbe & Intermediate-braun & Krause \\
\hline & CCR5 & & \\
\hline & IRI 3_1 & & \\
\hline & IRI 3_2 & & \\
\hline & $\Delta$ F508 & & \\
\hline DO 3714 & Haarfarbe & hellbraun & Schücker \\
\hline & C82Y & & \\
\hline
\end{tabular}

\begin{tabular}{|l|c|c|c|}
\hline FundNr & Marker & Ausprägung & Bearbeiter \\
\hline \hline & H63D & & \\
\hline & IL6-174 & & \\
\hline & IL10-1082 & & \\
\hline & IL10-819 & & \\
\hline & IL10-592 & & \\
\hline & IL10-1087 & & \\
\hline & IL10-2849 & & \\
\hline & TLR2_753 & & \\
\hline
\end{tabular}

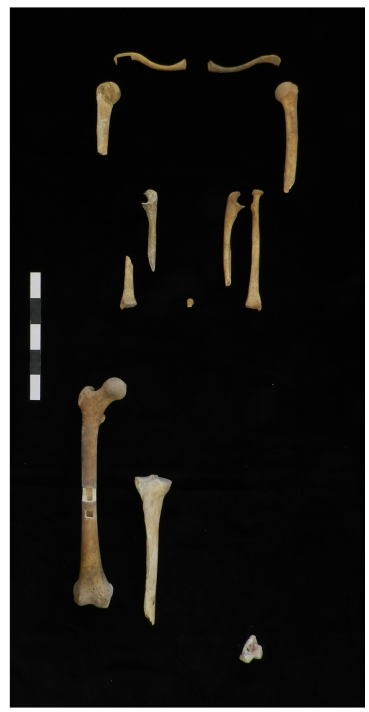

\begin{tabular}{|l|c|l|l|}
\hline FundNr & Marker & Ausprägung & Bearbeiter \\
\hline \hline & TLR4_299 & & \\
\hline & TLR4_399 & & \\
\hline & IL4-524 & & \\
\hline & IL4-Ra576 & & \\
\hline & Lac & & \\
\hline & Rhesus D & & \\
\hline & DRD4 & & \\
\hline
\end{tabular}


DO BS/FK 3742 (F9)

\begin{tabular}{|c|c|c|c|c|c|c|c|c|c|c|c|c|c|c|c|}
\hline Amelo & D3S1358 & VWA & FGA & D8S1179 & D21S11 & D18S51 & D5S818 & D13S317 & D7S820 & CSF1PO & TH01 & D16S539 & D2S1338 & D19S433 & D9S1120 \\
\hline X/- & $14 / 16$ & $13 / 14$ & $24 /-$ & $11 / 13$ & $29 / 32.2$ & $12 / 15$ & $10 / 13$ & $8 / 10$ & $9 / 10$ & $10 / 12$ & $9.3 /-$ & $11 / 12$ & $20 / 24$ & $13.2 / 15$ & $15 / 17$ \\
\hline
\end{tabular}

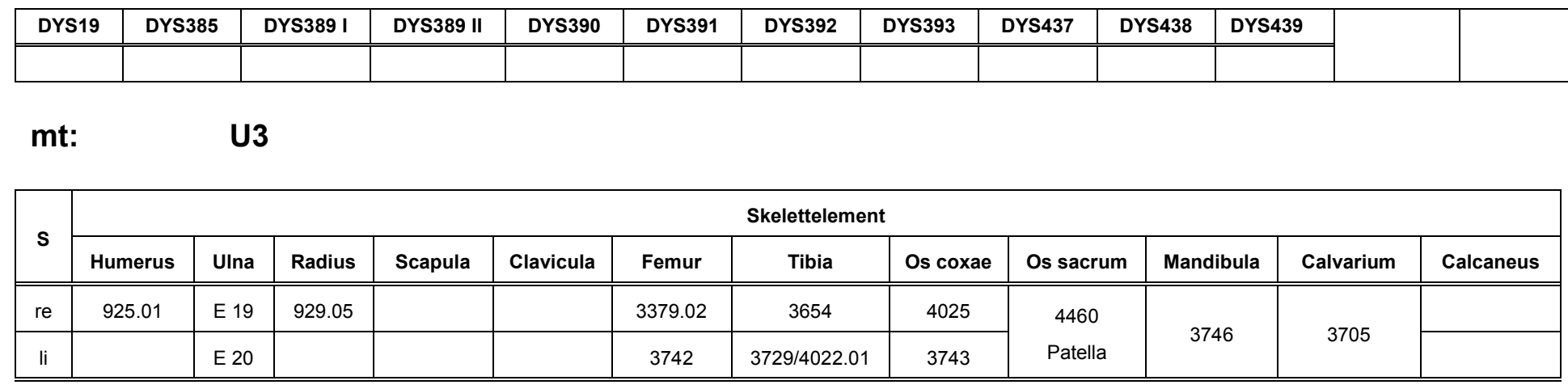

Alter: fjuv (Histologie Knochen; DO 3742)

\section{Körperhöhe:}

Geschlecht:

\begin{tabular}{|l|c|c|l|}
\hline FundNr & Marker & Ausprägung & Bearbeiter \\
\hline \hline DO 3742 & AB0-Blutgruppe & A01v & Seidenberg \\
\hline DO 3742 & Augenfarbe & braun & Krause \\
\hline DO 3742 & CCR5 & wt/A32 & Bertermann \\
\hline DO 3742 & IRI 3_1 & $108 / 118$ & Bertermann \\
\hline DO 3742 & IRI 3_2 & $161 /-$ & Bertermann \\
\hline $\begin{array}{l}\text { DO 3746; } \\
\text { DO 3705 }\end{array}$ & DF508 & wt/wt & Scholten \\
\hline DO 3742 & Haarfarbe & dunkel & Schücker \\
\hline $\begin{array}{l}\text { DO 3654; } \\
\text { DO 3746; } \\
\text { DO 3705 }\end{array}$ & C82Y & G/G & Krause \\
\hline
\end{tabular}

\begin{tabular}{|l|c|c|l|}
\hline FundNr & Marker & Ausprägung & Bearbeiter \\
\hline \hline $\begin{array}{l}\text { DO 3654; DO 3746; } \\
\text { DO 3705 }\end{array}$ & H63D & C/- & Krause \\
\hline DO 3746; DO 3705 & IL6-174 & G/C & Pepperl \\
\hline DO 3742 & IL10-1082 & $-/-$ & Suray \\
\hline DO 3742 & IL10-819 & (C)/- & Suray \\
\hline DO 3742 & IL10-592 & (C)/- & Suray \\
\hline DO 3746; DO 3705 & IL10-1087 & G/A & Pepperl \\
\hline DO 3746; DO 3705 & IL10-2849 & G/A & Pepperl \\
\hline DO 3746; DO 3705 & TLR2_753 & G/G & Pepperl \\
\hline
\end{tabular}

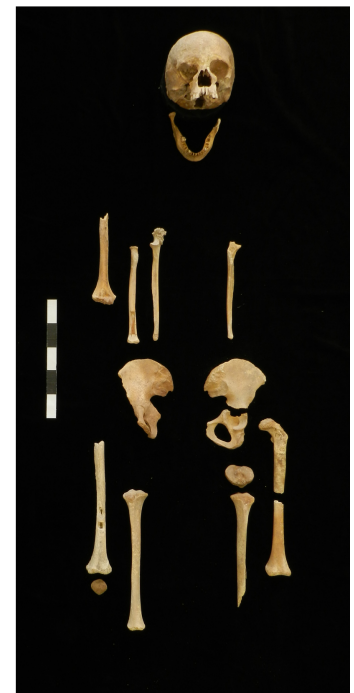

\begin{tabular}{|l|c|c|l|}
\hline FundNr & Marker & Ausprägung & Bearbeiter \\
\hline \hline $\begin{array}{l}\text { DO 3746; } \\
\text { DO 3705 }\end{array}$ & TLR4_299 & A/A & Pepperl \\
\hline $\begin{array}{l}\text { DO 3746; } \\
\text { DO 3705 }\end{array}$ & TLR4_399 & C/C & Pepperl \\
\hline $\begin{array}{l}\text { DO 3746; } \\
\text { DO 3705 }\end{array}$ & IL4-524 & C/(T) & Pepperl \\
\hline $\begin{array}{l}\text { DO 3746; } \\
\text { DO 3705 }\end{array}$ & IL4-Ra576 & G/A & Pepperl \\
\hline DO 3742 & Lac & C/C (intolerant) & Fulge \\
\hline DO 3742 & Rhesus D & positiv & Rohlf \\
\hline & DRD4 & & \\
\hline
\end{tabular}


DO BS/RG 3748 (F8)

\begin{tabular}{|c|c|c|c|c|c|c|c|c|c|c|c|c|c|c|c|}
\hline Amelo & D3S1358 & VWA & FGA & D8S1179 & D21S11 & D18S51 & D5S818 & D13S317 & D7S820 & CSF1PO & TH01 & D16S539 & D2S1338 & D19S433 & D9S1120 \\
\hline $\mathrm{X} / \mathrm{-}$ & 18/- & $14 / 17$ & $21 / 25$ & $11 / 13$ & $30 / 30.2$ & $15 / 17$ & $12 /-$ & $8 / 12$ & 10/11 & $11 / 13$ & $6 / 9.3$ & $(11) / 12$ & $19 /(26)$ & $14 / 15$ & $16 / 17$ \\
\hline
\end{tabular}

\begin{tabular}{|l|l|l|l|l|l|l|l|l|l|l|l|}
\hline DYS19 & DYS385 & DYS389 I & DYS389 II & DYS390 & DYS391 & DYS392 & DYS393 & DYS437 & DYS438 & DYS439 & \\
\hline \hline & & & & & & & & & & & \\
\hline
\end{tabular}

$\mathrm{mt}$ :

U5b

\begin{tabular}{|c|c|c|c|c|c|c|c|c|c|c|c|c|}
\hline \multirow{2}{*}{$\mathbf{s}$} & \multicolumn{12}{|c|}{ Skelettelement } \\
\hline & Humerus & Ulna & Radius & Scapula & Clavicula & Femur & Tibia & Os coxae & Os sacrum & Mandibula & Calvarium & Calcaneus \\
\hline re & 5521 & 323.01 & 5598 & 3986.01 & 3841.01 & 3635 & 3748 & 87.13 & \multirow{2}{*}{1179} & & \multirow{2}{*}{3631} & \\
\hline $\mathrm{li}$ & 3664 & 1189 & 4342.01 & 5592 & 3993.01 & & 5533 & 1603 & & & & 3841.03 \\
\hline
\end{tabular}

Alter: $\quad$ fad - mad (Histologie Knochen; DO 3635)

Körperhöhe: 166,2 $\pm 3,1 \mathrm{~cm}$

Geschlecht:

\begin{tabular}{|l|c|c|l|}
\hline FundNr & Marker & Ausprägung & Bearbeiter \\
\hline \hline DO 3635 & AB0-Blutgruppe & 0101 & Seidenberg \\
\hline DO 5521 & Augenfarbe & Intermediate-braun & Krause \\
\hline $\begin{array}{l}\text { DO 5521; } \\
\text { DO 3635 }\end{array}$ & CCR5 & wt/wt & Mazanec \\
\hline $\begin{array}{l}\text { DO 5521; } \\
\text { DO 3635 }\end{array}$ & IRI 3_1 & $112 /-$ & Mazanec \\
\hline $\begin{array}{l}\text { DO 5521; } \\
\text { DO 3635 }\end{array}$ & IRI 3_2 & $139 / 169$ & Mazanec \\
\hline DO 3631 & AF508 & wt/wt & Scholten \\
\hline DO 5521 & Haarfarbe & Dunkelblond-braun & Schücker \\
\hline DO 3631 & C82Y & G/G & Krause \\
\hline
\end{tabular}

\begin{tabular}{|l|c|c|l|}
\hline FundNr & Marker & Ausprägung & Bearbeiter \\
\hline \hline DO 3631 & H63D & C/G & Krause \\
\hline DO 3631 & IL6-174 & C/- & Pepperl \\
\hline DO 3631 & IL10-1082 & A/G & Suray \\
\hline DO 3631 & IL10-819 & C/T & Suray \\
\hline DO 3631 & IL10-592 & C/A & Suray \\
\hline DO 3631 & IL10-1087 & G/A & Pepperl \\
\hline DO 3631 & IL10-2849 & (G)/(A) & Pepperl \\
\hline DO 3631 & TLR2_753 & G/G & Pepperl \\
\hline
\end{tabular}

\begin{tabular}{|l|c|c|l|}
\hline FundNr & Marker & Ausprägung & Bearbeiter \\
\hline \hline DO 3631 & TLR4_299 & A/A & Pepperl \\
\hline DO 3631 & TLR4_399 & C/- & Pepperl \\
\hline DO 3631 & IL4-524 & C/C & Pepperl \\
\hline DO 3631 & IL4-Ra576 & A/A & Pepperl \\
\hline $\begin{array}{l}\text { DO 5521; } \\
\text { DO 3635 }\end{array}$ & Lac & C/T (tolerant) & Seebode \\
\hline $\begin{array}{l}\text { DO 3635; } \\
\text { DO 5521 }\end{array}$ & Rhesus D & positiv & Rohlf \\
\hline & DRD4 & & \\
\hline
\end{tabular}


DO BS 3757 (M8)

\begin{tabular}{|c|c|c|c|c|c|c|c|c|c|c|c|c|c|c|c|}
\hline Amelo & D3S1358 & VWA & FGA & D8S1179 & D21S11 & D18S51 & D5S818 & D13S317 & D7S820 & CSF1PO & TH01 & D16S539 & D2S1338 & D19S433 & D9S1120 \\
\hline$X / Y$ & $17 / 18$ & $17 / 18$ & $21 / 25$ & $10 / 11$ & $24.2 / 30.2$ & $12 / 17$ & $10 / 12$ & $10 / 12$ & 9/11 & $12 / 13$ & $6 / 9.3$ & $(11) /(12)$ & $-/-$ & (14)/- & $(17) /-$ \\
\hline
\end{tabular}

\begin{tabular}{|c|c|c|c|c|c|c|c|c|c|c|c|c|}
\hline DYS19 & DYS385 & DYS389 I & DYS389 II & DYS390 & DYS391 & DYS392 & DYS393 & DYS437 & DYS438 & DYS439 & \multirow{2}{*}{ Y 1} & \multirow{2}{*}{$\mathbf{1 2 b}(100)$} \\
\hline 16 & 13-17 & 12 & 28 & 25 & 11 & 11 & 13 & 15 & 10 & 11 & & \\
\hline
\end{tabular}

mt:

U5b

\begin{tabular}{|c|c|c|c|c|c|c|c|c|c|c|c|c|}
\hline \multirow{2}{*}{$\mathbf{s}$} & \multicolumn{12}{|c|}{ Skelettelement } \\
\hline & Humerus & Ulna & Radius & Scapula & Clavicula & Femur & Tibia & Os coxae & Os sacrum & Mandibula & Calvarium & Calcaneus \\
\hline re & 3971 & 2309.02 & 2064 & & 1098 & 4361.01 & 3703 & 3626 & & & & \\
\hline li & 2389 & & 2057 & 2098 & 1834.01 & 3808 & 327.02 & 5603 & & & & \\
\hline
\end{tabular}

Alter: $\quad$ inf I-inf II (Morphologie/Zahnstatus; ca. 6-7 Jahre)

Körperhöhe:

Geschlecht:

\begin{tabular}{|l|c|c|l|}
\hline FundNr & Marker & Ausprägung & Bearbeiter \\
\hline \hline & AB0-Blutgruppe & & \\
\hline & Augenfarbe & & \\
\hline DO 3757 & CCR5 & wt/wt & Mazanec \\
\hline DO 3757 & IRI 3_1 & $(112) /((118))$ & Mazanec \\
\hline DO 3757 & IRI 3_2 & $(139) /-$ & Mazanec \\
\hline DO 3757 & $\Delta$ F508 & wt/wt & Scholten \\
\hline & Haarfarbe & & \\
\hline & C82Y & & \\
\hline
\end{tabular}

\begin{tabular}{|l|c|c|l|}
\hline FundNr & Marker & Ausprägung & Bearbeiter \\
\hline \hline & H63D & & \\
\hline DO 3757 & IL6-174 & C/C & Pepperl \\
\hline DO 3757 & IL10-1082 & A/G & Suray \\
\hline DO 3757 & IL10-819 & C/T & Suray \\
\hline DO 3757 & IL10-592 & C/A & Suray \\
\hline DO 3757 & IL10-1087 & (G)/(A) & Pepperl \\
\hline DO 3757 & IL10-2849 & G/(A) & Pepperl \\
\hline DO 3757 & TLR2_753 & G/G & Pepperl \\
\hline
\end{tabular}

\begin{tabular}{|l|c|c|l|}
\hline FundNr & Marker & Ausprägung & Bearbeiter \\
\hline \hline DO 3757 & TLR4_299 & (A)/- & Pepperl \\
\hline DO 3757 & TLR4_399 & C/C & Pepperl \\
\hline DO 3757 & IL4-524 & (C)/- & Pepperl \\
\hline DO 3757 & IL4-Ra576 & (A)/- & Pepperl \\
\hline DO 3757 & Lac & C/(T) (tolerant) & Seebode \\
\hline DO 3757 & Rhesus D & positiv & Rohlf \\
\hline & DRD4 & & \\
\hline
\end{tabular}


DO BS/RG/FK/HS 3886 (M16)

\begin{tabular}{|c|c|c|c|c|c|c|c|c|c|c|c|c|c|c|c|}
\hline Amelo & D3S1358 & VWA & FGA & D8S1179 & D21S11 & D18S51 & D5S818 & D13S317 & D7S820 & CSF1PO & TH01 & D16S539 & D2S1338 & D19S433 & D9S1120 \\
\hline$X / Y$ & $17 / 18$ & $14 / 17$ & $24 / 25$ & $10 / 13$ & $29 / 30.2$ & $12 / 15$ & $10 / 12$ & $8 / 10$ & $8 / 11$ & $11 / 12$ & $6 / 9.3$ & $11 / 12$ & $19 / 20$ & $13 / 14$ & $17 /-$ \\
\hline
\end{tabular}

\begin{tabular}{|c|c|c|c|c|c|c|c|c|c|c|c|c|}
\hline DYS19 & DYS385 & DYS389 I & DYS389 II & DYS390 & DYS391 & DYS392 & DYS393 & DYS437 & DYS438 & DYS439 & \multirow{2}{*}{ Y 1} & \multirow{2}{*}{$\mathbf{1 2 b}(100)$} \\
\hline (16) & 13-17 & 12 & 28 & 25 & 11 & 11 & 13 & 15 & 10 & 11 & & \\
\hline
\end{tabular}

mt:

U5b

\begin{tabular}{|c|c|c|c|c|c|c|c|c|c|c|c|c|}
\hline \multirow{2}{*}{$\mathbf{s}$} & \multicolumn{12}{|c|}{ Skelettelement } \\
\hline & Humerus & Ulna & Radius & Scapula & Clavicula & Femur & Tibia & Os coxae & Os sacrum & Mandibula & Calvarium & Calcaneus \\
\hline re & & 4046 & 3856.01 & 3379.11 & & & & $\begin{array}{c}1744.32 / \\
931.03 / 3792\end{array}$ & & & 3886 & \\
\hline $\mathrm{li}$ & 5403 & 5192 & 5424 & 3881.01 & & $3793 / 1150.01$ & 3788.01 & & & & & \\
\hline
\end{tabular}

Alter: $\quad$ inf I (Morphologie)

Körperhöhe:

Geschlecht: $\nwarrow$

\begin{tabular}{|l|c|c|l|}
\hline FundNr & Marker & Ausprägung & Bearbeiter \\
\hline \hline & AB0-Blutgruppe & & \\
\hline & Augenfarbe & & \\
\hline & CCR5 & & \\
\hline & IRI 3_1 & & \\
\hline DO 3886 & IRI 3_2 & & \\
\hline & DF508 & wt/wt & Scholten \\
\hline DO 3886 & Haarfarbe & & \\
\hline
\end{tabular}

\begin{tabular}{|l|c|c|l|}
\hline FundNr & Marker & Ausprägung & Bearbeiter \\
\hline \hline DO 3886 & H63D & G/G & Krause \\
\hline DO 3886 & IL6-174 & G/C & Pepperl \\
\hline DO 3886 & IL10-1082 & A/G & Suray \\
\hline DO 3886 & IL10-819 & C/T & Suray \\
\hline DO 3886 & IL10-592 & C/A & Suray \\
\hline DO 3886 & IL10-1087 & G/A & Pepperl \\
\hline DO 3886 & IL10-2849 & G/A & Pepperl \\
\hline DO 3886 & TLR2_753 & G/G & Pepperl \\
\hline
\end{tabular}

\begin{tabular}{|l|c|c|l|}
\hline FundNr & Marker & Ausprägung & Bearbeiter \\
\hline \hline DO 3886 & TLR4_299 & A/A & Pepperl \\
\hline DO 3886 & TLR4_399 & C/C & Pepperl \\
\hline DO 3886 & IL4-524 & C/C & Pepperl \\
\hline DO 3886 & IL4-Ra576 & A/A & Pepperl \\
\hline & Lac & & \\
\hline & Rhesus D & & \\
\hline DO 3886 & DRD4 & $3 / 4$ & Blume \\
\hline
\end{tabular}


DO BS/FK 4008 (M5)

\begin{tabular}{|c|c|c|c|c|c|c|c|c|c|c|c|c|c|c|c|}
\hline Amelo & D3S1358 & VWA & FGA & D8S1179 & D21S11 & D18S51 & D5S818 & D13S317 & D7S820 & CSF1PO & TH01 & D16S539 & D2S1338 & D19S433 & D9S1120 \\
\hline$X / Y$ & $15 / 17$ & $16 / 19$ & $20 / 25$ & $10 / 14$ & $28 / 30$ & $15 / 19$ & $11 / 13$ & $8 / 14$ & $10 / 13$ & $10 / 12$ & $7 / 9.3$ & $12 / 13$ & $16 / 24$ & $13 / 15$ & $16 /-$ \\
\hline
\end{tabular}

\begin{tabular}{|c|c|c|c|c|c|c|c|c|c|c|c|c|}
\hline DYS19 & DYS385 & DYS389 I & DYS389 II & DYS390 & DYS391 & DYS392 & DYS393 & DYS437 & DYS438 & DYS439 & \multirow{2}{*}{ Y 6} & \multirow{2}{*}{$\mathbf{1 2 b}(100)$} \\
\hline 16 & 13-17 & 12 & 28 & 24 & 11 & 11 & 13 & 15 & 10 & 11 & & \\
\hline
\end{tabular}

mt:

H \#5

\begin{tabular}{|c|c|c|c|c|c|c|c|c|c|c|c|c|}
\hline \multirow{2}{*}{$\mathbf{s}$} & \multicolumn{12}{|c|}{ Skelettelement } \\
\hline & Humerus & UIna & Radius & Scapula & Clavicula & Femur & Tibia & Os coxae & Os sacrum & Mandibula & Calvarium & Calcaneus \\
\hline re & 4767 & 2060 & 4008 & 3652 & & 3752 & 2096/E 5.02 & 4001 & & & & \\
\hline li & 5503.01 & 5597 & 4079 & 4004.01 & 4315.01 & & 3704 & 3666 & & & 000 & \\
\hline
\end{tabular}

Alter: $\quad$ fad (Morphologie)

Körperhöhe: $170,0 \pm 3,5 \mathrm{~cm}$

Geschlecht:

\begin{tabular}{|l|c|c|l|}
\hline FundNr & Marker & Ausprägung & Bearbeiter \\
\hline \hline & AB0-Blutgruppe & & \\
\hline DO 2096 & Augenfarbe & blau & Krause \\
\hline $\begin{array}{l}\text { DO 3752; } \\
\text { DO 3380.01 }\end{array}$ & CCR5 & wt/(wt) & Mazanec \\
\hline $\begin{array}{l}\text { DO 3752; } \\
\text { DO 3380.01 }\end{array}$ & IRI 3_1 & $112 /-$ & Mazanec \\
\hline $\begin{array}{l}\text { DO 3752; } \\
\text { DO 3380.01 }\end{array}$ & IRI 3_2 & $-/-$ & Mazanec \\
\hline $\begin{array}{l}\text { DO 908 } \\
\text { DO 2096 }\end{array}$ & Haarfarbe & dunkelblond-braun & Schücker \\
\hline DO 908 & C82Y & G/G & Krause \\
\hline
\end{tabular}

\begin{tabular}{|l|c|c|l|}
\hline FundNr & Marker & Ausprägung & Bearbeiter \\
\hline \hline DO 908 & H63D & C/C & Krause \\
\hline DO 3380.01 & IL6-174 & $-/-$ & Pepperl \\
\hline $\begin{array}{l}\text { DO 3380.01; } \\
\text { DO 908 }\end{array}$ & IL10-1082 & A/G & Suray \\
\hline $\begin{array}{l}\text { DO 3380.01; } \\
\text { DO 908 }\end{array}$ & IL10-819 & C/(T) & Suray \\
\hline $\begin{array}{l}\text { DO 3380.01; } \\
\text { DO 908 }\end{array}$ & IL10-592 & C/(A) & Suray \\
\hline DO 3380.01 & IL10-1087 & $-/-$ & Pepperl \\
\hline DO 3380.01 & IL10-2849 & (A)/- & Pepperl \\
\hline DO 3380.01 & TLR2_753 & $-/-$ & Pepperl \\
\hline
\end{tabular}

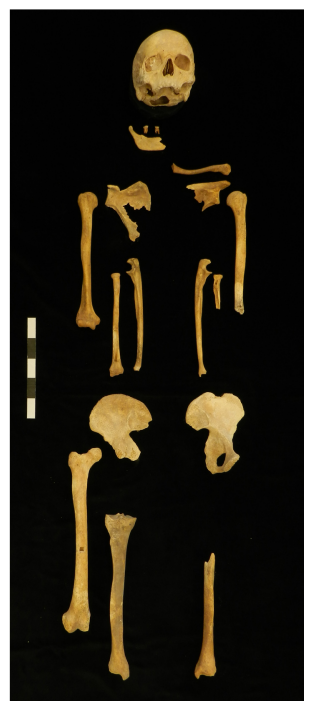

\begin{tabular}{|l|c|c|l|}
\hline FundNr & Marker & Ausprägung & Bearbeiter \\
\hline \hline DO 3380.01 & TLR4_299 & $-/-$ & Pepperl \\
\hline DO 3380.01 & TLR4_399 & $-/-$ & Pepperl \\
\hline DO 3380.01 & IL4-524 & $-/-$ & Pepperl \\
\hline DO 3380.01 & IL4-Ra576 & A/- & Pepperl \\
\hline $\begin{array}{l}\text { DO 908; } \\
\text { DO 3752 }\end{array}$ & Lac & C/C (intolerant) & Seebode \\
\hline $\begin{array}{l}\text { DO 908; } \\
\text { DO 2096; } \\
\text { DO 3752; } \\
\text { DO 4767 }\end{array}$ & Rhesus D & (positiv) & Rohlf \\
\hline & DRD4 & & \\
\hline
\end{tabular}


DO BS/GK 4310.01

\begin{tabular}{|c|c|c|c|c|c|c|c|c|c|c|c|c|c|c|c|}
\hline Amelo & D3S1358 & VWA & FGA & D8S1179 & D21S11 & D18S51 & D5S818 & D13S317 & D7S820 & CSF1PO & TH01 & D16S539 & D2S1338 & D19S433 & D9S1120 \\
\hline$X / Y$ & $-/-$ & $-1-$ & $25 /-$ & $(10) /-$ & $30.2 / 33.2$ & (10)/- & $(11) /(13)$ & $11 /(12)$ & $-1-$ & $-1-$ & $6 / 9.3$ & $-/-$ & $-1-$ & (13)/- & $-1-$ \\
\hline
\end{tabular}

\begin{tabular}{|c|c|c|c|c|c|c|c|c|c|c|c|}
\hline DYS19 & DYS385 & DYS389 I & DYS389 II & DYS390 & DYS391 & DYS392 & DYS393 & DYS437 & DYS438 & DYS439 & n.d. \\
\hline \hline- & -- & 12 & - & - & - & $(9)$ & - & - & $(10)$ & $(11)$ & \\
\hline
\end{tabular}

mt:

U5b

\begin{tabular}{|c|c|c|c|c|c|c|c|c|c|c|c|c|}
\hline \multirow{2}{*}{$\mathbf{s}$} & \multicolumn{12}{|c|}{ Skelettelement } \\
\hline & Humerus & Ulna & Radius & Scapula & Clavicula & Femur & Tibia & Os coxae & Os sacrum & Mandibula & Calvarium & Calcaneus \\
\hline re & 4058 & 2399 & 4310.01 & 3810 & & 2918 & E 31 & 3380.03 & & & & \\
\hline li & 3812 & 2442 & 3850 & & & & & 3660 & & & & \\
\hline
\end{tabular}

Alter: $\quad$ inf I-inf II (Morphologie)

\section{Körperhöhe:}

Geschlecht:

\begin{tabular}{|l|c|c|l|}
\hline FundNr & Marker & Ausprägung & Bearbeiter \\
\hline \hline & AB0-Blutgruppe & & \\
\hline & Augenfarbe & & \\
\hline DO 3812 & CCR5 & wt/- & Mazanec \\
\hline DO 3812 & IRI 3_1 & $-/-$ & Mazanec \\
\hline DO 3812 & IRI 3_2 & $((145)) /-$ & Mazanec \\
\hline & SF508 & & \\
\hline & Haarfarbe & & \\
\hline & C82Y & & \\
\hline
\end{tabular}

\begin{tabular}{|l|c|c|c|}
\hline FundNr & Marker & Ausprägung & Bearbeiter \\
\hline \hline & H63D & & \\
\hline & IL6-174 & & \\
\hline & IL10-1082 & & \\
\hline & IL10-819 & & \\
\hline & IL10-592 & & \\
\hline & IL10-1087 & & \\
\hline & IL10-2849 & & \\
\hline & TLR2_753 & & \\
\hline
\end{tabular}

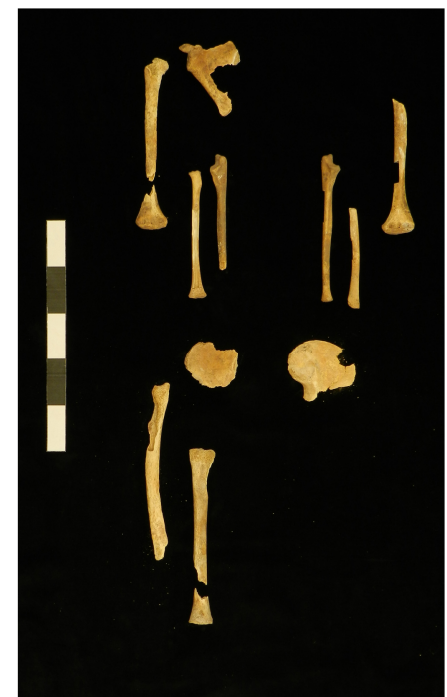

\begin{tabular}{|l|c|c|l|}
\hline FundNr & Marker & Ausprägung & Bearbeiter \\
\hline \hline & TLR4_299 & & \\
\hline & TLR4_399 & & \\
\hline & IL4-524 & & \\
\hline & IL4-Ra576 & & \\
\hline DO 3812 & Lac & $-/-$ & Seebode \\
\hline & Rhesus D & & \\
\hline & DRD4 & & \\
\hline
\end{tabular}


DO BS 5517 (F6)

\begin{tabular}{|c|c|c|c|c|c|c|c|c|c|c|c|c|c|c|c|}
\hline Amelo & D3S1358 & VWA & FGA & D8S1179 & D21S11 & D18S51 & D5S818 & D13S317 & D7S820 & CSF1PO & TH01 & D16S539 & D2S1338 & D19S433 & D9S1120 \\
\hline X/- & $16 / 18$ & 17/- & $21 / 25$ & $12 / 13$ & $29 / 32.2$ & $16 / 17$ & $11 / 12$ & $9 / 12$ & $8 / 10$ & $10 / 13$ & $9 / 9.3$ & $12 / 13$ & $19 / 25$ & 14/- & $15 / 17$ \\
\hline
\end{tabular}

\begin{tabular}{|l|l|l|l|l|l|l|l|l|l|l|l|}
\hline DYS19 & DYS385 & DYS389 I & DYS389 II & DYS390 & DYS391 & DYS392 & DYS393 & DYS437 & DYS438 & DYS439 & \\
\hline \hline & & & & & & & & & & & \\
\hline
\end{tabular}

$\mathrm{mt}$

T2b \#1

\begin{tabular}{|c|c|c|c|c|c|c|c|c|c|c|c|c|}
\hline \multirow{2}{*}{$\mathbf{s}$} & \multicolumn{12}{|c|}{ Skelettelement } \\
\hline & Humerus & Ulna & Radius & Scapula & Clavicula & Femur & Tibia & Os coxae & Os sacrum & Mandibula & Calvarium & Calcaneus \\
\hline re & 3710 & 4052 & 4007 & 5663 & 4318.02 & 3728 & 3669 & 3379.08 & & & & \\
\hline li & 3994 & 3621 & 3379.03 & 4026 & & 3750 & $3707 / 4326.01$ & 3982 & & & & 4032.01 \\
\hline
\end{tabular}

Alter: $\quad$ sjuv (Histologie Knochen; DO 3750)

\section{Körperhöhe:}

Geschlecht:

\begin{tabular}{|l|c|c|l|}
\hline FundNr & Marker & Ausprägung & Bearbeiter \\
\hline \hline DO 3994 & $\begin{array}{c}\text { AB0- } \\
\text { Blutgruppe }\end{array}$ & 0101 & Seidenberg \\
\hline DO 3710; DO 3750 & Augenfarbe & braun & Krause \\
\hline DO 3750 & CCR5 & wt/wt & $\begin{array}{l}\text { Bertermann } \\
\text { Mazanec }\end{array}$ \\
\hline DO 3750 & IRI 3_1 & $((114)) /-$ & $\begin{array}{l}\text { Bertermann } \\
\text { Mazanec }\end{array}$ \\
\hline DO 3750 & IRI 3_2 & $-/-$ & $\begin{array}{l}\text { Bertermann } \\
\text { Mazanec }\end{array}$ \\
\hline DO 3709; DO 5517 & AF508 & wt/wt & Scholten \\
\hline DO 3710 & Haarfarbe & dunkel & Schücker \\
\hline $\begin{array}{l}\text { DO 3709;DO 5517; } \\
\text { DO 4032.01 }\end{array}$ & C82Y & G/G & Krause \\
\hline
\end{tabular}

\begin{tabular}{|l|c|c|l|}
\hline FundNr & Marker & Ausprägung & Bearbeiter \\
\hline \hline $\begin{array}{l}\text { DO 3709; DO 5517; } \\
\text { DO 4032.01 }\end{array}$ & H63D & C/G & Krause \\
\hline DO 3709; DO 5517 & IL6-174 & C/- & Pepperl \\
\hline DO 3750; DO 5517 & IL10-1082 & (A)/G & Suray \\
\hline DO 3750; DO 5517 & IL10-819 & C/(T) & Suray \\
\hline DO 3750; DO 5517 & IL10-592 & C/(A) & Suray \\
\hline DO 3709; DO 5517 & IL10-1087 & G/A & Pepperl \\
\hline DO 3709; DO 5517 & IL10-2849 & (A)/- & Pepperl \\
\hline DO 3709; DO 5517 & TLR2_753 & G/- & Pepperl \\
\hline
\end{tabular}

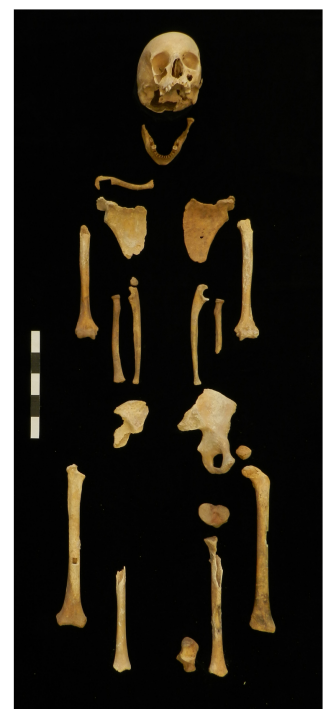

\begin{tabular}{|l|c|c|l|}
\hline FundNr & Marker & Ausprägung & Bearbeiter \\
\hline \hline $\begin{array}{l}\text { DO 3709; } \\
\text { DO 5517 }\end{array}$ & TLR4_299 & A/A & Pepperl \\
\hline $\begin{array}{l}\text { DO 3709; } \\
\text { DO 5517 }\end{array}$ & TLR4_399 & C/- & Pepperl \\
\hline $\begin{array}{l}\text { DO 3709; } \\
\text { DO 5517 }\end{array}$ & IL4-524 & C/C & Pepperl \\
\hline $\begin{array}{l}\text { DO 3709; } \\
\text { DO 5517 }\end{array}$ & IL4-Ra576 & A/A & Pepperl \\
\hline DO 3750 & Lac & C/T (tolerant) & Fulge \\
\hline DO 4032.01 & Rhesus D & negativ & Rohlf \\
\hline & DRD4 & & \\
\hline
\end{tabular}


DO JS 7043.01

\begin{tabular}{|c|c|c|c|c|c|c|c|c|c|c|c|c|c|c|c|}
\hline Amelo & D3S1358 & VWA & FGA & D8S1179 & D21S11 & D18S51 & D5S818 & D13S317 & D7S820 & CSF1PO & TH01 & D16S539 & D2S1338 & D19S433 & D9S1120 \\
\hline$X / Y$ & $15 / 18$ & $15 / 17$ & $21 / 22$ & 13/- & $31.2 /-$ & $15 / 17$ & $12 /-$ & 8/- & $11 /(14)$ & & $6 / 9$ & $11 / 13$ & $24 /(25)$ & $14 / 16$ & $13 / 16$ \\
\hline
\end{tabular}

\begin{tabular}{|c|c|c|c|c|c|c|c|c|c|c|c|c|}
\hline DYS19 & DYS385 & DYS389 I & DYS389 II & DYS390 & DYS391 & DYS392 & DYS393 & DYS437 & DYS438 & DYS439 & \multirow{2}{*}{ Y1 } & \multirow{2}{*}{ I2b (100) } \\
\hline 16 & 13-17 & 12 & 28 & 25 & 11 & 11 & 13 & 15 & 10 & 11 & & \\
\hline
\end{tabular}

mt:

H6 \#3

\begin{tabular}{|c|c|c|c|c|c|c|c|c|c|c|c|c|}
\hline \multirow{2}{*}{$\mathbf{s}$} & \multicolumn{12}{|c|}{ Skelettelement } \\
\hline & Humerus & UIna & Radius & Scapula & Clavicula & Femur & Tibia & Os coxae & Os sacrum & Mandibula & Calvarium & Calcaneus \\
\hline re & 7043.02 & & 7043.03 & 7043.07 & 7043.05 & 7030.06 & 6982 & $7030.07 / 7052.02$ & & & 7043.01/ & \\
\hline li & 7227.02 & 6987.01 & 7052.01 & 7043.06 & 7043.04 & 6962 & 7339 & 7030.08 & & 1221.03 & $\begin{array}{l}\text { Maxilla } \\
7270.10\end{array}$ & \\
\hline
\end{tabular}

Alter: $\quad$ finf I (Morphologie/Zahnstatus; ca. 1 Jahr)

Körperhöhe:

Geschlecht:

\begin{tabular}{|l|c|l|l|}
\hline FundNr & Marker & Ausprägung & Bearbeiter \\
\hline \hline & AB0-Blutgruppe & & \\
\hline & Augenfarbe & & \\
\hline & CCR5 & & \\
\hline & IRI 3_1 & & \\
\hline & IRI 3_2 & & \\
\hline & $\Delta$ F508 & & \\
\hline & Haarfarbe & & \\
\hline & C82Y & & \\
\hline
\end{tabular}

\begin{tabular}{|l|c|c|c|}
\hline FundNr & Marker & Ausprägung & Bearbeiter \\
\hline \hline & H63D & & \\
\hline & IL6-174 & & \\
\hline & IL10-1082 & & \\
\hline & IL10-819 & & \\
\hline & IL10-592 & & \\
\hline & IL10-1087 & & \\
\hline & IL10-2849 & & \\
\hline & TLR2_753 & & \\
\hline
\end{tabular}

\begin{tabular}{|l|c|l|l|}
\hline FundNr & Marker & Ausprägung & Bearbeiter \\
\hline \hline & TLR4_299 & & \\
\hline & TLR4_399 & & \\
\hline & IL4-524 & & \\
\hline & IL4-Ra576 & & \\
\hline & Lac & & \\
\hline & Rhesus D & & \\
\hline & DRD4 & & \\
\hline
\end{tabular}


DO JS 7075.01

\begin{tabular}{|c|c|c|c|c|c|c|c|c|c|c|c|c|c|c|c|}
\hline Amelo & D3S1358 & VWA & FGA & D8S1179 & D21S11 & D18S51 & D5S818 & D13S317 & D7S820 & CSF1PO & TH01 & D16S539 & D2S1338 & D19S433 & D9S1120 \\
\hline $\mathrm{X} /-$ & $16 / 18$ & 17/18 & $20 / 22$ & $12 / 13$ & 28/- & $14 / 15$ & $11 / 12$ & $12 / 13$ & $10 / 11$ & & $7 / 9.3$ & $9 / 12$ & $20 / 25$ & $14 / 18.2$ & $13 / 16$ \\
\hline
\end{tabular}

\begin{tabular}{|l|l|l|l|l|l|l|l|l|l|l|l|}
\hline DYS19 & DYS385 & DYS389 I & DYS389 II & DYS390 & DYS391 & DYS392 & DYS393 & DYS437 & DYS438 & DYS439 & \\
\hline \hline & & & & & & & & & & & \\
\hline
\end{tabular}

mt:

$H^{*}$

\begin{tabular}{|c|c|c|c|c|c|c|c|c|c|c|c|c|}
\hline \multirow{2}{*}{$\mathbf{s}$} & \multicolumn{12}{|c|}{ Skelettelement } \\
\hline & Humerus & Ulna & Radius & Scapula & Clavicula & Femur & Tibia & Os coxae & Os sacrum & Mandibula & Calvarium & Calcaneus \\
\hline re & 7230 & & & 7156.01 & 7227.01 & & & 6983 & & & & \\
\hline li & & & & 7231 & & & 7058 & & 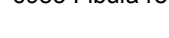 & & & \\
\hline
\end{tabular}

Alter: $\quad$ mad (Histologie Knochen; DO 7058)

\section{Körperhöhe:}

Geschlecht: ?

\begin{tabular}{|l|c|l|l|}
\hline FundNr & Marker & Ausprägung & Bearbeiter \\
\hline \hline & AB0-Blutgruppe & & \\
\hline & Augenfarbe & & \\
\hline & CCR5 & & \\
\hline & IRI 3_1 & & \\
\hline & IRI 3_2 & & \\
\hline & SF508 & & \\
\hline & Haarfarbe & & \\
\hline & C82Y & & \\
\hline
\end{tabular}

\begin{tabular}{|l|c|c|c|}
\hline FundNr & Marker & Ausprägung & Bearbeiter \\
\hline \hline & H63D & & \\
\hline & IL6-174 & & \\
\hline & IL10-1082 & & \\
\hline & IL10-819 & & \\
\hline & IL10-592 & & \\
\hline & IL10-1087 & & \\
\hline & IL10-2849 & & \\
\hline & TLR2_753 & & \\
\hline
\end{tabular}

\begin{tabular}{|l|c|l|l|}
\hline FundNr & Marker & Ausprägung & Bearbeiter \\
\hline \hline & TLR4_299 & & \\
\hline & TLR4_399 & & \\
\hline & IL4-524 & & \\
\hline & IL4-Ra576 & & \\
\hline & Lac & & \\
\hline & Rhesus D & & \\
\hline & DRD4 & & \\
\hline
\end{tabular}


DO FK/KS E 11

\begin{tabular}{|c|c|c|c|c|c|c|c|c|c|c|c|c|c|c|c|}
\hline Amelo & D3S1358 & VWA & FGA & D8S1179 & D21S11 & D18S51 & D5S818 & D13S317 & D7S820 & CSF1PO & TH01 & D16S539 & D2S1338 & D19S433 & D9S1120 \\
\hline$X / Y$ & 16/- & (15)/- & $(22) /(25)$ & $-/-$ & $(29) /-$ & 16/- & (13)/- & $-1-$ & $-1-$ & & $9.3 /-$ & $(11) /(12)$ & $-1-$ & (13)/- & $-1-$ \\
\hline
\end{tabular}

\begin{tabular}{|c|c|c|c|c|c|c|c|c|c|c|c|}
\hline DYS19 & DYS385 & DYS389 I & DYS389 II & DYS390 & DYS391 & DYS392 & DYS393 & DYS437 & DYS438 & DYS439 & n.d. \\
\hline \hline- & -- & 12 & - & - & $(11)$ & 11 & - & - & - & 11 & \\
\hline
\end{tabular}

mt:

H39

\begin{tabular}{|c|c|c|c|c|c|c|c|c|c|c|c|c|}
\hline \multirow{2}{*}{ s } & \multicolumn{12}{|c|}{ Skelettelement } \\
\hline & Humerus & Ulna & Radius & Scapula & Clavicula & Femur & Tibia & Os coxae & Os sacrum & Mandibula & Calvarium & Calcaneus \\
\hline re & E 11 & E 23 & 3190.01 & 923.01 & & E OF 1 & 913.01 & E 08 & & & & \\
\hline li & E 12 & & 909.03 & 33 & 914.02 & E 03 & E 30 & $\begin{array}{c}\text { E 09/103.03/ } \\
905.04\end{array}$ & & & & \\
\hline
\end{tabular}

Alter: $\quad$ inf Il-fjuv (Morphologie)

Körperhöhe:

Geschlecht: $ぇ$

\begin{tabular}{|l|c|l|l|}
\hline FundNr & Marker & Ausprägung & Bearbeiter \\
\hline \hline & AB0-Blutgruppe & & \\
\hline & Augenfarbe & & \\
\hline & CCR5 & & \\
\hline & IRI 3_1 & & \\
\hline & IRI 3_2 & & \\
\hline & $\Delta$ F508 & & \\
\hline & Haarfarbe & & \\
\hline & C82Y & & \\
\hline
\end{tabular}

\begin{tabular}{|l|c|l|l|}
\hline FundNr & Marker & Ausprägung & Bearbeiter \\
\hline \hline & H63D & & \\
\hline & IL6-174 & & \\
\hline & IL10-1082 & & \\
\hline & IL10-819 & & \\
\hline & IL10-592 & & \\
\hline & IL10-1087 & & \\
\hline & IL10-2849 & & \\
\hline & TLR2_753 & & \\
\hline
\end{tabular}

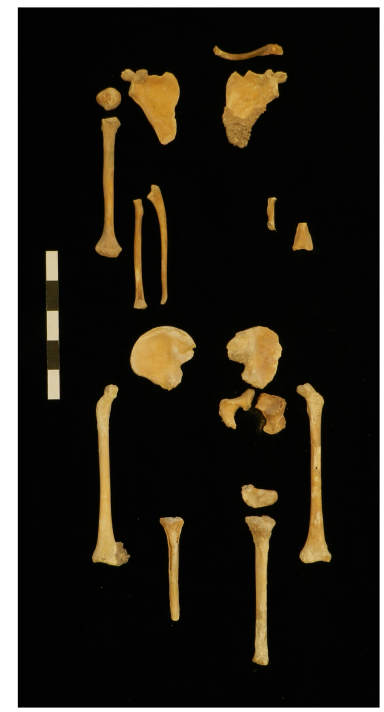

\begin{tabular}{|l|c|l|l|}
\hline FundNr & Marker & Ausprägung & Bearbeiter \\
\hline \hline & TLR4_299 & & \\
\hline & TLR4_399 & & \\
\hline & IL4-524 & & \\
\hline & IL4-Ra576 & & \\
\hline & Lac & & \\
\hline & Rhesus D & & \\
\hline & DRD4 & & \\
\hline
\end{tabular}


DO E 33 (M12)

\begin{tabular}{|c|c|c|c|c|c|c|c|c|c|c|c|c|c|c|c|}
\hline Amelo & D3S1358 & VWA & FGA & D8S1179 & D21S11 & D18S51 & D5S818 & D13S317 & D7S820 & CSF1PO & TH01 & D16S539 & D2S1338 & D19S433 & D9S1120 \\
\hline$X / Y$ & $15 / 18$ & $16 / 18$ & $20 / 21$ & $12 / 13$ & $30 / 33.2$ & $15 / 18$ & 9/11 & $11 /-$ & 9/(13) & 13/- & $7 / 9.3$ & $11 / 13$ & $17 /(25)$ & 13/- & $(16) / 17$ \\
\hline
\end{tabular}

\begin{tabular}{|c|c|c|c|c|c|c|c|c|c|c|c|c|}
\hline DYS19 & DYS385 & DYS389 I & DYS389 II & DYS390 & DYS391 & DYS392 & DYS393 & DYS437 & DYS438 & DYS439 & \multirow{2}{*}{ Y 4} & \multirow{2}{*}{ I2b $(99,9)$} \\
\hline 17 & (13)-(17) & 12 & (28) & - & 11 & - & - & - & 10 & 11 & & \\
\hline
\end{tabular}

mt: J1c

\begin{tabular}{|c|c|c|c|c|c|c|c|c|c|c|c|c|}
\hline \multirow{2}{*}{$\mathbf{s}$} & \multicolumn{12}{|c|}{ Skelettelement } \\
\hline & Humerus & Ulna & Radius & Scapula & Clavicula & Femur & Tibia & Os coxae & Os sacrum & Mandibula & Calvarium & Calcaneus \\
\hline \multicolumn{13}{|c|}{ re } \\
\hline $\mathrm{li}$ & & & & & & & & & & ᄃJ0 & & \\
\hline
\end{tabular}

Alter: $\quad$ inf II (Morphologie/ Zahnstatus)

\section{Körperhöhe:}

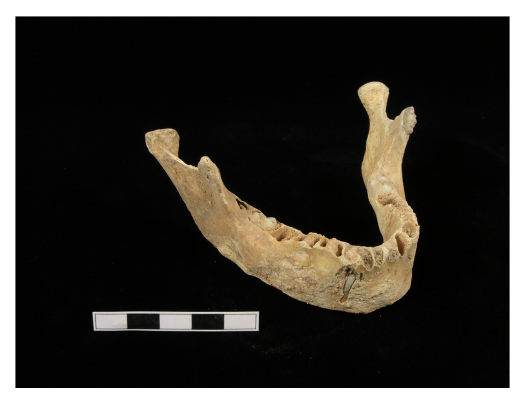

Geschlecht:

\begin{tabular}{|l|c|c|l|}
\hline FundNr & Marker & Ausprägung & Bearbeiter \\
\hline \hline & AB0-Blutgruppe & & \\
\hline & Augenfarbe & & \\
\hline & CCR5 & & \\
\hline & IRI 3_1 & & \\
\hline & IRI 3_2 & & \\
\hline DO E 33 & DF508 & wt/wt & Scholten \\
\hline & Haarfarbe & & \\
\hline DO E 33 & C82Y & $-/-$ & Krause \\
\hline
\end{tabular}

\begin{tabular}{|l|c|c|l|}
\hline FundNr & Marker & Ausprägung & Bearbeiter \\
\hline \hline DO E 33 & H63D & $-/-$ & Krause \\
\hline DO E 33 & IL6-174 & $-/-$ & Pepperl \\
\hline DO E 33 & IL10-1082 & A/G & Suray \\
\hline DO E 33 & IL10-819 & C/T & Suray \\
\hline DO E 33 & IL10-592 & C/A & Suray \\
\hline DO E 33 & IL10-1087 & $-/-$ & Pepperl \\
\hline DO E 33 & IL10-2849 & (A)/- & Pepperl \\
\hline DO E 33 & TLR2_753 & (G)/- & Pepperl \\
\hline
\end{tabular}

\begin{tabular}{|l|c|c|l|}
\hline FundNr & Marker & Ausprägung & Bearbeiter \\
\hline \hline DO E 33 & TLR4_299 & $-/-$ & Pepperl \\
\hline DO E 33 & TLR4_399 & (C)/- & Pepperl \\
\hline DO E 33 & IL4-524 & $-/-$ & Pepperl \\
\hline DO E 33 & IL4-Ra576 & (A)/- & Pepperl \\
\hline & Lac & & \\
\hline & Rhesus D & & \\
\hline & DRD4 & & \\
\hline
\end{tabular}


DO E 37 (F21)

\begin{tabular}{|c|c|c|c|c|c|c|c|c|c|c|c|c|c|c|c|}
\hline Amelo & D3S1358 & VWA & FGA & D8S1179 & D21S11 & D18S51 & D5S818 & D13S317 & D7S820 & CSF1PO & TH01 & D16S539 & D2S1338 & D19S433 & D9S1120 \\
\hline$X / Y$ & $(14) / 16$ & 16/- & $22 / 24$ & $15 /-$ & $(29) /-$ & $-1-$ & $(10) /(11)$ & $8 /(13)$ & (8)/- & $(10) /-$ & $9.3 /-$ & $-1-$ & $-/$ & (15)/- & $-/-$ \\
\hline
\end{tabular}

\begin{tabular}{|c|c|c|c|c|c|c|c|c|c|c|c|}
\hline DYS19 & DYS385 & DYS389 I & DYS389 II & DYS390 & DYS391 & DYS392 & DYS393 & DYS437 & DYS438 & DYS439 & \multirow{2}{*}{ Y 1 o. Y 6 } \\
\hline \hline$(16)$ & $17--$ & - & - & - & $(11)$ & 11 & $(13)$ & - & 10 & 11 & \\
\hline
\end{tabular}

\section{$\mathrm{mt}: \quad \mathrm{H} \# \mathbf{5}$}

\begin{tabular}{|c|c|c|c|c|c|c|c|c|c|c|c|c|}
\hline \multirow{2}{*}{$\mathbf{s}$} & \multicolumn{12}{|c|}{ Skelettelement } \\
\hline & Humerus & Ulna & Radius & Scapula & Clavicula & Femur & Tibia & Os coxae & Os sacrum & Mandibula & Calvarium & Calcaneus \\
\hline \multicolumn{13}{|c|}{ re } \\
\hline li & & & & & & & & & & & & \\
\hline
\end{tabular}

Alter: $\quad$ inf II (Morphologie/ Zahnstatus)

\section{Körperhöhe:}

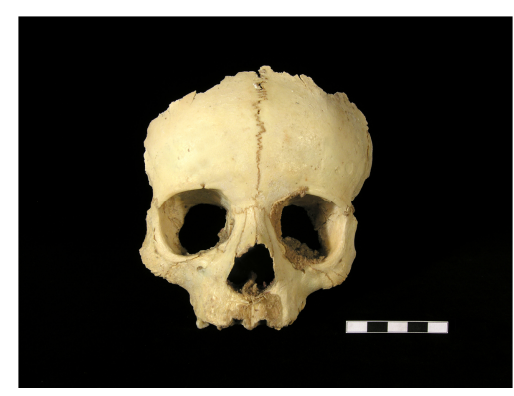

Geschlecht:

\begin{tabular}{|l|c|l|l|}
\hline FundNr & Marker & Ausprägung & Bearbeiter \\
\hline \hline & AB0-Blutgruppe & & \\
\hline & Augenfarbe & & \\
\hline & CCR5 & & \\
\hline & IRI 3_1 & & \\
\hline & IRI 3_2 & & \\
\hline & DF508 & & \\
\hline & Haarfarbe & & \\
\hline & C82Y & & \\
\hline
\end{tabular}

\begin{tabular}{|l|c|c|l|}
\hline FundNr & Marker & Ausprägung & Bearbeiter \\
\hline \hline & H63D & & \\
\hline DO E 37 & IL6-174 & - -- & Pepperl \\
\hline DO E 37 & IL10-1082 & - -- & Suray \\
\hline DO E 37 & IL10-819 & - -- & Suray \\
\hline DO E 37 & IL10-592 & $-/-$ & Suray \\
\hline DO E 37 & IL10-1087 & - -- & Pepperl \\
\hline DO E 37 & IL10-2849 & (A)/- & Pepperl \\
\hline DO E 37 & TLR2_753 & - -- & Pepperl \\
\hline
\end{tabular}

\begin{tabular}{|l|c|c|l|}
\hline FundNr & Marker & Ausprägung & Bearbeiter \\
\hline \hline DO E 37 & TLR4_299 & (A)/- & Pepperl \\
\hline DO E 37 & TLR4_399 & $-/-$ & Pepperl \\
\hline DO E 37 & IL4-524 & $-/-$ & Pepperl \\
\hline DO E 37 & IL4-Ra576 & (A)/- & Pepperl \\
\hline & Lac & & \\
\hline & Rhesus D & & \\
\hline & DRD4 & & \\
\hline
\end{tabular}


DO HS/GK N 957.01

\begin{tabular}{|c|c|c|c|c|c|c|c|c|c|c|c|c|c|c|c|}
\hline Amelo & D3S1358 & VWA & FGA & D8S1179 & D21S11 & D18S51 & D5S818 & D13S317 & D7S820 & CSF1PO & TH01 & D16S539 & D2S1338 & D19S433 & D9S1120 \\
\hline $\mathrm{X} /(\mathrm{Y})$ & $-1-$ & $-/-$ & $-1-$ & $-1-$ & $-/-$ & $-1-$ & $(12) /-$ & $(9) /(10)$ & & $(10) /(13)$ & $(6) /(9.3)$ & $-1-$ & $-1-$ & (13)/- & $-1-$ \\
\hline
\end{tabular}

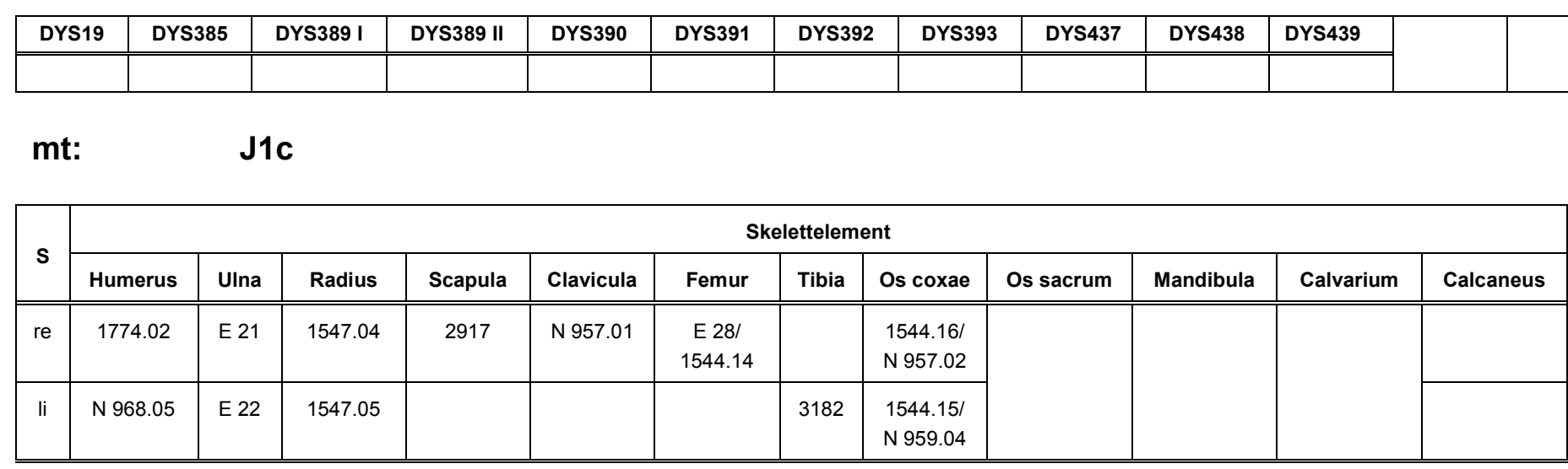

Alter: $\quad$ inf II (Morphologie)

Körperhöhe:

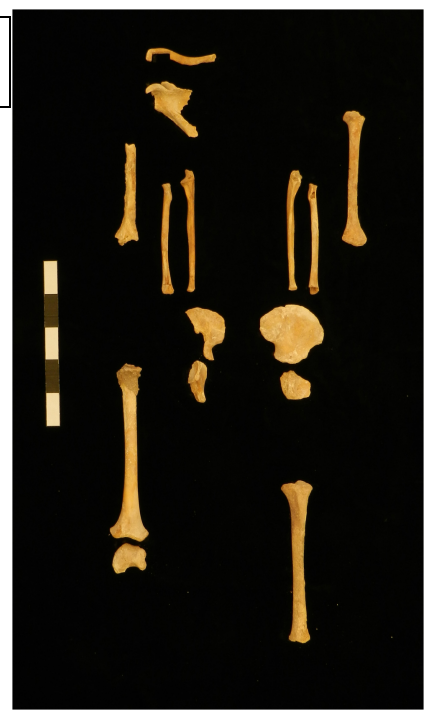

Geschlecht: (đ)

\begin{tabular}{|l|c|l|l|}
\hline FundNr & Marker & Ausprägung & Bearbeiter \\
\hline \hline & AB0-Blutgruppe & & \\
\hline & Augenfarbe & & \\
\hline & CCR5 & & \\
\hline & IRI 3_1 & & \\
\hline & IRI 3_2 & & \\
\hline & SF508 & & \\
\hline & Haarfarbe & & \\
\hline & C82Y & & \\
\hline
\end{tabular}

\begin{tabular}{|l|c|l|l|}
\hline FundNr & Marker & Ausprägung & Bearbeiter \\
\hline \hline & H63D & & \\
\hline & IL6-174 & & \\
\hline & IL10-1082 & & \\
\hline & IL10-819 & & \\
\hline & IL10-592 & & \\
\hline & IL10-1087 & & \\
\hline & IL10-2849 & & \\
\hline & TLR2_753 & & \\
\hline
\end{tabular}

\begin{tabular}{|l|c|l|l|}
\hline FundNr & Marker & Ausprägung & Bearbeiter \\
\hline \hline & TLR4_299 & & \\
\hline & TLR4_399 & & \\
\hline & IL4-524 & & \\
\hline & IL4-Ra576 & & \\
\hline & Lac & & \\
\hline & Rhesus D & & \\
\hline & DRD4 & & \\
\hline
\end{tabular}


DO BS/FK/RG/HS/GK/KS N 962.01

\begin{tabular}{|c|c|c|c|c|c|c|c|c|c|c|c|c|c|c|c|}
\hline Amelo & D3S1358 & VWA & FGA & D8S1179 & D21S11 & D18S51 & D5S818 & D13S317 & D7S820 & CSF1PO & TH01 & D16S539 & D2S1338 & D19S433 & D9S1120 \\
\hline$X /-$ & $-/-$ & $-1-$ & (22)/- & $(13) /-$ & $(29) /(32.2)$ & $(14) / 16$ & $(10) / 11$ & $(9) / 13$ & $-1-$ & & $7 /(9.3)$ & & & & \\
\hline
\end{tabular}

\begin{tabular}{|l|l|l|l|l|l|l|l|l|l|l|l|}
\hline DYS19 & DYS385 & DYS389 I & DYS389 II & DYS390 & DYS391 & DYS392 & DYS393 & DYS437 & DYS438 & DYS439 & \\
\hline \hline & & & & & & & & & & & \\
\hline
\end{tabular}

mt:

\section{HV6a}

\begin{tabular}{|c|c|c|c|c|c|c|c|c|c|c|c|c|}
\hline \multirow{2}{*}{$\mathbf{s}$} & \multicolumn{12}{|c|}{ Skelettelement } \\
\hline & Humerus & Ulna & Radius & Scapula & Clavicula & Femur & Tibia & Os coxae & Os sacrum & Mandibula & Calvarium & Calcaneus \\
\hline re & & & E 25 & & N 969.09 & 2103 & 4047 & & & & & \\
\hline li & & 3190.14 & N 962.01 & 915.04 & & & 2088 & 307.02 & & & & \\
\hline
\end{tabular}

Alter: $\quad$ inf II (Morphologie)

\section{Körperhöhe:}

Geschlecht:

\begin{tabular}{|l|c|l|c|}
\hline FundNr & Marker & Ausprägung & Bearbeiter \\
\hline \hline & AB0-Blutgruppe & & \\
\hline & Augenfarbe & & \\
\hline & CCR5 & & \\
\hline & IRI 3_1 & & \\
\hline & IRI 3_2 & & \\
\hline & SF508 & & \\
\hline & Haarfarbe & & \\
\hline & C82Y & & \\
\hline
\end{tabular}

\begin{tabular}{|l|c|l|l|}
\hline FundNr & Marker & Ausprägung & Bearbeiter \\
\hline \hline & H63D & & \\
\hline & IL6-174 & & \\
\hline & IL10-1082 & & \\
\hline & IL10-819 & & \\
\hline & IL10-592 & & \\
\hline & IL10-1087 & & \\
\hline & IL10-2849 & & \\
\hline & TLR2_753 & & \\
\hline
\end{tabular}

\begin{tabular}{|l|c|l|l|}
\hline FundNr & Marker & Ausprägung & Bearbeiter \\
\hline \hline & TLR4_299 & & \\
\hline & TLR4_399 & & \\
\hline & IL4-524 & & \\
\hline & IL4-Ra576 & & \\
\hline DO N 962.01 & Lac & T/- (tolerant) & Seebode \\
\hline & Rhesus D & & \\
\hline & DRD4 & & \\
\hline
\end{tabular}


DO RG/FK R 1 (F12)

\begin{tabular}{|c|c|c|c|c|c|c|c|c|c|c|c|c|c|c|c|}
\hline Amelo & D3S1358 & VWA & FGA & D8S1179 & D21S11 & D18S51 & D5S818 & D13S317 & D7S820 & CSF1PO & TH01 & D16S539 & D2S1338 & D19S433 & D9S1120 \\
\hline$X /-$ & $16 /-$ & $14 / 17$ & $21 /-$ & 13/- & $29 / 33.2$ & $16 / 17$ & $9 / 12$ & $11 / 12$ & $11 / 12$ & $10 / 11$ & 9.3/- & $11 / 12$ & $19 / 21$ & $15 /-$ & $16 /-$ \\
\hline
\end{tabular}

\begin{tabular}{|l|l|l|l|l|l|l|l|l|l|l|l|}
\hline DYS19 & DYS385 & DYS389 I & DYS389 II & DYS390 & DYS391 & DYS392 & DYS393 & DYS437 & DYS438 & DYS439 & \\
\hline \hline & & & & & & & & & & & \\
\hline
\end{tabular}

$\mathrm{mt}$ :

H39

\begin{tabular}{|c|c|c|c|c|c|c|c|c|c|c|c|c|}
\hline \multirow{2}{*}{$\mathrm{s}$} & \multicolumn{12}{|c|}{ Skelettelement } \\
\hline & Humerus & Ulna & Radius & Scapula & Clavicula & Femur & Tibia & Os coxae & Os sacrum & Mandibula & Calvarium & Calcaneus \\
\hline re & & 410 & 1537.01 & & 906.01 & 67.02 & & & & & & \\
\hline li & & 126.01 & 1571 & & & & & & & & & \\
\hline
\end{tabular}

Alter: $\quad$ sad-fmat (Histologie Zahn; DO R 1)

Körperhöhe:

Geschlecht:

\begin{tabular}{|l|c|c|l|}
\hline FundNr & Marker & Ausprägung & Bearbeiter \\
\hline \hline & AB0-Blutgruppe & & \\
\hline & Augenfarbe & & \\
\hline & CCR5 & & \\
\hline & IRI 3_1 & & \\
\hline & IRI 3_2 & & \\
\hline DO R 1 & DF508 & wt/wt & Scholten \\
\hline & Haarfarbe & & \\
\hline DO R 1 & C82Y & G/G & Krause \\
\hline
\end{tabular}

\begin{tabular}{|l|c|c|l|}
\hline FundNr & Marker & Ausprägung & Bearbeiter \\
\hline \hline DO R 1 & H63D & C/C & Krause \\
\hline DO R 1 & IL6-174 & C/C & Pepperl \\
\hline DO R 1 & IL10-1082 & A/- & Suray \\
\hline DO R 1 & IL10-819 & C/T & Suray \\
\hline DO R 1 & IL10-592 & C/A & Suray \\
\hline DO R 1 & IL10-1087 & A/- & Pepperl \\
\hline DO R 1 & IL10-2849 & G/A & Pepperl \\
\hline DO R 1 & TLR2_753 & G/G & Pepperl \\
\hline
\end{tabular}

\begin{tabular}{|l|c|c|l|}
\hline FundNr & Marker & Ausprägung & Bearbeiter \\
\hline \hline DO R 1 & TLR4_299 & A/- & Pepperl \\
\hline DO R 1 & TLR4_399 & C/C & Pepperl \\
\hline & IL4-524 & $-/-$ & Pepperl \\
\hline DO R 1 & IL4-Ra576 & A/- & Pepperl \\
\hline DO R 1 & Lac & C/C (intolerant) & Fulge \\
\hline & Rhesus D & & \\
\hline & DRD4 & & \\
\hline
\end{tabular}




\subsection{Liste der Examensarbeiten zur Lichtensteinhöhle}

Tabelle 40: Übersicht über die innerhalb der Forschungsprojekte zur Lichtensteinhöhle angefertigten Abschlussarbeiten.

\begin{tabular}{|c|c|c|c|}
\hline Autor & Jahr & Titel & Abschluss \\
\hline Burger, J & 1997 & $\begin{array}{l}\text { Erhaltungszustand von DNA aus praehistorischen Zähnen } \\
\text { unterschiedlichen Liegemilieus und verschiedener Art der Lagerung }\end{array}$ & Magisterarbeit \\
\hline Schultes, T & 1997 & $\begin{array}{l}\text { Zuordnung isolierter Skelettelemente mittels Typisierung von alter } \\
\text { DNA }\end{array}$ & Diplomarbeit \\
\hline Haack, K & 1999 & $\begin{array}{l}\text { Detektion von aDNA-Sequenzen mit über } 300 \text { bp Länge aus } \\
\text { menschlichen bodengelagerten Skelettmaterial }\end{array}$ & Diplomarbeit \\
\hline Schmerer, WM & 1999 & $\begin{array}{l}\text { Optimierung der STR-Genotypenanalyse an Extrakten alter DNA aus } \\
\text { bodengelagertem menschlichem Skelettmaterial }\end{array}$ & Dissertation \\
\hline Burger, J & 2000 & $\begin{array}{l}\text { Sequenzierung, RFLP-Analyse und STR-Genotypisierung alter DNA } \\
\text { aus archäologischen Funden und historischen Werkstoffen }\end{array}$ & Dissertation \\
\hline Krebs, O & 2000 & Extraktion von aDNA aus stark inhibierten Proben durch HPLC & Diplomarbeit \\
\hline Müller, A & 2000 & DNA-Extraktion aus Knochen - ein Methodenvergleich & Diplomarbeit \\
\hline Schultes, T & 2000 & $\begin{array}{l}\text { Typisierung alter DNA zur Rekonstruktion von Verwandtschaft in } \\
\text { einem bronzezeitlichen Skelettkollektiv }\end{array}$ & Dissertation \\
\hline Müller, B & 2002 & $\begin{array}{l}\text { Design einer Multiplex-PCR zur Typisierung von Y-STR Haplotypen } \\
\text { aus degradierter DNA }\end{array}$ & Diplomarbeit \\
\hline Hess, C & 2003 & $\begin{array}{l}\text { Prinzipien des Nachweises langer Deletionen an degradierter DNA } \\
\text { aus forensischem und historischem Probenmaterial }\end{array}$ & Diplomarbeit \\
\hline Schilz, F & 2003 & $\begin{array}{l}\text { Design einer Multiplex-PCR zur Typisierung von } 16 \text { short tandem } \\
\text { repeats in degradierter DNA aus forensischem und historischem } \\
\text { Probenmaterial }\end{array}$ & Diplomarbeit \\
\hline Bertermann, U & 2004 & $\begin{array}{l}\text { Alte STR- Haplotypen und delta32 ccr5 - Untersuchungen zur } \\
\text { Datierungsfrage einer immunologisch relevanten Mutation an } \\
\text { Skelettfunden der Lichtensteinhöhle und des Frankenbergquartiers }\end{array}$ & $\begin{array}{l}\text { Staatsexamens- } \\
\text { arbeit }\end{array}$ \\
\hline Pollmann, J & 2004 & Zerstörungsfreie DNA - Extraktion aus historischen Skelettelementen. & Diplomarbeit \\
\hline Schmidt, D & 2004 & Entwicklung neuer Markersysteme für die ancient DNA - Analyse & Dissertation \\
\hline Croll, St & 2005 & $\begin{array}{l}\text { Fingerprinting an Tibiae aus der Lichtensteinhöhle - } \\
\text { Molekulargenetische Analysen von short tandem repeats zur } \\
\text { Aufdeckung von Verteilungsmustern isoliert vorliegender } \\
\text { Skelettelemente aus einer bronzezeitlichen gestörten Fundsituation }\end{array}$ & Diplomarbeit \\
\hline Gaertner, S & 2005 & $\begin{array}{l}\text { Fingerprinting an bronzezeitlichen Ossa radii - Molekulargenetische } \\
\text { Analysen von short tandem repeats zur Aufdeckung von } \\
\text { Verteilungsmustern isoliert vorliegender Skelettelemente aus einer } \\
\text { gestörten Fundsituation }\end{array}$ & $\begin{array}{l}\text { Staatsexamens- } \\
\text { arbeit }\end{array}$ \\
\hline Fulge, M & 2005 & $\begin{array}{l}\text { Laktosetoleranz in der bronzezeitlichen Lichtensteinhöhle - } \\
\text { Molekulargenetischer Nachweis des Polymorphismus C/T } 13910 \text { an } \\
\text { prähistorischer DNA }\end{array}$ & $\begin{array}{l}\text { Staatsexamens- } \\
\text { arbeit }\end{array}$ \\
\hline Klingner, S & 2005 & $\begin{array}{l}\text { Fingerprinting an Calcanei aus der Lichtensteinhöhle - } \\
\text { Molekulargenetische Analysen von short tandem repeats zur } \\
\text { Aufdeckung von Verteilungsmustern isoliert vorliegender } \\
\text { Skelettelemente aus einer bronzezeitlich gestörten Fundsituation }\end{array}$ & Diplomarbeit \\
\hline Mußlick, D & 2005 & $\begin{array}{l}\text { Fingerprinting an Humeri aus der Lichtensteinhöhle - } \\
\text { Molekulargenetische Analysen an short tandem repeats zur } \\
\text { Aufdeckung von Verteilungsmustern isoliert vorliegender } \\
\text { Skelettelemente aus einer bronzezeitlich gestörten Fundsituation }\end{array}$ & Diplomarbeit \\
\hline Puder, Y & 2005 & $\begin{array}{l}\text { Molekulargenetische Identifikationen der Allelhäufigkeit eines } \\
\text { immungenetischen Markers der IL-6-Promotorregion bei } \\
\text { bronzezeitlichen Individuen aus Mitteleuropa }\end{array}$ & Diplomarbeit \\
\hline Stauch, J & 2005 & $\begin{array}{l}\text { Die Lichtensteinhöhle im Harz - Archäologisch-anthropologische } \\
\text { Untersuchungen anhand isolierter Skelettreste eines Individuums mit } \\
\text { Trepanation aus einem bronzezeitlichen Skelettkollektiv }\end{array}$ & Magisterarbeit \\
\hline Zierdt, H & 2005 & $\begin{array}{l}\text { Steroidhormone in bodengelagertem Skelettmaterial - Ein Ansatz zur } \\
\text { Abschätzung von Fertilitätsparametern in historischen Bevölkerungen }\end{array}$ & Dissertation \\
\hline
\end{tabular}


Fortsetzung Tabelle 40: Übersicht über die innerhalb der Forschungsprojekte zur Lichtensteinhöhle angefertigten Abschlussarbeiten.

\begin{tabular}{|c|c|c|c|}
\hline Autor & Jahr & Titel & Abschluss \\
\hline Adler, M & 2006 & $\begin{array}{l}\text { Degradierungsmuster alter DNA Quantifizierung von DNA-Erhaltung } \\
\text { unterschiedlicher chromosomaler Lokalisation durch Real-Time-PCR }\end{array}$ & Diplomarbeit \\
\hline Krause, S & 2006 & $\begin{array}{l}\text { Genetische Analysen zur Bestimmung der Allelfrequenz von } \\
\text { C282Y/H63D (erbliche Eisenpeicherkrankheit) an Skelettelementen } \\
\text { eines bronzezeitlichen Fundkomplexes }\end{array}$ & $\begin{array}{l}\text { Staatsexamens } \\
\text { arbeit }\end{array}$ \\
\hline Schilz, F & 2006 & $\begin{array}{l}\text { Molekulargenetische Verwandtschaftsanalysen am prähistorischen } \\
\text { Skelettkollektiv der Lichtensteinhöhle }\end{array}$ & Dissertation \\
\hline Scholten, A & 2006 & $\begin{array}{l}\text { Genetische Analysen zur Bestimmung der Allelfrequenz von } \Delta \text { F508 } \\
\text { an menschlichen Skelettelementen eines bronzezeitlichen } \\
\text { Fundkomplexes }\end{array}$ & Diplomarbeit \\
\hline Wenzel, M & 2006 & $\begin{array}{l}\text { Optimierung der Parameter der Probenvorbereitung und Extraktion } \\
\text { mit dem BioRobot EZ1 }\end{array}$ & Diplomarbeit \\
\hline Otto, M & 2007 & $\begin{array}{l}\text { Mitochondriale Haplotypen in einer rezenten Bevölkerung des } \\
\text { Harzvorlandes }\end{array}$ & $\begin{array}{l}\text { Staatsexamens } \\
\text { arbeit }\end{array}$ \\
\hline Riesen, M & 2007 & $\begin{array}{l}\text { Y-chromosomale Haplotypen in einer rezenten Bevölkerung des } \\
\text { Harzvorlandes }\end{array}$ & $\begin{array}{l}\text { Staatsexamens } \\
\text { arbeit }\end{array}$ \\
\hline Stelz, S & 2007 & $\begin{array}{l}\text { Untersuchungen zur DNA-Degradierung in Abhängigkeit von Zustand, } \\
\text { Aufbereitung und Lagerungsdauer des Probenmaterials }\end{array}$ & Diplomarbeit \\
\hline Suray, D & 2007 & $\begin{array}{l}\text { Interleukin-10-Haplotypen eines bronzezeitlichen Skelettkollektivs aus } \\
\text { dem Harzer Vorland. }\end{array}$ & Diplomarbeit \\
\hline Jungk, A & 2008 & $\begin{array}{l}\text { Identifikation und Zuordnung von prähistorischen menschlichen } \\
\text { Skelettelementen der oberen Extremität aus zwei Abschnitten der } \\
\text { Lichtensteinhöhle }\end{array}$ & $\begin{array}{l}\text { Staatsexamens } \\
\text { arbeit }\end{array}$ \\
\hline Pepperl, J & 2008 & $\begin{array}{l}\text { Immungenetische Marker im Wandel der Zeit. Molekulargenetische } \\
\text { Analyse von single nucleotide Polymorphismen immungenetischer } \\
\text { Rezeptoren und Interleukine in historischen Bevölkerungen. }\end{array}$ & Dissertation \\
\hline Schiel, M & 2008 & $\begin{array}{l}\text { Identifikation und Zuordnung von prähistorischen menschlichen } \\
\text { Skelettelementen aus zwei Abschnitten der Lichtensteinhöhle }\end{array}$ & Bachelorarbeit \\
\hline Hollerbuhl, T & 2009 & $\begin{array}{l}\text { Identifikation und Zuordnung prähistorischer menschlicher } \\
\text { Skelettelemente aus dem Bernd-Saal der Lichtensteinhöhle anhand } \\
\text { morphologischer und molekulargenetischer Kriterien }\end{array}$ & Diplomarbeit \\
\hline Söchtig, J & 2009 & $\begin{array}{l}\text { Entwicklung von molekulargenetischen Analysesystemen zur } \\
\text { Rekonstruktion der Pigmentierung von Augen und Haaren }\end{array}$ & Diplomarbeit \\
\hline Schubert, J & 2009 & $\begin{array}{l}\text { Identifikation und Zuordnung prähistorischer menschlicher } \\
\text { Skelettelemente aus der Reinhardsgrotte und der Fiddi-Kluft der } \\
\text { Lichtensteinhöhle anhand morphologischer und molekulargenetischer } \\
\text { Kriterien }\end{array}$ & Diplomarbeit \\
\hline Blume, A & 2010 & $\begin{array}{l}\text { Zur Frage der Nutzung der Lichtensteinhöhle als Primär- oder } \\
\text { Sekundärbestattungsplatz - Prüfung des DNA-Erhalts auf } \\
\text { Abhängigkeit von in situ-Lage und Individuenzugehörigkeit genetisch } \\
\text { analysierter Skelettelemente }\end{array}$ & Bachelorarbeit \\
\hline Brandt, A & 2010 & $\begin{array}{l}\text { Untersuchung der Mikrostruktur der Femurkompakta mit dem Ziel der } \\
\text { Altersdiagnose und der Dokumentation hypermineralisierter Linien am } \\
\text { prähistorischen Skelettkollektiv der Lichtensteinhöhle }\end{array}$ & Bachelorarbeit \\
\hline Knorre, K & 2010 & $\begin{array}{l}\text { Zur Frage der Nutzung der Lichtensteinhöhle als Primär- oder } \\
\text { Sekundärbestattungsplatz - Untersuchung von } \\
\text { Dekompositionserscheinungen an ausgewählten, menschlichen } \\
\text { Skelettelementen }\end{array}$ & Bachelorarbeit \\
\hline Mazanec, J & 2010 & $\begin{array}{l}\text { Die Lichtensteinhöhle als genetisches Archiv - Untersuchung des } \\
\text { Markers delta32ccr5 an den bronzezeitlichen Individuen }\end{array}$ & Diplomarbeit \\
\hline Merkes, M & 2010 & $\begin{array}{l}\text { Zur Frage der Nutzung der Lichtensteinhöhle als Primär- oder } \\
\text { Sekundärbestattungsplatz - Klassifizierung und Bewertung der } \\
\text { Oberflächentextur ausgewählter menschlicher Skelettelemente }\end{array}$ & Bachelorarbeit \\
\hline Oberthür, R & 2010 & $\begin{array}{l}\text { Rekonstruktion der Körperhöhe aus Maßen der Langknochen von } \\
\text { Individuen des prähistorischen Skelettkollektives der } \\
\text { Lichtensteinhöhle }\end{array}$ & Bachelorarbeit \\
\hline
\end{tabular}


Fortsetzung Tabelle 40: Übersicht über die innerhalb der Forschungsprojekte zur Lichtensteinhöhle angefertigten Abschlussarbeiten.

\begin{tabular}{|c|c|c|c|}
\hline Autor & Jahr & Titel & Abschluss \\
\hline Seebode, C & 2010 & $\begin{array}{l}\text { Die Lichtensteinhöhle als genetisches Archiv - Untersuchung des } \\
\text { Laktosetoleranzmarkers C/T } 13910 \text { an den bronzezeitlichen } \\
\text { Individuen }\end{array}$ & Diplomarbeit \\
\hline Zeidler, S & 2010 & $\begin{array}{l}\text { Zur Frage der Nutzung der Lichtensteinhöhle als Primär- oder } \\
\text { Sekundärbestattungsplatz - Eine Analyse des Verteilungsmusters } \\
\text { und Streuungsgrad innerhalb der Höhle. }\end{array}$ & Bachelorarbeit \\
\hline Becker, M & 2011 & $\begin{array}{l}\text { Molekulargenetische Überprüfung morphologischer Zuordnungen von } \\
\text { isolierten Skelettelementen aus der bronzezeitlichen } \\
\text { Lichtensteinhöhle }\end{array}$ & Diplomarbeit \\
\hline Rohlf, J & 2011 & $\begin{array}{l}\text { Molekulargenetische Typisierung der Rhesusfaktor D-Eigenschaften } \\
\text { in bronzezeitlichen Individuen der Lichtensteinhöhle }\end{array}$ & Diplomarbeit \\
\hline Blume, $\mathrm{A}$ & 2012 & $\begin{array}{l}\text { Prehistoric Risk Behavior: Development of an analysis system for the } \\
\text { 48bp variable number of tandem repeats polymorphism of the human } \\
\text { dopamine receptor D4 (DRD4) applicable to aDNA }\end{array}$ & Masterarbeit \\
\hline Krause, I & 2012 & $\begin{array}{l}\text { Reconstruction of the iris pigmentation from individuals of a Bronze } \\
\text { Age archeological site }\end{array}$ & Masterarbeit \\
\hline Schücker, K & 2012 & Analyses of hair pigmentation of human remains from the Bronze Age & Masterarbeit \\
\hline
\end{tabular}




\section{Anhang B}

\subsection{Abkürzungsverzeichnis}

\begin{tabular}{|c|c|}
\hline$\%$ & Prozent \\
\hline${ }^{\circ} \mathrm{C}$ & Grad Celsius \\
\hline$\&$ & und \\
\hline$=$ & gleich \\
\hline A & IUB Code: Adenin \\
\hline Abb. & Abbildung \\
\hline $\mathrm{ad}$ & adult \\
\hline aDNA & engl. ancient DNA, alte DNA \\
\hline BDT & Big Dye ${ }^{\circledR}$ Terminator \\
\hline BLAST & engl. Basic Local Alignment Tool \\
\hline $\mathrm{bp}$ & Basenpaar(e) \\
\hline $\mathrm{BS}$ & Berndsaal \\
\hline bzw. & beziehungsweise \\
\hline $\mathrm{C}$ & IUB Code: Cytosin \\
\hline ca. & circa \\
\hline Calc & Calcaneus \\
\hline Calv & Calvarium \\
\hline $\mathrm{Cl}$ & Clavicula \\
\hline $\mathrm{cm}$ & Zentimeter \\
\hline CODIS & engl. Combined DNA Index System \\
\hline Cox & Os coxae \\
\hline DAD & DNA Analyse Datei \\
\hline ddNTP & Didesoxynukleosidtriphosphat \\
\hline DNA & engl. desoxyribonucleic acid \\
\hline $\mathrm{dNTP}$ & Desoxynukleosidtriphosphat \\
\hline d.h. & das heißt \\
\hline DO & Dorste \\
\hline EDTA & Ethylendiamintetraacetat \\
\hline engl. & Englisch \\
\hline et al. & et alii, und andere \\
\hline evtl. & eventuell \\
\hline $\mathrm{F}_{\mathrm{x}}$ & Extrakt \\
\hline
\end{tabular}




\begin{tabular}{|c|c|}
\hline Exo I & Exonuklease eins \\
\hline fad & frühadult \\
\hline 6-FAM & 6-Carboxylflourescein $\square$ \\
\hline $\mathrm{Fe}$ & Femur \\
\hline finf I & früh-infans I \\
\hline fjuv & frühjuvenil \\
\hline FK & Fiddikluft \\
\hline fmat & frühmatur \\
\hline $\mathrm{g}$ & Gramm \\
\hline $\mathrm{G}$ & IUB Code: Guanin \\
\hline ggf. & gegebenenfalls \\
\hline GK & Grabkammer \\
\hline $\mathrm{h}$ & Stunde(n) \\
\hline HEX & 6-Carboxyl-2',4',7',4,7-Hexachlorofluorescein \\
\hline Hrsg. & Herausgeber \\
\hline HS & Horstspalte \\
\hline $\mathrm{Hu}$ & Humerus \\
\hline HVR I & Hypervariable Region eins \\
\hline HVR II & Hypervariable Region zwei \\
\hline $\inf \mathrm{I} / \mathrm{II}$ & infans I/II \\
\hline Jh. v. Chr. & Jahrhundert vor Christus \\
\hline JS & Jensschluf \\
\hline juv & juvenil \\
\hline $\mathrm{KS}$ & Kathrinsspalte \\
\hline li & links \\
\hline $\mathrm{m}$ & männlich \\
\hline M & Molar \\
\hline $\operatorname{mad}$ & mitteladult \\
\hline Mand & Mandibula \\
\hline mat & matur \\
\hline $\max$ & maximal \\
\hline $\mathrm{mg}$ & Milligramm \\
\hline $\min$ & Minuten \\
\hline $\mathrm{ml}$ & Milliliter \\
\hline
\end{tabular}




\begin{tabular}{|c|c|}
\hline mmat & mittelmatur \\
\hline $\mathrm{mt}$ & mitochondrial \\
\hline mtDNA & mitochondriale DNA \\
\hline$\mu 1$ & Mikroliter \\
\hline$\mu \mathrm{m}$ & Mikrometer \\
\hline$\mu \mathrm{M}$ & Mikromolar \\
\hline $\mathrm{n}$ & Stichprobenumfang \\
\hline nd & nicht determiniert \\
\hline NED & 2'-Chloro-5'-fluoro-7', 8' -benzo-1,4-dichloro-6-carboxyfluorescein \\
\hline $\mathrm{nm}$ & Nanometer \\
\hline Nr. & Nummer \\
\hline PCR & Polymerase Chain Reaction, Polymerasekettenreaktion \\
\hline $\mathrm{pH}$ & potentia hydrogenii, Protonenaktivitätsexponent \\
\hline POP & engl. Perfomance Optimized Polymer \\
\hline $\mathrm{Pp}$ & Os temporale pars petrosum \\
\hline ( & amtlich registrierte Marke \\
\hline $\mathrm{R}$ & IUB Code: Purin $=\mathrm{G}$ oder $\mathrm{A}$ \\
\hline $\mathrm{Ra}$ & Radius \\
\hline rAPid & Rapid Alkaline Phosphatase \\
\hline $\mathrm{rcf}$ & engl. relative centrifugal force, relative Zentripetalbeschleunigung \\
\hline rCRS & engl. revised Cambridge Reference Sequence \\
\hline re & rechts \\
\hline rfu & $\begin{array}{l}\text { engl. relative fluorescenct unit(s), Maß für die Signalintensität der Peaks } \\
\text { im Elektropherogramm }\end{array}$ \\
\hline RG & Reinhardsgrotte \\
\hline ROX & 6-Carboxylrhodamin \\
\hline s & Sekunde(n) \\
\hline s. & siehe \\
\hline S. & Seite \\
\hline sad & spätadult \\
\hline SBE & engl. single base extension \\
\hline Sc & Scapula \\
\hline SDS & engl. sodium dodecylsulfate, Natriumdodecylsulfat \\
\hline sen & senil \\
\hline
\end{tabular}




$\begin{array}{ll}\text { Seq } & \text { Sequenzierung } \\ \text { sjuv } & \text { spätjuvenil } \\ \text { smat } & \text { spätmatur } \\ \text { STR } & \text { engl. short tandem repeat } \\ \text { T } & \text { IUB Code: Thymin } \\ \text { Taq } & \text { Thermus aquaticus } \\ \text { Ti } & \text { Tibia } \\ \text { TM } & \text { Trademark } \\ \text { U } & \text { engl. units } \\ \text { u.a. } & \text { unter anderem } \\ \text { Ul } & \text { Ulna } \\ \text { v } & \text { engl. version } \\ \text { vs. } & \text { versus } \\ \text { Y } & \text { IUB Code: Pyrimidin = C oder T } \\ Z & \text { Zahn } \\ \text { Z.B. } & \text { zum Beispiel }\end{array}$

\subsection{Verwendete Geräte und Chemikalien}

\section{Geräte}

- $\quad$ TKA-Lab Reinstwassersystem, Thermo Scientific

- $\quad$ Dremel ${ }^{\circledR M u l t i}{ }^{\mathrm{TM}}$ Handbohrer 395 mit 3,2mm Hochgeschwindigkeitsfräseraufsatz

- DNA-Extraktor EZ1, Qiagen

- DNA-Sequencer Modell 310, PE Applied Biosystems

- $\quad$ DNA Thermal Cycler Typ Mastercycler®, Eppendorf

- $\quad$ DNA Thermal Cycler Typ Mastercycler ${ }^{\circledR}$ gradient, Eppendorf

- $\quad$ DNA Thermal Cycler Typ Mastercycler® personal, Eppendorf

- Elektrophoresekammern Horizon ${ }^{\circledR} 1060$ BD (5x8 cm), Gibco BRL

- Elektrophoresekammern Horizon ${ }^{\circledR} 1060$ BD (11x14 cm), Gibco BRL

- Elektrophoreskammern Midi large horizontal $(15 \times 17 \mathrm{~cm}), \mathrm{G} \& P$ Kunststofftechnik

- Elektrophoreskammern Mini horizontal $(8 \times 10 \mathrm{~cm})$ G\&P Kunststofftechnik

- $\quad$ Gel Jet Imager \& Analyzer mit Software IntasGel Capture, Intas

- Glaskapillaren, 310 Capillaries $47 \mathrm{~cm}$ x $50 \mu \mathrm{m}$ 5/pkg, PE Applied Biosystems

- Kugelschwingmühle Typ MM2 mit Mahlbechern, Retsch

- $\quad$ LightCycler 2.0 ${ }^{\mathrm{TM}}$ Real-Time PCR System, Roche 
- $\quad$ Magnetrührer Ikamag® RET, Ikamag® MTC. Ikamag® RH, Janke \& Kunkel IkaWerk

- QiaVac-System (Vakuumpumpe) inkl. entsprechender Aufsätze, Qiagen

- Quadra 650, Apple Computer Inc.

- Power Macintosh 7100/66, Apple Computer Inc.

- Power Macintosh G3, Apple Computer Inc.

- Präzisionswaage excellence Typ E 1200 S, Sartorius

- Rotator LC-1, Steward

- Sägeschnittmikrotom Leitz SP 1600, Leitz

- $\quad$ Stromversorgung Typ ST606 Electrophoresis Power Supply, Gibco BRL

- $\quad$ Thermomixer Typ 5437, Eppendorf

- $\quad$ Varipetten ${ }^{\circledR}$ Typ 4810, Satz: 0,5-10 $\mu 1,10-100 \mu 1,100-1000 \mu 1$, Eppendorf

- Wasser-Destilliergerät Typ Muldestor, Wagner \& Munz

- Zentrifuge Typ 5402, Eppendorf

- Zentrifuge Typ 5415C, Eppendorf

- Zentrifuge Typ 5415R, Eppendorf

\section{Chemikalien}

- $1 \mathrm{~Kb}$ DNA-Leiter (Molekulargewichtsstandard); Life Technologies

- 310 10X Buffer with EDTA, PE Applied Biosystems

- 310 POP-4 TM Polymer, PE Applied Biosystems

- 310 POP-6 TM Polymer, PE Applied Biosystems

- $\quad$ ABI Prism ${ }^{\circledR}$ BigDye ${ }^{\circledR}$ Terminator v1.1 Cycle Sequencing Kit, ABI

- Agarose Roti ${ }^{\circledR}$ Agarose, Roth

- Alconox (Detergenz), Aldrich

- Ambion ${ }^{\circledR}$ Wasser, Invitrogen

- AmpliTaq-Gold ${ }^{\mathrm{TM}}$ DNA-Polymerase (5 U/ $\left.\mu \mathrm{l}\right)$, Perkin Elmer Cetus

- Ampuwa ${ }^{\circledR}$ (steriles Wasser), Fresenius

- Aqua bidestillata, eigene Herstellung

- Buffer PB, Buffer PE, Qiagen

- $\quad$ Borsäure, p.a., Merck

- Bromphenolblau, p.a., Serva

- $\quad$ EDTA (Ethylendinitrotetraacetat Dinatriumsalz-Dihydrat):Titriplex ${ }^{\circledR} I I I$, Merck 
- Ethanol absolut, p.a., Abgabestelle der Bundesmonopolverwaltung: Zander Göttingen

- $\quad$ Ethidiumbromid, wässrige Lösung $1 \%(\mathrm{w} / \mathrm{v}), 10 \mathrm{mg} / \mathrm{ml}$, Serva

- $\quad$ EZ1 DNA Tissue Kit, Qiagen

- Formamid, Fluka

- Genescan-500 ${ }^{\mathrm{TM}}$ ROX-Kit (spurinterner Standard, loading buffer), PE Applied Biosystems

- Isopropanol p.a., Merck

- $\quad$ LiChrosolv®, HPLC-Wasser zur Chromatographie, Merck

- $\quad$ MinElute $^{\mathrm{TM}}$ PCR Purification Kit, Qiagen

- $\quad$ NucleoSeq Kit Dye Terminator Removal, Macherey-Nagel

- $\quad$ Qiagen ${ }^{\circledR}$ Multiplex 2x PCR Kit plus, Qiagen

- $\quad$ Proteinase K, Merck

- $\quad$ Tris (Tri[hydroxymethyl]aminoethan), Trizma ${ }^{\mathrm{TM}}$ Base, p.a., Sigma

\section{Einwegmaterialien und Hilfsmittel}

- Dental-Diamantsägeblätter Typ Diaflex-T H 350 220, Horico

- Einmaluntersuchungshandschuhe Safeskin Satin Plus Powder-free, KimberleyClark ${ }^{\circledR}$

- Eppendorf Reaktionsgefäße (0,5 ml) safe-lock, Eppendorf

- Eppendorf Reaktionsgefäße (2,0 ml) safe-lock, Eppendorf

- FalconTubes (15 ml), Sarstedt

- FalconTubes (50 ml), Sarstedt

- Gesichtsmasken: Surgine face mask, Johnson + Johnson

- Kimwipes ${ }^{\circledR}$ Lite, Kinberley Clark ${ }^{\circledR}$

- $\quad$ OP-Haube Astronautenform Surgine ${ }^{\circledR}$, Mölnlycke Health Care, Inc.

- $\quad$ Parafilm ${ }^{\circledR}$ M, American National Clan ${ }^{\mathrm{TM}}$

- PE-Zentrifugationsgefäße, Blue Max ${ }^{\mathrm{TM}} 50 \mathrm{ml}$ Conical Tubes 2070, Falcon ${ }^{\circledR}$

- Pipettenspitzen: blaue Spitzen $1 \mathrm{ml}$, Sarstedt

- Pipettenspitzen: gelbe Spitzen $100 \mu 1$, Sarstedt

- $\quad$ Pipettenspitzen: Standardtips $10 \mu \mathrm{l}$, Eppendorf 


\subsection{Verwendete Software, Internetseiten und Dateien auf der beigefügten CD}

\section{Software}

- $\quad 3500$ Series Data Collection Software v2.0, Life Technologies

- $\quad$ ABI PRISM 310 Data Collection v3.1.0, Applied Biosystems

- $\quad$ ABI PRISM® 310 Sequencing Analysis v5.1.1, Applied Biosystems

- $\quad$ ABI PRISM® 310 GeneScan-Analysis v3.1.2, Applied Biosystems

- $\quad$ ABI PRISM® 310 GeneScan-Analysis v2.1, Applied Biosystems

- $\quad$ ABI PRISM® 310 Collection v2.0.2, Applied Biosystems

- $\quad$ EditSeq $^{\mathrm{TM}}$, DNAStar Lasergene 8 v8.0.2, DNAStar Inc.

- Familias v1.97, http://www.familias.name/

- GeneMapper® Software v5.0, Life Technologies

- $\quad$ PrimerSelect ${ }^{\mathrm{TM}}$, DNAStar Lasergene 8 v8.0.2, DNAStar Inc.

- $\quad$ MegAlign ${ }^{\mathrm{TM}}$, DNAStar Lasergene 8 v8.0.2, DNAStar Inc.

- $\quad$ SeqMan ${ }^{\mathrm{TM}}$, DNAStar Lasergene 8 v8.0.2, DNAStar Inc.

- Sequencing Analysis Software v6.0 (Life Technologies).

\section{Internetseiten}

http://allstr.de/allstr/home.seam

http://www.familias.name/

https://haplogrep.uibk.ac.at/

http://www.hoehlen-erlebnis-zentrum.de/

http://www.hprg.com/hapest5/

http://www.ncbi.nlm.nih.gov

http://www.phylotree.org

http://www.yhrd.org

\section{Dateien auf der beigefügten CD}

Lichtensteinhöhle Fundkatalog Menschenknochen.accdb

Lichtensteinhöhle Einzeltypisierungen autosomale STRs.xls

Lichtensteinhöhle Einzeltypisierungen Y-chromosomale STRs und mtDNA.xls

Lichtensteinhöhle Einzeltypisierungen diverse Marker.xls 


\subsection{Längenstandards}

1 Kb Leiter, Invitrogen, Life Technologies (Größen in bp)

75 - 134 - 154 - 201 - 220 - 298 - 344 - 396 - 506 - 517 - 1018 - 1636 - 2036 $3054-4072-5090-6108-7126-8144-9162-10180-11198-12216$

50 bp Leiter, Invitrogen, Life Technologies (Größen in bp)

$50-100-150-200-250-300-350-450-600-800$

Low Molecular Weight Leiter, New England Biolabs (Größen in bp)

$25-50-75-100-150-200-250-300-350-500-766$

GeneScan 600 LIZ, Applied Biosystems (Größen in bp)

20 - 40 - 60 - 80 - 100 - 114 - 120 - 140 - 160 - 180 - 200 - 214 - 220 - 240 - 250 -

260 - 280 - $300-314-320-340-360-380-400-414-420-440-460-480$ -

$500-514-530-540-560-580-600$

CC5 ILS 500, Promega (Größen in bp)

$60-65-80-100-120-140-160-180-200-225-250-275-300-325-350$

$-375-400-425-450-475-500$

GeneScan 500 ROX, Applied Biosystems (Größen in bp)

$35-50-75-100-139-150-160-200-250-300-340-350-400-450-490$ $-500$

GeneScan 120 LIZ, Applied Biosystems (Größen in bp)

$15-20-25-35-50-62-80-110-120$ 